\title{
The geochemistry of pāua as a potential proxy for past and present environmental change
}

\author{
Ramona Mahia White
}

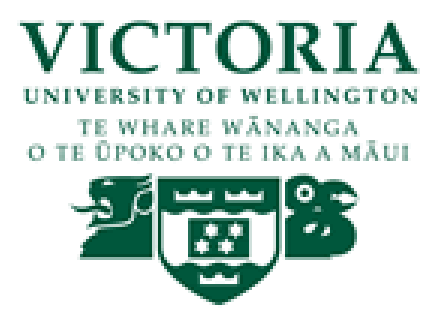

\author{
A thesis submitted to \\ Victoria University of Wellington \\ In partial fulfilment of the requirements for the degree of \\ Masters of Science in Geology
}

School of Geography, Environment and Earth Sciences

Victoria University of Wellington 

This is for you Dad. 


\section{ABSTRACT}

Nearshore New Zealand mollusca (shellfish) have the potential to be important archives of environmental conditions and change. Ambient ocean chemistry can be incorporated into the calcium carbonate $\left(\mathrm{CaCO}_{3}\right)$ shell during the life span of the mollusc providing a high resolution temporal record of the chemical and physical changes of the environments the mollusc lived in. Previous studies on foraminifera and coral have shown that the substitution of magnesium or strontium for calcium (Mg, $\mathrm{Sr} / \mathrm{Ca}$ ) during the formation of the $\mathrm{CaCO}_{3}$ shell is directly correlated with ocean temperatures. Other divalent cations (e.g., $\mathrm{Sr}^{2+}$, $\mathrm{Ba}^{2+}, \mathrm{Pb}^{2+}$ can also provide information on ambient salinity, primary productivity or nutrient levels, and local anthropogenic pollution. This study uses new geochemical techniques that have been developed to measure the trace element chemistry of $\mathrm{CaCO}_{3}$ mollusc shells at high temporal resolution, using laser ablation inductively coupled plasma mass spectrometry (LA-ICP-MS) in order to calibrate shell chemistry with environmental conditions. This study is the first to explore the use of the geochemistry of Haliotis iris as a potential proxy for (paleo-) environmental conditions.

Pāua (Haliotis iris) were collected from six different localities around New Zealand and the Chatham Islands as well as a cultured environment (OceaNZ Blue Ltd). The shells were sectioned following the axis of maximum growth exposing both $\mathrm{CaCO}_{3}$ layers; the prismatic (predominantly calcite) and nacreous (aragonite) layers. The shells were analysed by LA-ICP-MS at $25 \mu \mathrm{m}$ spot sizes through a high temporal transect of both layers. Observed differences in the element/Ca ratios between the prismatic and nacreous layer reflect the differing crystallinity of each layer.

High temporal resolution $\mathrm{Mg} / \mathrm{Ca}$ ratio data of the prismatic layer of the samples which grew in a cultured environment were compared with temperature and growth data supplied by OceaNZ Blue Ltd. The results showed that temperature was not the primary control on the uptake of Mg within the shells and that influences from biological factors including increased growth rate were also evident. Sr/Ca ratios show a weak inverse relationship with increased growth 
rate assumed. These results, however, are not reproducible within samples collected from the wild, showing that external factors (high wave energy, diet, predation, lack of food) place metabolic stress on the pāua. The monitoring of other element/Ca including $\mathrm{Ba} / \mathrm{Ca}, \mathrm{Al} / \mathrm{Ca}, \mathrm{Pb} / \mathrm{Ca}$ and $\mathrm{Zn} / \mathrm{Ca}$ ratios have the potential to provide information into the past frequency of storm events that deliver sediment into the oceans and remobilise other sediments and changing levels of environmental pollution. This is reflected through increased $\mathrm{Al} / \mathrm{Ca}$, $\mathrm{Pb} / \mathrm{Ca}$ and $\mathrm{Zn} / \mathrm{Ca}$ ratios during the winter season in a number of samples $(\mathrm{n}=3)$ gained from the high resolution analysis of the prismatic layers. Overall, element/Ca ratios are difficult to correlate environmental conditions in samples from the wild as there are many different parameters influencing the uptake of element/Ca ratios with the shells of pāua. Uncertainties lie with a lack of understanding of the biological controls influencing pāua during biomineralisation including the transportation of the elements within organism to the extrapallial fluid to be biomineralised, ontogeny, and the rate and regularity of biomineralisation of shell material. 


\section{ACKNOWLEDGEMENTS}

First and foremost thank you to Joel Baker and Marc-Alban Millet. Joel, I really appreciate your patience, persistence, support and supervision you have provided to me over the last few years. Marc, there has never been a moment that I have knocked on your office, that you haven't dropped what you were doing to help (even if the fate of a multi-million dollar machine was in my hands). Thank you also to Adele Whyte for your contribution to this thesis. Your emotional support during my first year of my thesis was well appreciated and the connections you have provided me with have been amazing.

A large support has come from the Foundation for Research, Science and Technology for funding from the Te Tipu Putaiao Fellowship. Acknowledgments must also go to Rachel Stockwell from the VUW Scholarships office, The Science Faculty office staff (Belinda, Shona, Johan, etc) and the SGEES office staff (Susan, Suzanne, Hayley, Lauren, Torzie, etc). Your help has never gone unnoticed.

Thank you to those who donated pāua samples for this research (I'd like to think I gave you an excuse to go diving). Thank you to Saandra Mauger and team at the Ministry of Fisheries for delivering samples from the unreachable places. To Doug Hauraki and family, Paul Patuwai and family, Zack Makoare, Dave Murphy, Tyler White and Grant O'Brien. Also, to Rodney Roberts from OceaNZ Blue Ltd for providing me with spreadsheets of temperature and growth data, checking up on my work progress and offering your expertise in pāua.

There is also a large number of staff and students that deserve an enormous amount of gratitude for their support through this thesis. You are all epic. Thank you to Stewart Bush, Ash Pocock, Sandra Fogliani and Julie Vry for their help in researching and preparing samples; Aidan Allan for his assistance with the LA-ICPMS and answering my trivial questions with a straight face; John Creech and Julene Marr for their help with $\mathrm{Mg} / \mathrm{Ca}$ ratio and data questions; Jess Orsman for the coffees, brainstorms, book/article swaps and the constant help; George Cooper for his lab access - without it EVERY weekend, I would not have gotten into the lab, let alone the university to get this thing done; Catherine Davis for her expertise in pāua and her invaluable friendship; and Matt Ryan (MFR) for being a brain to bounce 
ideas off, helping me with CorelDraw and also having a great looking thesis of which contributed to the format and layout of this one. High fives to my fellow geology homies who made Cotton Building not only a great place to be in, but a place where there was always interesting 'science' (read gossip) going on. To Kylie, Kim, Megan, Ben, Condor, Rookie, Katy, Andy K, Alexa, Holly, Melissa, Jodi (idol), and everyone else who has been a great friend over the years. I am so privileged to have been in such great company and around people with such great minds.

I am forever thankful to Liz Richardson, Vivian Wei and the Awhina whanau for providing me a home away from home. Liz, you are one busy lady, but you always take the time to smile and check up on me. To Panther and Boots; I would never have considered doing an MSc without you both planting the seed. This one's for you. Also to my statistics mentors Miles Benton and Hautahi Kingi for first helping me get data, and secondly helping me understand it. Geniuses!

But overall, I owe my sanity and positive energies (what I have left) to my closest friends and family. You are the battery chargers for when I am running on low. Katie Collins, what can I say that could ever make up for what you have done for me? Thank you for all your help, from editing chapters, to sharing expert biology knowledge and excitement over interesting results. Shalen (Crayfish) Kumar, Catherine Davis, Mandy Gunn and Andy Zeller - you provided me with great laughs and great cooking every Monday! Zara Rawlinson, Elaine Brent, Jaya DiasWanigasekera, Lina Schroeter, Gemma Wihare and Franchesca Walker - you are ALL insane, however, without your laughs, smiles, love and shared moments, I would be a lost, ignorant person. True story. Gemma and Zara - Having you both there throughout this journey as a fellow postgrad with your endless understanding and constant support has been indescribable. I owe you.

To my nephew Wiremu, I just wrote a thesis, so you can only refer to me as 'Captain' now and not 'stupid Aunty Mona'. On a serious note, I love you more than anything and if you ever need me, I'll be there. Melanie, you are the best big sister anyone could ever ask for. You make me smile when I am down (you also make me down when I am smiling), but you always have my back and you inspire me with your drive to succeed. Lastly, Mum, you have always supported me, called to see if I was ok and chucked a cheeky dollar my way to go towards 'living' (read beer). If I was to have at least half the strength as you, I know I can be proud of myself. 


\section{CONTENTS}

Abstract

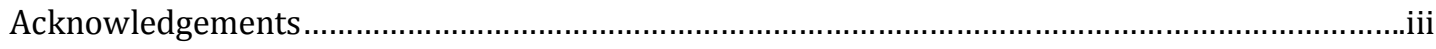

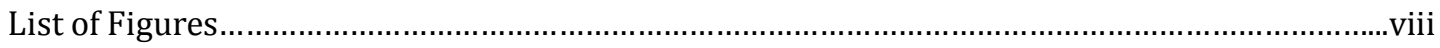

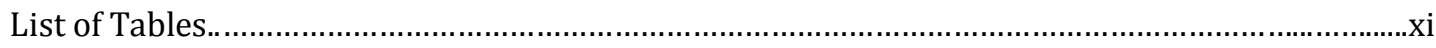

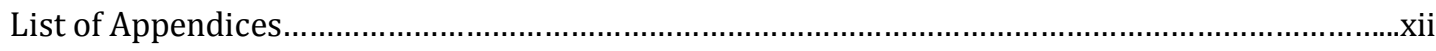

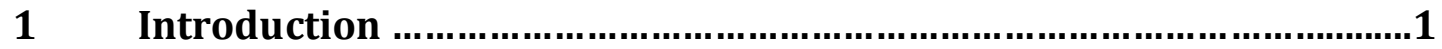

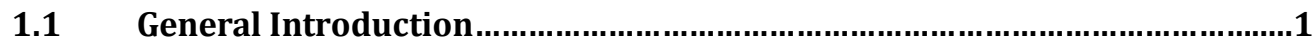

Motivations for research, thesis outline and objectives..............................3

1.2.1 Importance for New Zealand.............................................................

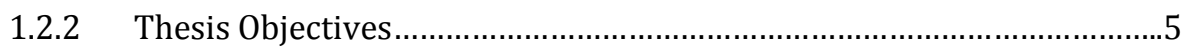

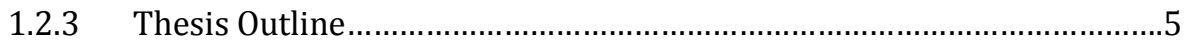

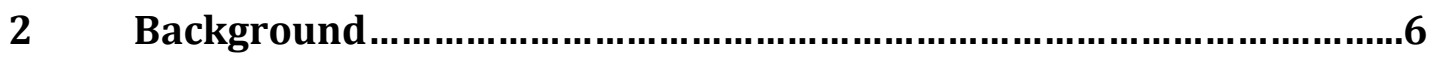

2.1 Trace elements in carbonate as a proxy for paleoclimatology ...................6

2.1.1 Paleoclimate records from foraminifera and coral................................6

2.2 Molluscs and their potential as a paleoclimate archive.............................

2.3 Trace element proxies........................................................................11

2.3.1 Mg and Sr in carbonate as proxies of paleo-ocean temperatures.........11

2.3.2 Other trace elements as proxies of environmental conditions.............12

2.3.3 Trace metal contaminants: a trace for anthropogenic pollution?..........13

2.4 Factors influencing trace element incorporation in molluscs...................14

2.4.1 Shell formation and biomineralisation ............................................... 15

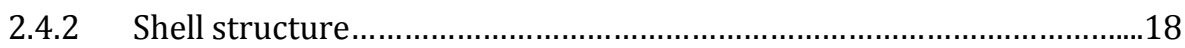

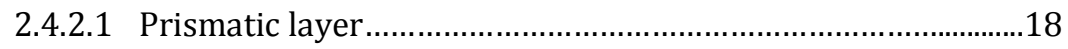

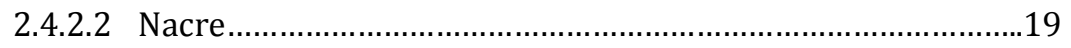

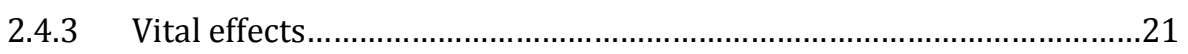

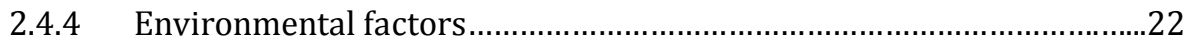

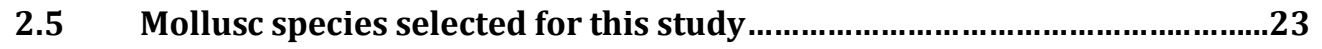

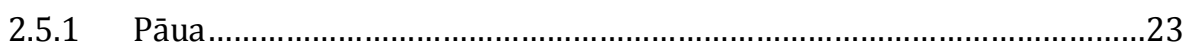

2.5.2 Pāua in Aotearoa New Zealand........................................................24 


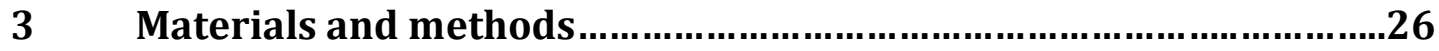

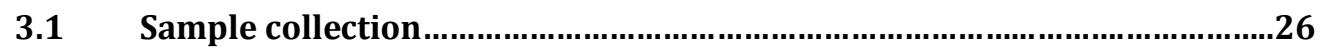

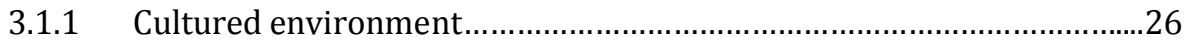

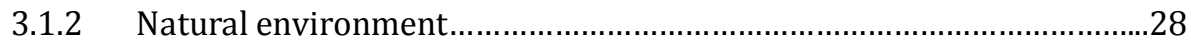

3.1.2.1 Pourerere Beach..........................................................................30

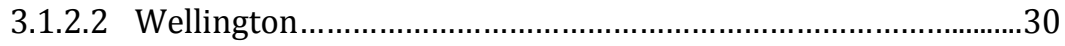

3.1.2.3 Kaikoura ..............................................................................

3.1.2.4 Chatham Islands ......................................................................30

3.1.2.5 Moeraki .......................................................................................

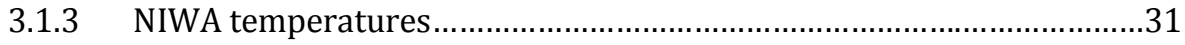

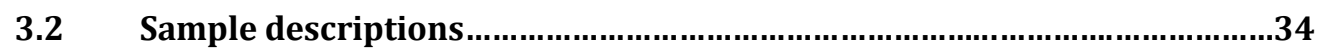

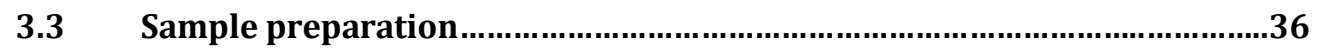

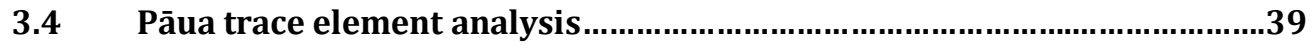

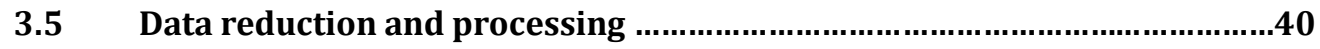

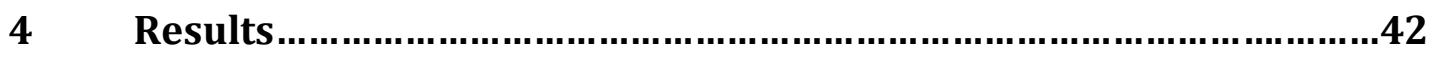

4.1 Average inter-shell chemistry variation ...................................................

4.1.1 Prismatic layer versus nacreous trace element chemistry ...................42

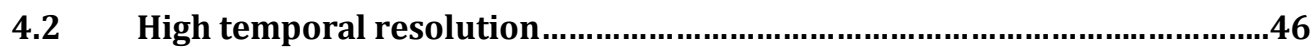

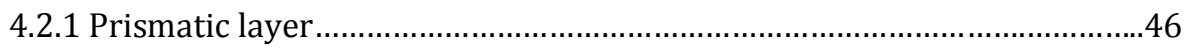

4.2.1.1 OceaNZ Blue Ltd......................................................................4

4.2.1.2 Pourerere ............................................................................... 47

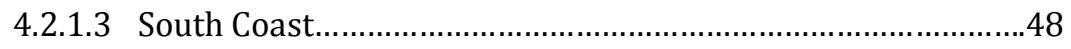

4.2.1.4 Moa Point............................................................................... 48

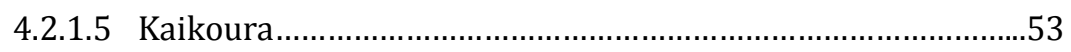

4.2.1.6 Chatham Islands....................................................................

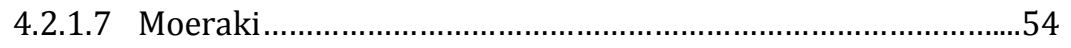

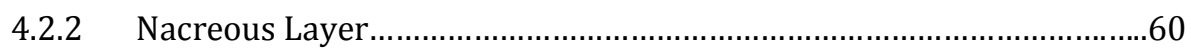

4.2.2.1 OceaNZ Blue Ltd.............................................................60

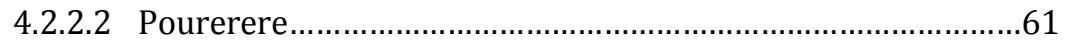

4.2.2.3 South Coast..................................................................................62

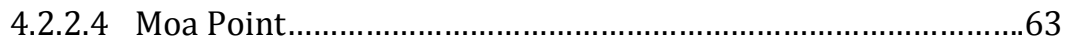

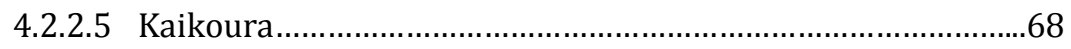


4.2.2.6 Chatham Islands.........................................................6 69

4.2.2.7 Moeraki............................................................................ 70

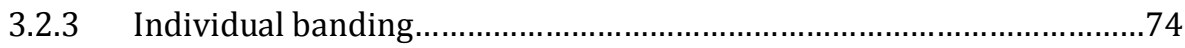

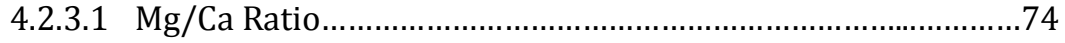

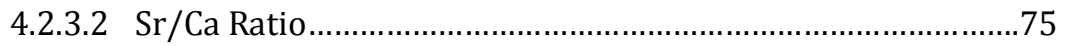

4.2.3.3 Ba/Ca Ratio ..................................................................... 76

Element/Ca pearsons correlation coefficient...........................................81

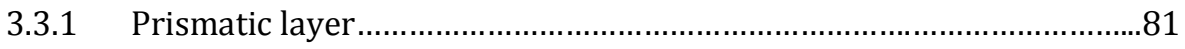

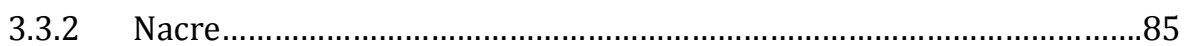

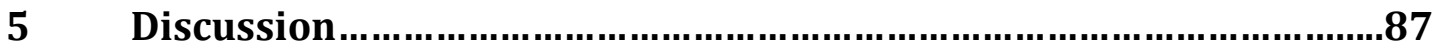

5.1 Intra-individual variations in shell chemistry ...................................87

5.1.1 Uptake of elements into different shell layers...............................87

5.1.2 Analysis of individual bands ...................................................... 90

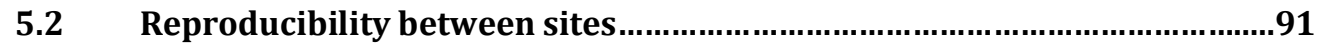

5.3 High resolution analysis of pāua as an environmental proxy?.....................94

5.3.1 Pāua prismatic layer colouration..................................................... 94

5.3.2 $\mathrm{Mg} / \mathrm{Ca}$ and $\mathrm{Sr} / \mathrm{Ca}$ ratio in pāua as a paleo-ocean thermometer..........100

5.3.2.1 OceaNZ Blue Ltd temperature correlation .............................100

5.3.2.2 Temperature records from samples from the wild..............104

P.4 Pāua as an archive for post pollution events.....................................108

5.4.1 Element/Ca ratios at Moa Point........................................................109

The nacreous layer as a useful archive of past climates.........................116

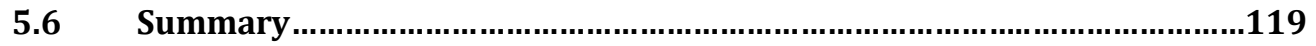

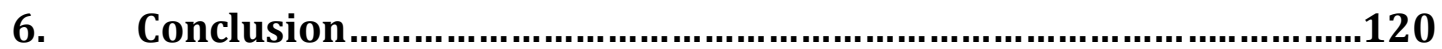

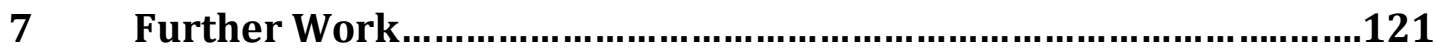

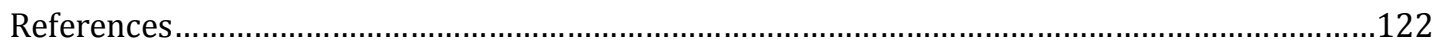

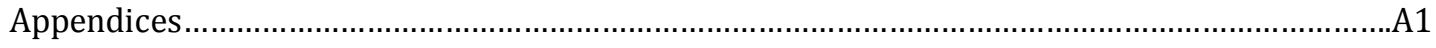




\section{LIST OF FIGURES}

Fig. 1.1 IPCC global temperature change from 1999 to $2100 \ldots \ldots \ldots \ldots \ldots \ldots \ldots \ldots \ldots \ldots . . . .2$

Fig. 2.1 Mg/Ca ratio of planktonic foraminifera ..................................................

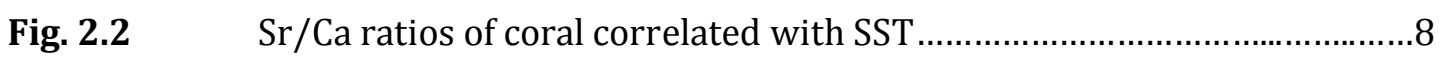

Fig. 2.3 Cross section through a mussel shell and mantle...................................15

Fig. 2.4 The molluscan mineralising system....................................................16

Fig.2.5 Structure of a typical mollusc shell......................................................18

Fig. 2.6 Stages of prismatic layer crystal growth.............................................19

Fig. 2.7 Stages of nacreous layer crystal growth ................................................20

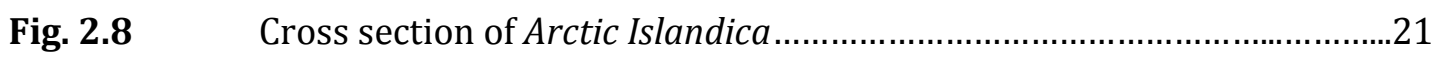

Fig 2.9 The exterior and interior of a pāua shell...............................................23

Fig. 3.1 New Zealand and Chatham Island sample sites ......................................26

Fig. 3.2 OceaNZ Blue Ltd daily mean temperatures ...........................................27

Fig. 3.3 Recorded monthly shell lengths of OBL samples ....................................28

Fig. 3.4a North Island pāua sample locations ...........................................................

Fig. 3.4b South Island pāua sample locations .......................................................33

Fig. 3.5 Photographs of the exterior and interior of each sample analysed.........35

Fig. 3.6 Pāua shell sample transect location .........................................................36

Fig. 3.7 Pāua inter-shell transects within the prismatic and nacreous

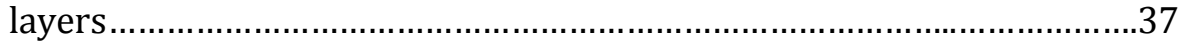

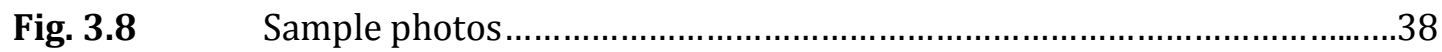

Fig. 3.9 Diagram of the sample setup within the laser ablation chamber..............39

Fig. 3.10 The ablation and washout period duration for

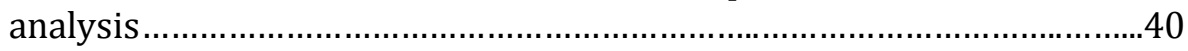

Fig. 4.1a Mean element/Ca ratios of the prismatic layer and nacreous

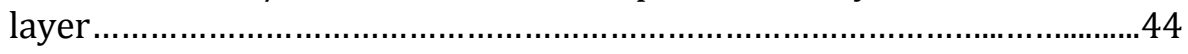

Fig. 4.1b Continued mean element/Ca ratios of the prismatic layer and nacreous

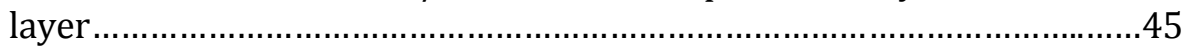

Fig. 4.2a High temporal element/Ca analysis of the prismatic layer of RW75 and

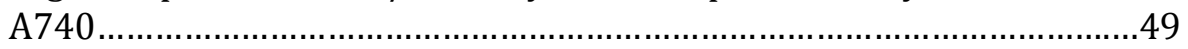

Fig. 4.2b High temporal element/Ca analysis of the prismatic layer of P04A and

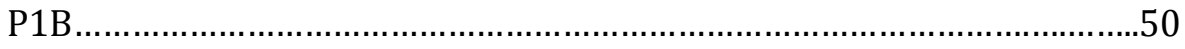


Fig. 4.2c High temporal element/Ca analysis of the prismatic layer of SC1A and

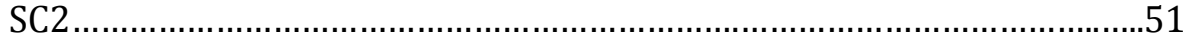

Fig. 4.2d High temporal element/Ca analysis of the prismatic layer of

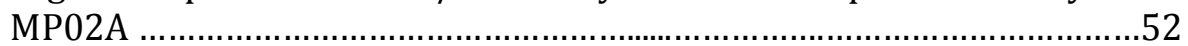

Fig. 4.2e High temporal element/Ca analysis of the prismatic layer of

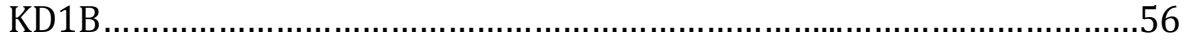

Fig. 4.2f High temporal element/Ca analysis of the prismatic layer of $\mathrm{K} 3 \mathrm{~A}$ and

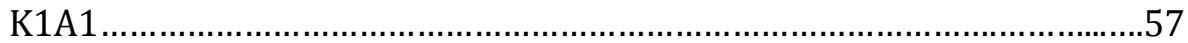

Fig. 4.2g High temporal element/Ca analysis of the prismatic layer of MR2 and AR1

Fig. 4.2h High temporal element/Ca analysis of the prismatic layer of MD1 and

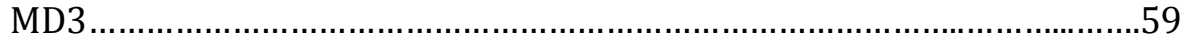

Fig. 4.3 Direction of analysis through the nacre ................................................60

Fig. 4.4a High temporal element/Ca analysis of the nacreous layer of RW75 and

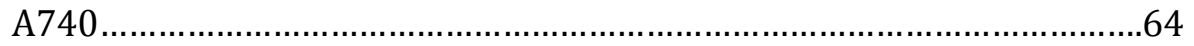

Fig. 4.4b High temporal element/Ca analysis of the nacreous layer of P04A and

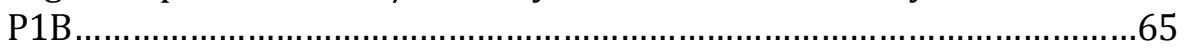

Fig. 4.4c High temporal element/Ca analysis of the nacreous layer of SC1A and

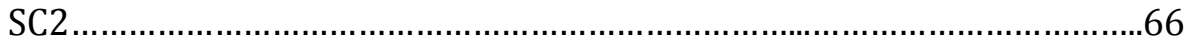

Fig. 4.4d High temporal element/Ca analysis of the nacreous layer of MP02A and KD1B.

Fig. 4.4e High temporal element/Ca analysis of the nacreous layer of $\mathrm{K} 3 \mathrm{~A}$ and

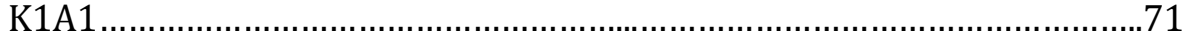

Fig. 4.4f High temporal element/Ca analysis of the nacreous layer of MD1 and

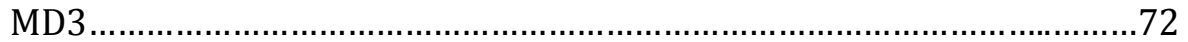

Fig. 4.4g High temporal element/Ca analysis of the nacreous layer of AR1 and

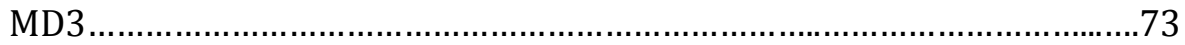

Fig. 4.5 Direction of analysis following an individual growth band .....................74

Fig. 4.6a $\mathrm{Mg} / \mathrm{Ca}$ ratios of a transect following the growth banding in the prismatic

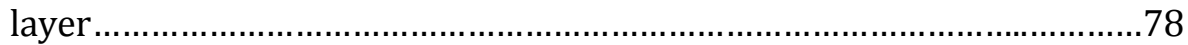

Fig. 4.6b $\quad \mathrm{Sr} /$ Ca ratios of a transect following the growth banding in the prismatic layer.

Fig. 4.6c $\quad \mathrm{Ba} / \mathrm{Ca}$ ratios of a transect following the growth banding in the prismatic layer. .80

Fig. 5.1 The crystal structure of aragonite and calcite .88

Fig. 5.2 Mean element/Ca ratios of the prismatic and nacreous layer of all samples grouped by location. 
Fig. 5.3a-d $\mathrm{Mg} / \mathrm{Ca}$ ratios of the prismatic layer transect and shell

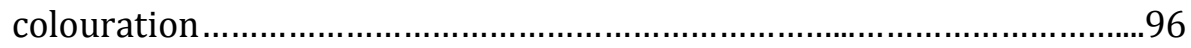

Fig. 5.4 OBL $\mathrm{Sr} / \mathrm{Ca}$ and $\mathrm{Mg} / \mathrm{Ca}$ ratios with temperature and growth .................103

Fig. 5.5 von Bertalanffy curve of pāua ……........................................................104

Fig 5.6 MP02A Mg/Ca ratios and Wellington air temperatures........................106

Fig. 5.7a $\quad$ MP02A trace metal/Ca ratios and Wellington air temperatures..........112

Fig 5.7b Element/Ca ratio of K3A and MD3 and local air temperatures.............113

Fig. 5.8 $\quad \mathrm{Mn}, \mathrm{Pb}$ and $\mathrm{Zn}$ concentrations of Perna canaliculus soft tissue..............114

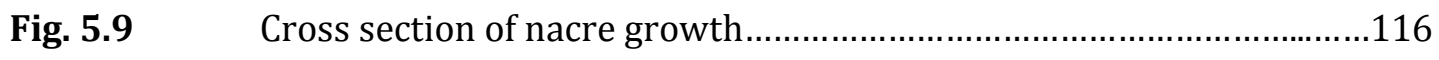

Fig. 5.10 Photograph of the conchiolin in natural and plane-polarised

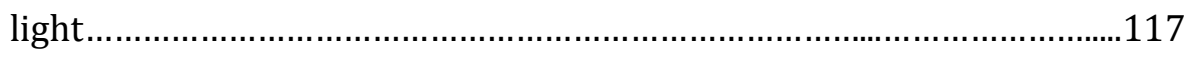




\section{LIST OF TABLES}

Table 3.1 Pāua shell descriptions and NIWA minimum and maximum temperatures .29

Table 3.2 NIWA Mean air temperatures from May 2008 to October 2010..............31

Table 3.3 ICP-MS and laser ablation settings......................................................40

Table 3.4 GeoReM preferred trace element concentrations.................................41

Table 4.1 Sr/Ca ratio vs. various element/Ca ratios in the prismatic layer............83

Table 4.2 $\mathrm{Ba} /$ Ca ratio vs. various element/Ca ratios in the prismatic layer.............84

Table 4.3 Nacreous layer element/Ca Pearsons Correlation Coefficient..................86

Table 5.1 Crystal properties of calcite and aragonite............................................89

Table 5.2 Growth rates of pāua from various studies..........................................105

Table 5.3 preferred characteristics of bioindicator organisms...........................108 


\section{LIST OF APPENDICES}

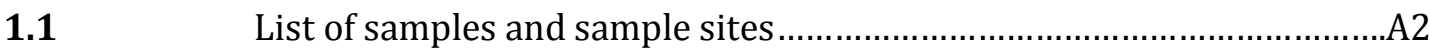

2.1 OceaNZ Blue Ltd growth vs temperature graph...................................A3

3.1 element/Ca prismatic layer correlation coefficient matrices ..................A4

3.2 element/Ca nacreous layer correlation coefficient matrices..................A12

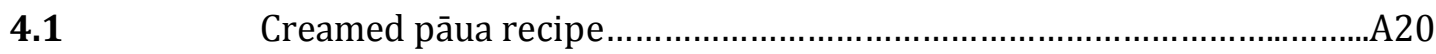

\section{ROM}

5.1 Element/Ca ratio data of prismatic layer transects

5.2 Element/Ca ratio data of nacreous layer transects

5.3 Element/Ca ratio data of individual growth band transects 


\section{INTRODUCTION}

\subsection{GENERAL INTRODUCTION}

The Earth system is a complex system regulated by physical, chemical and biological interactions between the atmosphere, oceans, cryosphere, continents and all living entities (Bradley, 2000; Henderson, 2002; IPCC, 2007a; Snyder, 2010). The ocean is particularly important within this system as it covers $>70 \%$ of Earth's surface (Lea, 2003). Both the oceans and its temperature affect Earth's climate through the high heat capacity of the ocean which is 1,000 times larger than that of the atmosphere (IPCC, 2007a). Heat is generally stored in the upper layers of the ocean and may move great distances and be exchanged between the oceans and atmosphere (Benton, 1974; Clark et al., 2002; IPCC, 2007a). The transportation of heat around Earth in the form of the Thermohaline Circulation system has also been referred to as the 'Achilles Heel' in our understanding of Earth's climate system (Broecker, 1997).

Over the last 130 years, human documentation and advances in technology such as meteorological instruments have contributed to the understanding of the spatial-temporal variability of the Earth's climate system as a whole (Bradley, 2000; Broecker, 2001).Recently, climate scientists have also used observational data and computer modelling in order to understand present and future climate (Henderson, 2002). Current observations of the recent and ongoing changes in the Earth's climate have suggested significant anthropogenically-driven changes are taking place. The ocean, along with the rest of the planet, is warming due to the increase of anthropogenic $\mathrm{CO}_{2}$ emissions (IPCC, 2007b). The Intergovernmental Panel on Climate Change (IPCC), provides the world with a clear scientific view on the current state of knowledge in climate change (IPCC, 2011). Climate scientists of the IPCC have created models in order to predict the future of Earth's climate. The scientific models predict that global mean temperatures will increase by $>4{ }^{\circ} \mathrm{C}$ in the coming century in a worst-case scenario (Fig. 1.1). 


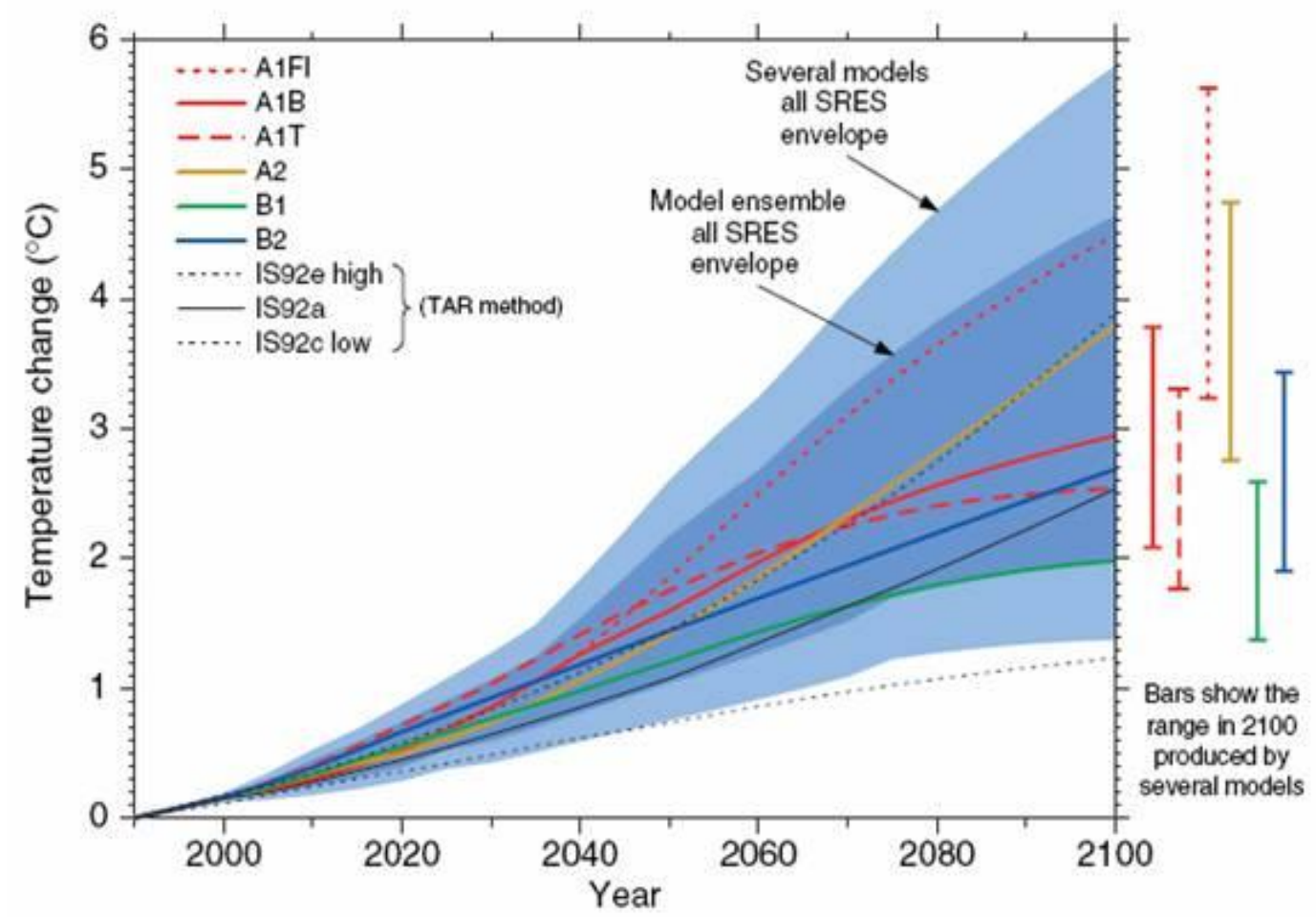

Fig. 1.1. IPCC diagram showing predicted global temperature change from 1999 to 2100. The predicted changes are based on six non-mitigation scenarios with respect to emissions of anthropogenic $\mathrm{CO}_{2}$ (IPCC, 2007b).

New Zealand has also experienced local sea temperatures increase by $0.7^{\circ} \mathrm{C}$ since 1871, with the Chatham Islands having experienced temperature increases of $1.0^{\circ} \mathrm{C}$ over the last $100 \mathrm{yr}$ (IPCC, 2007c). The relative sea levels in New Zealand have risen $1.6 \mathrm{~mm}$ on average each year since 1800 (IPCC, 2007c). This marked change in climate has been attributed to anthropogenic input of $\mathrm{CO}_{2}$ and other pollutants into the atmosphere.

Plausible projected climate models, however, are judged on how well the models represent or mimic current climates (Bradley, 2000; Hargreaves and Annan, 2009; Shen et al., 1996). Natural forcing of current climate is strongly overprinted by anthropogenic influences (Bradley, 2000; Hargreaves and Annan, 2009). Thus researchers examine climate change in the geological past not only as a source of information about an Earth without the influence of human activity, but also to understand the potential climates and responses expected to occur in the future (Bauwens et al., 2010; Hargreaves and Annan, 2009; Henderson, 2002; Snyder, 2010). Moreover, as anthropogenic activity increases, 
pre-industrial environmental baselines are an important aid to the assessment of the impacts caused to marine ecosystems by global climate change (Bauwens et al., 2010; Carroll et al., 2009).

Geochemical proxies applied to biological archives are becoming increasingly important in gathering information on climates and environmental conditions that are no longer in existence. Advances in geochemical techniques allow biological shell archives to be analysed at high spatial resolutions. (Vander Putten et al., 2000). The application of Laser ablation plasma mass spectrometry (LA-ICP-MS) offer direct multi-elemental analysis of the shell material providing high temporal information of weekly or even daily events. The use of biological carbonate skeletons preserved in the geological record, along with geochemistry, can provide this information from the geological past (Henderson, 2002).

\subsection{MOTIVATION FOR RESEARCH, THESIS OUTLINE AND OBJECTIVES}

\subsubsection{Importance for New Zealand}

New Zealand is a 270,692 $\mathrm{km}^{2}$ landmass located in the southwest Pacific Ocean with a coastline of $15,134 \mathrm{~km}$. It is separated into two main islands (North and South Island), and a number of smaller islands (Stewart Island, Chatham Island, etc.). The climate in New Zealand is variable due to its latitude, isolated location and physical characteristics including high altitude mountainous regions and long coastlines. With the current attention about the projected increase in global temperatures by the IPCC (2007c), New Zealand faces many questions about how this region will respond, for example:

- How will New Zealand, with its isolated geographic position, respond to the projected global changes?

- Will regional temperature changes be magnified, muted or be consistent with the global average? 
- How has New Zealand responded to past climate warming and cooling events?

- Past Northern Hemispheric events such as the Medieval Warm Period (MWP) and the Little Ice Age (LIA) have yet to be proven to have occurred in the Southern Hemisphere, and thus be global events (Broecker, 2001; Peetet, 1995; Villalba, 1994). Evidence from glacial extent, modelling and pollen records have proven that periods of warming and cooling of temperatures did occur around New Zealand, but to what extent were these events and are their timing synchronous in both hemispheres?

- What are the baseline temperatures prior to the Industrial Revolution around New Zealand, and what impact has anthropogenic pollution had on the climate and marine environment?

Pre-industrial baselines are important for quantitative assessment of the effects of anthropogenic activity on climate and ecosystems (Carroll et al., 2009; Schöne et al., 2005). Pre-pollution events are harder to monitor, due to the difficulty of finding archives that are able to track changes in the environment before, during and after these events.

The geochemistry of nearshore New Zealand mollusc carbonate shells can potentially be developed as a proxy for past and present environmental change. Establishing a modern calibration between element/Ca ratios within the shell, and recent environmental conditions of different species is the first step to utilising this approach. If successful, the modern calibration can then be applied to fossil shells that have been radiocarbon dated to trace the effect of past climatic change events of interest and anthropogenic activity in the New Zealand region. 


\subsubsection{Thesis Objectives}

This thesis had two main objectives:

Analytical technique development - The development of techniques for the high temporal resolution analysis of the trace element chemistry of the carbonate shells of pāua shells using LA-ICP-MS. Pāua were chosen specifically for this study as they are abundant, easily accessible and are wide spread across New Zealand rocky coastal settings.

Modern shellfish chemistry - The analysis and interpretation of the LA-ICP-MS trace element data of multiple modern pāua samples from well constrained coastal marine settings around New Zealand and correlating the results with air and ocean temperatures and water chemistry.

\subsubsection{Thesis Outline}

This thesis is presented in seven chapters. Chapter Two outlines background information on the use of the trace element chemistry of carbonates as a paleoclimate proxy, and the factors that affect the trace element chemistry of carbonate shells. Chapter Two also introduces the mollusc species used in this research - Haliotis iris (pāua). Chapter Three describes the methodology and materials used to prepare and analyse the samples. Chapter Four presents the results obtained on the pāua samples. These results are then interpreted and discussed in Chapter Five. Chapter Six summarises the conclusions that were made as a result of this study and Chapter Seven briefly mentions future work that could potentially further the work carried out in this study. 


\section{BACKGROUND}

\subsection{TRACE ELEMENTS IN CARBONATE AS A PROXY FOR PALEOCLIMATOLOGY}

Paleoclimatology has been at the forefront of geoscience research over the last 50 years (Henderson, 2002; Krantz, 1990; Latal et al., 2006; Lazareth et al., 2007; Lea, 2003). Many advances in paleoclimate studies have been made during this time, from the invention of the piston core to retrieve undisturbed foraminifera samples from sediment cores, through to the use of $\delta^{18} 0$ content in carbonate species (e.g., foraminifera, corals) as a proxy for past ocean temperatures (Lea, 2003).

One research area that has advanced significantly is the analysis of trace element chemistry in calcareous skeletons of marine organisms (Lea, 2003). Frank Clarke was the first to recognise that these geochemical variations have the potential to record ocean temperatures when he documented the relationship between the magnesium (Mg) content of biogenic carbonates, and their growth temperature (Lea, 2003). Clarke and Wheeler (1922) identified that the $\mathrm{Mg} / \mathrm{Ca}$ ratio in the ocean was relatively constant over long time-scales and, therefore, the $\mathrm{Mg} / \mathrm{Ca}$ ratio variations in biogenic carbonate were caused by other variables such as temperature (Lea, 2003). A similar relationship was discovered in 1979 when it was established that the Sr/Ca ratios of scleractinian corals decrease by $0.8 \%$ per ${ }^{\circ} \mathrm{C}$ increase in ocean temperature (Broecker, 2002; Shen et al., 1996). Continual improvements in (micro-) sampling methodologies, analytical and geochemical techniques have led to higher temporal resolution climate records of the past.

\subsubsection{Paleoclimate Records from Foraminifera and Coral}

The calcium carbonate $\left(\mathrm{CaCO}_{3}\right)$ shells produced by marine organisms including foraminifera, ostracods, pteropods and corals have been shown to be excellent archives of the environment in which these organisms have lived (Freitas et al., 2006; Mitsuguchi et al., 1996; Pearce and Mann, 2006). Mg/Ca ratios in 
planktonic foraminifera are now widely used as a proxy for sea surface temperatures (SST) through establishing a temperature equation relating foraminiferal $\mathrm{Mg} / \mathrm{Ca}$ to ocean temperature (below) (e.g., Anand et al., 2003; Barker et al., 2005; Lea, 2003).

$$
\mathrm{Mg} / \mathrm{Ca}(\mathrm{mmol} / \mathrm{mol})=\mathrm{B} \times \exp ^{(\mathrm{A} \times \mathrm{T})}
$$

Where:

$T=$ calcification temperature $\left({ }^{\circ} \mathrm{C}\right)$

$A$ and $B=$ species-specific constants

The $\mathrm{Mg} / \mathrm{Ca}$ ratios of a range of species of planktonic foraminifera were measured by Anand et al. (2003) and the $\mathrm{Mg} / \mathrm{Ca}$ ratio was demonstrated to have a sensitivity of ca. $9 \%$ with every ${ }^{\circ} \mathrm{C}$ increase of temperature (Barker et al., 2005).

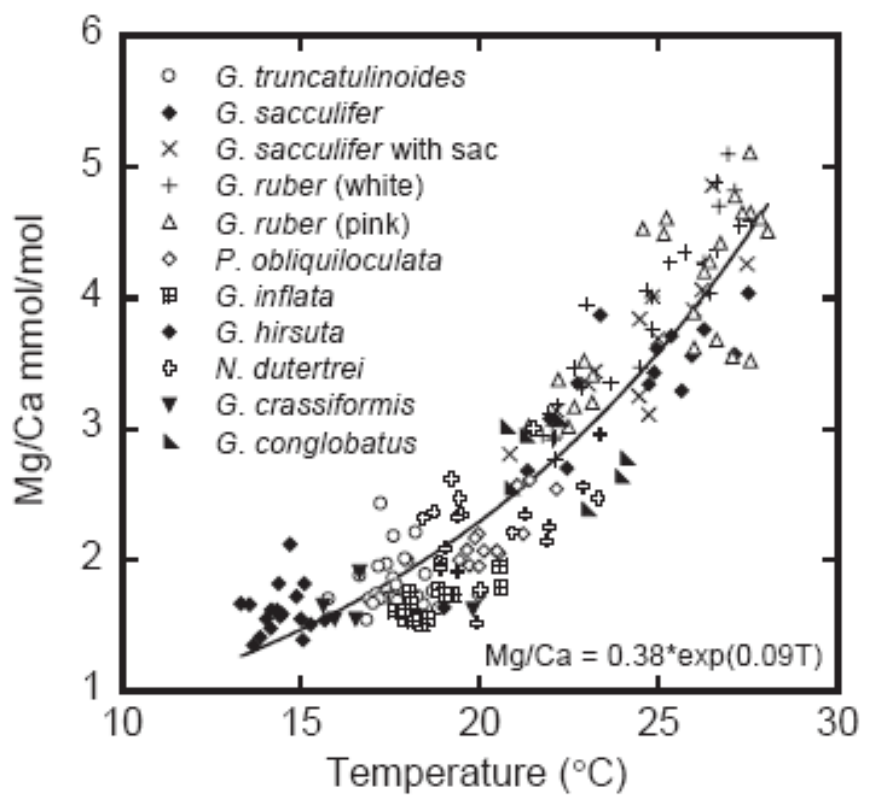

Fig. 2.1. $\mathrm{Mg} / \mathrm{Ca}$ ratios of a range of planktonic foraminifera species and isotopically derived calcification temperatures studied by Anand et al. (2003) (Barker et al., 2005).

The application of $\mathrm{Mg} / \mathrm{Ca}$ thermometry to foraminiferal calcite has been successfully used to reconstruct past ocean temperatures. Elderfield and Ganssen (2000) used Mg/Ca ratios along with $\delta^{18} \mathrm{O}$ of 8 species of planktonic 
foraminifera to interpret glacial and interglacial changes in the North Atlantic from the Last Glacial Maximum (LGM) through to the Holocene. The $\mathrm{Mg} / \mathrm{Ca}$ ratio in benthic foraminifera has also used to reconstruct a deep sea temperature record for the past 50 Myr (Lear et al., 2000).

The Sr/Ca ratio in various species of coral has also been widely studied as a proxy for SST and sea surface salinity (SSS) (Lea, 2003; McCulloch et al., 1996; Mitsuguchi et al., 1996). Corals form annual bands within their aragonite skeletons, which allow for sub-annual environmental reconstruction (Henderson, 2002; Shen et al., 1996). The relationship between coral and seawater temperature is derived by the equation below (Lea, 2003).

$$
\mathrm{Sr} / \mathrm{Ca}_{\text {coral }}\left(\mathrm{mmol} \mathrm{mol}^{-1}\right)=b+m(\mathrm{SST})
$$

The substitution of $\mathrm{Sr}$ for $\mathrm{Ca}$ in aragonite of coral has an inverse relationship with temperature as the consequence of this being an exothermic reaction (Fig. 2.2) (Lea, 2003).

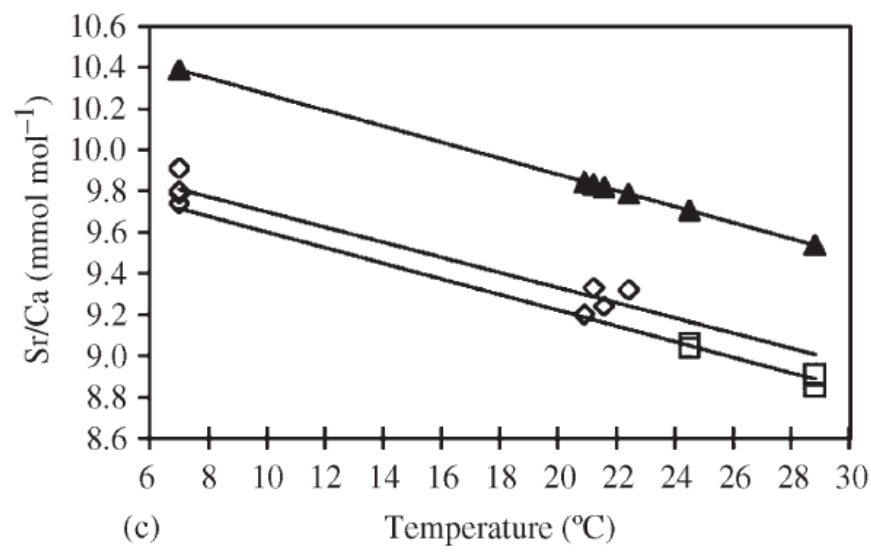

Fig. 2.2. Correlation of Sr/Ca with SST data for the asymbiont coral skeleton of Astrangia (squares), the night time skeleton of Porites (diamonds) and inorganic aragonite precipitated at equilibrium (triangles) (Lea, 2003). The slope is indicative of the temperature sensitivity of $\mathrm{Sr} / \mathrm{Ca}$ uptake into the coral skeleton.

Although the potential of $\mathrm{Sr} / \mathrm{Ca}$ ratios as a paleo-ocean thermometer has been known since the 1970s, the application only became effective in the early 1990s through the development of more precise analytical techniques (Broecker, 2002; 
Lea, 2003; Shen et al., 1996). The use of isotope dilution thermal ionisation mass spectrometry (ID-TIMS) was used to show clear Sr/Ca cycles associated with seasonal banding from a fossil coral from Vanuatu that had been radiocarbon dated to an age of 10,000 yr BP (Broecker, 2002; Lea, 2003). McCulloch et al. (1996) were then able to apply Sr/Ca calibrations to uplifted Holocene coral terraces from Papua New Guinea to attain almost weekly resolution SST data.

Both foraminifera and coral are limited in some ways with the paleoclimate information they can provide. Foraminifera only provide one mean temperature data throughout their life (Elderfield and Ganssen, 2000). Planktonic foraminifera also fluctuate within the water column throughout their lives, recording the isotopic and trace element signature at different depths. Corals provide high temporal resolution data through the successive deposition of their $\mathrm{CaCO}_{3}$ shell layers over time however provide a record that is restricted to tropical environments and thus the records they preserve are of limited application in a global context (Gillikin, 2005; Henderson, 2002). Molluscan species, like coral, also successively deposit their $\mathrm{CaCO}_{3}$ layers allowing a higher resolution of seasonal or daily events to be recorded. Molluscs,, however, are found widespread throughout the world in coastal and freshwater environments, and as such can contribute to theproviding more of an understand to the regional and global temperature changes.

\subsection{MOLLUSCS AND THEIR POTENTIAL AS A PALEOCLIMATE ARCHIVE?}

Mollusca are soft bodied metazoans with more than 35,000 fossil species and over 110,000 living mollusc species. Molluscs are the largest phylum on Earth and include the class of bivalves (mussels, oysters, clams and scallops), gastropods (pteropods, abalone), scaphopods (tusk shells) and cephalopods (nautilus) (Prothero, 1998; Simkiss and Wilbur, 1989). Some species precipitate external calcified structures that support their living tissue and protect against predators (Marin \& Luquet, 2004; Davis, 2008). 
Molluscs and more specifically bivalves have been widely studied as a potential archive for past and present environmental conditions due to their incremental deposition of shell material over time (Frietas et al., 2006; Rosenthal and Katz, 1989; Schöne et al., 2005; Wanamaker et al., 2007). This shows their potential to reconstruct, at high temporal resolution, the varying environmental conditions that the animal has experienced during its life (Frietas et al., 2006; Schöne et al., 2005; Vander Putten et al., 2000). Molluscs can be found today in a wide range of different habitats from shallow waters to deep sea environments (Schöne et al., 2005). Mollusc shells are also abundant in the geologic record, which makes such shells an ideal potential archive of past and present environmental conditions (Frietas et al., 2006; Killingley and Berger, 1979; Vander Putten et al., 2000).

Recent studies have applied the use of trace element chemistry to different species of bivalves in order to correlate the geochemistry of the shells with environmental conditions (Vander Putten et al., 2000). The geochemistry of Mytilus spp. has been widely studied as a potential proxy for past environmental conditions (Gillikin et al., 2006; Klein et al., 1996; Vander Putten et al., 2000). The $\mathrm{Mg} / \mathrm{Ca}$ chemistry of $M$. trossulus was investigated by Klein and others (1996a) in order to attempt to reconstruct SST. The temperature, salinity and seawater isotopic composition were collected from the habitat of the $M$. trossulus in order to make an empirical calibration of shell chemistry to environmental conditions (Klein et al., 1996a). Mg/Ca ratios were calibrated to temperature with an accuracy of $\pm 1.5^{\circ} \mathrm{C}$ (Klein et al., 1996a). Vander Putten and colleagues (2000) also examined the environmental and biological factors that affect M. edulis during shell formation.

In addition, Freitas et al. (2006) investigated the effects of environmental and biological controls on elemental ratios of $\mathrm{Mg} / \mathrm{Ca}, \mathrm{Sr} / \mathrm{Ca}$ and $\mathrm{Mn} / \mathrm{Ca}$ in the king scallop Pecten maximus. Powdered samples were collected from the king scallop by milling the surface along the main axis of growth at increments ranging from 1 to $2 \mathrm{~mm}$ (Frietas et al., 2006). It was shown that in this case seasonal variations existed that could potentially reflect intra-annual variations of 
dissolved $\mathrm{Mn}^{2+}$ in seawater, whereas $\mathrm{Sr} / \mathrm{Ca}$ in the shell was mainly controlled by precipitation, and $\mathrm{Mg} / \mathrm{Ca}$ was weakly correlated to temperature.

Fewer studies have looked into the geochemical signature recorded within gastropod shells. Each individual species of mollusc, however, will vary in the biological controls on biomineralisaton, which will result in each species displaying unique mineral properties, including size, shape, crystallinity and trace element composition (Frietas et al., 2006). With this in mind, individual species need to be tested for their potential as archives of environmental change.

\subsection{TRACE ELEMENT PROXIES}

Trace elements are present in seawater in both dissolved and particulate matter, and vary widely in concentration and are taken up by $\mathrm{CaCO}_{3}$ producing organisms in varying concentrations. The distribution of elements such as $\mathrm{Mg}$, $\mathrm{Sr}, \mathrm{Ba}, \mathrm{Mn}$ and others has been measured within the shells of carbonate organisms and has provided proxies for paleotemperature, paleosalinity, primary production and pollution (Barker et al., 2005; Carré et al., 2006; Freitas et al., 2006; Lazareth et al., 2007; Pearce and Mann, 2006; Schöne et al., 2005; Tynan et al., 2005).

Several divalent cations, including $\mathrm{Mg}^{2+}$, can be substituted for $\mathrm{Ca}^{2+}$ in the crystal lattice of $\mathrm{CaCO}_{3}$ during the formation of biogenic carbonate (Barker et al., 2005). The incorporation of such elements can then reflect the physico-chemical (including temperature and salinity), biological (primary productivity) and anthropogenic (pollution) conditions that the organism is exposed to during its life span (Barker et al., 2005; Lazareth et al., 2003; Schöne et al., 2005).

\subsubsection{Mg and $\mathrm{Sr}$ in carbonate as proxies of paleo-ocean temperatures}

Firstly, it is important to understand the mechanisms of elemental substitution in carbonates. Molluscs have the potential to precipitate $\mathrm{CaCO}_{3}$ as any of its six 
polymorphs (Davis, 2008). The two main polymorphs that make up the mineralogy of $\mathrm{CaCO}_{3}$ shell-bearing organisms are calcite and aragonite (Davis, 2008; Dodd, 1967; Ming, 2006; Skinner and Jahren, 2007). Both polymorphs are anhydrous, and have rhombohedral and orthorhombic crystal structures, respectively (Davis, 2008; Dodd, 1967; Ming, 2006). The uptake of Mg into the crystal structure of $\mathrm{CaCO}_{3}$ is favoured in calcite over aragonite as the smaller $\mathrm{Mg}^{2+}$ ion more readily substitutes into the calcite lattice which is isostructural with magnesite (Dodd, 1967). The larger $\mathrm{Sr}^{2+}$ ion, which has a crystal lattice isostructural with strontianite has a stronger binding affinity within aragonite (Dodd, 1967).

The aforementioned use of $\mathrm{Mg} / \mathrm{Ca}$ and $\mathrm{Sr} / \mathrm{Ca}$ paleothermometry in foraminifera and corals has proven a reliable method. The uptake of $\mathrm{Mg}^{2+}$ into the $\mathrm{CaCO}_{3}$ shell is thermodynamically controlled, and is influenced by the ambient temperature of the surrounding sea water, resulting in $\mathrm{Mg} / \mathrm{Ca}$ ratios increasing with increasing temperatures (Barker et al., 2005; Lea, 2003). Few studies have successfully used $\mathrm{Mg} / \mathrm{Ca}$ paleothermometry within molluscs as the internal biological controls affect the chemistry of the shell as well as temperature (Frietas et al., 2006; Lazareth et al., 2007).

Research into Sr/Ca ratios of aragonitic bivalves has also shown varying degrees of success in its application to paleo-ocean thermometry (Gillikin et al., 2005). Gillikin et al. (2005) showed that Sr/Ca ratios in Saxidomus giganteas shells had a very weak correlation with temperature and could not be used as a reliable proxy. Vander Putten et al. (2000) presented results that indicate that processes other than variations in seawater chemistry and temperature were responsible for $\mathrm{Sr} / \mathrm{Ca}$ ratio variations seen within the shell. Other research has discovered a strong $\mathrm{Sr} / \mathrm{Ca}$ co-variance with shell growth rate which is, then in turn, influenced partly by seawater temperature (Frietas et al., 2006).

\subsubsection{Other trace elements as proxies of environmental conditions}

Recent studies have delved into using $\mathrm{Ba} / \mathrm{Ca}$ and $\mathrm{Mn} / \mathrm{Ca}$ ratio of carbonates as a proxy for primary productivity events (Gillikin et al., 2006; Lazareth et al., 2003). 
Ba generally enters seawater in particulate form from rivers and coastal ground water inputs (Carré et al., 2006; Gillikin et al., 2006; Lazareth et al., 2003). Ba then enters the mollusc via ingestion or through the gills (Gillikin et al., 2006). Dissolved $\mathrm{Ba}^{2+}$ concentrations in seawater are low (34 nmol/L) and, therefore, the incorporation of Ba into carbonate shells is controlled by availability (Carré et al., 2006). The formation of barite and primary productivity are closely associated, so any increase in $\mathrm{Ba}$ in $\mathrm{CaCO}_{3}$ shells is usually attributed to a diatom bloom or other planktonic event caused by increased nutrients in the system (Carré et al., 2006; Gillikin et al., 2006; Lazareth et al., 2003). High resolution study of $M$. edulis shells has been used to track fluctuating $\mathrm{Ba}$ and thus fluctuating nutrient supply in the ocean system (Gillikin et al., 2006).

The incorporation of $\mathrm{Mn}^{2+}$ from seawater into inorganic calcite is directly linked to the dissolved $\mathrm{Mn}^{2+}$ concentration in the ocean through the ingestion of enriched particulate matter including phytoplankton and diatoms (Freitas et al., 2006; Lazareth et al., 2003). Thus, the Mn/Ca ratio could provide a proxy for seasonal changes in primary production and increased river discharge events that have been associated with phytoplankton blooms (Frietas et al., 2006; Lazareth et al., 2003; Vander Putten et al., 2000). Mn/Ca ratios have been observed to co-vary with $\mathrm{Ba} / \mathrm{Ca}$ in studies of the gastropod Concholepas concholepas, allowing their use as a proxy for primary productivity (Lazareth et al., 2003).

\subsubsection{Trace metal contaminants: A tracer for anthropogenic pollution?}

The monitoring of trace metal pollutants in shell-bearing molluscs also has the potential to record changes in the environmental conditions in which the organisms have lived (Boening, 1999; Carroll et al., 2009; Pearce and Mann, 2006; Price and Pearce, 1997; Protasowicki et al., 2008: Raith et al., 1996; Tynan et al., 2005; Whyte, 2006; Yap et al., 2003). Trace metals are released into seawater from both natural sources (e.g., geochemical cycling), and anthropogenic sources (Chester, 1999; Protasowicki et al., 2008). Such anthropogenic sources include paint leaching into storm drains or road runoff, 
partially-treated sewage, and waste discharge from mines, and galvanising and wood treatment plants (Whyte, 2006). Many trace metals found in the ocean have toxic effects on the ecosystem with many marine species suffering adverse effects to elevated trace metal concentrations (Boening, 1999).

Trace elements including aluminium $(\mathrm{Al})$, zinc $(\mathrm{Zn})$, lead $(\mathrm{Pb})$ along with other heavy metals, can accumulate in both the soft tissue and hard $\mathrm{CaCO}_{3}$ shell of molluscs (Price and Pearce, 1997; Protasowicki et al., 2008; Tynan et al., 2005). The shells, however, are more practical for use in monitoring metal contamination as they reveal less variability, can be preserved in the geological record (unlike soft tissue) and record the changing levels of pollutants over the life of the organism (Carroll et al., 2009; Protasowicki et al., 2008). This makes shells useful in assessing the extent of environmental contamination in marine ecosystems, and measuring levels prior to pollution events (Pearce and Mann, 2006; Protasowicki et al., 2008; Raith et al., 1996; Yap et al., 2003). Molluscs also provide an archive for reconstructing the effects of pollution after it has taken place (Foster and Cravo, 2002; Carter, 1980). Price and Pearce (1997) investigated elements including $\mathrm{Pb}, \mathrm{Zn}$ and $\mathrm{U}$ in the shell of the cockle Cerastoderma edule from the British Isles using LA-ICP-MS. Results showed that due to the high resolution of the laser ablation technique, it is possible to identify short-term pollution events within the shell layers.

\subsection{FACTORS INFLUENCING TRACE ELEMENT INCORPORATION IN MOLLUSCS}

Many factors need to be considered when examining the controls on the geochemistry of mollusc shells (Anadón et al., 2006). Biological factors largely control the chemistry of the shell. Other controls are shell mineralogy and ambient trace element water chemistry (Anadón et al., 2006; Carré et al., 2006; Schöne, 2008; Wilbur and Saleuddin, 1983). Cessation of shell growth can occur due to predation, rough waters or lack of food. The ambient water chemistry has an effect on which elements will be incorporated into the shell, as only the 
elements the mollusc is exposed to can be taken up and incorporated into its shell. It is important to analyse each individual species as in some biological controls are constant enough to allow environmental conditions and trace element chemistry to be correlated (Carré et al., 2006).

\subsubsection{Shell Formation and Biomineralisation}

To understand trace element incorporation into mollusc shells, it is important to first understand how the shell grows. There are four main divisions of the shell formation system. These are: (1) the external medium, (2) the hemolymph and body tissues, (3) the extrapallial fluid compartments (EPS), and (4) the shell itself (Fig. 2.3) (Wilbur and Saleuddin, 1983).

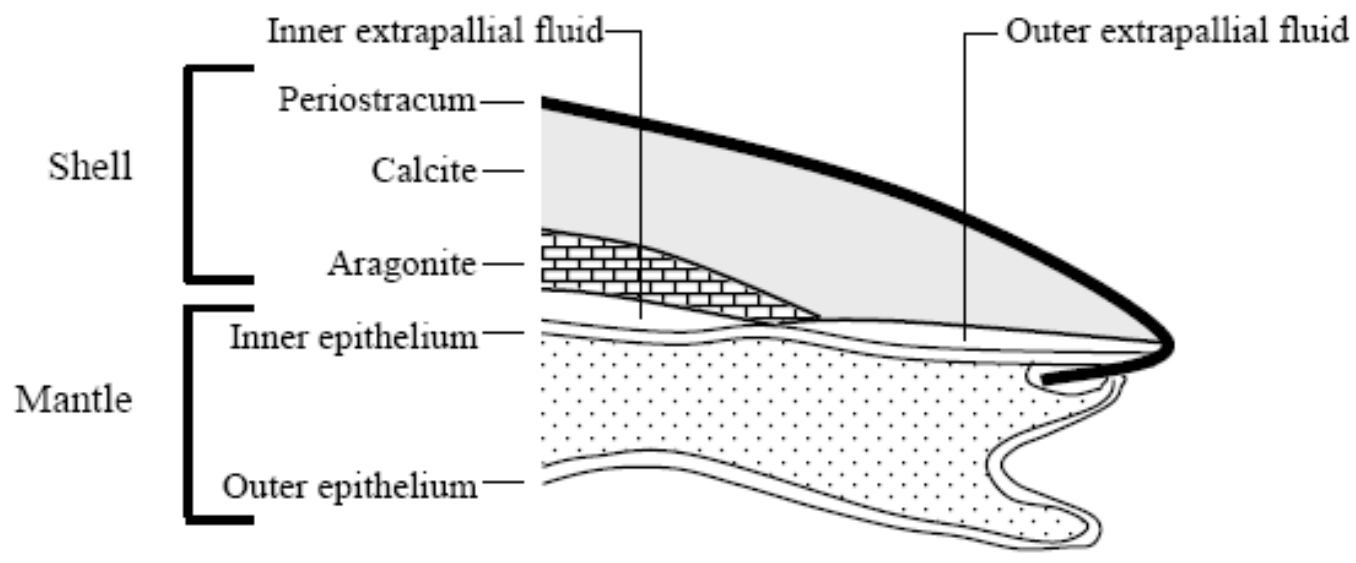

Fig. 2.3. Schematic cross section through a mussel shell (periostracum and the calcite and aragonite layers) and mantle (inner and outer epithelium) showing the internal compartments including the extrapallial fludi associated with shell formation (Gillikin, 2005).

Shell formation involves the movement of ions from the external medium through the soft tissue of the mollusc in order for biomineralisation to occur (Fig 2.4) (Wilbur and Saleuddin, 1983). Biomineralisation is the process by which living organisms influence the precipitation of mineral by converting ions in solution into solid materials (Davis, 2008; Lin and Meyers, 2005; Simkiss and Wilbur, 1989; Skinner and Jahren, 2007; Weiner and Dove, 2003). 
This takes place in the extrapallial fluid, which is located between the mantle epithelium and the inner layer of the shell surface (Gillikin, 2005; Wilbur and Saleuddin, 1983).

The first stage of shell formation is the uptake of calcium $\left(\mathrm{Ca}^{2+}\right)$ and bicarbonate $\left(\mathrm{HCO}_{3}{ }^{-}\right)$ions from the external environment, through the body epithelium and hemolymph of the mollusc (Marin and Luquet, 2004; Wilbur and Saleuddin, 1983; Simkiss and Wilbur, 1989). Ions primarily enter the hemolymph through the gills (and occasionally through the gut) of the organism (Gillikin et al., 2006). The mantle epithelium then transfers them from the hemolymph to the extrapallial fluid compartment where biomineralisation and shell deposition take place (Marin and Luquet, 2005; Wilbur and Saleuddin, 1983; Simkiss and Wilbur, 1989). The extrapallial fluid compartment, not only receives ions from the external sea water medium but from the tissue of the organism (Freitas et al., 2006).

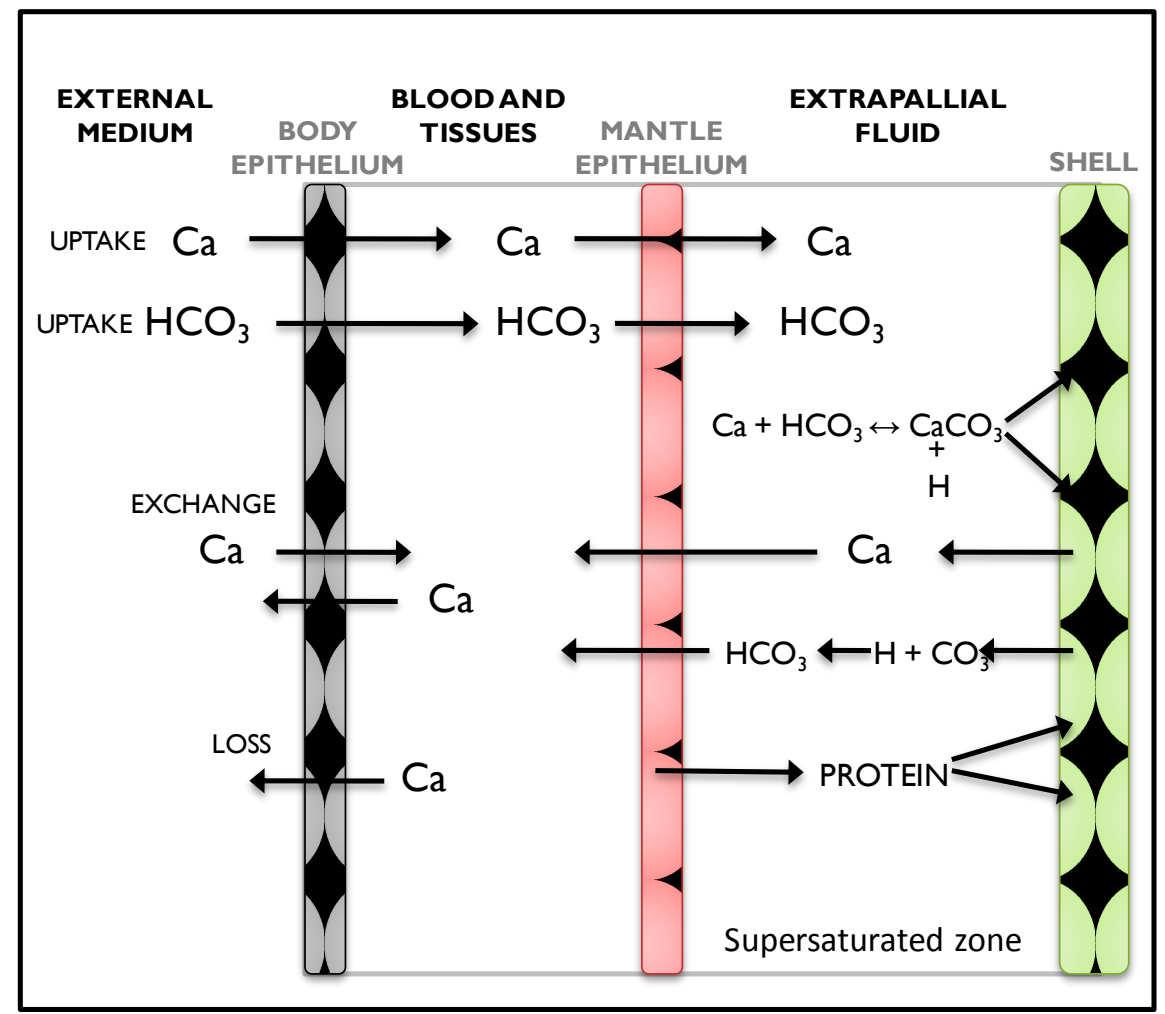

Fig. 2.4. The molluscan mineralising system as described by Wilbur and Saleuddin (1983). The diagram represents the movement of ions from the external medium to the extrapallial fluid. 
The extrapallial fluid is an enclosed region with no contact to living tissue and the ambient seawater (Davis, 2008; Marin and Luquet, 2005). This creates optimum conditions for biomineralisation (Davis, 2008; Marin and Luquet, 2005; Wilbur and Saleuddin, 1983; Vander Putten et al., 2000). In order to create conditions favouring crystal nucleation, the extrapallial fluid must be supersaturated (Wilbur and Saleuddin, 1983). Calcification will occur when the extrapallial fluid is supersaturated, only allowing crystallisation to occur when appropriate, and controlling what is recorded in the carbonate shell (Marin and Luquet, 2004). Concentrations of $\mathrm{Ca}^{2+}$ and $\mathrm{HCO}_{3}$ - must exceed the solubility of the products for the removal of $\mathrm{H}^{+}$ions to take place in order to form $\mathrm{CaCO}_{3}$ (Davis, 2008; Wilbur and Saleuddin, 1983; Vander Putten et al., 2000). The formation of $\mathrm{CaCO}_{3}$ minerals is based on a reaction between $\mathrm{Ca}^{2+}$ and $\mathrm{HCO}_{3}$ - ions within the extrapallial space (Simkiss and Wilbur, 1989). Once mineralisation has started, $\mathrm{H}^{+}$ions need to be removed from the calcifying matrix in order for the process to continue (Crenshaw, 1980; Wilbur and Saleuddin, 1983).

$$
\mathrm{Ca}^{2+}+\mathrm{HCO}_{3}^{-} \leftrightarrow \mathrm{CaCO}_{3}+\mathrm{H}^{+}
$$

$\mathrm{Ca}^{2+}$ and $\mathrm{HCO}_{3}$ are not the only inorganic ions in the extrapallial fluid, with $\mathrm{Na}^{+}$, $\mathrm{K}^{+}, \mathrm{Mg}^{2+}$ and $\mathrm{Cl}^{-}$also being present (Simkiss and Wilbur, 1989). However, the uptake of ions other than $\mathrm{Ca}^{2+}$ into the body and their substitution into the shell is also dependent on the binding site affinity for each ion species and the channel pathway of the ions through the calcifying mantle (Carre et al., 2006). Calcium channels are required to move $\mathrm{Ca}^{2+}$ around the body epithelium of the mollusc to the extrapallial fluid for biomineralisation. As $\mathrm{Ca}^{2+}$ ions are greatly out numbered by other ions in the ambient seawater, the calcium channels must be extremely selective to only allow an influx of $\mathrm{Ca}^{2+}$ rather than other cations (Hess and Tsien, 1984). Other trace elements (including $\mathrm{Sr}^{2+}$ and $\mathrm{Ba}^{2+}$ ) have a stronger affinity to the binding sites within the calcium channels (Carré et al., 2006). 


\subsubsection{Shell Structure}

Many mollusc shells are made up of three main layers: (1) the periostracum, (2) the outer prismatic layer, and (3) the inner nacreous layer (Fig. 2.5) (Simkiss and Wilbur, 1989). Both the prismatic and nacreous layers of the shell consist of $\mathrm{CaCO}_{3}$ polymorphs, generally calcite, aragonite or both (Davis, 2008; Lin and Meyers, 2005; Simkiss and Wilbur, 1989; Skinner and Jahren, 2007). The two forms of $\mathrm{CaCO}_{3}$ constitute up to $95-99 \%$ of the shell weight with the remaining shell weight made up of organic material (Lin and Meyers, 2005; Carter, 1980). The periostracum is a thin organic layer which forms the outermost part of the shell (Saleuddin and Petit, 1983). This layer is important for shell deposition, as it serves as a matrix for the carbonate crystals to grow on and also protects the shell from corrosion by seawater and colonization by epibionts and endobionts (Gray and Smith, 2004; Saleuddin and Petit, 1983).

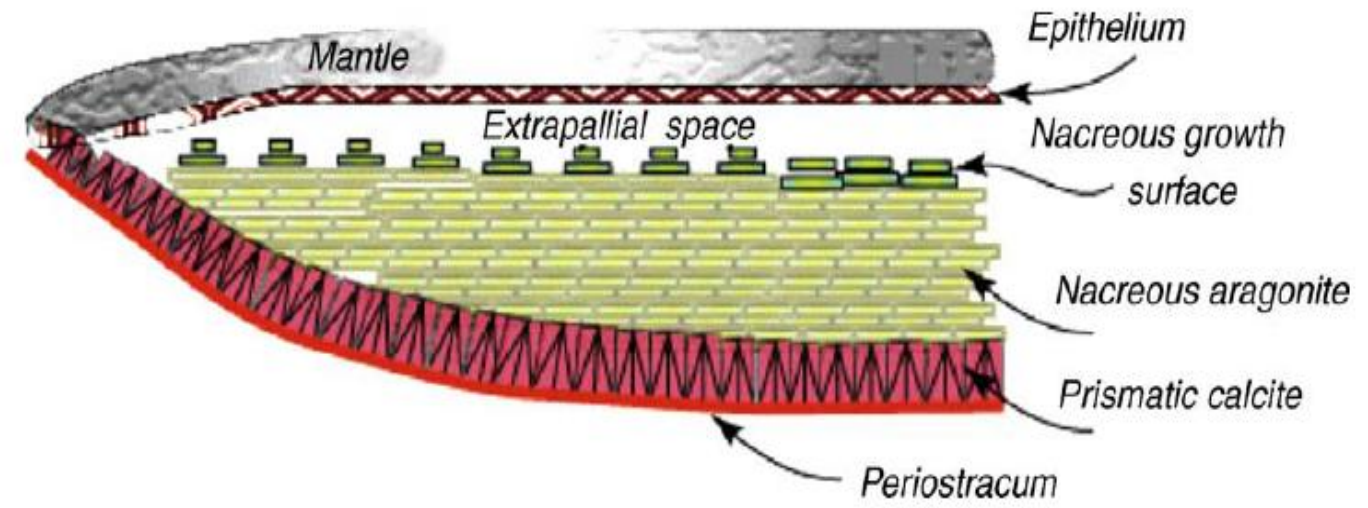

Fig. 2.5. Structure of a typical mollusc shell displaying the growth pattern in both the nacreous (aragonite crystals) and prismatic (calcite crystals) layers (Lin and Meyer, 2005).

\subsubsection{Prismatic Layer}

The prismatic layer is the outermost $\mathrm{CaCO}_{3}$ layer, and is the first to be precipitated from the extrapallial fluid (Simkiss and Wilbur, 1989). This layer is made up of long prisms and spherulites, up to $100 \mathrm{~nm}$ in diameter, surrounded by an organic matrix which separates them (Gray and Smith, 2004; Simkiss and Wibur, 1989; Wilbur and Saleuddin, 1983). The calcite prisms are precipitated 
and grow inwards from the periostracum (Simkiss and Wilbur, 1989). The periostracum influences the deposition of the $\mathrm{CaCO}_{3}$ prismatic layer, as it prevents lateral growth of the crystals, causing them to grow perpendicular to the periostracum (Saleuddin and Petit, 1983; Wilbur and Saleuddin, 1983). Wilbur and Saleuddin (1983) show evidence of the formation of the prismatic layer of many molluscs through the growth of spherulites (Fig. 2.6). The spherulites form in polygonal blocks at the outer shell as elongated crystal structures beginning to form. Spherulites at different stages of growth will be blocked by lack of space, and other crystals continue their growth and become larger in size. The organic material they are grow from will be displaced and replaced with the organic matrix.

a)

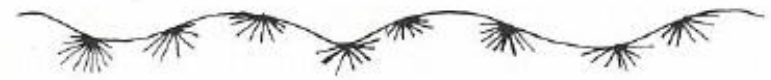

b)

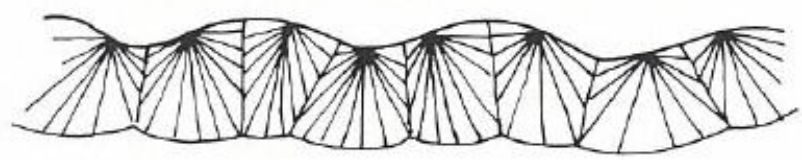

c)

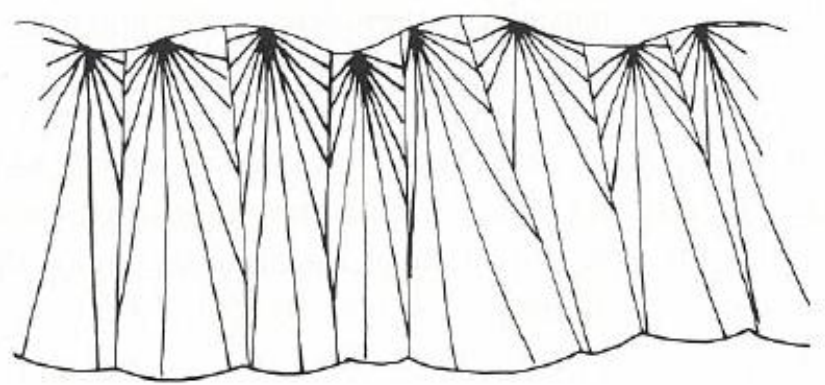

Fig. 2.6. The stages of crystal growth of the prismatic layer described by Wilbur and Saleuddin (1989).

\subsubsection{Nacre}

The nacre is the innermost layer of the shell and is composed of tabular, tiled crystalline aragonite surrounded by an organic matrix in a structure that 
resembles a brick and mortar (Fig. 2.7) (Gray and Smith, 2004; Lin and Meyers, 2005; Lin et al., 2008). This organic glycoprotein matrix only makes up 5 weight \% of the Haliotis nacreous shell composition however increases the fracture resistance of the shell by. 3000 times the fracture resistance compared to a shell of completely composed of inorganic $\mathrm{CaCO}_{3}$ crystals (Lin et al., 2008). Any energy related to defecting the brittle $\mathrm{CaCO}_{3}$ is propagated along the organic layers instead of the crystals (Davis, 2008; Gray and Smith, 2004).

The formation of the nacre begins with the deposition of mineralised granules and the secretion of matrix. Through continual growth, the granules become rounded, flattened crystals which are then covered by the organic matrix. The crystals are deposited in conical stacks with the youngest precipitated crystals having the smallest diameter (Wilbur and Saleuddin, 1989). Sheets of matrix will then secrete, filling the gaps of the crystal stacks. The lateral growth of the crystals continues, bringing crystals in contact with neighbouring stacks. The organism injects the organic matrix periodically when the animal is arrested (Lin and Meyers, 2005). These nacre aragonite plates of Haliotis iris are ca. 300 to $450 \mathrm{~nm}$ thick (Gray and Smith, 2004).
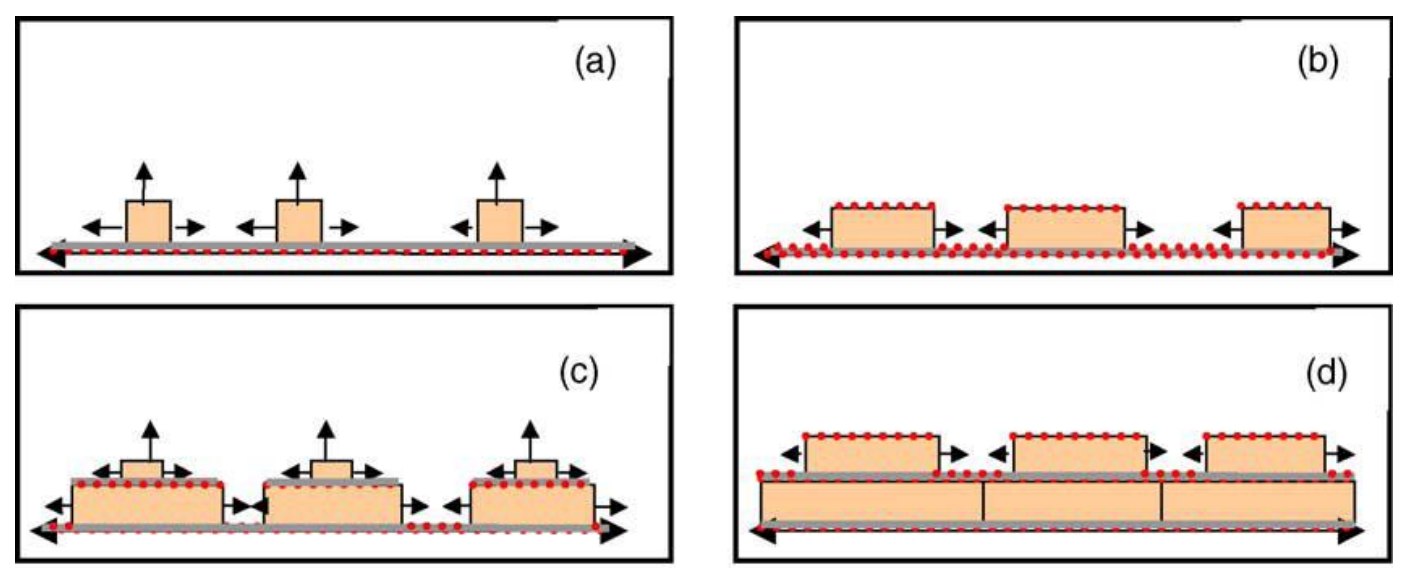

Fig. 2.7. A schematic representation of the formation of the nacreous layer in Haliotis species through the stacking of aragonite tiles (Lin and Meyers, 2005). Figure (a) represents the nucleation of aragonite intermittent with the protein layers (red dots). Figure (b-d) show the growth with the tiles periodically lain down protein layers. 


\subsubsection{Vital Effects}

Metabolic and physiological processes play a large part in the geochemistry of a mollusc's shell (Schöne, 2008; Vander Putten et al., 2000). The term 'vital effects' is given to metabolic processes that influence the chemical composition of the carbonate secreting fluid (Lazareth et al., 2007; Schöne, 2008; Vander Putten et al., 2000). The uptake of trace elements into the shell of molluscs is affected by many factors, including growth rate changes, $\mathrm{pH}$ variations of precipitating fluid and the transport of ions throughout the body tissue (Lazareth et al., 2007). If the element is not favourable for the system tracts within the mollusc then it is less likely to make its way to the EPF and be secreted within the shell (Wilbur and Saleuddin, 1983).

Growth rates of mollusc shells appear to vary between juvenile and mature specimens with many $\mathrm{CaCO}_{3}$-shell-bearing organisms experiencing growth deceleration with increasing age (Gardner et al., 1993; Wanamaker et al., 2007) Some species actually cease growth of their carbonate shells on a regular daily or semi-diurnal basis, during spawning, and when placed under stressful situations (Schöne, 2008). The prominent growth bands (Fig. 2.8) in mollusc shells are formed through the waxing and waning of shell growth as carbonate production varies (Schöne, 2008).

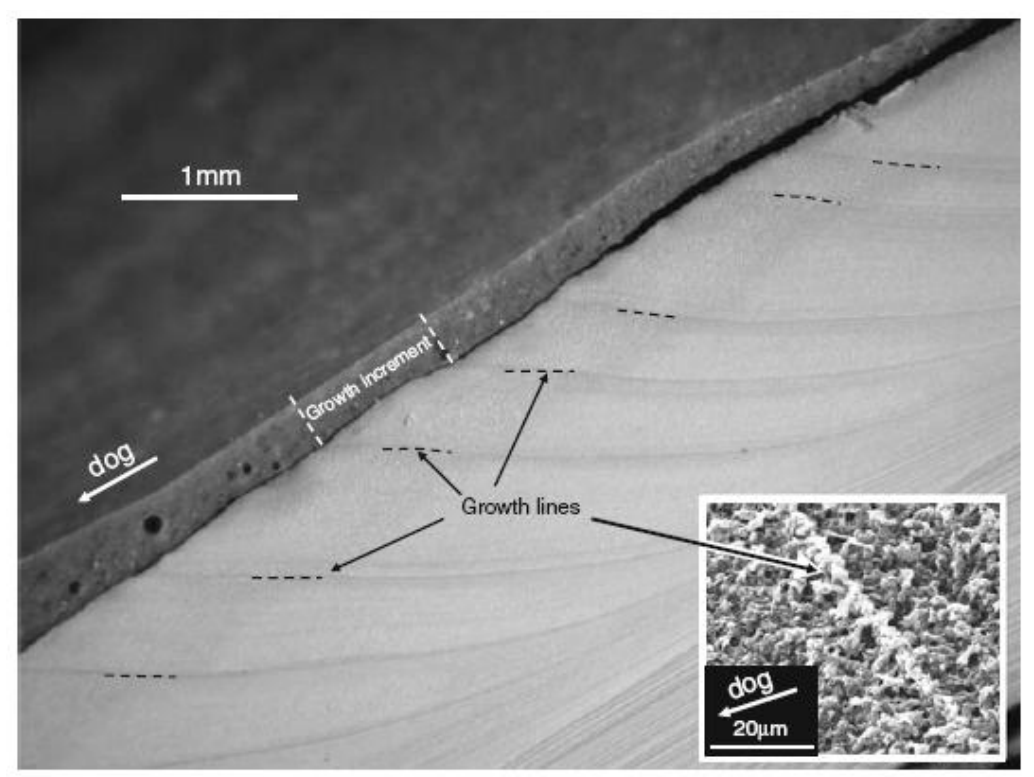

Fig 2.8. A polished cross section of an Arctica islandica showing the prominent growth lines from the cessation of precipitation of the calcium carbonate shell (Schöne, 2008). 


\subsubsection{ENVIRONMENTAL FACTORS}

Environmental conditions, including temperature, salinity and $\mathrm{pH}$ levels can alter and affect shell shape, microstructure, mineralogy and chemistry (Dodd, 1965; Rhoads and Lutz, 1980).

Temperature is the primary environmental factor that can influence the survival of many species (Searle et al., 2006; Schöne, 2008). Temperatures near the physiological optimum will favour shell production, whereas temperatures that exceed the species' thermal capacity will cause reduced shell production and even cause a cessation in shell growth (Schöne, 2008). In determining the upper thermal limit of organisms, thermal resistance has becoming increasingly important in the area of aquaculture development (Searle et al., 2006). The effect of temperature on the growth of Haliotis iris (pāua) has been investigated to determine optimal growth temperatures for the species (Searle et al., 2006). The results presented show that juvenile pāua have a higher thermal maximum than adult pāua by $1-2^{\circ} \mathrm{C}$ (Searle et al., 2006).

The salinity, $\mathrm{pH}$, sedimentation rates, water chemistry, and water quality of an environment can also place stress upon organisms (Schöne, 2008). Donovan and Taylor (2008) investigated the metabolic response of pāua in high waveswept environments. It was observed that even low-energy wave environments increase the metabolic rate of pāua, however, this is balanced by increased food availability and enhanced extraction of oxygen from the water (Donovan and Taylor, 2008).

Diet of the species and food availability are also important to the trace element chemistry of mollusc shells. Trace metals are taken up from all sources, including water and food. Therefore, high accumulated metal concentrations in a sample can be seen as an indicator of high ambient availabilities of that concentrated element (Protasowicki et al., 2007). 


\section{$2.5 \quad$ MOLLUSC SPECIES SELECTED FOR THIS STUDY}

\subsubsection{PĀUA}

The species chosen for this study is the gastropod Haliotis iris which is commonly known as the black foot abalone or, locally, by the Māori name pāua (Gray and Smith, 2004).

The name Haliotis iris is derived from the Latin names halios (marine) otus (ear) and iris (rainbow). There are over 100 species of Haliotis spp. found worldwide with three species including Haliotis iris (i.e. Haliotis australis (yellow foot pāua) and Haliotis virginea (white foot paua)) endemic to modern New Zealand waters. Pāua are widely recognized by the iridescent blue and green colours of its shell (Fig. 2.9).

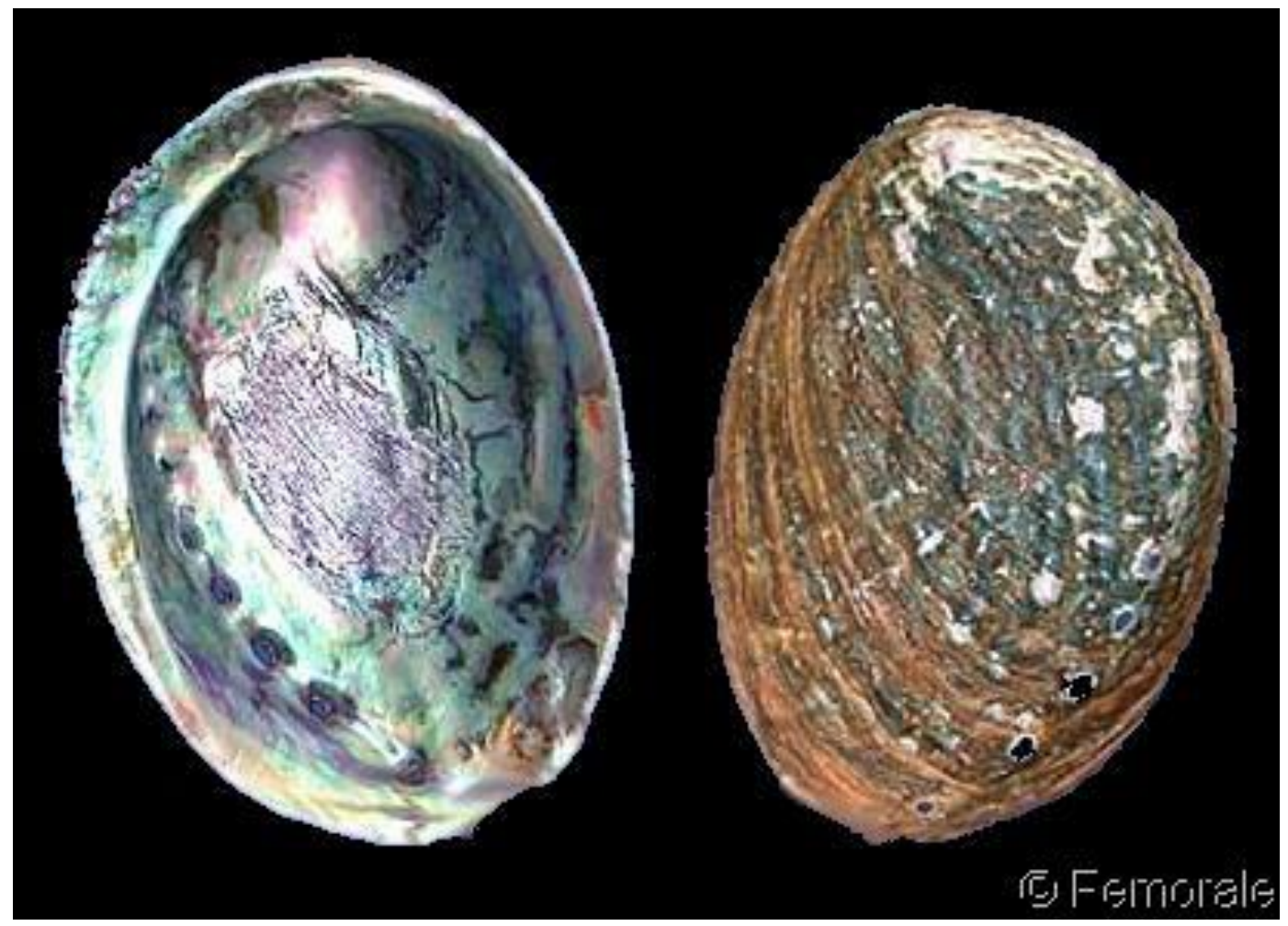

Fig. 2.9. The exterior and interior of a Haliotis iris shell. Photograph credit from gastropod.com.

Pāua is the largest of the New Zealand Haliotis family (maximum length $=180$ $\mathrm{mm})$. Pāua prefer low sedimentation rates, however, the environment in which they live varies from sheltered to very exposed locations (Gray and Smith, 2004). 
Pāua grow larger in cooler waters in the lower North Island and the South Island, than in the warmer waters of the northern part of New Zealand (Estes et al., 2005; Gray and Smith, 2004). This is due to cooler waters favouring calcite precipitation (Carter, 1980). The deposition of the pāua shell occurs spirally represented by a line of pores (tremata) that form approximately parallel to the outer contour of the shell (Gray and Smith, 2004).

Pāua in the wild feed on larger seaweeds including Polysiphonia spp. and Pterocladia lucida (red algae) and Carpoplyllum maschalocarpum and Ecklonia radiata (brown algae) (Poore, 1972a). Donovan and Taylor (2008) describe pāua's feeding habits as a 'sit and wait' strategy which involves the pāua remaining stationary until they can trap the algae between their foot and the rocky substrate beneath them.

Pāua have been investigated in many different studies including an extensive study of 'the ecology of New Zealand abalones, Haliotis species' by Poore (1972a, 1972b). The stable oxygen isotope composition of pāua were analysed through an organised shell layer transect in order to validate the growth rate, age and reproductive patterns (Naylor et al., 2007). In order to identify these factors, $H$. iris shells were tagged on a known date and with growth measured for a given period (Naylor et al., 2007). Oxygen isotopes can also be used in determining ambient temperatures during shell growth.

\subsubsection{Pāua in Aotearoa New Zealand: Cultural and Economic Importance}

Pāua have been harvested for several hundred years as a traditional food by Māori (Gray and Smith, 2004). Māori place great importance and reliance on fishing sources and customary fishing as iwi (tribe) and hapu (sub-tribe) from coastal regions (who did not go inland to hunt) would rely on the ocean for kai moana. Māori place strong spiritual connection on the ocean as kai moana within ocean are seen as the children of Tangaroa (Māori God of the Sea) which should be cherished and protected. The sustainability of kai moana is also respected and sustained in order to use it to support future generations. Pāua provides a food source for important events like tangi (funerals) or hui 
(meetings) and helps uphold the mana (prestige) of the hosts. The inner iridescent shell of pāua is also widely used in many Māori craft outlining the eyes and other features and bone and wood carvings on the marae (meeting house).

Pāua are in high demand worldwide for both their meat and shells (Gray and Smith, 2004; Symonds and Heath, 2008). The 2009 commercial market for both flesh and shells of pāua brought in over NZD \$48 million with 85\% of exportation going to Singapore and Hong Kong (New Zealand Seafood Industry Council, 2011). The iridescent, colourful inner shell has also created a demand for pāua jewellery products (Gray and Smith, 2004). Past years have seen a decline in wild stocks of pāua due to over-fishing and poaching, creating an under-supply of pāua on the worldwide market, resulting in the increase of development of aquaculture and pāua farming (Symonds and Heath, 2008).

New Zealand pāua fisheries are managed by the Quota Management Systems and enforced by the Ministry of Fisheries (New Zealand Seafood Industry Council, 2011). Legal harvesting size of pāua is $125 \mathrm{~mm}$ and with a maximum recreational catch of 10 pāua per fisher per day (MFISH, 2011). 


\section{MATERIALS AND METHODS}

\subsection{SAMPLE COLLECTION}

Pāua used in this research were collected from two different types of environment; a cultured environment and a range of natural sites throughout New Zealand (Fig. 3.1).

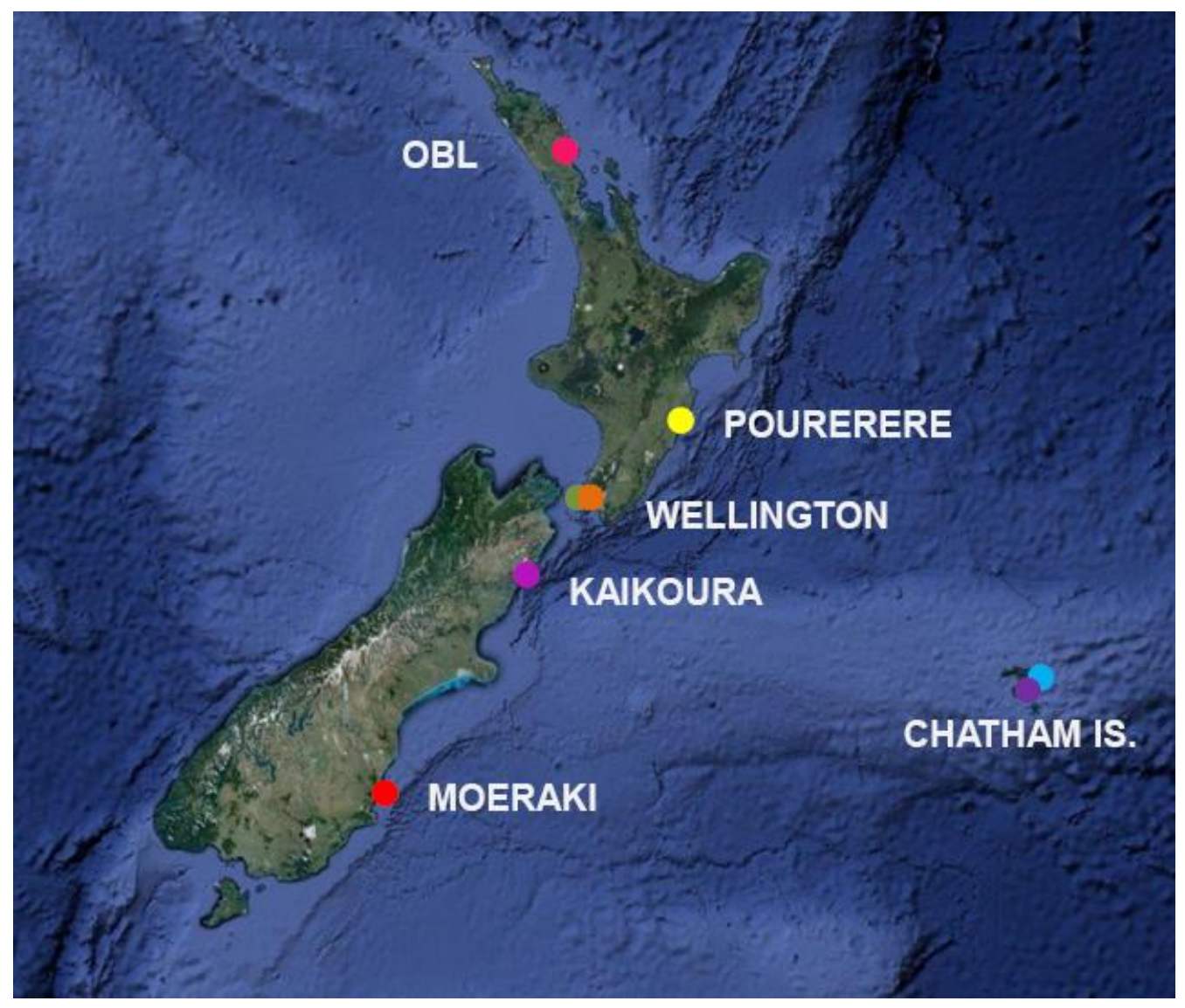

Fig. 3.1. The six pāua sample sites located around New Zealand and the Chatham Islands.

\subsubsection{Cultured Environment}

OceaNZ Blue Ltd (OBL) in collaboration with the National Institute of Water and Atmospheric Research (NIWA), have established an aquaculture pāua farm which involves spawning, settling, on-growing and processing pāua for supply to international food markets (OceaNZ Blue, 2011). OBL is located at NIWA's Bream Bay park facility in 
Ruakaka, Northland. Creating the right environment for pāua to grow in is important with emphasis on controlling and maintaining environmental factors such as temperature, oxygen levels, $\mathrm{pH}$, water salinity and sediment load (OceaNZ Blue, 2011).

Cultured pāua are grown in a system that uses both fresh and recirculated seawater from within the facility. Fresh incoming seawater is sourced $600 \mathrm{~m}$ offshore and at a depth of $10 \mathrm{~m}$ below the surface to ensure its cleanliness (OceaNZ Blue, 2011). This water is filtered through modern spin disc Arkal $10 \mu \mathrm{m}$ sand filters to remove worms, plankton and parasites before it is added to the circulation system (OceaNZ Blue, 2011). The water in which the pāua are grown is recirculated in order to control water chemistry (oxygen and $\mathrm{pH}$ ) and water temperature. Monitoring these factors keeps the environment in which the pāua grow at optimum levels (OceaNZ Blue, 2011).

Growth and health of the pāua are also monitored at OBL (Symonds and Heath, 2008). Each shell is tagged once the animal reaches $15 \mathrm{~mm}$ in size for easy identification (Symonds and Heath, 2008). The pāua at OBL are fed manufactured pellets containing alfalfa, soybeans and other plant products consistently throughout the day (Heath, 2006).

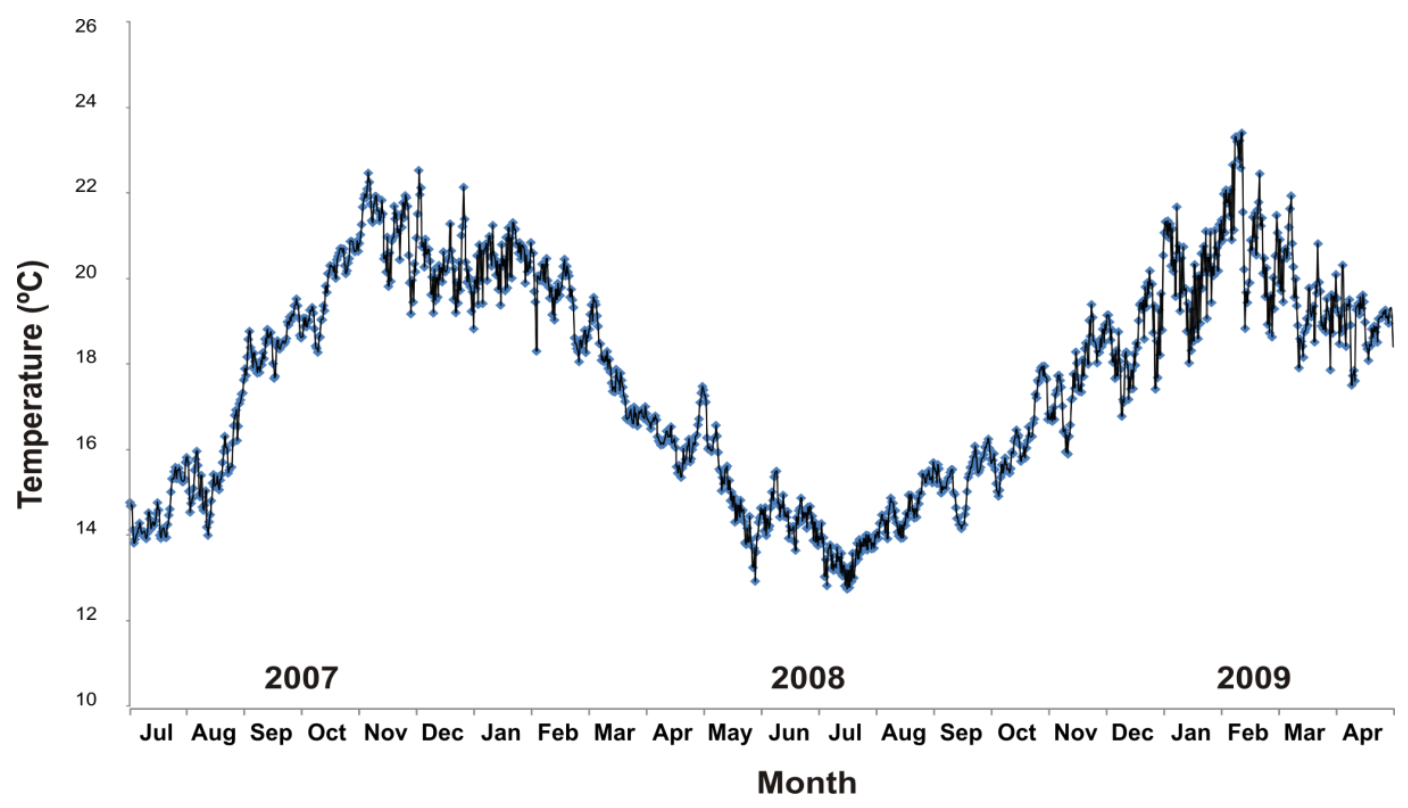

Fig. 3.2. Daily mean temperatures $\left({ }^{\circ} \mathrm{C}\right)$ (blue spots) of the recirculated water recorded by OBL over the months of July 2007 to April 2009. 
For this study, minimum and maximum daily temperatures were recorded every month for 18-20 months prior to harvesting (dating back to August 2007) and supplied to the author by Rodney Roberts from OBL. Pāua were selected and killed on April 23 2009. Temperatures were electronically archived and recorded at $30 \mathrm{~min}$ intervals. The temperature thermocouple was checked and recalibrated with a silver and gold thermometer. In addition to temperature, growth data were also collected prior to harvesting for 18-20 months (with a few gaps in this record where the pāua were not found in the monthly sampling programme).

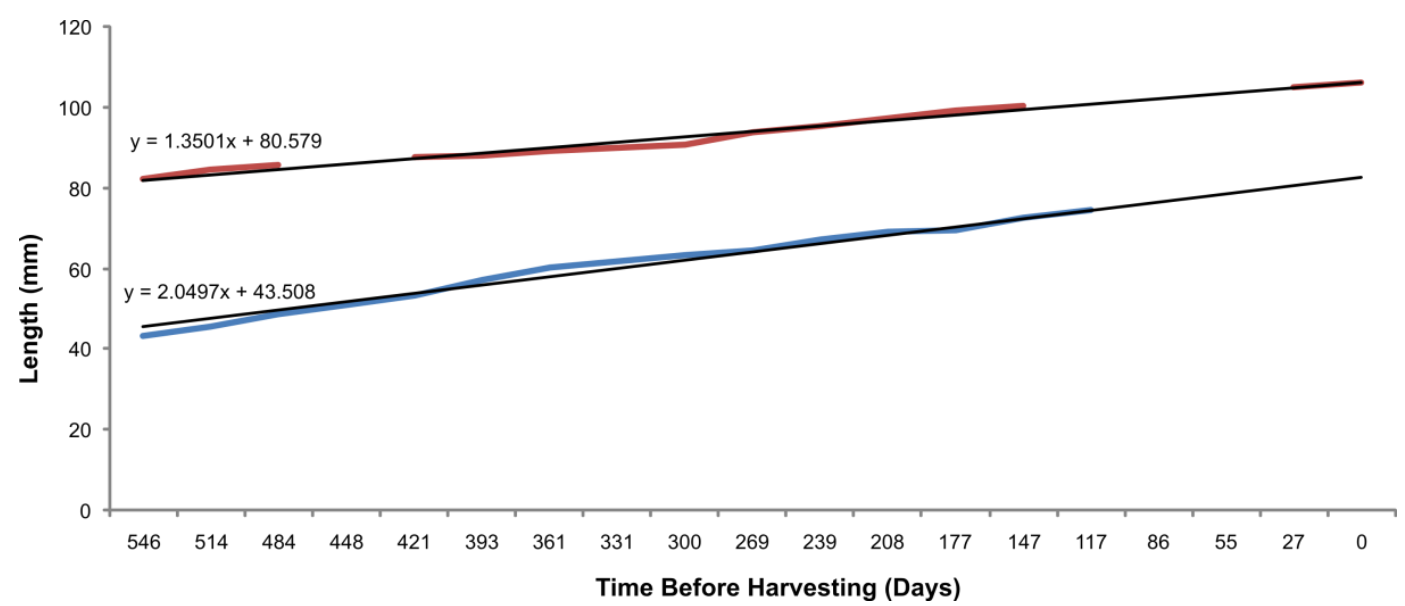

Fig. 3.3. Recorded length of shells RW75 (red) and A740 (blue) from OBL measured before death on April 23rd 2009.

\subsubsection{Natural Environment}

Live pāua were also collected from five sites from around New Zealand's coast: Pourerere, Kaikoura, Moeraki, two sites in Wellington (near Tarakena Bay and Moa Point) and the Chatham Islands (Ascot Reef and Manukau Reef). Pāua were collected by the Ministry of Fisheries (MFISH) or recreational fishers by free diving and removing the pāua from the rocks with a blunt knife or other tools as levers. Sample collection took place at different times from December 2009 to October 2010 (Table 3.1). As sampling was undertaken by others (many in which gathered the pāua during recreational dives), information regarding sampling depth, marine and terrestrial geomorphology were not recorded. 


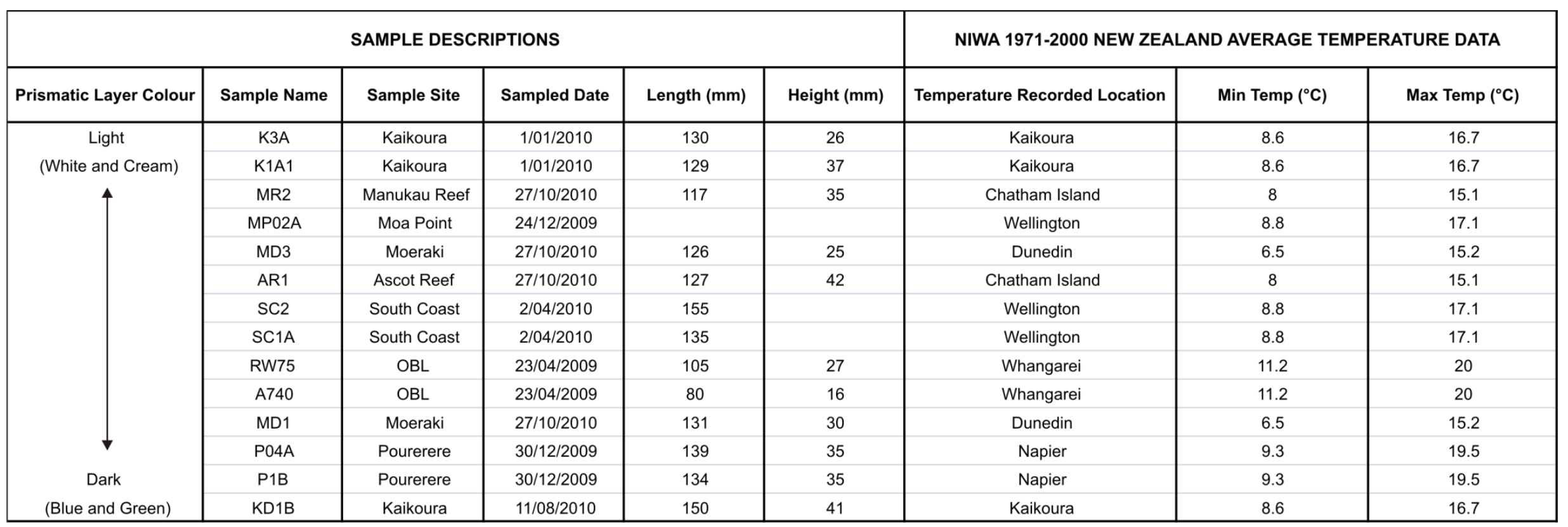

Table 3.1. Pāua sample descriptions including sample name, location and date collected along with length and height of each shell. The samples have also been grouped by environment (cultured versus wild) and colouring of the prismatic layer. NIWA $1971-2000$ New Zealand average minimum and maximum temperature data from the six different sites are also shown. 
Pourerere is located in the central Hawke's Bay district ca. $30 \mathrm{~km}$ southeast of Waipawa on the east coast of the North Island of New Zealand. Pourerere has sandy beaches separated by hard shore rock and siltstone intertidal reef platforms. Prior to European settlement, the Hawke's Bay coasts were heavily populated with $p \bar{a}$ (fortified village) situated at Pourerere as the reef platform was and continues to be an important source of kai moana to local communities. Local iwi continue to use Pourerere as a site to gather kai moana due to its thriving marine ecosystem.

Wellington

Pāua were sampled from two locations in the Wellington region's south coast. Samples used in this study were collected near Tarakena Bay and Moa Point. Moa Point is the location of the Wellington Sewage Treatment Plant outlet. Sewage is initially treated through a series of screens, tanks, bioreactors, clarifiers and by ultraviolet treatment before being discharged into the Cook Strait at Moa Point (Wellington City Council, 2010).

\subsubsection{Kaikoura}

Kaikoura is located on the east coast of the South Island, $180 \mathrm{~km}$ north of Christchurch. The Kaikoura coast consists of steep slopes and cliffs bordered by high mountains on the west reaching maximum heights of $2885 \mathrm{~m}$ only $12 \mathrm{~km}$ from the ocean to the east (Rattenbury et al., 2006). The samples were collected near the Kaikoura township (Fig. $3.4 \mathrm{~b}$ ) off the rocky peninsula. The region attracts and sustains many forms of marine life, including sperm whales and dolphins who inhabit the deep canyons off the coast of Kaikoura.

\subsubsection{4}

Chatham Islands

Chatham Island $\left(90 \mathrm{~km}^{2}\right)$ is $800 \mathrm{~km}$ due east of Christchurch off the mainland of New Zealand. Chatham Island is a renowned fishing area for pāua and other marine life. Pāua shells from two localities were chosen for analysis from the Chatham Islands; Ascot Reef and Manukau Reef, which both lie on the south-eastern coastline. 
Moeraki is a small fishing village located on the eastern coastline of north Otago in the South Island of New Zealand (Boles et al., 1985). Moeraki has a long history of Māori occupation as represented by a nearby historic $p \bar{a}$ site. Pāua shells from Moeraki were collected near the wharf by MFISH.

\subsubsection{NIWA Temperatures}

Mean monthly air temperature results taken from the NIWA database for 5 locations relatively close to sample locations were used to compare with the trace element chemistry obtained from each shell (Table 3.2). Air temperatures were used due to the lack of information of mean monthly sea temperature data for each region.

\begin{tabular}{|c|c|c|c|c|c|}
\hline height of staton MSL & $130 \mathrm{~m}$ & $4 \mathrm{~m}$ & $105 \mathrm{~m}$ & $21 \mathrm{~m}$ & $14 \mathrm{~m}$ \\
\hline MONTHIYEAR & WAIPAWA ( $\left.{ }^{\circ} \mathrm{C}\right)$ & WGTN AERO ( $\left.{ }^{\circ} \mathrm{C}\right)$ & KAIKOURA ('C) & PALMERSTON ( $\left.{ }^{\circ} \mathrm{C}\right)$ & CHATHAM IS. ( $\left.{ }^{\circ} \mathrm{C}\right)$ \\
\hline Oct-10 & 11.4 & 12.1 & 11.2 & 10.6 & 11.4 \\
\hline Sep-10 & 11.1 & 12.4 & 11.5 & 8.7 & 10.6 \\
\hline Aug-10 & 9 & 10.8 & 8.9 & 7 & 9.9 \\
\hline Jul-10 & 7 & 8.5 & 7.6 & 5.1 & 8.2 \\
\hline Jun-10 & 7.8 & 10.4 & 8.5 & 5.6 & 9.6 \\
\hline May-10 & 10.6 & 12.7 & 11.2 & 8.1 & 11.6 \\
\hline Apr-10 & 12.9 & 15.7 & 14.7 & 12 & 13.8 \\
\hline Mar-10 & 15.3 & 16.9 & 15.9 & 14.1 & 15.1 \\
\hline Feb-10 & 18.2 & 17.9 & 16.6 & 15 & 15.8 \\
\hline Jan-10 & 17.1 & 16.8 & 15.9 & 14.4 & 16 \\
\hline Dec-09 & 15.7 & 16.0 & 14.9 & 13.6 & 10.6 \\
\hline Nov-09 & 13.5 & 14.2 & 13 & 12.3 & 10.5 \\
\hline Oct-09 & 10.3 & 11.3 & 9.4 & 8.4 & \\
\hline Sep-09 & 9.8 & 11.6 & 10.5 & 8.8 & 9.7 \\
\hline Aug-09 & 10.1 & 11.5 & 10.6 & 7.9 & 9.7 \\
\hline Jul-09 & 6.6 & 8.8 & 7.5 & 4.7 & 6.8 \\
\hline Jun-09 & 6.8 & 8.8 & 7.8 & 5.1 & 7.7 \\
\hline May-09 & 8.7 & 10.7 & 9 & 6.6 & 10.6 \\
\hline Apr-09 & 6.2 & 11.2 & 11.1 & 10.8 & 12.7 \\
\hline Mar-09 & 14.2 & 16.1 & 15 & 12.9 & 14.1 \\
\hline Feb-09 & 18.1 & 17.6 & 15.7 & 13.3 & 15.5 \\
\hline Jan-09 & 18.6 & 18.5 & 18.2 & 16.4 & 16.8 \\
\hline Dec-08 & 17 & 17.1 & 15.6 & 14 & 15.8 \\
\hline Nov-0 & 14.2 & 14.9 & 14.5 & 12.7 & 12.3 \\
\hline Oct-08 & 12.4 & 13.0 & 11.7 & 10.1 & 10.9 \\
\hline Sep-08 & 10.6 & 12.0 & 10.6 & 10.2 & 10.7 \\
\hline Aug-08 & 8.8 & 9.9 & 7.9 & 5.9 & 8.6 \\
\hline Jul-08 & 8.3 & 10.1 & 8.3 & 5.3 & 8.5 \\
\hline Jun-08 & 7.7 & 11.1 & 9.7 & 6.4 & 9.2 \\
\hline May-08 & 9.1 & 11.0 & 9.6 & 6.5 & 10.1 \\
\hline \multicolumn{6}{|c|}{ KEY } \\
\hline Pourerere & South Coast & Moa Point & Kaikoura & Moeraki \& C.I & KD1B \\
\hline
\end{tabular}

Table 3.2. Mean air surface temperatures recorded by NIWA over the months of May 2008 to October 2010. The temperatures from stations of varying heights (m) are the nearest air temperature measurements taken from the sample sites used in this study. The different colours represent the last recorded month the pāua would have lived at each sample sites. 

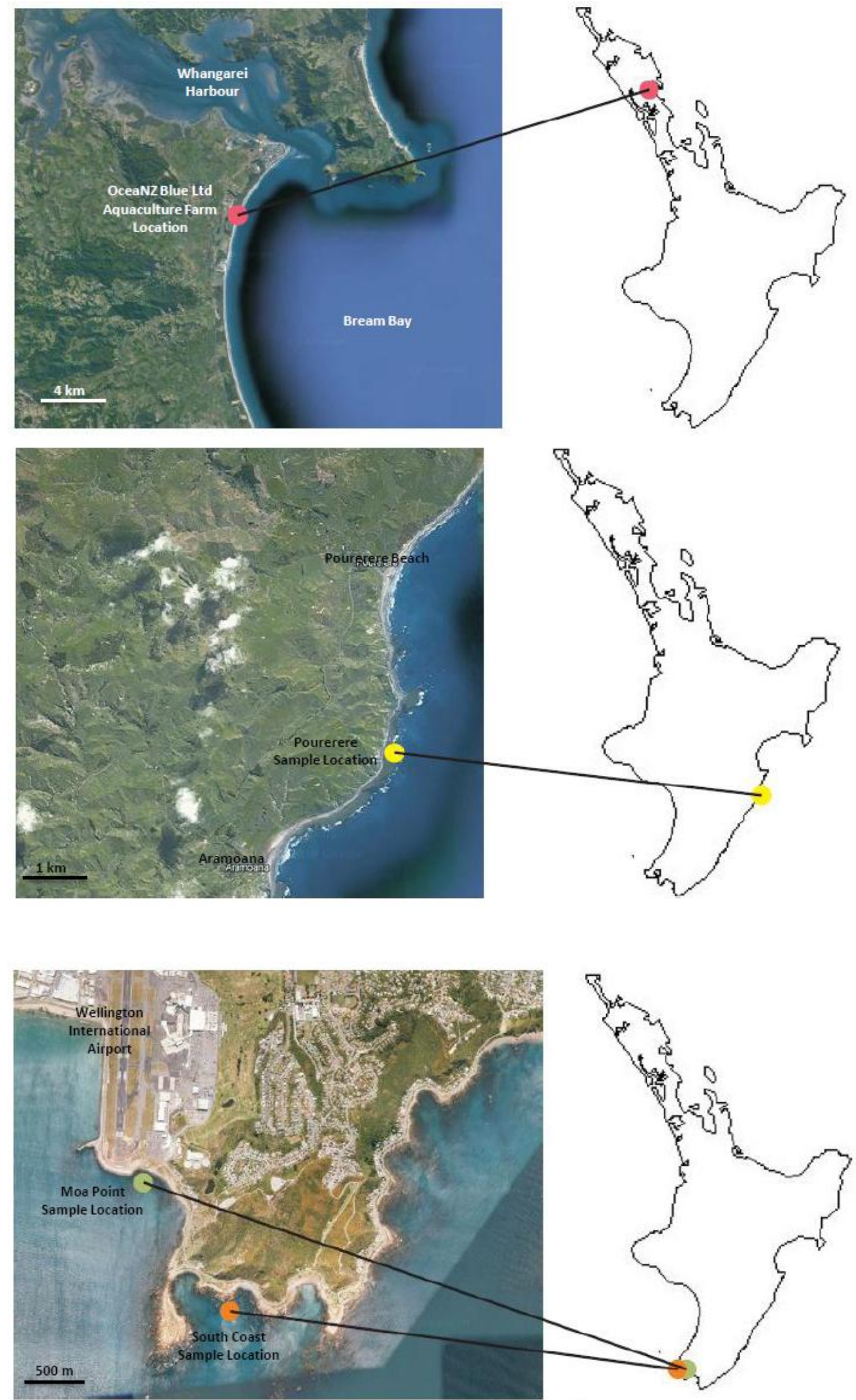

Fig. 3.4a. North Island pāua sample sites. Top - OceaNZ Blue Ltd site location in Ruakaka; Middle - Pourerere Beach in the Hawke's Bay; and bottom - The two Wellington sites, Moa Point (green) and south coast (orange). 

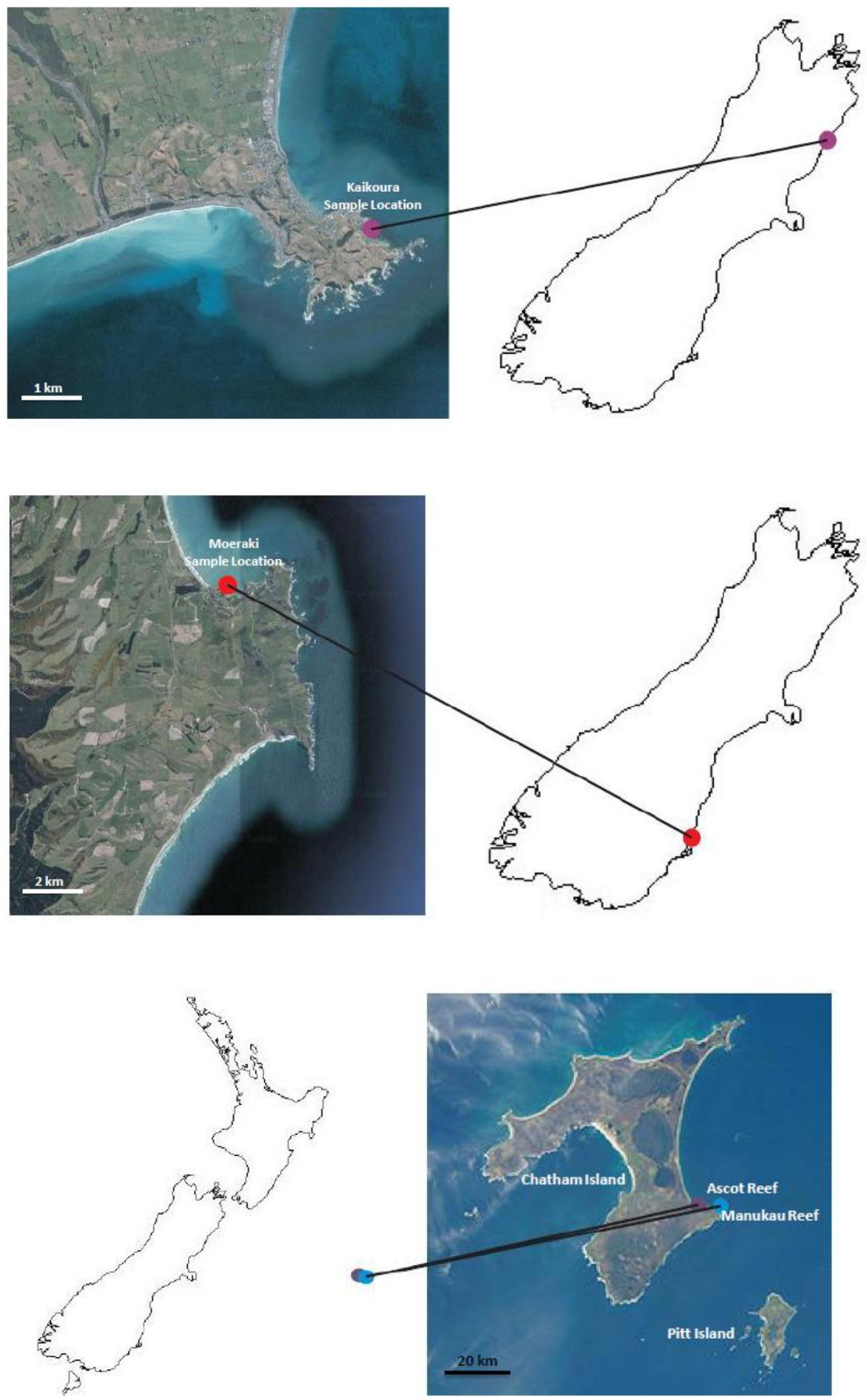

Fig. 3.4b. South Island sample pāua sites. Top - Kaikoura sample site; Middle - Moeraki sample site in Otago; and bottom - The two Chatham Island sites; Ascot Reef (purple) and Manukau Reef (blue). 


\subsection{SAMPLE DESCRIPTIONS}

The physical nature of the pāua shells sampled varied considerably with location. Many of the collected shells were inappropriate for analysis as they were too porous or altered by external biological activity including burrowing by worms and the colonisation by epifauna such as barnacles and limpets. Shells in this condition were not analysed. Size and colour varied within each shell sample. Two shells from OBL (RW75 and A740) were very thin in cross section being only 1-2 mm thick. The colour of the prismatic layer was alternating light blue and white and the nacre was light brown in colour.

The samples from OBL differ from the shells sampled from the wild. The shells taken from the wild are legally required to be a minimum length of $125 \mathrm{~mm}$. Shells that have been sampled from the wild were also stronger and thicker than the cultured pāua. There was also more variability of the colour of the prismatic layer of the shells sampled within the wild. This variation in the prismatic layer colour grading is described in Table 2.2 and is best observed in a cross section view through the shell (Fig. 3.8). 


\section{CHAPTER 3: Materials and Methods}

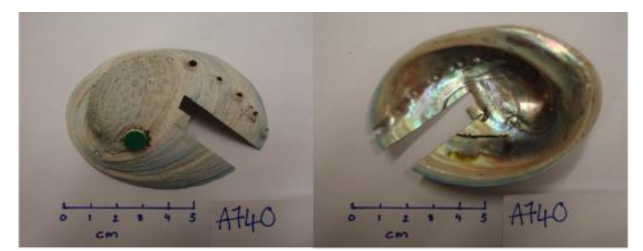

A740 (OBL)

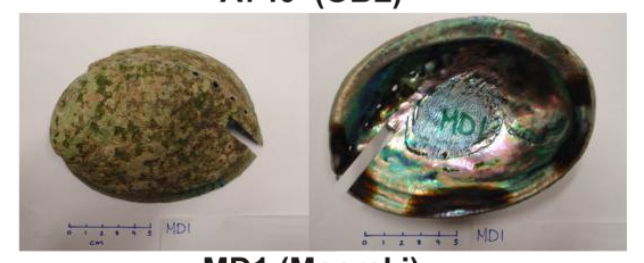

MD1 (Moeraki)

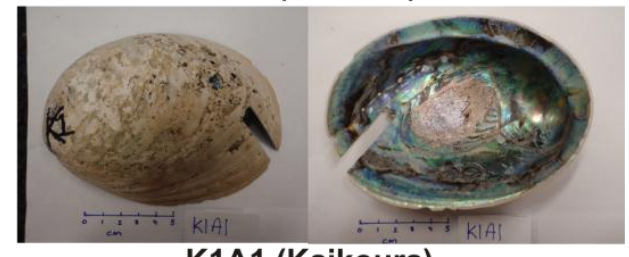

K1A1 (Kaikoura)

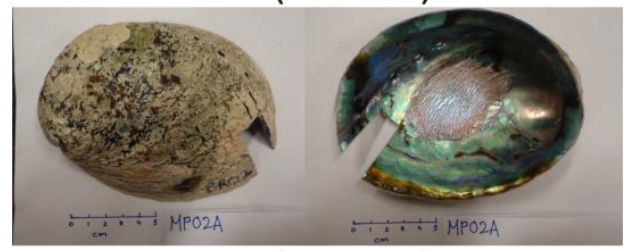

K1A1 (Kaikoura)

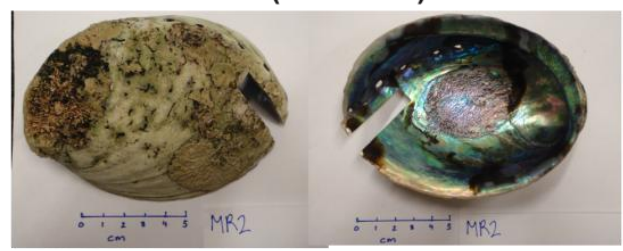

MR2 (Manukau Reef - Chatham Is.)

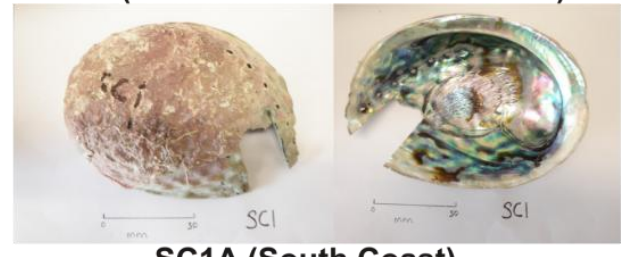

SC1A (South Coast)

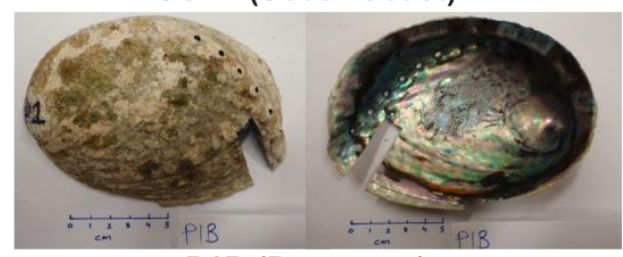

P1B (Pourerere)

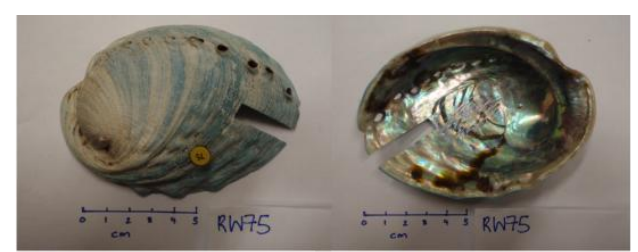

RW75 (OBL)

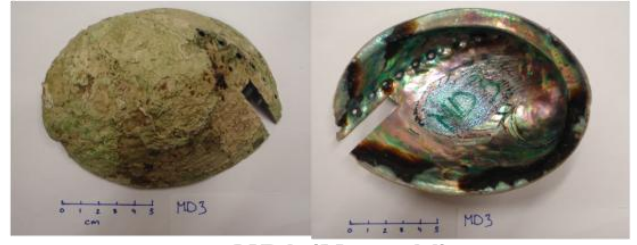

MD3 (Moeraki)

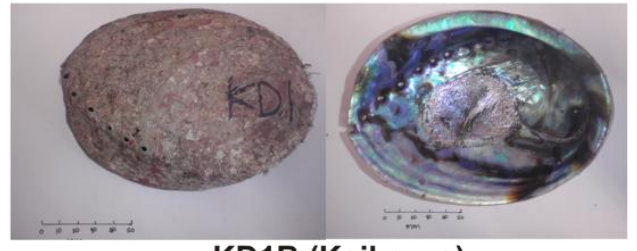

KD1B (Kaikoura)

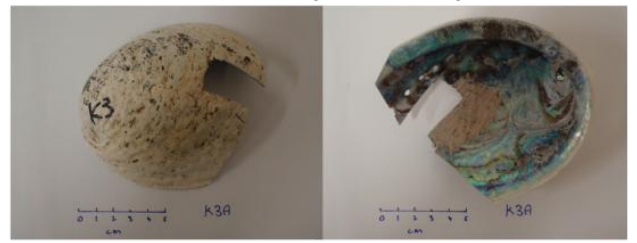

K3A (Kaikoura)

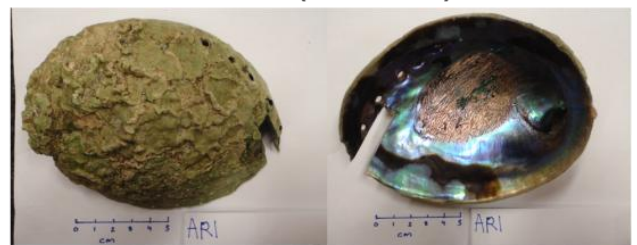

AR1 (Ascot Reef - Chatham Is.)

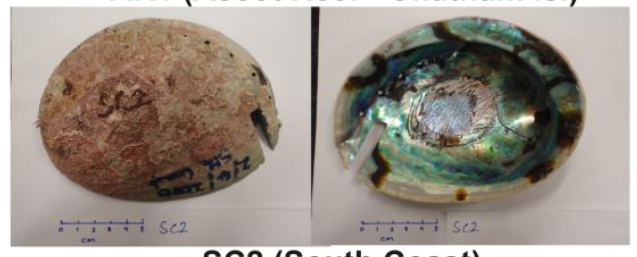

SC2 (South Coast)

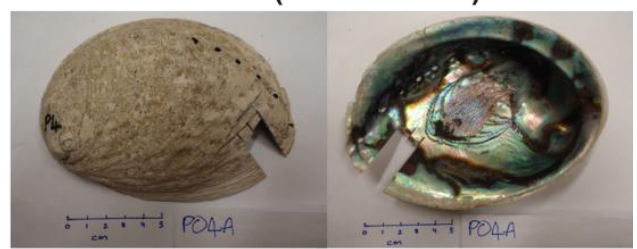

P04A (Pourerere)

Fig. 3.5. Photographs of the exterior and interior of each sample analysed in this study, labelled with sample number and locality. 


\subsection{SAMPLE PREPARATION}

The pāua flesh was removed from the shell prior to analysis. The shells were cleaned using a scrubbing brush under warm water to remove excess soft tissue, organic material and any algae growing on the exterior of the shell. The length and height of the shell were recorded. Each shell was then sectioned across a transect approximately 40 $\mathrm{mm}$ in length, following the tremata along the axis of maximal growth (Fig 3.6). Although the growth of the pāua is spiralled, the transect taken from each sample was cut in a straight line. The shell section was cleaned in a Metason50 ultrasonic bath for 2 min and left to dry for $24 \mathrm{hr}$ on a hot plate at $52^{\circ} \mathrm{C}$.

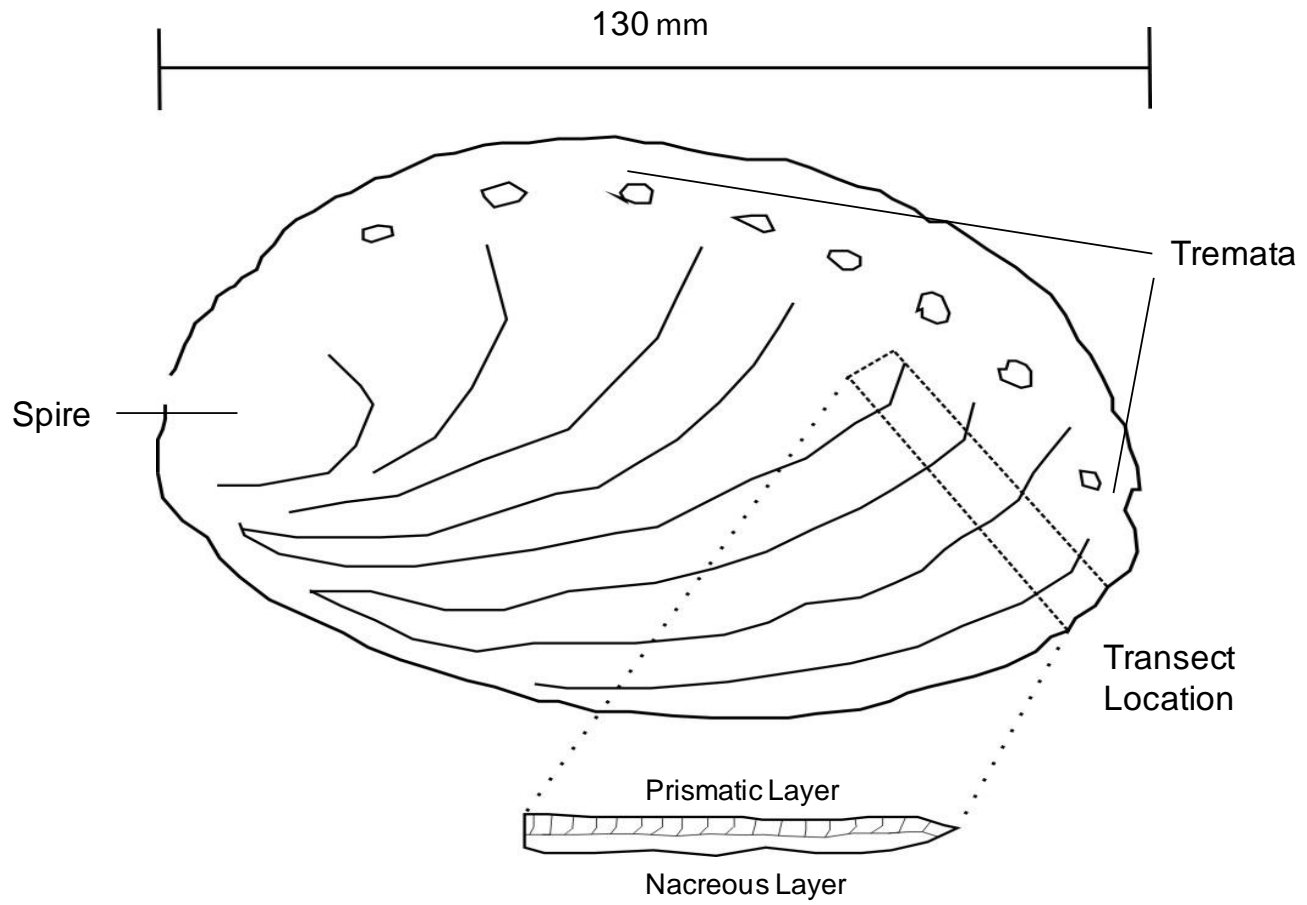

Fig. 3.6. Schematic diagram of the exterior of a pāua shell and transect location which follows the tremata along the axis of maximum growth. A cross section view of the transect highlighting the outer prismatic layer and inner nacreous layer is also shown.

The shell sample was snapped at random positions along its length in order to allow the shell fragments to fit inside the laser ablation chamber. The method of snapping the shell was preferred to sawing, as using a saw removes part of the shell material and thus the temporal record of shell chemistry. The sectioned shell was then mounted in a round epoxy mount oriented to expose growth bands and layers. The shells were set in 
epoxy resin with a fragment of the silicate glass standard NIST SRM 610, National Institute of Standard and Technology (NIST) (Pearce et al., 1997), and left to harden on a hot plate at $52^{\circ} \mathrm{C}$ for $24 \mathrm{hr}$. Samples were then polished using sand paper grades of $400 \mu \mathrm{m}, 600 \mu \mathrm{m}, 1200 \mu \mathrm{m}, 2500 \mu \mathrm{m}$ and $4000 \mu \mathrm{m}$. Polishing using $3 \mu \mathrm{m}$ and $1 \mu \mathrm{m}$ sheets and diamond liquid was finally undertaken to complete the polishing process. Photographs were then taken of the samples under plane polarised and natural light (Fig. 3.8). Finally, the mounts were washed with distilled water in an ultrasonic bath before trace element analysis.

Three intra-shell transect paths were chosen for laser ablation inductively coupled plasma mass spectrometry (LA-ICP-MS) trace element analyses (Fig. 3.7), including transects of (1) the prismatic layer, (2) the nacreous layer and (3) an individual growth band. The prismatic layer transect began at the foot of the shell and traversed inwards horizontally through a cross section of the shell. The nacreous layer transect began at the innermost part of the shell and traversed vertically through the nacre until it reached the base of the prismatic layer. The growth band transect began at the outmost part of the prismatic layer and traversed following the growth bands until it reached the prismatic-nacreous layer boundary. By beginning the transect of the prismatic layer at the foot of the shell to help correlate the trace element/Ca ratios in the youngest precipitated $\mathrm{CaCO}_{3}$ shell material with the day of harvesting.

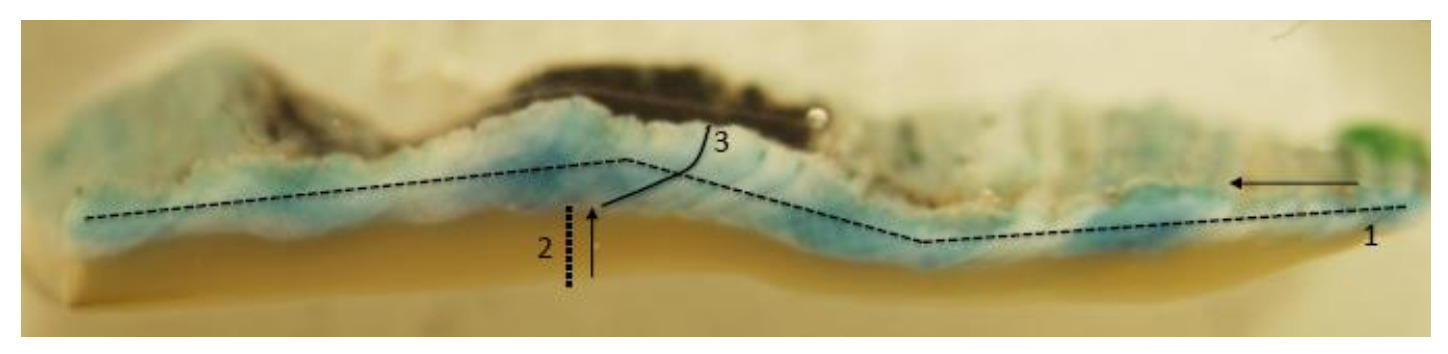

Fig. 3.7. The three intra-shell transects analysed per shell: (1) prismatic layer; (2) nacre and (3) an individual growth band within the prismatic layer. Arrows show the transect direction and growth direction from youngest part of the precipitated shell to older part of the precipitated shell. 


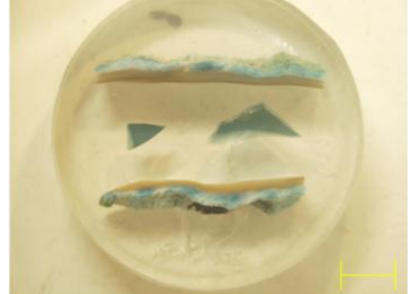

RW75

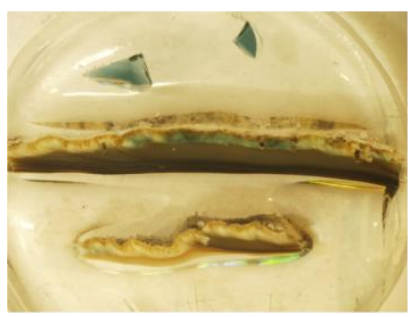

P04A

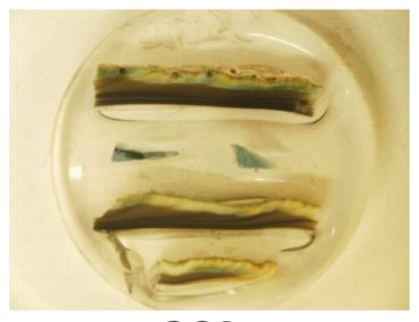

SC2

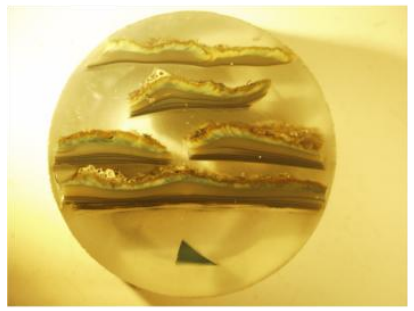

KD1B

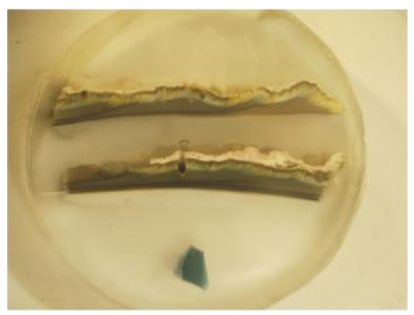

MD3

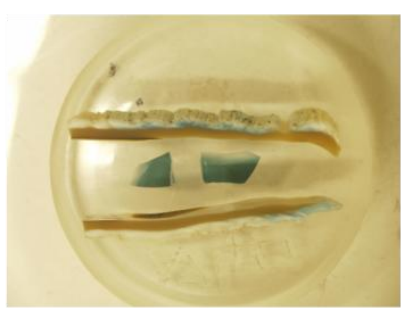

A740

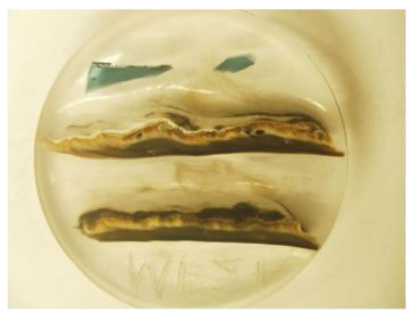

MP02A

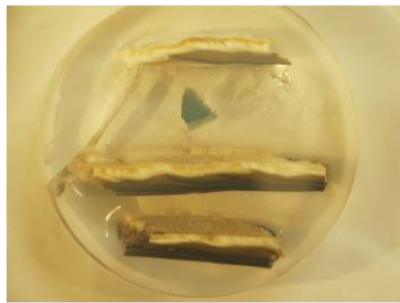

K1A1

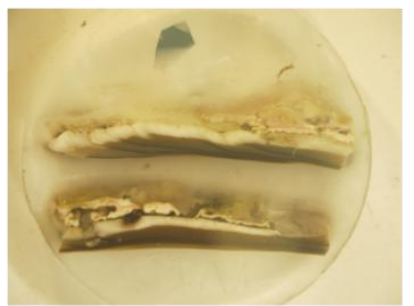

MR2

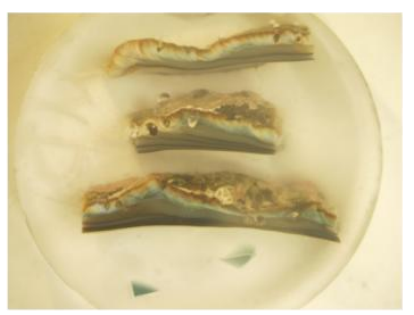

MD1

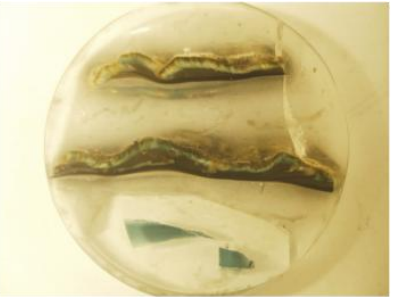

P1B

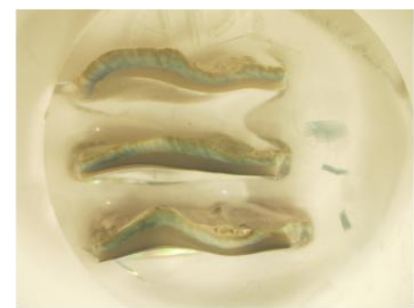

SC1A

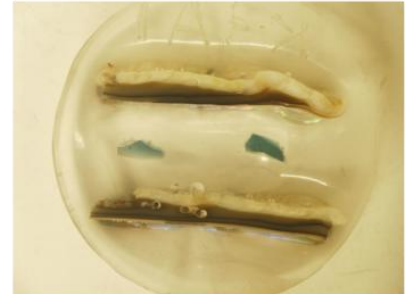

K3A

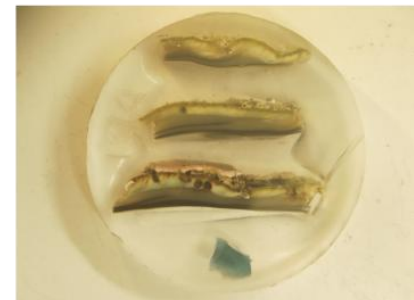

AR1

Fig. 3.8. Photographs of each analysed sample. The blue material within the epoxy mounts is the NIST 610 glass standard. 


\subsection{PĀUA TRACE ELEMENT ANALYSIS}

Analysis of the trace element chemistry of the pāua samples was undertaken by LA-ICPMS. The epoxy mounts were inserted into the laser chamber as shown in Fig. 3.9.

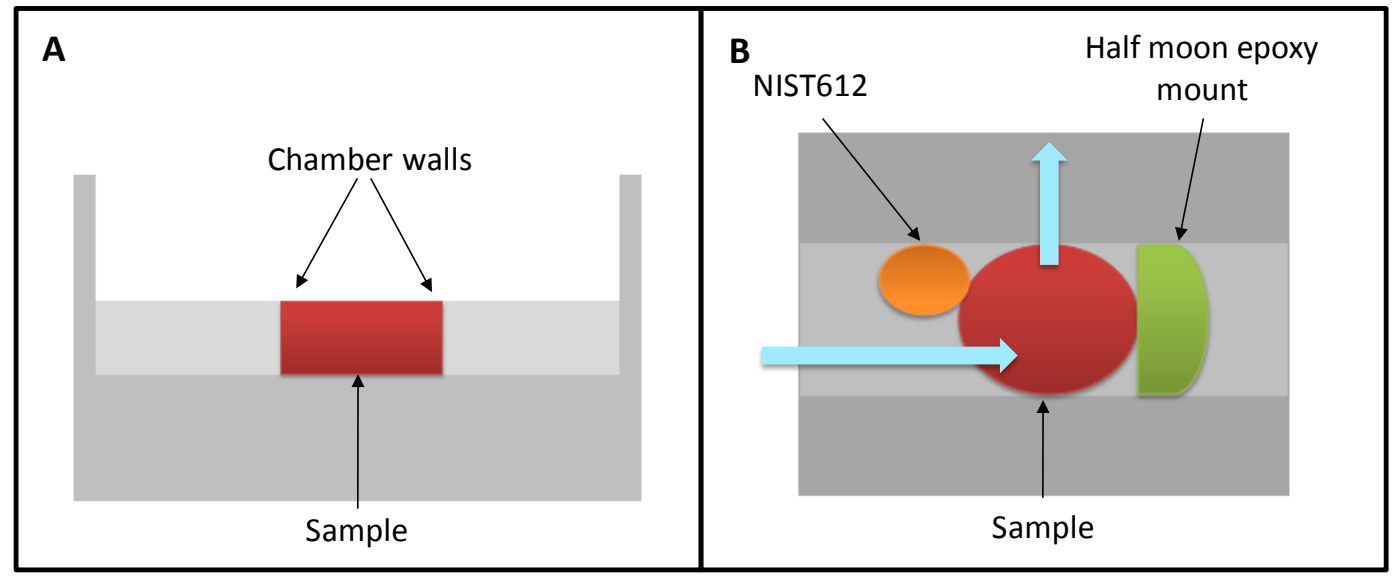

Fig. 3.9. Outline of the inside of the laser ablation chamber. A. A cross section view of the chamber showing the chamber walls and the sample. B. Plan view of the chamber outlining the location of the sample and NIST610 and half moon epoxy mount which directs gas flow. Helium gas flow is shown by bold blue arrows.

Tuning of the LA-ICP-MS was undertaken by rastering the laser across NIST610 between each run to ensure the signal stability was optimised prior to use. Laser ablation holes were spaced every $400 \mu \mathrm{m}$ in the prismatic layer and every $50 \mu \mathrm{m}$ in both the individual bands of the prismatic layer and nacre layer. Each laser spot was 25 $\mu \mathrm{m}$ in diameter and ablated at a frequency of $5 \mathrm{~Hz}$ and a laser power of $55 \%$. The NIST 610 standard was analysed before and after every six sample spots. Each standard spot was $35 \mu \mathrm{m}$ in diameter and measured at a frequency of $5 \mathrm{~Hz}$ and a laser power of $65 \%$. A typical analytical run consisted of analyses of:

1. NIST610

2. 6 sample analyses

3. NIST610

4. 6 sample analyses

5. NIST610

6. 6 sample analyses

7. NIST610 
A washout period of $120 \mathrm{~s}$ was utilised after each analysis. Both the sample and standard were ablated for $60 \mathrm{~s}$. The ablated sample or standard material was transported into the plasma source of the ICP-MS in the form of an aerosol by a mixture of a helium-argon carrier gas where the elements were ionised. Trace elements measured were ${ }^{7} \mathrm{Li},{ }^{11} \mathrm{~B},{ }^{24} \mathrm{Mg},{ }^{27} \mathrm{Al},{ }^{43} \mathrm{Ca},{ }^{55} \mathrm{Mn},{ }^{66} \mathrm{Zn},{ }^{86} \mathrm{Sr},{ }^{88} \mathrm{Sr},{ }^{138} \mathrm{Ba},{ }^{208} \mathrm{~Pb}$ and ${ }^{238} \mathrm{U}$. ICPMS settings are shown in Table 3.3.

\begin{tabular}{|l|c|l|c|}
\hline \multicolumn{2}{|c|}{ ICP-MS Settings } & \multicolumn{2}{c|}{ Laser Ablation Settings } \\
\hline RF Power & $1500 \mathrm{~W}$ & Laser Frequency & $5 \mathrm{~Hz}$ \\
Sample Depth & $3.5 \mathrm{~mm}$ & Laser Power (Sample) & $55 \%$ \\
Carrier Gas & $0.85 \mathrm{~L} / \mathrm{min}$ & Laser Power (Standard) & $65 \%$ \\
Optional Gas & 70.0 to $98.0 \mathrm{~L} / \mathrm{min}$ & Ablation Pit Size (Sample) & $25 \mu \mathrm{m}$ \\
& & Ablation Pit Size (Standard) & $35 \mu \mathrm{m}$ \\
\hline
\end{tabular}

Table 3.3. ICP-MS and laser ablation settings used for the analysis of the pāua samples.

\subsection{DATA REDUCTION AND PROCESSING}

Data was recorded in a CSV file which contained the trace element counts per second (cps) measured every $0.3 \mathrm{~s}$ of each analytical run. In order to reduce the data, the average cps of each trace element was made for both the washout (background) and the for the ablation period of each spot.

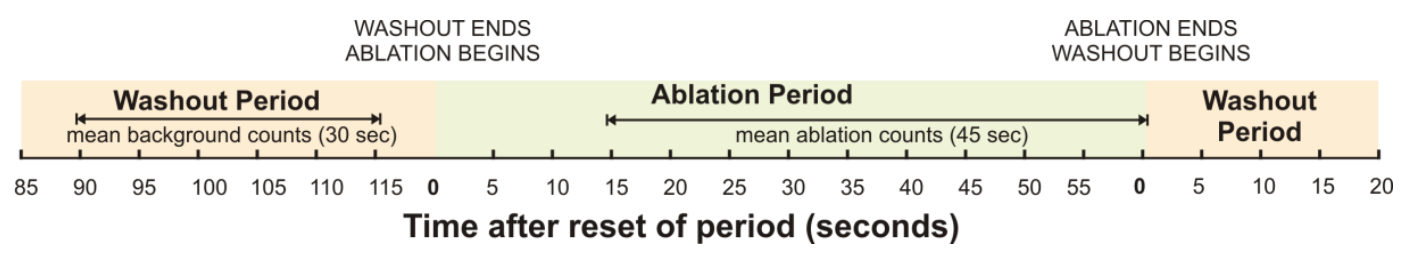

Fig. 3.10. Diagram illustrating the duration of washout (orange) and ablation (green) periods during an analytical run with respect to time (s) before the change from ablation to washout and vice versa. The period that was used to calculate mean counts per seconds are represented by the black line. 
Mean background cps values were calculated by taking the mean of a $30 \mathrm{~s}$ washout period beginning $5 \mathrm{~s}$ prior to ablation commencing. The mean ablation period (sample or standard) was taken for a $45 \mathrm{~s}$ period, beginning $15 \mathrm{~s}$ after ablation commenced. By excluding the counts $5 \mathrm{~s}$ prior to ablation beginning and $15 \mathrm{~s}$ after ablation began, any surfacial contamination of the shell is not included in the results. The mean background cps were then subtracted from the mean ablation counts to give the background corrected cps. Each element was then corrected as a ratio to Ca by reference to the bracketing analyses of the NIST 610 standard using the equation below.

$$
\frac{\text { Element }}{\mathrm{Ca}} \text { pāua, } \quad \text { real }=\frac{\frac{\text { Element }}{\mathrm{Ca}} \text { paua, measured }}{\frac{\text { Element }}{\mathrm{Ca}} \mathrm{Std}, \text { measured }} \times \frac{\text { Element }}{\mathrm{Ca}} \mathrm{Std}, \quad \text { real }
$$

The measured pāua and standard element/Ca ratios were calculated in $\mathrm{mmol} / \mathrm{mol}$. The "real" standard value refers to the GeoReM preferred values for NIST610 shown in Table 3.4 (GeoReM, 2010).

\begin{tabular}{|c|r|}
\hline \multicolumn{2}{|c|}{ GeoReM preferred NIST 610 value } \\
\hline element & $\begin{array}{c}\text { element/Ca ratio } \\
\text { (mmol/mol) }\end{array}$ \\
\hline $\mathrm{Li}$ & 34.07 \\
$\mathrm{~B}$ & 16.06 \\
$\mathrm{Mg}$ & 9.33 \\
$\mathrm{Al}$ & 195.13 \\
$\mathrm{Mn}$ & 4.30 \\
$\mathrm{Zn}$ & 3.47 \\
$\mathrm{Sr}$ & 2.87 \\
$\mathrm{Ba}$ & 1.54 \\
$\mathrm{~Pb}$ & 1.00 \\
$\mathrm{U}$ & 0.95 \\
\hline
\end{tabular}

Table 3.4. GeoReM preferred values of element/Ca ratio (mmol/mol) for the NIST610 standard used to correct the pāua trace element data for trace element fractionation during ablation and mass spectrometry. 


\section{RESULTS}

This chapter presents laser ablation inductively coupled plasma mass spectrometry (LA-ICP-MS) trace element analysis of the two main inorganic calcium carbonate layers; the prismatic layer and the nacreous layer, of pāua sampled from seven localities around New Zealand and the Chatham Islands.

\subsection{AVERAGE INTER-SHELL CHEMISTRY VARIATIONS}

\subsubsection{Prismatic layer versus nacreous trace element chemistry}

Mean element/Ca ratios of the prismatic and nacreous layers were calculated for each sample and are illustrated in Figures 4.1a and 4.1b. $\mathrm{Mg} / \mathrm{Ca}, \mathrm{Li} / \mathrm{Ca}, \mathrm{Al} / \mathrm{Ca}$ and $\mathrm{Mn} / \mathrm{Ca}$ ratios show higher element/Ca ratios in the prismatic layer compared with the nacreous layer. The $\mathrm{Mg} / \mathrm{Ca}$ ratio in the prismatic layer ranges between $3.76 \mathrm{mmol} / \mathrm{mol}$ and $8.95 \mathrm{mmol} / \mathrm{mol}$. These results are an order of magnitude higher than those in the nacreous layer, which range between 0.22 $\mathrm{mmol} / \mathrm{mol}$ and $0.72 \mathrm{mmol} / \mathrm{mol}$. The Li/Ca mean ratios are significantly higher in the prismatic layer across all samples when compared with the nacre. $\mathrm{Al} / \mathrm{Ca}$ ratios are higher in the prismatic layer than the nacre, but also higher in shells sampled from Pourerere, Moa Point and one sample (KD1B) from Kaikoura. $\mathrm{Mn} / \mathrm{Ca}$ mean values are generally similar in shells across all sample sites. OBL samples (A740 and RW75) and SC1A and K1A1 show higher element/Ca ratios in the nacre than in the prismatic layer, but the differences are small. As is the case with $\mathrm{Al} / \mathrm{Ca}$ ratios, the highest $\mathrm{Mn} / \mathrm{Ca}$ ratios within the prismatic layer are observed in sample MP02A and both samples from Pourerere.

Both $\mathrm{Sr} / \mathrm{Ca}$ and $\mathrm{B} / \mathrm{Ca}$ mean ratios are higher in the nacre of each shell compared to the outer prismatic layer. The highest $\mathrm{Sr} / \mathrm{Ca}$ ratios in the nacre layer are seen in the Kaikoura sample K1A1. B/Ca generally shows higher values in nacre, compared with the prismatic layer, with the exception of SC1A, where the prismatic layer values exceeds nacreous layer values by $0.012 \mathrm{mmol} / \mathrm{mol}$, and A740, in which prismatic layer values exceed nacre values by $0.0026 \mathrm{mmol} / \mathrm{mol}$. 
The remaining element ratios including $\mathrm{Ba} / \mathrm{Ca} \mathrm{Zn} / \mathrm{Ca}, \mathrm{Pb} / \mathrm{Ca}$ and $\mathrm{U} / \mathrm{Ca}$, show variations in the relative elemental affinity to either the prismatic layer or the nacre. Apart from the shells that grew in the cultured environment, the samples from the North Island have lower values of $\mathrm{Ba} / \mathrm{Ca}$ ratios within the nacreous layer than all other shells.

$\mathrm{Zn} / \mathrm{Ca}$ ratios also show variable results between samples. Shells from OBL are again different from those from other sites, with both shells showing higher $\mathrm{Zn} / \mathrm{Ca}$ ratios in the nacre than the prismatic layer. K1A1 has significantly higher nacre $\mathrm{Zn} / \mathrm{Ca}$ values than any other shell, with $\mathrm{Zn} / \mathrm{Ca}$ values of $0.014 \mathrm{mmol} / \mathrm{mol}$. 

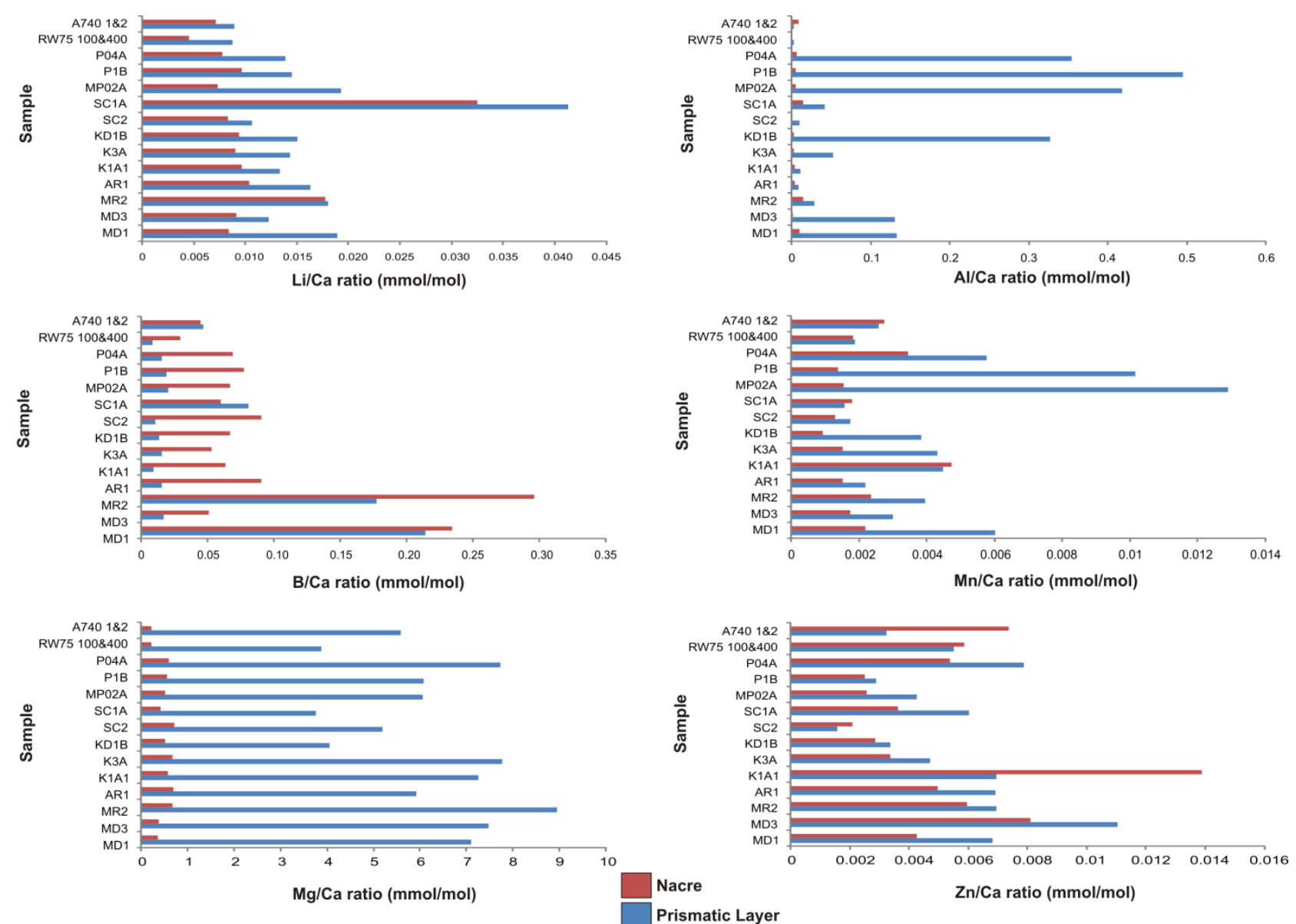

Fig. 4.1a. Shell mean element/Ca ratios ( $\mathrm{mmol} / \mathrm{mol}$ ) of the prismatic (blue) and nacreous (red) layers in all samples. The samples are ordered by location, with the northernmost samples at the top and the southernmost samples shells at the bottom of each graph. 

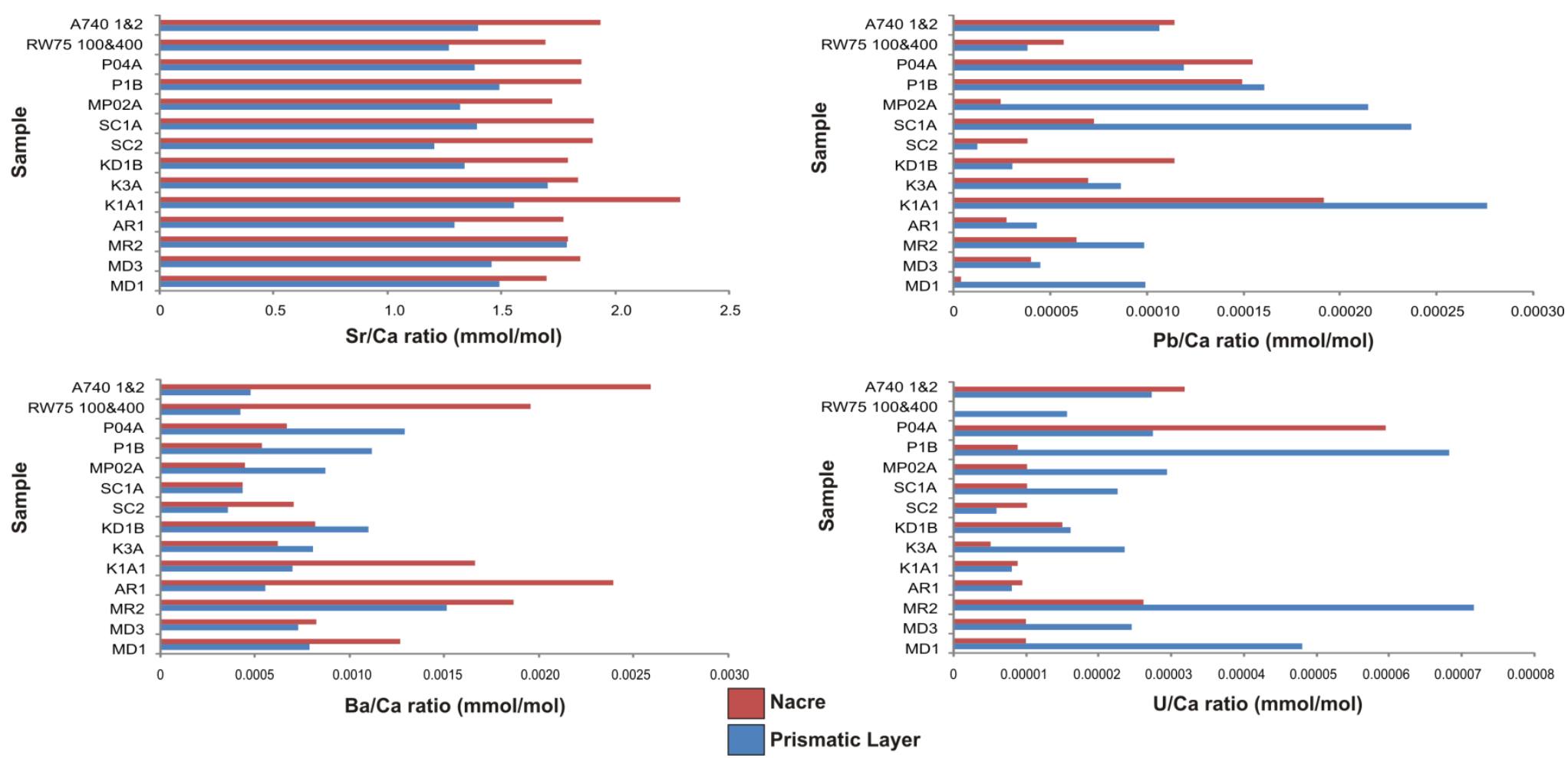

Fig. 4.1b. Shell mean element/Ca ratios (mmol/mol) of the prismatic (blue) and nacreous (red) layers in all samples. The samples are ordered by location, with the northernmost samples at the top and the southernmost samples shells at the base of each graph. 


\subsection{TEMPORAL CHANGES IN PĀUA SHELL CHEMISTRY}

\subsubsection{Prismatic Layer}

The prismatic layers of the shell samples were analysed using $25 \mu \mathrm{m}$ spots every $400 \mu \mathrm{m}$ over transects approximately $40 \mathrm{~mm}$ in length. The results presented in Figures $4.2 \mathrm{a}$ through to $4.2 \mathrm{~g}$ show a 3 point moving average of element/Ca ratios for each spot analysis. The results presented summarise the analyses from each site in order to show comparability between the trace element chemistries for each site. The gray bands within each figure are drawn to highlight areas of similar changes in element/Ca ratios. Each transect is then aligned with a photograph of the corresponding prismatic shell layer. Analyses were deleted if anomalies within the data were correlated with areas of contamination, for example, cracks or a poorly polished area of the shell.

\subsubsection{OceaNZ Blue Ltd (OBL) (RW75 and A740)}

Figure 4.2a illustrates element/Ca profiles through the prismatic layer of two pāua shells cultured in OceaNZ Blue Ltd's pāua-rearing farm. $\mathrm{Mg} / \mathrm{Ca}$ ratios for the two shells have slightly different values with A740 consistently having slightly higher $\mathrm{Mg} / \mathrm{Ca}$ ratios $(1-2 \mathrm{mmol} / \mathrm{mol})$ than $\mathrm{RW} 75$. The 3 point moving mean shows that $\mathrm{Mg} / \mathrm{Ca}$ values change from ca. 2-12 $\mathrm{mmol} / \mathrm{mol}$, although variations in each shell are generally not well correlated between shells with the exception of the foot areas. Sr/Ca ratios for both shells show a restricted range (1.0-1.5 mmol/mol) and small-scale variability on a scale of $2-3 \mathrm{~mm}$, but again, the variability within the two shells is not well correlated. Li/Ca ratios are low (0.0-0.1 $\mathrm{mmol} / \mathrm{mol}$ ) but generally slightly higher in shell RW75 compared with A740, with no obvious correlation of $\mathrm{Li} / \mathrm{Ca}$ variations between each shells. B/Ca ratios are again low (0.0-0.02 $\mathrm{mmol} / \mathrm{mol})$ and comparable between shells RW75 and A740, with again no obvious correlation between shells. U/Ca ratios in both RW75 and A740 are extremely low (ca. $<0.0005 \mathrm{mmol} / \mathrm{mol}$ ), however, unlike other element/Ca ratios, a significant number $(\mathrm{n}=7)$ of $(1-2 \mathrm{~mm}$ widths $) \mathrm{U} / \mathrm{Ca}$ peaks in both shells appear to correlate. $\mathrm{Ba} / \mathrm{Ca}, \mathrm{Mn} / \mathrm{Ca}, \mathrm{Zn} / \mathrm{Ca}$ and $\mathrm{Al} / \mathrm{Ca}$ ratios in both OceaNZ Blue Ltd shells have comparable low ratios (all element/Ca 
ratios $<0.02 \mathrm{mmol} / \mathrm{mol}$ ), but no clear correlation in the variations are observed in each shell.

\subsubsection{Pourerere (P1B and P04A)}

Figure $4.2 \mathrm{~b}$ illustrates element/Ca profiles through the prismatic layer of two shells sampled from Pourerere in the Hawke's Bay on December 30 2009. These shells, P04A and P1B, show similar values of $\mathrm{Mg} / \mathrm{Ca}, \mathrm{Sr} / \mathrm{Ca}$ and $\mathrm{Li} / \mathrm{Ca}$. The 3 point moving average of $\mathrm{Mg} / \mathrm{Ca}$ ratio for $\mathrm{P} 04 \mathrm{~A}$ ranges from 0.90-37.26 $\mathrm{mmol} / \mathrm{mol}$, and $\mathrm{P} 1 \mathrm{~B}$ range between $1.5-21.9 \mathrm{mmol} / \mathrm{mol}$. The $\mathrm{Mg} / \mathrm{Ca}$ ratios of both samples correlates reasonably well with similarities seen near the foot of the shell and 19 to $28 \mathrm{~mm}$ from the foot. Sr/Ca ratios for both shells show a restricted range $(0.9-3.0 \mathrm{mmol} / \mathrm{mol})$ and are not well correlated. $\mathrm{Li} / \mathrm{Ca}$ ratios are low (0.0-0.5 mmol/mol) and again are not well correlated. B/Ca ratios are also low (0.0-0.15mmol/mol) with slightly higher ratios within P1B (0.1 mmol) than P04A. B/Ca ratios also show a number of peaks $(n=2)$ that are $1-2 \mathrm{~mm}$ in width and correlate well between shells. The first peak, located $16 \mathrm{~mm}$ from the foot, shows a small $(0.8 \mathrm{~mm})$ lag between P1B and P04A. This is also seen at the same point in the profiles for $\mathrm{Mn} / \mathrm{Ca}$ and $\mathrm{U} / \mathrm{Ca}$, with slightly higher values in $\mathrm{P} 1 \mathrm{~B}$ than P04A. Pb/Ca ratios also exhibit higher values in P1B (ca. $<0.0003$ $\mathrm{mmol} / \mathrm{mol})$, however, $\mathrm{Pb} / \mathrm{Ca}$ ratios also have a higher number of peaks $(\mathrm{n}=4)$ compared to other element/Ca ratios. $\mathrm{Zn} / \mathrm{Ca}$ ratios are very low (ca. <0.01 $\mathrm{mmol} / \mathrm{mol}$ ) and are not well correlated between samples.

\subsubsection{South Coast (SC1A and SC2)}

The element/Ca profiles through the prismatic layers of two shells (SC1A and SC2) are illustrated in Figure 4.2c. Both shells were collected from Wellington's south coast on April $2^{\text {nd }} 2010 . \mathrm{Mg} / \mathrm{Ca}$ ratios for both shells are comparable, ranging from ca. 2-10 mmol/mol. Apart from the final ca. $15 \mathrm{~mm}$ of the profile, $\mathrm{Mg} / \mathrm{Ca}$ variations in the shell are not well correlated. Sr/Ca ratios for both shells are poorly correlated, with a restricted range of ca. $0.8-1.8 \mathrm{mmol} / \mathrm{mol}$ and large 
scale variability on a scale of $10 \mathrm{~mm}$. Li/Ca ratios are higher in SC1A (ca. 0.0-0.2 $\mathrm{mmol} / \mathrm{mol}$ ) compared with SC2 (ca. 0.00-0.02 mmol/mol). B/Ca, U/Ca, Pb/Ca, $\mathrm{Ba} / \mathrm{Ca}, \mathrm{Zn} / \mathrm{Ca}$ and $\mathrm{Al} / \mathrm{Ca}$ ratios also show higher SC1A values comparable with SC2 with low element/Ca ratios (ca. $<0.03 \mathrm{mmol} / \mathrm{mol}$ ). B/Ca ratios in both SC1A and SC2 show a significant number $(n=6)$ of peaks which is unlike the other element/Ca profiles. Each peak appears to be 1-2 mm in width. U/Ca and $\mathrm{Al} / \mathrm{Ca}$ ratios also show a few comparable peaks between both shell samples. $\mathrm{Mn} / \mathrm{Ca}$ ratios for SC1A and SC2 are comparable with no clear correlation. $\mathrm{Pb} / \mathrm{Ca}$ also has no clear correlation between both shells, with extremely low values (ca. $<0.00075 \mathrm{mmol} / \mathrm{mol}$ ).

\subsubsection{Moa Point (MP02A)}

The element/Ca ratio profiles of the prismatic layer of MP02A are illustrated in Figure 4.2d. Mg/Ca ratios range between 2.0-17.0 mmol/mol. Close to the foot of the shell (0-24 mm) there are a series of changes in $\mathrm{Mg} / \mathrm{Ca}$, with gradual decreases in values over widths of 6.0-8.0 $\mathrm{mm}$ and sharp increases in values over widths of 1-2 mm. Sr/Ca ratios are restricted in range (1.0-2.5 mmol/mol). $\mathrm{Li} / \mathrm{Ca}$ ratios of MP02A are low (ca. $<0.06 \mathrm{mmol} / \mathrm{mol}$ ). The 3-point moving average of $\mathrm{Li} / \mathrm{Ca}$ ratios near the foot of the shell shows consistently sharp changes in values over widths of $0.4 \mathrm{~mm}$. This is followed by a flat period ( $5 \mathrm{~mm}$ ) which is seen in both $\mathrm{Mg} / \mathrm{Ca}$ and $\mathrm{Sr} / \mathrm{Ca}$ ratios. $\mathrm{B} / \mathrm{Ca}, \mathrm{Ba} / \mathrm{Ca}, \mathrm{Mn} / \mathrm{Ca}, \mathrm{Pb} / \mathrm{Ca}$ and $\mathrm{Al} / \mathrm{Ca}$ ratios in MP02A show a correlation between a number of peaks $(\mathrm{n}=3)$. These element/Ca ratio also have low values (0.0-0.6 mmol/mol). $\mathrm{Pb} / \mathrm{Ca}$ ratios show variability over widths of 2-3 $\mathrm{mm}$. $\mathrm{Pb} / \mathrm{Ca}$ ratios are also extremely low (ca. $<0.0004 \mathrm{mmol} / \mathrm{mol}$ ), and similar to U/Ca ratios (ca. $<0.0003 \mathrm{mmol} / \mathrm{mol}$ ). Low in $\mathrm{Zn} / \mathrm{Ca}$ ratios are also evident $(0-0.015 \mathrm{mmol} / \mathrm{mol})$. 


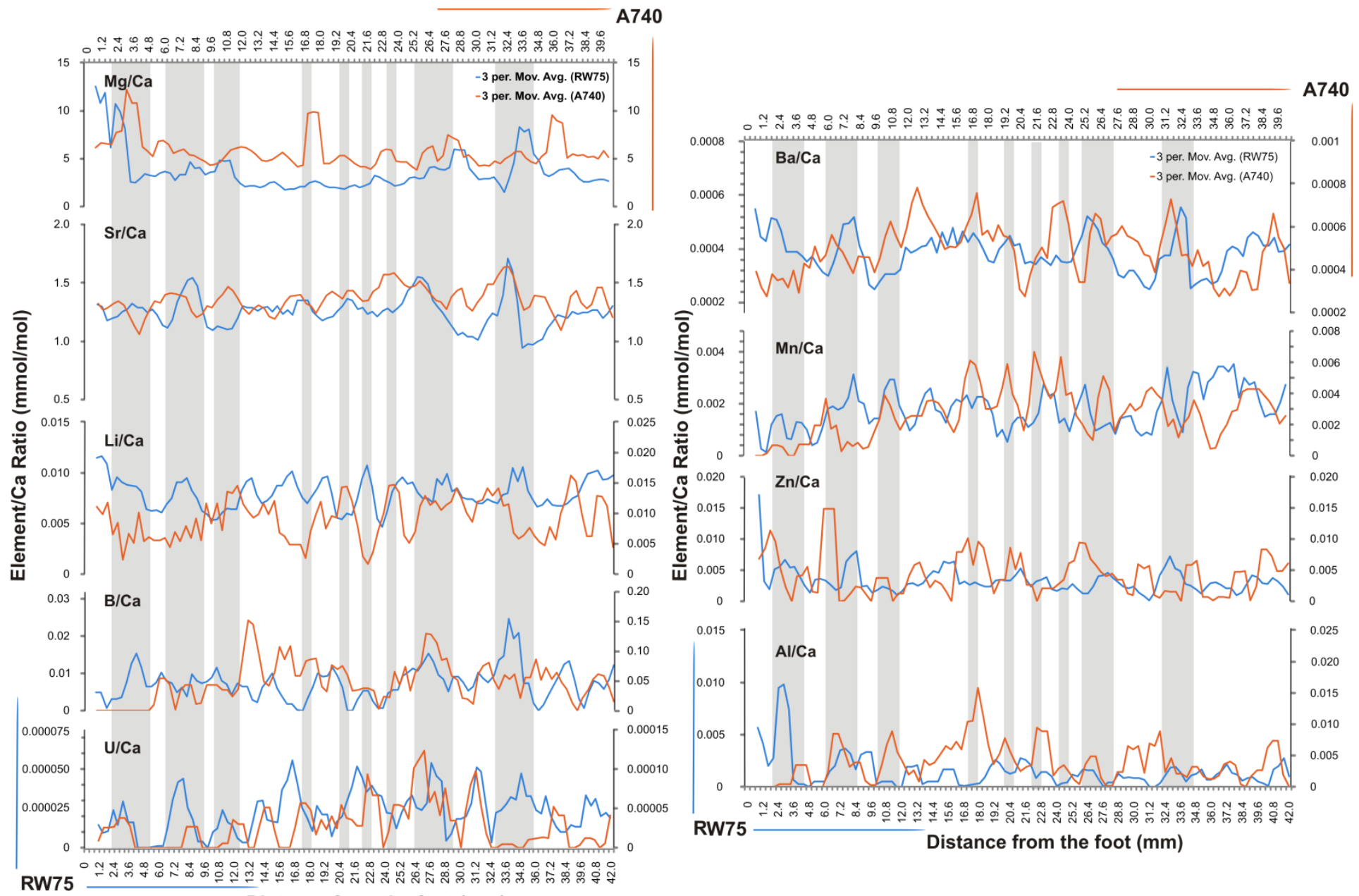

Fig. 4.2a. Plots of the 3-point moving average of element/Ca ratios of samples A740 (red) and RW75 (blue) from OceaNZ Blue Ltd measured from the foot of the shell through the prismatic layer.. The scale for RW75 is represented on the left and bottom axes with A740 represented on the right and top axes. Grey banding highlights element/Ca ratios that are well correlated. 
CHAPTER 4: Results
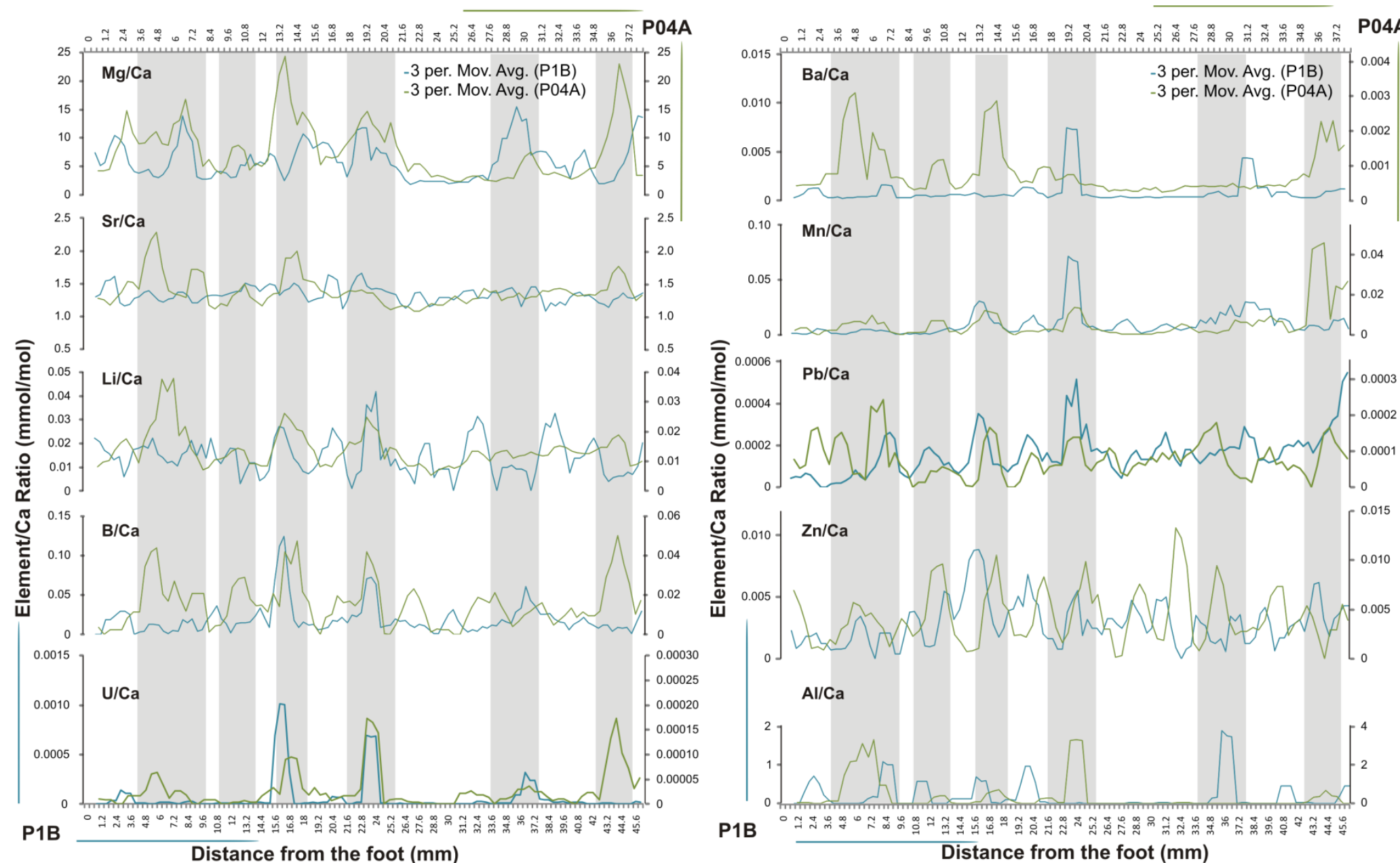

Fig. 4.2b. Plots of the 3-point moving average of element/Ca ratios of samples P04A (green) and P1B (blue) from Pourerere measured from the foot of the shell through the prismatic layer.. The scale for P1B is represented on the left and bottom axes with P04A represented on the right and top axes. Grey banding highlights element/Ca ratios that are well correlated. 

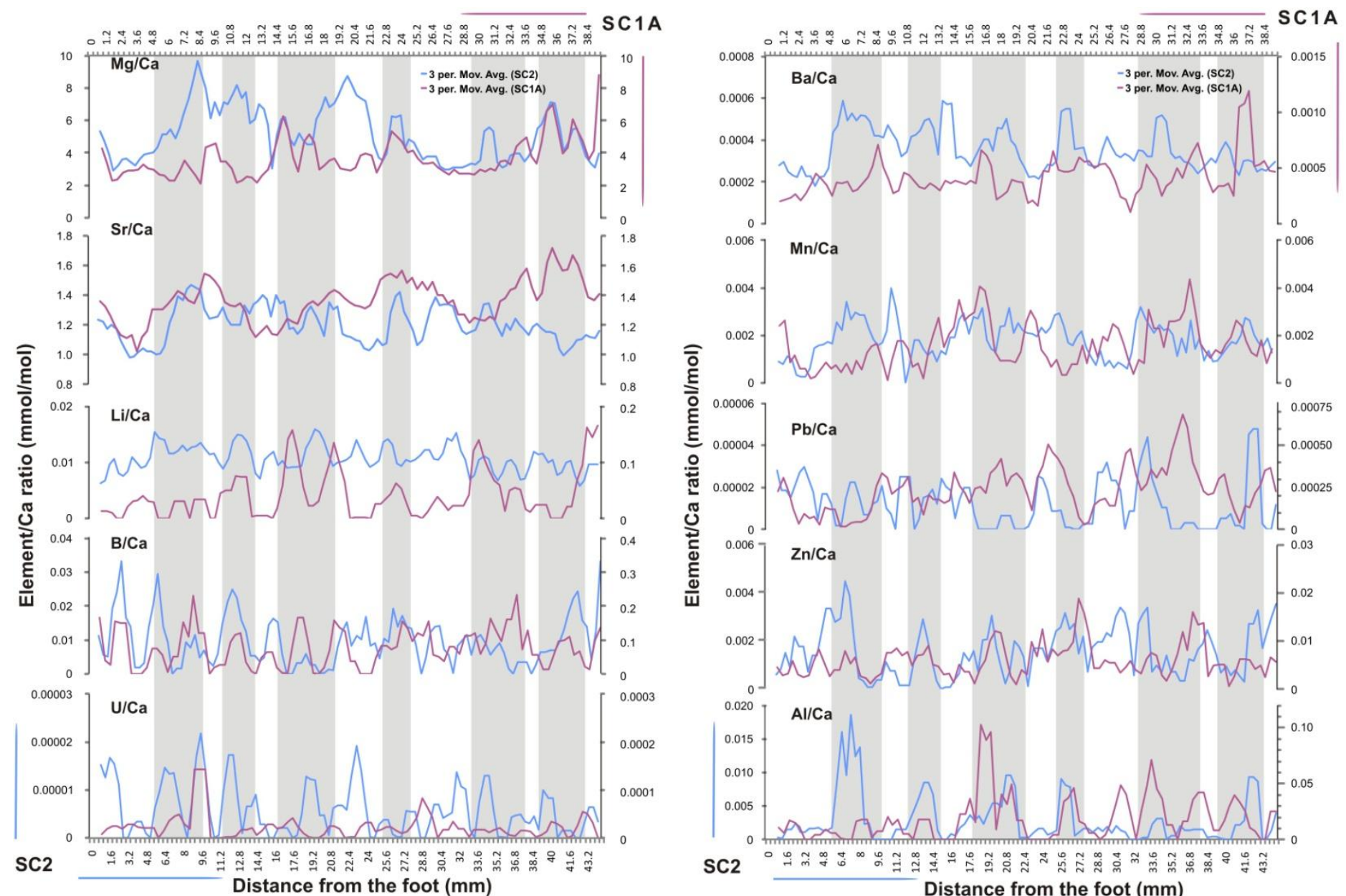

Fig. 4.2c. Plots of the 3-point moving average of element/Ca ratios of samples SC1A (pink) and SC2 (blue) from the Wellington south coast measured from the foot of the shell through the prismatic layer. The scale for SC2 is represented on the left and bottom axes with SC1A represented on the right and top axes. Grey banding highlights element/Ca ratios that are well correlated. 

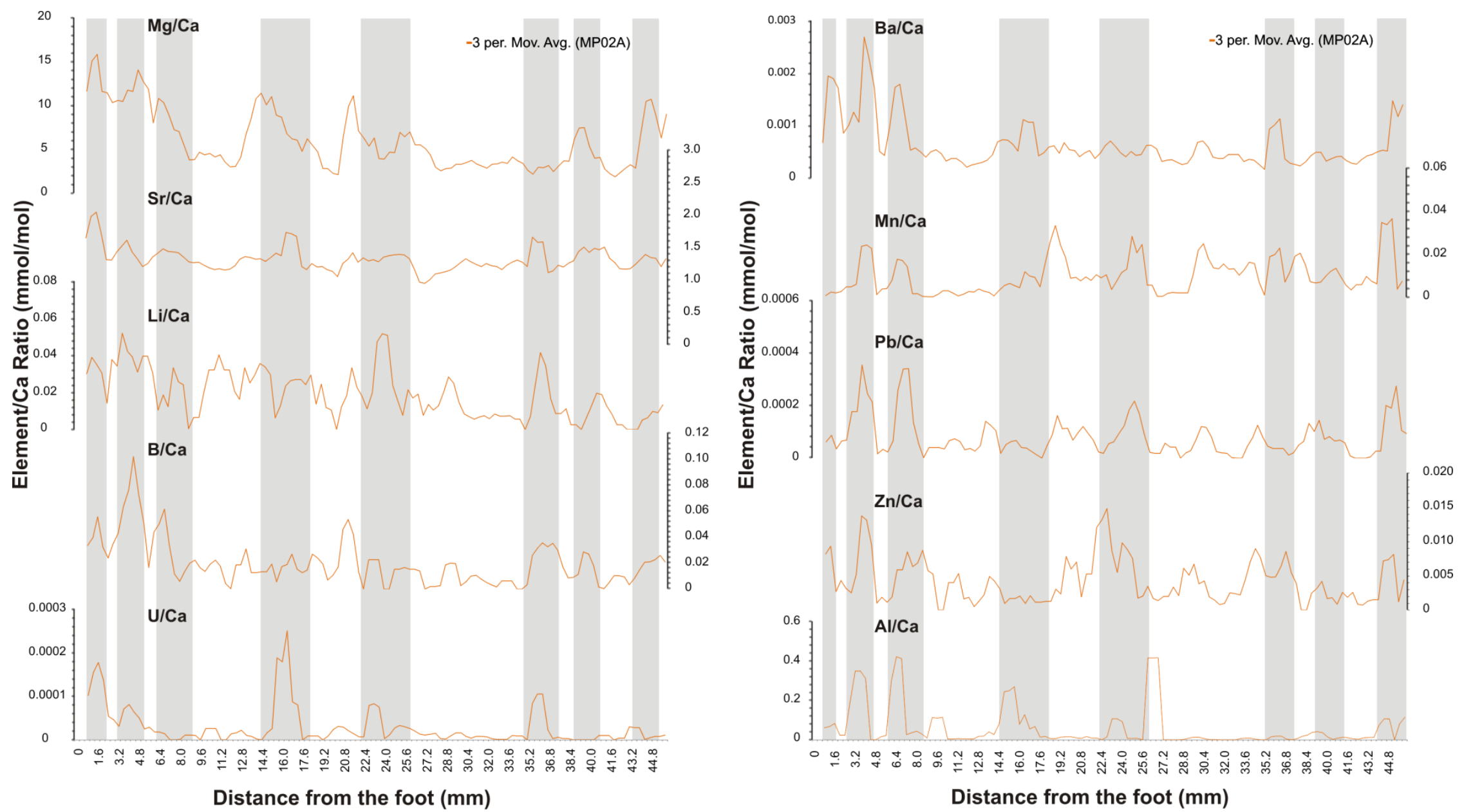

Fig. 4.2d. Plots of the 3-point moving average of the element/Ca ratios of samples MP02A from Moa Point in Wellington measured from the foot of the shell through the prismatic layer. Grey banding highlights element/Ca ratios that are well correlated. 
Figure 4.2e illustrates the 3-point moving average of the element/Ca profiles of KD1B. The shell was collected in Kaikoura on August 11 th 2010. The profile is long $(<80.0 \mathrm{~mm})$ compared with the other samples analysed in this research (32-46 mm). Mg/Ca ratios range between 1.5-17.3 mmol/mol. Higher $\mathrm{Mg} / \mathrm{Ca}$ ratios values are observed $0.0-20.0 \mathrm{~mm}$ from the foot before values fall below $10 \mathrm{mmol} / \mathrm{mol}$. Sr/Ca ratios are also restricted $(1.0-2.0 \mathrm{mmol} / \mathrm{mol})$, with the exception of a peak observed $69 \mathrm{~mm}$ from the foot of the shell. The peak has a width of $2-3 \mathrm{~mm}$ and is reproduced in $\mathrm{Ba} / \mathrm{Ca}, \mathrm{Mn} / \mathrm{Ca}$ and $\mathrm{Zn} / \mathrm{Ca}$ ratios. Low values are also seen in $\mathrm{Ba} / \mathrm{Ca}(0.004 \mathrm{mmol} / \mathrm{mol}), \mathrm{Mn} / \mathrm{Ca}(0.025 \mathrm{mmol} / \mathrm{mol})$ and $\mathrm{Zn} / \mathrm{Ca}$ ratios (0.005 mmol/mol). Zn/Ca, B/Ca and $\mathrm{Li} / \mathrm{Ca}$ ratios are low (ca. 0.02 $\mathrm{mmol} / \mathrm{mol}$ ) and show small scale variability over 1-2 mm. U/Ca and $\mathrm{Pb} / \mathrm{Ca}$ ratios are extremely low (ca. $<0.0001 \mathrm{mmol} / \mathrm{mol}$ ) with large variability in values over small distances $(<1 \mathrm{~mm})$. Al/Ca ratios are low $(0-0.04 \mathrm{mmol} / \mathrm{mol})$.

Figure 4.2f illustrates the element/Ca profiles through the prismatic layer of two pāua shells (K3A and K1A1) from Kaikoura. The shells were collected from Kaikoura on January $1^{\text {st }} 2010$.

$\mathrm{Mg} / \mathrm{Ca}$ ratios in both samples are comparable, ranging from ca. 3-20 mmol/mol. There are a number $(n=4)$ of peaks seen in both K3A and K1A1 that are 1-2 $\mathrm{mm}$ in width. With the exception of these peaks, the variations in each sample are generally not well correlated. Sr/Ca ratios in both samples are also not well correlated. K3A has a larger range in $\mathrm{Sr} / \mathrm{Ca}$ (ca. 1.0-3.0 mmol/mol) compared with $\mathrm{K} 1 \mathrm{~A} 1$ (1.0-2.0 $\mathrm{mmol} / \mathrm{mol})$. Li/Ca ratios are comparable in both $\mathrm{K} 3 \mathrm{~A}$ and $\mathrm{K} 1 \mathrm{~A} 1$, with a range of between $0-0.04 \mathrm{mmol} / \mathrm{mol}$. Apart from the first $0-10 \mathrm{~mm}$ from the foot, both samples are poorly correlated. B/Ca ratios are also low (ca. < $0.06 \mathrm{mmol} / \mathrm{mol}$ ), but both samples are comparable and are moderately well correlated. $\mathrm{Ba} / \mathrm{Ca}$ ratios are also very low (ca. $<0.002 \mathrm{mmol} / \mathrm{mol}$ ) but comparable and also moderately well correlated. $\mathrm{Mn} / \mathrm{Ca}$ ratios are also comparable, with a range from $0.000-0.017 \mathrm{mmol} / \mathrm{mol}$. $\mathrm{Pb} / \mathrm{Ca}$ ratios are extremely low (ca. $<0.0006 \mathrm{mmol} / \mathrm{mol}$ ) with large-scale variability over minimum widths of $4 \mathrm{~mm}$. Al/Ca ratios are higher in $\mathrm{K} 3 \mathrm{~A}$ (ca. $<0.50 \mathrm{mmol} / \mathrm{mol}$ ) 
compared with K1A1 (ca. $<0.06 \mathrm{mmol} / \mathrm{mol}$ ), however, the variations in both samples are poorly correlated.

\subsubsection{Chatham Islands (MR2 and AR1)}

Figure 4.2g illustrates the element/Ca profiles through the prismatic layer of MR2 and AR1. Both shells were collected off the east coast of the Chatham Islands on October $24^{\text {th }} 2010 . \mathrm{Mg} / \mathrm{Ca}$ ratios of both samples are comparable with a higher range seen in MR2 (ca. $<25 \mathrm{mmol} / \mathrm{mol}$ ) compared with AR1 (ca. $13 \mathrm{mmol} / \mathrm{mol}$ ). $\mathrm{Mg} / \mathrm{Ca}$ and $\mathrm{Sr} / \mathrm{Ca}$ ratios in both samples are also poorly correlated. The $\mathrm{Sr} / \mathrm{Ca}$ ratios in AR1 range are restricted (ca. $1.0-2.0 \mathrm{mmol} / \mathrm{mol}$ ) whereas a number of large peaks $(n=4)$ are observed in MR2 that have a width of 1.0-2.0 mm. Li/Ca ratios are low (0.0-0.06 $\mathrm{mmol} / \mathrm{mol})$ and are comparable between both samples but poorly correlated. B/Ca ratios for the two samples have different values, with MR2 consistently having higher B/Ca ratios than AR1 ( $0.2 \mathrm{mmol} / \mathrm{mol}$ ). MR2 has higher values of $\mathrm{U} / \mathrm{Ca}, \mathrm{Mn} / \mathrm{Ca}, \mathrm{Pb} / \mathrm{Ca}$ and $\mathrm{Al} / \mathrm{Ca}$ when compared with AR1, and these are not well correlated between samples. All values are low (ca. $<0.2 \mathrm{mmol} / \mathrm{mol}$ ). Ba/Ca ratios are comparable in both shells (ca. $<0.004 \mathrm{mmol} / \mathrm{mol}$ ) but again, are poorly correlated. $\mathrm{Zn} / \mathrm{Ca}$ values are low (0.00-0.02 $\mathrm{mmol} / \mathrm{mol})$ with a number of peaks $(\mathrm{n}=4)$ seen in both shells. AR1 peaks precede that of MR2 by $0.4-1.2 \mathrm{~mm}$. Apart from the peaks, there is no clear correlation in the $\mathrm{Zn} / \mathrm{Ca}$ ratio of each shell.

\subsubsection{Moeraki (MD1 and MD3)}

The element/Ca profiles of two samples (MD1 and MD3) are illustrated Figure 4.2h. MD1 and MD3 were collected from Moeraki on October 27th 2010. The 3point moving average of $\mathrm{Mg} / \mathrm{Ca}$ ratios has a range of 3.0-17.0 mmol/mol. There are also a number of peaks $(\mathrm{n}=3)$ which correlated well between samples. $\mathrm{Sr} / \mathrm{Ca}$ ratios are restricted in range $(1.0-2.2 \mathrm{mmol} / \mathrm{mol})$, as seen in all other samples. Both individuals have poor correlation but comparable $\mathrm{Sr} / \mathrm{Ca}$ values. $\mathrm{Li} /$ Ca ratios are low $(0.00-0.06 \mathrm{mmol} / \mathrm{mol})$ but slightly higher $(0.03 \mathrm{mmol} / \mathrm{mol})$ in MD1 compared with MD3. B/Ca ratios are also higher in MD1 (ca. $<0.6$ $\mathrm{mmol} / \mathrm{mol})$ compared with MD3 $(0.06 \mathrm{mmol} / \mathrm{mol})$. B/Ca ratios again are poorly 
correlated. $\mathrm{U} / \mathrm{Ca}$ and $\mathrm{Pb} / \mathrm{Ca}$ ratios in both shells are extremely low $(0.0000$ $0.0004 \mathrm{mmol} / \mathrm{mol}$ ) but are comparable. $\mathrm{Zn} / \mathrm{Ca}$ ratios are low (ca. $<0.04$ $\mathrm{mmol} / \mathrm{mol}$ ) but comparable between samples. There is also a moderate $\mathrm{Zn} / \mathrm{Ca}$ correlation with slightly higher values $(0.0025-0.0050 \mathrm{mmol} / \mathrm{mol})$ in MD1 compared with MD3. Ba/Ca ratios are poorly correlated, but have a number of peaks $(\mathrm{n}=2)$ over widths of $1-2 \mathrm{~mm}$ that are similar in both samples. $\mathrm{Ba} / \mathrm{Ca}$, $\mathrm{Mn} / \mathrm{Ca}$ and $\mathrm{Al} / \mathrm{Ca}$ ratios in both shells are low (ca. $<0.80 \mathrm{mmol} / \mathrm{mol}$ ) with slightly higher values seen in MD1 compared with MD3. As observed in other element/Ca profiles, there is no clear correlation seen in both samples. 

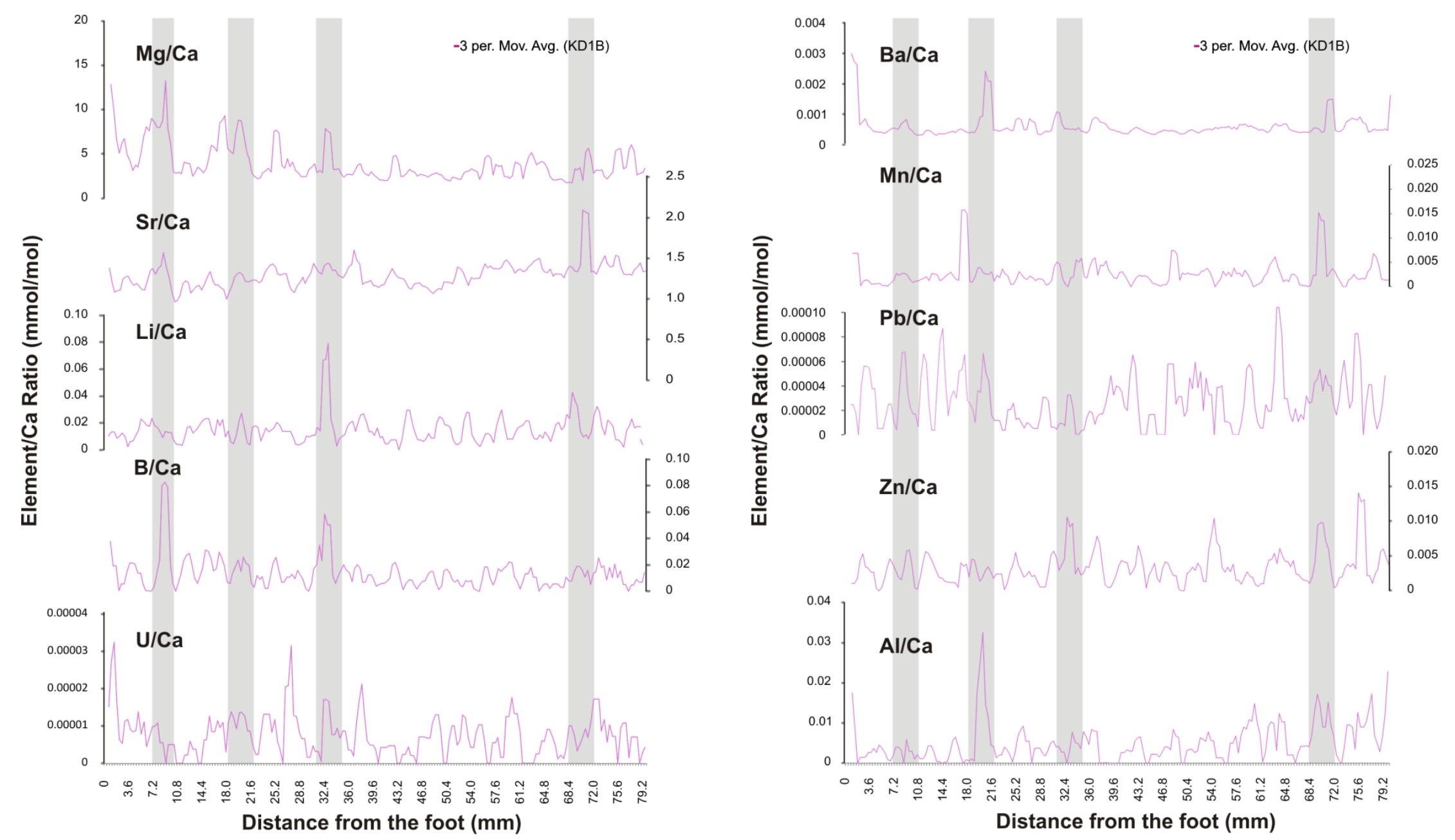

Fig. 4.2e. Plots of the 3-point moving average of the element/Ca ratios of samples KD1B from Kaikoura measured from the foot of the shell through the prismatic layer. Grey banding highlights element/Ca ratios that are well correlated. 

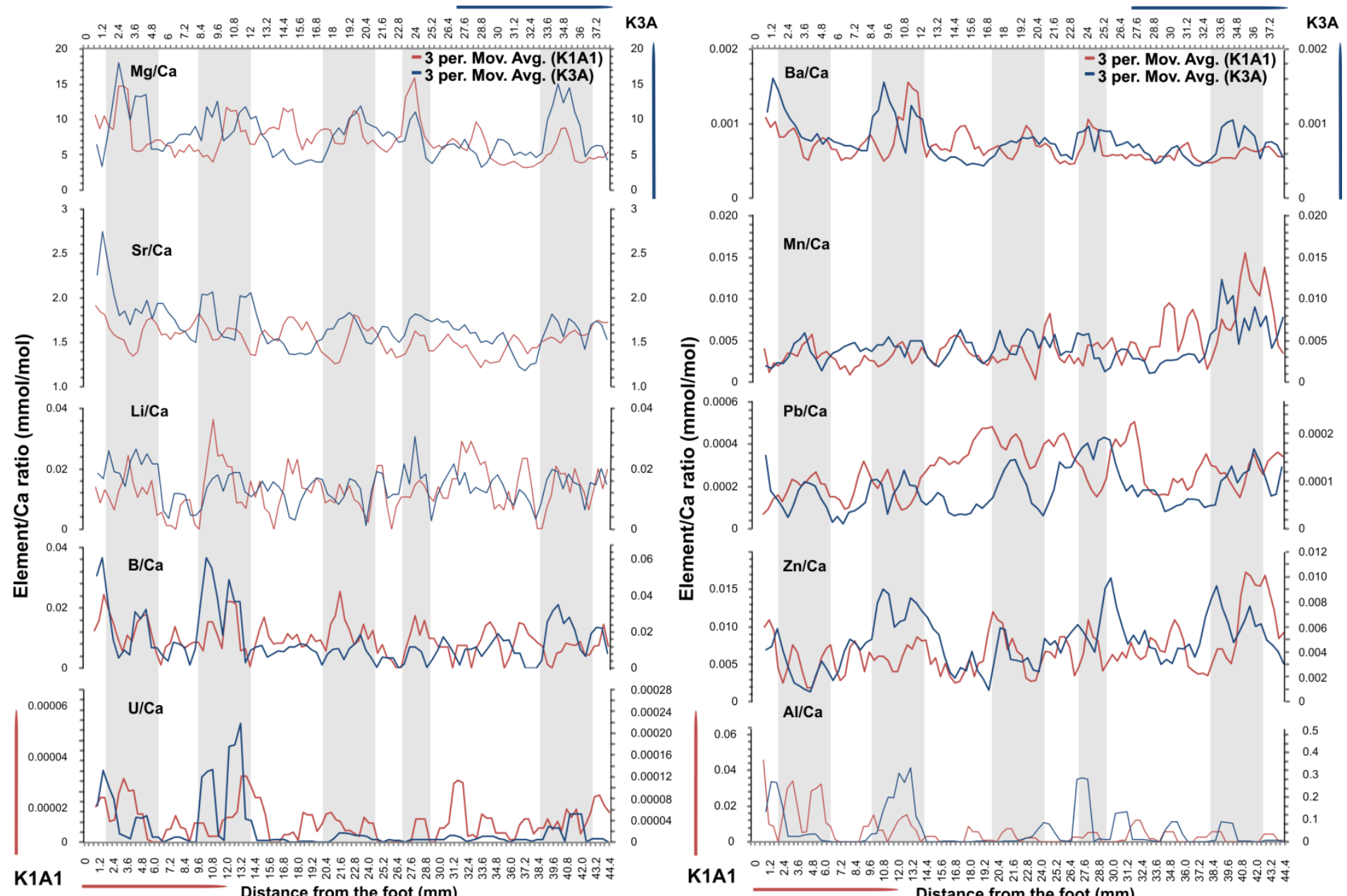

Fig. 4.2f. Plots of the 3-point moving average of the element/Ca ratios of samples K3A (blue) and K1A1 (red) from Kaikoura measured from the foot of the shel $(\mathrm{mm})$ through the prismatic layer. The scale for K1A1 is represented on the left and bottom axes with K3A represented on the right and top axes. Grey banding highlights element/Ca ratios that are well correlated. 

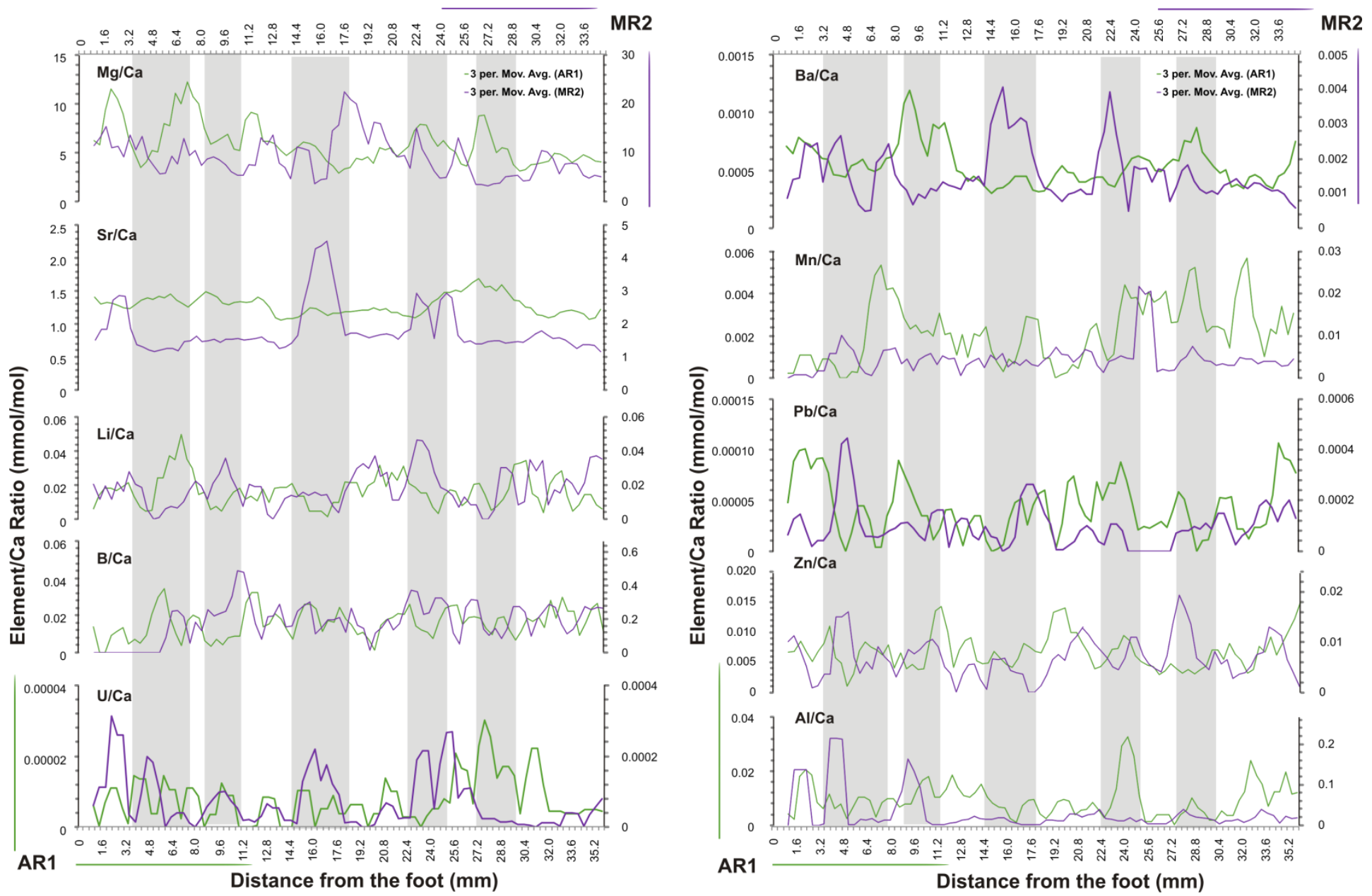

Fig. 4.2g. Plots of the 3-point moving average of the element/Ca ratios of samples AR1 (green) and MR2 (purple) from Chatham Islands measured from the foot of the shell through the prismatic layer. The scale for AR1 is represented on the left and bottom axes with MR2 represented on the right and top axes. Grey banding highlights element/Ca ratios that are well correlated. 

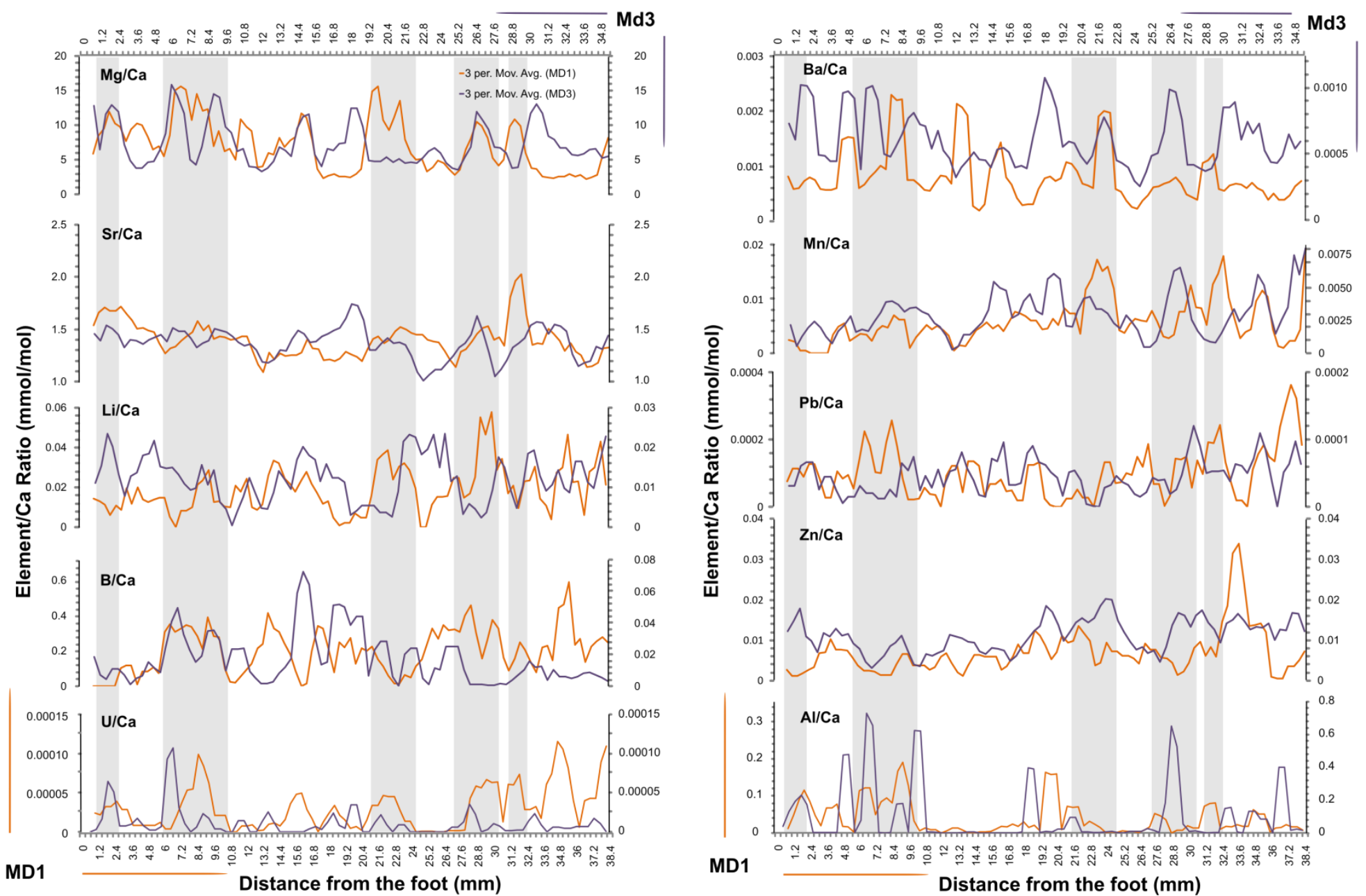

Fig. 4.2h. Plots of the 3-point moving average of the element/Ca ratios of samples MD1 (orange) and MD3 (purple) from Moeraki measured from the foot of the shell through the prismatic layer. The scale for MD1 is represented on the left and bottom axes with MD3 represented on the right and top axes. Grey banding highlights element/Ca ratios that are well correlated. 
At different locations within nacreous layer of each sample, a transect was analysed with $25 \mu \mathrm{m}$ spot sizes every $50 \mu \mathrm{m}$ across the axis of maximum growth. The transect paths can be seen in Figure 4.3 for sample K3A. The results of the nacreous layer analyses are then compared with photographs of the samples based on their element/Ca ratio, to examine if the nacre showed reproducible results at different locations across the shell. Laser ablation spots that were analysed on the black lines (Fig. 4.3) produced anomalously high trace element/Ca ratios and were removed from the graphs. Element/Ca ratios that did not show consistent results above background counts were not presented in graphical form in section 4.2.2, but the data can be viewed in the Appendix 5.

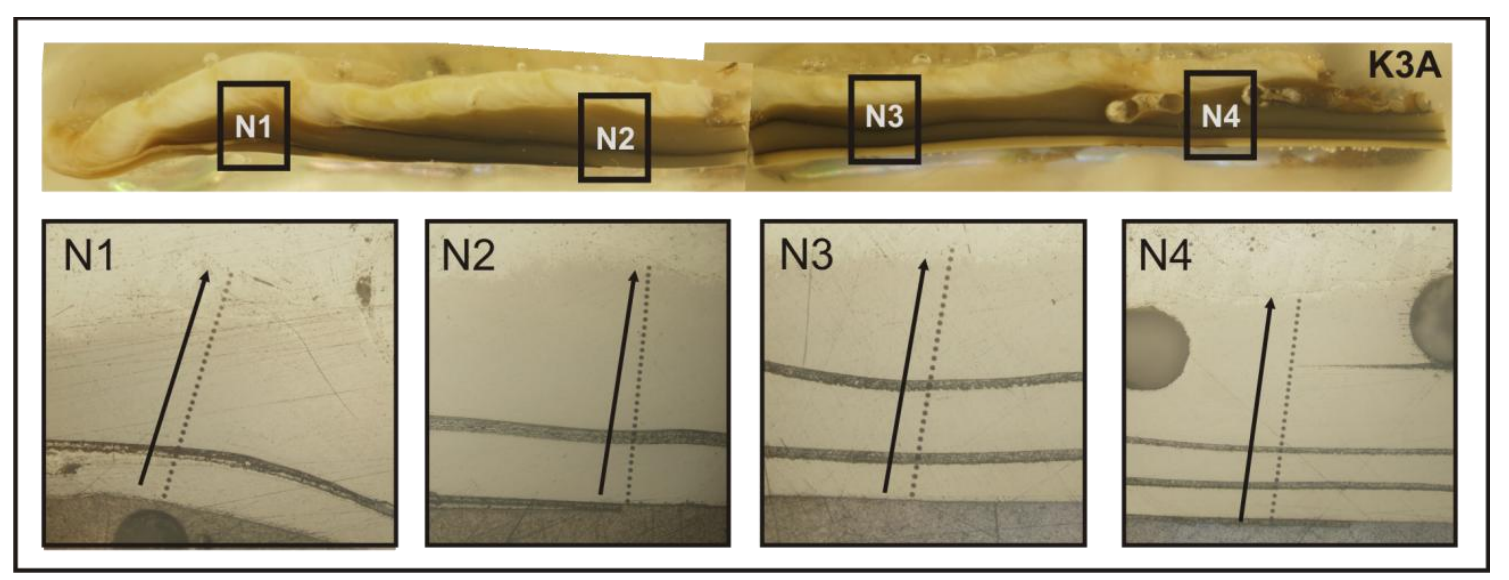

Fig. 4.3. Example of the transect direction of the analysis through the nacreous layer of shell K3A. The transect follows a growth band from the inner shell towards the prismatic-nacreous layer boundary with spots spaced $50 \mu \mathrm{m}$ apart.

\subsubsection{1}

\section{OceaNZ Blue Ltd (OBL) (A740 and RW75)}

Figure 4.4a illustrates the element/Ca ratio profiles of the nacreous layer of A740 (top) and RW75 (bottom). Six different profiles were analysed in A740 and five profiles in RW75. Mg/Ca ratios of A740 are comparable in all transects. The 3-point moving average in both samples show a range from 0.0-0.5 $\mathrm{mmol} / \mathrm{mol}$. $\mathrm{Mg} / \mathrm{Ca}$ ratios show a sharp increase over $1 \mathrm{~mm}$ adjacent to the 
boundary between the nacreous and prismatic layer boundary. This increase in $\mathrm{Mg} / \mathrm{Ca}$ ratios correlates with a decrease in $\mathrm{Ba} / \mathrm{Ca}$. $\mathrm{Ba} / \mathrm{Ca}$ ratios are very low (0.0012-0.0050 $\mathrm{mmol} / \mathrm{mol})$ with poor correlation across all nacre profiles. $\mathrm{Sr} / \mathrm{Ca}$ ratios, on the other hand, are very similar in all transect profiles. $\mathrm{Sr} / \mathrm{Ca}$ ratios are very restricted (ca. $1.5-2.5 \mathrm{mmol} / \mathrm{mol}$ ) showing significant variability over distances of $0.4 \mathrm{~mm}$. Mn/Ca ratios are comparable at low values (ca. < $0.005 \mathrm{mmol} / \mathrm{mol}$ ) which are all poorly correlated.

$\mathrm{Mg} / \mathrm{Ca}$ ratios of all the RW75 nacre transects are comparable, and range from ca. $0.0-0.5 \mathrm{mmol} / \mathrm{mol}$. Mg/Ca ratios for N3 and N5 shows variable results over 0.1$0.2 \mathrm{~mm} . \mathrm{Sr} / \mathrm{Ca}$ ratios in all transects show very restricted values (ca. 1.5-2.0 $\mathrm{mmol} / \mathrm{mol}$ ) and are well correlated between samples. Ba/ Ca ratios of N2, N3 and $\mathrm{N} 4$ correlate well, with large-scale variability over $0.5 \mathrm{~mm}$. N1 and N5 transects show small scale variability over $0.2 \mathrm{~mm}$. Ba/Ca and $\mathrm{Mn} / \mathrm{Ca}$ ratios are also very low (ca. $<0.005 \mathrm{mmol} / \mathrm{mol}$ ). As observed in A740, Mn/Ca ratios are also poorly correlated in all profiles.

\subsubsection{Pourerere (P1B and P04A)}

The results of the nacreous layer transects of samples from Pourerere Beach, P04A (top) and P1B (bottom), are displayed in Figure 4.4b. Four nacre transects were measured in both shells at various distances from the foot. The $\mathrm{Mg} / \mathrm{Ca}$ ratios of different profiles through the nacre of P04A are not comparable. N1 has a significantly lower $\mathrm{Mg} / \mathrm{Ca}$ ratio (ca. $<0.2 \mathrm{mmol} / \mathrm{mol}$ ) when compared with $\mathrm{N} 2$, N3 and $\mathrm{N} 4(0.2-1.4 \mathrm{mmol} / \mathrm{mol}) . \mathrm{Sr} / \mathrm{Ca}$ ratios again show a restricted range (1.5-3.0 $\mathrm{mmol} / \mathrm{mol}$ ) with slightly higher values in P04A compared with P1B. $\mathrm{Sr} / \mathrm{Ca}$ ratios of each nacre profile are not well correlated. Ba/Ca ratios are also not well correlated and show very low values (ca. $<0.0014 \mathrm{mmol} / \mathrm{mol}$ ). $\mathrm{Ba} / \mathrm{Ca}$ ratios show breaks within the first $0.2 \mathrm{~mm}$ of transects $\mathrm{N} 2$ and $\mathrm{N} 3$, which are also observed in the $\mathrm{Mg} / \mathrm{Ca}$ and $\mathrm{Sr} / \mathrm{Ca}$ profiles. B/Ca ratios show no obvious correlations, with values ranging from $0.0-0.2 \mathrm{mmol} / \mathrm{mol}$.

$\mathrm{Mg} / \mathrm{Ca}$ ratios in $\mathrm{P} 1 \mathrm{~B}$ are comparable with ranges ca. $0.2-0.8 \mathrm{mmol} / \mathrm{mol}$. Variations generally occur ca. $0.2-0.4 \mathrm{~mm}$ within profiles $\mathrm{N} 1$ and $\mathrm{N} 2$, whereas 
$\mathrm{N} 3$ and N4 show smaller-scale variation (over $2 \mathrm{~mm}$ ) and are well correlated. $\mathrm{Sr} / \mathrm{Ca}$ ratios show a narrow range, $1.5-2.5 \mathrm{mmol} / \mathrm{mol}$, and are well correlated. Peaks in N1 compare with peaks in N2, N3 and N4, which have a width of 2-3 $\mathrm{mm}$. Ba/Ca and $\mathrm{Pb} / \mathrm{Ca}$ ratios are extremely low (ca. $<0.001 \mathrm{mmol} / \mathrm{mol}$ ). Unlike the other transect profiles of $\mathrm{Pb} / \mathrm{Ca}$ ratios, N3 shows more variability, ranging across 0.0000-0.0006 mmol/mol. B/Ca values are low (ca. $<0.08 \mathrm{mmol} / \mathrm{mol}$ ) and do not correlate well in all transect profiles of P1B.

\subsubsection{South Coast (SC1A and SC2)}

The element/Ca ratio profiles of nacreous layer transects across SC1A (top) and SC2 (bottom) are illustrated in Figure 4.4c. The Mg/Ca ratios for SC1A show very different results, with $\mathrm{N} 2$ (0.3-0.6 $\mathrm{mmol} / \mathrm{mol}$ ) having higher values compared with $\mathrm{N} 1(0.2-0.4 \mathrm{mmol} / \mathrm{mol})$. $\mathrm{N} 3$ also shows large $\mathrm{Mg} / \mathrm{Ca}$ ratio variation (0.3-0.7 mmol/mol) over a small scale $(0.1 \mathrm{~mm})$. Sr/Ca ratios have a small range of ca. $1.5-2.5 \mathrm{mmol} / \mathrm{mol}$ with comparable results and good correlation between all three profiles. Peaks located $0.9 \mathrm{~mm}$ from the inner shell are also seen in $\mathrm{Mg} / \mathrm{Ca}, \mathrm{Sr} / \mathrm{Ca}, \mathrm{Ba} / \mathrm{Ca}$ and $\mathrm{B} / \mathrm{Ca}$ ratios, with widths of 0.1-0.2 mm. $\mathrm{Ba} / \mathrm{Ca}$ and $\mathrm{Pb} / \mathrm{Ca}$ ratios are extremely low $(<0.0007 \mathrm{mmol} / \mathrm{mol})$ and do not correlate well between transects. $\mathrm{B} / \mathrm{Ca}$ ratios are also low $(<0.2 \mathrm{mmol} / \mathrm{mol})$ and do not correlate well in the nacre of SC1A.

The element/Ca ratios of 4 different transects across the nacreous layer of SC2 were analysed. The 3-point moving average of $\mathrm{Mg} / \mathrm{Ca}$ ratios shows variation in all transects from 0.2-0.9 mmol/mol. All results are comparable but do not correlate well. Variability is observed in all transects from ca. 0.2-0.4 mm. Similarly to SC1A, Sr/Ca ratios are restricted in range $(1.5-2.5 \mathrm{mmol} / \mathrm{mol})$. N1 and N2 show more variability closer to the inner shell edge, with higher $\mathrm{Sr} / \mathrm{Ca}$ values compared with $\mathrm{N} 3$ and $\mathrm{N} 4$. Ba/Ca ratios are again similar to SC1A and very low (ca. $<0.0012 \mathrm{mmol} / \mathrm{mol}$ ). Small-scale variability is observed at widths of ca. 0.2-0.4 $\mathrm{mm}$ in the $\mathrm{Ba} / \mathrm{Ca}$ ratio profiles, with all transects showing poor correlation with each other. B/Ca ratios are also poorly correlated. N1 has lower values (ca. $<0.06 \mathrm{mmol} / \mathrm{mol}$ ) compared with $\mathrm{N} 4$ (0.06-0.12 mmol/mol). A large 
peak followed by a sharp decrease is observed at $1.6 \mathrm{~mm}$ from the inner shell in $\mathrm{B} / \mathrm{Ca}$ of $\mathrm{N} 2$ and is also observed in $\mathrm{Ba} / \mathrm{Ca}$ and $\mathrm{Sr} / \mathrm{Ca}$.

\subsubsection{Moa Point (MP02A)}

The element/Ca ratio profiles through the nacre of MP02A are illustrated in the upper diagram of Figure 4.4d. A number of profiles $(n=4)$ were measured in the shell, with $\mathrm{Mg} / \mathrm{Ca}, \mathrm{Sr} / \mathrm{Ca}, \mathrm{Ba} / \mathrm{Ca}$ and $\mathrm{B} / \mathrm{Ca}$ ratios presented in Figure $4.4 \mathrm{~d}$ $\mathrm{Mg} / \mathrm{Ca}$ ratios are well correlated in all transects, with values ca. $<1.5 \mathrm{mmol} / \mathrm{mol}$. $\mathrm{Sr} / \mathrm{Ca}$ ratios are restricted in value $(1.5-2.5 \mathrm{mmol} / \mathrm{mol})$. A peak is seen at 0.7 $\mathrm{mm}$ from the inner shell in both $\mathrm{N} 3$ and N4 profiles of Sr/Ca ratios. The beginning of each profile is well correlated but variations are observed $0.3 \mathrm{~mm}$ from the inner shell layer. Ba/Ca ratios are extremely low $(0.00008 \mathrm{mmol} / \mathrm{mol})$, with values that are variable in all profiles and a number of peaks $(n=2)$ that correlate well in N2, N3 and N4. Aside from the peaks, the nacre profiles are poorly correlated but compare well. B/Ca ratios are also low (0.02-0.10 $\mathrm{mmol} / \mathrm{mol}$ ). The variations in each profile are poorly correlated but two peaks compare well in N2 and N4. 

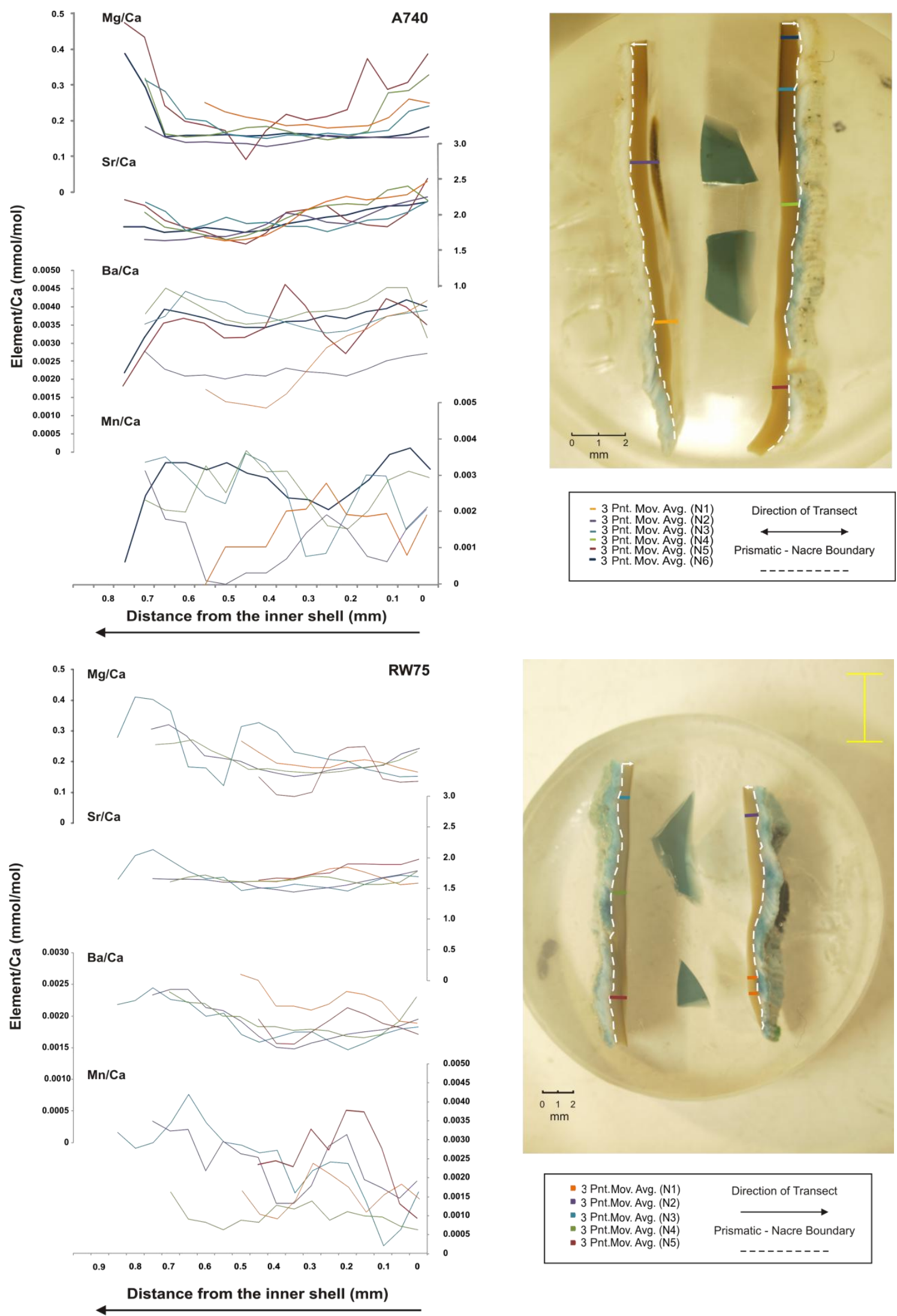

Fig. 4.4a. Plots of nacreous layer element/Ca ratios in samples A740 and RW75 from OBL. The left panel presents the element/Ca values through a high resolution analysis taken from the inner shell towards the prismatic-nacre boundary. The right panel shows transect locations on the sample mounts. 

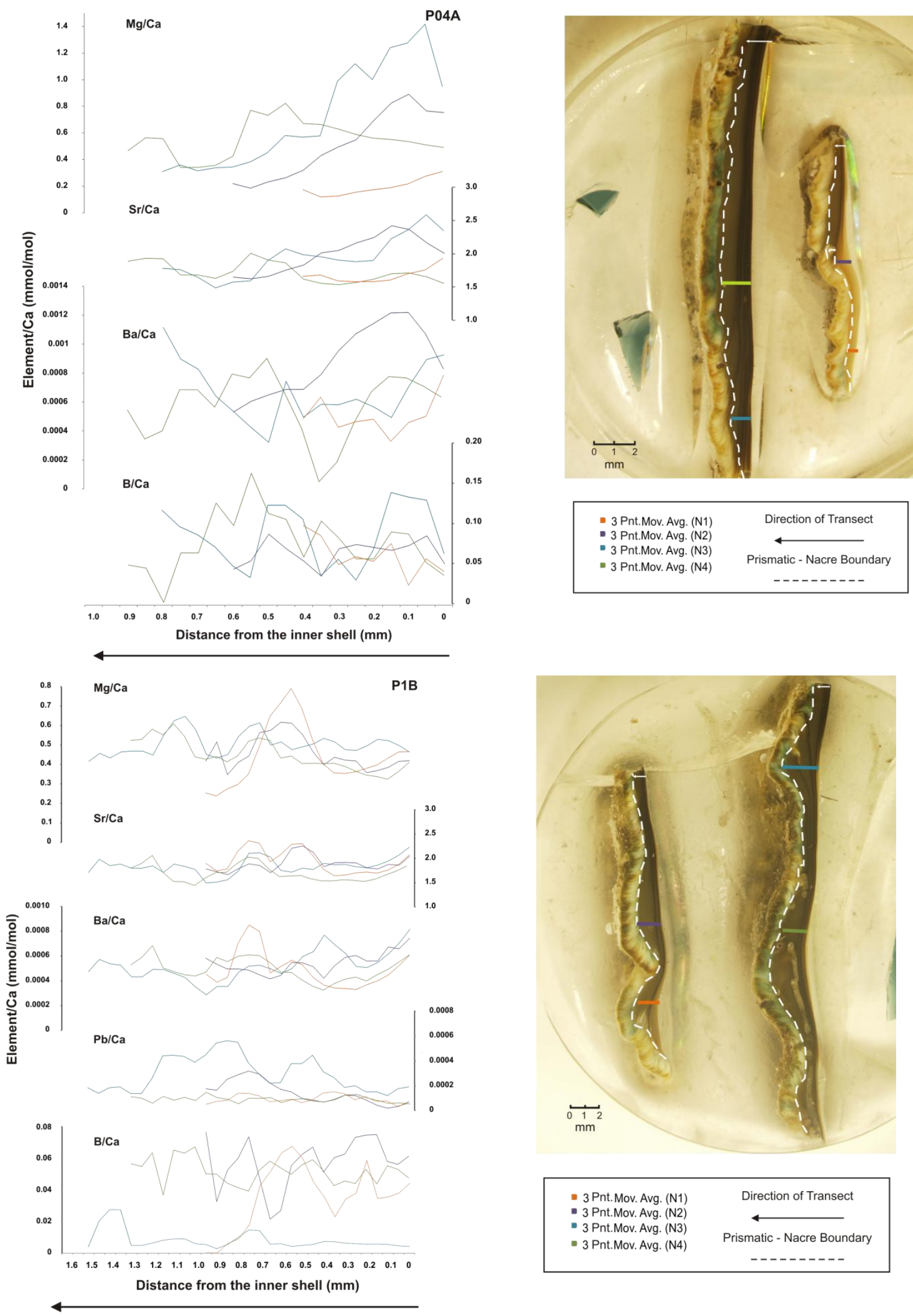

Fig. 4.4b. Plots of nacreous layer element/Ca ratios in samples P04A and P1B from Pourerere Beach. The left panel presents the element/Ca values through a high resolution analysis taken from the inner shell towards the prismatic-nacre boundary. The right panel shows transect locations on the sample mounts. 

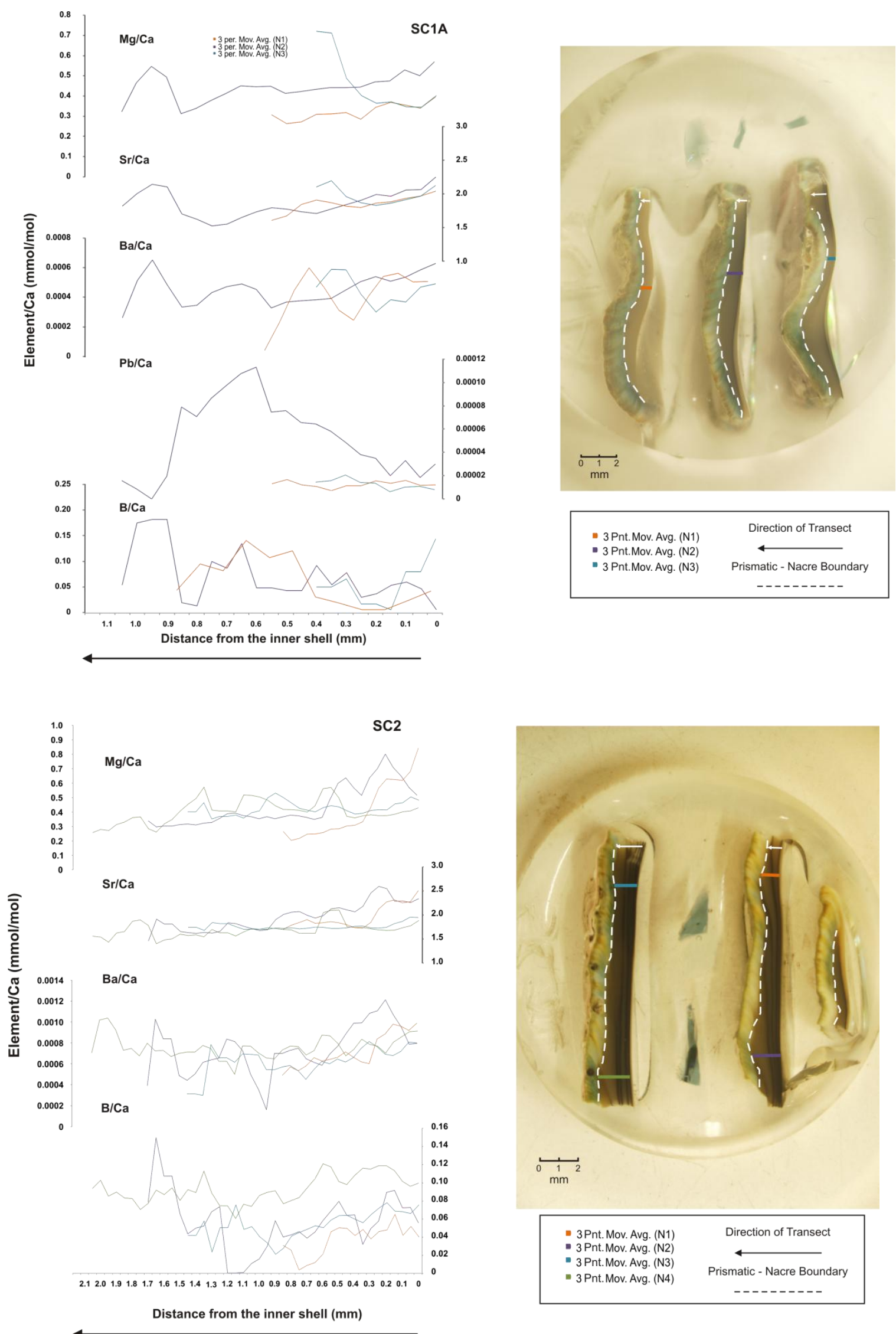

Fig. 4.4c. Plots of nacreous layer element/Ca ratios in samples SC1A and SC2 from South Coast, Wellington. The left panel presents the element/Ca values through a high resolution analysis taken from the inner shell towards the prismatic-nacre boundary. The right panel shows transect locations on the sample mounts. 

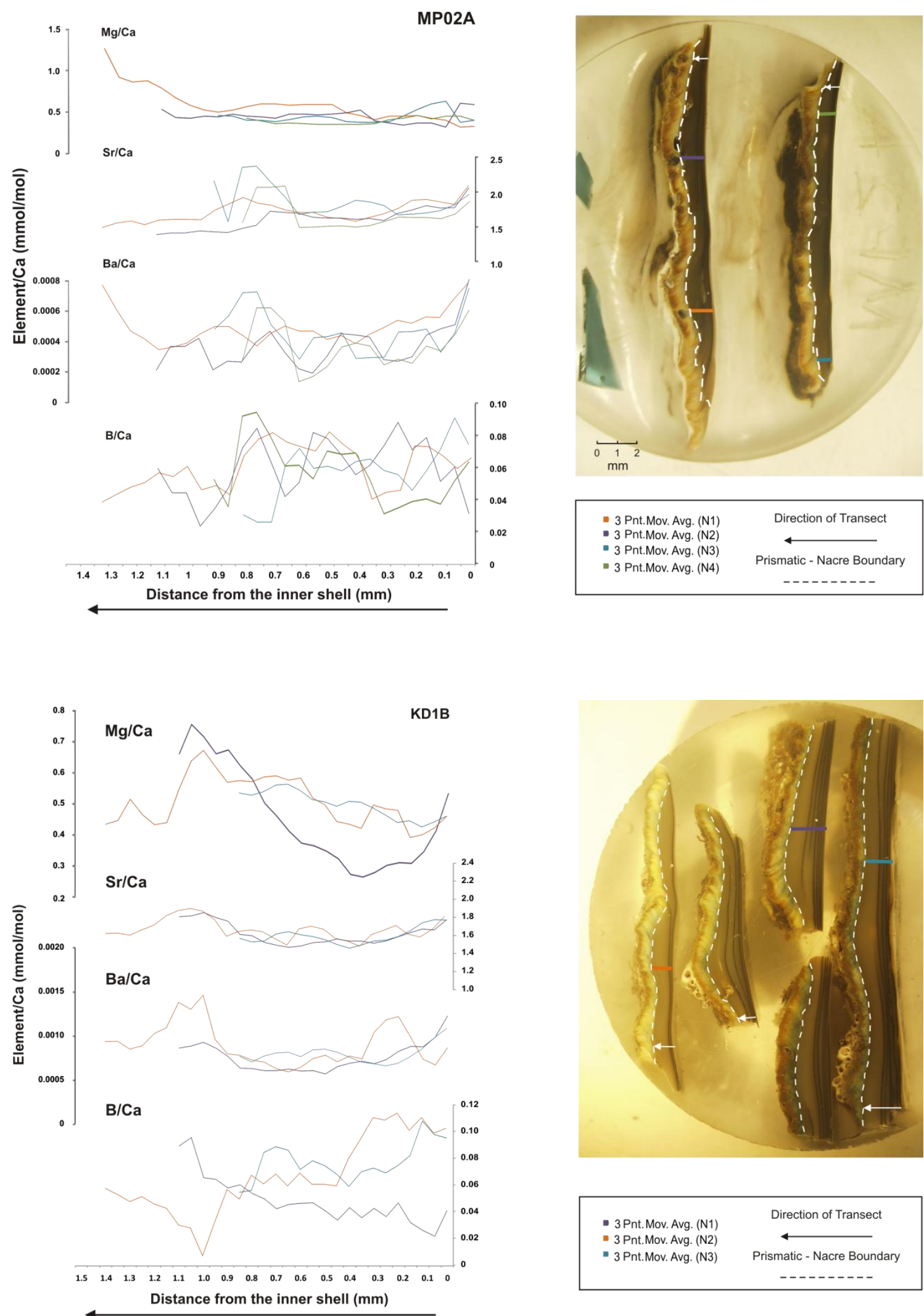

Fig. 4.4d. Plots of nacreous layer element/Ca ratios in samples MP02A from Moa Point and KD1B from Kaikoura. The left panel presents the element/Ca values through a high resolution analysis taken from the inner shell towards the prismatic-nacre boundary. The right panel shows transect locations on the sample mounts. 
The lower diagram of Figure $4.4 \mathrm{~d}$ shows the element/Ca ratio profiles of three nacreous layer transects in sample $\mathrm{KD} 1 \mathrm{~B} . \mathrm{Mg} / \mathrm{Ca}$ ratios of each transect are variable with values ranging from $0.2-0.8 \mathrm{mmol} / \mathrm{mol}$. Maximum values are observed in the same location on transects $\mathrm{N} 1$ and $\mathrm{N} 2$ at $1.1-1.2 \mathrm{~mm}$ from the inner shell, with slightly higher values observed in N1 (ca. $0.05 \mathrm{mmol} / \mathrm{mol}$ ). Large-scale variation is also evident in N1 with increasing values of 0.5 $\mathrm{mmol} / \mathrm{mol}$ over a width of $0.6 \mathrm{~mm}$. Sr/Ca ratios are restricted (1.4-2.1 $\mathrm{mmol} / \mathrm{mol}$ ). All transects are well correlated with each other. N2 show smallscale variation over widths of 0.1-0.2 mm. Ba/Ca ratios are low (0.0005-0.0015 $\mathrm{mmol} / \mathrm{mol}$ ) and have values that compare well. N2 show a different relationship compared with $\mathrm{N} 1$ and N3, with a number of peaks $(\mathrm{n}=2)$ along the $\mathrm{Ba} / \mathrm{Ca}$ profile that have widths of 0.2-0.3 $\mathrm{mm}$. B/Ca ratios are also low (0.02-0.12 $\mathrm{mmol} / \mathrm{mol}$ ) and are poorly correlated. $\mathrm{N} 2$ has significantly higher $\mathrm{B} / \mathrm{Ca}$ ratios compared with $\mathrm{N} 1(0.06 \mathrm{mmol} / \mathrm{mol})$ near the inner shell. N1 also exhibits increases in $\mathrm{B} / \mathrm{Ca}$ ratios as distances from the inner shell increase, whereas N3 has decreasing B/Ca with increasing distance from the inner shell.

Figure 4.4e illustrates the element/Ca ratio profiles through the nacreous layers of K1A1 (top) and K3A (bottom). Five profiles were measured at different locations in the nacreous layer of K1A1, with four different transects taken from the nacreous layer of $\mathrm{K} 3 \mathrm{~A} . \mathrm{Mg} / \mathrm{Ca}$ ratios of $\mathrm{K} 1 \mathrm{~A} 1$ range between $0.2-1.1$ $\mathrm{mmol} / \mathrm{mol}$. All transects (N1-N5) are comparable with each other but poorly correlated. $\mathrm{Sr} / \mathrm{Ca}$ ratios have a restricted range (2.5-3.5 mmol/mol). $\mathrm{Sr} / \mathrm{Ca}$ values also show small scale variations over distances of 0.1-0.2 $\mathrm{mm}$. Although values closer to the inner shell are similar, the $\mathrm{Sr} / \mathrm{Ca}$ ratio variations are poorly correlated. Ba/Ca ratios are low (ca. $<0.0025 \mathrm{mmol} / \mathrm{mol}$ ) with poor correlation between all transects. B/Ca transects are also poorly correlated between each transect with values between $0.0-16 \mathrm{mmol} / \mathrm{mol}$.

$\mathrm{Mg} / \mathrm{Ca}$ ratios of $\mathrm{K} 3 \mathrm{~A}$ have variable results with a broad range (0.0-1.4 $\mathrm{mmol} / \mathrm{mol}$ ). $\mathrm{Mg} / \mathrm{Ca}$ ratios also have a poor correlation between all nacre transects (N1-N4). A peak with a width of $0.3 \mathrm{~mm}$ is observed in the $\mathrm{Mg} / \mathrm{Ca}$ ratio of $\mathrm{N} 2$. This peak is reproducible in $\mathrm{Sr} / \mathrm{Ca}$ and $\mathrm{Ba} / \mathrm{Ca}$ ratios. $\mathrm{Sr} / \mathrm{Ca}$ ratios are 
restricted in range $(2.0-3.5 \mathrm{mmol} / \mathrm{mol})$ and are comparable. $\mathrm{Sr} / \mathrm{Ca}$ ratios correlate well, with peaks observed in all transects at 0.8-1.1 mm from the inner shell. The Sr/Ca ratios in N1 are also consistently higher (ca. $<0.2 \mathrm{mmol} / \mathrm{mol}$ ) than N2, N3 and N4. Ba/Ca ratios show a similar signal in all nacre transects to the $\mathrm{Sr} / \mathrm{Ca}$ ratios. The $\mathrm{Ba} / \mathrm{Ca}$ ratios in $\mathrm{K} 3 \mathrm{~A}$ are very low (0.0002-0.0014 $\mathrm{mmol} / \mathrm{mol}$ ). All transects are also comparable and correlated well, with prominent peaks seen in N1, N2 and N3. B/Ca ratios are also low (ca. $<0.10$ $\mathrm{mmol} / \mathrm{mol}$ ). However, the variations in each transect of K3A show no clear correlation.

\subsubsection{Moeraki (MD1 and MD3)}

Figure 4.4f illustrates the element/Ca ratio of transects through the nacreous layer of two samples, MD1 (top) and MD3 (bottom) sampled from Moeraki, Otago. Only one element/Ca ratio profile was measured in the nacre of MD1. $\mathrm{Mg} / \mathrm{Ca}$ ratios range between 0.1-0.6 $\mathrm{mmol} / \mathrm{mol}$ and show variations over broad distances $(0.5 \mathrm{~mm})$. Sr/Ca ratios in MD1 has a restricted range (1.5-2.0 $\mathrm{mmol} / \mathrm{mol}$ ) and small-scale variation over distances of $0.2 \mathrm{~mm}$. Ba/Ca ratios are extremely low $(0.0005-0.0020 \mathrm{mmol} / \mathrm{mol})$ and exhibit variations over large distances which are also seen in the $\mathrm{Mg} / \mathrm{Ca}$ ratio profile. $\mathrm{B} / \mathrm{Ca}$ ratios are also low (ca. $<0.5 \mathrm{mmol} / \mathrm{mol}$ ) with a number of peaks $(\mathrm{n}=2$ ) with widths of 0.1-0.2 mm.

The element/Ca ratios of four nacre profiles (N1, N2, N3 and N4) of MD3 are shown in the lower diagram of Figure 3.4f. $\mathrm{Mg} / \mathrm{Ca}$ ratios of the profiles range between 0.1-0.7 mmol/mol. N1 and N2 are well correlated close to the inner shell $(0.0$ to $0.6 \mathrm{~mm}) . \mathrm{Mg} / \mathrm{Ca}$ ratios of $\mathrm{N} 3$ and $\mathrm{N} 4$ are variable with large-scale variations $(0.2 \mathrm{mmol} / \mathrm{mol})$ over distances of 0.2-0.3 mm. Sr/Ca ratios are again restricted in range $(1.5-3.0 \mathrm{mmol} / \mathrm{mol})$ as seen in the nacreous layer of samples from all locations. N1, N2 and N3 show comparable results, however, N4 has a number $(\mathrm{n}=2)$ of peaks with relatively wide widths (ca. $0.3 \mathrm{~mm}$ ). These peaks are reproduced in $\mathrm{Mg} / \mathrm{Ca}$ and $\mathrm{Ba} / \mathrm{Ca}$ profiles of $\mathrm{N} 4$. $\mathrm{Ba} / \mathrm{Ca}$ ratios of all profiles show variable results, with low values (0.0004-0.0014 mmol/mol). N1 and N2 again are well correlated close to the inner shell $(0.0$ to $0.6 \mathrm{~mm})$. B/Ca ratios are 
low (0.01-0.10 mmol/mol) and poorly correlated. All profiles of B/Ca ratios have a general decreasing trend as distances increase from the inner shell.

\subsubsection{Chatham Islands (AR1 and MR2)}

The element/Ca ratios of the nacreous layer of two samples AR1 (top) and MR2 (bottom) are illustrated in Figure 4.4g. $\mathrm{Mg} / \mathrm{Ca}$ ratios of AR1 range between 0.1 $0.9 \mathrm{mmol} / \mathrm{mol}$. These values show large-scale variation $(0.5 \mathrm{~mm})$. Apart from close to the inner shell (0.0-0.6 mm), there is poor correlation. All transects (N1$\mathrm{N} 4$ ) show a sharp decrease in $\mathrm{Mg} / \mathrm{Ca}$ ratios in the final $0.1 \mathrm{~mm}$ of the profiles. $\mathrm{Sr} / \mathrm{Ca}$ ratios show a restricted range (1.5-2.5 $\mathrm{mmol} / \mathrm{mol}$ ) and are comparable in each transect. N3 and N4 Sr/Ca profiles are well correlated whereas N1 and N2 are not. Ba/Ca ratios are extremely low (0.0000-0.0006 mmol/mol). N3 and N4 have consistently higher $\mathrm{Ba} / \mathrm{Ca}$ ratios compared with $\mathrm{N} 1$ and $\mathrm{N} 2$, with poor correlation. B/Ca ratios vary between $0.01-0.9 \mathrm{mmol} / \mathrm{mol}$ and are poorly correlated in all transects as well.

$\mathrm{Mg} / \mathrm{Ca}$ ratios of the four nacre transects of MR2 also have a broad range (0.4-2.0 $\mathrm{mmol} / \mathrm{mol}$ ). Transects N1, N3 and N4 are comparable and correlate well, with values ranging between $0.5-1.0 \mathrm{mmol} / \mathrm{mol}$. N2, however, show an increases in $\mathrm{Mg} / \mathrm{Ca}$ as distance increases from the inner shell which is not observed in other $\mathrm{Mg} / \mathrm{Ca}$ profiles. The $\mathrm{Sr} / \mathrm{Ca}$ ratios of MR2 are again restricted in range, with values between 1.5-2.5 mmol/mol. The values are comparable but do not correlate well. $\mathrm{Ba} / \mathrm{Ca}$ ratios also do not correlate well, and have values that are extremely low (ca. $<0.0025 \mathrm{mmol} / \mathrm{mol}$ ). Variability is also seen over distances of $0.3 \mathrm{~mm}$ in the $\mathrm{Ba} / \mathrm{Ca}$ ratio profiles. $\mathrm{B} / \mathrm{Ca}$ ratios are low $(0.0-0.6 \mathrm{mmol} / \mathrm{mol}$ ) with variations that have no apparent correlation. 


\section{CHAPTER 4: Results}
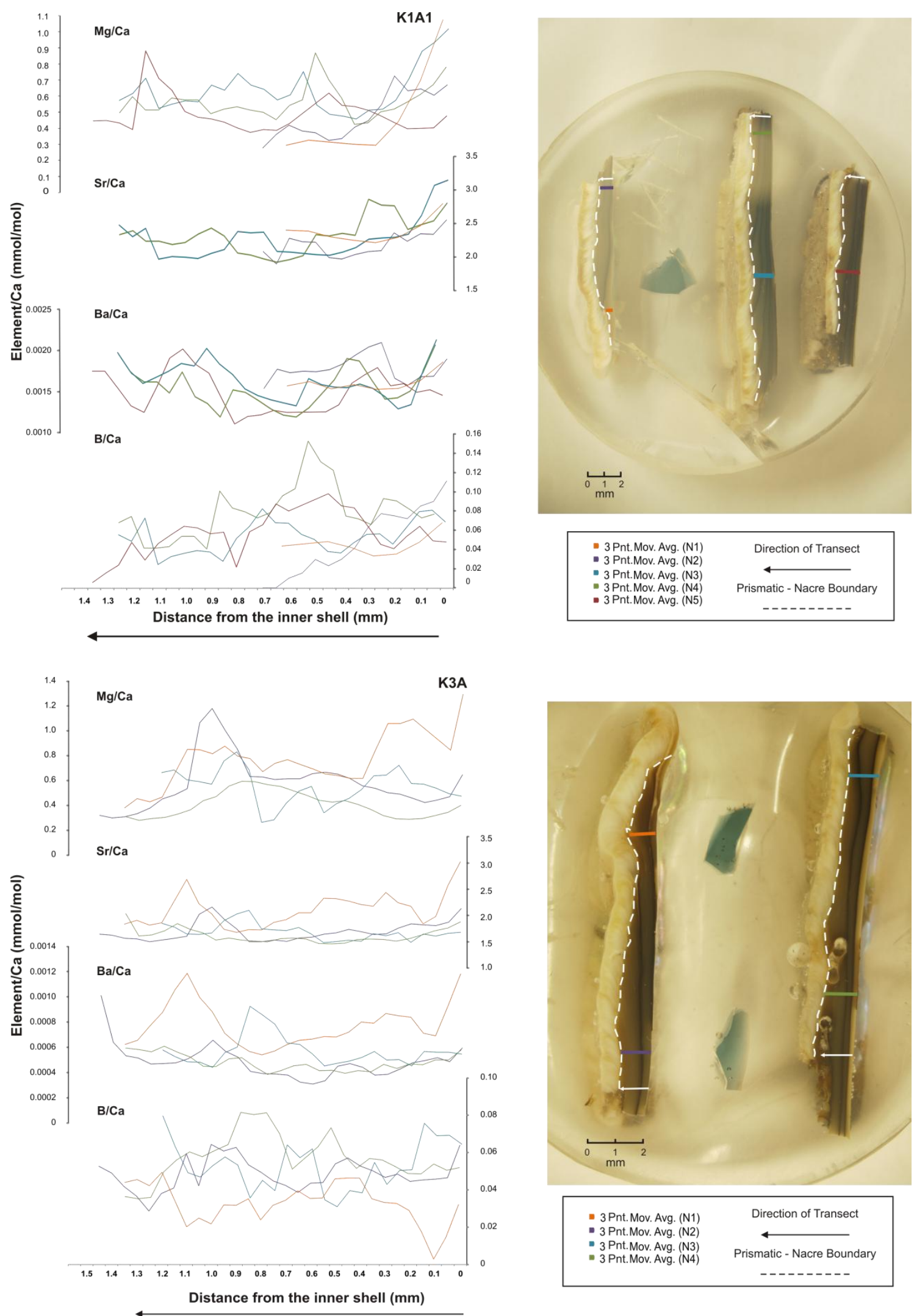

Fig. 4.4e. Plots of nacreous layer element/Ca ratios in samples K1A1 and K3A from Kaikoura. The left panel presents the element/Ca values through a high resolution analysis taken from the inner shell towards the prismatic-nacre boundary. The right panel shows transect locations on the sample mounts. 

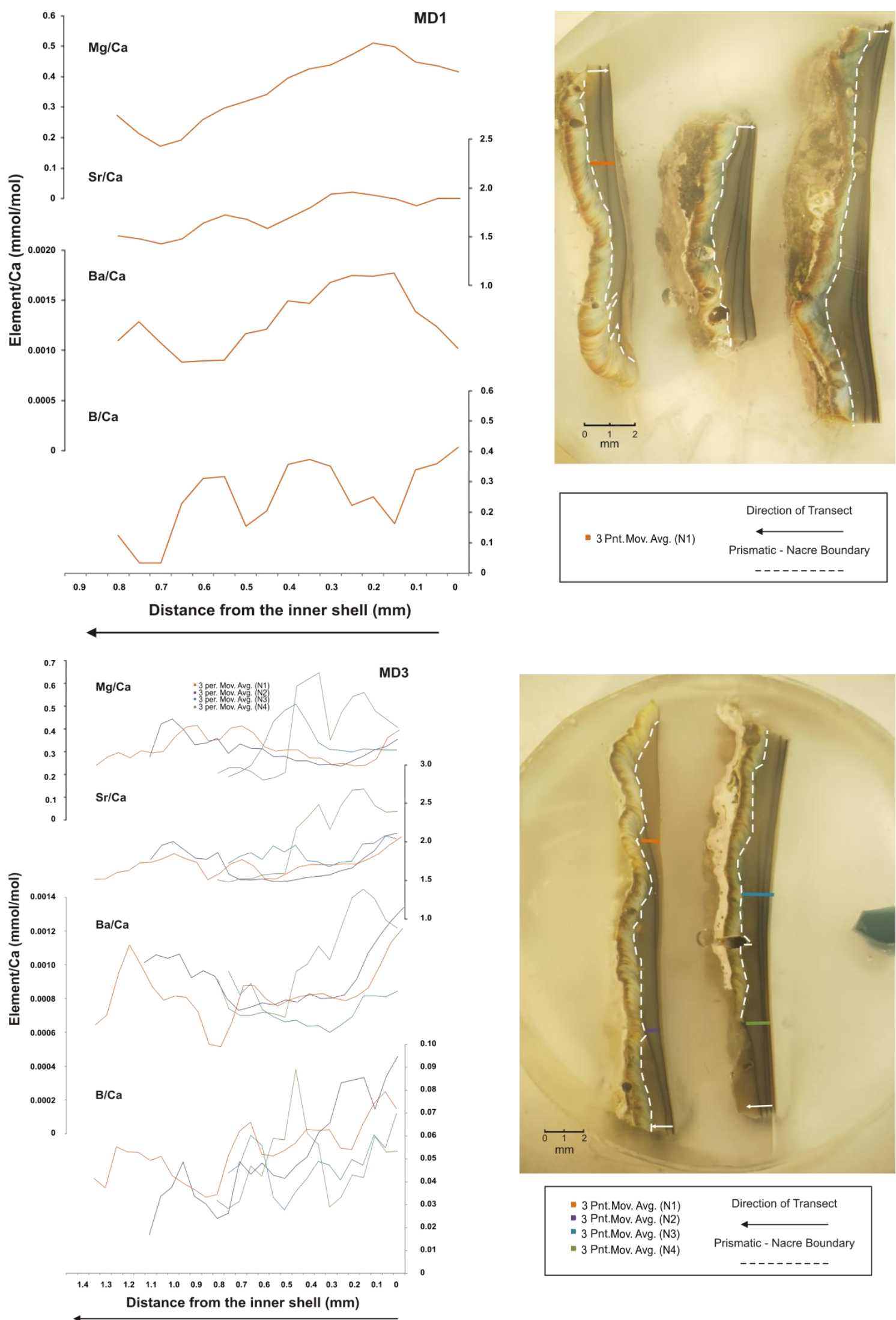

Fig. 4.4f. Plots of nacreous layer element/Ca ratios in samples MD1 and MD3 from Moeraki, Otago. The left panel presents the element/Ca values through a high resolution analysis taken from the inner shell towards the prismatic-nacre boundary. The right panel shows transect locations on the sample mounts. 

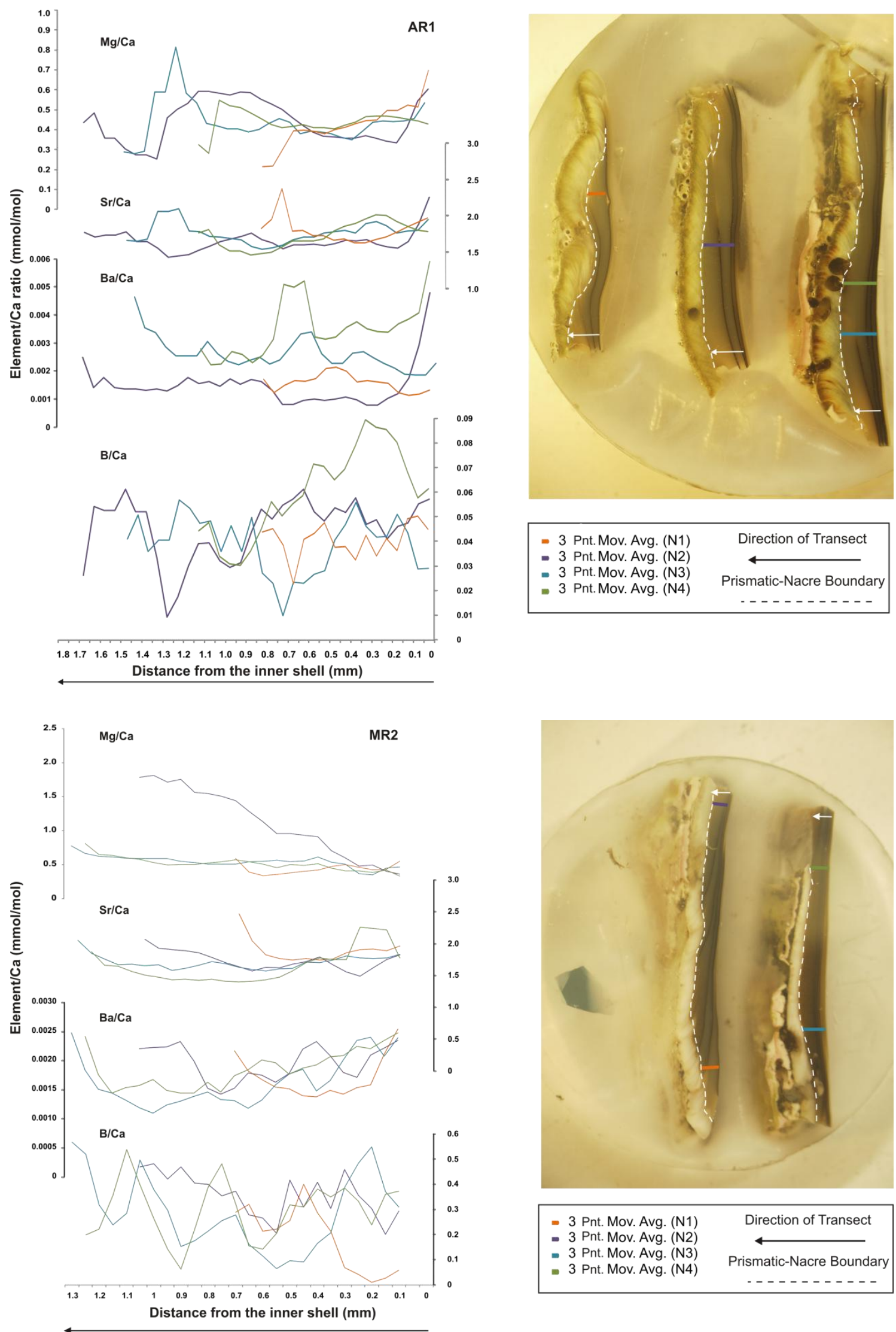

Fig. 4.4g. Plots of nacreous layer element/Ca ratios in samples AR1 and MR2 from the Chatham Islands. The left panel presents the element/Ca values through a high resolution analysis taken from the inner shell towards the prismatic-nacre boundary. The right panel shows transect locations on the sample mounts. 
Results of the analysis of multiple transects following individual growth banding within each shell sample (Fig. 4.5) are shown in Figures 4.6. The results that are presented show only elements that have trace element concentrations above background levels. LA-ICP-MS trace element analyses of the individual growth banding of all shells yielded data for $\mathrm{Mg} / \mathrm{Ca}, \mathrm{Sr} / \mathrm{Ca}$ and $\mathrm{Ba} / \mathrm{Ca}$.

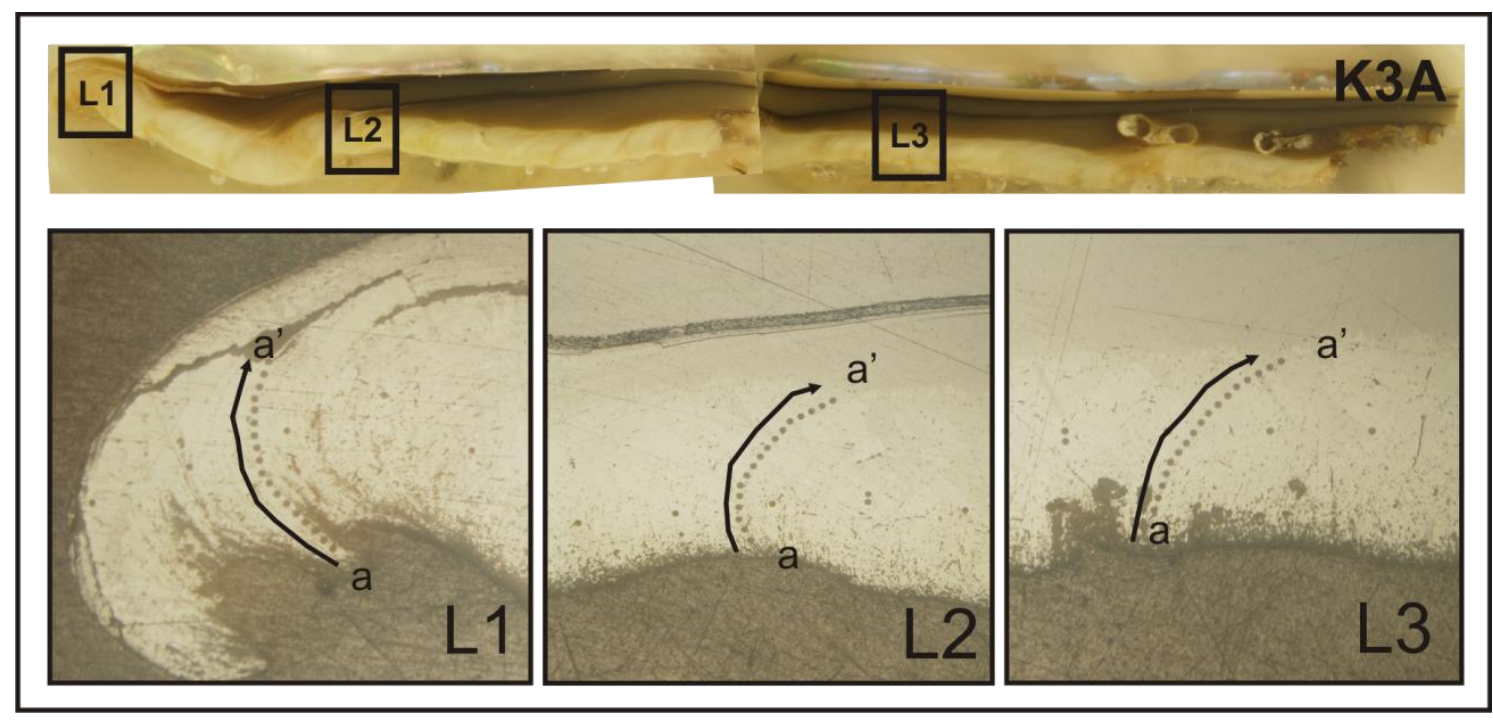

Fig. 4.5. Example of the transect direction of the individual growth bands throughout the shell of K3A. The transect follows a growth band from the outer shell (a), towards the nacre (a') with spots spaced $50 \mu \mathrm{m}$ apart.

\subsubsection{1 $\quad \mathrm{Mg} /$ Ca ratios}

The $\mathrm{Mg} / \mathrm{Ca}$ ratios of a number of transects $(\mathrm{n}<4)$ per sample are illustrated in Figure 4.6a. $\mathrm{Mg} / \mathrm{Ca}$ ratios exhibit a broad range of values through these transects in all samples. Three $\mathrm{Mg} / \mathrm{Ca}$ ratio profiles were measured through an individual growth band of RW75. All values range between 2.0-14.0 mmol/mol. All profiles are well correlated closer to the outer shell, with higher values seen in L1 and L2 compared with L3. A number of profiles $(n=2)$ were measured through an individual growth band of $\mathrm{A} 740$. The $\mathrm{Mg} / \mathrm{Ca}$ ratio of both transects are poorly correlated, but have a peak seen in the same location in both profiles. The $\mathrm{Mg} / \mathrm{Ca}$ ratios in $\mathrm{P} 1 \mathrm{~B}$ are variable compared to $\mathrm{L} 2$ and $\mathrm{L} 3$ but are well 
correlated closer to the prismatic-nacre boundary. P04A has variable results in each transect. L3 has consistently higher $\mathrm{Mg} / \mathrm{Ca}$ ratios (ca. $2 \mathrm{mmol} / \mathrm{mol}$ ) than $\mathrm{L} 1$. The profile for $\mathrm{L} 2$ has large scale $\mathrm{Mg} / \mathrm{Ca}$ variability, showing changes in values (ca. $11-12 \mathrm{mmol} / \mathrm{mol}$ ) over short distances. SC1A Mg/Ca profiles are well correlated closer to the prismatic-nacre boundary. L1 decreases in $\mathrm{Mg} / \mathrm{Ca}$ (ca. $15 \mathrm{mmol} / \mathrm{mol}$ ) as distances increase from the outer shell. The $\mathrm{Mg} / \mathrm{Ca}$ ratios of transects of SC2 are broad with L2 having consistently higher values compared to L1 and L4. K1A1 transects of $\mathrm{Mg} / \mathrm{Ca}$ ratio correlate well with values $<20$ $\mathrm{mmol} / \mathrm{mol}$. All profiles show a general decrease in $\mathrm{Mg} / \mathrm{Ca}$ ratios as distances increase from the outer shell. Three profiles of the individual growth bands of K3A were analysed. L1 and L3 are well correlated with each other and have comparable values. $\mathrm{L} 2$ has a number of peaks $(\mathrm{n}=2)$ with large-scale variability (5-20 mmol/mol). MD3 has variable results. L1 has consistently stable values (5-10 $\mathrm{mmol} / \mathrm{mol}$ ) compared to L2 and L3. One profile each was measured for the element/Ca ratios of MP02A, KD1B, MD1, AR1 and MR2. The Mg/Ca ratio of MP02A has a broad range $(6-16 \mathrm{mmol} / \mathrm{mol})$, decreasing with distance away from the outer shell. KD1B and MD1 have variable results with $\mathrm{Mg} / \mathrm{Ca}$ ratios that fluctuate along the profile. The $\mathrm{Mg} / \mathrm{Ca}$ ratio of AR1 consists of high values $(10-25 \mathrm{mmol} / \mathrm{mol})$. Values are variable closer to the outer shell. Overall, $\mathrm{Mg} / \mathrm{Ca}$ ratios of profiles of individual growth bands show considerable variability and do not show a consistent relationship decreasing from the outer shell towards the prismatic-nacre boundary.

\subsubsection{Sr/Ca ratios}

Figure 4.6b illustrates the $\mathrm{Sr} / \mathrm{Ca}$ ratios of individual growth band profiles of all samples. A number of profiles $(n=3)$ were measured in RW75. All profiles have variable results and values. L3 transect has a consistent $\mathrm{Sr} / \mathrm{Ca}$ ratio (1.0-1.5 $\mathrm{mmol} / \mathrm{mol}$ ) where L1 and L2 are poorly correlated. A740's individual growth bands (L1 and L2) are well correlated, with $\mathrm{Sr} / \mathrm{Ca}$ ratios varying between 1.0$4.0 \mathrm{mmol} / \mathrm{mol}$. Close to the outer shell, the $\mathrm{Sr} / \mathrm{Ca}$ ratios in A740 decrease as distances increase from the outer shell. The $\mathrm{Sr} / \mathrm{Ca}$ ratio of P1B is strongly correlated in all transects $(n=4)$. Close to the outer shell, L1 and L4 exhibit a 
sharp decrease in $\mathrm{Sr} / \mathrm{Ca}$ ratios. The $\mathrm{Sr} / \mathrm{Ca}$ ratios of a number of profiles $(\mathrm{n}=3)$ of P04A range between $1.0-3.5 \mathrm{mmol} / \mathrm{mol}$, but the variations in each transect do not correlate well. $\mathrm{Sr} / \mathrm{Ca}$ ratios in the growth banding of SC2 have a restricted range (1.0-2.5 mmol/mol). L2 has consistently higher $\mathrm{Sr} / \mathrm{Ca}$ ratios (0.1-0.3 $\mathrm{mmol} / \mathrm{mol}$ ) compared with L1 and L4. SC1A also has a restricted range (0.5-2.0 $\mathrm{mmol} / \mathrm{mol}$ ). Profiles have poor overall correlation, with L2 showing consistently lower $\mathrm{Sr} /$ Ca ratios compared with L1 and L3.

$\mathrm{K} 3 \mathrm{~A}$ has $\mathrm{Sr} / \mathrm{Ca}$ ratios that are well correlated, with values that range between $(1.0-2.5 \mathrm{mmol} / \mathrm{mol})$. A number of transects $(\mathrm{n}=3)$ of K3A show a broad range $(1.0-5.0 \mathrm{mmol} / \mathrm{mol})$ in $\mathrm{Sr} / \mathrm{Ca}$ ratios. $\mathrm{L} 2$ and $\mathrm{L} 3$ show a good correlation closer to the prismatic-nacre boundary, whereas L1 and L2 show good correlation closer to the outer shell. The $\mathrm{Sr} / \mathrm{Ca}$ ratios of a number $(\mathrm{n}=3)$ of growth banding profiles of MD3 are comparable with a range between 1.0-4.0 mmol/mol. L3 has consistently higher $\mathrm{Sr} /$ Ca values (ca. $0.5 \mathrm{mmol} / \mathrm{mol}$ ) compared to L1 and L2. All transects in MD3 correlate well as distances increase away from the outer shell.

Samples MP02A, KD1B, AR1, MR2 and MD1 have only one Sr/Ca ratio profile presented in Figure 3.6b. All $\mathrm{Sr} / \mathrm{Ca}$ ratios have a restricted range (1.0-1.6 $\mathrm{mmol} / \mathrm{mol}$ ). MP02A and KD1B show a decreasing trend further away from the outer shell. This decreasing trend is also seen in the Sr/Ca ratio profile of MR2 which is then followed by a sharp increase in values at the prismatic-nacre boundary. AR1 and MD1 have variable Sr/Ca ratios throughout the profiles.

In general $\mathrm{Sr} / \mathrm{Ca}$ ratios along growth bands show muted variations compared to $\mathrm{Mg} / \mathrm{Ca}$ ratios and all samples are broadly comparable, with $\mathrm{Sr} / \mathrm{Ca}$ values ranging between $0.5-5.0 \mathrm{mmol} / \mathrm{mol}$.

\subsubsection{3 $\quad$ Ba/Ca ratios}

Figure 4.6c illustrates the $\mathrm{Ba} / \mathrm{Ca}$ ratios of the growth banding transects of all samples. The $\mathrm{Ba} / \mathrm{Ca}$ ratios of the growth banding of RW75 range between $0.0002-0.0008 \mathrm{mmol} / \mathrm{mol}$ with considerable scatter due to analytical error and the low concentration of Ba. All transects (L1, L2 and L3) are poorly correlated. 
The $\mathrm{Ba} / \mathrm{Ca}$ ratios of the profiles through $\mathrm{A} 740$ have a large range $(\mathrm{ca} .<0.002$ $\mathrm{mmol} / \mathrm{mol}$ ). The variations in both $\mathrm{Ba} / \mathrm{Ca}$ ratio profiles of $\mathrm{A740}$ are well correlated. $\mathrm{Ba} / \mathrm{Ca}$ ratios of $\mathrm{P} 04 \mathrm{~A}$ growth banding profiles are larger than other samples (ca. $<0.01 \mathrm{mmol} / \mathrm{mol}$ ). Variability in L1 and L3 profiles are comparable near the prismatic-nacre boundary. Both SC2 and SC1A have a number of profiles $(n=3)$ that are poorly correlated within each shell. The range of the $\mathrm{Ba} / \mathrm{Ca}$ variation in the two shells is between $0.0000-0.0014 \mathrm{mmol} / \mathrm{mol}$. Ba/Ca ratios of the growth banding of K1A1 are restricted in range (0.0005-0.0025 $\mathrm{mmol} / \mathrm{mol}$ ). Both profiles correlate reasonably well with comparable values. $\mathrm{K} 3 \mathrm{~A}$ and MD3 both have $\mathrm{Ba} / \mathrm{Ca}$ ratios measured from three individual growth bands. Both shells have values $<0.006 \mathrm{mmol} / \mathrm{mol}$. All profiles in K3A have poor correlation near the outer shell but show similar results near the prismatic/nacre boundary. L3 in MD3 has generally higher $\mathrm{Ba} / \mathrm{Ca}$ ratios compared with L1 and L2 by $0.0005-0.0010 \mathrm{mmol} / \mathrm{mol}$. L1 and L2 also show good correlation further away from the outer shell.

One profile was made of the $\mathrm{Ba} / \mathrm{Ca}$ ratios of samples MP02A, KD1B, AR1, MR2 and MD3. All $\mathrm{Ba} / \mathrm{Ca}$ ratios are between 0.0002-0.0014 mmol/mol. All samples show variation from one another, but a general decreasing trend of $\mathrm{Ba} / \mathrm{Ca}$ ratios is evident further away from the outer shell. 

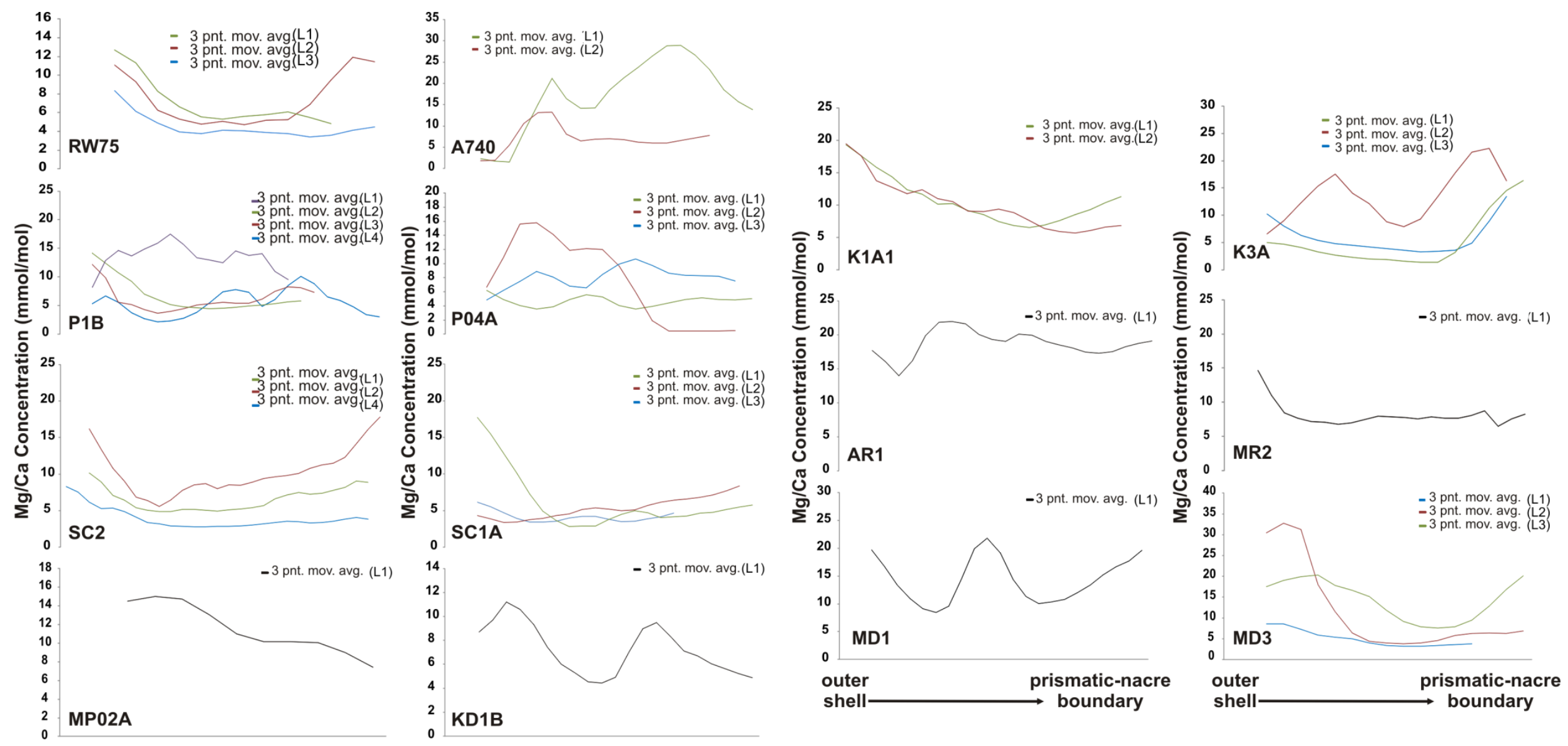

outer

prismatic-nacre outer

prismatic-nacre

shell

$\rightarrow$ boundary

shell

boundary

Fig. 4.6a. $\mathrm{Mg} / \mathrm{Ca}$ ratios (mmol/mol) through transects of individual growth band transects for each sample. The transect is taken from the outer shell and follows the growth banding towards the prismatic-nacre boundary shown in Figure 4.5. 


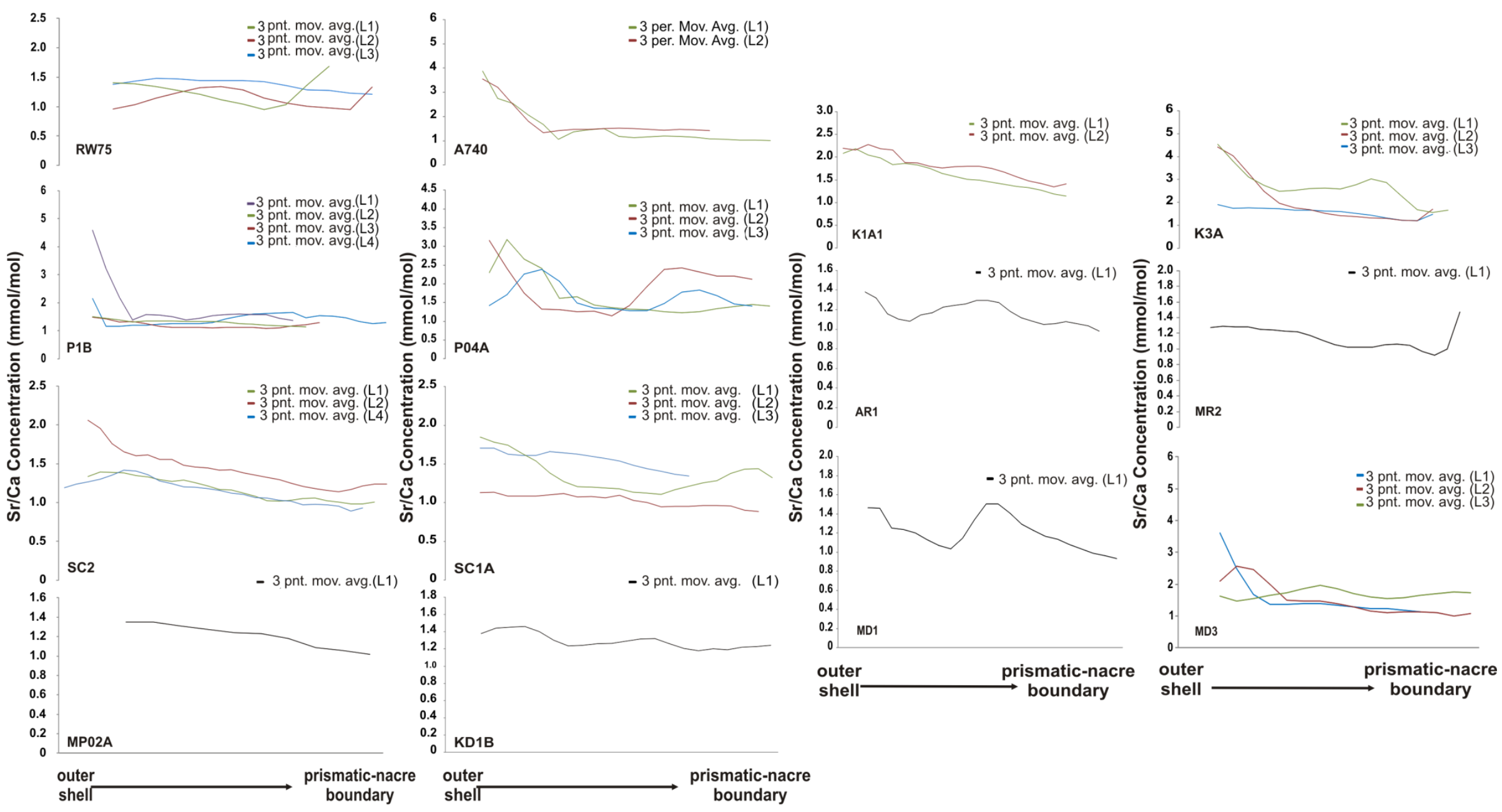

Fig. 4.6b. Sr/Ca ratios (mmol/mol) through transects of individual growth band transects for each sample. The transect is taken from the outer shell and follows the growth banding towards the prismatic-nacre boundary shown in Figure 4.5. 


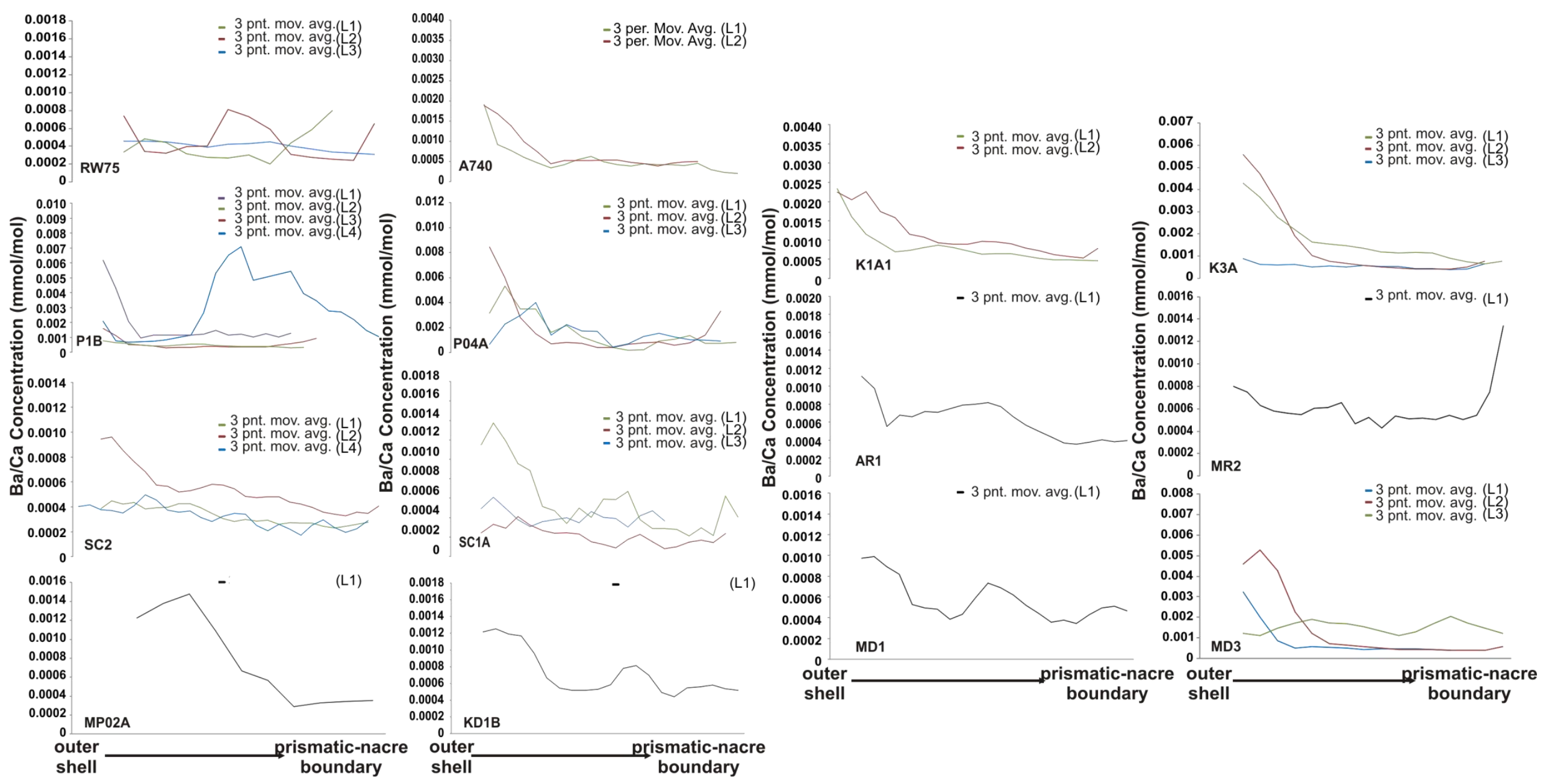

Fig. 4.6c. Ba/Ca ratios (mmol/mol) through transects of individual growth band transects for each sample. The transect is taken from the outer shell and follows the growth banding towards the prismatic-nacre boundary shown in Figure 4.5. 


\subsection{ELEMENT/CA RATIO CORRELATIONS}

Pearsons Product Moment correlation coefficient is a measure of the correlation, or linear relationship, between two variables ( $X$ and $Y$ ) (Clark \& Randal, 2011). The correlation is represented by a value, or coefficient, which ranges from - 1 to 1 , indicating the direction and strength of the correlation between the two variables. A coefficient of -1 represents a negative correlation, which indicates an inverse relationship between $X$ and $Y$. A coefficient of 0 displays an independent relationship between the two variables, and a coefficient of 1 represents a positive correlation between $X$ and $Y$ (Clark \& Randal, 2011). The correlation coefficient of element/Ca ratios with $\mathrm{Sr} / \mathrm{Ca}, \mathrm{Ba} / \mathrm{Ca}$ and $\mathrm{Mg} / \mathrm{Ca}$ ratios in both the prismatic and nacreous layers of each shell sample are shown in Tables 4.1-4.3. The 2 tailed significance is also displayed (Sig (2-tailed)) along with the with the test size (n). It is important to note that all element/Ca ratios that equal zero were excluded from the correlation analysis. The values that are highlighted orange represent element/Ca ratios that are well correlated and have significance between 0.0001-0.009. The logarithmic function was applied to element/Ca ratios that were not normally distributed. The element/Ca ratios that did not exhibit a strong relationship with $\mathrm{Sr} / \mathrm{Ca}, \mathrm{Ba} / \mathrm{Ca}$ and $\mathrm{Mg} / \mathrm{Ca}$ ratio are presented in Appendix 2. Both samples from OBL RW75 and A740 were also analysed twice. RW75 was analysed with ablation spot distances every $400 \mu \mathrm{m}$ (RW75(400)) and every $100 \mu \mathrm{m}$ (RW75(100)). A740 was also measured twice with each ablation spot measurement taken every $400 \mu \mathrm{m}$ apart. $A 740(1)$ profile began at the foot of the shell of the transect and A740(2) analysis was offset by $200 \mu \mathrm{m}$ from A740(1).

\subsubsection{Prismatic Layer}

Table 4.1 shows the Pearson's correlation coefficient comparing five element/Ca ratios with $\mathrm{Sr} / \mathrm{Ca}$ ratio from data of the prismatic layer profiles. $\mathrm{Sr} / \mathrm{Ca}$ and $\mathrm{Ba} / \mathrm{Ca}$ ratios are strongly correlated (significance of ca. $<0.001$ ) in all samples excluding SC1A. All samples have coefficients that range from 0.36-0.80. $\mathrm{Mg} / \mathrm{Ca}$ and $\mathrm{Sr} / \mathrm{Ca}$ ratios show a negative coefficient value in both samples from 
OBL. RW75 has a strongly significant coefficient (ca. < 0.002) and A740 does not show significance with levels ranging between 0.022-0.26. All three samples from Wellington have coefficient values of $0.34,0.54$ and 0.35 respectively. A large number of samples $(n=8)$ gave a moderate coefficient value between $\mathrm{Sr} / \mathrm{Ca}$ and $\mathrm{U} / \mathrm{Ca}$ with high significance levels ( $\mathrm{ca}<0.005)$. K3A has the strongest correlation between $\mathrm{Sr} / \mathrm{Ca}$ and $\mathrm{U} / \mathrm{Ca}$ with a coefficient of $0.70 \mathrm{Al} / \mathrm{Ca}$ and $\mathrm{B} / \mathrm{Ca}$ have are moderately correlated with $\mathrm{Sr} / \mathrm{Ca}$ ratios in some samples. Both shells from Pourerere (P1B and P04A) have coefficients of 0.31 and 0.50, respectively, and significant values ca. $<0.004$.

The Pearson's correlation coefficient of element/Ca ratios compared with $\mathrm{Ba} / \mathrm{Ca}$ ratios of each sample are presented in Table $4.2 \mathrm{Mg} / \mathrm{Ca}$ ratios are generally moderately correlated with $\mathrm{Ba} / \mathrm{Ca}$ in the prismatic layer of each sample with coefficient values ranging between 0.33 and 0.55 . However, a number of samples $(\mathrm{n}=7)$ are poorly correlated at low significance levels. $\mathrm{Mg} / \mathrm{Ca}$ versus $\mathrm{Ba} / \mathrm{Ca}$ in RW75 and A740 from OBL are poorly correlated with negative coefficient values. A correlation of high significance between $\mathrm{Ba} / \mathrm{Ca}$ and $\mathrm{U} / \mathrm{Ca}$ is generally seen in the shells sampled from the wild in the North Island (Pourerere and Wellington) compared with those from the South Island and OBL. Shells SC2 and SC1A from Wellington, however, both show a negative correlation between $\mathrm{Ba} / \mathrm{Ca}$ and $\mathrm{U} / \mathrm{Ca}$. $\mathrm{Al} / \mathrm{Ca}$ and $\mathrm{Ba} / \mathrm{Ca}$ ratios are moderately to well correlated with coefficient values ranging from 0.45-0.85. B/Ca and $\mathrm{Mn} / \mathrm{Ca}$ ratios correlated against $\mathrm{Ba} / \mathrm{Ca}$ show variable results in each sample. 


\begin{tabular}{|c|c|c|c|c|c|c|c|c|c|c|c|c|c|c|c|}
\hline \multirow{4}{*}{ SAMPLE NAME } & \multicolumn{15}{|c|}{ Prismatic Layer Correlation Coefficient } \\
\hline & \multicolumn{15}{|c|}{$\mathrm{Sr} / \mathrm{Ca}$} \\
\hline & \multicolumn{3}{|c|}{$\mathrm{Ba} / \mathrm{Ca}$} & \multicolumn{3}{|c|}{$\mathrm{Mg} / \mathrm{Ca}$} & \multicolumn{3}{|c|}{$\mathrm{U} / \mathrm{Ca}$} & \multicolumn{3}{|c|}{$\mathrm{Al} / \mathrm{Ca}$} & \multicolumn{3}{|c|}{$\mathrm{B} / \mathrm{Ca}$} \\
\hline & Pearsons & (2 tailed) & $\mathrm{N}$ & Pearsonsk & (2 tailed) & $\mathrm{N}$ & Pearsons & (sig. (2 tailed) & $\mathrm{N}$ & Pearsonsts & ig. (2 tailed) & $\mathrm{N}$ & Pearsons & (sig. (2 tailed) & $\mathrm{N}$ \\
\hline RW75 (400) & 0.707 & $0.000^{*}$ & 105 & -0.296 & 0.002 & 106 & -0.212 & 0.070 & 74 & 0.055 & 0.657 & 68 & 0.366 & 0.001 & 77 \\
\hline RW75 (100) & & & & -0.315 & $0.000^{*}$ & 330 & 0.225 & 0.005 & 155 & -0.010 & 0.898 & 170 & 0.100 & 0.152 & 206 \\
\hline A740 (1) & 0.602 & $0.000^{*}$ & 120 & -0.208 & 0.022 & 120 & & & & -0.135 & 0.344 & 51 & & & \\
\hline A740 (2) & 0.364 & $0.000^{*}$ & 100 & -0.114 & 0.261 & 99 & -0.051 & 0.752 & 41 & 0.078 & 0.575 & 54 & -0.079 & 0.526 & 67 \\
\hline P1B & 0.532 & $0.000^{*}$ & 109 & 0.455 & $0.000^{*}$ & 109 & 0.475 & $0.000^{*}$ & 62 & 0.270 & 0.032 & 63 & 0.312 & 0.004 & 82 \\
\hline P04A & 0.717 & $0.000^{*}$ & 93 & 0.250 & 0.014 & 96 & 0.337 & 0.011 & 56 & 0.535 & $0.000^{*}$ & 70 & 0.502 & $0.000^{*}$ & 70 \\
\hline $\mathrm{SC} 2$ & 0.797 & $0.000^{*}$ & 116 & 0.339 & $0.000^{*}$ & 116 & -0.125 & 0.350 & 58 & 0.175 & 0.177 & 61 & -0.228 & 0.049 & 75 \\
\hline SC1A & 0.236 & 0.021 & 95 & 0.525 & $0.000^{*}$ & 97 & -0.051 & 0.712 & 55 & 0.195 & 0.206 & 44 & -0.069 & 0.615 & 55 \\
\hline MP02A & 0.627 & $0.000^{*}$ & 112 & 0.350 & 0.006 & 72 & 0.463 & $0.000^{*}$ & 63 & 0.322 & 0.006 & 72 & 0.277 & 0.015 & 77 \\
\hline K3A & 0.780 & $0.000^{*}$ & 91 & 0.205 & 0.046 & 95 & 0.701 & $0.000^{*}$ & 54 & 0.407 & 0.001 & 61 & 0.494 & $0.000^{*}$ & 68 \\
\hline $\mathrm{K} 1 \mathrm{~A} 1$ & 0.586 & $0.000^{*}$ & 112 & 0.329 & 0.001 & 95 & 0.022 & 0.871 & 58 & 0.396 & 0.031 & 39 & 0.086 & 0.459 & 76 \\
\hline KD1B & 0.417 & $0.000^{*}$ & 197 & 0.226 & 0.001 & 197 & 0.292 & 0.003 & 197 & 0.294 & 0.001 & 125 & 0.172 & 0.046 & 134 \\
\hline MR2 & 0.650 & $0.000^{*}$ & 61 & -0.070 & 0.596 & 59 & 0.468 & 0.004 & 36 & -0.129 & 0.440 & 38 & 0.141 & 0.372 & 42 \\
\hline AR1 & 0.480 & $0.000^{*}$ & 90 & 0.177 & 0.096 & 90 & -0.077 & 0.633 & 41 & -0.100 & 0.432 & 64 & -0.099 & 0.424 & 68 \\
\hline MD1 & 0.457 & $0.000^{*}$ & 93 & 0.518 & $0.000^{*}$ & 95 & 0.382 & 0.005 & 52 & 0.364 & 0.005 & 59 & -0.030 & 0.806 & 69 \\
\hline MD3 & 0.764 & $0.000^{*}$ & 87 & 0.232 & 0.030 & 88 & 0.469 & 0.002 & 41 & 0.422 & 0.001 & 58 & 0.444 & $0.000^{*}$ & 58 \\
\hline
\end{tabular}

${ }^{*} p<0.001$

Table 4.1. The Pearson's Product Moment correlation coefficient values, the significance (sig. 2 tailed), and test size (N) of Sr/Ca ratios of each analysed ablation spot in each sample in the prismatic layer. Orange highlighted boxes represented well correlated elements and grey boxes show element/Ca with no comparison. 


\begin{tabular}{|c|c|c|c|c|c|c|c|c|c|c|c|c|c|c|c|}
\hline \multirow{4}{*}{ SAMPLE NAME } & \multicolumn{15}{|c|}{ Prismatic Layer Correlation Coefficient } \\
\hline & \multicolumn{15}{|c|}{$\mathrm{Ba} / \mathrm{Ca}$} \\
\hline & \multicolumn{3}{|c|}{$\mathrm{Mg} / \mathrm{Ca}$} & \multicolumn{3}{|c|}{$\mathrm{U} / \mathrm{Ca}$} & \multicolumn{3}{|c|}{$\mathrm{Al} / \mathrm{Ca}$} & \multicolumn{3}{|c|}{$\mathrm{B} / \mathrm{Ca}$} & \multicolumn{3}{|c|}{$\mathrm{Mn} / \mathrm{Ca}$} \\
\hline & Pearsons (s & (sig. (2 tailed) & $\mathrm{N}$ & Pearsons & (sig. (2 tailed) & $\mathrm{N}$ & Pearsonsts & (sig. (2 tailed) & $\mathrm{N}$ & Pearsons & (sig. (2 tailed) & $\mathrm{N}$ & Pearsons & (sig. (2 tailed) & $\mathrm{N}$ \\
\hline RW75 (400) & -0.010 & 0.922 & 105 & -0.077 & 0.520 & 73 & 0.180 & 0.144 & 67 & 0.066 & 0.571 & 76 & 0.163 & 0.113 & 96 \\
\hline \multicolumn{16}{|l|}{ RW75 (100) } \\
\hline A740 (1) & -0.155 & 0.087 & 122 & & & & -0.153 & 0.283 & 51 & & & & & & \\
\hline A740 (2) & -0.106 & 0.302 & 97 & 0.044 & 0.787 & 41 & 0.118 & 0.400 & 53 & 0.176 & 0.530 & 67 & 0.057 & 0.614 & 80 \\
\hline P1B & 0.341 & 0.001 & 89 & 0.549 & $0.000^{*}$ & 62 & 0.756 & $0.000^{*}$ & 96 & 0.358 & 0.001 & 82 & 0.385 & $0.000^{*}$ & 96 \\
\hline P04A & 0.272 & 0.270 & 66 & 0.414 & 0.002 & 54 & 0.853 & $0.000^{*}$ & 69 & 0.596 & $0.000^{*}$ & 67 & 0.539 & $0.000^{*}$ & 64 \\
\hline $\mathrm{SC} 2$ & 0.545 & $0.000^{*}$ & 116 & -0.190 & 0.888 & 58 & 0.217 & 0.092 & 61 & -0.238 & 0.040 & 75 & 0.117 & 0.255 & 97 \\
\hline SC1A & 0.164 & 0.113 & 95 & -0.358 & 0.009 & 53 & 0.281 & 0.068 & 43 & & & & 0.225 & 0.067 & 67 \\
\hline MP02A & 0.488 & $0.000^{*}$ & 112 & 0.333 & $0.000^{*}$ & 112 & 0.668 & $0.000^{*}$ & 72 & 0.383 & 0.001 & 74 & 0.251 & 0.016 & 92 \\
\hline $\mathrm{K} 3 \mathrm{~A}$ & 0.329 & 0.001 & 95 & 0.670 & $0.000^{*}$ & 54 & 0.662 & $0.000^{*}$ & 61 & 0.348 & 0.004 & 68 & 0.317 & 0.002 & 91 \\
\hline $\mathrm{K} 1 \mathrm{~A} 1$ & 0.539 & $0.000^{*}$ & 112 & 0.227 & 0.086 & 57 & 0.451 & 0.004 & 39 & 0.262 & 0.022 & 76 & 0.160 & 0.107 & 103 \\
\hline KD1B & 0.482 & $0.000^{*}$ & 196 & 0.206 & 0.037 & 103 & 0.755 & $0.000^{*}$ & 126 & 0.323 & $0.000^{*}$ & 135 & 0.369 & $0.000^{*}$ & 153 \\
\hline MR2 & 0.162 & 0.221 & 59 & 0.339 & 0.043 & 36 & 0.017 & 0.917 & 38 & 0.083 & 0.601 & 42 & 0.274 & 0.062 & 47 \\
\hline AR1 & 0.241 & 0.043 & 90 & -0.267 & 0.092 & 41 & 0.117 & 0.358 & 64 & 0.045 & 0.716 & 68 & 0.134 & 0.238 & 66 \\
\hline MD1 & 0.423 & $0.000^{*}$ & 93 & 0.158 & 0.273 & 50 & 0.509 & $0.000^{*}$ & 58 & -0.089 & 0.474 & 67 & -0.084 & 0.474 & 74 \\
\hline MD3 & 0.452 & $0.000^{*}$ & 87 & 0.413 & 0.007 & 41 & 0.611 & $0.000^{*}$ & 58 & 0.460 & $0.000^{*}$ & 58 & 0.213 & 0.060 & 79 \\
\hline
\end{tabular}

${ }^{*} p<0.001$

Table 4.2. The Pearson's Product Moment correlation coefficient values, the significance (sig. 2 tailed), and test size (N) produced by Ba/Ca ratios of each analysed ablation spot in each sample in the prismatic layer. Orange highlighted boxes represented well correlated elements and grey boxes show element/Ca with no comparison. 


\subsubsection{Nacreous Layer}

Table 4.3 displays the Pearson's correlation coefficient of element/Ca ratios compared against $\mathrm{Sr} / \mathrm{Ca}$ and $\mathrm{Mg} / \mathrm{Ca}$ ratios in the nacreous layer of all samples. $\mathrm{Ba} / \mathrm{Ca}$ ratios compared against $\mathrm{Sr} / \mathrm{Ca}$ ratios have varying results. Both samples from OBL (RW75 and A740) and AR1 and MD1 are poorly correlated with low two tailed significance values (ca < 0.125). Almost all samples (excluding A740, P04A and MR2) have a strong relationship between $\mathrm{Mg} / \mathrm{Ca}$ and $\mathrm{Sr} / \mathrm{Ca}$ ratios within the nacreous layer. The largest coefficients of 0.81 and 0.81 are seen in RW75(100) and MD1 which also have small test sizes (ca. <28). U/Ca and Sr/Ca ratios are all poorly correlated with low significance levels. A number of samples $(n=5)$ also have a negative correlation between U/Ca and Sr/Ca. Two samples (RW75(100) and SC2) have a strong correlation between $\mathrm{Ba} / \mathrm{Ca}$ and $\mathrm{Mg} / \mathrm{Ca}$ with coefficients of 0.81 and 0.78 . Only MP02A shows a correlation of modest significance levels when comparing $\mathrm{Mg} / \mathrm{Ca}$ and $\mathrm{B} / \mathrm{Ca}$. 


\begin{tabular}{|c|c|c|c|c|c|c|c|c|c|c|c|c|c|c|}
\hline \multirow{4}{*}{ SAMPLE NAME } & \multicolumn{14}{|c|}{ Nacreous Layer Correlation Coefficient } \\
\hline & \multicolumn{8}{|c|}{$\mathrm{Sr} / \mathrm{Ca}$} & \multicolumn{6}{|c|}{$\mathrm{Mg} / \mathrm{Ca}$} \\
\hline & \multicolumn{3}{|c|}{$\mathrm{Ba} / \mathrm{Ca}$} & \multicolumn{3}{|c|}{$\mathrm{Mg} / \mathrm{Ca}$} & \multicolumn{2}{|l|}{$\mathrm{U} / \mathrm{Ca}$} & \multicolumn{3}{|c|}{$\mathrm{Ba} / \mathrm{Ca}$} & \multicolumn{3}{|c|}{$\mathrm{B} / \mathrm{Ca}$} \\
\hline & Pearsons & (sig. (2 tailed) & $\mathrm{N}$ & Pearsons & (sig. (2 tailed) & $\mathrm{N}$ & Pearsons (sig. (2 tailed) & $\mathrm{N}$ & Pearsons & (sig. (2 tailed) & $\mathrm{N}$ & Pearsons)(si & ig. (2 tailed) & $\mathrm{N}$ \\
\hline RW75 (400) & 0.414 & 0.004 & 46 & 0.480 & 0.001 & 46 & & & 0.414 & 0.004 & 46 & & & \\
\hline RW75 (100) & 0.291 & 0.125 & 29 & 0.814 & $0.000^{*}$ & 28 & 0.391 & 13 & 0.814 & $0.000^{*}$ & 28 & 0.289 & 0.144 & 27 \\
\hline A740 (1) & 0.195 & 0.078 & 83 & 0.520 & $0.000^{*}$ & 81 & & & -0.158 & 0.160 & 81 & & & \\
\hline A740 (2) & 0.420 & 0.094 & 17 & -0.059 & 0.822 & 17 & -0.352 & 13 & -0.333 & 0.191 & 17 & 0.312 & 0.222 & 17 \\
\hline P1B & 0.766 & $0.000^{*}$ & 102 & 0.481 & $0.000^{*}$ & 99 & -0.097 & 46 & 0.252 & 0.012 & 99 & 0.265 & 0.011 & 92 \\
\hline P04A & 0.537 & $0.000^{*}$ & 55 & 0.284 & 0.037 & 54 & -0.190 & 28 & 0.284 & 0.037 & 54 & 0.133 & 0.373 & 47 \\
\hline SC2 & 0.557 & $0.000^{*}$ & 105 & 0.784 & $0.000^{*}$ & 105 & 0.623 & 47 & 0.784 & $0.000^{*}$ & 105 & 0.118 & 0.236 & 102 \\
\hline SC1A & 0.378 & 0.009 & 47 & 0.617 & $0.000^{*}$ & 48 & 0.591 & 27 & 0.378 & 0.009 & 47 & 0.115 & 0.568 & 27 \\
\hline MP02A & 0.540 & $0.000^{*}$ & 80 & 0.582 & 0.001 & 84 & 0.086 & 36 & 0.429 & $0.000^{*}$ & 78 & 0.371 & 0.001 & 84 \\
\hline K3A & 0.723 & $0.000^{*}$ & 106 & 0.563 & $0.000^{*}$ & 102 & 0.193 & 48 & 0.377 & $0.000^{*}$ & 101 & 0.125 & 0.210 & 102 \\
\hline K1A1 & 0.307 & 0.003 & 93 & 0.598 & $0.000^{*}$ & 89 & -0.057 & 41 & 0.152 & 0.156 & 89 & 0.463 & 0.000 & 83 \\
\hline KD1B & 0.665 & $0.000^{*}$ & 72 & 0.442 & $0.000^{*}$ & 71 & -0.235 & 36 & 0.233 & 0.051 & 71 & 0.241 & 0.043 & 71 \\
\hline MR2 & 0.511 & $0.000^{*}$ & 89 & 0.221 & 0.038 & 89 & 0.125 & 46 & 0.174 & 0.103 & 89 & 0.200 & 0.079 & 78 \\
\hline AR1 & 0.244 & 0.014 & 100 & 0.442 & $0.000^{*}$ & 99 & 0.098 & 51 & -0.038 & 0.707 & 99 & -0.021 & 0.840 & 97 \\
\hline MD1 & 0.493 & 0.032 & 19 & 0.805 & $0.000^{*}$ & 19 & 0.251 & 12 & 0.495 & 0.031 & 19 & 0.051 & 0.851 & 16 \\
\hline MD3 & 0.708 & $0.000^{*}$ & 88 & 0.748 & $0.000^{*}$ & 89 & 0.707 & 47 & 0.453 & $0.000^{*}$ & 88 & 0.160 & 0.134 & 89 \\
\hline
\end{tabular}

$$
{ }^{*} p<0.001
$$

Table 4.3. The Pearson's Product Moment correlation coefficient values, the significance (sig. 2 tailed), and test size (N) produced by $\mathrm{Sr} / \mathrm{Ca}$ and $\mathrm{Mg} / \mathrm{Ca}$ ratios of each analysed ablation spot in each sample in the nacreous layer. Orange highlighted boxes represented well correlated elements and grey boxes show element/Ca with no comparison. 


\section{DISCUSSION}

\subsection{INTRA-INDIVIDUAL VARIATIONS IN SHELL CHEMISTRY}

\subsubsection{Uptake of elements into the different shell layers}

Clear differences are observed in the element/Ca ratios of the prismatic and nacreous layers of all shell samples. Factors that account for the differences in mean element/Ca ratio include the crystallinity and microstructure of the layers, shell biomineralisation and variation of uptake of different trace elements through the mantle epithelium of the organism (Chave, 1954; Price and Pearce, 1997; Takesue et al., 2008; Wilbur, 1964).

Differences are observed in the $\mathrm{Mg} / \mathrm{Ca}$ ratios in both layers of all samples, with the prismatic layer having significantly higher $\mathrm{Mg} / \mathrm{Ca}$ values (by one order of magnitude), compared with the nacreous layer. The differences in $\mathrm{Mg} / \mathrm{Ca}$ ratios can be explained by the variable lattice dimensions and crystallinty of the shell layers. The prismatic layer consists predominantly of calcite, whereas the nacreous layer is predominantly aragonite. Aragonite and calcite have similar crystal structures and thermodynamic stabilities, however, calcite is more stable than aragonite at ambient temperatures and pressures (Weiner and Addadi, 1997). Both calcite and aragonite are composed of alternating layers of calcium ions and carbonate ions perpendicular to the $c$ axis (a vertically orientated crystal axis - usually the principal axis) (Weiner and Addadi, 1997). The calcium ions occupy almost the same plane in both structures but the carbonate ions in aragonite are raised in the $c$ direction to allow the substitution of larger ions for $\mathrm{Ca}^{2+}$ (Fig. 5.1) (Weiner and Addadi, 1997). This accounts for the higher $\mathrm{Mg} / \mathrm{Ca}$ ratios in the prismatic layers of all shell samples compared with that of the nacreous layers. The smaller $\mathrm{Mg}^{2+}$ ion substitutes more readily into the rhombohedral calcite lattice, which is isostructural with magnesite $\left(\mathrm{MgCO}_{3}\right)$ (Dodd, 1967). This also explains the higher element/Ca ratios of the other ions (including $\mathrm{Mn}, \mathrm{Zn}, \mathrm{Li}$ and $\mathrm{Al}$ ) in the prismatic layer of the shell samples. The rhomobohedral structure allows $\mathrm{Mn}$ and $\mathrm{Zn}$ to substitute for $\mathrm{Ca}^{2+}$ 
and form rhodochrosite $\left(\mathrm{MnCO}_{3}\right)$ and smithsonite $\left(\mathrm{ZnCO}_{3}\right)$, which are also isostructural with calcite (Foster and Chacko, 1995; Ming, 2006).

(a)

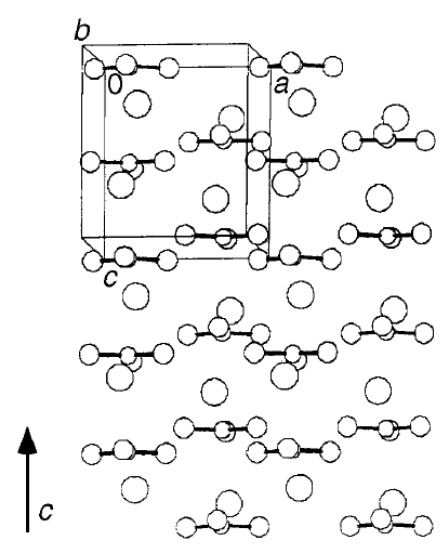

(b)

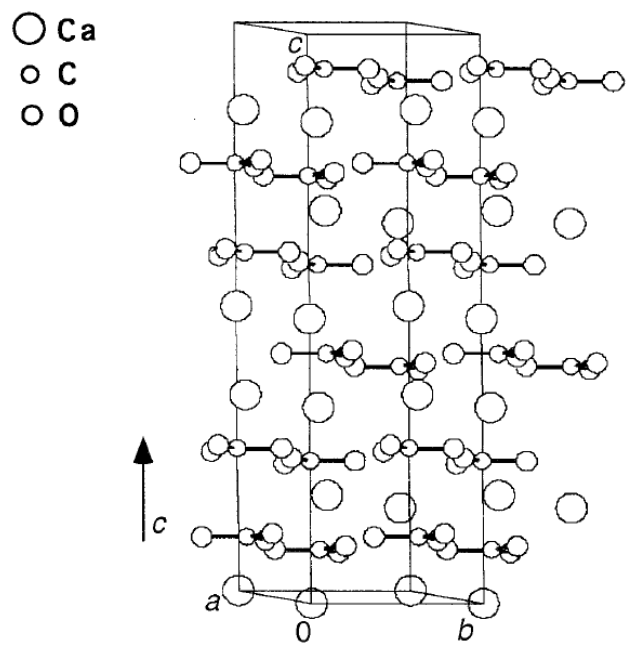

Fig. 5.1. The crystal structures of (a) aragonite and (b) calcite with the c arrow representing the $c$ axis (Weiner and Addadi, 1997).

Average Sr/Ca ratios are similar in both the prismatic and nacreous layers in all shell samples, with only slightly higher $\mathrm{Sr} / \mathrm{Ca}$ values in the nacre. $\mathrm{Sr}^{2+}$ has a larger ionic radius than $\mathrm{Ca}^{2+}$, which is more readily available to substitute for $\mathrm{Ca}^{2+}$ in the crystal lattice of aragonite. Aragonite has an orthorhombic crystal structure that is isostructural with strontianite $\left(\mathrm{SrCO}_{3}\right)$ (Dodd, 1967). This principle can also be applied to account for the higher element/Ca ratios observed in the nacreous layer compared with the prismatic layer with respect to $\mathrm{Ba}$ and in some cases $\mathrm{Pb}$. Both of these elements are large divalent cations with ionic radii ca. $>0.1 \mathrm{~nm}$, and when substituted in place of $\mathrm{Ca}^{2+}$, form witherite $\left(\mathrm{BaCO}_{3}\right)$ and cerussite $\left(\mathrm{PbCO}_{3}\right)$, which are isotructural with aragonite (Foster and Chacko, 1995; Ming, 2006; Sinclair and McCulloch, 2004).

Although $\mathrm{B}$ has a small ionic radius, higher values in the majority of shell samples are observed in the aragonitic nacreous layer. Takesue et al. (2008) concluded that, like Sr, B is exclusively found in the aragonitic fraction of some mollusc shells. B is present in seawater as the borate anion and substitutes for 
carbon in $\mathrm{CaCO}_{3}$ (Takesue et al., 2008). Higher element/Ca ratios could also be due to the transect location (discussed further in section 5.3) as some trace element/Ca ratios are elevated closer to the outer surface of the shell.

\begin{tabular}{|lllr|}
\hline Carbonate group & \multicolumn{1}{c}{ Ideal unit-cell formula } & \multicolumn{1}{c|}{ Crystal system } & Specific gravity \\
\hline Calcite group & & Hexagonal (rhomobohedral) & \\
Calcite & $\mathrm{CaCO}_{3}$ & Hexagonal & 2.71 \\
Magnesite & $\mathrm{MgCO}_{3}$ & Hexagonal & 3.00 \\
Siderite & $\mathrm{FeCO}_{3}$ & Hexagonal & 3.97 \\
Rhodochrosite & $\mathrm{MnCO}_{3}$ & Hexagonal & 3.70 \\
Smithsonite & $\mathrm{ZnCO}_{3}$ & Hexagonal & 4.43 \\
Otavite & $\mathrm{CdCO}_{3}$ & Hexagonal & 4.96 \\
Gaspéite & $\mathrm{NiCO}_{3}$ & & 4.39 \\
Aragonite group & & Orthorhombic & \\
Aragonite & $\mathrm{CaCO}_{3}$ & Orthorhombic & 2.95 \\
Witherite & $\mathrm{BaCO}_{3}$ & Orthorhombic & 4.3 \\
Strontianite & $\mathrm{SrCO}_{3}$ & Orthorhombic & 3.7 \\
Cerussite & $\mathrm{PbCO}_{3}$ & & 6.55 \\
\hline
\end{tabular}

Table 5.1. Selected properties including ideal unit-cell formula, crystal system and specific gravity of the common carbonates: calcite and aragonite (Ming, 2006).

Discrimination of $\mathrm{Sr}^{2+}$ during biomineralisation can also contribute to the increase of $\mathrm{Sr} / \mathrm{Ca}$ ratios in either the prismatic and nacreous shell layers. Carré et al. (2006) discussed a model for $\mathrm{Ca}^{2+}$ transportation through the mantle epithelium of two bivalve species, Mesodesma donacium and Chione subrugosa. In summary, calcium channels have a higher sensitivity and selectivity to allow $\mathrm{Ca}^{2+}$ influx rather than any other cation due to suitable bind sites that facilitate diffusion and transport of $\mathrm{Ca}^{2+}$ from the surrounding medium (i.e. seawater) to the extrapallial fluid (Carré et al., 2006; Hess and Tsien, 1984). The calcium channel selectivity of ions other than $\mathrm{Ca}^{2+}$ is dependent on the channel type, the binding site affinity for each ion species and the chemical composition of the fluid either side of the channel (Carré et al., 2006). Both $\mathrm{Sr}^{2+}$ and $\mathrm{Ba}^{2+}$ have a higher affinity in replacing $\mathrm{Ca}^{2+}$ in the calcium channel. 


\subsubsection{Analyses of individual bands: best locations to extract data?}

The element/Ca ratios along a transect following the growth bands of pāua were measured with the intent of investigating whether an individual growth band produced consistent trace element/Ca ratio results. This is important as it is essential to know where it is appropriate to place the temporal transect through the prismatic layer in order to measure reliable and comparable data. Anomalies throughout a transect could potentially reflect variations within the growth band, compared with environmental factors influencing the trace element chemistry of the overall shell through time. Sr/Ca and $\mathrm{Ba} / \mathrm{Ca}$ ratios of all the individual growth bands have higher element/Ca ratios closer to the outermost part of the prismatic layer. The outer layer of pāua, and many other molluscs, is a non-mineralised protein layer called the periostracum (Su et al., 2002). The periostracum is a 0.1-0.2 $\mu \mathrm{m}$ thick protein membrane that protects the carbonate shell (Su et al., 2002). The periostracum is in direct contact with the ambient seawater, whereas the extrapallial fluid that precipitates the shell minerals is not. Hence, the shell material closest to the periostracum can adsorb the trace elements directly. Higher $\mathrm{Sr} / \mathrm{Ca}$ and $\mathrm{Ba} / \mathrm{Ca}$ ratios are observed closest to the periostracum, which could be due to adsorption. The surface of a crystal is the prime location for trace element adsorption (Weiner and Dove, 2003). Dodd (1967) also suggested that certain organic compounds may contain metallic elements which can contribute to the significant amounts of trace elements present in the shell.

The main observations drawn by form of analysis of growth banding is that the trace elements/Ca ratios along growth bands are variable. This study indicates that it is best to analyse the trace element/Ca ratios midway between the outermost layer of the prismatic layer and the nacre where the $\mathrm{Sr} / \mathrm{Ca}$ and $\mathrm{Ba} / \mathrm{Ca}$ ratios are relatively constant. However, as such, uncertainties in results can be magnified due to issues in tracing the growth banding accurately. Due to the spot size $(25 \mu \mathrm{m})$, sometimes it was hard to analyse the growth band itself. Furthermore, growth banding relates to a period of cessation of precipitation of $\mathrm{CaCO}_{3}$ material and an increase of organic material precipitation. Anomalous 
$\mathrm{Sr} / \mathrm{Ca}$ ratios were sometimes observed in some shells. Cracks along the transect will also produce anomalous results, which could mask the environmental controls on trace element/Ca ratios.

\subsection{INTER-INDIVIDUAL SHELL CHEMISTRY: REPRODUCIBILITY WITHIN SHELLS FROM THE SAME SAMPLING SITES}

For a species to be an effective archive of past environmental conditions and changes, individual shells from the same site should produce similar chemistry data. As such, two or more shells were measured at each site to examine if both shells produced similar trace element chemistries.

Generally, shells from the same site produce comparable element/Ca ratios (Fig. 5.2). The $\mathrm{Mg} / \mathrm{Ca}$ ratios of the prismatic layer of samples collected from the same sampling site vary by ca. $1-2 \mathrm{mmol} / \mathrm{mol}$. A comparison of all samples shows that $\mathrm{Mg} / \mathrm{Ca}$ ratios at a specific sample site show large variability. Mean $\mathrm{Mg} / \mathrm{Ca}$ ratios can be misleading through anomalous spot values which could increase the mean values. As sea surface temperatures are generally colder in the south compared with northern waters, it will hold that thermodynamics and temperature are not solely responsible for the $\mathrm{Mg} / \mathrm{Ca}$ ratios uptake into the pāua and biomineralisation of the shell, as samples collected from southern sites have higher $\mathrm{Mg} / \mathrm{Ca}$ ratios compared with samples collected from northern sites. Also having samples collected from varying locations in the intertidal zone would mean that different species would be exposed to ambient seawater and air temperatures daily. $\mathrm{Sr} / \mathrm{Ca}$ ratios are more comparable within samples from similar locations in both the nacreous and prismatic layers. However, there is generally a narrow range between $\mathrm{Sr} /$ Ca ratios sampled from all sites which like $\mathrm{Mg} / \mathrm{Ca}$, a distinguished $\mathrm{Sr} / \mathrm{Ca}$ ratio can not be applied per sample site. 

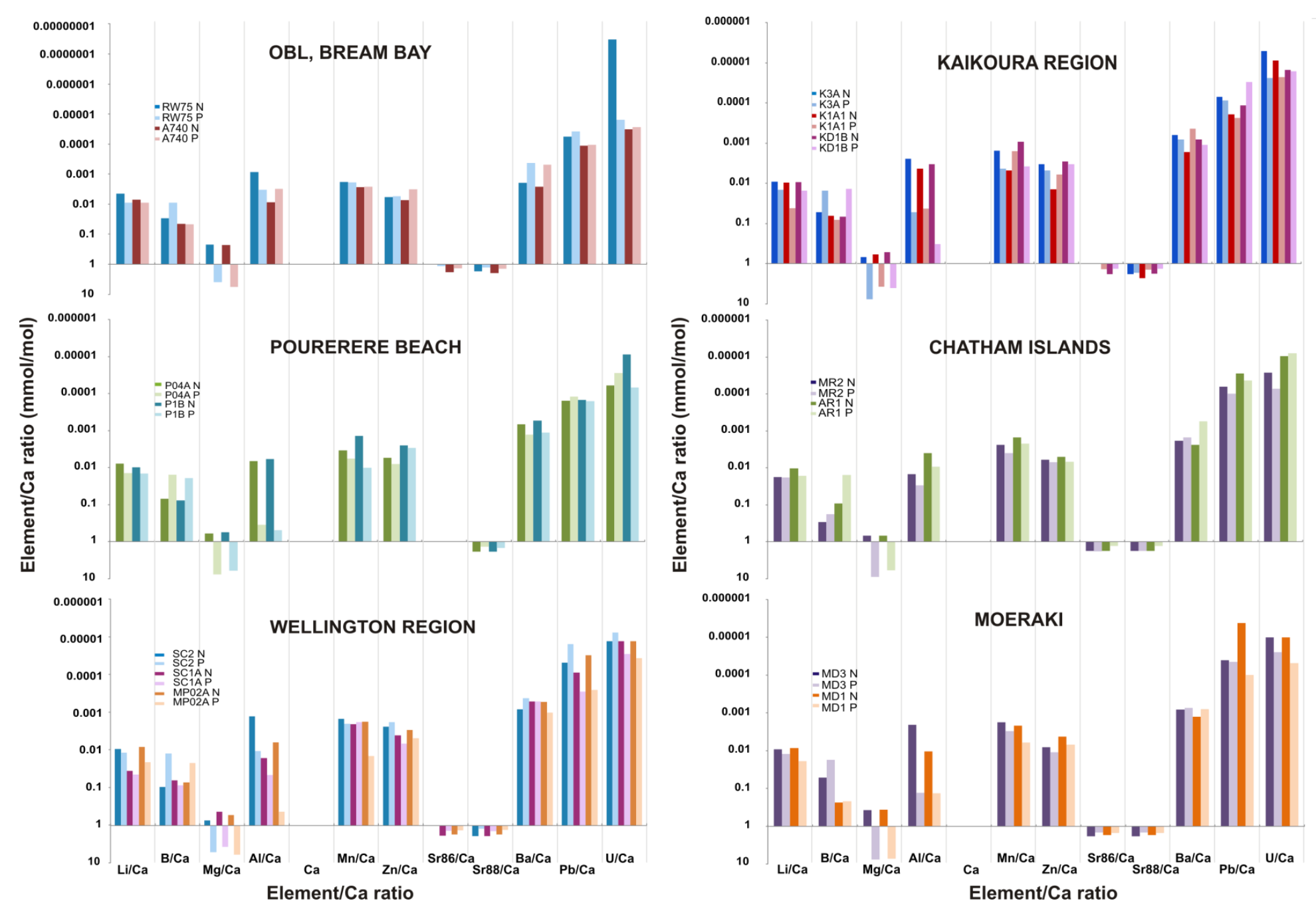

Fig. 5.2. The mean element/Ca ratio $(\mathrm{mmol} / \mathrm{mol})$ of the prismatic layer $(\mathrm{P})$ and the nacreous layer $(\mathrm{N})$ of individual pāua showing similarities based on sample site. All data is plotted on a logarithmic scale. 
Mean $\mathrm{Al} / \mathrm{Ca}$ ratios are comparable in all samples collected from the same location. However, elevated values were observed in samples KD1B from Kaikoura, MP02A from Moa Point and both samples from Pourerere, P04A and P1B. Similar values are seen in the prismatic shells from Moeraki (MD1 and MD3). The higher mean $\mathrm{Al} / \mathrm{Ca}$ ratios observed in the samples can be assumed to reflect higher levels of $\mathrm{Al}$ in the ambient environment as the amount of metal incorporation into the shell is assumed to provide an indication of the degree of bioavailable metal present in the environment (Section 5.4) (Tynan et al., 2005). Very low Al/Ca ratios characterise the OBL samples (RW75 and A740), where the water chemistry and trace metals are measured, monitored and altered if conditions fluctuate from the optimum growing conditions for the pāua. As is the case for $\mathrm{Al} / \mathrm{Ca}$ ratios, $\mathrm{Ba} / \mathrm{Ca}$ and $\mathrm{Mn} / \mathrm{Ca}$ ratios were also similar in shells based on sample site.

$\mathrm{Ba} / \mathrm{Ca}$ ratios generally produce higher values within the nacreous layer, however, a number of samples ( $\mathrm{n}=5$ ), have higher $\mathrm{Ba} / \mathrm{Ca}$ ratios in the prismatic layer. Four of these samples (P04A, P1B, MP04A and KD1B) also show the anomalously high $\mathrm{Al} / \mathrm{Ca}$ ratios in the prismatic shell. $\mathrm{Mn} / \mathrm{Ca}$ ratios are also higher in the prismatic layer of these shells. The increase of $\mathrm{Ba} / \mathrm{Ca}$ and $\mathrm{Mn} / \mathrm{Ca}$ ratios in the prismatic layer of the aforementioned samples could be due to the increase of $\mathrm{Ba}$ and $\mathrm{Mn}$ in the ocean, associated with the increase of nutrients and primary productivity from diatom and phytoplankton blooms. Gillikin et al. (2006) suggests that the incorporation of elements in calcite with ionic radii larger than calcium is expected to be strongly affected by external factors. This strengthens the idea that the elevated $\mathrm{Ba} / \mathrm{Ca}$ ratios in the prismatic layer could reflect the environmental conditions during growth.

Some differences in trace element/Ca ratios are also observed amongst individuals within each site (e.g., B/Ca and U/Ca ratios). Variations of the trace element/Ca ratios in each sample collected from the same location might be due to dietary differences (Beldi et al., 2006; Naylor et al., 2006), subtle differences in local inputs of elements, exposure to energetic environments (Wells et al., 1998) and the ontogenetic stage of the animal (Arai et al., 2003; Klein et al., 1996b; Schöne, 2008). 
Pāua live on both exposed and sheltered shores (Wells, et al., 1998). Exposure to the varying energy environments can not only add metabolic stress to the animal but also affect the abundance of food. Higher energy wave environments have the potential to drift more macro-algae to the pāua (Donovan and Taylor, 2008), compared to the pāua sheltered in crevices and behind rocks. Macroalgae is an additional source of trace elements to the pāua which could explain the variations in the trace element/Ca ratio chemistry in shells collected from the same site.

Having shells of different ontogenetic stages from the same site also adds further complexity to inter-individual chemistry differences observed at the same site. The growth of pāua slows significantly during ontogeny so the transect analysed will reflect different time spans (Schöne, 2008). Pirker and Schiel (1993) described the adult length of pāua as being ca. > $115 \mathrm{~mm}$, with these individuals having significantly slower growth rates than that of juvenile pāua $(<70 \mathrm{~mm})$. Faster precipitation of the shell would have the potential to record more of the environmental events versus the slower precipitation from the older organism. If age differences characterise shells at each location, the 30-40 $\mathrm{mm}$ transect analysed in this study will preferentially produce different element/Ca ratios as faster growing younger species would record shorter term fluctuations of environmental parameters (more winters and summers) (Vander Putten et al., 2000). Furthermore, it has also been shown that growth rate may affect the incorporation of trace elements into the shells of mollusc species (Schöne, 2008)

\subsection{HIGH TEMPORAL RESOLUTION ANALYSIS OF PĀUA AS A (PALEO-) ENVIRONMENTAL PROXY?}

\subsubsection{Pāua prismatic layer colouration}

The prismatic layers of many pāua samples show alternating lighter to darker blue and green bands. Past studies have identified the effect of diet on shell colouration of many Haliotis spp. (Poore, 1972a). Feeding experiments have 
found that the shell colouration in different organisms can be explained through changes in diet and the type of algae that the animal feeds on (Leighton and Boolootian, 1963; Olsen, 1968; Poore, 1972a; Sakai, 1960). Sakai (1960) investigated the colouration of Haliotis spp. shells with respect to the different types of algae consumed. When the animal consumed brown and green algae, the prismatic layer became bluish-green in colour (Sakai, 1960). However, when the animal consumed brown algae, it produced brown shell material (Sakai, 1960). Poore (1972a) also noted the effect of diet on the shell colour of Haliotis iris. In general, red algae (Hymenocladia lanceolata) promoted the growth of dark red or brown shell in pāua, and brown algae (Macrocystis pyrifera and Lessonia variegata) promoted growth of a light blue-green shell (Poore, 1972a). Studies of Haliotis cracherodii attribute the colour change from white to red in juvenile specimens to a change in diet from diatoms to calcareous algae (Leighton and Boolootian, 1963). The change to the red to darker green/dark bluish-black is then thought to be due to the introduction of macro-algae into the diet of the species as an adult (Leighton and Boolootian, 1963).

Figures 5.4a-5.4d shows $\mathrm{Mg} / \mathrm{Ca}$ ratios overlain on photographic images of the shells studied in this thesis. Many samples have higher $\mathrm{Mg} / \mathrm{Ca}$ ratios associated with lighter coloured parts of the prismatic layer and lower $\mathrm{Mg} / \mathrm{Ca}$ ratios associated with darker coloured parts of the prismatic layer. Pāua feed on macro-algae with the greatest amounts of this food being available in the winter (Poore, 1972a). Different species of macro-algae (brown algae) have been recorded to be in greater densities in June/July and maximum size in August/September (Schiel and Nelson, 1990). The intake and abundance of food in winter could relate to the darker banding characterised during the $\mathrm{Mg} / \mathrm{Ca}$ ratio minima which could indicate that both $\mathrm{Mg} / \mathrm{Ca}$ ratios and colouration of shell could be an indication for potential temperature changes related to diet. 

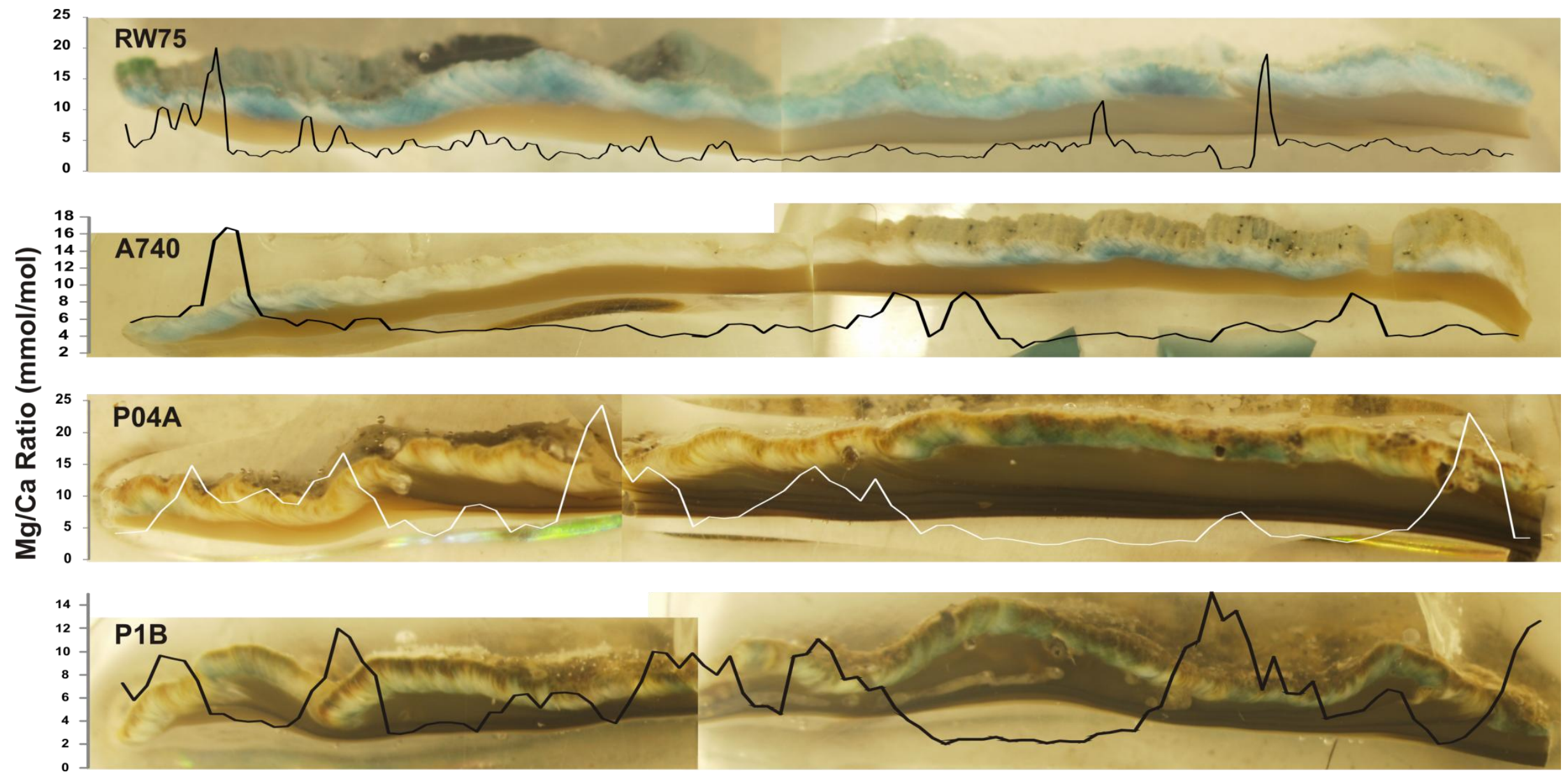

Fig. 5.3a. $\mathrm{Mg} / \mathrm{Ca}$ ratios of a high temporal resolution transect through the prismatic layer of all samples ( 3 point moving average). The majority of the peaks in $\mathrm{Mg} / \mathrm{Ca}$ ratios coincide with lighter coloured shell material. 


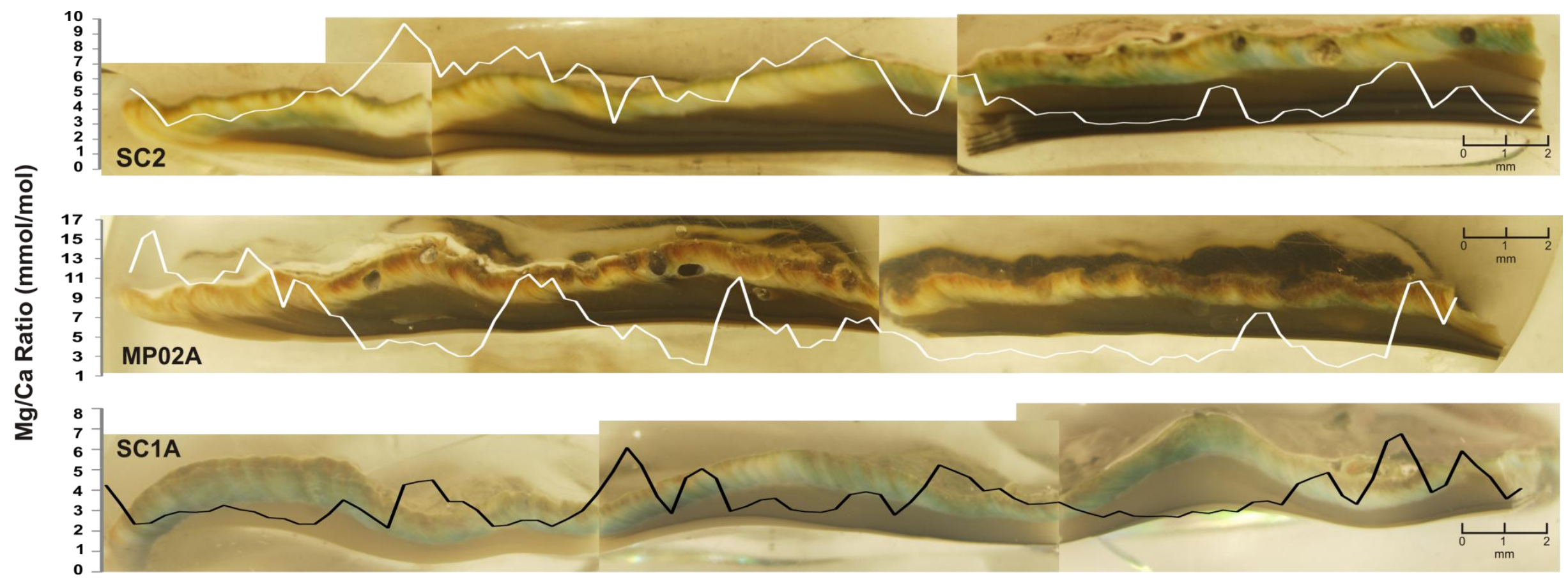

Fig. 5.3b. $\mathrm{Mg} /$ Ca ratios of a high temporal resolution transect through the prismatic layer of all samples (3 point moving average). The majority of the peaks in $\mathrm{Mg} / \mathrm{Ca}$ ratios coincide with lighter coloured shell material. 


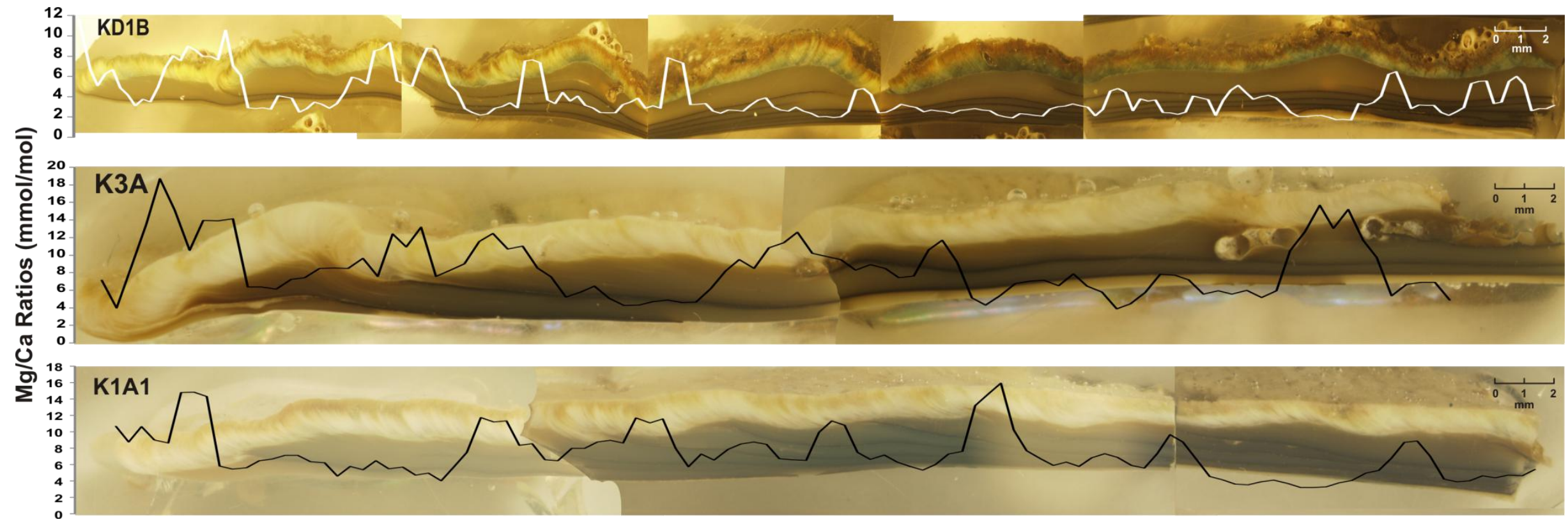

Fig. 5.3c. $\mathrm{Mg} / \mathrm{Ca}$ ratios of a high temporal resolution transect through the prismatic layer of all samples ( 3 point moving average). The majority of the peaks in $\mathrm{Mg} / \mathrm{Ca}$ ratios coincide with lighter coloured shell material. 

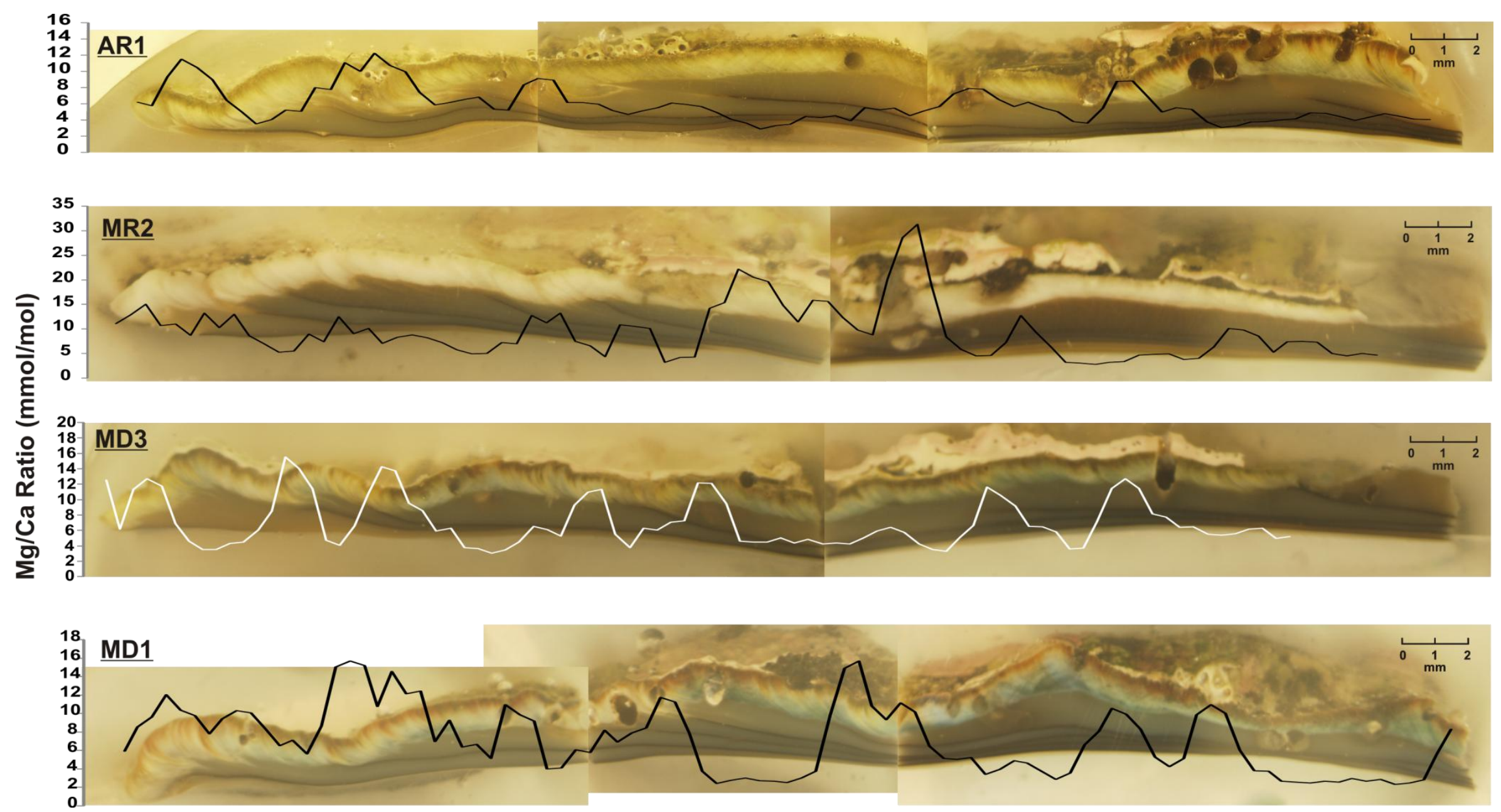

Fig. 5.3d. $\mathrm{Mg} / \mathrm{Ca}$ ratios of a high temporal resolution transect through the prismatic layer of all samples ( 3 point moving average). The majority of the peaks in $\mathrm{Mg} / \mathrm{Ca}$ ratios coincide with lighter coloured shell material. 


\subsection{2 $\mathrm{Mg} / \mathrm{Ca}$ and $\mathrm{Sr} / \mathrm{Ca}$ ratios in pāua as a paleo-ocean thermometer}

\subsubsection{OceaNZ Blue Ltd trace element/Ca and temperature correlation?}

$\mathrm{Mg} / \mathrm{Ca}$ and $\mathrm{Sr} / \mathrm{Ca}$ ratios in foraminifera and coral, respectively, have routinely been used as to reconstruct past ocean temperatures (Elliot et al., 2009; McCulloch et al., 1996). These elemental ratios were measured in all pāua samples to examine if pāua also recorded changes in $\mathrm{Mg} / \mathrm{Ca}$ and $\mathrm{Sr} / \mathrm{Ca}$ ratios in response to temperature.

The cultured OceaNZ Blue Ltd pāua provide a particularly good example to examine this, as water temperature was continuously monitored and measured during pāua growth. In the first instance, the recorded monthly growth of both OBL samples was compared with recorded monthly temperatures provided by OBL. The results showed that A740, a juvenile pāua, had maximum growth when temperatures were high, whereas RW75, an adult specimen, showed an inverse relationship with maximum growth while temperatures were low. Juvenile pāua have been noted to show a positive correlation between water temperature and metabolic rate until thermal maxima is attained (Naylor et al., 2006). Three other juvenile pāua were also provided by OBL and also showed maximum shell growth during warmer months (Appendix 2

.1). This is an effect of ontogeny with the larger adult sample showing a growth rate lag to temperature. With respect to the element/Ca ratios, it is important to note that growth rates are not consistent, with variations seen annually and throughout the life span of the pāua. Naylor et al. (2006) noted the onset of an inverse relationship of growth rate and temperature in adult pāua reflected the onset of sexual maturity as resources are relocated to gonad for development.

$\mathrm{Mg} / \mathrm{Ca}$ ratios in both $\mathrm{A} 740$ and RW75 show higher values with increased temperature and increased growth rate, although peaks in both temperature and growth do not always exactly coincide. This suggests that a number of factors influence the incorporation of $\mathrm{Mg}$ within the shell of pāua including temperature and calcification rate. A temperature dependence of $\mathrm{Mg} / \mathrm{Ca}$ ratio within the mussel shell of Mytilus trossulus was described by Klein et al. (1996a) 
with increased $\mathrm{Mg} / \mathrm{Ca}$ ratios associated with warmer temperatures. The increase of $\mathrm{Mg} / \mathrm{Ca}$ ratios also occurred during periods of increased growth rate.

There also seems to be a slight lag between peak temperatures and increased $\mathrm{Mg} / \mathrm{Ca}$ which could suggest there is a time lag between the uptake of trace elements from the ambient environment, travel through the mantle epithelium, and precipitation into the carbonate shell. RW75 shows increased $\mathrm{Mg} / \mathrm{Ca}$ ratios in February 2009, but fails to show elevated Mg/Ca ratios in 2008. Both A740 and RW75 show low Sr/Ca ratios with peak growth (represented by black boxes in Figure 5.5). $\mathrm{Sr} / \mathrm{Ca}$ ratios in corals and molluscs have also been observed to be a function of calcification rate (Gillikin et al., 2005; Stecher III et al., 1996). This inverse relationship of growth or calcification rate with $\mathrm{Sr} / \mathrm{Ca}$ ratios is also seen in corals and the bivalve, Mytilus trossulus (Gillikin et al., 2005; Klein et al., 1996b). As discussed in Section 5.1, Ca uptake is inhibited by calcium channels which allow $\mathrm{Sr}^{2+}$ to travel within similar pathways as $\mathrm{Ca}^{2+}$ (Gillikin et al., 2005). An important enzyme within the biomineralisation process is $\mathrm{Ca}^{2+}$-ATPase (Gillikin et al., 2005; Klein et al., 1996b). Ca ${ }^{2+}$-ATPase is instrumental in pumping $\mathrm{Ca}^{2+}$, removing $\mathrm{H}^{+}$ions and concentrating $\mathrm{CO}_{3}{ }^{2+}$ at the calcification site (Gillikin et al., 2005). When biomineralisation increases, $\mathrm{Ca}^{2+}$-ATPase activity also increases and raises the $\mathrm{Ca}^{2+}$ affinity towards the enzyme site compared with $\mathrm{Sr}^{2+}$ explaining the inverse correlation between $\mathrm{Sr} / \mathrm{Ca}$ ratios and growth rate (Gillikin et al., 2005). Growth rates have then been able to indirectly reflect temperature as some mollusc species experience increased growth during warmer temperatures (Gillikin et al., 2005 Klein et al., 1996b). This tool used with pāua shells will produce unreliable results as growth rates and temperature of the water in which they grew in differ from individual to individual.

$\mathrm{Sr} / \mathrm{Ca}$ ratios of $\mathrm{A} 740$ also show shorter-term oscillations on what appear to be monthly cycles (Fig. 5.4). Meibom et al., (2003) recognised a similar Sr/Ca ratio relationship in the aragonitic coral Porites lutea. The monthly $\mathrm{Sr} / \mathrm{Ca}$ and $\mathrm{Ba} / \mathrm{Ca}$ ratio oscillations were explained due to metabolic effects that are synchronous with the lunar cycle (Meibom et al., 2003). Such metabolic effects including coral 
spawning and larval release, are possibly triggered due to lunar irradiance and cause the diversion of resources that are used for calcification (Meibom et al., 2003). Reproduction in other marine species has also been linked to lunar and tidal changes (Baynes, 2009). Studies of Haliotis asinia in Indonesia have identified short-term reproductive cycles influenced by the lunar cycles (Setyono, 2006). 

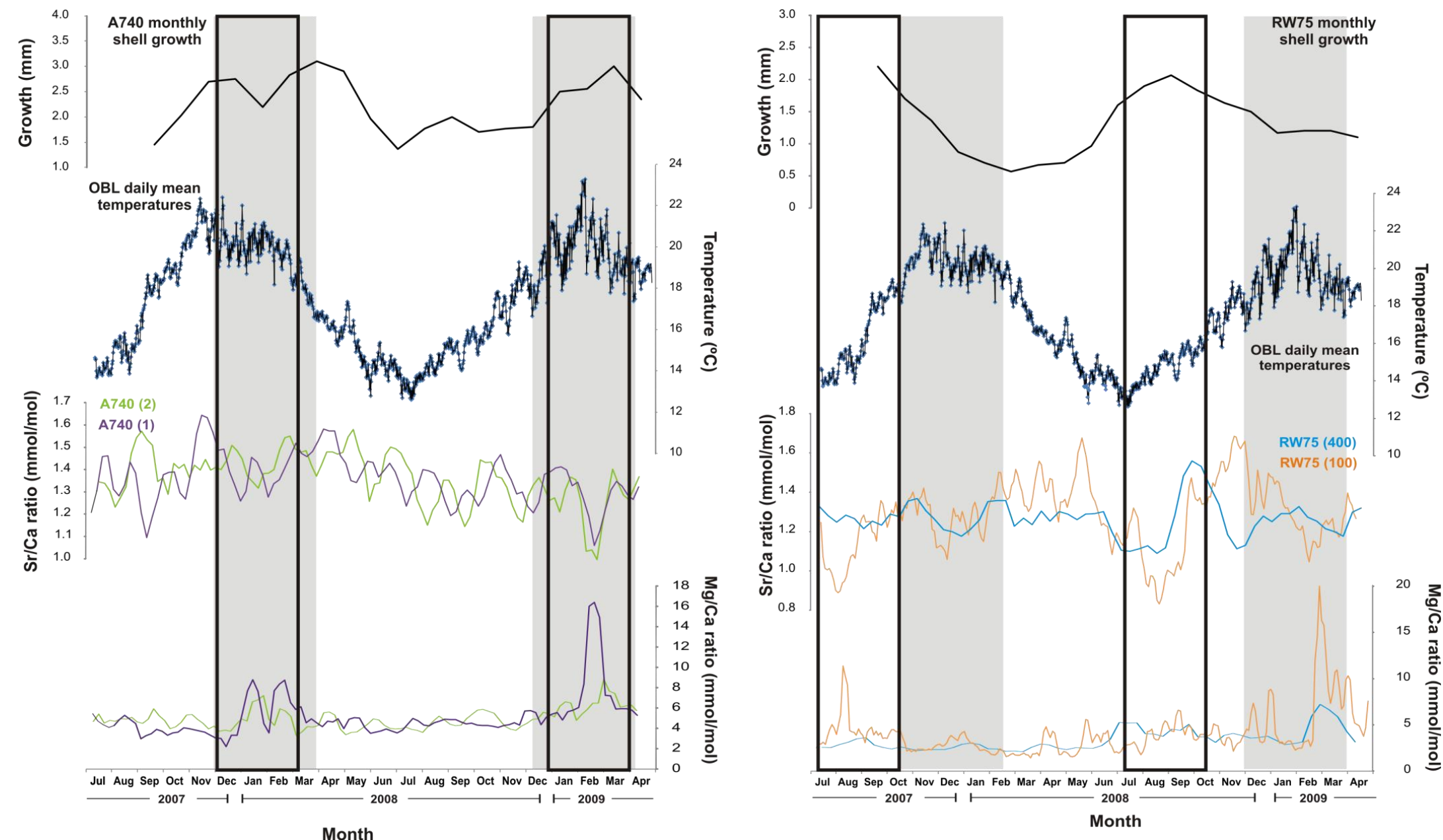

Fig. 5.4. Measured monthly shell growth of A740 (left) and RW75 (right) plotted against OBL daily temperatures and Sr/Ca and Mg/Ca ratios. Grey bands represent peaks in temperature where black boxes represent significant changes in element/Ca ratios. Also to note A740 has increased growth in warmer temperatures whereas RW75 has increased growth rate in colder temperatures. 
Before comparing temperature data (Table 3.1) with the $\mathrm{Mg} / \mathrm{Ca}$ and $\mathrm{Sr} / \mathrm{Ca}$ ratios of the prismatic layer of pāua shells collected from the wild, growth rates were calculated in order to map element/Ca ratios variations on to a temporal framework. The shells sampled from the wild range in size from 117-155 mm, which means that growth rates for each specimen vary due to each individual's ontogenetic development (Fig. 5.5). An average growth rate for the shells collected from the wild was calculated by estimating the daily growth rate (mm/day) of shells that were measured and analysed in three different studies on Haliotis iris (Table 5.2) (Heath and Moss, 2009; Naylor et al., 2007; Poore, 1972b). This estimate assumes a constant annual growth rate and throughout the life span of the pāua. This approach can only be considered an approximation as shell growth rates are dependent on the waxing and wanning of shell precipitation, which is not constant throughout in the year (Schöne, 2008). Daily changes of shell growth rate also occur with night temperatures dropping below some species' thermal limit (Schöne, 2008).

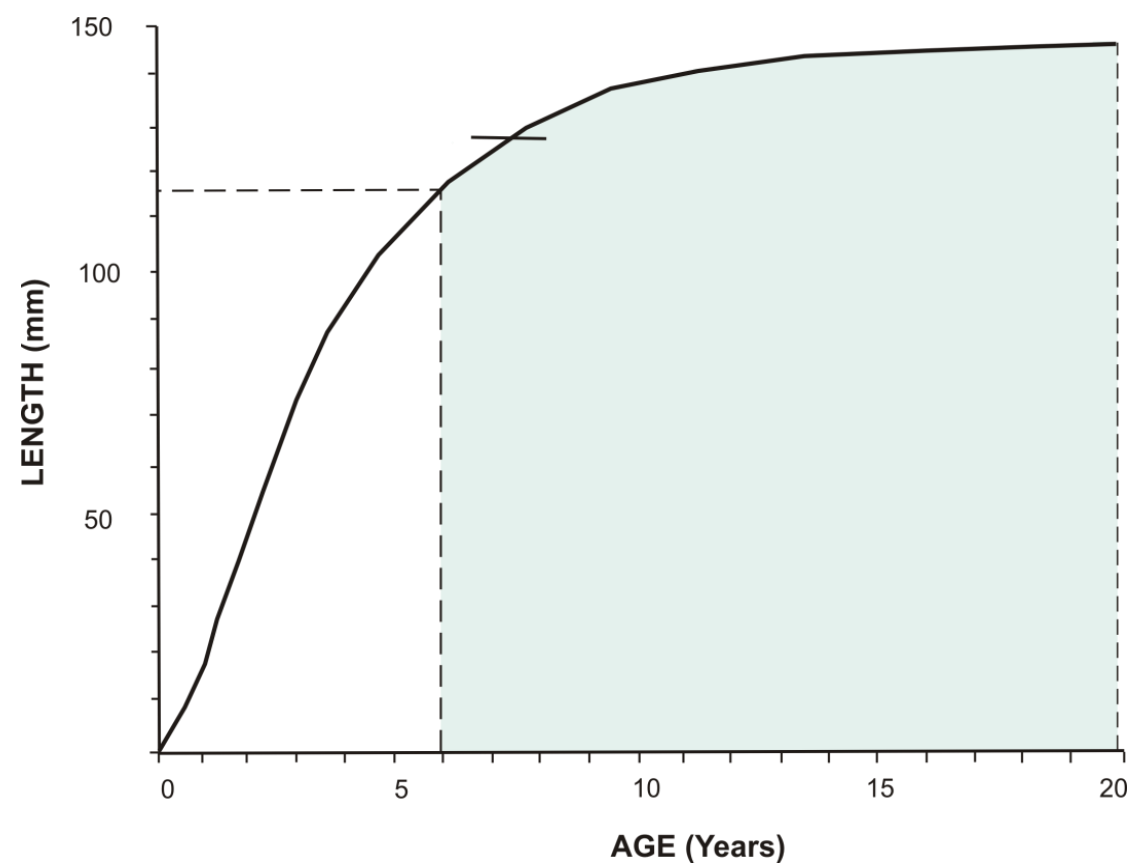

Fig. 5.5. The calculated von Bertalanffy curve showing growth (length versus age) for Haliotis iris taken from Poore (1972). The solid horizontal line on the curve represents the minimum legal size on pāua that can be recreationally taken from New Zealand coastal waters. The dashed horizontal line represents the minimum-sized sample measured in this study (117 mm) and the green box under the curve is the range of ages of pāua studied in this thesis. 


\begin{tabular}{|c|c|c|c|c|}
\hline Reference & $\begin{array}{l}\text { Length at release } \\
\qquad(\mathrm{mm})\end{array}$ & $\begin{array}{c}\text { Length at recovery } \\
(\mathrm{mm})\end{array}$ & $\begin{array}{l}\text { Time at liberty } \\
\text { (days) }\end{array}$ & $\begin{array}{c}\text { Growth rate } \\
(\mathrm{mm} / \text { day })\end{array}$ \\
\hline \multirow{5}{*}{ Naylor et al., 2007} & 86 & 110 & 502 & 0.0478 \\
\hline & 60 & 109 & 531 & 0.0923 \\
\hline & 91 & 120 & 502 & 0.0578 \\
\hline & 90 & 112 & 511 & 0.0431 \\
\hline & 104 & 119 & 384 & 0.0391 \\
\hline \multirow{7}{*}{ Poore, 1972} & 70 & 116 & 1170 & 0.0393 \\
\hline & 76 & 131 & 1170 & 0.0470 \\
\hline & 81 & 120 & 1170 & 0.0333 \\
\hline & 93 & 129 & 1200 & 0.0300 \\
\hline & 98 & 137 & 1200 & 0.0325 \\
\hline & 119 & 139 & 1170 & 0.0171 \\
\hline & 135 & 146 & 1350 & 0.0081 \\
\hline OBL (RW75) & 82 & 106 & 546 & 0.0440 \\
\hline \multirow{7}{*}{$\begin{array}{l}\text { Heath and Moss, } \\
2009\end{array}$} & 10 & 17 & 176 & 0.0369 \\
\hline & 15 & 24 & 176 & 0.0507 \\
\hline & 22 & 31 & 176 & 0.0534 \\
\hline & 14 & 22 & 176 & 0.0460 \\
\hline & 10 & 18 & 175 & 0.0445 \\
\hline & 14 & 22 & 176 & 0.0465 \\
\hline & 19 & 27 & 170 & 0.0477 \\
\hline AVERAGE & & & & 0.0429 \\
\hline
\end{tabular}

Table 5.2. Growth rates of pāua (mm/day) calculated by length of release and recovery of pāua in studies by Naylor et al. (2007) and Poore (1972) and using the growth data supplied by OBL for sample RW75. The average growth rate for adult pāua was applied to the shell samples collected from the wild in this study.

$\mathrm{Mg} / \mathrm{Ca}$ ratios in the prismatic layer are variable in samples from the wild. Applied average growth rates were hard to compare with seasonal temperature variations and subsequently with $\mathrm{Mg} / \mathrm{Ca}$ ratios. While MPO2A showed a correlation between Wellington monthly air temperatures and $\mathrm{Mg} / \mathrm{Ca}$ ratios (Fig. 5.6), other shell samples from other sites failed to produce the same results. The relative dependency of $\mathrm{Mg} / \mathrm{Ca}$ ratios observed in both OBL samples and MP02A reflect a $1 \mathrm{mmol} / \mathrm{mol}$ increase in $\mathrm{Mg} / \mathrm{Ca}$ ratios with a $1^{\circ} \mathrm{C}$ increase in temperatures. Peaks of $\mathrm{Mg} / \mathrm{Ca}$ ratio in some samples (A740 in Fig 5.4) do not show a gradual increase of $\mathrm{Mg} / \mathrm{Ca}$ ratios with increasing temperatures but instead exhibit sudden sharp peaks. As other biological effects occur during precipitation, this could be due to the redistribution of resources used for biomineralisation and transportation of ions to the EPF to other areas of the organism for gonad development or reproduction (Meibom et al., 2003).

Pāua live in high wave-energy environments that can cause the metabolism of the pāua to shut down, which results in an interruption of the recording of 
element/Ca ratios within the shell (Schöne, 2008). Pāua also live in the subtidal zone, which means that water can retreat from the habitat during low tide and that no water temperature can be recorded (Schöne, 2008). These reasons might explain why $\mathrm{Mg} / \mathrm{Ca}$ ratios have failed to be recorded reliably in the pāua shells from the wild. The lack of evident seasonal temperature fluctuations in the $\mathrm{Mg} / \mathrm{Ca}$ ratio could also suggest that biological factors exert a predominant control on pāua Mg uptake. Many other molluscs (Elliot et al., 2009; Lazareth et al., 2007; Vander Putten et al., 2000) also fail to show Mg/Ca ratios correlating with ambient ocean temperature changes.

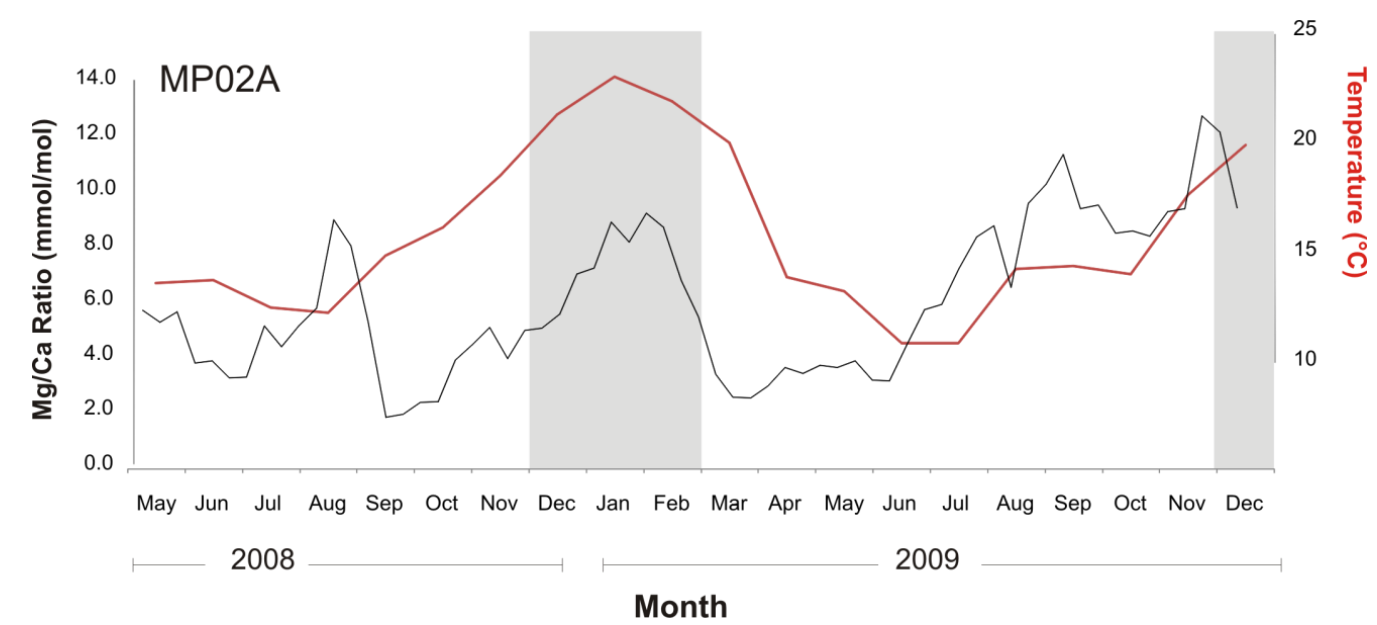

Fig. 5.6. The 3-point moving average of MP02A Mg/Ca ratios (black) using a daily shell growth rate of $0.043 \mathrm{~mm} /$ day compared with mean monthly air temperatures of Wellington from May 2008 to December 2009. Grey bands show correlations between peaks in temperature and $\mathrm{Mg} /$ Ca ratios.

$\mathrm{Sr} / \mathrm{Ca}$ ratios in pāua do not appear to be a strong proxy for ambient ocean temperatures. $\mathrm{Sr} / \mathrm{Ca}$ ratios have been widely studied in many different molluscan species yielding varying results (Gillikin et al., 2005). Sr/Ca ratio peaks occurr out of cycle with minimum and maximum temperatures and highlight that primary factors influencing the uptake of $\mathrm{Sr}^{2+}$ into the $\mathrm{CaCO}_{3}$ shell of pāua are not necessarily environmentally related, and physiology and vital effects could play a larger role (Schöne, 2008). Controls on the Sr/Ca ratios of the bivalve Saxidomus giganteus were studied extensively and showed that biological processes dominate (Gillikin et al., 2005). This physiological effect not only could influence the amount of $\mathrm{Sr}$ in the carbonate secreting fluid in the EPF but also the timing and the rate at which the pāua shell grew (Schöne, 2008). 
$\mathrm{Mg} / \mathrm{Ca}$ and $\mathrm{Sr} / \mathrm{Ca}$ ratios in other mollusc shells have also showed varying results, identifying the need for individual species-specific element/Ca ratio proxies to be established. Sr/Ca ratios have been shown to increase with increasing growth rate in the aragonitic bivalve Saxidomus giganteus (Gillinkin et al., 2005). However, without a clear understanding of vital effects of each species, it is difficult to know when the 'recording' of environments is accurate (Weiner and Dove, 2003).

$\mathrm{Sr} / \mathrm{Ca}$ and $\mathrm{Ba} / \mathrm{Ca}$ ratios show a moderate to strong correlation in the prismatic layer, with significance levels $<0.001$ in all samples excluding SC1A. One explanation for the strong correlation seen between $\mathrm{Sr} / \mathrm{Ca}$ and $\mathrm{Ba} / \mathrm{Ca}$ ratios in different layers of pāua could be the similar pathways that $\mathrm{Sr}^{2+}$ and $\mathrm{Ba}^{2+}$ travel from the external medium, through the mantle epithelium, to the extrapallial fluid ready for biomineralisation (Carré et al., 2006). However, high growth rates and other environmental conditions could also explain such correlations (Carré et al., 2006). Moderate correlations of Sr/Ca against B/Ca ratios, with coefficients between $0.31-0.50$ and high significance $(p<0.001)$ are seen in the prismatic layer of five samples. Similar relationships were seen in a shell of $C$. amurensis in studies by Takesue et al. (2008). It was suggested that B/Ca and $\mathrm{Sr} / \mathrm{Ca}$ may have similar transportation through the mantle epithelial channels as $\mathrm{Sr}$.

Both Naylor et al. (2007) and Kim and Hudson (2007) suggest that oxygen isotope $\left(\delta^{18} 0\right)$ profiles within pāua shells reflect water temperatures at the time of precipitation. The application of $\delta^{18} 0$ mimics the relationship of ambient water. Stable isotope analysis of wild pāua samples as a 'temperature' gauge would help further understand if $\mathrm{Mg} / \mathrm{Ca}$ ratios have any underlying environmental influence when the carbonate shell is being formed. 


\subsection{PĀUA AS AN ARCHIVE FOR POST POLLUTION EVENTS}

Trace element/Ca ratios have been recorded at high temporal resolutions within the shell samples of pāua with results presented in section 4.2. The purpose of analysing trace metals in addition to $\mathrm{Sr}$ and $\mathrm{Mg}$ (e.g. $\mathrm{Zn} / \mathrm{Ca}, \mathrm{Pb} / \mathrm{Ca}$ and $\mathrm{Al} / \mathrm{Ca}$ ratios) was to investigate whether pāua have the potential to be a bioindicator of the ambient environments in which the pāua lived. Boening (1999) highlighted the key characteristics (Table 5.3) that are important for an organism to be potentially used as a bioindcator.

Tolerance to a wide range of metal exposures; ability to accumulate metals without suffering mortality

Sedentary habits; slow and limited range of movement

Sufficient life span to allow for sampling of more than a one year class

Abundance in the study area

Sufficient size to allow chemical analysis of tissue samples

Hardiness; ability to remain healthy during sampling and laboratory incubation

Relative ease of sampling and identification

High metal accumulation rates

Responsiveness to changes in metal exposure

Table 5.3. The key characteristics for useful bioindicator organisms (Boening, 1999).

Coastal zones and other aquatic environments in which pāua live, receive large amounts of metal pollution as a result of human industrial and agricultural activity (Beldi et al., 2006; Luoma, 1989; Protasowicki et al., 2008). Any metals incorporated into the carbonate structure can be assumed to have been taken up directly from the environment and actively metabolised by the pāua. The presence of some metals ( $\mathrm{Zn}, \mathrm{Pb}$ and $\mathrm{Al}$ ) in the environment is a serious problem due to their toxicity and ability for available metals to accumulate in living organisms (bioavailability) (Beldi et al., 2006; Brooks and Rumsby, 1965; John and Leventhal, 2005). Pāua are exposed to these trace metals through ingestion from either the surrounding aquatic medium or from food intake (Luoma, 1989; Rainbow, 1997; Rainbow, 2002). The fate of the trace metal is 
dependent on the physiology of the animal, specifically, as to whether the metal is to be used for an essential metabolic purpose, excreted, bond with biomolecules or stored in the body or shell (Rainbow, 2002). The substitution of such trace metals for $\mathrm{Ca}^{2+}$ ions can only occur once the elements reach the extrapallial fluid, where they can then be incorporated into the carbonate lattice. Measuring trace metal chemistry will help provide an indication of the extent of magnitude of environmental contamination introduced into the water system (Tynan et al., 2005). The bioaccumulation of such metals can have toxic effects to both pāua and also humans who consume them (Protasowicki et al., 2008).

\subsubsection{Element/Ca ratios at Moa Point}

Pāua from Moa Point (sample MP02A) were specifically investigated to examine how the trace elements that come out of the Moa Point sewage outlet would be recorded in the shell. Mean trace element/Ca ratios from the high temporal resolution transect of the prismatic layer of MP02A show significantly higher $\mathrm{Pb} / \mathrm{Ca}, \mathrm{Al} / \mathrm{Ca}$ and $\mathrm{Mn} / \mathrm{Ca}$ ratios compared with the other shells analysed in this study (Fig. 4.1a and 4.1b), suggesting an increase of such elements in the ambient environment around Moa Point The high temporal resolution analysis of the element/Ca ratios of MP02A shows stable fluctuations of element/Ca whereas other samples show more irregular changes. $\mathrm{Mn} / \mathrm{Ca}, \mathrm{Ba} / \mathrm{Ca}, \mathrm{Zn} / \mathrm{Ca}$ and $\mathrm{Pb} / \mathrm{Ca}$ ratios were plotted against the temperature data from NIWA, using daily growth rates of $0.043 \mathrm{~mm} /$ day (Table 5.2). The harvesting of the animal was on December 31, 2009. The temperature given for the dates between May 2008 and December 2009 show the increases of $\mathrm{Zn} / \mathrm{Ca}$ and $\mathrm{Pb} / \mathrm{Ca}$ ratios coincide with the colder months. Other samples show similar element/Ca ratio relationships (figure 5.7b).

Peak element/Ca ratio occurs between the months of June and October 2008 in sample MP02A. These months are in the winter season and exhibit increased wave action and energy from the increase frequency of storm events and colder, windier weather. The increase of element/Ca ratios could be due to many sources. Firstly, peak discharge flow at Moa Point Sewage Plant can increase due 
to storm water entering the plant, which will increase the flux of trace elements into the ambient environment. The increase in $\mathrm{Pb} / \mathrm{Ca}$ could also be a result of increased terrestrial run off from heavy rains. The increase of $\mathrm{Mn} / \mathrm{Ca}$ and $\mathrm{Ba} / \mathrm{Ca}$ ratios could then be caused by nutrient blooms related to the increase of trace metals input into the system by the sewage outlet.

The increase of element/Ca ratios can also be due to desorption of bioavailable trace metals from sediments. Storm events can cause turbulent environments which can cause the resuspending of sediments (Gillikin et al., 2005). The trace elements can then be taken up by the mollusc and will contribute to the elevated element/Ca ratios in shell material. Where profiles show sudden increases in element/Ca ratios, this could be due to many factors. Increase in metal content in Cerastoderma edule was explained by Price and Pearce (1997) in three ways: (1) by brief periods of extreme pollution resulting from increase of water and sediment input into a region; (2) disturbances and remobilisation of existing particulate metals due to storm related events; and (3) an increase of sediments and elements due to anthropogenic activity. Any of these examples could provide information on the trace element/Ca ratios seen in the analysis of the prismatic layer. As discharges of effluent occur monthly, the disturbances of existing particulate material in the windier and stormier months could produced the anomalies in trace metal/Ca ratios in the MP02A shell.

Studies of pollution risk assessment require a comprehensive comparative study an ecosystem's response to nutrient increase in a localised environment (Brasier, 1995). It is also important to consider why trace element chemistry could be elevated in the environment, but it is also important to examine why trace element/Ca ratios are increased in the carbonate shell. Certain quantities of trace metals are essential in the body of aquatic invertebrates to meet metabolic needs, however, excessive amounts can potentially be toxic, with the need for excretion or detoxification (Rainbow, 2002).

Increases in local bioavailability of a trace metal, whether dissolved or in the diet, can cause an increase in the uptake rate of that particular metal into the body of the species (Rainbow, 2002). As discussed in Section 5.3.1, the uptake of feed of macro-algae for pāua is highest in winter (Poore, 1972a), with macro- 
algae also taking in a sufficient amount of trace metals as well (Phillips and Rainbow, 1988). Metal accumulation in a prey species, including the macroalgae, has the potential to be taken up by the pāua and accumulated in the soft tissue and shell depending on the accumulation pattern and uptake channels of particular trace metals (Rainbow, 2002). This could explain the elevated Zn/Ca and $\mathrm{Pb} / \mathrm{Ca}$ ratios seen in MP02A and other samples (Fig. 5.7a,b). With excessive uptake of trace metals, a threshold can be reached where an equivalent amount of trace elements are excreted to match the rate of uptake (Rainbow, 2002). This threshold can also deliver toxic effects on to the aquatic organism and cause metabolic decline. This could explain a double peak of $\mathrm{Zn} / \mathrm{Ca}, \mathrm{Mn} / \mathrm{Ca}$ and $\mathrm{Pb} / \mathrm{Ca}$ ratios seen in around the months of July and October for in both 2008 and 2009, however a greater knowledge of the accumulation pattern of pāua for $\mathrm{Zn}, \mathrm{Pb}$ and $\mathrm{Mn}$ would be essential in order to establish this. Before any inference on metal contamination in the shell can be made, a relationship between the trace metal chemistry in the environment and the flesh of the pāua needs to be established. 


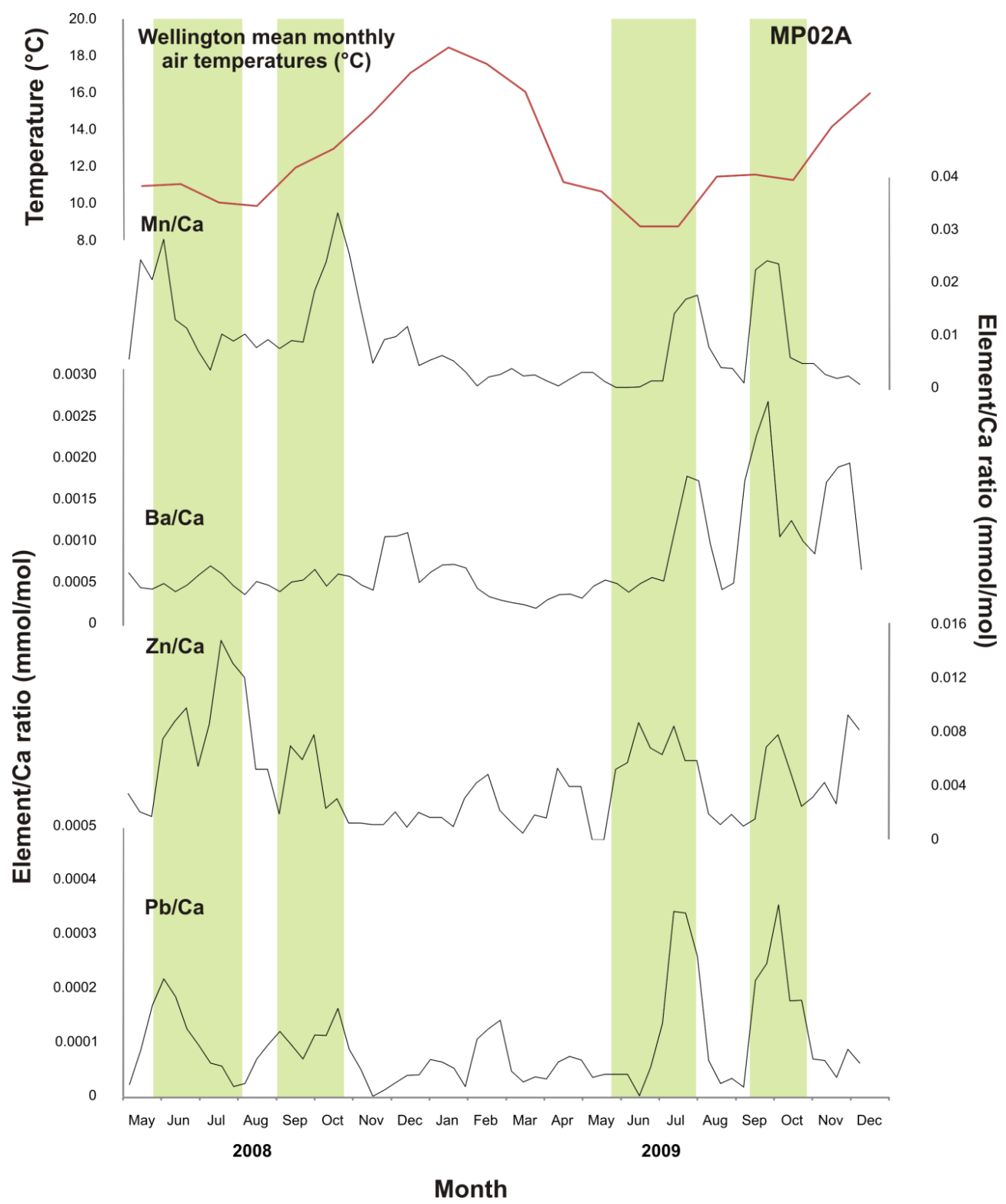

Fig. 5.7a. Element/Ca ratios of sample MP02A compared with the mean monthly air temperatures in Wellington (NIWA) from May 2008 - December 2009. The green bars represent the higher element/Ca ratios which correspond to the colder temperature months. 

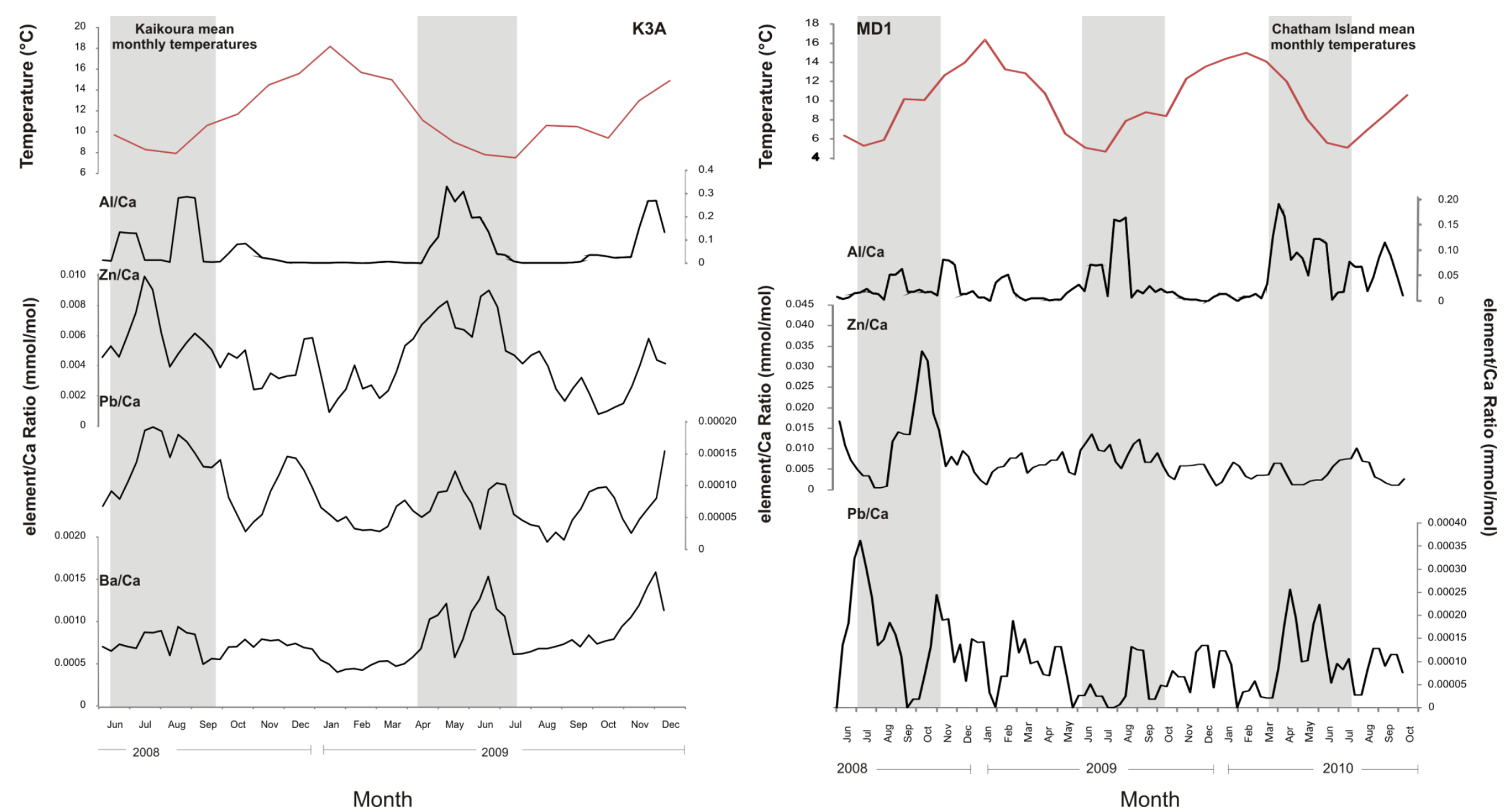

Fig 5.7b. Element/Ca ratios of sample K3A (left panel) and MD3 (right panel) compared with the NIWA mean monthly air temperatures of the sampling locations (Kaikoura and the Chatham Islands). The grey bars represent the higher element/Ca ratios which correspond to the colder temperature months. 
Soft tissue and shell trace element/Ca ratio can present similar results. $\mathrm{Pb}$ levels in whole shells of the New Zealand cockle Austrovenus stutchburyi were also seen comparable to those in the soft tissue (Bellotto and Miekeley, 2007; Richardson et al., 2001). Anderlini (1992) studied the effect of sewage from Wellington Harbour on the trace metal concentrations in the soft tissue of mussels Mytilus edulis aoteanus and Perna canaliculus collected from Fitzroy Bay. Collections were made once a month during February 1986 through to June 1987. Peaks were seen in the $\mathrm{Zn}, \mathrm{Mn}$ and $\mathrm{Pb}$ concentrations within the $P$. canaliculus during the study period. Smaller peaks were also seen to occur in March and April (Fig. 5.8).

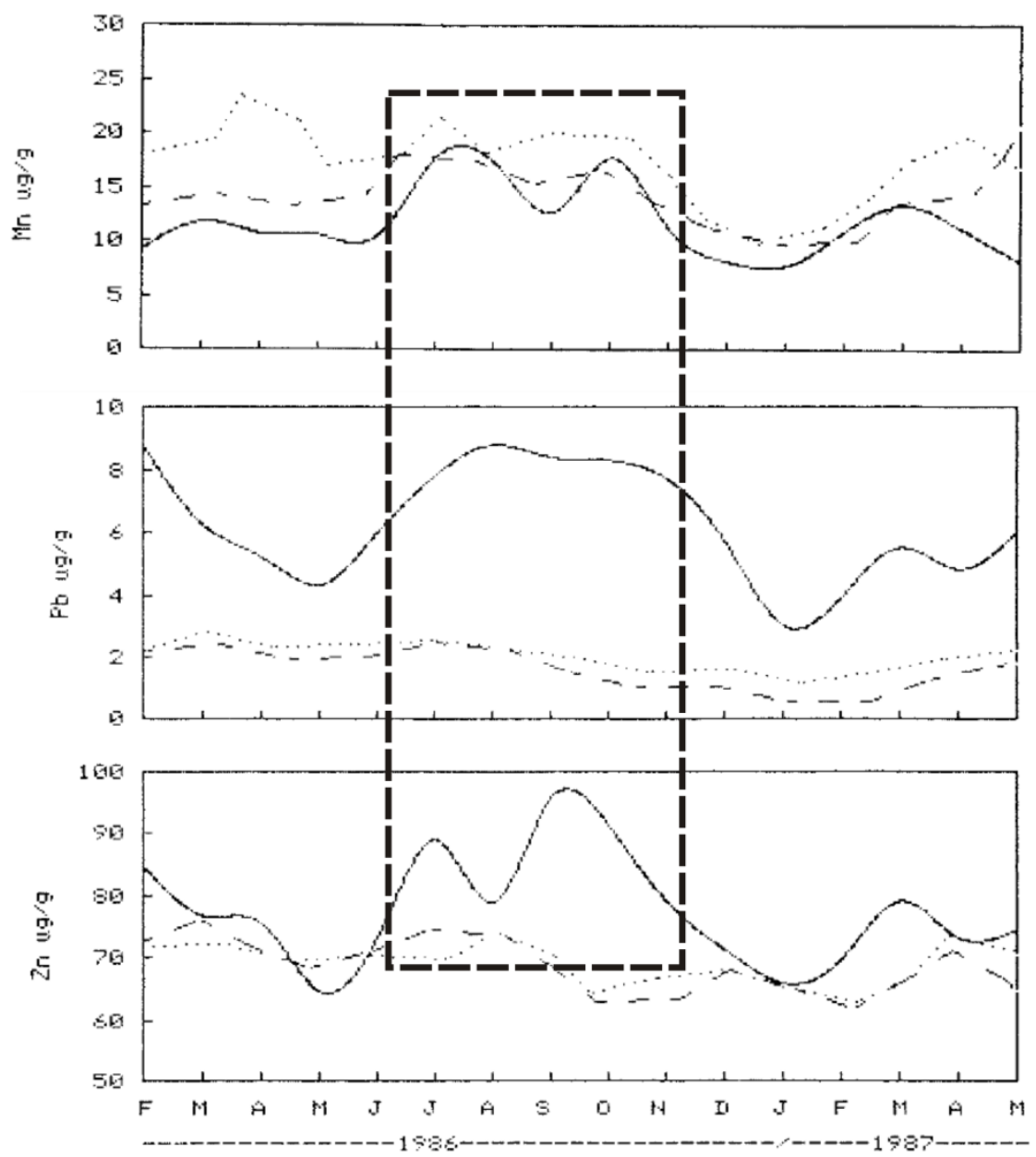

Fig. 5.8. $\mathrm{Mn}, \mathrm{Pb}$ and $\mathrm{Zn}$ concentrations recorded in Perna canaliculus soft tissue from multiple locations at varying distances from the sewage outsource at Fitzroy Bay (Anderlini, 1992). The dashed box represents the concentrations between the months of June to November 1986 showing the double spike in $\mathrm{Mn}$ and $\mathrm{Zn}$ which can also been seen in the same months as that seen in MP02A (Fig. 5.8a). The Mn peaks lag that of $\mathrm{Zn}$ and Pb. 
Beldi et al (2006) also found the highest recorded $\mathrm{Zn}$ concentrations in the bivalve Donax trunculus occurred during winter. The application of this in pāua does show promising results, and could potentially be explored at a higher temporal resolution. Metal contaminants, however, have different physiological routes of uptake available to them (Protasowicki et al., 2008). There are also many other issues that may corrupt the element/Ca ratios recorded in the shell. Pāua live in high energy environments in rocky coastal settings (Wells et al., 1998). The wave action and storm surges can disturb sediment and suspend contaminated material, which will possibly desorb the sediment bound metals and increase the trace metal bioavailable for the pāua to uptake (Boening, 1999). It has also been shown by Donovan and Taylor (2008) that wave action can cause increased metabolic demands and slower growth rates. 


\subsection{THE NACREOUS LAYER AS A USEFUL ARCHIVE OF PAST ENVIRONMENTAL CONDITIONS?}

Shell growth is important to understanding the trace element chemistry seen in the nacreous layer of the shell. Element/Ca ratios are comparable across different profiles throughout different locations within the nacre. Sr/Ca ratio were almost always comparable in all samples, showing that similar signals are recorded in the same location across transects of the nacre. This can be attributed to the longitudinal growth of the nacre (Fig. 5.9) (Heinemann et al., 2011).

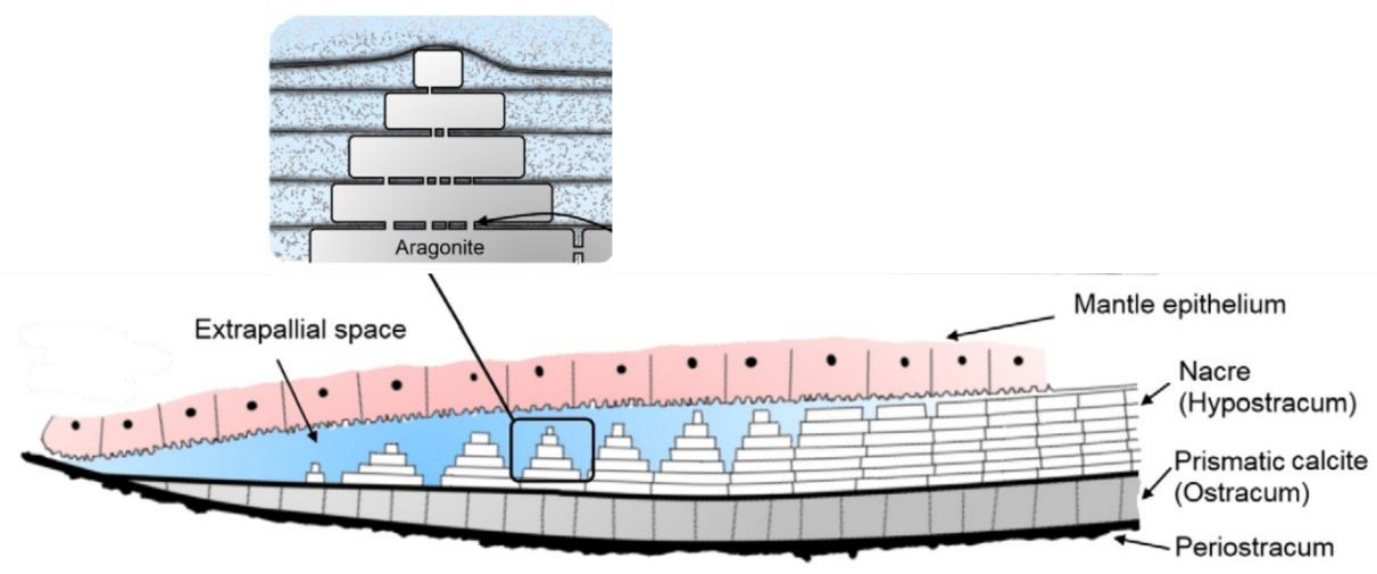

Fig. 5.9. A schematic vertical cross section of the outer mantle edge and growing shell in Haliotis spp., taken from Heinemann et al. (2011). The mantle epithelium controls the composition of the extrapallial fluid from where the shell is biomineralised. The inset diagram shows nacre growth.

This study failed to produce a clear trace element/Ca correlation between the nacreous layer and the prismatic layer and/or the ambient environment, however, comparable relationships were seen between the same trace element/Ca ratios from different transect locations of the nacreous layer in the same shell sample. This shows that the nacreous layer is useful at recording a similar signal or element/Ca ratio across the same profile whereas the chemistry of an individual growth band within the prismatic layer is variable (section 5.6). The strongest comparable relationships were seen in $\mathrm{Sr} / \mathrm{Ca}$ and $\mathrm{Ba} / \mathrm{Ca}$, which are more readily substituted for $\mathrm{Ca}$ into the aragonite crystal lattice, due to their large ion size (Section 5.1). The comparable nature of $\mathrm{Sr} / \mathrm{Ca}$ 
and $\mathrm{Ba} / \mathrm{Ca}$ ratios with each varying transect can be put down to their stronger affinity of these ions to be taken into the shell structure more easily than other elements.

The significant correlation between $\mathrm{Sr} / \mathrm{Ca}$ and $\mathrm{Mg} / \mathrm{Ca}$ ratio is observed in more samples $(n=12)$ in the nacreous layer than prismatic layer $(n=8)$. As $\mathrm{Mg}^{2+}$ has a smaller ionic radius than $\mathrm{Sr}^{2+}$ it be accomidated more readily in the crystal lattice of aragonite (nacre) than $\mathrm{Sr}^{2+}$ into calcite (prismatic layer).

The thick dark bands seen in the nacreous layer of other Haliotis species $(\mathrm{H}$. rufescens and $\mathrm{H}$. fulgens) were identified as protein layers or the conchiolin (Fig. 5.10) (Lin and Meyer, 2005). These protein layers were interpreted as being formed within the shell layer during periods of little calcification or growth cessation, and could represent seasonal changes and aging of the animal (Lin and Meyer, 2005). However, this still needs to be validated (Pirker and Schiel, 1993).
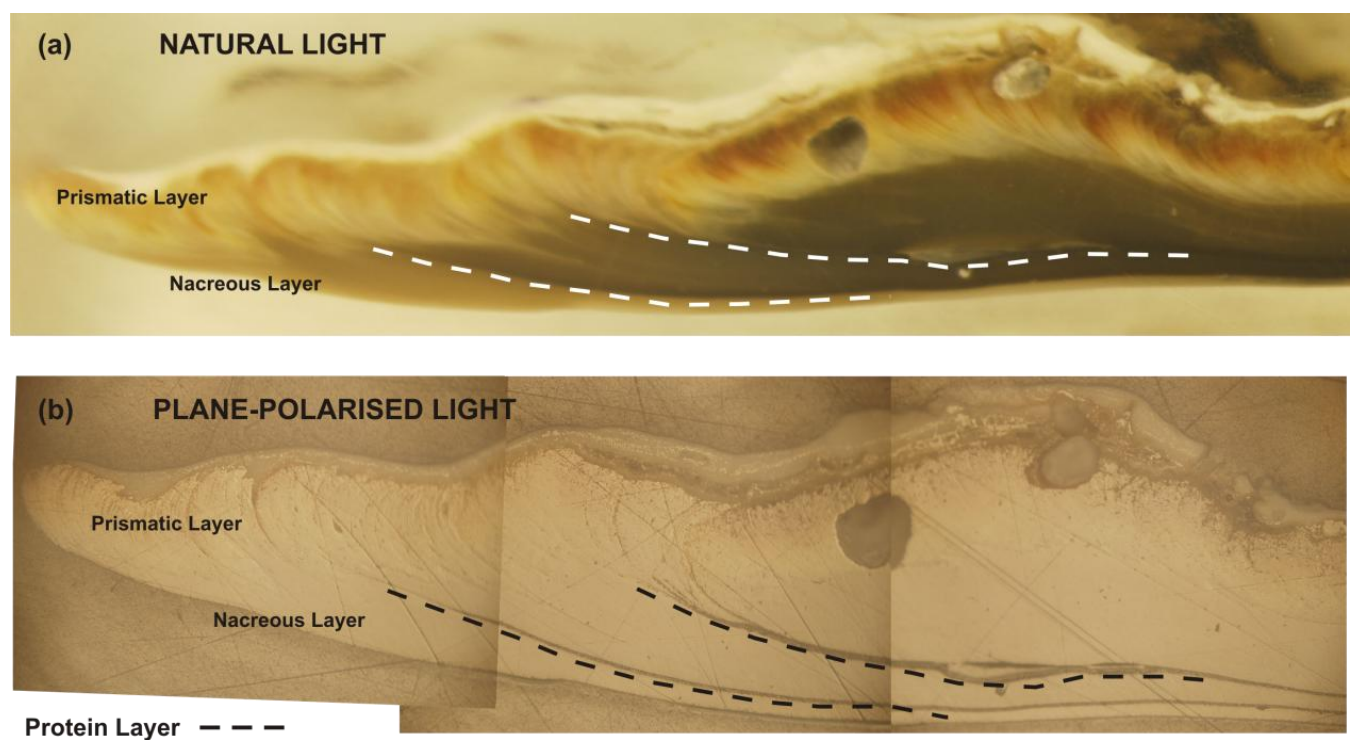

Fig. 5.10. Sample MP02A: (a) taken in natural light with the protein layers represented with white dashes and; (b) taken in plane polarised light with the protein layers represented by black dashes.

The conchiolin could also have formed when pāua have been put in undesirable conditions including suboptimal temperatures, environments or stressful situations, as these may inhibit $\mathrm{CaCO}_{3}$ secretion and may stimulate the pāua to release protein matter. Laser ablation spots analysed on the black lines 
presented high anomalous results in trace element chemistry. The black lines also formed an indent in the sample, which could have accumulated foreign detritus and other matter which could cause anomalous trace element/Ca ratios during the preparation phase of the sample.

The anomalies were deleted from the results Figures 4.4a-4.4g. Temperature results were hard to compare with the element/Ca ratio, as there is no definite knowledge of the rate of precipitation of the nacreous layer.

\subsection{SUMMARY}

Evident differences in trace element/Ca ratios between the two layers; prismatic and nacreous, can be attributed primarily to the structural dimensions of the crystal lattice. Smaller cations will more readily substitute for $\mathrm{Ca}^{2+}$ in calcite and larger cations will more readily substitute for $\mathrm{Sr}^{2+}$ in aragonite. $\mathrm{Sr} / \mathrm{Ca}$ ratios in the samples from OBL produce an inverse relationship with growth rates whereas $\mathrm{Mg} / \mathrm{Ca}$ ratios increase with both increasing temperatures and growth rates. Shell samples collected from the wild, however, are harder to correlate with environmental factors. This could be due to more stresses including predation or minimum and maximum thermal temperatures that cause the metabolism of the pāua to slow or shut down, altering the potential environmental record. Shells collected from the coastal areas however do provide some insight into anthropogenic contamination to a region through increased trace metal/Ca ratios seen within the shell. Elevated $\mathrm{Mn} / \mathrm{Ca}$ and $\mathrm{Ba} / \mathrm{Ca}$ could also provide information within pāua shells of increased nutrients within an area.

Dark banding within the prismatic layer of some pāua shell samples seem to correlate well with low $\mathrm{Mg} / \mathrm{Ca}$ ratios where lighter coloured shell seem to coincide with increased $\mathrm{Mg} / \mathrm{Ca}$ ratios. The colouration of paua shells has seen to be attributed due to diet. Low $\mathrm{Mg} / \mathrm{Ca}$ ratios during darker shell material could indirectly reflect temperature as pāua increase their food intake in winters compared to any other time of year. The nacreous layer failed to produce concise information on environmental conditions within the pāua, however, 
showed reproducible element/Ca ratios along different transects of the nacreous layer. The nacre shell growth initially begins laterally before growth continues towards the epithelium. This growth style has been explained to look like a brick and mortar and can also explain why lateral similarities are recorded in the element/Ca ratios. The analysis of individual growth bands also highlighted that the most stable element/Ca ratios are best analysed between the middle of the prismatic layer and close to the prismatic-nacreous boundary. 


\section{CONCLUSIONS}

The main objectives of this thesis were to develop and apply in situ geochemical techniques to investigate whether pāua (Haliotis iris) could potentially be used as a proxy for present environmental conditions and past environmental change. The following are the key outcomes of this work:

- The prismatic (calcitic) and nacreous (aragonitic) layers of pāua shells have distinctive trace element chemistries reflecting the ease of incorporation of different trace elements into calcite and aragonite mineral structures.

- Individual pāua from the same sites generally have reproducible shell chemistries.

- The incorporation of Mg in pāua shells appears to be influenced by a number of factors. Two primary factors include temperature and growth rate.

- The incorporation of Sr in pāua shells has an inverse relationship with shell growth rate.

- Environmental controls on trace element/Ca ratios of pāua collected from the wild are too weak to develop suitable proxies with the available data. Vital effects play a large role on the trace element chemistry and interrupt the potential record that could be documented.

- $\mathrm{Mg} / \mathrm{Ca}$ ratios appear to co-vary with the colouration of the pāua shells that may reflect dietary changes related to seasonality and ocean temperatures.

- Trace metals such as $\mathrm{Pb} / \mathrm{Ca}$ and $\mathrm{Zn} /$ Ca ratios in some pāua shells have show seasonal variations and with additional information has the potential to be used as a proxy for environmental contamination and anthropogenic pollution events. Increases of $\mathrm{Mn} / \mathrm{Ca}$ and $\mathrm{Ba} / \mathrm{Ca}$ ratios have also been observed to increase with increased trace metals/Ca ratio which could reflect primary productivity responses to environmental controls. 


\section{SUGGESTIONS FOR FURTHER WORK}

This research has raised further questions regarding the use of the geochemistry of pāua and its potential application as an archive of past and present environmental change. In particular, a lack of published information regarding interactions of pāua and its environment has restricted an in-depth linking of the measured trace element/Ca ratios to environmental conditions.

Firstly, the shell samples measure from OceaNZ Blue Ltd showed promising relationships between $\mathrm{Mg} / \mathrm{Ca}$ and $\mathrm{Sr} / \mathrm{Ca}$ ratios and temperature and growth rate, however, samples from the wild were harder to constrain or failed to produce similar results. The $\delta^{18} 0$ of paua has seen to reflect ambient temperatures of the ambient water during the time of precipitation (Naylor et al., 2007). Thus, an important area for future research would be to link $\delta^{18} 0$ measurements with element/Ca ratio data to examine the different controls of Mg uptake into pāua shells.

The comparison of the chemistry of fossil pāua with modern pāua might also allow for a detailed evaluation of environment changes at particular coastal sites around New Zealand. A second important line of research would thus be to examine how the trace metal chemistry differs in modern pāua compared with pāua from midden sites post-māori arrival to New Zealand and recent shells.

Lastly, a comprehensive understanding between the trace element chemistry of the ambient environment and the soft tissue of pāua can help provide additional information into the potential of pāua shells as a biomonitor and a proxy for environmental contamination and anthropogenic pollution events. 


\section{REFERENCES}

Addadi, L., Joester, D., Nudelman, F. and Weiner, S. (2006). Mollusk Shell Formation: A source of new concepts for understanding biomineralization processes. Chemistry- A European Journal, 12: 980-987.

Allen, V. J., Marsden, I. D., Ragg, N. L. C. \& Gieseg, S. (2006). The effects of tactile stimulants on feeding, growth, behaviour, and meat quality of cultured Backfoot abalone, Haliotis iris. Aquaculture, 257: 294-308.

Anadón, P., Moscariello, A., Rodríguez-Lázaro, J. \& Filippi, M.L. (2006). Holocene environmental changes of Lake Geneva (Lac Léman) from stable isotopes $\left(\delta^{13} \mathrm{C}, \delta^{18} \mathrm{O}\right)$ and trace element records of ostracod and gastropod carbonates. Journal of Paleolimnology, 35: 593-616.

Anadón, P., Utrilla, R., Vázquez, A., Martín-Rubio, M., Rodriquez-Lázaro, J. \& Robles, F. (2008). Journal of Paleoliminology, 39: 399-419.

Anand, P., Elderfield, H. \& Conte, M. (2003). Calibration of Mg/Ca thermometry in planktonic foraminifera from a sediment trap time series.

Paleoceanography, 18

Anderlini, V. C. (1992). The effect of sewage on trace metal concentrations and scope for growth in Mytilus edulis aoteanus and Perna canaliculus from Wellington Harbour, New Zealand. The Science of the Total Environment, 125: 263-288.

Arai, T., Maeda, M., Yamakawa, H., Kamatani, A., Ohji, M \& Miyazaki, N. (2003). Uptake and elimination of trace metals in shells of abalone Haliotis spp. Bulletin of Environmental Contamination and Toxicology, 71: 75-82.

Barker, S., Cacho, I., Benway, H. \& Tachikawa, K. (2005). Planktonic foraminiferal $\mathrm{Mg} / \mathrm{Ca}$ as a proxy for past oceanic temperatures: a methodological overview and data compilation for the Last Glacial Maximum. Quaternary Science Reviews, 24: 821-834.

Bauwens, M., Ohlsson, H., Barbé, K., Beelaerts, V., Schoukens, J. \& Dehairs, F. (2010). A nonlinear multi-proxy model based on manifold learning to reconstruct water temperature from high resolution trace element profiles in biogenic carbonates. Geoscientific Model Development, 3: 653-667.

Baynes, A. L. (2009). Reproductive effects in two species of native freshwater gastropod mollusc exposed to $17 \beta$ - oestradiol or an environmentally relevant mixture of oestrogenic chemicals in outdoor mesocosms. Thesis (PhD). Brunel University.

Beldi, H., Gimbert, F., Maas, S., Scheifler, R. \& Soltana, N. (2006). Seasonal variations of $\mathrm{Cd}, \mathrm{Cu}, \mathrm{Pb}$ and $\mathrm{Zn}$ in the edible mollusc Donax trunculus (Mollusca, Bivalvia) from the gulf of Annaba, Algeria. African Journal of Agricultural Research, 1: 85-90. 
Bellotto, V. R. \& Miekeley, N. (2007). Trace metals in mussel shells and corresponding soft tissue samples: a validation experiment for the use for Perna perna shells in pollution monitoring. Analytical and Bioanalytical Chemistry, 389: 769-776.

Benton, G. S. (1974). Atmosphere and Oceans, in Oceanography: The last frontier, Vetter, R. C. (Eds). Washington, Voice of America. 241-251.

Boening, D. W. (1999). An evaluation of bivalves as biomonitors of heavy metals pollution in marine waters. Environmental Monitoring and Assessment, 55: 459-470.

Boles, J. R., Landis, C. A. \& Dale, P. (1985). The Moeraki Boulders; anatomy of some septarian concretions. Journal of Sedimentary Research, 55: 398-406.

Bradley, R. S. (2000). Past global changes and their significance for the future. Quaternary Science Reviews, 19: 391-402.

Brasier, M. (1995). Fossil indicators of nutrient levels.1: Eutrophication and climate change. Geological Society London Special Publications, 83

Bresler, V., Abelson, A., Fishelson, L., Feldstein, T., Rosenfeld, M. \& Mokady, O. (2003). Marine molluscs in environmental monitoring. I. Cellular and molecular responses. Helgoland Marine Research, 57: 157-165.

Brooks, R. R. \& Rumsby, M. G. (1965). The biogeochemistry of trace element uptake by some New Zealand Bivalves. Limnology and Oceanography, 10(4): 521-527.

Broecker, W. (1997). Thermohaline circulation, the achilles heel of our climate system: will man-made $\mathrm{CO}_{2}$ upset the current balance? Science, 278(5343): 1582-1588.

Broecker, W. (2001). Was the Medieval Warm Period global? Science, 291:14971499.

Broecker, W. (2002). The glacial world according to Wally. New York, Eldigo Press

Carré, M., Bentaleb, I., Bruguier, O., Ordinola, E., Barrett, N. T. \& Fontugne, M. (2006). Calcification rate influence on trace element concentrations in aragonitic bivalve shells: Evidences and mechanisms. Geochimica et Cosmochimica Acta, 70: 4906-4920.

Carroll, M. L., Johnson, B. J., Henkes, G. A., McMahon, K. W., Voronkov, A., Ambrose Jr. W. G. \& Denisenko, S. G. (2009). Bivalves as indicators of environmental variation and potential anthropogenic impacts in the southern Barents Sea. Marine Pollution Bulletin, 59(4-7): 193-206.

Carroll, M. \& Romanek, C, S. (2008). Shell layer variation in trace element concentration for the fresh water bivalve Elliptio complanata. Geo-Marine Letters, 28: 369-381. 
Carter, J. G. (1980). Environmental and biological controls of bivalve shell mineralogy and microstructure, in Skeletal growth of aquatic organisms. Rhoads, D. C. \& Lutz, R. A (Eds). New York, Plenum Press. 69-114.

Chave, K. E. (1954). Aspects of the biogeochemistry of Magnesium 2. Calcareous sediments and rocks. The Journal of Geology, 62(6): 587-599.

Chave, K. E. (1984). Physics and chemistry of Biomineralization. Annual Review of Earth and Planetary Sciences, 12: 293-305.

Chen, T., Neville, A. \& Yuan, M. (2006). Influence of $\mathrm{Mg}^{2+}$ on $\mathrm{CaCO}_{3}$ formation Bulk precipitation and surface deposition. Chemical Engineering Science, 61: 5318-5327.

Clark, F. W. \& Wheeler, W. C. (1922). The inorganic constituents of marine invertebrates. U.S Geological Survey Professional Paper, 124: 1-62.

Clark, M. J. \& Randal, J. A. (2011). A first course in applied statistics, $2^{\text {nd }}$ Edition. North Shore. Pearson New Zealand Ltd.

Clark, P. U., Pisias, N. G., Stocker, T. F. \& Weaver, A. J. (2002). The role of the thermohaline circulation in abrupt climate change. Nature, 414:863-869.

Corrège, T. (2006). Sea surface temperature and salinity reconstruction from coral geochemical tracers. Palaeogeography, Palaeoclimatology, Palaeoecology, 232: 408-428.

Crenshaw, M. A. (1980). Mechanisms of shell formation and dissolution, in Skeletal growth of aquatic organisms, Rhoads, D. C. \& Lutz, R. A. (Eds). New York, Plenum Press. 115-132.

Cusack, M. \& Freer, A. (2008). Biomineralization: Elemental and organic influences in Carbonate systems. Chemical Reviews, 108: 4433-4454.

Davies, N. A., Taylor, M. G. \& Simkiss, K. (1997). The influence of particle surface characteristics on pollutants metal uptake by cells. Environmental Pollution, 92: 179-184.

Davis, C. (2008). Investigation of regulatory roles of water soluble proteins in pāua (Haliotis iris) shell development. Thesis, (Hon). Victoria University of Wellington.

Dodd, J. R. (1965). Environmental control of strontium and magnesium in Mytilis. Geochimica et Cosmochimica Acta, 29: 385-398.

Dodd, J. R. (1967). Magnesium and strontium in calcareous skeletons: A Review. Journal of Paleontology, 41: 1313-1329.

Donovan, D. \& Taylor, H. H. (2008). Metabolic consequences of living in a waveswept environment: Effects of simulated wave forces on oxygen consumption, heart rate, and activity of the shell adductor muscle of the abalone Haliotis iris. Journal of Experimental Marine Biology and Ecology, 354: 231-240. 
Elliot, M., Welsh, K., Chilcott, C., McCulloch, M., Chapelle, J. \& Ayling, B. (2009). Profiles of trace elements and stable isotopes derived from giant longlived Tridacna gigas bivalves: Potential applications in paleoclimate studies. Palaeogeography, Palaeoclimatology, Palaeoecology, 280: 132-142.

Elderfield, H. \& Ganssen, G. (2000). Past temperature and $\delta^{18} 0$ of surface ocean waters inferred from foraminiferal Mg/Ca ratios. Nature, 405: 442-445.

Estes, J. A., Lindberg, D. R. \& Wray, C. (2005). Evolution of large body size in abalones (Haliotis): patterns and implications. Paleobiology, 31: 591-607.

Freitas, P. D., Clarke, L. J., Kennedy, H., Richardson, C. A. \& Abrantes, F. (2006). Environmental and biological controls on elemental $(\mathrm{Mg} / \mathrm{Ca}, \mathrm{Sr} / \mathrm{Ca}$ and $\mathrm{Mn} / \mathrm{Ca}$ ) ratios in shells of the king scallop Pecten maximus. Geochimica et Cosmochimica Acta, 70: 5119-5133.

Freitas, P., Clarke, L. J., Kennedy, H. \& Richardson, C. (2005). Mg/Ca, Sr/Ca, and stable-isotopes $\left(\delta^{18} 0\right.$ and $\left.\delta^{13} \mathrm{C}\right)$ ratio profiles from the fan mussel Pinna nobilis: Seasonal records and temperature relationships. Geochemistry, Geophysics, Geosystems, 6

Foster, P. \& Chacko, J. (1995). Minor and trace elements in the shell of Patella vulgata (L). Marine Environmental Research, 40(1): 55-76.

Foster, P. \& Cravo, A. (2003). Water, Air, and Soil Pollution, 145: 53-65.

Fuge, R., Palmer, T. J., Pearce, N. J. G. \& Perkins, W. T. (1993). Minor and trace element chemistry of modern shells: a laser ablation inductively coupled plasma mass spectrometry study. Applied Geochemistry, 2: 111-116.

Gaetani, G. A. \& Cohen, A. L. (2006). Element partitioning during precipitation of aragonite from seawater: A framework for understanding paleoproxies. Geochimica et Cosmochimica Acta 70: 4617-4634.

Gardner, J. P. A., Skibinski, D. O. F. \& Bajdik, C. D. (1993). Shell growth and viability differenes between the marine mussels Mytilus edulis (L.), Mytilus galloprovincialis (Lmk.), and their hybrids from two sympatric populations in S.W. England. Biological Bulletin, 185: 405-416.

Gillikin, D. P. 2005. Geochemistry of Marine Bivalve Shells: the potential for paleoenvironmental reconstruction. Thesis, (PhD). Vrije Universiteit Brussel.

Gillikin, D. P., Dehairs, F., Lorrain, A., Steenmans, D., Baeyens, W. \& André, L. (2006). Barium uptake into the shells of the common mussel (Mytilus edulis) and the potential for esuarine paleo-chemistry reconstruction. Geochimica et Cosmochimica Acta, 70: 395-407.

Gillikin, D. P., Dehairs, F., Baeyens, W., Navez, J., Lorrain, A. \& André, L. (2005). Inter- and intra-annual variations of $\mathrm{Pb} / \mathrm{Ca}$ ratios in clam shells (Mercenaria mercenaria): A record of anthropogenic lead pollution? Marine Pollution Bulletin, 50: 1530-1540. 
Gillikin, D. P., Lorrain, A., Navez, J., Taylor, J. W., André, L., Keppens, E., Baeyens, W. \& Dehairs, F. (2005). Strong biological controls on Sr/Ca ratios in aragonitic marine bivalve shells. Geochemistry Geophysics Geosystems, 6

Goodkin, N. F., Hughen, K. A., Cohen, A. L. \& Smith, S. R. (2005). Record of Little Ice Age sea surface temperatures at Bermuda using a growth-dependent calibration of coral Sr/Ca. Paleoceanography, 20

Gray, B. E. \& Smith, A. M. (2004). Mineralogical variation in shells of the Blackfoot Abalone, Haliotis iris Mollusca: Gastropoda: Haliotideae), in Southern New Zealand. Pacific Science, 58: 47-64.

Guo, D. (2010). Microstructure and crystallography of abalone shells. Thesis (MSc) University of Glasgow.

Hargreaves, J. C. \& Annan, J. D. (2009). The importance of paleoclimate modelling for the improving predictions of future climate change. Climate of the Past Discussions, 5: 2053-2080.

Heath, P. (2006). Creating the right conditions for paua. Water and Atmosphere, 14: 12-13.

Heath, P. \& Moss, G. (2009). Is size grading important for farming the abalone Haliotis iris? Aquaculture, 290: 80-86.

Heinemann, F., Launspach, M., Gries, K. \& Fritz, M. (2011). Gastropod nacre: Structure, properties and growth - Biological, chemical and physical basics. Biophysical Chemistry, 153: 126-153.

Henderson, G. M. (2002). New oceanic proxies for paleoclimate. Earth and Planetary Science Letters, 203: 1-13.

Hess, P. \& Tsien, R. W. (1984). Mechanism of ion permeation through calcium channels. Nature, 309: 453-456.

Huang, X., Guo, F., Ke, C. \& Wang, W. (2010). Responses of abalone Haliotis diversicolor to sublethal exposure of waterborne and dietary silver and cadmium. Ecotoxicology and Environmental Safety, 73: 1130-1137.

Immenhauser, A., Nägler, T. F., Steuber, T. \& Hippler, D. (2005). A critical assessment of mollusc ${ }^{18} \mathrm{O} /{ }^{16} \mathrm{O}, \mathrm{Mg} / \mathrm{Ca}$, and ${ }^{44} \mathrm{Ca} /{ }^{40} \mathrm{Ca}$ ratios as proxies for Creataceous seawater temperature seasonality. Palaeogeography, Palaeoclimatology, Palaeoecology, 215: 221-237.

Intergovernmental Panel on Climate Change. (2007a). Chapter 1, Historical overview of climate change science, in Contribution of Working Group I to the Fourth Assessment Report of the Intergovernmental Panel on Climate Change, Solomon, S. D., Qin, D., Manning, M., Chen, Z., Marquis, M., Averyt, K. B., Tignor, M. \& Miller, H. L. (Eds.). Cambridge, Cambridge University Press. 93-127.

Intergovernmental Panel on Climate Change. (2007b). Chapter 5, Observations: Oceanic climate change and sea level, in Contribution of Working Group I to 
the Fourth Assessment Report of the Intergovernmental Panel on Climate Change, Solomon, S. D., Qin, D., Manning, M., Chen, Z., Marquis, M., Averyt, K. B., Tignor, M. \& Miller, H. L. (Eds.). Cambridge, Cambridge University Press. 385-431.

Intergovernmental Panel on Climate Change. (2007c). Chapter 11, Regional Climate Projections: Australia and New Zealand, in Contribution of Working Group I to the Fourth Assessment Report of the Intergovernmental Panel on Climate Change, Solomon, S. D., Qin, D., Manning, M., Chen, Z., Marquis, M., Averyt, K. B., Tignor, M. \& Miller, H. L. (Eds.). Cambridge, Cambridge University Press. 508-540.

Intergovernmental Panel on Climate Change. (no date). Organisation [Online] Available from: http://www.ipcc.ch/organization/organization.shtml [Accessed 5th February 2011]

John, D. A. \& Leventhal, J. S. (1995). Bioavailability of Metals, in Preliminary compilation of Geoenvironmental mineral deposit models, edited by Du Bray, F. A. Denver: U.S Geological Survey, 10-18.

Killingley, J. S. Berger, W. H. (1979). Stable isotopes in a mollusk shell: detection of upwelling events. Science, 205: 186-188.

Kim, S. W. \& Hudson, I. L. (2007). Tracking indices as measures of synchronization of isotopic temperature of NZ abalone shells with ambient water temperature. Australian Mathematical Sciences Institute Summer Symposium. 56-78.

Klein, R. T., Lohmann, K, C. \& Thayer, C. W. (1996a). Bivalve skeletons record sea-surface temperatures and $\delta^{18} \mathrm{O}$ via $\mathrm{Mg} / \mathrm{Ca}$ and ${ }^{18} \mathrm{O} /{ }^{16} \mathrm{O}$ ratios. Geology, 24(5): 415-418.

Klein, R. T., Lohmann, K. C., \& Thayer, C. W. (1996b). Sr/Ca and ${ }^{13} \mathrm{C} /{ }^{12} \mathrm{C}$ ratios in skeletal calcite of Mytilus trossulus: Covariation with metabolic rate, salinity and carbon isotopic composition of seawater. Geochimica et Cosmochimica Acta, 60(21): 4207-4221.

Krampitz, G. \& Graser, G. (1988). Molecular mechanisms of biomineralization in the formation of calcified shells. Angewandte Chemie International Edition, 27:1145-1156.

Krantz, D. E. (1990). Mollusk-isotope records of Plio-Pleistocene marine paleoclimate, U.S. Middle Atlantic Coastal Plain. Palaios, 5: 317-335.

Latal, C., Piller,W. P. \& Harzhauser, M. (2006). Small-scale environmental changes: indications from stable isotope of gastropods (Early Miocene, Korneuburg Basin, Austria). International Journal of Earth Sciences, 95: 95106.

Lazareth, C. E., Guzman, N., Poitrasson, F., Candaudap, F. Ortlieb, L. (2007). Nyctemeral variations of magnesium intake in the calcitic layer of a 
Chilean mollusc shell (Concholepas concholepas, Gastropoda). Geochimica et Cosmochimica Acta, 71: 5369-5383.

Lazareth, C. E., Vander Putten, E., André, L. \& Dehairs, F. (2003). High-resolution trace element profiles in shells of the mangrove bivalve Isognomon ephippium: a record of environmental spatio-temporal variations? Estuarine, Coastal and Shelf Science, 57: 1103-1114.

Lea, D. W. (2003). Elemental and isotopic proxies of past ocean temperatures, in Treatise on Geochemistry, Edited by Elderfield, H. Amsterdam. Elesvier. 6: 365-390.

Lear, C. H., Elderfield, H. \& Wilson, P. A. (2000). Cenozoic deep-sea temperatures and global ice volumes from $\mathrm{Mg} / \mathrm{Ca}$ in benthic foraminiferal calcite. Science, 287: 269-272.

Lear, C. H., Rosenthal, Y. \& Slowey, N. (2002). Benthic foraminifera Mg/Capaleothermometry: A revised core-top calibration. Geochimica et Cosmochimica Acta, 66: 3375-3387.

Leighton, D. \& Boolootian, R. A. (1963). Diet and growth in the black abalone Haliotis cracherodii. Ecology, 44: 227-238.

Lin, A. Y., Chen, P. \& Meyers, M. A. (2008). The growth of nacre in the abalone shell. Acta Biomaterialia, 4: 131-138.

Lin, A. \& Meyers, M. A. (2005). Growth and structure in abalone shell. Materials Science and Engineering, 390: 27-41.

Luoma, S. N. (1989). Can we determine the biological availability of sedimentbound trace elements? Hydrobiologia, 176/177: 379-397.

Marin, F. \& Luquet, G. (2004). Molluscan shell proteins. Comptes Redus Palevol, 3: 469-492.

Markich, S. J., Jeffree, R. A. \& Burke, P. T. (2002). Freshwater bivalves shells as archival indicators of metal pollution from a copper-uranium mine in tropical Northern Australia. Environmental Science and Technology, 36: 821-831.

GeoRem (no date). NISTSRM610: GeoRem preferred values [Online] Accessed from: http://georem.mpch-mainz.gwdg.de/sample query pref.asp [9th May 2010].

McCulloch, M., Mortimer, G., Esat, T., Xianhua, L., Pillans, B. \& Chappell, J. (1996). High resolution windows into early Holocene climate: $\mathrm{Sr} / \mathrm{Ca}$ coral records from the Huon Peninsula. Earth and Planetary Science Letters, 138: 169178.

McShane, P. E. (1997). Environmental effects of sea-based farming of paua (Haliotis spp.) and kina (Evechinus chloroticus). Conversation Advisory Science Notes No. 143, Department of Conservation, Wellington. 
McShane, P. E., Schiel, D. R., Mercer, S. F. \& Murray, T. (1994). Morphometric variation in Haliotis iris (Mollusca: Gastropoda): Analysis of 61 populations. New Zealand Journal of marine and Freshwater Research, 28: 357-364.

Meibom, A., Stage, M., Wooden, J., Constantz, b, r., Dunbar, R. B., Owen, A., Grumet, N., Bacon, C. R. \& Chamberlain, C. P. (2003). Geophysical Research Letters, 30: 1418-1422.

Ming, D. W. (2006). Carbonates, in Encyclopedia or Soil Science, Second Edition, edited by Lal, $\mathrm{R}$.

Ministry of Fisheries. (2007). Paua, Guidelines for gathering paua. [Online] Available from: http://www.fish.govt.nz/ennz/Recreational/Most+Popular+Species/Paua/ [Accessed 19th December 2009].

Mitsuguchi, T., Matsumoto, E., Abe, O., Uchida, T. \& Isdale, P. J. (1996). Mg/Ca thermometry in coral skeletons. Science, 274: 961-963.

Morse, J. W., Wang, Q. \& Tsio, M Y. (1997). Influences of temperature and Mg/Ca ratio on $\mathrm{CaCO}_{3}$ precipitates from seawater. Geology, 25(1): 85-87.

Naylor, J. R., Andrew, N. L. \& Kim, S. W. (2006). Demographic variation in the New Zealand abalone Haliotis iris. Marine and Freshwater Research, 57: 215-224.

Naylor, J. R., Manighetti, B. M., Neil, H. L. \& Kim, S. W. (2007). Validated estimation of growth and age in the New Zealand abalone Haliotis iris using stable oxygen isotopes. Marine and Freshwater Research, 58: 354362 .

New Zealand Seafood Industry Council. (no date). Paua. [Online] Available from: http://www.seafoodindustry.co.nz/n1119,205.html [Accessed 23 ${ }^{\text {rd }}$ March 2011].

OceaNZ Blue Ltd (no date). New Zealand, the ultimate environment [Online] Available from: http://www.oceanzblue.co.nz/nzfarm.aspx [Accessed 19th December 2009].

Olsen, D. (1968). Banding patterns of Haliotis rufescens as indicators of botanical and animal succession. Biological Bulletin, 134(1): 139-147.

Pearce, N. J. G. \& Mann, V. L. (2006). Trace metal variations in the shells of Ensis siliqua record pollution and environmental conditions in the sea to the west of mainland Britain. Marine Pollution Bulletin, 52: 739-755.

Pearce, N. J. G., Perkins, W. T., Westgate, J. A., Gorton, M. P., Jackson, S. E., Neal, C. R. \& Chenery, S. P. (1997). A compilation of new and published major and trace element data for NIST SRM 610 and NIST SRM 612 glass reference materials. The journal of Geostandards and Geoanalysis. 21: 115-144.

Peteet, D. 1995. Global Younger Dryas? Quaternary International, 28: 93-104. 
Phillips, D. J. H. \& Rainbow, P. S. (1989). Strategies of Trace Metal Sequestration in Aquatic Organisms. Marine Environmental Research, 28: 207-210.

Phillips, D. J. H. (1976). The common mussel Mytilus edulis as an indicator of pollution by zinc, cadmium, lead and copper. I. Effects of environmental variables on uptake of metals. Marine Biology, 38: 59-69.

Phillips, D. J. H. \& Rainbow, P. S. (1988). Barnacles and mussels as biomonitors of trace elements: a comparative study. Marine Ecology Progress Series, 49: 83-93.

Pilkey, H. \& Goodell, H. G. (1963). Trace elements in recent mollusc shells. Limnology and Oceanography, 8(2): 137-148.

Pirker, J. G. \& Schiel, D. R. (1993). Tetracycline as a fluorescent shell-marker in the abalone Haliotis iris. Marine Biology, 116: 81-86.

Poore, G. C. B. (1972a). Ecology of New Zealand abalones, Haliotis species (Mollusca: Gastropoda) 1. Feeding. New Zealand Journal of marine and Freshwater Research, 6(1\&2): 11-22.

Poore, G. C. B. (1972b). Ecology of New Zealand abalones, Haliotis species (Mollusca: Gastropoda) 3. Growth. New Zealand Journal of Marine and Freshwater Research, 6(4): 534-548.

Price, G. D. \& Pearce, N. J. G. (1997). Biomonitoring of pollution by Cerastoderma edule from the British Isles: a Laser Ablation ICP-MS study. Marine Pollution Bulletin, 34(12): 1025-1031.

Protasowicki, M., Dural, M. \& Jaremek, J. (2008). Trace metals in the shells of blue mussels (Mytilus edulis) from the Poland coast of Baltic Sea. Environmental Monitoring and Assessment, 141: 329-337.

Prothero, D.R. (1998). Bringing Fossils to Life. Boston, McGraw-Hill.

Proudfoot, L., Kaehler, S. \& McQuaid, C. D. 2008. Using growth band autofluorescence to investigate large-scale variation in growth of the abalone Haliotis midae. Marine Biology, 153: 789-796.

Rainbow, P. S. (1997). Ecophysiology of trace metal uptake in crustaceans. Estuarine, Coastal and Shelf Science, 44: 169-175.

Rainbow, P. S. (2002). Trace metal concentrations in aquatic invertebrates: why and so what? Environmental Pollution, 120: 497-507.

Raith, A., Perkins, W. T., Pearce, N. J. G. \& Jeffries, T. E. (1996). Environmental monitoring on shellfish using UV laser ablation ICP-MS. Fresenius' Journal of Analytical Chemistry, 355: 789-792.

Rattenbury, M. S., Townsend, D. B \& Jonhnston, M. R. (2006). Geology of the Kaikoura area, 1:250,000. Geological Map, GNS Science, Lower Hutt, New Zealand. 
Richardson, C. A. (2001). Mollusc as archives of environmental change. Oceanography and Marine Biology: An annual review, 39: 103-164.

Richardson, C. A., Chenery, S. R. N. \& Cook, J. M. (2001). Assessing the history of trace metal $(\mathrm{Cu}, \mathrm{Zn}, \mathrm{Pb})$ contamination in the North Sea through laser ablation - ICP-MS of horse mussel Modiolus modiolus shells. Marine Ecology Progress Series, 211: 157-167.

Rosenthal, Y. Katz, A. (1989). The applicability of trace elements in freshwater shells for paleogeochemical studies. Chemical Geology, 78: 65-76.

Sainsbury, K. J. (1982). Population dynamics and fishery management of the paua, Haliotis iris, I. Population structure, growth, reproduction, and mortality. New Zealand Journal of Marine and Freshwater Research, 16: 147-161.

Sakai, S. (1960). On the formation of the annual ring on the shell of the abalone, Haliotis discus var. Hannai ino. Tohoku Journal of Agricultural Research, 11: 239-241.

Saleuddin, A. S. M. \& Petit, H. (1983). The mode of formation of the periostracum, in The Mollusca, Vol 4. Saleuddin, A. S. M. \& Wilbur, K. M. (Eds). New York, Academic Press. 199-234.

Schaefer, J.M., Denton, G.H., Kaplan, M., Putnam, A., Finkel, R.C., Barrell, D.J.A., Anderson, B.G., Schwartz, R., Mackintosh, A., Chinn, T. \& Schlüchter, C. (2009). High-Frequency Holocene Glacier Fluctuations in New Zealand Differ from the Northern Signature. Science, 324: 622-625.

Schiel, D. R. (1990). Macroalgal assemblages in New Zealand: structure, interactions and demography. Hydrobiologia, 192: 59-76.

Schiel, D. R. \& Breen, P. A. (1991). Population structure, ageing and fishing mortality of the New Zealand abalone Haliotis iris. Fishery Bulletin, U.S, 89:681-691.

Schiel, D. R. \& Nelson, W. A. (1990).The harvesting of macroalgae in New Zealand. Hydrobiologia, 204/205: 25-33.

Schöne, B. R. (2008). The curse of physiology - challenges and opportunities in the interpretation of geochemical data from mollusc shells. Geo-Marine Letters, 28: 269-285.

Schöne, B. R., Fiebig, J., Pfeiffer, M., Gle $\beta$, R., Hickson, J., Johnson, A. L. A., Dreyer, W. \& Oschmann, W. (2005). Climate records from a bivalved Methuselah (Arctica islandica, Mollusca; Iceland). Palaeogeography, Palaeoclimatology, Palaeoecology, 228: 130-148.

Schöne, B. R., Zhang, Z., Jacob, D., Gillikin, D. P., Tütken, T., Garbe-Schönberg, D., McConnaughhey, T. \& Soldati, A. (2010). Effect of organic matrices on the determination of the trace element chemistry (Mg, Sr, $\mathrm{Mg} / \mathrm{Ca}, \mathrm{Sr} / \mathrm{Ca}$ ) of aragonitic bivalve shells (Arctica islandica) - Comparison of ICP-OES and LA-ICP-MS data. Geochemical Journal, 44: 23-37. 
Searle, T., Roberts, R. D. \& Lokman, P. M. (2006). Effects of temperature on growth of juvenile blackfoot abalone, Haliotis iris Gmelin. Aquaculture Research, 37: 1441-1449.

Setyono, D. E. D. (2006). Reproductive aspects of the tropical abalone, Haliotis Asinina, from Southern Lombok waters, Indonesia. Journal of Marine Research Indonesia, 30: 1-14.

Shen, C., Lee, T., Chen, C., Wang, C., Dai, C. \& Li, L. (1996). The calibration of $D[\mathrm{Sr} / \mathrm{Ca}]$ versus sea surface temperature relationship for Porites corals. Geochimica et Cosmochimica Acta, 60(20): 3849-3858.

Simkiss, K. \& Wilbur, K. M. (1989). Biomineralization: Cell biology and mineral deposition. San Diego, Academic Press.

Sinclair, D. J. \& McCulloch, M. T. (2004). Corals record low mobile barium concentrations in Burdekin River during the 1974 flood: evidence for limited Ba supply to rivers? Palaeogeography, Palaeoclimatology, Palaeoecology, 214: 155-174.

Skinner, H. C. W. \& Jahren, A. H. (2004). Biomineralization, in Biogeochemistry, Treatise on Geochemsitry, edited by Schlesinger, W. New York. Elsevier. 8: 118-184.

Snyder, C. W. (2010). The value of paleoclimate research in our changing climate, an editorial comment. Climate Change, 100: 407-418.

Stecher III ,H. A., Krantz, D. E., Lord III, C. J., Luther III, G. W. \& Bock, K. W. (1996). Profiles of strontium and barium in Mercenaria mercenaria and Spisula solidissima shells. Geochimica et Cosmochimica Acta, 60(18): 3445-3456.

Symonds, J. \& Heath, P. (2008). Getting picky with paua: selective breeding to improve productivity. Water and Atmosphere, 16(1): 20-21.

Su, X., Belcher, A. M., Zaremba, C. M., Morse, D. E., Stucky, G. D. \&Heuer, A. H. (2002). Structural and microstructural characterization of the growth lines and prismatic microarchitecture in red abalone shell and the microstructures of abalone "flat pearls". Chemistry of Materials, 14: 31063117.

Takesue, R. K., Bacon, C. R., Thompson, J. K. (2008). Influences of organic matter and calcification rate on trace elements in aragonitic estuarine bivalve shells. Geochimica et Cosmochimica ActaI, 72: 5431-5445.

Tynan, S., Eggins, S., Kinsley, L, Welch, S.A. \& Kirste, D. (2005). Mussel shells as environmental tracers: An example from the Loveday Basin, in Ten Years of CRC LEME, Roach, I. C. (Ed). Adelaide and Canberra, Cooperative Research Centre for Landscape Environments \& Mineral Investigation. 314-317.

Villalba, R. (1994). Tree-ring and glacial evidence for the Medieval Warm Epoch and the Little Ice Age in southern South America. Climate Change, 26: 183197. 
Vander Putten, E., Dehairs, F., Keppens, E. \& Baeyens, W. (2000). High resolution distribution of trace elements in the calcite shell layer of modern Mytilus edulis: Environmental and biological controls. Geochimica et Cosmochimica Acta, 64(6): 997-1011.

Wanamaker Jr., A. D., Kreutz, K. J., Borns Jr., H. W., Introne, D. S., Feindel, S., Funder, S., Rawson, R. D. \& Barber, B. J. (2007). Experimental determination of salinity, temperature, growth, and metabolic effects on shell isotope chemistry of Mytilus edulis collected from Maine and Greenland. Paleoceanography, 22

Wang, W. \& Dei, R. C. H. (1999). Factors affecting trace element uptake in the black mussel Septifer virgatus. Marine Ecology Progress Series, 186: 161172.

Weiner, S. \& Addadi, L. (1997). Design strategies in mineralized biological materials. Journal of Material Chemistry, 7(5): 689-702.

Weiner, S. and Dove, P. M. (2003). An overview of biomineralization processes and the problem of the vital effect. Reviews in Mineralogical and Geochemistry, 54(1): 1-29.

Wellington City Council. (no date). Sewage Treatment Plants [Online] Accessed from:

http://www.wellington.govt.nz/services/sewerage/treatment/treatment. html [5th December 2010]

Wells, R. M. G., Baldwin, J., Speed, S. R. \& Weber, R. E. (1998). Haemocyanin function in the New Zealand abalones Haliotis iris and H. australis. Relationship between oxygen-binding properties, muscle metabolism and habitat. Marine Freshwater Research, 49:143-149.

Whyte, A. L. H. (2006). Environmental toxicology of Perna canaliculus. Thesis, (PhD). Victoria University of Wellington.

Widerland, A. \& Andersson, P. S. (2006). Strontium isotopic composition of modern and Holocene mollusc shells as a palaeosalinity indicator for the Baltic Sea. Chemical Geology, 232: 54-66.

Wilbur, K. M. (1964). Shell formation and regeneration, in Physiology of mollusca, Vol. 1, Wilbur, K. M. \& Yonge, C. M. (Eds). New York, Academic Press.

Wilbur, K. M. \& Saleuddin, A. S. M. (1983). Shell Formation, in The Mollusca, Vol. 4. Saleuddin, A. S. M and Wilbur, K. M. (Eds). New York, Academic Press. 235-287. 
Yap, C. K., Ismail, A., Tan, S. G. \& Abdul Rahim, I. (2003). Can the shell of the green-lipped mussel Perna viridis from the west coast of Peninsula Malaysia be a potential biomonitoring material for $\mathrm{Cd}, \mathrm{Pb}$ and $\mathrm{Zn}$ ? Estuarine, Coastal and Shelf Science, 57: 623-630. 


\section{APPENDICES}


APPENDIX 1.1 Lists of samples and collected sites

$\begin{array}{ll}\text { RW75 } & \text { OceaNZ Blue Ltd, Bream Bay, Ruakaka } \\ \text { A740 } & \text { OceaNZ Blue Ltd, Bream Bay, Ruakaka } \\ \text { P04A } & \text { Pourerere, Hawke's Bay } \\ \text { P1B } & \text { Pourerere, Hawke's Bay } \\ \text { SC2 } & \text { South Coast, Wellington } \\ \text { SC1A } & \text { South Coast, Wellington } \\ \text { MP02A } & \text { Moa Point, Wellington } \\ \text { KD1B } & \text { Kaikoura Coast, Kaikoura } \\ \text { K3A } & \text { Kaikoura } \\ \text { K1A1 } & \text { Kaikoura } \\ \text { AR1 } & \text { Ascot Reef, Chatham Islands } \\ \text { MR2 } & \text { Manukau Reef, Chatham Islands } \\ \text { MD1 } & \text { Moeraki, Otago } \\ \text { MD3 } & \text { Moeraki, Otago }\end{array}$


APPENDIX 2.1 OceaNZ Blue Ltd growth data

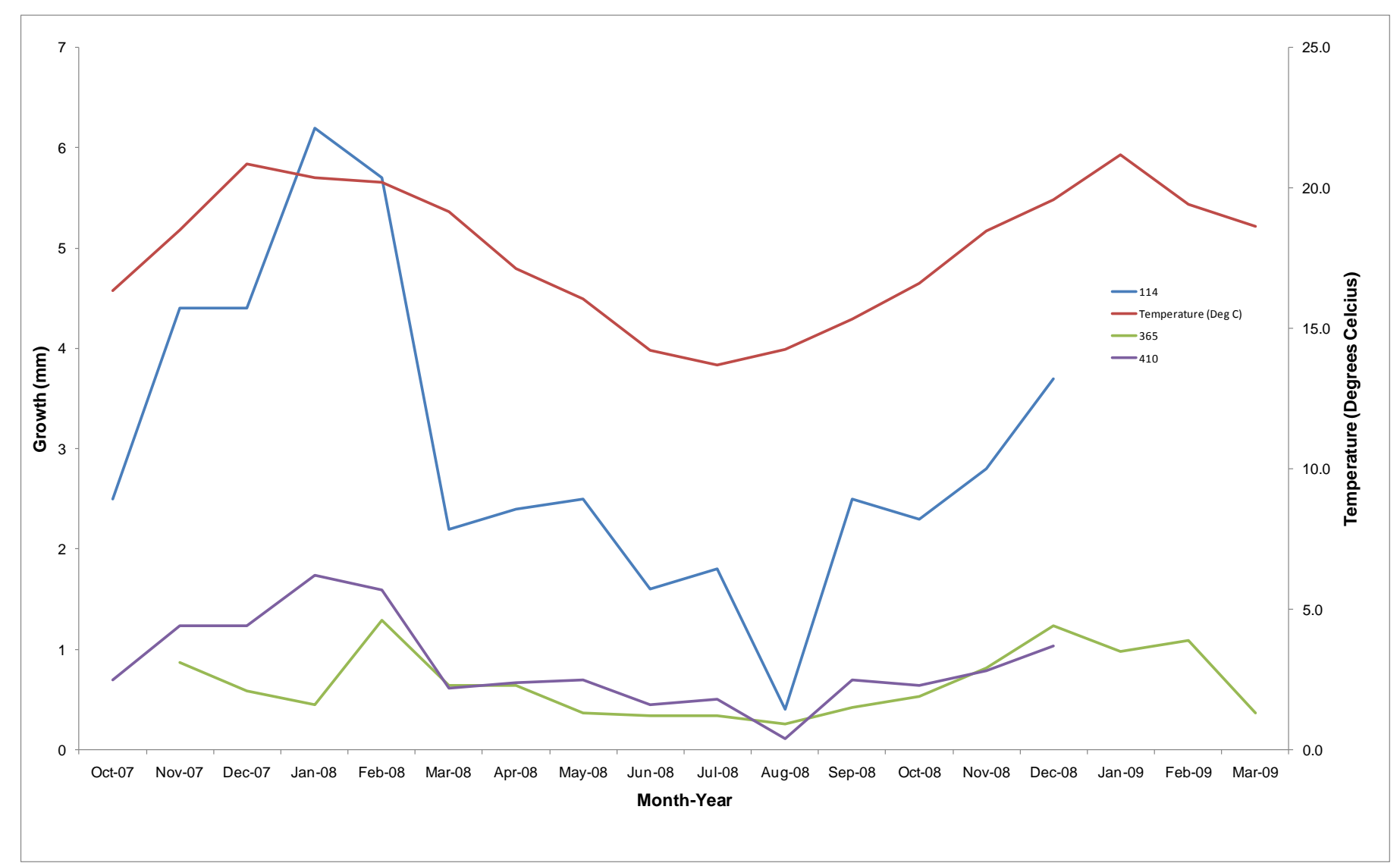

Appendix 2.1. Monthly growth data (mm) from October 2007 to March 2009 of pāua shells 114, 365 and 410, three juvenile pāua from OBL. Maximum growth in the juvenile pāua occurs during warmer temperatures. 
APPENDIX 3.1 Prismatic layer correlation matrices

\begin{tabular}{|c|c|c|c|c|c|c|c|c|c|c|c|c|}
\hline \multicolumn{2}{|c|}{ A740(2) Correlations Prismatic } & $\mathrm{Li} / \mathrm{Ca}$ & $\mathrm{Mg} / \mathrm{Ca}$ & Sr86/Ca & Sr88/Ca & $\mathrm{Ba} / \mathrm{Ca}$ & $\mathrm{Pb} / \mathrm{Ca}$ & $\mathrm{U} / \mathrm{Ca}$ & $\begin{array}{l}\text { B/Ca } \\
\text { Log10 }\end{array}$ & $\begin{array}{l}\text { Al/Ca } \\
\text { Log10 }\end{array}$ & $\begin{array}{l}\mathrm{Mn} / \mathrm{Ca} \\
\mathrm{Log} 10\end{array}$ & $\begin{array}{l}\mathrm{Zn} / \mathrm{Ca} \\
\mathrm{Log} 10\end{array}$ \\
\hline \multirow{3}{*}{ Li/Ca } & Pearson Correlation & & .040 & $.254^{\circ}$ & $.260^{\circ}$ & $.226^{\circ}$ & .156 & .064 & .121 & .185 & -.011 & -.187 \\
\hline & Sig. (2-tailed) & & .718 & .017 & .015 & .038 & .294 & .721 & .371 & .214 & .927 & .203 \\
\hline & $\mathrm{N}$ & & 84 & 87 & 87 & 85 & 47 & 34 & 57 & 47 & 71 & 48 \\
\hline \multirow{3}{*}{$\mathrm{Mg} / \mathrm{Ca}$} & Pearson Correlation & & & -.120 & -.114 & -106 & .084 & -151 & -.041 & -151 & -.055 & .138 \\
\hline & Sig. (2-tai & & & .238 & .261 & .302 & .528 & .358 & .743 & .286 & .630 & .311 \\
\hline & $\mathrm{N}$ & & & 99 & 99 & 97 & 59 & 39 & 65 & 52 & 80 & 56 \\
\hline \multirow{3}{*}{ Sr86/Ca } & Pearson Correlation & & & & $.982^{\circ}$ & $329^{\circ}$ & -104 & -078 & -.090 & .085 & .047 & .047 \\
\hline & Sig. (2-tailed) & & & & .000 & .001 & .431 & .626 & .467 & .541 & .675 & .727 \\
\hline & $\mathrm{N}$ & & & & 102 & 100 & 60 & 41 & 67 & 54 & 82 & 57 \\
\hline \multirow{3}{*}{$\mathrm{Sr} 88 / \mathrm{Ca}$} & Pearson Correlation & & & & & $.364^{-1}$ & $\begin{array}{cc}-.088 \\
\end{array}$ & -051 & -.079 & .078 & .029 & .036 \\
\hline & Sig. (2-tailed) & & & & & .000 & .506 & .752 & .526 & .575 & .798 & .793 \\
\hline & $\mathrm{N}$ & & & & & 100 & 60 & 41 & 67 & 54 & 82 & 57 \\
\hline \multirow{3}{*}{$\mathrm{Ba} / \mathrm{Ca}$} & Pearson Correlation & & & & & & -.071 & .044 & .176 & .118 & .057 & .209 \\
\hline & Sig. (2-tailed & & & & & & .589 & .787 & .153 & .400 & .614 & .125 \\
\hline & N & & & & & & 60 & 41 & 67 & 53 & 80 & 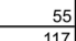 \\
\hline \multirow[t]{2}{*}{$\mathrm{Pb} / \mathrm{Ca}$} & $\begin{array}{l}\text { Pearson Correlation } \\
\text { Sig. (2-tailed) }\end{array}$ & & & & & & & $\begin{array}{r}.300 \\
.145\end{array}$ & $\begin{array}{l}.018 \\
.912\end{array}$ & $\begin{array}{l}.041 \\
.823\end{array}$ & $\begin{array}{r}-.019 \\
.902\end{array}$ & $\begin{array}{l}.117 \\
.490\end{array}$ \\
\hline & $\mathrm{N}$ & & & & & & & 25 & 39 & & 45 & 47 \\
\hline \multirow[t]{2}{*}{$\mathrm{U} / \mathrm{Ca}$} & $\begin{array}{l}\text { Pearson Correlation } \\
\text { Sig. (2-tailed) }\end{array}$ & & & & & & & & $\begin{array}{r}-.111 \\
.553\end{array}$ & $\begin{array}{r}-.067 \\
.749\end{array}$ & $\begin{array}{l}.263 \\
.127\end{array}$ & $\begin{array}{l}.043 \\
.831\end{array}$ \\
\hline & \begin{tabular}{|l|}
$\mathrm{N}$ \\
Pearson Correlation
\end{tabular} & & & & & & & & 31 & $\begin{array}{r}25 \\
.173\end{array}$ & $\begin{array}{r}35 \\
-159\end{array}$ & \begin{tabular}{r|}
27 \\
.022
\end{tabular} \\
\hline $\begin{array}{l}\text { B/Ca } \\
\text { Log10 }\end{array}$ & Sig. (2-tailed) & & & & & & & & & .306 & $\begin{array}{r}.232 \\
58\end{array}$ & 892 \\
\hline & Pearson Correlation & & & & & & & & & & .030 & .077 \\
\hline $\begin{array}{l}\text { A/lCa } \\
\text { Log10 }\end{array}$ & Sig. (2-tailed) & & & & & & & & & & $\begin{array}{r}.839 \\
49\end{array}$ & .708 \\
\hline $\begin{array}{l}\mathrm{Mn} / \mathrm{Ca} \\
\log 10\end{array}$ & $\begin{array}{l}\text { Pearson Correlation } \\
\text { Sig. (2-tailed) }\end{array}$ & & & & & & & & & & & $\begin{array}{l}.157 \\
.303\end{array}$ \\
\hline $\begin{array}{l}\mathrm{Zn} / \mathrm{Ca} \\
\log 10\end{array}$ & $\begin{array}{l}\text { Pearson Correlation } \\
\text { Sig. (2-tailed) }\end{array}$ & & & & & & & & & & & \\
\hline
\end{tabular}

\begin{tabular}{|c|c|c|c|c|c|c|c|c|}
\hline \multicolumn{2}{|c|}{$\begin{array}{l}\text { A740(1) Correlations Prismatic } \\
\text { Layer }\end{array}$} & $\mathrm{Mg} / \mathrm{Ca}$ & $\mathrm{A} / / \mathrm{Ca}$ & $\mathrm{Zn} / \mathrm{Ca}$ & $\mathrm{Sr} / \mathrm{Ca}$ & $\mathrm{Ba} / \mathrm{Ca}$ & $\begin{array}{l}\text { Al/Ca } \\
\text { Log10 } \\
\end{array}$ & $\begin{array}{l}\mathrm{Zn} / \mathrm{Ca} \\
\mathrm{Log} 10 \\
\end{array}$ \\
\hline $\mathrm{Mg} / \mathrm{Ca}$ & $\begin{array}{l}\text { Pearson Correlation } \\
\text { Sig. (2-tailed) } \\
N \text { N }\end{array}$ & & $\begin{array}{r}.000 \\
.999 \\
51\end{array}$ & $\begin{array}{r}-.177 \\
.161 \\
64\end{array}$ & $\begin{array}{r}-.208 \\
.022 \\
120\end{array}$ & $\begin{array}{r}-.155 \\
.087 \\
122\end{array}$ & $\begin{array}{r}.103 \\
.471 \\
51\end{array}$ & $\begin{array}{r}-.045 \\
.726 \\
64\end{array}$ \\
\hline $\mathrm{Al} / \mathrm{Ca}$ & \begin{tabular}{|l|} 
Pearson Correlation \\
Sig. (2-tailed) \\
$\mathrm{N}$
\end{tabular} & & & $\begin{array}{r}.04 \\
.700 " \\
.000 \\
29 \\
\end{array}$ & $\begin{array}{r}-.20 \\
-.078 \\
.586 \\
51 \\
\end{array}$ & $\begin{array}{r}.22 \\
.039 \\
.785 \\
51 \\
\end{array}$ & $\begin{array}{r}.653 " \\
.000 \\
51 \\
\end{array}$ & $\begin{array}{r}.380 \\
.042 \\
29 \\
\end{array}$ \\
\hline $\mathrm{Zn} / \mathrm{Ca}$ & $\begin{array}{l}\text { Pearson Correlation } \\
\text { Sig. (2-tailed) } \\
\text { N } \\
\end{array}$ & & & & $\begin{array}{r}-.085 \\
.513 \\
62 \\
\end{array}$ & $\begin{array}{r}.507 \\
.000 \\
64 \\
\end{array}$ & $\begin{array}{r}.532 " \\
.003 \\
29 \\
\end{array}$ & $\begin{array}{l}.798^{\circ} \\
.000\end{array}$ \\
\hline $\mathrm{Sr} / \mathrm{Ca}$ & $\begin{array}{l}\text { Pearson Correlation } \\
\text { Sig. (2-tailed) } \\
\text { N }\end{array}$ & & & & & \begin{tabular}{r|}
.602 \\
.000 \\
120 \\
\end{tabular} & $\begin{array}{r}-.135 \\
.344 \\
51 \\
\end{array}$ & $\begin{array}{r}-.022 \\
.865 \\
62 \\
\end{array}$ \\
\hline $\mathrm{Ba} / \mathrm{Ca}$ & $\begin{array}{l}\text { Pearson Correlation } \\
\text { Sig. (2-tailed) } \\
\text { N } \\
\end{array}$ & & & & & & $\begin{array}{r}-.153 \\
.283 \\
51 \\
\end{array}$ & $\begin{array}{r}.233 \\
.063 \\
64\end{array}$ \\
\hline $\begin{array}{l}\text { Al/Ca } \\
\text { Log10 }\end{array}$ & $\begin{array}{l}\text { Pearson Correlation } \\
\text { Sig. (2-tailed) } \\
\text { N }\end{array}$ & & & & & & & $\begin{array}{r}.435 \\
.018 \\
29\end{array}$ \\
\hline $\begin{array}{l}\mathrm{Zn} / \mathrm{Ca} \\
\log 10\end{array}$ & $\begin{array}{l}\text { Pearson Correlation } \\
\text { Sig. (2-tailed) } \\
\text { N. } \\
\end{array}$ & & & & & & & \\
\hline
\end{tabular}

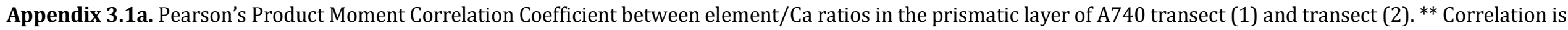
significant at the 0.01 level and * correlation is significant at the 0.05 level. 


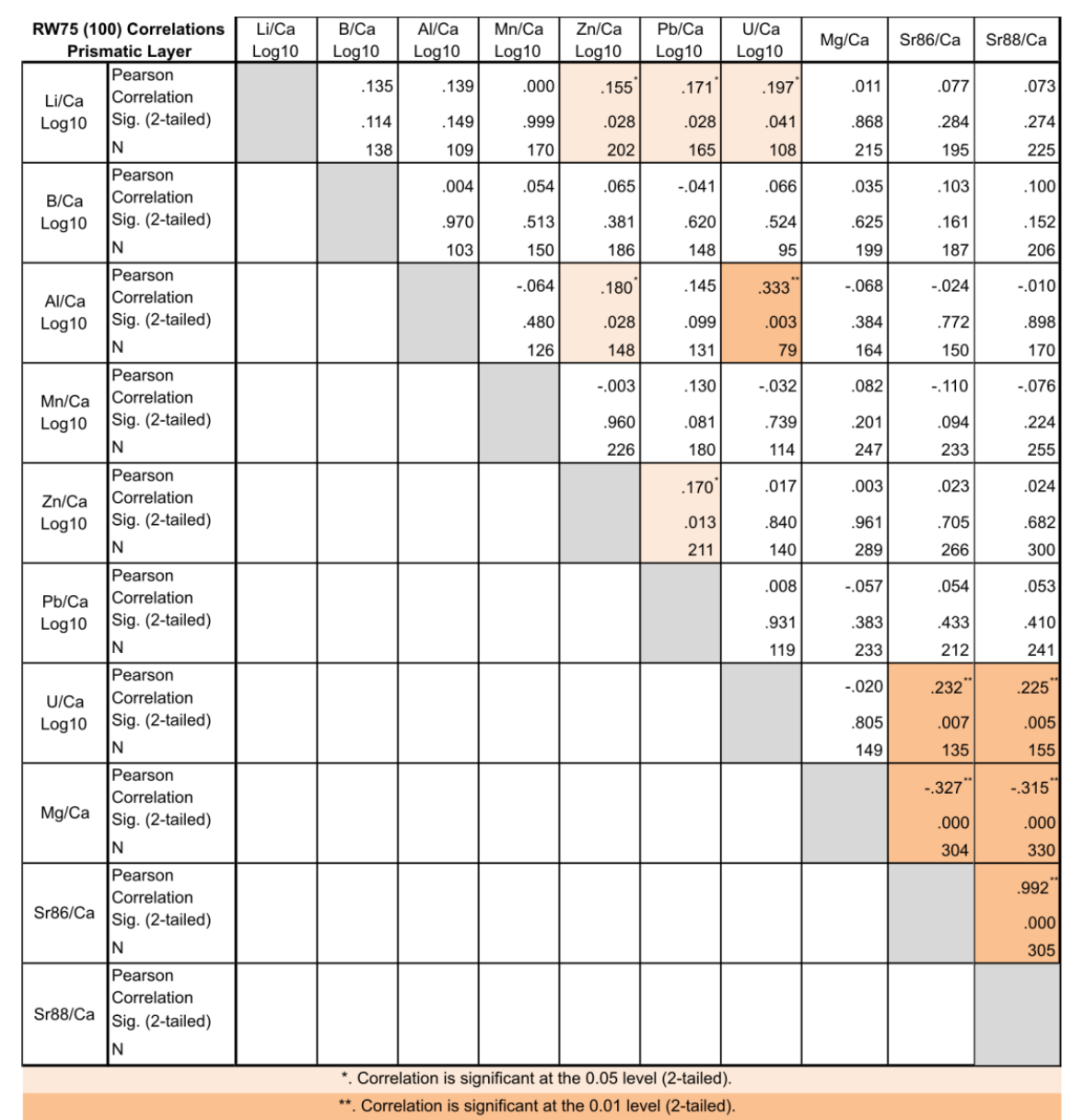

\begin{tabular}{|c|c|c|c|c|c|c|c|c|c|c|}
\hline \multicolumn{2}{|c|}{$\begin{array}{l}\text { RW75 (400) Correlations } \\
\text { Prismatic Layer }\end{array}$} & $\begin{array}{l}\text { Al/Ca } \\
\log 10\end{array}$ & $\begin{array}{l}\mathrm{Mn} / \mathrm{Ca} \\
\mathrm{Log} 10\end{array}$ & $\begin{array}{l}\mathrm{Zn} / \mathrm{Ca} \\
\mathrm{Log} 10\end{array}$ & $\begin{array}{l}\mathrm{U} / \mathrm{Ca} \\
\mathrm{Log} 10\end{array}$ & $\mathrm{Li} / \mathrm{Ca}$ & $\mathrm{B} / \mathrm{Ca}$ & $\mathrm{Mg} / \mathrm{Ca}$ & Sr88/Ca & $\mathrm{Ba} / \mathrm{Ca}$ \\
\hline $\begin{array}{l}\text { Al/Ca } \\
\text { Log10 }\end{array}$ & \begin{tabular}{|l|} 
Pearson \\
Correlation \\
Sig. (2-tailed) \\
$\mathrm{N}$ \\
\end{tabular} & & $\begin{array}{r}.002 \\
.986 \\
62 \\
\end{array}$ & $\begin{array}{r}.290^{\circ} \\
.020 \\
64 \\
\end{array}$ & $\begin{array}{r}.088 \\
.562 \\
46\end{array}$ & $\begin{array}{r}.093 \\
.449 \\
68 \\
\end{array}$ & $\begin{array}{r}.003 \\
.982 \\
47\end{array}$ & $\begin{array}{r}.344 \\
.004 \\
68\end{array}$ & $\begin{array}{r}.055 \\
.657 \\
68 \\
\end{array}$ & $\begin{array}{l}.180 \\
.144\end{array}$ \\
\hline $\begin{array}{l}\mathrm{Mn} / \mathrm{Ca} \\
\log 10\end{array}$ & \begin{tabular}{|l|} 
Pearson \\
Correlation \\
Sig. (2-tailed) \\
$\mathrm{N}$
\end{tabular} & & & $\begin{array}{r}.035 \\
.739 \\
91 \\
\end{array}$ & \begin{tabular}{r|}
.113 \\
.362 \\
67 \\
\end{tabular} & \begin{tabular}{r|}
.163 \\
.110 \\
97 \\
\end{tabular} & \begin{tabular}{r|}
.005 \\
.967 \\
71 \\
\end{tabular} & \begin{tabular}{r|}
.014 \\
.896 \\
97 \\
\end{tabular} & $\begin{array}{r}.112 \\
.274 \\
97 \\
\end{array}$ & $\begin{array}{l}.163 \\
.113\end{array}$ \\
\hline $\begin{array}{l}\mathrm{Zn} / \mathrm{Ca} \\
\mathrm{Log} 10\end{array}$ & \begin{tabular}{|l|} 
Pearson \\
Correlation \\
Sig. (2-tailed) \\
N \\
\end{tabular} & & & & $\begin{array}{r}-.133 \\
.279 \\
68\end{array}$ & $\begin{array}{r}.041 \\
.687 \\
99\end{array}$ & $\begin{array}{r}.036 \\
.765 \\
70\end{array}$ & $\begin{array}{r}.033 \\
.747 \\
99\end{array}$ & $\begin{array}{r}.279 \\
.005 \\
99\end{array}$ & $\begin{array}{r}.493 \\
.000 \\
98\end{array}$ \\
\hline $\begin{array}{l}\mathrm{U} / \mathrm{Ca} \\
\mathrm{Log} 10\end{array}$ & \begin{tabular}{|l|} 
Pearson \\
Correlation \\
Sig. (2-tailed) \\
$\mathrm{N}$ \\
\end{tabular} & & & & & \begin{tabular}{r|}
.160 \\
.174 \\
74 \\
\end{tabular} & \begin{tabular}{r|}
.053 \\
.705 \\
54 \\
\end{tabular} & \begin{tabular}{r|}
.197 \\
.093 \\
74 \\
\end{tabular} & \begin{tabular}{r|}
.212 \\
.070 \\
74
\end{tabular} & $\begin{array}{r}-.077 \\
.520 \\
73\end{array}$ \\
\hline Li/Ca & \begin{tabular}{|l|} 
Pearson \\
Correlation \\
Sig. (2-tailed) \\
$\mathrm{N}$
\end{tabular} & & & & & & \begin{tabular}{r|}
.112 \\
.333 \\
77 \\
\end{tabular} & \begin{tabular}{c|}
$.283^{\circ}$ \\
.003 \\
106
\end{tabular} & $\begin{array}{l}.109 \\
.268 \\
106 \\
\end{array}$ & $\begin{array}{l}.064 \\
105 \\
\end{array}$ \\
\hline $\mathrm{B} / \mathrm{Ca}$ & $\begin{array}{l}\text { Pearson } \\
\text { Correlation } \\
\text { Sig. (2-tailed) } \\
\mathrm{N} \\
\end{array}$ & & & & & & & $\begin{array}{r}-.141 \\
.221 \\
77 \\
\end{array}$ & $\begin{array}{r}.366 \\
.001 \\
77\end{array}$ & $\begin{array}{r}.066 \\
.571 \\
76\end{array}$ \\
\hline $\mathrm{Mg} / \mathrm{Ca}$ & 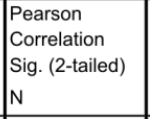 & & & & & & & & $\begin{array}{r}-.296 " \\
.002 \\
106\end{array}$ & $\begin{array}{r}.010 \\
.922 \\
105\end{array}$ \\
\hline Sr88/Ca & $\begin{array}{l}\text { Pearson } \\
\text { Correlation } \\
\text { Sig. (2-tailed) } \\
\mathrm{N}\end{array}$ & & & & & & & & & $\begin{array}{r}.707 \\
.000 \\
105\end{array}$ \\
\hline $\mathrm{Ba} / \mathrm{Ca}$ & \begin{tabular}{|l|} 
Pearson \\
Correlation \\
Sig. (2-tailed) \\
$\mathrm{N}$
\end{tabular} & & & & & & & & & \\
\hline
\end{tabular}

Appendix 3.1b. Pearsons correlation between element/Ca ratios in the prismatic layer of RW75 transect (400) and transect (100). ${ }^{* *}$ Correlation is significant at the 0.01 level and * correlation is significant at the 0.05 level. 


\begin{tabular}{|c|c|c|c|c|c|c|c|c|c|c|c|}
\hline \multicolumn{2}{|c|}{ P1B Correlations Prismatic Layer } & $\begin{array}{l}\text { Li/Ca } \\
\text { Log10 }\end{array}$ & $\begin{array}{l}\text { B/Ca } \\
\text { Log10 }\end{array}$ & $\begin{array}{l}\mathrm{Mg} / \mathrm{Ca} \\
\log 10\end{array}$ & $\begin{array}{l}\text { Al/Ca } \\
\text { Log10 }\end{array}$ & $\begin{array}{l}\mathrm{Mn} / \mathrm{Ca} \\
\log 10\end{array}$ & $\begin{array}{l}\mathrm{Zn} / \mathrm{Ca} \\
\log 10\end{array}$ & $\begin{array}{l}\text { Ba/Ca } \\
\text { Log10 }\end{array}$ & $\begin{array}{l}\mathrm{Pb} / \mathrm{Ca} \\
\mathrm{Log} 10\end{array}$ & $\begin{array}{l}\text { U/Ca } \\
\text { Log10 }\end{array}$ & $\mathrm{Sr} 88 / \mathrm{Ca}$ \\
\hline $\begin{array}{l}\text { LilCa } \\
\text { Log10 }\end{array}$ & \begin{tabular}{|l} 
Pearson Correlation \\
Sig. (2-tailed) \\
$\mathrm{N}$
\end{tabular} & & \begin{tabular}{r|}
.077 \\
.544 \\
65
\end{tabular} & $\begin{array}{r}.014 \\
.894 \\
89\end{array}$ & \begin{tabular}{r|r|}
.193 \\
.163 \\
54
\end{tabular} & $\begin{array}{r}.059 \\
.605 \\
78\end{array}$ & \begin{tabular}{r|}
.043 \\
.734 \\
64 \\
\end{tabular} & \begin{tabular}{r|}
.044 \\
.695 \\
83
\end{tabular} & $\begin{array}{r}.083 \\
.469 \\
79\end{array}$ & $\begin{array}{r}.376 \\
.005 \\
55\end{array}$ & $\begin{array}{l}.080 \\
.474 \\
\end{array}$ \\
\hline $\begin{array}{l}\text { B/Ca } \\
\log 10\end{array}$ & \begin{tabular}{|l} 
Pearson Correlation \\
Sig. (2-tailed) \\
$\mathrm{N}$
\end{tabular} & & & $\begin{array}{r}.341 \\
.001 \\
89\end{array}$ & \begin{tabular}{r|}
.202 \\
.154 \\
51
\end{tabular} & $\begin{array}{r}.257 \\
.023 \\
78\end{array}$ & $\begin{array}{r}.249^{\circ} \\
.039 \\
69\end{array}$ & $\begin{array}{r}.358 \\
.001 \\
82\end{array}$ & $\begin{array}{r}.102 \\
.366 \\
81\end{array}$ & $\begin{array}{r}.476 \\
.000 \\
54\end{array}$ & $\begin{array}{r}.312 \\
.004 \\
82\end{array}$ \\
\hline $\begin{array}{l}\mathrm{Mg} / \mathrm{Ca} \\
\log 10\end{array}$ & \begin{tabular}{|l} 
Pearson Correlation \\
Sig. (2-tailed) \\
$\mathrm{N}$ \\
\end{tabular} & & & & $\begin{array}{r}.531 \\
.000 \\
67 \\
\end{array}$ & $\begin{array}{r}.258 \\
.009 \\
102 \\
\end{array}$ & \begin{tabular}{r|r|}
.046 \\
.670 \\
88 \\
\end{tabular} & $\begin{array}{r}.637^{-1} \\
.000 \\
109 \\
\end{array}$ & $\begin{array}{l}.131 \\
.184 \\
105 \\
\end{array}$ & $\begin{array}{r}.285^{\circ} \\
.018 \\
69 \\
\end{array}$ & $\begin{array}{r}.455 \\
.000 \\
109 \\
\end{array}$ \\
\hline $\begin{array}{l}\text { Al/Ca } \\
\text { Log10 }\end{array}$ & \begin{tabular}{|l} 
Pearson Correlation \\
Sig. (2-tailed) \\
$\mathrm{N}$
\end{tabular} & & & & & $\begin{array}{r}.218 \\
.092 \\
61 \\
\end{array}$ & $\begin{array}{r}.071 \\
.626 \\
50 \\
\end{array}$ & $\begin{array}{r}.756 \\
.000 \\
63 \\
\end{array}$ & $\begin{array}{r}.210 \\
.111 \\
59 \\
\end{array}$ & $\begin{array}{r}.489 " \\
.001 \\
43 \\
\end{array}$ & $270^{\circ}$ \\
\hline $\begin{array}{l}\mathrm{Mn} / \mathrm{Ca} \\
\log 10\end{array}$ & $\begin{array}{l}\text { Pearson Correlation } \\
\text { Sig. (2-tailed) } \\
\text { N }\end{array}$ & & & & & & \begin{tabular}{r|r|}
.103 \\
.367 \\
79
\end{tabular} & $\begin{array}{r}.385 \\
.000 \\
96\end{array}$ & \begin{tabular}{r|}
$.339^{" \prime}$ \\
.001 \\
93
\end{tabular} & $\begin{array}{r}.445^{" \prime} \\
.000 \\
62\end{array}$ & 189 \\
\hline $\begin{array}{l}\mathrm{Zn} / \mathrm{Ca} \\
\log 10\end{array}$ & $\begin{array}{l}\text { Pearson Correlation } \\
\text { Sig. (2-tailed) } \\
\text { N }\end{array}$ & & & & & & & \begin{tabular}{r|}
.102 \\
.363 \\
81
\end{tabular} & $\begin{array}{r}.244^{\circ} \\
.026 \\
83\end{array}$ & $\begin{array}{r}.318^{\circ} \\
.024 \\
50\end{array}$ & .008 \\
\hline $\begin{array}{l}\mathrm{Ba} / \mathrm{Ca} \\
\mathrm{Log} 10\end{array}$ & \begin{tabular}{|l} 
Pearson Correlation \\
sig. (2-tailed) \\
$\mathrm{N}$ \\
\end{tabular} & & & & & & & & \begin{tabular}{r|r|}
.165 \\
.103 \\
99 \\
\end{tabular} & $\begin{array}{r}.549^{" \prime} \\
.000 \\
62\end{array}$ & .532 \\
\hline $\begin{array}{l}\mathrm{Pb} / \mathrm{Ca} \\
\log 10\end{array}$ & \begin{tabular}{|l} 
Pearson Correlation \\
sig. (2-tailed) \\
$\mathrm{N}$ \\
\end{tabular} & & & & & & & & & $\begin{array}{r}.382 " \\
.002 \\
64\end{array}$ & -.11 \\
\hline $\begin{array}{l}\text { U/Ca } \\
\text { Log10 }\end{array}$ & \begin{tabular}{|l} 
Pearson Correlation \\
Sig. (2-tailed) \\
N.
\end{tabular} & & & & & & & & & & $.475^{\prime \prime}$ \\
\hline $\mathrm{Sr} 88 / \mathrm{Ca}$ & $\begin{array}{l}\text { Pearson Correlation } \\
\text { sig. (2-tailed) } \\
\text { N }\end{array}$ & & & & & & & & & & \\
\hline
\end{tabular}

\begin{tabular}{|c|c|c|c|c|c|c|c|c|c|c|c|}
\hline \multicolumn{2}{|c|}{$\begin{array}{l}\text { P04A Correlations Prismatic } \\
\text { Layer }\end{array}$} & $\begin{array}{c}\mathrm{B} / \mathrm{Ca} \\
\log 10\end{array}$ & $\begin{array}{l}\mathrm{Mg} / \mathrm{Ca} \\
\mathrm{Log} 10\end{array}$ & $\begin{array}{l}\text { Al/Ca } \\
\text { Log10 }\end{array}$ & $\begin{array}{l}\mathrm{Mn} / \mathrm{Ca} \\
\mathrm{Log} 10\end{array}$ & $\begin{array}{l}\mathrm{Zn/Ca} \\
\mathrm{Log} 10\end{array}$ & $\begin{array}{l}\mathrm{Ba} / \mathrm{Ca} \\
\mathrm{Log} 10\end{array}$ & $\begin{array}{l}\mathrm{Pb} / \mathrm{Ca} \\
\mathrm{Log} 10\end{array}$ & $\begin{array}{c}\text { U/Ca } \\
\text { Log10 }\end{array}$ & Li/Ca & $\mathrm{Sr} 88 / \mathrm{Ca}$ \\
\hline $\begin{array}{l}\text { B/Ca } \\
\text { Log10 }\end{array}$ & \begin{tabular}{|l|} 
Pearson Correlation \\
Sig. (2-tailed) \\
$\mathrm{N}$
\end{tabular} & & \begin{tabular}{r|}
$.400^{\circ}$ \\
.001 \\
70
\end{tabular} & \begin{tabular}{r|}
$.533^{\prime \prime}$ \\
.000 \\
54
\end{tabular} & $\begin{array}{r}.416 \\
.002 \\
52\end{array}$ & $\begin{array}{r}-.012 \\
.932 \\
56\end{array}$ & $\begin{array}{r}.596 \\
.000 \\
67\end{array}$ & \begin{tabular}{r|}
.209 \\
.141 \\
51
\end{tabular} & \begin{tabular}{r|}
.293 \\
.057 \\
43 \\
\end{tabular} & $\begin{array}{r}.428 \\
.000 \\
70\end{array}$ & $\begin{array}{r}.501 \\
.000 \\
70\end{array}$ \\
\hline $\begin{array}{l}\mathrm{Mg} / \mathrm{Ca} \\
\mathrm{Log} 10\end{array}$ & \begin{tabular}{|l|} 
Pearson Correlation \\
Sig. (2-tailed) \\
$\mathrm{N}$
\end{tabular} & & & $\begin{array}{r}.583 " \\
.000 \\
70\end{array}$ & $\begin{array}{r}.272 \\
.027 \\
66\end{array}$ & $\begin{array}{r}-.164 \\
.154 \\
77\end{array}$ & $\begin{array}{r}.524 \\
.000 \\
93\end{array}$ & \begin{tabular}{r|}
.091 \\
.458 \\
68
\end{tabular} & \begin{tabular}{r|}
.262 \\
.051 \\
56
\end{tabular} & $\begin{array}{r}.532 " \\
.000 \\
95\end{array}$ & $\begin{array}{r}.250 \\
.014 \\
96\end{array}$ \\
\hline $\begin{array}{l}\text { Al/Ca } \\
\text { Log10 }\end{array}$ & $\begin{array}{l}\text { Pearson Correlation } \\
\text { Sig. (2-tailed) } \\
\text { N }\end{array}$ & & & & $\begin{array}{r}.522 \\
.000 \\
53\end{array}$ & $\begin{array}{r}.223 \\
.102 \\
55 \\
\end{array}$ & $\begin{array}{r}.853^{" \prime} \\
.000 \\
69 \\
\end{array}$ & $\begin{array}{r}.285 \\
.041 \\
52 \\
\end{array}$ & \begin{tabular}{r|}
$.399 "$ \\
.007 \\
44 \\
\end{tabular} & $\begin{array}{r}.621 \\
.000 \\
70\end{array}$ & $\begin{array}{r}.535 \\
.000 \\
70\end{array}$ \\
\hline $\begin{array}{l}\mathrm{Mn} / \mathrm{Ca} \\
\mathrm{Log} 10\end{array}$ & \begin{tabular}{|l|} 
Pearson Correlation \\
Sig. (2-tailed) \\
N
\end{tabular} & & & & & $\begin{array}{r}.087 \\
.546 \\
50 \\
\end{array}$ & $\begin{array}{r}.539 \\
.000 \\
64\end{array}$ & \begin{tabular}{r|r}
.256 \\
.082 \\
47 \\
\end{tabular} & $\begin{array}{r}.513 \\
.001 \\
42\end{array}$ & $\begin{array}{r}.464 \\
.000 \\
66 \\
\end{array}$ & $\begin{array}{r}.383 \\
.001 \\
66\end{array}$ \\
\hline $\begin{array}{l}\mathrm{Zn} / \mathrm{Ca} \\
\mathrm{Log} 10\end{array}$ & $\begin{array}{l}\text { Pearson Correlation } \\
\text { Sig. (2-tailed) } \\
\mathrm{N} \\
\end{array}$ & & & & & & $\begin{array}{r}.143 \\
.221 \\
75 \\
\end{array}$ & \begin{tabular}{r|r}
.182 \\
.176 \\
57 \\
\end{tabular} & \begin{tabular}{r|}
-.121 \\
.433 \\
44 \\
\end{tabular} & \begin{tabular}{r|}
-.032 \\
.779 \\
77 \\
\end{tabular} & $\begin{array}{r}.068 \\
.560 \\
77 \\
\end{array}$ \\
\hline $\begin{array}{l}\mathrm{Ba} / \mathrm{Ca} \\
\mathrm{Log} 10\end{array}$ & \begin{tabular}{|l|} 
Pearson Correlation \\
Sig. (2-tailed) \\
N
\end{tabular} & & & & & & & $\begin{array}{r}.225 \\
.070 \\
66 \\
\end{array}$ & \begin{tabular}{r|}
.414 \\
.002 \\
54 \\
\end{tabular} & $\begin{array}{r}.618 \\
.000 \\
92\end{array}$ & $\begin{array}{r}.717 \\
.000 \\
93\end{array}$ \\
\hline $\begin{array}{l}\mathrm{Pb} / \mathrm{Ca} \\
\mathrm{Log} 10\end{array}$ & \begin{tabular}{|l|} 
Pearson Correlation \\
Sig. (2-tailed) \\
$\mathrm{N}$ \\
\end{tabular} & & & & & & & & \begin{tabular}{r|}
.011 \\
.948 \\
37
\end{tabular} & \begin{tabular}{r|}
.147 \\
.232 \\
68
\end{tabular} & $\begin{array}{r}.114 \\
.353 \\
68\end{array}$ \\
\hline $\begin{array}{c}\mathrm{U} / \mathrm{Ca} \\
\mathrm{Log} 10\end{array}$ & \begin{tabular}{|l|} 
Pearson Correlation \\
Sig. (2-tailed) \\
$\mathrm{N}$
\end{tabular} & & & & & & & & & $\begin{array}{r}.381 \\
.004 \\
55\end{array}$ & $\begin{array}{r}.337 \\
.011 \\
56\end{array}$ \\
\hline $\mathrm{Li} / \mathrm{Ca}$ & $\begin{array}{l}\text { Pearson Correlation } \\
\text { Sig. (2-tailed) } \\
\mathrm{N}\end{array}$ & & & & & & & & & & $\begin{array}{r}.327 \\
.001 \\
95\end{array}$ \\
\hline $\mathrm{Sr} 88 / \mathrm{Ca}$ & \begin{tabular}{|l|} 
Pearson Correlation \\
Sig. (2-tailed) \\
$\mathrm{N}$
\end{tabular} & & & & & & & & & & \\
\hline
\end{tabular}

Appendix 3.1c. Pearsons correlation between element/Ca ratios in the prismatic layer of samples P1B and P04A from Pourerere. ** Correlation is significant at the 0.01 level and * correlation is significant at the 0.05 level. 


\begin{tabular}{|c|c|c|c|c|c|c|c|c|c|c|c|}
\hline \multicolumn{2}{|c|}{$\begin{array}{l}\text { SC2 Correlations } \\
\text { Prismatic Layer }\end{array}$} & $\begin{array}{l}\mathrm{B} / \mathrm{Ca} \\
\text { Log10 }\end{array}$ & $\begin{array}{l}\text { Mg/Ca } \\
\text { Log10 }\end{array}$ & $\begin{array}{l}\text { Al/Ca } \\
\text { Log10 }\end{array}$ & $\begin{array}{l}\mathrm{Mn} / \mathrm{Ca} \\
\text { Log10 }\end{array}$ & $\begin{array}{l}\mathrm{Zn} / \mathrm{Ca} \\
\mathrm{Log} 10\end{array}$ & $\begin{array}{l}\mathrm{Pb} / \mathrm{Ca} \\
\mathrm{Log} 10\end{array}$ & Li/Ca & $\mathrm{Sr} 88 / \mathrm{Ca}$ & $\mathrm{Ba} / \mathrm{Ca}$ & $\mathrm{U} / \mathrm{Ca}$ \\
\hline $\begin{array}{l}\mathrm{B} / \mathrm{Ca} \\
\mathrm{Log} 10\end{array}$ & \begin{tabular}{|l|} 
Pearson \\
Correlation \\
Sig. (2-tailed) \\
$\mathrm{N}$ \\
\end{tabular} & & $\begin{array}{r}-.092 \\
.433 \\
75 \\
\end{array}$ & $\begin{array}{r}.164 \\
.324 \\
38 \\
\end{array}$ & $\begin{array}{r}-.118 \\
.354 \\
64 \\
\end{array}$ & $\begin{array}{r}-185 \\
.193 \\
51 \\
\end{array}$ & $\begin{array}{r}-.155 \\
.388 \\
33 \\
\end{array}$ & $\begin{array}{r}-100 \\
.391 \\
75 \\
\end{array}$ & $\begin{array}{r}.228 \\
.049 \\
75 \\
\end{array}$ & $\begin{array}{r}-238^{\circ} \\
.040 \\
75 \\
\end{array}$ & $\begin{array}{r}.249 \\
.149 \\
35 \\
\end{array}$ \\
\hline $\begin{array}{l}\mathrm{Mg} / \mathrm{Ca} \\
\mathrm{Log} 10\end{array}$ & \begin{tabular}{|l|} 
Pearson \\
Correlation \\
Sig. (2-tailed) \\
$\mathrm{N}$ \\
\end{tabular} & & & \begin{tabular}{r|}
.172 \\
.184 \\
61 \\
\end{tabular} & $\begin{array}{r}.275 \\
.006 \\
97 \\
\end{array}$ & \begin{tabular}{r|}
.046 \\
.691 \\
77 \\
\end{tabular} & $\begin{array}{r}.034 \\
.811 \\
52 \\
\end{array}$ & $\begin{array}{r}.469 \\
.000 \\
116 \\
\end{array}$ & $\begin{array}{r}.339 \\
.000 \\
116 \\
\end{array}$ & $\begin{array}{c}.545 \\
.000 \\
116 \\
\end{array}$ & $\begin{array}{r}.196 \\
.140 \\
58 \\
\end{array}$ \\
\hline $\begin{array}{l}\text { Al/Ca } \\
\text { Log10 }\end{array}$ & \begin{tabular}{|l|} 
Pearson \\
Correlation \\
Sig. (2-tailed) \\
$\mathrm{N}$ \\
\end{tabular} & & & & $\begin{array}{r}.072 \\
.609 \\
53 \\
\end{array}$ & $\begin{array}{r}.238 \\
.119 \\
44 \\
\end{array}$ & $\begin{array}{r}.100 \\
.598 \\
30 \\
\end{array}$ & $\begin{array}{r}.037 \\
.775 \\
61 \\
\end{array}$ & $\begin{array}{r}.175 \\
.177 \\
61 \\
\end{array}$ & $\begin{array}{r}.217 \\
.092 \\
61 \\
\end{array}$ & $\begin{array}{r}-203 \\
.283 \\
30 \\
\end{array}$ \\
\hline $\begin{array}{l}\mathrm{Mn} / \mathrm{Ca} \\
\mathrm{Log} 10\end{array}$ & \begin{tabular}{|l|} 
Pearson \\
Correlation \\
Sig. (2-tailed) \\
$\mathrm{N}$ \\
\end{tabular} & & & & & $\begin{array}{r}-.016 \\
.897 \\
65 \\
\end{array}$ & $\begin{array}{r}.050 \\
.757 \\
41 \\
\end{array}$ & $\begin{array}{r}.063 \\
.538 \\
97 \\
\end{array}$ & $\begin{array}{r}-.008 \\
.937 \\
97 \\
\end{array}$ & $\begin{array}{r}.117 \\
.255 \\
97 \\
\end{array}$ & $\begin{array}{r}.045 \\
.756 \\
50 \\
\end{array}$ \\
\hline $\begin{array}{l}\mathrm{Zn} / \mathrm{Ca} \\
\mathrm{Log} 10\end{array}$ & \begin{tabular}{|l|} 
Pearson \\
Correlation \\
Sig. (2-tailed) \\
$\mathrm{N}$ \\
\end{tabular} & & & & & & $\begin{array}{r}-.002 \\
.993 \\
36 \\
\end{array}$ & $\begin{array}{r}.260^{\circ} \\
.022 \\
77 \\
\end{array}$ & $\begin{array}{r}.087 \\
.453 \\
77 \\
\end{array}$ & $\begin{array}{r}.131 \\
.256 \\
77 \\
\end{array}$ & $\begin{array}{r}-.158 \\
.332 \\
40 \\
\end{array}$ \\
\hline $\begin{array}{l}\mathrm{Pb} / \mathrm{Ca} \\
\mathrm{Log} 10\end{array}$ & \begin{tabular}{|l} 
Pearson \\
Correlation \\
Sig. (2-tailed) \\
$\mathrm{N}$
\end{tabular} & & & & & & & $\begin{array}{r}-.079 \\
.577 \\
52 \\
\end{array}$ & $\begin{array}{r}-.054 \\
.706 \\
52\end{array}$ & $\begin{array}{r}-.051 \\
.720 \\
52 \\
\end{array}$ & \begin{tabular}{r|}
-.078 \\
.719 \\
24 \\
\end{tabular} \\
\hline $\mathrm{Li} / \mathrm{Ca}$ & \begin{tabular}{|l|} 
Pearson \\
Correlation \\
Sig. (2-tailed) \\
$\mathrm{N}$ \\
\end{tabular} & & & & & & & & $\begin{array}{r}.387 \\
.000 \\
116 \\
\end{array}$ & $\begin{array}{r}.523 " \\
.000 \\
116 \\
\end{array}$ & $\begin{array}{r}.294 \\
.025 \\
58 \\
\end{array}$ \\
\hline Sr88/Ca & \begin{tabular}{|l|} 
Pearson \\
Correlation \\
Sig. (2-tailed) \\
$\mathrm{N}$ \\
\end{tabular} & & & & & & & & & $\begin{array}{r}.797^{\circ} \\
.000 \\
116 \\
\end{array}$ & $\begin{array}{r}-.125 \\
.350 \\
58 \\
\end{array}$ \\
\hline $\mathrm{Ba} / \mathrm{Ca}$ & \begin{tabular}{|l|} 
Pearson \\
Correlation \\
Sig. (2-tailed) \\
$\mathrm{N}$ \\
\end{tabular} & & & & & & & & & & $\begin{array}{r}-.019 \\
.888 \\
58 \\
\end{array}$ \\
\hline $\mathrm{U} / \mathrm{Ca}$ & \begin{tabular}{|l} 
Pearson \\
Correlation \\
Sig. (2-tailed) \\
$\mathrm{N}$
\end{tabular} & & & & & & & & & & \\
\hline
\end{tabular}

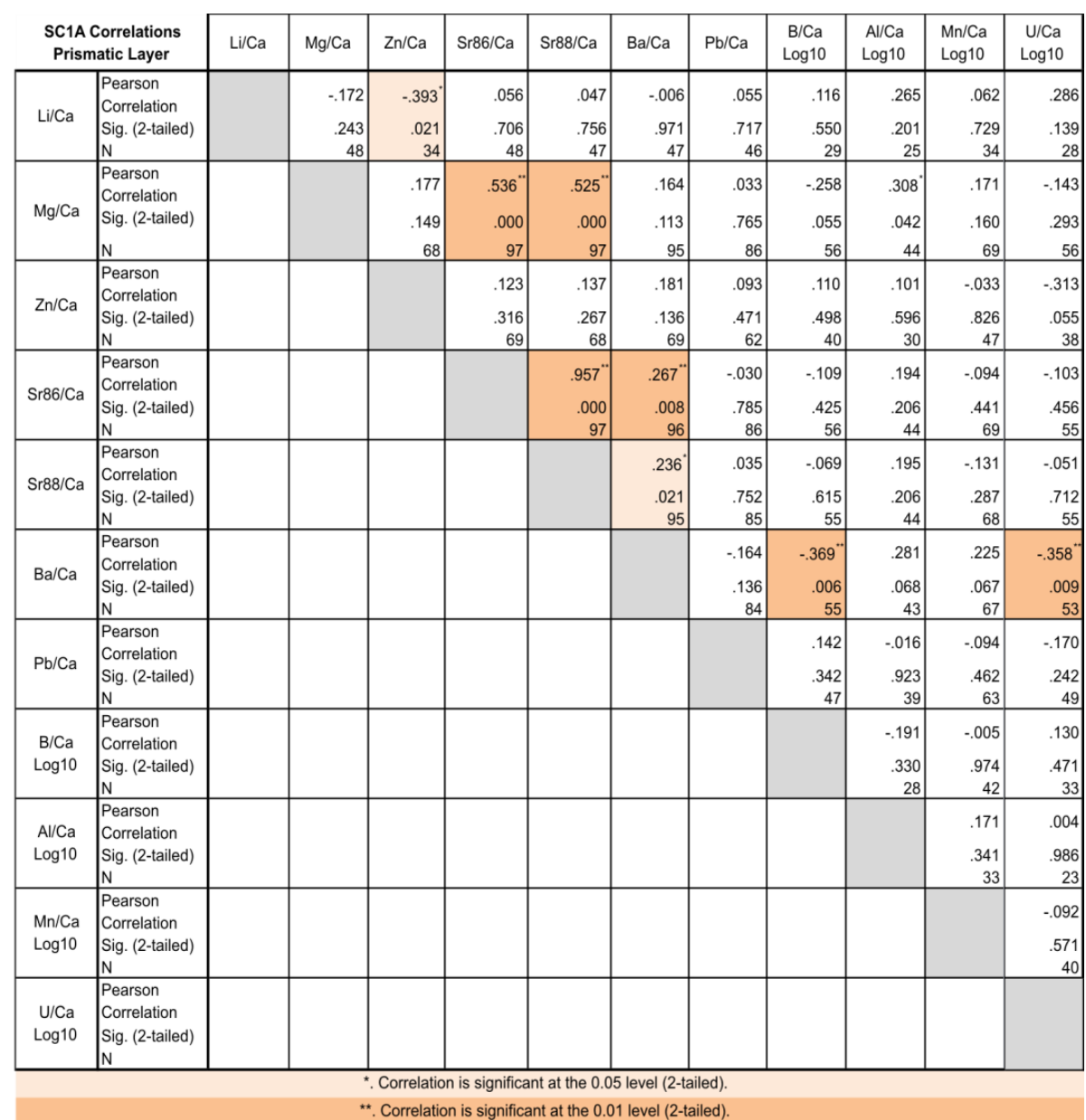

Appendix 3.1d .Pearsons correlation between element/Ca ratios in the prismatic layer of samples SC2 and SC1A from the South Coast of Wellington. ** Correlation is significant at the 0.01 level and * correlation is significant at the 0.05 level. 


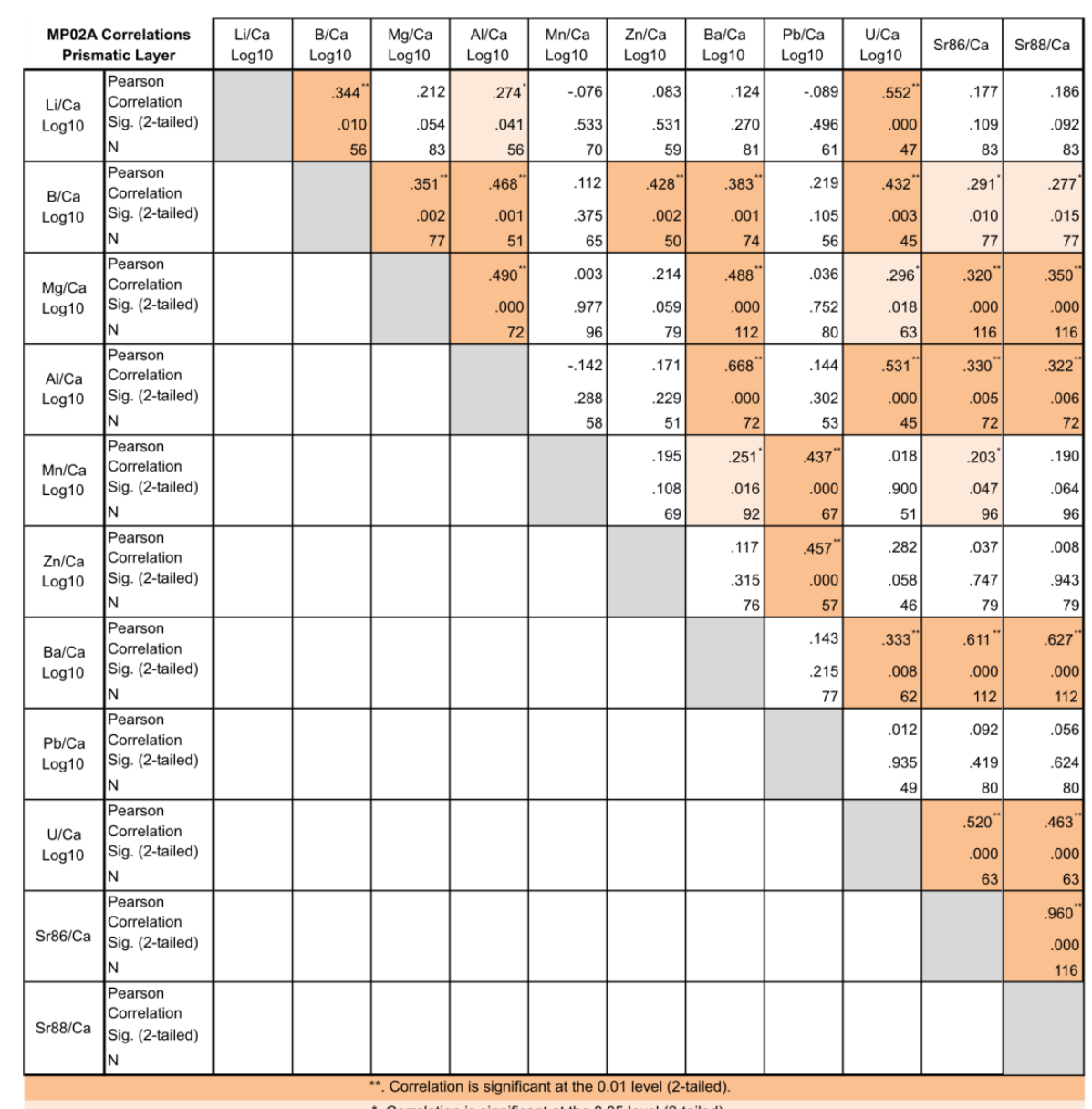

$\because$. Correleation is significant at the 0.01 level (2-tailed).

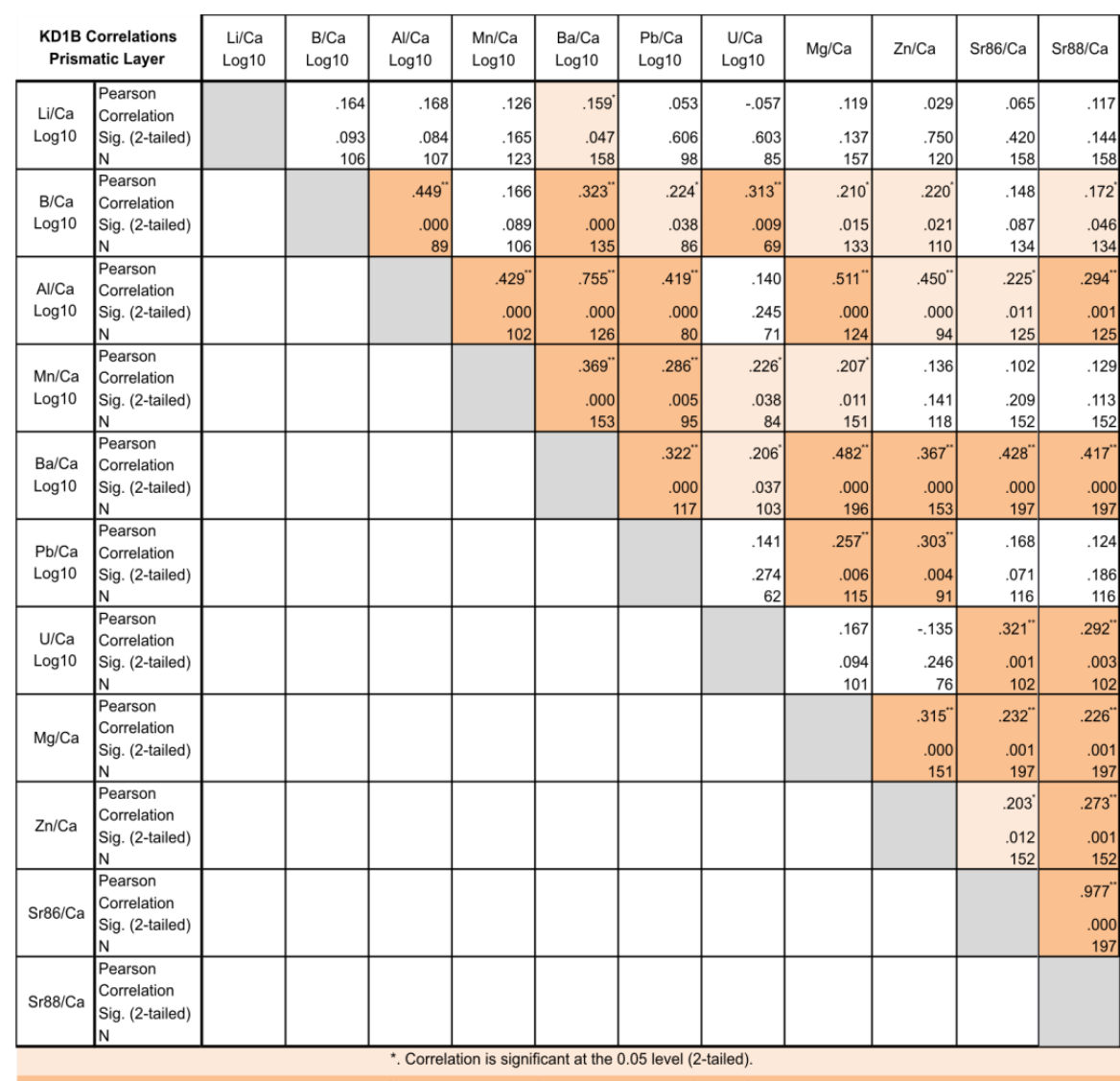

(c)

Appendix 3.1e. Pearsons correlation between element/Ca ratios in the prismatic layer of samples MP02A from Moa Point and KD1B from Kaikoura. ${ }^{* *}$ Correlation is significant at the 0.01 level and * correlation is significant at the 0.05 level. 


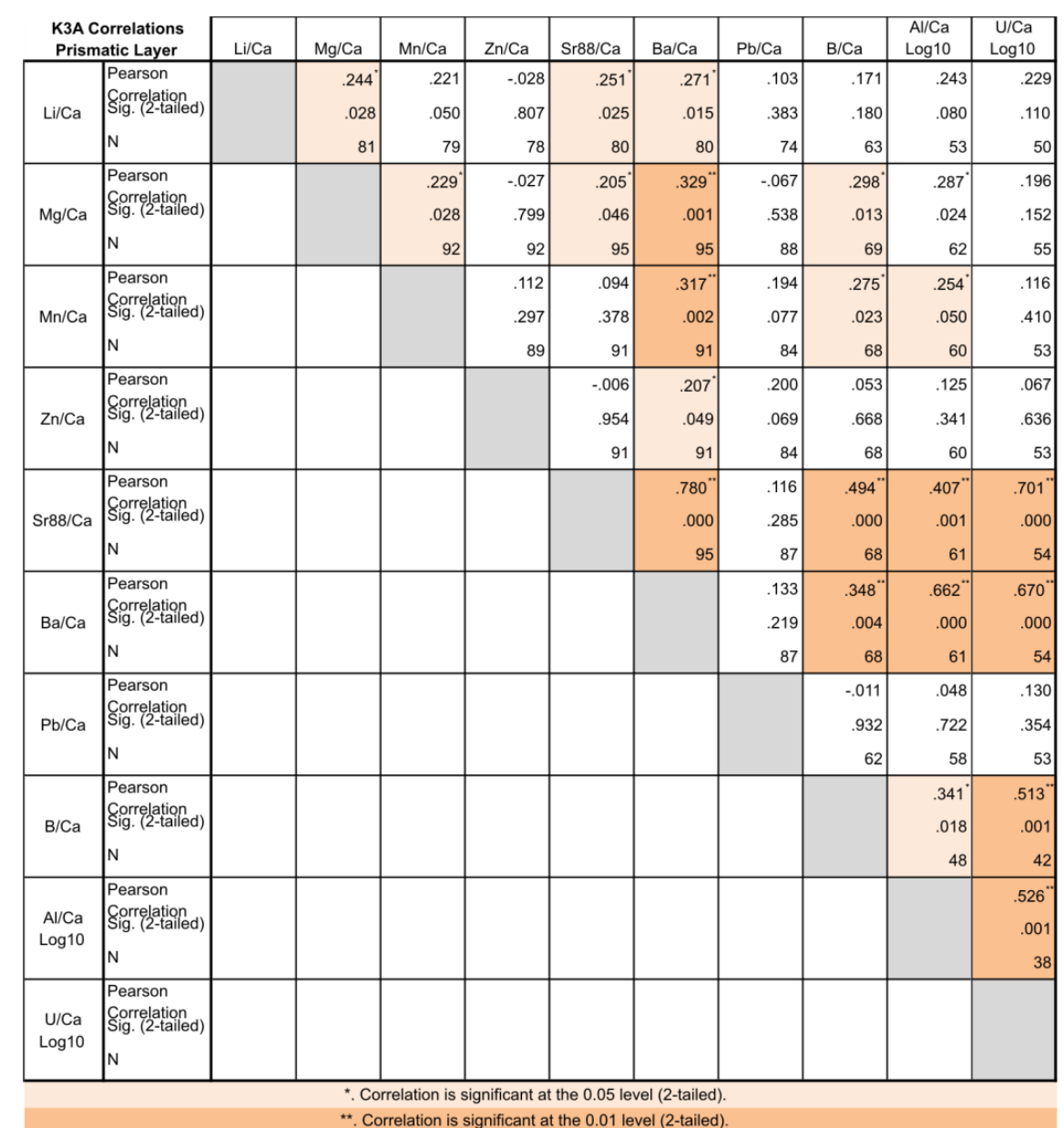

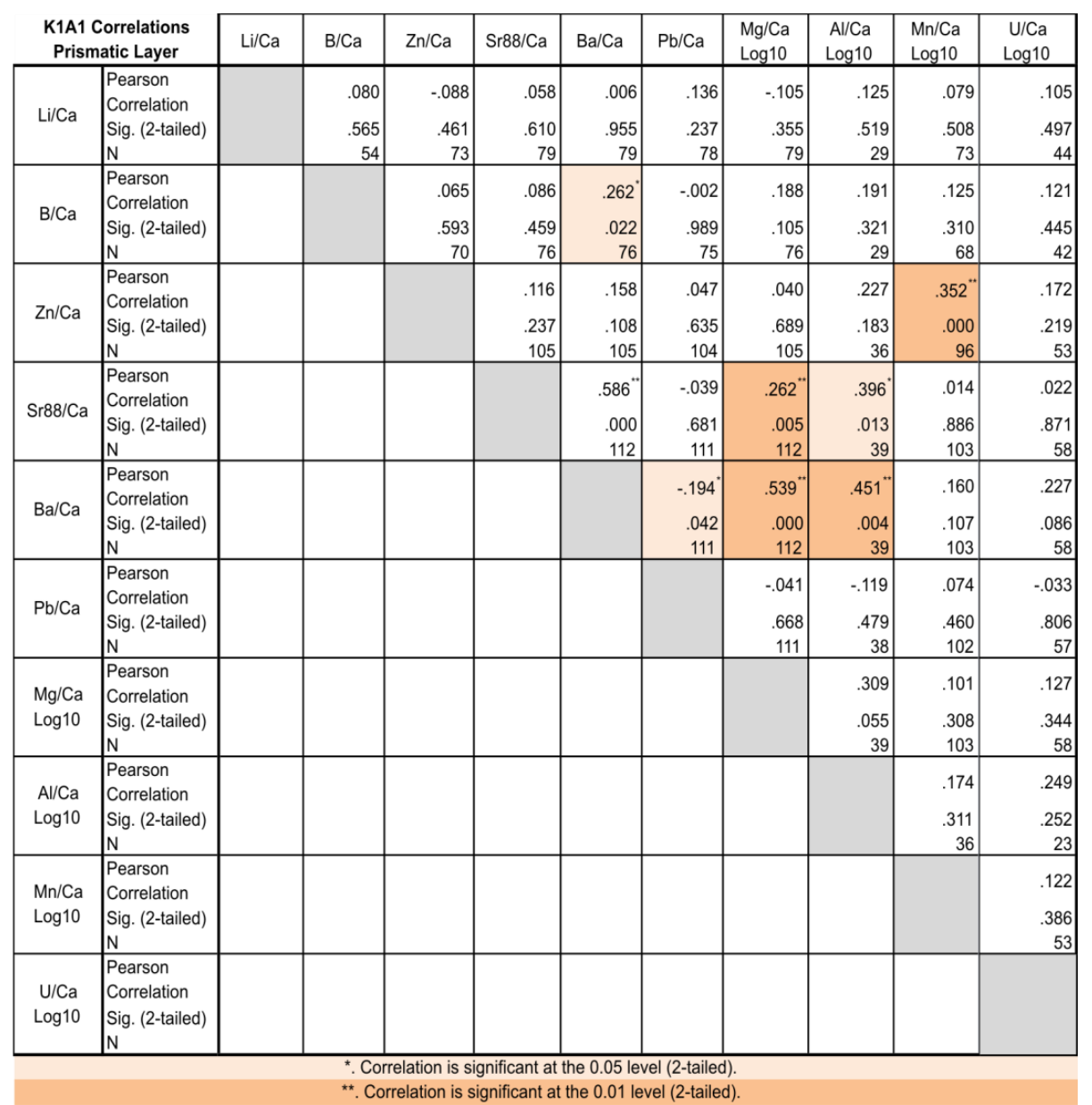

Appendix 3.1f. Pearsons correlation between element/Ca ratios in the prismatic layer of samples K3A and K1A1 from Kaikoura. ${ }^{* *}$ Correlation is significant at the 0.01 level and * correlation is significant at the 0.05 level. 

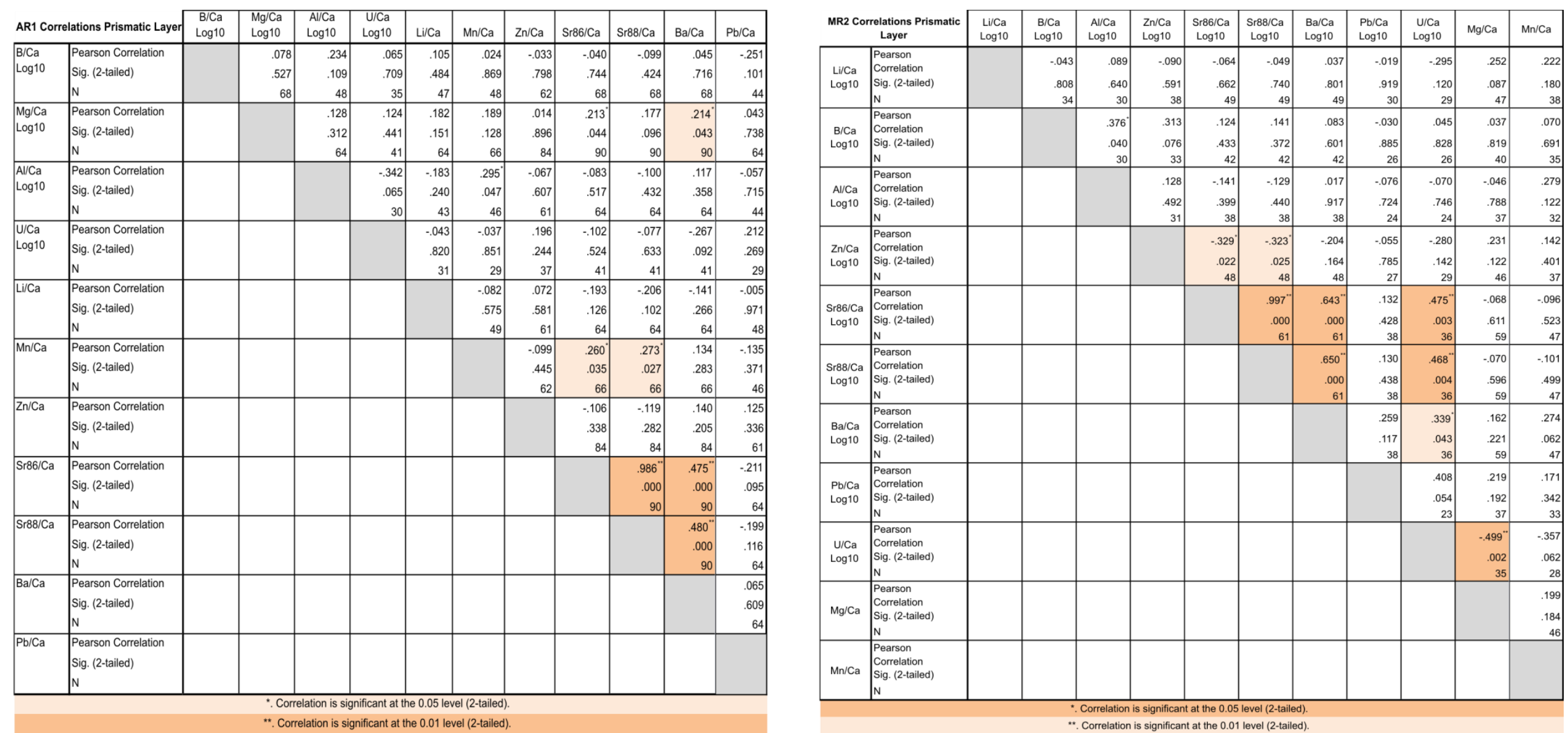

Appendix 3.1g. Pearsons correlation between element/Ca ratios in the prismatic layer of samplesAR1 and MR2 from Chatham Island. ${ }^{* *}$ Correlation is significant at the 0.01 level and * correlation is significant at the 0.05 level. 


\begin{tabular}{|c|c|c|c|c|c|c|c|c|c|c|c|c|}
\hline \multicolumn{2}{|c|}{$\begin{array}{c}\text { MD1 Correlations } \\
\text { Prismmatic Layer }\end{array}$} & $\begin{array}{l}\text { Li/Ca } \\
\text { Log10 }\end{array}$ & $\begin{array}{l}\mathrm{B} / \mathrm{Ca} \\
\log 10\end{array}$ & $\begin{array}{l}\mathrm{Mg} / \mathrm{Ca} \\
\mathrm{Log} 10\end{array}$ & $\begin{array}{l}\text { Al/Ca } \\
\text { Log10 }\end{array}$ & $\begin{array}{l}\mathrm{Mn} / \mathrm{Ca} \\
\mathrm{Log} 10\end{array}$ & $\begin{array}{l}\mathrm{Zn} / \mathrm{Ca} \\
\mathrm{Log} 10\end{array}$ & $\begin{array}{l}\mathrm{U} / \mathrm{Ca} \\
\mathrm{Log} 10\end{array}$ & $\mathrm{Sr} 86 / \mathrm{Ca}$ & $\mathrm{Sr} 88 / \mathrm{Ca}$ & $\mathrm{Ba} / \mathrm{Ca}$ & $\mathrm{Pb} / \mathrm{Ca}$ \\
\hline $\begin{array}{l}\text { Li/Ca } \\
\text { Log10 }\end{array}$ & $\begin{array}{l}\text { Pearson } \\
\text { Correlation } \\
\text { Sig. (2-tailed) } \\
\text { N }\end{array}$ & & $\begin{array}{r}.185 \\
.189 \\
52 \\
\end{array}$ & $\begin{array}{r}-.027 \\
.819 \\
73 \\
\end{array}$ & $\begin{array}{r}-242 \\
.132 \\
40 \\
\end{array}$ & $\begin{array}{r}.341 \\
.008 \\
60 \\
\end{array}$ & \begin{tabular}{r|}
.105 \\
.474 \\
49 \\
\end{tabular} & $\begin{array}{r}.382 \\
.010 \\
44 \\
\end{array}$ & $\begin{array}{r}.071 \\
.550 \\
73 \\
\end{array}$ & $\begin{array}{r}. .141 \\
.241 \\
71 \\
\end{array}$ & $\begin{array}{r}-.097 \\
.430 \\
69 \\
\end{array}$ & $\begin{array}{l}.282 \\
.060 \\
4\end{array}$ \\
\hline $\begin{array}{l}\mathrm{B} / \mathrm{Ca} \\
\text { Log10 }\end{array}$ & \begin{tabular}{|l} 
Pearson \\
Correlation \\
Sig. (2-tailed) \\
$\mathrm{N}$
\end{tabular} & & & $\begin{array}{r}-.118 \\
.328 \\
71 \\
\end{array}$ & \begin{tabular}{r|}
.133 \\
.376 \\
46 \\
\end{tabular} & \begin{tabular}{r|}
.169 \\
.202 \\
59 \\
\end{tabular} & \begin{tabular}{r|}
.076 \\
.604 \\
49 \\
\end{tabular} & $\begin{array}{l}.141 \\
.411 \\
36 \\
\end{array}$ & $\begin{array}{r}.173 \\
.148 \\
71\end{array}$ & $\begin{array}{r}-.030 \\
.806 \\
69 \\
\end{array}$ & $\begin{array}{r}-.089 \\
.474 \\
67 \\
\end{array}$ & $\begin{array}{r}.335 \\
.028 \\
43 \\
\end{array}$ \\
\hline $\begin{array}{l}\mathrm{Mg} / \mathrm{Ca} \\
\text { Log10 }\end{array}$ & \begin{tabular}{|l} 
Pearson \\
Correlation \\
Sig. (2-tailed) \\
$\mathrm{N}$
\end{tabular} & & & & $\begin{array}{r}.247 \\
.057 \\
60\end{array}$ & \begin{tabular}{r|}
.045 \\
.693 \\
78 \\
\end{tabular} & $\begin{array}{r}-.038 \\
.757 \\
68\end{array}$ & $\begin{array}{r}.102 \\
.465 \\
54\end{array}$ & $\begin{array}{r}.071 \\
.491 \\
97\end{array}$ & $\begin{array}{r}.518 \\
.000 \\
95\end{array}$ & $\begin{array}{r}.423 " \\
.000 \\
93\end{array}$ & $\begin{array}{r}-.036 \\
.789 \\
58\end{array}$ \\
\hline $\begin{array}{l}\text { Al/Ca } \\
\text { Log10 }\end{array}$ & \begin{tabular}{|l|} 
Pearson \\
Correlation \\
Sig. (2-tailed) \\
$\mathrm{N}$
\end{tabular} & & & & & \begin{tabular}{r|}
-.002 \\
.987 \\
46 \\
\end{tabular} & \begin{tabular}{r|}
.105 \\
.507 \\
42 \\
\end{tabular} & \begin{tabular}{r|}
.064 \\
.742 \\
29 \\
\end{tabular} & $\begin{array}{r}.076 \\
.566 \\
60\end{array}$ & \begin{tabular}{r|}
.364 \\
.005 \\
59 \\
\end{tabular} & $\begin{array}{r}.509 " \\
.000 \\
58\end{array}$ & $\begin{array}{r}-.155 \\
.366 \\
36\end{array}$ \\
\hline $\begin{array}{l}\mathrm{Mn} / \mathrm{Ca} \\
\text { Log10 }\end{array}$ & \begin{tabular}{|l|} 
Pearson \\
Correlation \\
Sig. (2-tailed) \\
N
\end{tabular} & & & & & & \begin{tabular}{r|r}
.166 \\
.231 \\
54 \\
\end{tabular} & $\begin{array}{r}.386 \\
.007 \\
48\end{array}$ & $\begin{array}{r}.115 \\
.316 \\
78\end{array}$ & \begin{tabular}{r|}
.101 \\
.386 \\
76
\end{tabular} & $\begin{array}{r}-.084 \\
.474 \\
74\end{array}$ & $\begin{array}{r}.245 \\
.105 \\
45\end{array}$ \\
\hline $\begin{array}{l}\mathrm{Zn} / \mathrm{Ca} \\
\mathrm{Log} 10\end{array}$ & $\begin{array}{l}\text { Pearson } \\
\text { Correlation } \\
\text { Sig. (2-tailed) } \\
\mathrm{N}\end{array}$ & & & & & & & $\begin{array}{r}-.115 \\
.505 \\
36\end{array}$ & $\begin{array}{r}.040 \\
.743 \\
68\end{array}$ & \begin{tabular}{r|}
.074 \\
.550 \\
67
\end{tabular} & $\begin{array}{l}.020 \\
.871 \\
66\end{array}$ & $\begin{array}{r}.045 \\
.775 \\
43\end{array}$ \\
\hline $\begin{array}{l}\mathrm{U} / \mathrm{Ca} \\
\text { Log10 }\end{array}$ & \begin{tabular}{|l} 
Pearson \\
Correlation \\
Sig. (2-tailed) \\
$\mathrm{N}$
\end{tabular} & & & & & & & & $\begin{array}{r}.533^{\prime \prime} \\
.000 \\
54\end{array}$ & \begin{tabular}{r|}
.382 \\
.005 \\
52
\end{tabular} & \begin{tabular}{r|r|}
.158 \\
.273 \\
50
\end{tabular} & 118 \\
\hline $\mathrm{Sr} 86 / \mathrm{Ca}$ & \begin{tabular}{|l} 
Pearson \\
Correlation \\
Sig. (2-tailed) \\
N
\end{tabular} & & & & & & & & & \begin{tabular}{r|}
$.983 "$ \\
.000 \\
95
\end{tabular} & \begin{tabular}{r|}
$.419^{\prime}$ \\
.000 \\
93
\end{tabular} & $\begin{array}{r}-.020 \\
.881 \\
58\end{array}$ \\
\hline $\mathrm{Sr} 88 / \mathrm{Ca}$ & $\begin{array}{l}\text { Pearson } \\
\text { Correlation } \\
\text { Sig. (2-tailed) } \\
\mathrm{N}\end{array}$ & & & & & & & & & & $\begin{array}{r}.457 \\
.000 \\
93 \\
\end{array}$ & $\begin{array}{r}-.107 \\
.426 \\
57 \\
\end{array}$ \\
\hline $\mathrm{Ba} / \mathrm{Ca}$ & \begin{tabular}{|l} 
Pearson \\
Correlation \\
Sig. (2-tailed) \\
$\mathrm{N}$
\end{tabular} & & & & & & & & & & & $\begin{array}{r}-127 \\
.352 \\
52\end{array}$ \\
\hline $\mathrm{Pb} / \mathrm{Ca}$ & \begin{tabular}{|l} 
Pearson \\
Correlation \\
Sig. (2-tailed) \\
N
\end{tabular} & & & & & & & & & & & \\
\hline
\end{tabular}

\begin{tabular}{|c|c|c|c|c|c|c|c|c|c|c|c|c|}
\hline \multicolumn{2}{|c|}{$\begin{array}{l}\text { MD3 Correlations } \\
\text { Prismatic Layer }\end{array}$} & $\begin{array}{l}\text { B/Ca } \\
\text { Log10 }\end{array}$ & $\begin{array}{l}\text { Mg/Ca } \\
\text { Log10 }\end{array}$ & $\begin{array}{l}\text { Al/Ca } \\
\text { Log10 }\end{array}$ & $\begin{array}{l}\text { Mn/Ca } \\
\text { Log10 }\end{array}$ & $\begin{array}{l}\mathrm{Pb} / \mathrm{Ca} \\
\mathrm{Log10}\end{array}$ & $\begin{array}{l}\text { U/Ca } \\
\text { Log10 }\end{array}$ & Li/Ca & $\mathrm{Zn} / \mathrm{Ca}$ & sr86/Ca & $\mathrm{sr} 88 / \mathrm{Ca}$ & $\mathrm{Ba} / \mathrm{Ca}$ \\
\hline \begin{tabular}{|c} 
B/Ca \\
Log10
\end{tabular} & 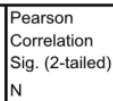 & & $\begin{array}{l}.311 \\
.017 \\
59\end{array}$ & $\begin{array}{r}.387 \\
.015 \\
39\end{array}$ & $\begin{array}{r}.119 \\
.405 \\
51\end{array}$ & $\begin{array}{r}.150 \\
.360 \\
39\end{array}$ & $\begin{array}{r}.114 \\
.579 \\
26\end{array}$ & $\begin{array}{l}.318^{\circ} \\
.030 \\
47\end{array}$ & $\begin{array}{r}.054 \\
.692 \\
56\end{array}$ & $\begin{array}{r}.500^{\circ} \\
.000 \\
59\end{array}$ & $\begin{array}{r}.444 " \\
.000 \\
58\end{array}$ & $\begin{array}{r}.460^{\circ} \\
.000 \\
58\end{array}$ \\
\hline $\begin{array}{l}\mathrm{Mg} / \mathrm{Ca} \\
\mathrm{Log} 10\end{array}$ & \begin{tabular}{|l} 
Pearson \\
Correlation \\
Sig. (2-tailed) \\
N
\end{tabular} & & & \begin{tabular}{r|}
.427 \\
.001 \\
59
\end{tabular} & \begin{tabular}{r|}
.128 \\
.255 \\
81
\end{tabular} & \begin{tabular}{r|}
.128 \\
.339 \\
58
\end{tabular} & \begin{tabular}{r|}
.283 \\
.073 \\
41
\end{tabular} & \begin{tabular}{r|}
.144 \\
.241 \\
68
\end{tabular} & $\begin{array}{r}.089 \\
.417 \\
86\end{array}$ & \begin{tabular}{r|r|}
$.330^{\circ}$ \\
.002 \\
89
\end{tabular} & $\begin{array}{r}.232^{\circ} \\
.030 \\
88\end{array}$ & $\begin{array}{r}.452^{\circ} \\
.000 \\
87\end{array}$ \\
\hline \begin{tabular}{|l} 
Al/Ca \\
Log10
\end{tabular} & \begin{tabular}{|l} 
Pearson \\
Correlation \\
Sig. (2-tailed) \\
N
\end{tabular} & & & & \begin{tabular}{r|}
.256 \\
.064 \\
53
\end{tabular} & \begin{tabular}{r|}
.131 \\
.402 \\
43 \\
\end{tabular} & \begin{tabular}{r|}
.182 \\
.319 \\
32
\end{tabular} & $\begin{array}{r}.219 \\
.135 \\
48\end{array}$ & \begin{tabular}{r|r|}
.178 \\
.190 \\
56
\end{tabular} & \begin{tabular}{r|r|}
$.488 "$ \\
.000 \\
59
\end{tabular} & \begin{tabular}{r|}
$.422 "$ \\
.001 \\
58
\end{tabular} & $\begin{array}{r}.611 \\
.000 \\
58\end{array}$ \\
\hline $\begin{array}{l}\text { Mn/Ca } \\
\text { Log10 }\end{array}$ & \begin{tabular}{|l} 
Pearson \\
Correlation \\
Sig. (2-tailed) \\
N
\end{tabular} & & & & & $\begin{array}{r}-.112 \\
.423 \\
53\end{array}$ & \begin{tabular}{r|}
.133 \\
.426 \\
38
\end{tabular} & \begin{tabular}{r|}
.024 \\
.850 \\
63
\end{tabular} & $\begin{array}{r}.001 \\
.993 \\
78\end{array}$ & $\begin{array}{r}.226 \\
.042 \\
81\end{array}$ & \begin{tabular}{r|}
.185 \\
.101 \\
80
\end{tabular} & $\begin{array}{r}.213 \\
.060 \\
79\end{array}$ \\
\hline $\begin{array}{l}\mathrm{Pb} / \mathrm{Ca} \\
\mathrm{Log} 10\end{array}$ & \begin{tabular}{|l} 
Pearson \\
Correlation \\
Sig. (2-tailed) \\
N
\end{tabular} & & & & & & $\begin{array}{r}.223 \\
.245 \\
29\end{array}$ & $\begin{array}{r}.009 \\
.954 \\
44\end{array}$ & $\begin{array}{r}.231 \\
.086 \\
56\end{array}$ & $\begin{array}{r}.204 \\
.124 \\
58\end{array}$ & $\begin{array}{r}.112 \\
.405 \\
57\end{array}$ & $\begin{array}{r}.108 \\
.423 \\
57\end{array}$ \\
\hline \begin{tabular}{|l} 
U/Ca \\
Log10
\end{tabular} & \begin{tabular}{|l} 
Pearson \\
Correlation \\
Sig. (2-tailed) \\
N
\end{tabular} & & & & & & & $\begin{array}{r}-132 \\
.471 \\
32\end{array}$ & $\begin{array}{l}.117 \\
.485 \\
38\end{array}$ & \begin{tabular}{r|}
.451 \\
.003 \\
41
\end{tabular} & \begin{tabular}{r|}
$.469^{\circ}$ \\
.002 \\
41
\end{tabular} & $\begin{array}{c}.413 \\
.007 \\
41\end{array}$ \\
\hline Li/Ca & \begin{tabular}{|l} 
Pearson \\
Correlation \\
Sig. (2-tailed) \\
N \\
\end{tabular} & & & & & & & & \begin{tabular}{r|r}
.165 \\
.187 \\
66
\end{tabular} & \begin{tabular}{r|}
.225 \\
.065 \\
68
\end{tabular} & \begin{tabular}{r|r|}
.062 \\
.618 \\
67
\end{tabular} & $\begin{array}{r}.203 \\
.100 \\
67\end{array}$ \\
\hline $\mathrm{Zn} / \mathrm{Ca}$ & \begin{tabular}{|l} 
Pearson \\
Correlation \\
Sig. (2-tailed) \\
N
\end{tabular} & & & & & & & & & \begin{tabular}{r|}
.009 \\
.937 \\
86
\end{tabular} & \begin{tabular}{r|r|}
.021 \\
.852 \\
85
\end{tabular} & $\begin{array}{r}.172 \\
.118 \\
84\end{array}$ \\
\hline Sr86/Ca & \begin{tabular}{|l} 
Pearson \\
Correlation \\
sig. (2-tailed) \\
N \\
\end{tabular} & & & & & & & & & & \begin{tabular}{r|r|}
$.996 "$ \\
.000 \\
88
\end{tabular} & $\begin{array}{r}.764^{\circ} \\
.000 \\
87\end{array}$ \\
\hline Sr88/Ca & \begin{tabular}{|l} 
Pearson \\
Correlation \\
Sig. (2-tailed) \\
N
\end{tabular} & & & & & & & & & & & $\begin{array}{r}.763 \\
.000 \\
87\end{array}$ \\
\hline $\mathrm{Ba} / \mathrm{Ca}$ & \begin{tabular}{|l} 
Pearson \\
Correlation \\
Sig. (2-tailed) \\
N
\end{tabular} & & & & & & & & & & & \\
\hline
\end{tabular}

Appendix 3.1h. Pearsons correlation between element/Ca ratios in the prismatic layer of samples MD1 and MD3 from Moeraki. ** Correlation is significant at the 0.01 level and * correlation is significant at the 0.05 level. 
APPENDIX 3.2

Nacreous layer correlations matrices

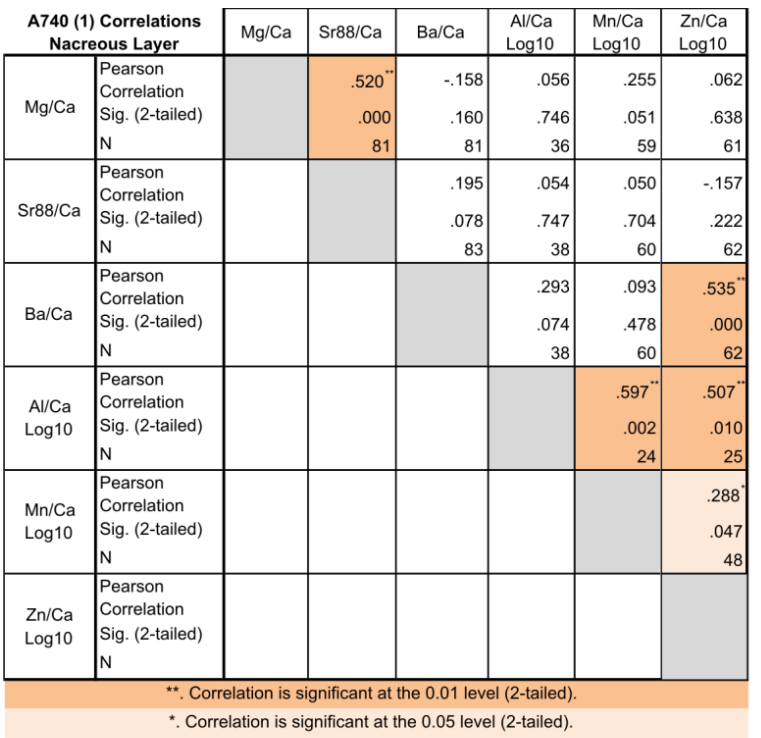

\begin{tabular}{|c|c|c|c|c|c|c|c|c|c|c|c|}
\hline \multicolumn{2}{|c|}{$\begin{array}{c}\text { A740 (2) Correlations } \\
\text { Nacreous Layer }\end{array}$} & $\begin{array}{l}\text { Al/Ca } \\
\text { Log10 }\end{array}$ & $\mathrm{Ba} / \mathrm{Ca}$ & Li/Ca & $\mathrm{B} / \mathrm{Ca}$ & $\mathrm{Mg} / \mathrm{Ca}$ & $\mathrm{Mn} / \mathrm{Ca}$ & $\mathrm{Zn} / \mathrm{Ca}$ & Sr88/Ca & $\mathrm{Ba} / \mathrm{Ca}$ & $\mathrm{U} / \mathrm{Ca}$ \\
\hline $\begin{array}{l}\text { Al/Ca } \\
\text { Log10 }\end{array}$ & $\begin{array}{l}\text { Pearson } \\
\text { Correlation } \\
\text { Sig. (2-tailed) } \\
N\end{array}$ & & $\begin{array}{r}.527 \\
.096 \\
11\end{array}$ & \begin{tabular}{r|}
-.013 \\
.971 \\
10
\end{tabular} & $\begin{array}{r}.040 \\
.907 \\
11\end{array}$ & $\begin{array}{r}-.139 \\
.683 \\
11\end{array}$ & $\begin{array}{r}.080 \\
.826 \\
10\end{array}$ & $\begin{array}{r}.474 \\
.141 \\
11\end{array}$ & $\begin{array}{r}.399 \\
.224 \\
11\end{array}$ & $\begin{array}{r}-.043 \\
.900 \\
11\end{array}$ & $\begin{array}{r}-.159 \\
.706 \\
8\end{array}$ \\
\hline $\mathrm{Ba} / \mathrm{Ca}$ & \begin{tabular}{|l}
$\begin{array}{l}\text { Pearson } \\
\text { Correlation } \\
\text { Sig. (2-tailed) } \\
\text { N }\end{array}$ \\
\end{tabular} & & & $\begin{array}{r}.451 \\
.079 \\
16 \\
\end{array}$ & \begin{tabular}{r|}
-.076 \\
.772 \\
17 \\
\end{tabular} & \begin{tabular}{r|}
-.333 \\
.191 \\
17 \\
\end{tabular} & \begin{tabular}{r|}
.007 \\
.978 \\
16 \\
\end{tabular} & \begin{tabular}{r|}
.066 \\
.803 \\
17 \\
\end{tabular} & \begin{tabular}{r|}
.440 \\
.077 \\
17 \\
\end{tabular} & \begin{tabular}{r|}
.303 \\
.237 \\
17 \\
\end{tabular} & \begin{tabular}{r|}
.037 \\
.904 \\
13 \\
\end{tabular} \\
\hline Li/Ca & $\begin{array}{l}\text { Pearson } \\
\text { Correlation } \\
\text { Sig. (2-tailed) } \\
\text { N } \\
\end{array}$ & & & & \begin{tabular}{r|}
-.272 \\
.308 \\
16 \\
\end{tabular} & $\begin{array}{r}-.137 \\
.613 \\
16 \\
\end{array}$ & $\begin{array}{r}-.028 \\
.922 \\
15 \\
\end{array}$ & $\begin{array}{r}-.193 \\
.475 \\
16 \\
\end{array}$ & $\begin{array}{r}-.257 \\
.337 \\
16 \\
\end{array}$ & \begin{tabular}{r|}
-.129 \\
.634 \\
16 \\
\end{tabular} & $\begin{array}{r}.056 \\
.862 \\
12 \\
\end{array}$ \\
\hline $\mathrm{B} / \mathrm{Ca}$ & $\begin{array}{l}\text { learson } \\
\text { Correlation } \\
\text { Sig. (2-tailed) } \\
N_{N}\end{array}$ & & & & & $\begin{array}{r}.312 \\
.222 \\
17\end{array}$ & $\begin{array}{r}-232 \\
.386 \\
16\end{array}$ & $\begin{array}{r}.213 \\
.411 \\
17\end{array}$ & \begin{tabular}{r|r}
.439 \\
.078 \\
17
\end{tabular} & $\begin{array}{r}-.093 \\
.723 \\
17\end{array}$ & $\begin{array}{r}-351 \\
.240 \\
13\end{array}$ \\
\hline $\mathrm{Mg} / \mathrm{Ca}$ & \begin{tabular}{|l} 
Pearson \\
Correlation \\
Sig. (2-tailed) \\
N
\end{tabular} & & & & & & $\begin{array}{r}-.575 \\
.020 \\
16 \\
\end{array}$ & \begin{tabular}{r|}
-.443 \\
.075 \\
17 \\
\end{tabular} & $\begin{array}{r}-.059 \\
.822 \\
17 \\
\end{array}$ & $\begin{array}{r}.822 \\
.000 \\
17 \\
\end{array}$ & $\begin{array}{r}-.213 \\
.486 \\
13 \\
\end{array}$ \\
\hline $\mathrm{Mn} / \mathrm{Ca}$ & $\begin{array}{l}\text { Pearson } \\
\text { Correlation } \\
\text { Sig. (2-tailed) } \\
\text { N }\end{array}$ & & & & & & & $\begin{array}{r}.226 \\
.401 \\
16\end{array}$ & $\begin{array}{r}-.154 \\
.570 \\
16\end{array}$ & $\begin{array}{r}.628^{\prime \prime} \\
.009 \\
16\end{array}$ & $\begin{array}{r}-.344 \\
.250 \\
13\end{array}$ \\
\hline $\mathrm{Zn} / \mathrm{Ca}$ & $\begin{array}{l}\text { Pearson } \\
\text { 林elation } \\
\text { Sig. (2-tailed) } \\
\text { N }\end{array}$ & & & & & & & & $\begin{array}{r}-.073 \\
.780 \\
17 \\
\end{array}$ & $\begin{array}{r}.357 \\
.159 \\
17 \\
\end{array}$ & $\begin{array}{r}-.011 \\
.972 \\
13 \\
\end{array}$ \\
\hline $\mathrm{Sr} 88 / \mathrm{Ca}$ & $\begin{array}{l}\text { Pearson } \\
\text { Correlation } \\
\text { Sig. (2-tailed) } \\
\text { N } \\
\end{array}$ & & & & & & & & & $\begin{array}{r}.420 \\
.094 \\
17 \\
\end{array}$ & $\begin{array}{r}.352 \\
.238 \\
13 \\
\end{array}$ \\
\hline $\mathrm{Ba} / \mathrm{Ca}$ & $\begin{array}{l}\text { Pearson } \\
\text { Correlation } \\
\text { Sig. (2-tailed) } \\
\mathbb{N}\end{array}$ & & & & & & & & & & $\begin{array}{r}-.245 \\
.421 \\
13\end{array}$ \\
\hline $\mathrm{U} / \mathrm{Ca}$ & $\begin{array}{l}\text { Pearson } \\
\text { Correlation } \\
\text { Sig. (2-tailed) } \\
\mathbb{N}\end{array}$ & & & & & & & & & & \\
\hline
\end{tabular}

Appendix 3.2a. Pearsons correlation between element/Ca ratios in the nacreous layer of samples A740 (1 \&2) from OBL. ** Correlation is significant at the 0.01 level and * correlation is significant at the 0.05 level. 


\begin{tabular}{|c|c|c|c|c|c|c|c|c|c|c|c|}
\hline \multicolumn{2}{|c|}{$\begin{array}{c}\text { RW75 (100) Correlations } \\
\text { Nacreous Layer } \\
\end{array}$} & $\begin{array}{l}\mathrm{A} / / \mathrm{Ca} \\
\text { Log10 }\end{array}$ & $\begin{array}{l}\mathrm{Mn} / \mathrm{Ca} \\
\log 10\end{array}$ & $\begin{array}{l}\mathrm{Pb} / \mathrm{Ca} \\
\text { Log10 }\end{array}$ & Li/Ca & $\mathrm{B} / \mathrm{Ca}$ & $\mathrm{Mg} / \mathrm{Ca}$ & $\mathrm{Zn} / \mathrm{Ca}$ & Sr88/Ca & $\mathrm{Ba} / \mathrm{Ca}$ & $\mathrm{U} / \mathrm{Ca}$ \\
\hline $\begin{array}{l}\mathrm{A} / / \mathrm{Ca} \\
\text { Log10 }\end{array}$ & \begin{tabular}{|l|}
$\begin{array}{l}\text { Pearson } \\
\text { Correlation } \\
\text { Sig. (2-tailed) } \\
\text { N }\end{array}$ \\
\end{tabular} & & \begin{tabular}{r|}
.076 \\
.787 \\
15 \\
\end{tabular} & $\begin{array}{r}.061 \\
.823 \\
16 \\
\end{array}$ & $\begin{array}{r}.725 \\
.027 \\
9 \\
\end{array}$ & $\begin{array}{r}.063 \\
.810 \\
17 \\
\end{array}$ & $\begin{array}{r}-.010 \\
.968 \\
17 \\
\end{array}$ & $\begin{array}{r}-.161 \\
.524 \\
18 \\
\end{array}$ & $\begin{array}{r}.034 \\
.895 \\
18 \\
\end{array}$ & $\begin{array}{r}.031 \\
.903 \\
18 \\
\end{array}$ & $\begin{array}{r}.585 \\
.168 \\
7 \\
\end{array}$ \\
\hline $\begin{array}{l}\mathrm{Mn} / \mathrm{Ca} \\
\log 10\end{array}$ & \begin{tabular}{|l|} 
Pearson \\
Correlation \\
Sig. (2-tailed) \\
N \\
\end{tabular} & & & $\begin{array}{r}-387 \\
.068 \\
23 \\
\end{array}$ & $\begin{array}{r}.183 \\
.481 \\
17 \\
\end{array}$ & $\begin{array}{r}-.259 \\
.222 \\
24 \\
\end{array}$ & $\begin{array}{r}-.011 \\
.960 \\
24 \\
\end{array}$ & $\begin{array}{r}-.132 \\
.530 \\
25 \\
\end{array}$ & $\begin{array}{r}.301 \\
.144 \\
25 \\
\end{array}$ & $\begin{array}{r}.018 \\
.931 \\
25 \\
\end{array}$ & $\begin{array}{r}-.035 \\
.914 \\
12 \\
\end{array}$ \\
\hline $\begin{array}{l}\mathrm{Pb} / \mathrm{Ca} \\
\log 10\end{array}$ & \begin{tabular}{|l} 
Pearson \\
Correlation \\
Sig. (2-tailed) \\
$\mathrm{N}$ \\
\end{tabular} & & & & $\begin{array}{r}-.323 \\
.222 \\
16 \\
\end{array}$ & $\begin{array}{r}.230 \\
.258 \\
26 \\
\end{array}$ & $\begin{array}{r}.191 \\
.351 \\
26 \\
\end{array}$ & $\begin{array}{r}.062 \\
.759 \\
27 \\
\end{array}$ & $\begin{array}{r}-.267 \\
.178 \\
27 \\
\end{array}$ & $\begin{array}{r}.068 \\
.736 \\
27 \\
\end{array}$ & $\begin{array}{r}.448 \\
.167 \\
11 \\
\end{array}$ \\
\hline Li/Ca & \begin{tabular}{|l} 
Pearson \\
Correlation \\
Sig. (2-tailed) \\
$\mathrm{N}$ \\
\end{tabular} & & & & & $\begin{array}{r}-.536 \\
.027 \\
17\end{array}$ & $\begin{array}{r}-.033 \\
.898 \\
18 \\
\end{array}$ & $\begin{array}{r}.046 \\
.857 \\
18 \\
\end{array}$ & $\begin{array}{r}-.230 \\
.358 \\
18 \\
\end{array}$ & $\begin{array}{r}.021 \\
.934 \\
18 \\
\end{array}$ & $\begin{array}{r}-.052 \\
.886 \\
10 \\
\end{array}$ \\
\hline B/Ca & \begin{tabular}{|l} 
Pearson \\
Correlation \\
Sig. (2-tailed) \\
$\mathrm{N}$ \\
\end{tabular} & & & & & & $\begin{array}{r}.289 \\
.144 \\
27 \\
\end{array}$ & $\begin{array}{r}.444^{\circ} \\
.018 \\
28 \\
\end{array}$ & $\begin{array}{r}.382^{\circ} \\
.045 \\
28 \\
\end{array}$ & $\begin{array}{r}.406^{\circ} \\
.032 \\
28 \\
\end{array}$ & $\begin{array}{r}.241 \\
.427 \\
13 \\
\end{array}$ \\
\hline $\mathrm{Mg} / \mathrm{Ca}$ & \begin{tabular}{|l} 
Pearson \\
Correlation \\
Sig. (2-tailed) \\
$\mathrm{N}$ \\
\end{tabular} & & & & & & & $\begin{array}{r}.137 \\
.485 \\
28 \\
\end{array}$ & $\begin{array}{r}.276 \\
.155 \\
28 \\
\end{array}$ & $\begin{array}{r}.814 \\
.000 \\
28 \\
\end{array}$ & $\begin{array}{r}.131 \\
.684 \\
12 \\
\end{array}$ \\
\hline $\mathrm{Zn} / \mathrm{Ca}$ & \begin{tabular}{|l} 
Pearson \\
Correlation \\
Sig. (2-tailed) \\
$\mathrm{N}$ \\
\end{tabular} & & & & & & & & $\begin{array}{r}.180 \\
.349 \\
29 \\
\end{array}$ & $\begin{array}{r}.416^{\circ} \\
.025 \\
29 \\
\end{array}$ & $\begin{array}{r}.147 \\
.631 \\
13 \\
\end{array}$ \\
\hline $\mathrm{Sr} 88 / \mathrm{Ca}$ & \begin{tabular}{|l} 
Pearson \\
Correlation \\
Sig. (2-tailed) \\
$\mathrm{N}$ \\
\end{tabular} & & & & & & & & & $\begin{array}{r}.291 \\
.125 \\
29 \\
\end{array}$ & $\begin{array}{r}.391 \\
.187 \\
13 \\
\end{array}$ \\
\hline $\mathrm{Ba} / \mathrm{Ca}$ & \begin{tabular}{|l} 
Pearson \\
Correation \\
Sig. (2-tailed) \\
$\mathrm{N}$ \\
\end{tabular} & & & & & & & & & & $\begin{array}{r}.109 \\
.722 \\
13 \\
\end{array}$ \\
\hline $\mathrm{U} / \mathrm{Ca}$ & \begin{tabular}{|l} 
Pearson \\
Correation \\
Sig. (2-tailed) \\
$\mathrm{N}$ \\
\end{tabular} & & & & & & & & & & \\
\hline
\end{tabular}

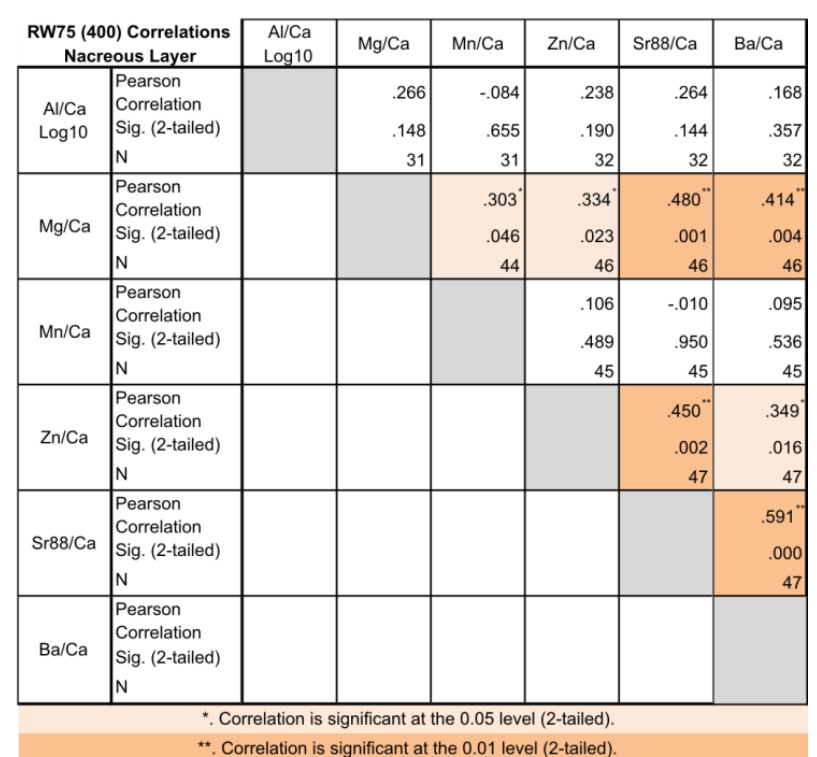

Appendix 3.2b. Pearsons correlation between element/Ca ratios in the nacreous layer of samples RW75 (1 \&2) from OBL. ** Correlation is significant at the 0.01 level and * correlation is significant at the 0.05 level. 


\begin{tabular}{|c|c|c|c|c|c|c|c|c|c|c|c|}
\hline \multicolumn{2}{|c|}{$\begin{array}{l}\text { P1B Correlations Nacreous } \\
\text { Layer }\end{array}$} & $\begin{array}{r}\text { B/Ca } \\
\text { Log10 } \\
\end{array}$ & $\begin{array}{l}\text { Al/Ca } \\
\text { Log10 } \\
\end{array}$ & $\begin{array}{l}\text { Mn/Ca } \\
\text { Log10 }\end{array}$ & $\begin{array}{l}\mathrm{Zn} / \mathrm{Ca} \\
\mathrm{Log} 10 \\
\end{array}$ & $\begin{array}{l}\mathrm{Pb} / \mathrm{Ca} \\
\mathrm{Log} 10\end{array}$ & $\begin{array}{l}\text { U/Ca } \\
\text { Log10 }\end{array}$ & $\mathrm{Li} / \mathrm{Ca}$ & $\mathrm{Mg} / \mathrm{Ca}$ & $\mathrm{Sr} 88 / \mathrm{Ca}$ & $\mathrm{Ba} / \mathrm{Ca}$ \\
\hline $\begin{array}{l}\mathrm{B} / \mathrm{Ca} \\
\log 10\end{array}$ & \begin{tabular}{|l|}
$\begin{array}{l}\text { Pearson } \\
\text { Correlation } \\
\text { Sig. (2-tailed) } \\
\text { N }\end{array}$ \\
\end{tabular} & & $\begin{array}{r}-.046 \\
.748 \\
52 \\
\end{array}$ & $\begin{array}{r}.003 \\
.980 \\
57 \\
\end{array}$ & $\begin{array}{r}-.073 \\
.575 \\
61 \\
\end{array}$ & $\begin{array}{r}.000 \\
.998 \\
87 \\
\end{array}$ & $\begin{array}{r}. .230 \\
.143 \\
42 \\
\end{array}$ & $\begin{array}{r}.209 \\
.106 \\
61 \\
\end{array}$ & $\begin{array}{r}.265^{\circ} \\
.011 \\
92 \\
\end{array}$ & $\begin{array}{r}.254^{\circ} \\
.014 \\
93 \\
\end{array}$ & $\begin{array}{r}.092 \\
.383 \\
93 \\
\end{array}$ \\
\hline $\begin{array}{l}\text { Al.Ca } \\
\text { Log10 }\end{array}$ & $\begin{array}{l}\text { Pearson } \\
\text { Correlation } \\
\text { Sig. (2-tailed) } \\
\text { N }\end{array}$ & & & \begin{tabular}{r|}
.228 \\
.181 \\
36 \\
\end{tabular} & $\begin{array}{r}.086 \\
.613 \\
37 \\
\end{array}$ & $\begin{array}{r}.229 \\
.106 \\
51 \\
\end{array}$ & $\begin{array}{r}.354 \\
.082 \\
25 \\
\end{array}$ & $\begin{array}{r}.203 \\
.249 \\
34 \\
\end{array}$ & $\begin{array}{r}.035 \\
.805 \\
52 \\
\end{array}$ & \begin{tabular}{r|}
.103 \\
.453 \\
55 \\
\end{tabular} & $\begin{array}{r}. .120 \\
.385 \\
55 \\
\end{array}$ \\
\hline $\begin{array}{l}\mathrm{Mn} / \mathrm{Ca} \\
\log 10\end{array}$ & $\begin{array}{l}\text { Pearson } \\
\text { Correlation } \\
\text { Sig. (2-tailed) } \\
\mathrm{N}\end{array}$ & & & & $\begin{array}{r}-.113 \\
.507 \\
37 \\
\end{array}$ & $\begin{array}{r}.032 \\
.814 \\
57 \\
\end{array}$ & $\begin{array}{r}.432^{\circ} \\
.024 \\
27 \\
\end{array}$ & $\begin{array}{r}.218 \\
.181 \\
39 \\
\end{array}$ & $\begin{array}{r}-.044 \\
.740 \\
58 \\
\end{array}$ & $\begin{array}{r}.120 \\
.361 \\
60 \\
\end{array}$ & $\begin{array}{r}.348 \\
.006 \\
60 \\
\end{array}$ \\
\hline $\begin{array}{l}\mathrm{Zn} / \mathrm{Ca} \\
\mathrm{Log} 10\end{array}$ & \begin{tabular}{|l} 
Pearson \\
Correlation \\
Sig. (2-tailed) \\
N
\end{tabular} & & & & & $\begin{array}{c}.411 \\
.001 \\
65 \\
\end{array}$ & $\begin{array}{r}.185 \\
.347 \\
28 \\
\end{array}$ & $\begin{array}{r}.236 \\
.107 \\
48 \\
\end{array}$ & $\begin{array}{r}.006 \\
.962 \\
66 \\
\end{array}$ & $\begin{array}{r}-.138 \\
.262 \\
68 \\
\end{array}$ & $\begin{array}{r}-.081 \\
.510 \\
68 \\
\end{array}$ \\
\hline $\begin{array}{l}\mathrm{Pb} / \mathrm{Ca} \\
\mathrm{Log} 10\end{array}$ & \begin{tabular}{|l} 
Pearson \\
Correlation \\
Sig. (2-tailed) \\
N.
\end{tabular} & & & & & & $\begin{array}{r}.188 \\
.215 \\
45\end{array}$ & $\begin{array}{r}.259 \\
.046 \\
60\end{array}$ & $\begin{array}{r}.133 \\
.203 \\
93 \\
\end{array}$ & $\begin{array}{r}-.126 \\
.220 \\
96 \\
\end{array}$ & $\begin{array}{r}-.038 \\
.715 \\
96 \\
\end{array}$ \\
\hline $\begin{array}{c}\mathrm{U} / \mathrm{Ca} \\
\log 10\end{array}$ & \begin{tabular}{|l|} 
Pearson \\
Correlation \\
Sig. (2-tailed) \\
N \\
\end{tabular} & & & & & & & $\begin{array}{r}-.077 \\
.690 \\
29 \\
\end{array}$ & $\begin{array}{r}-.178 \\
.248 \\
44 \\
\end{array}$ & $\begin{array}{r}-.128 \\
.397 \\
46 \\
\end{array}$ & $\begin{array}{r}-.097 \\
.523 \\
46 \\
\end{array}$ \\
\hline Li/Ca & \begin{tabular}{|l} 
Pearson \\
Correlation \\
Sig. (2-tailed) \\
N
\end{tabular} & & & & & & & & $\begin{array}{r}.085 \\
.509 \\
63 \\
\end{array}$ & $\begin{array}{r}.097 \\
.441 \\
65 \\
\end{array}$ & $\begin{array}{r}.247 \\
.047 \\
65 \\
\end{array}$ \\
\hline $\mathrm{Mg} / \mathrm{Ca}$ & \begin{tabular}{|l} 
Pearson \\
Correlation \\
Sig. (2-tailed) \\
$\mathrm{N}$
\end{tabular} & & & & & & & & & $\begin{array}{r}.481 \\
.000 \\
99 \\
\end{array}$ & $\begin{array}{r}.252 \\
.012 \\
99 \\
\end{array}$ \\
\hline $\mathrm{Sr} 88 / \mathrm{Ca}$ & \begin{tabular}{|l} 
Pearson \\
Correlation \\
Sig. (2-tailed) \\
N
\end{tabular} & & & & & & & & & & $\begin{array}{r}.766 \\
.000 \\
102 \\
\end{array}$ \\
\hline $\mathrm{Ba} / \mathrm{Ca}$ & $\begin{array}{l}\text { Pearson } \\
\text { Correlation } \\
\text { Sig. (2-tailed) } \\
\text { N }\end{array}$ & & & & & & & & & & \\
\hline
\end{tabular}

\begin{tabular}{|c|c|c|c|c|c|c|c|c|c|c|c|}
\hline \multicolumn{2}{|c|}{$\begin{array}{l}\text { P04A Correlations } \\
\text { Nacreous Layer }\end{array}$} & $\begin{array}{r}\mathrm{B} / \mathrm{Ca} \\
\mathrm{Log} 10 \\
\end{array}$ & $\begin{array}{l}\text { Al/Ca } \\
\text { Log10 }\end{array}$ & $\begin{array}{l}\mathrm{Mn} / \mathrm{Ca} \\
\text { Log10 }\end{array}$ & $\begin{array}{l}\mathrm{Zn} / \mathrm{Ca} \\
\mathrm{Log} 10\end{array}$ & $\begin{array}{l}\mathrm{Pb} / \mathrm{Ca} \\
\mathrm{Log} 10 \\
\end{array}$ & $\begin{array}{r}\mathrm{U} / \mathrm{Ca} \\
\mathrm{Log} 10\end{array}$ & $\mathrm{Li} / \mathrm{Ca}$ & $\mathrm{Mg} / \mathrm{Ca}$ & $\mathrm{Sr} 88 / \mathrm{Ca}$ & $\mathrm{Ba} / \mathrm{Ca}$ \\
\hline $\begin{array}{l}\mathrm{B} / \mathrm{Ca} 10 \\
\text { Log10 }\end{array}$ & \begin{tabular}{|l} 
Pearson \\
Correlation \\
Sig. (2-tailed) \\
$\mathrm{N}$
\end{tabular} & & $\begin{array}{r}-.173 \\
.419 \\
24\end{array}$ & $\begin{array}{r}-.010 \\
.963 \\
25 \\
\end{array}$ & $\begin{array}{r}-045 \\
.819 \\
28\end{array}$ & $\begin{array}{r}.170 \\
.417 \\
25 \\
\end{array}$ & $\begin{array}{r}.105 \\
.642 \\
22 \\
\end{array}$ & $\begin{array}{r}.216 \\
.220 \\
34\end{array}$ & $\begin{array}{r}.133 \\
.373 \\
47\end{array}$ & $\begin{array}{r}.211 \\
.150 \\
48 \\
\end{array}$ & $\begin{array}{r}-.062 \\
.688 \\
45\end{array}$ \\
\hline $\begin{array}{l}\text { Al/Ca } \\
\text { Log10 }\end{array}$ & \begin{tabular}{|l|} 
Pearson \\
Correlation \\
Sig. (2-tailed) \\
$\mathrm{N}$
\end{tabular} & & & \begin{tabular}{r|}
.012 \\
.963 \\
16
\end{tabular} & $\begin{array}{r}.094 \\
.701 \\
19\end{array}$ & \begin{tabular}{r|}
.014 \\
.963 \\
14
\end{tabular} & $\begin{array}{r}-.160 \\
.568 \\
15 \\
\end{array}$ & $\begin{array}{r}-.164 \\
.491 \\
20\end{array}$ & $\begin{array}{r}.153 \\
.428 \\
29\end{array}$ & $\begin{array}{r}-065 \\
.738 \\
29 \\
\end{array}$ & $\begin{array}{r}-.124 \\
.547 \\
26\end{array}$ \\
\hline $\begin{array}{l}\mathrm{Mn} / \mathrm{Ca} \\
\log 10\end{array}$ & $\begin{array}{l}\text { Pearson } \\
\text { Correlation } \\
\text { Sig. (2-tailed) } \\
\text { N } \\
\end{array}$ & & & & $\begin{array}{r}.669^{\prime \prime} \\
.001 \\
20 \\
\end{array}$ & \begin{tabular}{r|}
.247 \\
.322 \\
18 \\
\end{tabular} & $\begin{array}{r}.018 \\
.944 \\
17 \\
\end{array}$ & $\begin{array}{r}.172 \\
.410 \\
25 \\
\end{array}$ & $\begin{array}{r}.143 \\
.434 \\
32 \\
\end{array}$ & \begin{tabular}{r|}
-.017 \\
.925 \\
33 \\
\end{tabular} & $\begin{array}{r}.201 \\
.271 \\
32\end{array}$ \\
\hline $\begin{array}{l}\mathrm{Zn/Ca} \\
\text { Log10 }\end{array}$ & \begin{tabular}{|l} 
Pearson \\
Correlation \\
Sig. (2-tailed) \\
$\mathrm{N}$
\end{tabular} & & & & & $\begin{array}{r}.623^{\prime} \\
.004 \\
19 \\
\end{array}$ & $\begin{array}{r}.125 \\
.623 \\
18 \\
\end{array}$ & $\begin{array}{r}-.192 \\
.309 \\
30 \\
\end{array}$ & $\begin{array}{r}.327 \\
.052 \\
36 \\
\end{array}$ & $\begin{array}{r}.118 \\
.493 \\
36 \\
\end{array}$ & $\begin{array}{r}.112 \\
.527 \\
34 \\
\end{array}$ \\
\hline $\begin{array}{l}\mathrm{Pb} / \mathrm{Ca} \\
\mathrm{Log} 10\end{array}$ & $\begin{array}{l}\text { Pearson } \\
\text { Correlation } \\
\text { Sig. (2-tailed) } \\
\text { N }\end{array}$ & & & & & & $\begin{array}{r}.455 \\
.137 \\
12 \\
\end{array}$ & $\begin{array}{r}.185 \\
.434 \\
20 \\
\end{array}$ & $\begin{array}{r}.158 \\
.414 \\
29 \\
\end{array}$ & $\begin{array}{r}.100 \\
.605 \\
29 \\
\end{array}$ & $\begin{array}{r}.083 \\
.680 \\
27 \\
\end{array}$ \\
\hline $\begin{array}{r}\mathrm{U} / \mathrm{Ca} \\
\log 10\end{array}$ & \begin{tabular}{|l} 
Pearson \\
Correlation \\
Sig. (2-tailed) \\
$\mathrm{N}$
\end{tabular} & & & & & & & $\begin{array}{r}.180 \\
.400 \\
24\end{array}$ & $\begin{array}{r}-.270 \\
.164 \\
28\end{array}$ & \begin{tabular}{r|}
-.190 \\
.334 \\
28
\end{tabular} & $\begin{array}{r}-.147 \\
.482 \\
25\end{array}$ \\
\hline $\mathrm{Li} / \mathrm{Ca}$ & $\begin{array}{l}\text { Pearson } \\
\text { Correlation } \\
\text { Sig. (2-tailed) } \\
\text { N }\end{array}$ & & & & & & & & $\begin{array}{r}-.071 \\
.655 \\
42\end{array}$ & \begin{tabular}{r|}
-.069 \\
.662 \\
43
\end{tabular} & $\begin{array}{r}-.071 \\
.653 \\
42\end{array}$ \\
\hline $\mathrm{Mg} / \mathrm{Ca}$ & $\begin{array}{l}\text { Pearson } \\
\text { Correlation } \\
\text { Sig. (2-tailed) } \\
\mathrm{N}\end{array}$ & & & & & & & & & \begin{tabular}{r|}
.759 \\
.000 \\
58
\end{tabular} & $\begin{array}{r}.284 \\
.037 \\
54\end{array}$ \\
\hline Sr88/Ca & \begin{tabular}{|l} 
Pearson \\
Correlation \\
Sig. (2-tailed) \\
N
\end{tabular} & & & & & & & & & & $\begin{array}{r}.537 \\
.000 \\
55\end{array}$ \\
\hline $\mathrm{Ba} / \mathrm{Ca}$ & \begin{tabular}{|l|} 
Pearson \\
Correlation \\
Sig. (2-tailed) \\
N
\end{tabular} & & & & & & & & & & \\
\hline
\end{tabular}

Appendix 3.2c. Pearsons correlation between element/Ca ratios in the nacreous layer of samples P1B and P04A from Pourerere. ${ }^{* *}$ Correlation is significant at the 0.01 level and * correlation is significant at the 0.05 level. 


\begin{tabular}{|c|c|c|c|c|c|c|c|c|c|c|c|}
\hline \multicolumn{2}{|c|}{$\begin{array}{l}\text { SC2 Correlations } \\
\text { Nacreous Layer }\end{array}$} & $\begin{array}{l}\mathrm{U} / \mathrm{Ca} \\
\mathrm{Log} 10\end{array}$ & $\begin{array}{l}\mathrm{Zn} / \mathrm{Ca} \\
\log 10\end{array}$ & $\begin{array}{l}\mathrm{Mn} / \mathrm{Ca} \\
\mathrm{Log} 10\end{array}$ & $\begin{array}{l}\text { Al/Ca } \\
\text { Log10 }\end{array}$ & Li/Ca & $\mathrm{B} / \mathrm{Ca}$ & $\mathrm{Mg} / \mathrm{Ca}$ & $\mathrm{Sr88/Ca}$ & $\mathrm{Ba} / \mathrm{Ca}$ & $\mathrm{Pb} / \mathrm{Ca}$ \\
\hline $\begin{array}{l}\mathrm{U} / \mathrm{Ca} \\
\mathrm{Log} 10\end{array}$ & \begin{tabular}{|l|} 
Pearson \\
Correlation \\
Sig. (2-tailed) \\
N.
\end{tabular} & & $\begin{array}{r}.045 \\
.793 \\
36 \\
\end{array}$ & $\begin{array}{r}.329 \\
.061 \\
33 \\
\end{array}$ & $\begin{array}{r}.372 \\
.106 \\
20 \\
\end{array}$ & $\begin{array}{r}.168 \\
.235 \\
52 \\
\end{array}$ & $\begin{array}{r}.344 \\
.019 \\
46 \\
\end{array}$ & $\begin{array}{r}.134 \\
.370 \\
47 \\
\end{array}$ & \begin{tabular}{r|}
.074 \\
.623 \\
47 \\
\end{tabular} & $\begin{array}{r}-.004 \\
.978 \\
49 \\
\end{array}$ & $\begin{array}{r}.077 \\
.696 \\
28 \\
\end{array}$ \\
\hline $\begin{array}{l}\mathrm{Zn} / \mathrm{Ca} \\
\mathrm{Log} 10\end{array}$ & \begin{tabular}{|l} 
Pearson \\
Correlation \\
Sig. (2-tailed) \\
N
\end{tabular} & & & $\begin{array}{r}.314 \\
.066 \\
35\end{array}$ & $\begin{array}{r}.271 \\
.190 \\
25\end{array}$ & $\begin{array}{r}.165 \\
.173 \\
70\end{array}$ & $\begin{array}{r}-.148 \\
.252 \\
62\end{array}$ & $\begin{array}{r}-.193 \\
.136 \\
61\end{array}$ & $\begin{array}{r}-.095 \\
.461 \\
63\end{array}$ & $\begin{array}{r}-.046 \\
.716 \\
65\end{array}$ & $\begin{array}{r}.042 \\
.808 \\
36\end{array}$ \\
\hline $\begin{array}{l}\mathrm{Mn} / \mathrm{Ca} \\
\log 10\end{array}$ & \begin{tabular}{|l|} 
Pearson \\
Correlation \\
Sig. (2-tailed) \\
N
\end{tabular} & & & & \begin{tabular}{|r|r|}
.045 \\
.827 \\
26 \\
\end{tabular} & $\begin{array}{r}.042 \\
.749 \\
61 \\
\end{array}$ & $\begin{array}{r}.026 \\
.849 \\
54 \\
\end{array}$ & \begin{tabular}{r|}
.021 \\
.876 \\
56 \\
\end{tabular} & $\begin{array}{r}.090 \\
.504 \\
57 \\
\end{array}$ & \begin{tabular}{r|}
.197 \\
.138 \\
58 \\
\end{tabular} & \begin{tabular}{|r|}
.097 \\
.591 \\
33 \\
\end{tabular} \\
\hline $\begin{array}{l}\text { Al/Ca } \\
\text { Log10 }\end{array}$ & \begin{tabular}{|l} 
Pearson \\
Correlation \\
Sig. (2-tailed) \\
N
\end{tabular} & & & & & $\begin{array}{r}.033 \\
.821 \\
48\end{array}$ & $\begin{array}{r}-.145 \\
.347 \\
44\end{array}$ & $\begin{array}{r}-.003 \\
.985 \\
44\end{array}$ & $\begin{array}{r}-.047 \\
.764 \\
44\end{array}$ & $\begin{array}{r}-.074 \\
.630 \\
45\end{array}$ & $\begin{array}{r}-.168 \\
.402 \\
27\end{array}$ \\
\hline Li/Ca & \begin{tabular}{|l|} 
Pearson \\
Correlation \\
Sig. (2-tailed) \\
N
\end{tabular} & & & & & & $\begin{array}{r}-.154 \\
.120 \\
103 \\
\end{array}$ & $\begin{array}{l}.178 \\
.069 \\
105 \\
\end{array}$ & $\begin{array}{l}.224 \\
.020 \\
108 \\
\end{array}$ & $\begin{array}{l}.243^{\circ} \\
.011 \\
110 \\
\end{array}$ & $\begin{array}{l}.082 \\
.532 \\
61 \\
\end{array}$ \\
\hline B/Ca & \begin{tabular}{|l} 
Pearson \\
Correlation \\
Sig. (2-tailed) \\
N
\end{tabular} & & & & & & & $\begin{array}{l}.118 \\
.236 \\
102\end{array}$ & $\begin{array}{l}.022 \\
.823 \\
103\end{array}$ & $\begin{array}{l}.109 \\
.274 \\
103\end{array}$ & $\begin{array}{r}.056 \\
.689 \\
53\end{array}$ \\
\hline $\mathrm{Mg} / \mathrm{Ca}$ & \begin{tabular}{|l} 
Pearson \\
Correlation \\
Sig. (2-tailed) \\
N
\end{tabular} & & & & & & & & $\begin{array}{r}.784 \\
.000 \\
105 \\
\end{array}$ & $\begin{array}{r}.557 \\
.000 \\
105 \\
\end{array}$ & $\begin{array}{r}.033 \\
.808 \\
55 \\
\end{array}$ \\
\hline $\mathrm{Sr} 88 / \mathrm{Ca}$ & \begin{tabular}{|l} 
Pearson \\
Correlation \\
Sig. (2-tailed) \\
N
\end{tabular} & & & & & & & & & $\begin{array}{r}.650^{\circ} \\
.000 \\
108\end{array}$ & $\begin{array}{r}.112 \\
.408 \\
57 \\
\end{array}$ \\
\hline $\mathrm{Ba} / \mathrm{Ca}$ & \begin{tabular}{|l|} 
Pearson \\
Correlation \\
Sig. (2-tailed) \\
$\mathrm{N}$
\end{tabular} & & & & & & & & & & $\begin{array}{r}.017 \\
.898 \\
58 \\
\end{array}$ \\
\hline $\mathrm{Pb} / \mathrm{Ca}$ & \begin{tabular}{|l|} 
Pearson \\
Correlation \\
Sig. (2-tailed) \\
N
\end{tabular} & & & & & & & & & & \\
\hline
\end{tabular}

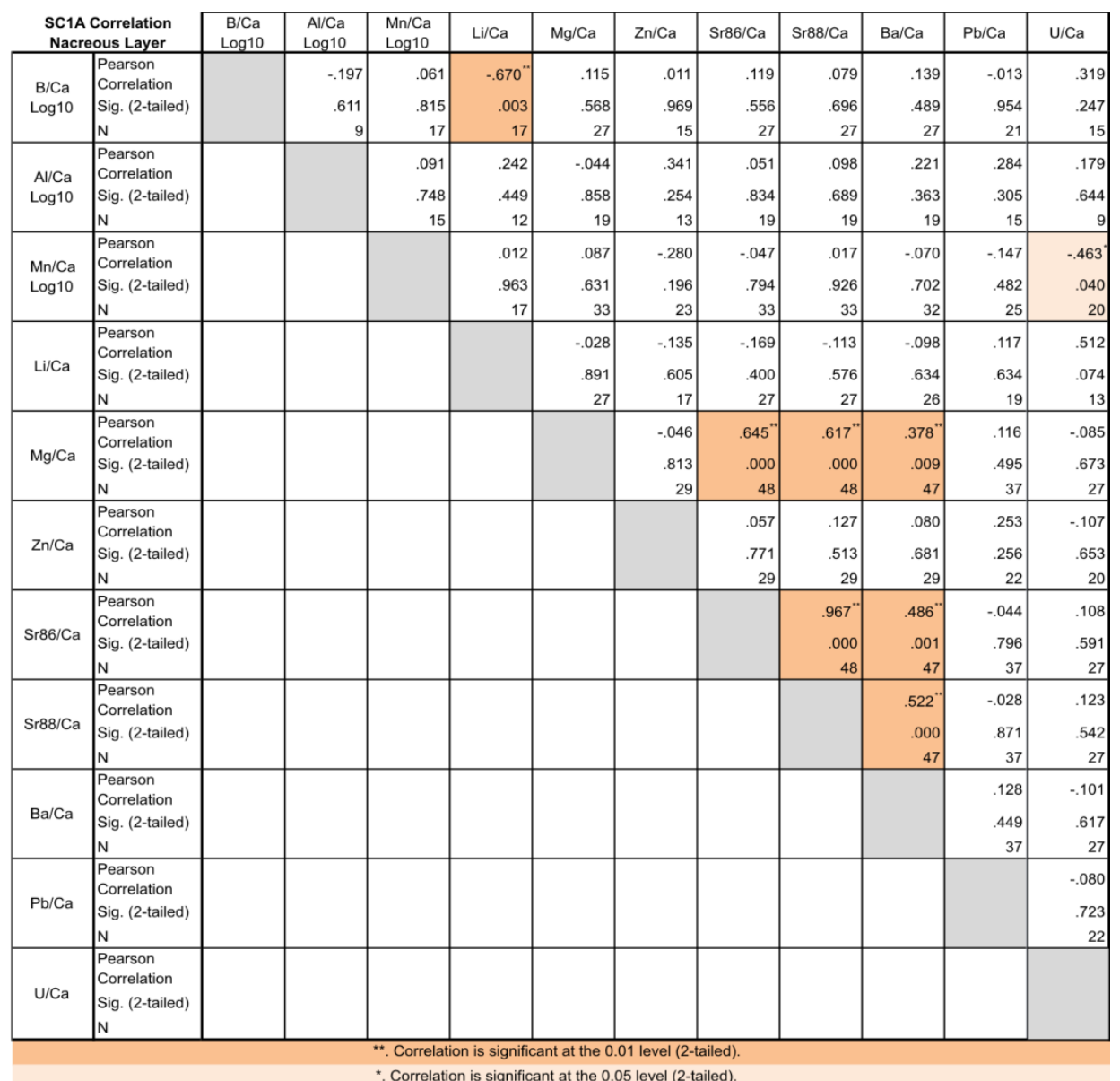

Appendix 3.2d. Pearsons correlation between element/Ca ratios in the nacreous layer of samples SC2 and SC1A from the South Coast of Wellington. ** Correlation is significant at the 0.01 level and ${ }^{*}$ correlation is significant at the 0.05 level. 

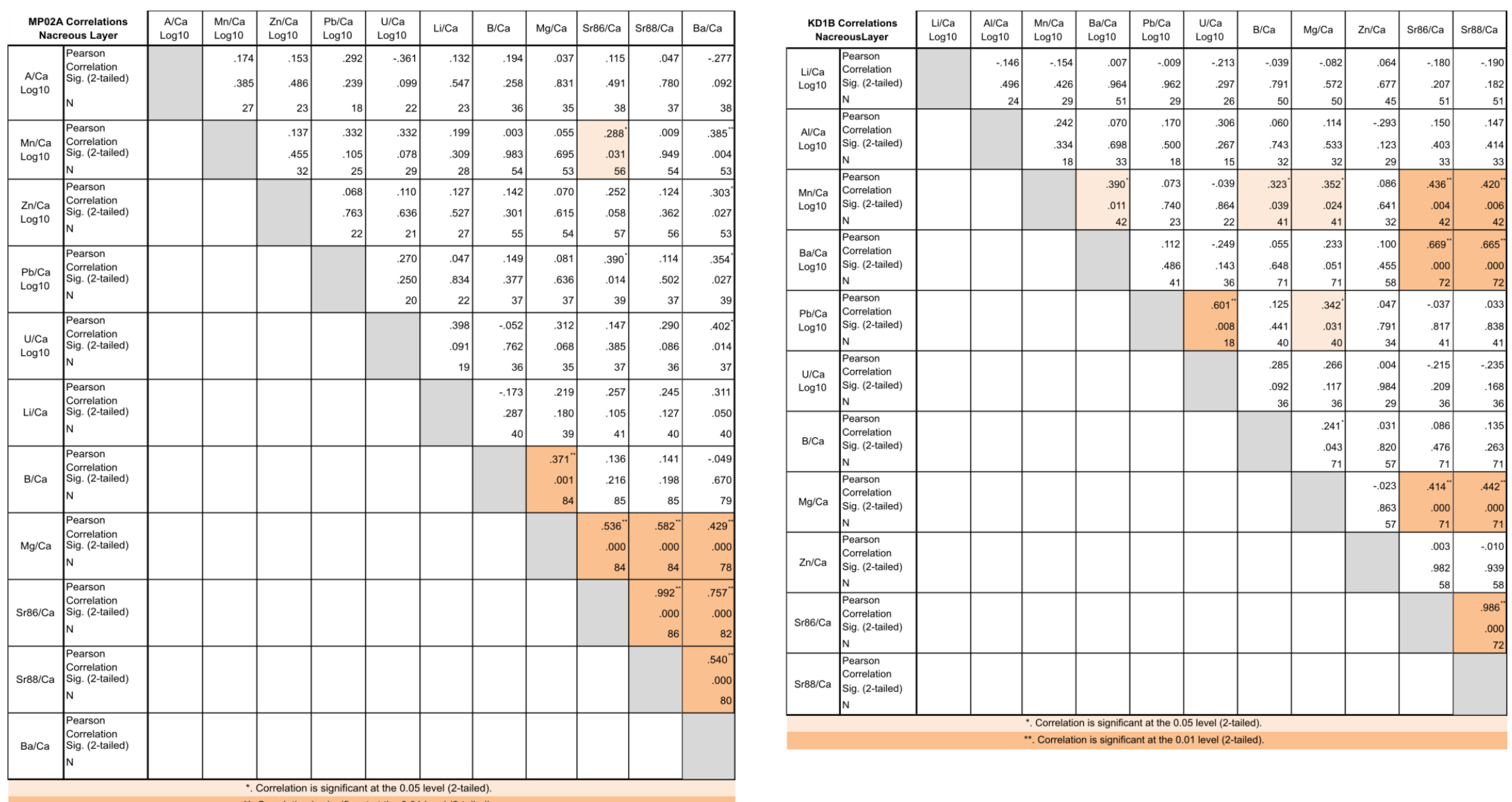

". Correlation is significant at the 001 level (2-tailed).

Appendix 3.2e. Pearsons correlation between element/Ca ratios in the nacreous layer of samples MP02A from Moa Point and KD1B from Kaikoura. ${ }^{* *}$ Correlation is significant at the 0.01 level and * correlation is significant at the 0.05 level. 


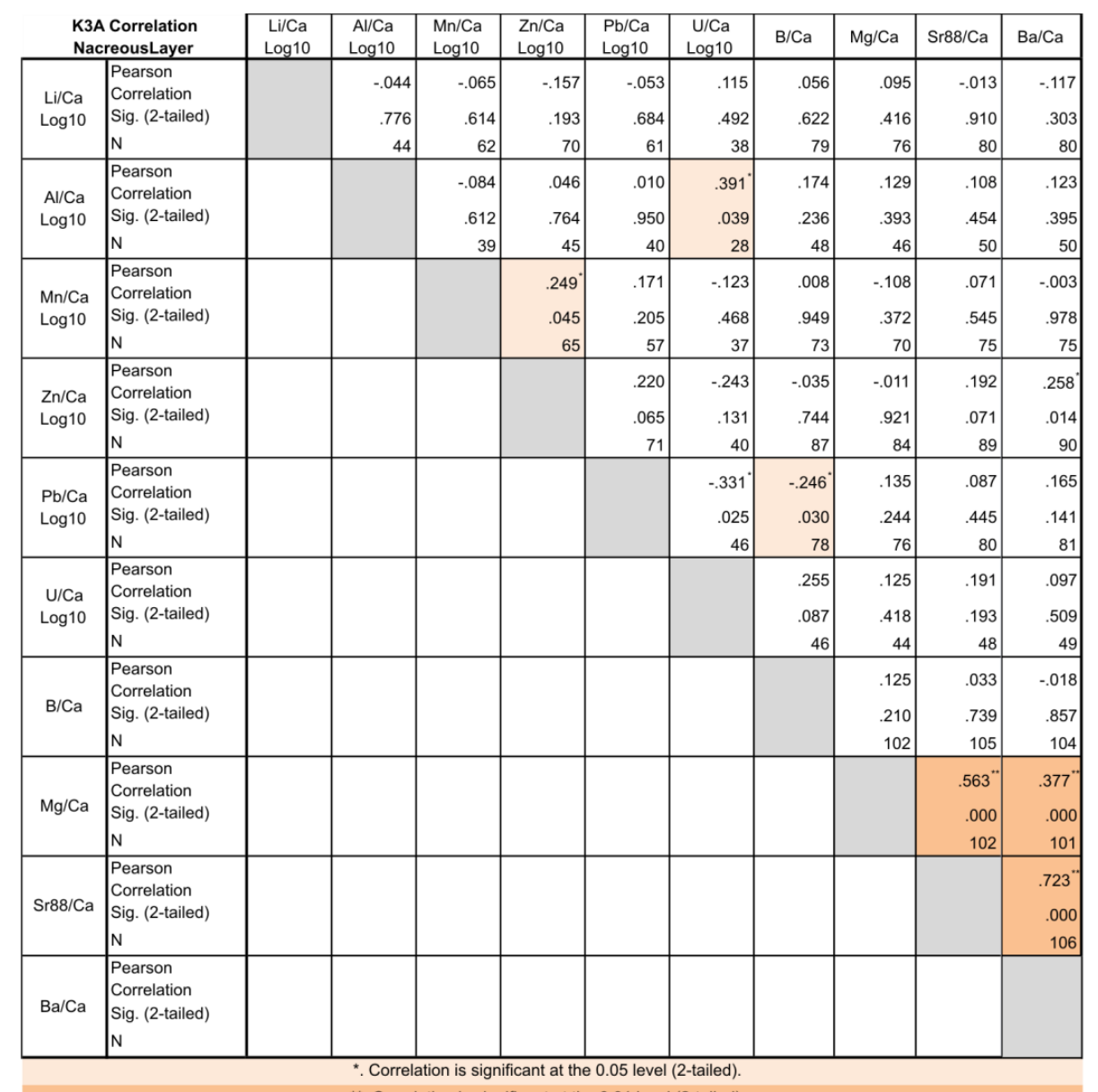

.. Correlation is significant at the 0.01 lovel (2tailed).

\begin{tabular}{|c|c|c|c|c|c|c|c|c|c|c|c|}
\hline \multicolumn{2}{|c|}{$\begin{array}{l}\text { K1A1 Correlation } \\
\text { Nacreous Layer }\end{array}$} & $\begin{array}{l}\text { Li/Ca } \\
\text { Log10 }\end{array}$ & $\begin{array}{l}\mathrm{Mg} / \mathrm{Ca} \\
\mathrm{Log} 10\end{array}$ & $\begin{array}{l}\text { Al/Ca } \\
\text { Log10 }\end{array}$ & $\begin{array}{l}\mathrm{Pb} / \mathrm{Ca} \\
\mathrm{Log} 10\end{array}$ & $\begin{array}{l}U / C a \\
\text { Log10 }\end{array}$ & $\mathrm{B} / \mathrm{Ca}$ & $\mathrm{Mn} / \mathrm{Ca}$ & $\mathrm{Zn} / \mathrm{Ca}$ & Sr88/Ca & $\mathrm{Ba} / \mathrm{Ca}$ \\
\hline $\begin{array}{l}\text { Li/Ca } \\
\text { Log10 }\end{array}$ & \begin{tabular}{|l} 
Pearson \\
Correlation \\
Sig. (2-tailed) \\
N
\end{tabular} & & $\begin{array}{r}.333 \\
.024 \\
46 \\
\end{array}$ & $\begin{array}{r}-.029 \\
.913 \\
17 \\
\end{array}$ & $\begin{array}{r}.113 \\
.455 \\
46 \\
\end{array}$ & $\begin{array}{r}.174 \\
.440 \\
22 \\
\end{array}$ & $\begin{array}{r}.172 \\
.265 \\
44 \\
\end{array}$ & $\begin{array}{r}-.078 \\
.606 \\
46 \\
\end{array}$ & \begin{tabular}{r|}
.014 \\
.928 \\
45 \\
\end{tabular} & $\begin{array}{r}.361 \\
.013 \\
47 \\
\end{array}$ & $\begin{array}{r}.053 \\
.726 \\
47 \\
\end{array}$ \\
\hline $\begin{array}{l}\mathrm{Mg} / \mathrm{Ca} \\
\mathrm{Log} 10\end{array}$ & \begin{tabular}{|l} 
Pearson \\
Correlation \\
Sig. (2-tailed) \\
N
\end{tabular} & & & $\begin{array}{r}.004 \\
.983 \\
31 \\
\end{array}$ & $\begin{array}{r}.216^{\circ} \\
.047 \\
85 \\
\end{array}$ & $\begin{array}{r}-.160 \\
.323 \\
40 \\
\end{array}$ & $\begin{array}{r}.463 " \\
.000 \\
83 \\
\end{array}$ & $\begin{array}{r}.037 \\
.736 \\
85 \\
\end{array}$ & $\begin{array}{r}-.386 " \\
.000 \\
88 \\
\end{array}$ & $\begin{array}{r}.598 \\
.000 \\
89 \\
\end{array}$ & $\begin{array}{r}.152 \\
.156 \\
89 \\
\end{array}$ \\
\hline $\begin{array}{l}\text { Al/Ca } \\
\text { Log10 }\end{array}$ & \begin{tabular}{|l|} 
Pearson \\
Correlation \\
Sig. (2-tailed) \\
N
\end{tabular} & & & & $\begin{array}{r}-.392^{\circ} \\
.027 \\
32 \\
\end{array}$ & \begin{tabular}{r|}
.405 \\
.151 \\
14 \\
\end{tabular} & $\begin{array}{r}.049 \\
.802 \\
29 \\
\end{array}$ & $\begin{array}{r}.249 \\
.185 \\
30 \\
\end{array}$ & \begin{tabular}{r|}
.010 \\
.957 \\
31 \\
\end{tabular} & $\begin{array}{r}-.007 \\
.970 \\
32 \\
\end{array}$ & $\begin{array}{r}-.127 \\
.490 \\
32 \\
\end{array}$ \\
\hline $\begin{array}{l}\mathrm{Pb} / \mathrm{Ca} \\
\mathrm{Log} 10\end{array}$ & \begin{tabular}{|l} 
Pearson \\
Correlation \\
Sig. (2-tailed) \\
N
\end{tabular} & & & & & $\begin{array}{r}-.368^{\circ} \\
.021 \\
39 \\
\end{array}$ & $\begin{array}{r}-201 \\
.074 \\
80 \\
\end{array}$ & $\begin{array}{r}-.069 \\
.530 \\
85 \\
\end{array}$ & $\begin{array}{r}.099 \\
.362 \\
87 \\
\end{array}$ & $\begin{array}{r}.108 \\
.313 \\
89 \\
\end{array}$ & $\begin{array}{r}.044 \\
.684 \\
89 \\
\end{array}$ \\
\hline $\begin{array}{l}\mathrm{U} / \mathrm{Ca} \\
\mathrm{Log} 10\end{array}$ & $\begin{array}{l}\text { Pearson } \\
\text { Correlation } \\
\text { Sig. (2-tailed) } \\
\text { N }\end{array}$ & & & & & & $\begin{array}{r}-.025 \\
.884 \\
37 \\
\end{array}$ & $\begin{array}{r}-.166 \\
.298 \\
41 \\
\end{array}$ & $\begin{array}{r}-.132 \\
.418 \\
40 \\
\end{array}$ & $\begin{array}{r}-.057 \\
.724 \\
41\end{array}$ & $\begin{array}{r}-235 \\
.139 \\
41\end{array}$ \\
\hline $\mathrm{B} / \mathrm{Ca}$ & \begin{tabular}{|l|} 
Pearson \\
Correlation \\
Sig. (2-tailed) \\
N
\end{tabular} & & & & & & & $\begin{array}{r}-.237 \\
.033 \\
81 \\
\end{array}$ & \begin{tabular}{r|}
$.359^{\prime \prime}$ \\
.001 \\
82 \\
\end{tabular} & $\begin{array}{r}.335^{\prime \prime} \\
.002 \\
83 \\
\end{array}$ & $\begin{array}{r}.097 \\
.385 \\
83 \\
\end{array}$ \\
\hline $\mathrm{Mn} / \mathrm{Ca}$ & \begin{tabular}{|l} 
Pearson \\
Correlation \\
Sig. (2-tailed) \\
N
\end{tabular} & & & & & & & & $\begin{array}{r}.416 \\
.000 \\
86 \\
\end{array}$ & $\begin{array}{r}-.111 \\
.305 \\
88 \\
\end{array}$ & $\begin{array}{r}.438 \\
.000 \\
88 \\
\end{array}$ \\
\hline $\mathrm{Zn} / \mathrm{Ca}$ & $\begin{array}{l}\text { Pearson } \\
\text { Correlation } \\
\text { Sig. (2-tailed) } \\
\text { N }\end{array}$ & & & & & & & & & $\begin{array}{r}-.273 \\
.009 \\
91 \\
\end{array}$ & $\begin{array}{r}.007 \\
.000 \\
91\end{array}$ \\
\hline Sr88/Ca & \begin{tabular}{|l|} 
Pearson \\
Correlation \\
Sig. (2-tailed) \\
N
\end{tabular} & & & & & & & & & & $\begin{array}{r}.307 \\
.003 \\
93 \\
\end{array}$ \\
\hline $\mathrm{Ba} / \mathrm{Ca}$ & \begin{tabular}{|l} 
Pearson \\
Correlation \\
Sig. (2-tailed) \\
$\mathrm{N}$
\end{tabular} & & & & & & & & & & \\
\hline
\end{tabular}

Correlation is significant at the 0.05 level (2-tailed).

Appendix 3.2f. Pearsons correlation between element/Ca ratios in the nacreous layer of samples K3A and K1A1 from Kaikoura. ** Correlation is significant at the 0.01 level and * correlation is significant at the 0.05 level. 

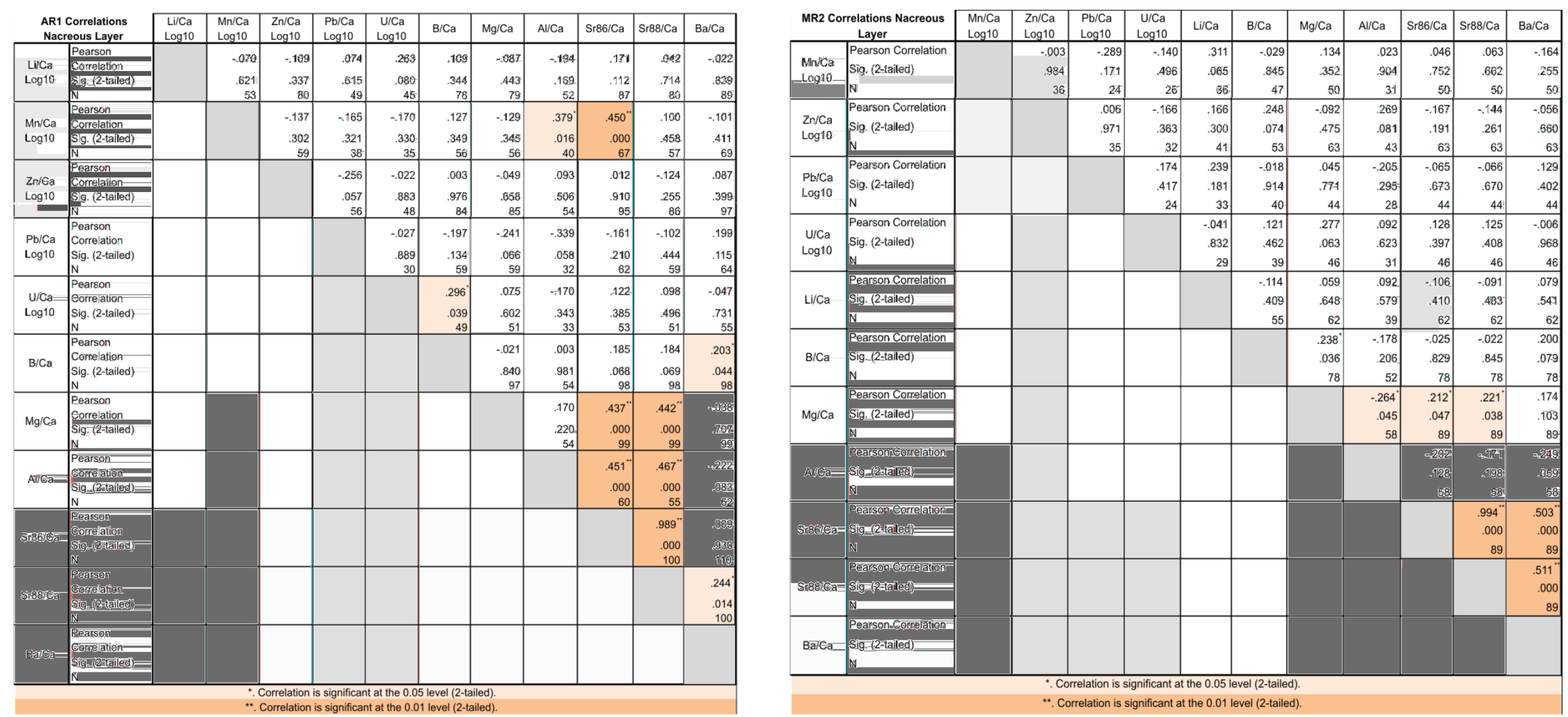

Appendix 3.2g. Pearsons correlation between element/Ca ratios in the nacreous layer of samples AR1 and MR2 from Chatham Islands. ${ }^{* *}$ Correlation is significant at the 0.01 level and * correlation is significant at the 0.05 level. 

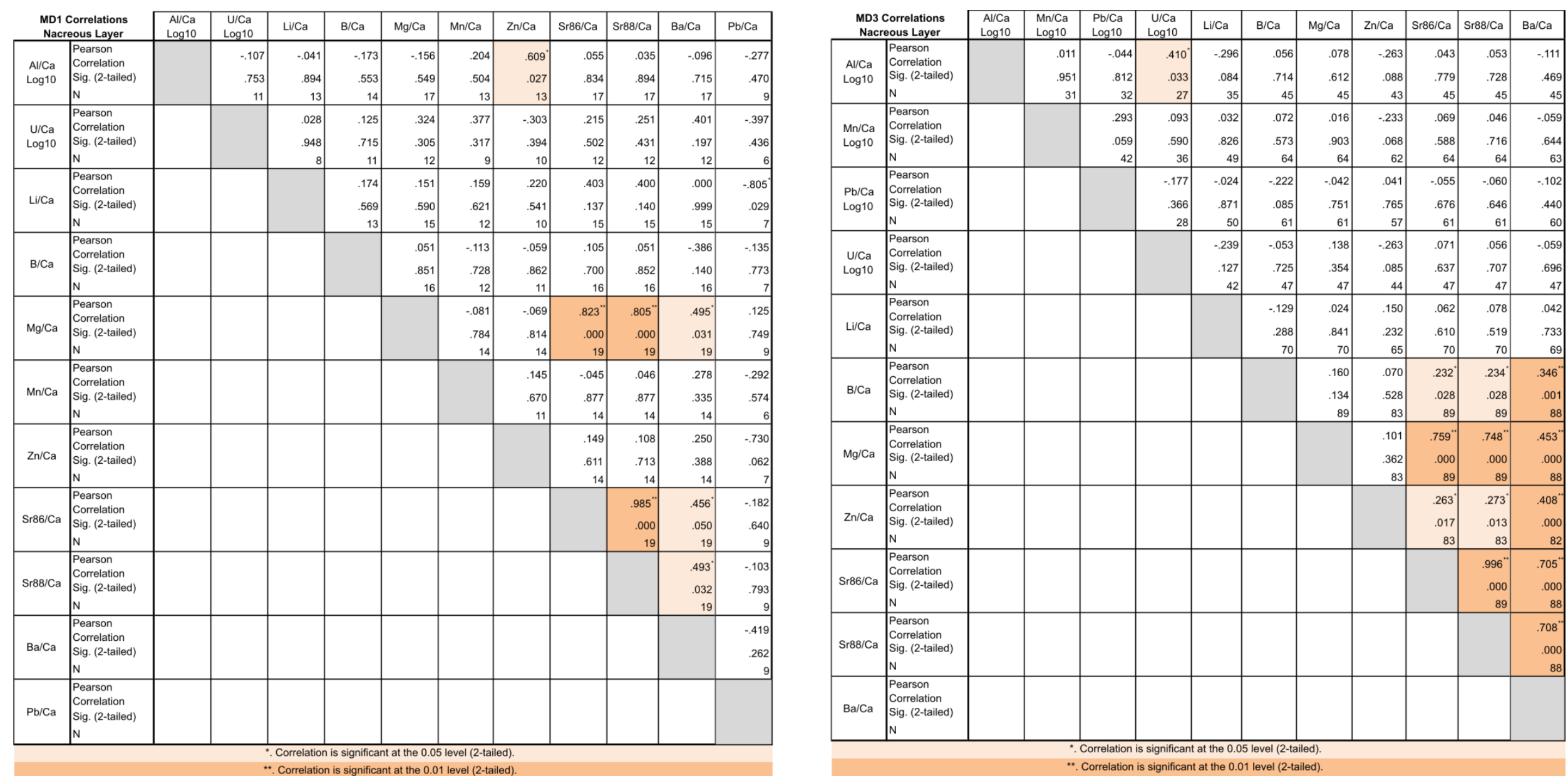

Appendix 3.2h. Pearsons correlation between element/Ca ratios in the nacreous layer of samples MD1 and MD3 from Moeraki. ${ }^{* *}$ Correlation is significant at the 0.01 level and * correlation is significant at the 0.05 level. 


\section{APPENDIX 4.1 CREAMED PĀUA RECIPE}

Note: This appendix has been added in response to the many enquiries from the academic community at the Geosciences 2010 Conference in Auckland for delicious ways to cook pāua.

\section{Ingredients}

3 medium sized pāua

$300 \mathrm{ml}$ bottle of cream

1 onion (diced)

1 teaspoon of crushed garlic

$300 \mathrm{ml}$ bottle of cream

2 tablespoons of flour

Salt and pepper

1 tablespoon of oil

\section{Method}

Shuck the pāua from the shell and clean

Remove the sac and teeth from the pāua and slice the meat thinly ( $5 \mathrm{~mm}$ thickness)

Heat a pan with the 1 tablespoon of oil

Once hot, fry the onions and crushed garlic until brown

Add the thinly sliced paua and fry until it starts to caramelize

Add the bottle of cream and bring to the boil

Add flour to thicken and salt and pepper to taste

Serve hot or cold 
APPENDIX 5.1a $\quad$ RW75 400 prismatic layer data

\begin{tabular}{|c|c|c|c|c|c|c|c|c|c|c|}
\hline \multirow{2}{*}{ Spot Number } & \multirow{2}{*}{ Distance from the foot (mm) } & \multicolumn{9}{|c|}{ RW75 400 prismatic layer transect data $(\mathrm{mmol} / \mathrm{mol})$} \\
\hline & & $\mathrm{Li} / \mathrm{Ca}$ & $\mathrm{B} / \mathrm{Ca}$ & $\mathrm{Mg} / \mathrm{Ca}$ & $\mathrm{Al} / \mathrm{Ca}$ & $\mathrm{Mn} / \mathrm{Ca}$ & $\mathrm{Zn} / \mathrm{Ca}$ & $\mathrm{Sr} 88 / \mathrm{Ca}$ & $\mathrm{Ba} / \mathrm{Ca}$ & $\mathrm{U} / \mathbf{C a}$ \\
\hline 1 & 0.0 & 0.00757 & 0.00000 & 10.24 & 0.00520 & 0.00427 & 0.04491 & 1.23 & 0.000726 & 0.0000434 \\
\hline 2 & 0.4 & 0.01059 & 0.01424 & 2.75 & 0.00672 & 0.00035 & 0.00469 & 1.52 & 0.000492 & 0.0000000 \\
\hline 3 & 0.8 & 0.01618 & 0.00000 & 24.77 & 0.00511 & 0.00042 & 0.00165 & 1.20 & 0.000419 & 0.0000000 \\
\hline 4 & 1.2 & 0.00818 & 0.00000 & 4.97 & 0.00071 & 0.00000 & 0.00302 & 1.18 & 0.000411 & 0.0000274 \\
\hline 5 & 1.6 & 0.00839 & 0.00200 & 5.84 & 0.00000 & 0.00000 & 0.00120 & 1.16 & 0.000451 & 0.0000031 \\
\hline 6 & 2.0 & 0.00843 & 0.00738 & 7.60 & 0.00736 & 0.00361 & 0.01109 & 1.27 & 0.000669 & 0.0000402 \\
\hline 7 & 2.4 & 0.01185 & 0.00000 & 18.81 & 0.02106 & 0.00099 & 0.00423 & 1.21 & 0.000396 & 0.0000000 \\
\hline 8 & 2.8 & 0.00685 & 0.00342 & 3.34 & 0.00105 & 0.00022 & 0.00474 & 1.27 & 0.000327 & 0.0000481 \\
\hline 9 & 3.2 & 0.00777 & 0.01934 & 2.16 & 0.00000 & 0.00081 & 0.00705 & 1.33 & 0.000436 & 0.0000000 \\
\hline 10 & 3.6 & 0.01164 & 0.01529 & 2.27 & 0.00080 & 0.00080 & 0.00479 & 1.37 & 0.000393 & 0.0000000 \\
\hline 11 & 4.0 & 0.00658 & 0.01139 & 3.03 & 0.00000 & 0.00228 & 0.00030 & 1.17 & 0.000329 & 0.0000000 \\
\hline 12 & 4.4 & 0.00629 & 0.00756 & 3.44 & 0.00000 & 0.00068 & 0.00235 & 1.33 & 0.000384 & 0.0000000 \\
\hline 13 & 4.8 & 0.00640 & 0.00000 & 3.61 & 0.00000 & 0.00000 & 0.00159 & 1.25 & 0.000333 & 0.0000000 \\
\hline 14 & 5.2 & 0.00607 & 0.01133 & 2.59 & 0.00144 & 0.00050 & 0.00656 & 1.25 & 0.000390 & 0.0000019 \\
\hline 15 & 5.6 & 0.00638 & 0.01149 & 3.29 & 0.00000 & 0.00100 & 0.00279 & 1.18 & 0.000286 & 0.0000019 \\
\hline 16 & 6.0 & 0.00583 & 0.00761 & 4.47 & 0.00000 & 0.00167 & 0.00052 & 0.96 & 0.000247 & 0.0000000 \\
\hline 17 & 6.4 & 0.00848 & 0.00495 & 3.23 & 0.00439 & 0.00267 & 0.00466 & 1.20 & 0.000355 & 0.0000365 \\
\hline 18 & 6.8 & 0.00815 & 0.00959 & 2.65 & 0.00155 & 0.00133 & 0.00000 & 1.39 & 0.000437 & 0.0000545 \\
\hline 19 & 7.2 & 0.01046 & 0.00000 & 2.25 & 0.00456 & 0.00124 & 0.00206 & 1.41 & 0.000402 & 0.0000334 \\
\hline 20 & 7.6 & 0.00860 & 0.00922 & 5.02 & 0.00487 & 0.00303 & 0.01690 & 1.48 & 0.000630 & 0.0000424 \\
\hline 21 & 8.0 & 0.00930 & 0.00182 & 2.58 & 0.00000 & 0.00235 & 0.00315 & 1.68 & 0.000448 & 0.0000000 \\
\hline 22 & 8.4 & 0.00676 & 0.01800 & 6.25 & 0.00000 & 0.00394 & 0.00402 & 1.49 & 0.000463 & 0.0000113 \\
\hline 23 & 8.8 & 0.00647 & 0.00415 & 3.08 & 0.00923 & 0.00000 & 0.00000 & 1.25 & 0.000312 & 0.0000000 \\
\hline 24 & 9.2 & 0.00541 & 0.00000 & 2.96 & 0.00081 & 0.00207 & 0.00338 & 1.09 & 0.000293 & 0.0000000 \\
\hline 25 & 9.6 & 0.00576 & 0.01896 & 3.98 & 0.00000 & 0.00158 & 0.00067 & 1.01 & 0.000184 & 0.0000000 \\
\hline 26 & 10.0 & 0.00473 & 0.00761 & 3.83 & 0.00000 & 0.00063 & 0.00109 & 1.17 & 0.000259 & 0.0000302 \\
\hline 27 & 10.4 & 0.00581 & 0.00824 & 3.06 & 0.00136 & 0.00210 & 0.00509 & 1.20 & 0.000383 & 0.0000057 \\
\hline 28 & 10.8 & 0.00768 & 0.00815 & 7.42 & 0.00000 & 0.00484 & 0.00000 & 0.97 & 0.000264 & 0.0000346 \\
\hline 29 & 11.2 & 0.00583 & 0.00465 & 3.79 & 0.00000 & 0.00186 & 0.00000 & 1.13 & 0.000256 & 0.0000083 \\
\hline
\end{tabular}




\begin{tabular}{|c|c|c|c|c|c|c|c|c|c|c|}
\hline \multirow{2}{*}{ Spot Number } & \multirow{2}{*}{ Distance from the foot $(\mathrm{mm})$} & \multicolumn{9}{|c|}{ RW75 400 prismatic layer transect data $(\mathrm{mmol} / \mathrm{mol})$ continued... } \\
\hline & & $\mathrm{Li} / \mathrm{Ca}$ & $\mathrm{B} / \mathrm{Ca}$ & $\mathrm{Mg} / \mathrm{Ca}$ & $\mathrm{Al} / \mathrm{Ca}$ & $\mathrm{Mn} / \mathrm{Ca}$ & $\mathrm{Zn} / \mathrm{Ca}$ & Sr88/Ca & $\mathrm{Ba} / \mathrm{Ca}$ & $\mathrm{U} / \mathrm{Ca}$ \\
\hline 30 & 11.6 & 0.00558 & 0.00000 & 3.21 & 0.00000 & 0.00211 & 0.00290 & 1.22 & 0.000388 & 0.0000000 \\
\hline 31 & 12.0 & 0.00779 & 0.01700 & 2.11 & 0.00000 & 0.00180 & 0.00200 & 1.23 & 0.000316 & 0.0000101 \\
\hline 32 & 12.4 & 0.01138 & 0.00202 & 1.81 & 0.00562 & 0.00055 & 0.00326 & 1.44 & 0.000501 & 0.0000000 \\
\hline 33 & 12.8 & 0.00815 & 0.00000 & 2.37 & 0.00011 & 0.00056 & 0.00341 & 1.19 & 0.000331 & 0.0000000 \\
\hline 34 & 13.2 & 0.00885 & 0.00639 & 2.19 & 0.00058 & 0.00251 & 0.00062 & 1.22 & 0.000342 & 0.0000452 \\
\hline 35 & 13.6 & 0.00643 & 0.00000 & 1.94 & 0.00000 & 0.00261 & 0.00447 & 1.37 & 0.000539 & 0.0000425 \\
\hline 36 & 14.0 & 0.00559 & 0.01201 & 1.75 & 0.00098 & 0.00209 & 0.00686 & 1.27 & 0.000344 & 0.0000016 \\
\hline 37 & 14.4 & 0.00954 & 0.01207 & 2.63 & 0.00050 & 0.00305 & 0.00319 & 1.26 & 0.000435 & 0.0000093 \\
\hline 38 & 14.8 & 0.00803 & 0.00584 & 3.00 & 0.00000 & 0.00016 & 0.00373 & 1.22 & 0.000362 & 0.0000384 \\
\hline 39 & 15.2 & 0.00852 & 0.00000 & 1.99 & 0.00456 & 0.00180 & 0.01195 & 1.43 & 0.000578 & 0.0000000 \\
\hline 40 & 15.6 & 0.00972 & 0.00509 & 1.57 & 0.00029 & 0.00186 & 0.00246 & 1.05 & 0.000282 & 0.0000710 \\
\hline 41 & 16.0 & 0.01073 & 0.00027 & 1.64 & 0.00011 & 0.00197 & 0.00463 & 1.32 & 0.000567 & 0.0000573 \\
\hline 42 & 16.4 & 0.00995 & 0.00000 & 2.18 & 0.00000 & 0.00260 & 0.00134 & 1.31 & 0.000382 & 0.0000372 \\
\hline 43 & 16.8 & 0.00519 & 0.00000 & 1.51 & 0.00000 & 0.00165 & 0.00364 & 1.43 & 0.000434 & 0.0000248 \\
\hline 44 & 17.2 & 0.00749 & 0.00000 & 2.39 & 0.00037 & 0.00275 & 0.00284 & 1.32 & 0.000454 & 0.0000146 \\
\hline 45 & 17.6 & 0.00812 & 0.01017 & 2.23 & 0.00036 & 0.00112 & 0.00256 & 1.30 & 0.000474 & 0.0000169 \\
\hline 46 & 18.0 & 0.00758 & 0.00808 & 2.87 & 0.00030 & 0.00288 & 0.00261 & 1.16 & 0.000360 & 0.0000000 \\
\hline 47 & 18.4 & 0.00977 & 0.01169 & 2.81 & 0.00197 & 0.00278 & 0.00185 & 1.18 & 0.000354 & 0.0000630 \\
\hline 48 & 18.8 & 0.01097 & 0.00710 & 1.88 & 0.00335 & 0.00058 & 0.00233 & 1.19 & 0.000341 & 0.0000000 \\
\hline 49 & 19.2 & 0.00805 & 0.00908 & 1.80 & 0.00233 & 0.00144 & 0.00570 & 1.23 & 0.000347 & 0.0000000 \\
\hline 50 & 19.6 & 0.00483 & 0.01858 & 2.18 & 0.00090 & 0.00018 & 0.00208 & 1.21 & 0.000495 & 0.0000210 \\
\hline 51 & 20.0 & 0.00367 & 0.00000 & 1.89 & 0.00115 & 0.00139 & 0.00219 & 1.35 & 0.000416 & 0.0000286 \\
\hline 52 & 20.4 & 0.00765 & 0.00000 & 1.69 & 0.00167 & 0.00000 & 0.00582 & 1.35 & 0.000422 & 0.0000098 \\
\hline 53 & 20.8 & 0.00654 & 0.00000 & 1.99 & 0.00150 & 0.00225 & 0.00419 & 1.39 & 0.000390 & 0.0000480 \\
\hline 54 & 21.2 & 0.00335 & 0.00000 & 2.41 & 0.00508 & 0.00208 & 0.00579 & 1.32 & 0.000435 & 0.0000576 \\
\hline 55 & 21.6 & 0.01198 & 0.00855 & 2.31 & 0.00117 & 0.00000 & 0.00066 & 1.12 & 0.000198 & 0.0000488 \\
\hline 56 & 22.0 & 0.01273 & 0.00743 & 1.32 & 0.00000 & 0.00117 & 0.00070 & 1.42 & 0.000417 & 0.0000263 \\
\hline 57 & 22.4 & 0.00731 & 0.00000 & 2.92 & 0.00132 & 0.00259 & 0.00826 & 1.15 & 0.000398 & 0.0000305 \\
\hline 58 & 22.8 & 0.00576 & 0.00000 & 3.04 & 0.00286 & 0.00108 & 0.00135 & 1.18 & 0.000277 & 0.0000603 \\
\hline 59 & 23.2 & 0.00324 & 0.00181 & 3.63 & 0.00000 & 0.00463 & 0.00189 & 1.31 & 0.000377 & 0.0000109 \\
\hline
\end{tabular}




\begin{tabular}{|c|c|c|c|c|c|c|c|c|c|c|}
\hline \multirow{2}{*}{ Spot Number } & \multirow{2}{*}{ Distance from the foot $(\mathrm{mm})$} & \multicolumn{9}{|c|}{ RW75 400 prismatic layer transect data $(\mathrm{mmol} / \mathrm{mol})$ continued... } \\
\hline & & $\mathrm{Li} / \mathrm{Ca}$ & $\mathrm{B} / \mathrm{Ca}$ & $\mathrm{Mg} / \mathrm{Ca}$ & $\mathbf{A l} / \mathbf{C a}$ & $\mathrm{Mn} / \mathrm{Ca}$ & $\mathrm{Zn} / \mathrm{Ca}$ & Sr88/Ca & $\mathrm{Ba} / \mathrm{Ca}$ & $\mathrm{U} / \mathrm{Ca}$ \\
\hline 60 & 23.6 & 0.00483 & 0.00000 & 2.61 & 0.00000 & 0.00114 & 0.00235 & 1.30 & 0.000353 & 0.0000267 \\
\hline 61 & 24.0 & 0.01065 & 0.01175 & 1.93 & 0.00027 & 0.00141 & 0.00063 & 1.24 & 0.000387 & 0.0000278 \\
\hline 62 & 24.4 & 0.00894 & 0.00455 & 2.90 & 0.00063 & 0.00126 & 0.00328 & 1.20 & 0.000307 & 0.0000092 \\
\hline 63 & 24.8 & 0.00753 & 0.00028 & 1.64 & 0.00041 & 0.00156 & 0.00204 & 1.39 & 0.000346 & 0.0000000 \\
\hline 64 & 25.2 & 0.01208 & 0.02317 & 2.08 & 0.00252 & 0.00000 & 0.00295 & 1.37 & 0.000391 & 0.0000564 \\
\hline 65 & 25.6 & 0.00696 & 0.00696 & 3.41 & 0.00000 & 0.00328 & 0.00060 & 1.54 & 0.000455 & 0.0000312 \\
\hline 66 & 26.0 & 0.00814 & 0.00379 & 3.48 & 0.00244 & 0.00318 & 0.00000 & 1.51 & 0.000491 & 0.0000113 \\
\hline 67 & 26.4 & 0.00903 & 0.02101 & 2.24 & 0.00216 & 0.00171 & 0.00311 & 1.62 & 0.000607 & 0.0000342 \\
\hline 68 & 26.8 & 0.00534 & 0.01327 & 2.96 & 0.00000 & 0.00000 & 0.00392 & 1.50 & 0.000395 & 0.0000254 \\
\hline 69 & 27.2 & 0.00792 & 0.01144 & 3.82 & 0.00000 & 0.00113 & 0.00505 & 1.34 & 0.000408 & 0.0000247 \\
\hline 70 & 27.6 & 0.00780 & 0.01452 & 5.31 & 0.00000 & 0.00203 & 0.00348 & 1.22 & 0.000457 & 0.0001116 \\
\hline 71 & 28.0 & 0.01233 & 0.00249 & 3.19 & 0.00129 & 0.00029 & 0.00499 & 1.32 & 0.000330 & 0.0000000 \\
\hline 72 & 28.4 & 0.00623 & 0.00787 & 3.09 & 0.00000 & 0.00148 & 0.00249 & 1.19 & 0.000285 & 0.0000137 \\
\hline 73 & 28.8 & 0.01118 & 0.00492 & 5.08 & 0.00246 & 0.00068 & 0.00149 & 1.04 & 0.000282 & 0.0000000 \\
\hline 74 & 29.2 & 0.00703 & 0.01419 & 4.13 & 0.00000 & 0.00210 & 0.00307 & 1.11 & 0.000301 & 0.0000133 \\
\hline 75 & 29.6 & 0.00719 & 0.00831 & 8.71 & 0.00031 & 0.00172 & 0.00144 & 1.00 & 0.000361 & 0.0000416 \\
\hline 76 & 30.0 & 0.00853 & 0.00000 & 4.83 & 0.00202 & 0.00073 & 0.00247 & 1.10 & 0.000284 & 0.0000000 \\
\hline 77 & 30.4 & 0.00653 & 0.00758 & 4.03 & 0.00000 & 0.00041 & 0.00000 & 1.01 & 0.000224 & 0.0000178 \\
\hline 78 & 30.8 & 0.00721 & 0.01140 & 3.09 & 0.00000 & 0.00113 & 0.00012 & 1.01 & 0.000257 & 0.0000675 \\
\hline 79 & 31.2 & 0.00721 & 0.01140 & 3.09 & 0.00000 & 0.00113 & 0.00012 & 1.01 & 0.000257 & 0.0000675 \\
\hline 80 & 31.6 & 0.00660 & 0.00316 & 2.36 & 0.00000 & 0.00009 & 0.00371 & 1.29 & 0.000329 & 0.0000092 \\
\hline 81 & 32.0 & 0.00832 & 0.00768 & 3.16 & 0.00086 & 0.00385 & 0.00845 & 1.25 & 0.000487 & 0.0000000 \\
\hline 82 & 32.4 & 0.00644 & 0.01701 & 3.20 & 0.00227 & 0.00243 & 0.00435 & 1.19 & 0.000298 & 0.0000000 \\
\hline 83 & 32.8 & 0.00608 & 0.01557 & 2.71 & 0.00231 & 0.00392 & 0.00883 & 1.22 & 0.000330 & 0.0000656 \\
\hline 84 & 33.2 & 0.01084 & 0.01127 & 1.00 & 0.00120 & 0.00000 & 0.00264 & 1.76 & 0.000771 & 0.0000053 \\
\hline 85 & 33.6 & 0.00711 & 0.04659 & 0.77 & 0.00038 & 0.00044 & 0.00290 & 2.14 & 0.0002533 & 0.0000120 \\
\hline 86 & 34.0 & 0.01348 & 0.00000 & 6.99 & 0.00000 & 0.00228 & 0.00279 & 0.88 & 0.000253 & 0.0000786 \\
\hline 87 & 34.4 & 0.00673 & 0.01572 & 5.96 & 0.00293 & 0.00512 & 0.00154 & 0.97 & 0.000244 & 0.0000000 \\
\hline 88 & 34.8 & 0.01141 & 0.00618 & 11.97 & 0.00089 & 0.00231 & 0.00129 & 0.97 & 0.000296 & 0.0000624 \\
\hline 89 & 35.2 & 0.00650 & 0.00000 & 5.47 & 0.00102 & 0.00200 & 0.00098 & 0.98 & 0.000300 & 0.0000348 \\
\hline
\end{tabular}




\begin{tabular}{|c|c|c|c|c|c|c|c|c|c|c|}
\hline \multirow{2}{*}{ Spot Number } & \multirow{2}{*}{ Distance from the foot $(\mathrm{mm})$} & \multicolumn{9}{|c|}{ RW75 400 prismatic layer transect data $(\mathrm{mmol} / \mathrm{mol})$ continued... } \\
\hline & & $\mathrm{Li} / \mathrm{Ca}$ & $\mathrm{B} / \mathrm{Ca}$ & $\mathrm{Mg} / \mathrm{Ca}$ & $\mathrm{Al} / \mathrm{Ca}$ & $\mathrm{Mn} / \mathrm{Ca}$ & $\mathrm{Zn} / \mathrm{Ca}$ & $\mathrm{Sr} 88 / \mathrm{Ca}$ & $\mathrm{Ba} / \mathrm{Ca}$ & $\mathbf{U} / \mathbf{C a}$ \\
\hline 90 & 35.6 & 0.00396 & 0.00000 & 6.67 & 0.00000 & 0.00218 & 0.00442 & 0.95 & 0.000258 & 0.0000000 \\
\hline 91 & 36.0 & 0.00939 & 0.00000 & 4.24 & 0.00101 & 0.00426 & 0.00325 & 1.06 & 0.000237 & 0.0000370 \\
\hline 92 & 36.4 & 0.00701 & 0.00463 & 3.14 & 0.00249 & 0.00266 & 0.00147 & 1.05 & 0.000329 & 0.0000277 \\
\hline 93 & 36.8 & 0.00580 & 0.00787 & 2.74 & 0.00096 & 0.00332 & 0.00323 & 1.21 & 0.000370 & 0.0000327 \\
\hline 94 & 37.2 & 0.00757 & 0.00714 & 3.64 & 0.00292 & 0.00429 & 0.00153 & 1.25 & 0.000468 & 0.0000000 \\
\hline 95 & 37.6 & 0.00673 & 0.01347 & 3.76 & 0.00000 & 0.00207 & 0.00139 & 1.21 & 0.000373 & 0.0000075 \\
\hline 96 & 38.0 & 0.00597 & 0.01686 & 3.99 & 0.00058 & 0.00422 & 0.00000 & 1.17 & 0.000341 & 0.0000222 \\
\hline 97 & 38.4 & 0.00829 & 0.00916 & 4.04 & 0.00122 & 0.00039 & 0.00280 & 1.21 & 0.000387 & 0.0000000 \\
\hline 98 & 38.8 & 0.00811 & 0.00000 & 3.88 & 0.00056 & 0.00433 & 0.00559 & 1.39 & 0.000585 & 0.0000205 \\
\hline 99 & 39.2 & 0.00672 & 0.00000 & 2.44 & 0.00081 & 0.00349 & 0.00385 & 1.10 & 0.000402 & $0.000018 s$ \\
\hline 100 & 39.6 & 0.01180 & 0.00190 & 2.32 & 0.00014 & 0.00061 & 0.00229 & 1.26 & 0.000349 & 0.0000000 \\
\hline 101 & 40.0 & 0.01109 & 0.01336 & 2.98 & 0.00000 & 0.00205 & 0.00244 & 1.38 & 0.000473 & 0.0000799 \\
\hline 102 & 40.4 & 0.00714 & 0.00860 & 2.47 & 0.00000 & 0.00182 & 0.00372 & 1.16 & 0.000405 & 0.0000000 \\
\hline 103 & 40.8 & 0.01248 & 0.00000 & 2.76 & 0.00506 & 0.00091 & 0.00502 & 1.25 & 0.000440 & 0.0000126 \\
\hline 104 & 41.2 & 0.00816 & 0.00856 & 3.21 & 0.00099 & 0.00204 & 0.00059 & 1.17 & 0.000313 & $0.000046 \mathrm{~s}$ \\
\hline 105 & 41.6 & 0.00744 & 0.01584 & 2.37 & 0.00201 & 0.00322 & 0.00136 & 1.28 & 0.000417 & 0.0000063 \\
\hline 106 & 42.0 & 0.01352 & 0.01204 & 2.41 & 0.00000 & 0.00289 & 0.00130 & 1.46 & 0.000508 & 0.0000034 \\
\hline
\end{tabular}


APPENDIX 5.1b $\quad$ RW75 100 prismatic layer data

\begin{tabular}{|c|c|c|c|c|c|c|c|c|c|c|c|}
\hline \multirow{2}{*}{ Spot Number } & \multirow{2}{*}{ Distance from the foot ( $\mathrm{mm})$} & \multicolumn{10}{|c|}{ RW75 100 prismatic layer transect corrected data $(\mathrm{mmol} / \mathrm{mol})$} \\
\hline & & $\mathrm{Li} / \mathrm{Ca}$ & $\mathrm{B} / \mathrm{Ca}$ & $\mathrm{Mg} / \mathrm{Ca}$ & $\mathrm{Al} / \mathrm{Ca}$ & $\mathrm{Mn} / \mathrm{Ca}$ & $\mathrm{Zn} / \mathrm{Ca}$ & Sr88/Ca & $\mathrm{Ba} / \mathrm{Ca}$ & $\mathrm{Pb} / \mathrm{Ca}$ & $\mathrm{U} / \mathbf{C a}$ \\
\hline 1 & 0.0 & 0.0258 & 0.0000 & 11.59 & 0.00309 & 0.00000 & 0.0558 & 1.26 & 0.000989 & 0.0001376 & 0.0000000 \\
\hline 2 & 0.4 & 0.0096 & 0.0000 & 8.37 & 0.00975 & 0.00000 & 0.0763 & 1.29 & 0.000913 & 0.0000838 & 0.0000113 \\
\hline 3 & 0.8 & 0.0093 & 0.0000 & 2.88 & 0.00000 & 0.00000 & 0.0137 & 1.25 & 0.000562 & 0.0000381 & 0.0000046 \\
\hline 4 & 1.2 & 0.0156 & 0.0151 & 2.93 & 0.00000 & 0.00000 & 0.0187 & 1.33 & 0.000476 & 0.0000069 & 0.0000114 \\
\hline 5 & 1.6 & 0.0130 & 0.0000 & 5.64 & 0.00300 & 0.00000 & 0.0259 & 1.42 & 0.000448 & 0.0000355 & 0.0000000 \\
\hline 6 & 2.0 & 0.0029 & 0.0104 & 4.65 & 0.00000 & 0.00000 & 0.0019 & 1.31 & 0.000456 & 0.0000385 & 0.0000094 \\
\hline 7 & 2.4 & 0.0073 & 0.0136 & 4.61 & 0.00000 & 0.00000 & 0.0058 & 1.46 & 0.000486 & 0.0000289 & 0.0000152 \\
\hline 8 & 2.8 & 0.0000 & 0.0240 & 5.93 & 0.00000 & 0.00000 & 0.0063 & 1.13 & 0.000355 & 0.0000225 & 0.0000002 \\
\hline 9 & 3.2 & 0.0000 & 0.0000 & 5.17 & 0.01158 & 0.00000 & 0.0000 & 1.21 & 0.000338 & 0.0000435 & 0.0000000 \\
\hline 10 & 3.6 & 0.0186 & 0.0127 & 7.78 & 0.00491 & 0.00024 & 0.0095 & 1.22 & 0.000430 & 0.0000000 & 0.0000000 \\
\hline 11 & 4.0 & 0.0122 & 0.0247 & 16.78 & 0.00333 & 0.00000 & 0.0164 & 1.08 & 0.000356 & 0.0000153 & 0.0000000 \\
\hline 12 & 4.4 & 0.0000 & 0.0000 & 6.54 & 0.00682 & 0.00086 & 0.0040 & 1.29 & 0.000401 & 0.0000000 & 0.0000000 \\
\hline 13 & 4.8 & 0.0059 & 0.0000 & 6.57 & 0.00069 & 0.00190 & 0.0061 & 1.21 & 0.000385 & 0.0000128 & 0.0000000 \\
\hline 14 & 5.2 & 0.0022 & 0.0000 & 8.18 & 0.00000 & 0.00008 & 0.0074 & 1.29 & 0.000459 & 0.0000224 & 0.0000000 \\
\hline 15 & 5.6 & 0.0022 & 0.0006 & 5.47 & 0.00389 & 0.00000 & 0.0033 & 1.24 & 0.000425 & 0.0000491 & 0.0000146 \\
\hline 16 & 6.0 & 0.0168 & 0.0200 & 13.21 & 0.00000 & 0.00196 & 0.0063 & 1.17 & 0.000347 & 0.0000148 & 0.0000000 \\
\hline 17 & 6.4 & 0.0182 & 0.0299 & 14.31 & 0.09983 & 0.00219 & 0.0058 & 1.36 & 0.000643 & 0.0000578 & 0.0000360 \\
\hline 18 & 6.8 & 0.0000 & 0.0268 & 4.70 & 0.01474 & 0.00125 & 0.0732 & 1.19 & 0.000785 & 0.0000552 & 0.0000101 \\
\hline 19 & 7.2 & 0.0206 & 0.0000 & 6.37 & 0.00978 & 0.00295 & 0.0072 & 1.14 & 0.000342 & 0.0000000 & 0.0000213 \\
\hline 20 & 7.6 & 0.0094 & 0.0000 & 10.99 & 0.00000 & 0.00131 & 0.0015 & 1.04 & 0.000243 & 0.0000586 & 0.0000018 \\
\hline 21 & 8.0 & 0.0189 & 0.0000 & 8.75 & 0.00556 & 0.00000 & 0.0047 & 1.17 & 0.000431 & 0.0000155 & 0.0000016 \\
\hline 22 & 8.4 & 0.0178 & 0.0410 & 17.76 & 0.02794 & 0.00092 & 0.0119 & 1.22 & 0.000559 & 0.0000423 & 0.0000291 \\
\hline 23 & 8.8 & 0.0011 & 0.0000 & 20.91 & 0.00000 & 0.00128 & 0.0058 & 1.06 & 0.000551 & 0.0000000 & 0.0000000 \\
\hline 24 & 9.2 & 0.0159 & 0.0006 & 10.42 & 0.00836 & 0.00044 & 0.0092 & 1.04 & 0.000417 & 0.0001027 & 0.0000176 \\
\hline 25 & 9.6 & 0.0099 & 0.0057 & 28.83 & 0.00000 & 0.00210 & 0.0044 & 1.04 & 0.000399 & 0.0000000 & 0.0000200 \\
\hline 26 & 10.0 & 0.0062 & 0.0255 & 4.79 & 0.04531 & 0.00048 & 0.0136 & 1.20 & 0.000961 & 0.0001113 & 0.0000071 \\
\hline 27 & 10.4 & 0.0099 & 0.0152 & 2.29 & 0.00526 & 0.00136 & 0.0041 & 1.25 & 0.000311 & 0.0000641 & 0.0000000 \\
\hline 28 & 10.8 & 0.0167 & 0.0046 & 3.00 & 0.00000 & 0.00277 & 0.0093 & 1.23 & 0.000344 & 0.0000335 & 0.0000000 \\
\hline 29 & 11.2 & 0.0142 & 0.0095 & 2.81 & 0.00370 & 0.00000 & 0.0139 & 1.14 & 0.000292 & 0.0001107 & 0.0000123 \\
\hline
\end{tabular}




\begin{tabular}{|c|c|c|c|c|c|c|c|c|c|c|c|}
\hline \multirow{2}{*}{ Spot Number } & \multirow{2}{*}{ Distance from the foot $(\mathrm{mm})$} & \multicolumn{10}{|c|}{ RW75 100 prismatic layer transect corrected data $(\mathrm{mmol} / \mathrm{mol})$ continued... } \\
\hline & & $\mathrm{Li} / \mathrm{Ca}$ & $\mathrm{B} / \mathrm{Ca}$ & $\mathrm{Mg} / \mathrm{Ca}$ & $\mathrm{Al} / \mathrm{Ca}$ & $\mathrm{Mn} / \mathrm{Ca}$ & $\mathrm{Zn} / \mathrm{Ca}$ & Sr88/Ca & $\mathrm{Ba} / \mathrm{Ca}$ & $\mathrm{Pb} / \mathrm{Ca}$ & $\mathrm{U} / \mathrm{Ca}$ \\
\hline 60 & 23.6 & 0.0000 & 0.0000 & 2.95 & 0.00000 & 0.00000 & 0.0061 & 1.64 & 0.000528 & 0.0000000 & 0.0000000 \\
\hline 61 & 24.0 & 0.0000 & 0.0126 & 4.22 & 0.01177 & 0.00211 & 0.0089 & 1.60 & 0.000643 & 0.0000511 & 0.0000000 \\
\hline 62 & 24.4 & 0.0137 & 0.0380 & 2.02 & 0.00524 & 0.00074 & 0.0009 & 1.45 & 0.000451 & 0.0000000 & 0.0000000 \\
\hline 63 & 24.8 & 0.0034 & 0.0000 & 1.95 & 0.00000 & 0.00261 & 0.0039 & 1.51 & 0.000592 & 0.0000697 & 0.0000000 \\
\hline 64 & 25.2 & 0.0000 & 0.0111 & 2.58 & 0.01305 & 0.00042 & 0.0057 & 1.55 & 0.000494 & 0.0000784 & 0.0000000 \\
\hline 65 & 25.6 & 0.0000 & 0.0000 & 5.50 & 0.00222 & 0.00187 & 0.0060 & 1.61 & 0.000643 & 0.0000022 & 0.0000103 \\
\hline 66 & 26.0 & 0.0063 & 0.0138 & 3.03 & 0.00000 & 0.00283 & 0.0012 & 1.50 & 0.000491 & 0.0000112 & 0.0000000 \\
\hline 67 & 26.4 & 0.0196 & 0.0000 & 2.37 & 0.01556 & 0.00458 & 0.0082 & 1.39 & 0.000478 & 0.0000461 & 0.0000170 \\
\hline 68 & 26.8 & 0.0082 & 0.0075 & 2.97 & 0.00041 & 0.00315 & 0.0146 & 1.51 & 0.000544 & 0.0000517 & 0.0000000 \\
\hline 69 & 27.2 & 0.0048 & 0.0000 & 3.85 & 0.00000 & 0.00171 & 0.0106 & 1.38 & 0.000554 & 0.0001247 & 0.0000000 \\
\hline 70 & 27.6 & 0.0063 & 0.0090 & 4.10 & 0.00060 & 0.00228 & 0.0043 & 1.45 & 0.000551 & 0.0000427 & 0.0000000 \\
\hline 71 & 28.0 & 0.0078 & 0.0232 & 6.83 & 0.00476 & 0.00349 & 0.0134 & 1.30 & 0.000435 & 0.0001234 & 0.0000193 \\
\hline 72 & 28.4 & 0.0000 & 0.0017 & 4.17 & 0.00029 & 0.00486 & 0.0020 & 1.38 & 0.000381 & 0.0000000 & 0.0000154 \\
\hline 73 & 28.8 & 0.0196 & 0.0000 & 4.52 & 0.00341 & 0.00393 & 0.0000 & 1.26 & 0.000416 & 0.0000227 & 0.0000106 \\
\hline 74 & 29.2 & 0.0005 & 0.0132 & 3.54 & 0.00224 & 0.00224 & 0.0069 & 1.39 & 0.000379 & 0.0000210 & 0.0000156 \\
\hline 75 & 29.6 & 0.0000 & 0.0000 & 3.71 & 0.00671 & 0.00000 & 0.0000 & 1.37 & 0.000450 & 0.0000340 & 0.0000000 \\
\hline 76 & 30.0 & 0.0031 & 0.0130 & 4.14 & 0.00000 & 0.00200 & 0.0026 & 1.36 & 0.000303 & 0.0000212 & 0.0000192 \\
\hline 77 & 30.4 & 0.0182 & 0.0000 & 4.21 & 0.00000 & 0.00115 & 0.0000 & 1.34 & 0.000244 & 0.0000000 & 0.0000000 \\
\hline 78 & 30.8 & 0.0000 & 0.0010 & 3.65 & 0.00000 & 0.00000 & 0.0063 & 1.40 & 0.000427 & 0.0000190 & 0.0000123 \\
\hline 79 & 31.2 & 0.0176 & 0.0014 & 4.16 & 0.00582 & 0.00000 & 0.0023 & 1.49 & 0.000403 & 0.0000168 & 0.0000099 \\
\hline 80 & 31.6 & 0.0081 & 0.0000 & 2.82 & 0.00000 & 0.00340 & 0.0039 & 1.52 & 0.000363 & 0.0000136 & 0.0000100 \\
\hline 81 & 32.0 & 0.0150 & 0.0017 & 3.14 & 0.00572 & 0.00063 & 0.0022 & 1.26 & 0.000326 & 0.0000853 & 0.0000074 \\
\hline 82 & 32.4 & 0.0089 & 0.0214 & 4.57 & 0.00657 & 0.00200 & 0.0026 & 1.16 & 0.000231 & 0.0000000 & 0.0000168 \\
\hline 83 & 32.8 & 0.0090 & 0.0112 & 6.33 & 0.00000 & 0.00130 & 0.0067 & 0.88 & 0.000277 & 0.0000183 & 0.0000246 \\
\hline 84 & 33.2 & 0.0000 & 0.0059 & 4.08 & 0.00000 & 0.00000 & 0.0028 & 1.08 & 0.000317 & 0.0000000 & 0.0000057 \\
\hline 85 & 33.6 & 0.0000 & 0.0106 & 3.75 & 0.00148 & 0.00000 & 0.0000 & 1.05 & 0.000262 & 0.0000000 & 0.0000000 \\
\hline 86 & 34.0 & 0.0056 & 0.0090 & 4.00 & 0.00735 & 0.00212 & 0.0051 & 1.00 & 0.000209 & 0.0000155 & 0.0000033 \\
\hline 87 & 34.4 & 0.0108 & 0.0184 & 6.49 & 0.00000 & 0.00327 & 0.0040 & 1.00 & 0.000248 & 0.0000000 & 0.0000000 \\
\hline 88 & 34.8 & 0.0087 & 0.0161 & 9.13 & 0.00480 & 0.00257 & 0.0036 & 0.92 & 0.000292 & 0.0000412 & 0.0000167 \\
\hline 89 & 35.2 & 0.0000 & 0.0000 & 4.32 & 0.00452 & 0.00304 & 0.0025 & 1.04 & 0.000262 & 0.0000171 & 0.0000066 \\
\hline
\end{tabular}




\begin{tabular}{|c|c|c|c|c|c|c|c|c|c|c|c|}
\hline \multirow{2}{*}{ Spot Number } & \multirow{2}{*}{ Distance from the foot $(\mathrm{mm})$} & \multicolumn{10}{|c|}{ RW75 100 prismatic layer transect corrected data $(\mathrm{mmol} / \mathrm{mol}$ ) continued... } \\
\hline & & $\mathrm{Li} / \mathrm{Ca}$ & $\mathrm{B} / \mathrm{Ca}$ & $\mathrm{Mg} / \mathrm{Ca}$ & $\mathrm{Al} / \mathrm{Ca}$ & $\mathrm{Mn} / \mathrm{Ca}$ & $\mathrm{Zn} / \mathrm{Ca}$ & Sr88/Ca & $\mathrm{Ba} / \mathrm{Ca}$ & $\mathrm{Pb} / \mathrm{Ca}$ & $\mathrm{U} / \mathrm{Ca}$ \\
\hline 90 & 35.6 & 0.0023 & 0.0115 & 4.59 & 0.00000 & 0.00000 & 0.0038 & 1.02 & 0.000239 & 0.0000756 & 0.0000007 \\
\hline 91 & 36.0 & 0.0158 & 0.0139 & 4.06 & 0.00008 & 0.00000 & 0.0000 & 0.94 & 0.000182 & 0.0000425 & 0.0000000 \\
\hline 92 & 36.4 & 0.0109 & 0.0000 & 4.53 & 0.00000 & 0.00217 & 0.0047 & 0.96 & 0.000306 & 0.0000000 & 0.0000000 \\
\hline 93 & 36.8 & 0.0127 & 0.0105 & 5.15 & 0.00000 & 0.00108 & 0.0062 & 0.81 & 0.000238 & 0.0000083 & 0.0000000 \\
\hline 94 & 37.2 & 0.0000 & 0.0000 & 6.24 & 0.00000 & 0.00286 & 0.0056 & 0.80 & 0.000245 & 0.0000000 & 0.0000039 \\
\hline 95 & 37.6 & 0.0000 & 0.0000 & 5.03 & 0.00233 & 0.00282 & 0.0009 & 0.88 & 0.000219 & 0.0000556 & 0.0000109 \\
\hline 96 & 38.0 & 0.0008 & 0.0000 & 3.87 & 0.00475 & 0.00000 & 0.0024 & 0.87 & 0.000208 & 0.0000028 & 0.0000000 \\
\hline 97 & 38.4 & 0.0184 & 0.0000 & 2.94 & 0.00211 & 0.00246 & 0.0030 & 1.09 & 0.000261 & 0.0000019 & 0.0000183 \\
\hline 98 & 38.8 & 0.0000 & 0.0000 & 3.44 & 0.00000 & 0.00000 & 0.0032 & 0.96 & 0.000174 & 0.0000007 & 0.0000000 \\
\hline 99 & 39.2 & 0.0069 & 0.0090 & 3.89 & 0.00000 & 0.00000 & 0.0000 & 0.87 & 0.000121 & 0.0000408 & 0.0000038 \\
\hline 100 & 39.6 & 0.0000 & 0.0273 & 3.52 & 0.00000 & 0.00425 & 0.0026 & 0.92 & 0.000297 & 0.0000000 & 0.0000000 \\
\hline 101 & 40.0 & 0.0015 & 0.0172 & 6.36 & 0.00689 & 0.00166 & 0.0014 & 1.01 & 0.000305 & 0.0000000 & 0.0000021 \\
\hline 102 & 40.4 & 0.0074 & 0.0000 & 3.23 & 0.00000 & 0.00359 & 0.0090 & 1.09 & 0.000367 & 0.0000620 & 0.0000000 \\
\hline 103 & 40.8 & 0.0194 & 0.0000 & 3.38 & 0.01056 & 0.00388 & 0.0161 & 1.11 & 0.000378 & 0.0000822 & 0.0000000 \\
\hline 104 & 41.2 & 0.0210 & 0.0000 & 1.79 & 0.00000 & 0.00201 & 0.0098 & 1.27 & 0.000414 & 0.0001189 & 0.0000284 \\
\hline 105 & 41.6 & 0.0000 & 0.0064 & 1.25 & 0.00000 & 0.00188 & 0.0081 & 1.42 & 0.000399 & 0.0000462 & 0.0000000 \\
\hline 106 & 42.0 & 0.0061 & 0.0065 & 2.37 & 0.00088 & 0.00000 & 0.0064 & 1.19 & 0.000340 & 0.0000969 & 0.0000051 \\
\hline 107 & 42.4 & 0.0057 & 0.0044 & 3.16 & 0.00000 & 0.00101 & 0.0000 & 1.34 & 0.000334 & 0.0000454 & 0.0000000 \\
\hline 108 & 42.8 & 0.0000 & 0.0000 & 2.90 & 0.00864 & 0.00000 & 0.0000 & 1.25 & 0.000234 & 0.0000141 & 0.0000000 \\
\hline 109 & 43.2 & 0.0000 & 0.0129 & 3.53 & 0.01214 & 0.00875 & 0.0000 & 1.12 & 0.000302 & 0.0000000 & 0.0000000 \\
\hline 110 & 43.6 & 0.0323 & 0.0184 & 2.64 & 0.00000 & 0.00000 & 0.0149 & 1.13 & 0.000286 & 0.0001357 & 0.0000184 \\
\hline 111 & 44.0 & 0.0553 & 0.0066 & 2.55 & 0.03290 & 0.00000 & 0.0000 & 1.22 & 0.000331 & 0.0000754 & 0.0000201 \\
\hline 112 & 44.4 & 0.0000 & 0.0000 & 3.46 & 0.10132 & 0.00144 & 0.0311 & 1.03 & 0.000415 & 0.0001116 & 0.0000000 \\
\hline 113 & 44.8 & 0.0323 & 0.0401 & 2.49 & 0.01602 & 0.00052 & 0.0027 & 1.18 & 0.000314 & 0.0000640 & 0.0000287 \\
\hline 114 & 45.2 & 0.0105 & 0.0000 & 1.79 & 0.00000 & 0.00442 & 0.0000 & 1.30 & 0.000326 & 0.0000604 & 0.0000156 \\
\hline 115 & 45.6 & 0.0000 & 0.0000 & 2.18 & 0.00695 & 0.00805 & 0.0244 & 1.09 & 0.000463 & 0.0000000 & 0.0000000 \\
\hline 116 & 46.0 & 0.0000 & 0.0286 & 2.01 & 0.00000 & 0.00174 & 0.0165 & 1.03 & 0.000234 & 0.0001108 & 0.0000000 \\
\hline 117 & 46.4 & 0.0168 & 0.0000 & 2.17 & 0.00383 & 0.00285 & 0.0000 & 1.12 & 0.000276 & 0.0000000 & 0.0000000 \\
\hline 118 & 46.8 & 0.0250 & 0.0000 & 1.95 & 0.00000 & 0.00425 & 0.0056 & 1.29 & 0.000312 & 0.0000661 & 0.0000000 \\
\hline 119 & 47.2 & 0.0030 & 0.0000 & 3.93 & 0.00650 & 0.00021 & 0.0056 & 1.26 & 0.000539 & 0.0000000 & 0.0000000 \\
\hline
\end{tabular}




\begin{tabular}{|c|c|c|c|c|c|c|c|c|c|c|c|}
\hline \multirow{2}{*}{ Spot Number } & \multirow{2}{*}{ Distance from the foot (mm) } & \multicolumn{10}{|c|}{ RW75 100 prismatic layer transect corrected data $(\mathrm{mmol} / \mathrm{mol})$ continued... } \\
\hline & & $\mathrm{Li} / \mathrm{Ca}$ & $\mathrm{B} / \mathrm{Ca}$ & $\mathrm{Mg} / \mathrm{Ca}$ & $\mathrm{Al} / \mathrm{Ca}$ & $\mathrm{Mn} / \mathrm{Ca}$ & $\mathrm{Zn} / \mathrm{Ca}$ & Sr88/Ca & $\mathrm{Ba} / \mathrm{Ca}$ & $\mathrm{Pb} / \mathrm{Ca}$ & $\mathrm{U} / \mathrm{Ca}$ \\
\hline 120 & 47.6 & 0.0248 & 0.0035 & 3.16 & 0.00000 & 0.00714 & 0.0178 & 1.14 & 0.000489 & 0.0000000 & 0.0000133 \\
\hline 121 & 48.0 & 0.0153 & 0.0000 & 6.25 & 0.00580 & 0.00777 & 0.0000 & 1.32 & 0.000460 & 0.0001110 & 0.0000000 \\
\hline 122 & 48.4 & 0.0460 & 0.0000 & 2.84 & 0.00000 & 0.00438 & 0.0048 & 1.23 & 0.000581 & 0.0000111 & 0.0000000 \\
\hline 123 & 48.8 & 0.0037 & 0.0187 & 3.28 & 0.00412 & 0.00143 & 0.0101 & 1.29 & 0.000493 & 0.0000347 & 0.0000234 \\
\hline 124 & 49.2 & 0.0000 & 0.0239 & 3.40 & 0.01483 & 0.00528 & 0.0097 & 1.44 & 0.000855 & 0.0000739 & 0.0000000 \\
\hline 125 & 49.6 & 0.0236 & 0.0123 & 4.74 & 0.00000 & 0.00017 & 0.0070 & 1.33 & 0.000719 & 0.0000000 & 0.0000000 \\
\hline 126 & 50.0 & 0.0000 & 0.0082 & 4.00 & 0.00000 & 0.00000 & 0.0073 & 1.35 & 0.000539 & 0.0000000 & 0.0000017 \\
\hline 127 & 50.4 & 0.0220 & 0.0000 & 2.02 & 0.00555 & 0.00000 & 0.0056 & 1.52 & 0.000548 & 0.0000180 & 0.0000000 \\
\hline 128 & 50.8 & 0.0000 & 0.0000 & 3.28 & 0.00182 & 0.00227 & 0.0000 & 1.58 & 0.000497 & 0.0000149 & 0.0000056 \\
\hline 129 & 51.2 & 0.0250 & 0.0000 & 7.66 & 0.00000 & 0.00344 & 0.0021 & 1.62 & 0.000533 & 0.0000000 & 0.0000000 \\
\hline 130 & 51.6 & 0.0099 & 0.0032 & 5.67 & 0.01087 & 0.00163 & 0.0017 & 1.67 & 0.000581 & 0.0000436 & 0.0000225 \\
\hline 131 & 52.0 & 0.0334 & 0.0019 & 3.59 & 0.00000 & 0.00314 & 0.0011 & 1.74 & 0.000536 & 0.0000000 & 0.0000000 \\
\hline 132 & 52.4 & 0.0106 & 0.0000 & 2.59 & 0.00000 & 0.00134 & 0.0043 & 1.50 & 0.000411 & 0.0000159 & 0.0000191 \\
\hline 133 & 52.8 & 0.0137 & 0.0159 & 2.11 & 0.00000 & 0.00000 & 0.0016 & 1.56 & 0.000536 & 0.0000202 & 0.0000000 \\
\hline 134 & 53.2 & 0.0000 & 0.0000 & 1.95 & 0.00987 & 0.00000 & 0.0067 & 1.39 & 0.000535 & 0.0001497 & 0.0000013 \\
\hline 135 & 53.6 & 0.0000 & 0.0138 & 1.54 & 0.00000 & 0.00000 & 0.0097 & 1.39 & 0.000493 & 0.0000560 & 0.0000000 \\
\hline 136 & 54.0 & 0.0045 & 0.0097 & 1.51 & 0.00000 & 0.00000 & 0.0018 & 1.40 & 0.000533 & 0.0000414 & 0.0000000 \\
\hline 137 & 54.4 & 0.0000 & 0.0211 & 1.66 & 0.00921 & 0.00266 & 0.0140 & 1.30 & 0.000464 & 0.0000540 & 0.0000147 \\
\hline 138 & 54.8 & 0.0000 & 0.0043 & 1.72 & 0.00000 & 0.00000 & 0.0053 & 1.27 & 0.000384 & 0.0000542 & 0.0000000 \\
\hline 139 & 55.2 & 0.0075 & 0.0078 & 2.53 & 0.00000 & 0.00270 & 0.0104 & 1.53 & 0.000505 & 0.0000587 & 0.0000000 \\
\hline 140 & 55.6 & 0.0051 & 0.0117 & 2.08 & 0.01217 & 0.00412 & 0.0056 & 1.25 & 0.000469 & 0.0000800 & 0.0000000 \\
\hline 141 & 56.0 & 0.0000 & 0.0012 & 1.91 & 0.00919 & 0.00118 & 0.0064 & 1.26 & 0.000396 & 0.0000733 & 0.0000000 \\
\hline 142 & 56.4 & 0.0024 & 0.0000 & 1.57 & 0.00000 & 0.00120 & 0.0124 & 1.22 & 0.000530 & 0.0000670 & 0.0000000 \\
\hline 143 & 56.8 & 0.0140 & 0.0276 & 1.92 & 0.00723 & 0.00095 & 0.0181 & 1.40 & 0.000538 & 0.0000591 & 0.0000013 \\
\hline 144 & 57.2 & 0.0000 & 0.0000 & 5.50 & 0.00000 & 0.00000 & 0.0055 & 1.46 & 0.000659 & 0.0000116 & 0.0000156 \\
\hline 145 & 57.6 & 0.0045 & 0.0000 & 5.05 & 0.00000 & 0.00026 & 0.0043 & 1.53 & 0.000675 & 0.0000000 & 0.0000000 \\
\hline 146 & 58.0 & 0.0000 & 0.0000 & 2.54 & 0.00605 & 0.00282 & 0.0138 & 1.42 & 0.000517 & 0.0001426 & 0.0000114 \\
\hline 147 & 58.4 & 0.0133 & 0.0282 & 3.40 & 0.00532 & 0.00157 & 0.0004 & 1.29 & 0.000431 & 0.0000276 & 0.0000266 \\
\hline 148 & 58.8 & 0.0000 & 0.0054 & 6.70 & 0.00000 & 0.00059 & 0.0033 & 1.49 & 0.000531 & 0.0000675 & 0.0000000 \\
\hline 149 & 59.2 & 0.0185 & 0.0109 & 4.46 & 0.00000 & 0.00487 & 0.0032 & 1.59 & 0.000510 & 0.0000000 & 0.0000000 \\
\hline
\end{tabular}




\begin{tabular}{|c|c|c|c|c|c|c|c|c|c|c|c|}
\hline \multirow{2}{*}{ Spot Number } & \multirow{2}{*}{ Distance from the foot (mm) } & \multicolumn{10}{|c|}{ RW75 100 prismatic layer transect corrected data $(\mathrm{mmol} / \mathrm{mol}$ ) continued... } \\
\hline & & $\mathrm{Li} / \mathrm{Ca}$ & $\mathrm{B} / \mathrm{Ca}$ & $\mathrm{Mg} / \mathrm{Ca}$ & $\mathrm{Al} / \mathrm{Ca}$ & $\mathrm{Mn} / \mathrm{Ca}$ & $\mathrm{Zn} / \mathrm{Ca}$ & Sr88/Ca & $\mathrm{Ba} / \mathrm{Ca}$ & $\mathrm{Pb} / \mathrm{Ca}$ & $\mathrm{U} / \mathrm{Ca}$ \\
\hline 150 & 59.6 & 0.0000 & 0.0280 & 1.73 & 0.00000 & 0.00575 & 0.0047 & 1.53 & 0.000443 & 0.0000374 & 0.0000277 \\
\hline 151 & 60.0 & 0.0043 & 0.0000 & 1.77 & 0.00000 & 0.00243 & 0.0072 & 1.55 & 0.000607 & 0.0000260 & 0.0000000 \\
\hline 152 & 60.4 & 0.0316 & 0.0154 & 1.57 & 0.00000 & 0.00069 & 0.0090 & 1.46 & 0.000417 & 0.0000207 & 0.0000000 \\
\hline 153 & 60.8 & 0.0262 & 0.0177 & 2.70 & 0.00716 & 0.00134 & 0.0160 & 1.36 & 0.000566 & 0.0001109 & 0.0000368 \\
\hline 154 & 61.2 & 0.0000 & 0.0266 & 1.42 & 0.00056 & 0.00141 & 0.0152 & 1.30 & 0.000439 & 0.0000357 & 0.0000014 \\
\hline 155 & 61.6 & 0.0210 & 0.0185 & 1.57 & 0.00698 & 0.00000 & 0.0169 & 1.30 & 0.000631 & 0.0000650 & 0.0000306 \\
\hline 156 & 62.0 & 0.0000 & 0.0000 & 1.44 & 0.00000 & 0.00186 & 0.0000 & 1.30 & 0.000514 & 0.0000136 & 0.0000232 \\
\hline 157 & 62.4 & 0.0068 & 0.0042 & 2.35 & 0.00132 & 0.00199 & 0.0090 & 1.38 & 0.000485 & 0.0001362 & 0.0000019 \\
\hline 158 & 62.8 & 0.0126 & 0.0345 & 1.68 & 0.00000 & 0.00013 & 0.0039 & 1.31 & 0.000462 & 0.0000527 & 0.0000198 \\
\hline 159 & 63.2 & 0.0166 & 0.0031 & 1.97 & 0.00432 & 0.00310 & 0.0061 & 1.52 & 0.000480 & 0.0000550 & 0.0000000 \\
\hline 160 & 63.6 & 0.0163 & 0.0293 & 1.93 & 0.00987 & 0.00340 & 0.0080 & 1.48 & 0.000624 & 0.0000331 & 0.0000000 \\
\hline 161 & 64.0 & 0.0000 & 0.0009 & 1.41 & 0.00000 & 0.00000 & 0.0043 & 1.46 & 0.000497 & 0.0000000 & 0.0000140 \\
\hline 162 & 64.4 & 0.0154 & 0.0000 & 1.94 & 0.00000 & 0.00185 & 0.0153 & 1.61 & 0.000662 & 0.0001143 & 0.0000094 \\
\hline 163 & 64.8 & 0.0075 & 0.0000 & 2.04 & 0.00311 & 0.00223 & 0.0040 & 1.29 & 0.000459 & 0.0000449 & 0.0000000 \\
\hline 164 & 65.2 & 0.0155 & 0.0000 & 1.93 & 0.02797 & 0.00092 & 0.0133 & 1.40 & 0.000452 & 0.0000873 & 0.0000132 \\
\hline 165 & 65.6 & 0.0210 & 0.0048 & 1.57 & 0.00897 & 0.00642 & 0.0158 & 1.43 & 0.000457 & 0.0001167 & 0.0000088 \\
\hline 166 & 66.0 & 0.0000 & 0.0158 & 1.63 & 0.00000 & 0.00197 & 0.0076 & 1.25 & 0.000386 & 0.0000000 & 0.0000001 \\
\hline 167 & 66.4 & 0.0000 & 0.0000 & 1.65 & 0.00000 & 0.00063 & 0.0068 & 1.48 & 0.000362 & 0.0000000 & 0.0000000 \\
\hline 168 & 66.8 & 0.0000 & 0.0099 & 2.90 & 0.00000 & 0.00460 & 0.0190 & 1.54 & 0.000822 & 0.0000510 & 0.0000041 \\
\hline 169 & 67.2 & 0.0141 & 0.0268 & 2.49 & 0.00102 & 0.00119 & 0.0166 & 1.49 & 0.000754 & 0.0000191 & 0.0000000 \\
\hline 170 & 67.6 & 0.0139 & 0.0130 & 1.92 & 0.00792 & 0.00000 & 0.0123 & 1.48 & 0.000496 & 0.0000752 & 0.0000000 \\
\hline 171 & 68.0 & 0.0122 & 0.0072 & 1.65 & 0.00000 & 0.00053 & 0.0170 & 1.29 & 0.000526 & 0.0000802 & 0.0000000 \\
\hline 172 & 68.4 & 0.0028 & 0.0000 & 1.80 & 0.00233 & 0.00181 & 0.0128 & 1.32 & 0.000624 & 0.0000611 & 0.0000000 \\
\hline 173 & 68.8 & 0.0195 & 0.0090 & 1.98 & 0.00000 & 0.00043 & 0.0093 & 1.51 & 0.000539 & 0.0000102 & 0.0000185 \\
\hline 174 & 69.2 & 0.0096 & 0.0000 & 1.87 & 0.00000 & 0.00000 & 0.0009 & 1.21 & 0.000443 & 0.0000000 & 0.0000194 \\
\hline 175 & 69.6 & 0.0123 & 0.0000 & 2.53 & 0.00000 & 0.00098 & 0.0037 & 1.21 & 0.000299 & 0.0000677 & 0.0000213 \\
\hline 176 & 70.0 & 0.0213 & 0.0000 & 2.36 & 0.00000 & 0.00322 & 0.0093 & 1.25 & 0.000351 & 0.0000534 & 0.0000032 \\
\hline 177 & 70.4 & 0.0045 & 0.0000 & 2.18 & 0.00363 & 0.00205 & 0.0000 & 0.99 & 0.000222 & 0.0000000 & 0.0000000 \\
\hline 178 & 70.8 & 0.0000 & 0.0001 & 2.37 & 0.00000 & 0.00285 & 0.0000 & 1.25 & 0.000431 & 0.0000381 & 0.0000000 \\
\hline 179 & 71.2 & 0.0000 & 0.0000 & 2.31 & 0.00000 & 0.00005 & 0.0024 & 1.37 & 0.000362 & 0.0000528 & 0.0000000 \\
\hline
\end{tabular}




\begin{tabular}{|c|c|c|c|c|c|c|c|c|c|c|c|}
\hline \multirow{2}{*}{ Spot Number } & \multirow{2}{*}{ Distance from the foot $(\mathrm{mm})$} & \multicolumn{10}{|c|}{ RW75 100 prismatic layer transect corrected data $(\mathrm{mmol} / \mathrm{mol})$ continued... } \\
\hline & & $\mathrm{Li} / \mathrm{Ca}$ & $\mathrm{B} / \mathrm{Ca}$ & $\mathrm{Mg} / \mathrm{Ca}$ & $\mathrm{Al} / \mathrm{Ca}$ & $\mathrm{Mn} / \mathrm{Ca}$ & $\mathrm{Zn} / \mathrm{Ca}$ & $\mathrm{Sr} 88 / \mathrm{Ca}$ & $\mathrm{Ba} / \mathrm{Ca}$ & $\mathrm{Pb} / \mathrm{Ca}$ & $\mathrm{U} / \mathrm{Ca}$ \\
\hline 180 & 71.6 & 0.0145 & 0.0142 & 3.27 & 0.00322 & 0.00006 & 0.0086 & 1.29 & 0.000433 & 0.0000239 & 0.0000089 \\
\hline 181 & 72.0 & 0.0000 & 0.0063 & 2.86 & 0.00000 & 0.00249 & 0.0052 & 1.38 & 0.000397 & 0.0000119 & 0.0000040 \\
\hline 182 & 72.4 & 0.0046 & 0.0107 & 3.15 & 0.00000 & 0.00235 & 0.0013 & 1.30 & 0.000398 & 0.0000501 & 0.0000000 \\
\hline 183 & 72.8 & 0.0079 & 0.0201 & 3.17 & 0.01115 & 0.00064 & 0.0065 & 1.09 & 0.000359 & 0.0000119 & 0.0000107 \\
\hline 184 & 73.2 & 0.0022 & 0.0000 & 3.63 & 0.00000 & 0.00101 & 0.0107 & 1.15 & 0.000379 & 0.0000657 & 0.0000000 \\
\hline 185 & 73.6 & 0.0000 & 0.0185 & 4.27 & 0.00701 & 0.00578 & 0.0061 & 1.39 & 0.000309 & 0.0000833 & 0.0000072 \\
\hline 186 & 74.0 & 0.0000 & 0.0182 & 5.08 & 0.00000 & 0.00000 & 0.0110 & 1.25 & 0.000323 & 0.0000454 & 0.0000000 \\
\hline 187 & 74.4 & 0.0072 & 0.0000 & 3.22 & 0.00000 & 0.00246 & 0.0000 & 1.26 & 0.000239 & 0.0000476 & 0.0000000 \\
\hline 188 & 74.8 & 0.0000 & 0.0000 & 3.47 & 0.00075 & 0.00245 & 0.0065 & 1.24 & 0.000291 & 0.0000000 & 0.0000000 \\
\hline 189 & 75.2 & 0.0136 & 0.0076 & 3.30 & 0.00000 & 0.00080 & 0.0046 & 1.35 & 0.000415 & 0.0000000 & 0.0000053 \\
\hline 190 & 75.6 & 0.0011 & 0.0059 & 3.80 & 0.00137 & 0.00326 & 0.0047 & 1.24 & 0.000261 & 0.0000326 & 0.0000155 \\
\hline 191 & 76.0 & 0.0049 & 0.0049 & 3.99 & 0.00566 & 0.00182 & 0.0071 & 1.36 & 0.000503 & 0.0000000 & 0.0000124 \\
\hline 192 & 76.4 & 0.0325 & 0.0050 & 3.90 & 0.00217 & 0.00443 & 0.0071 & 1.12 & 0.000272 & 0.0000000 & 0.0000000 \\
\hline 193 & 76.8 & 0.0000 & 0.0060 & 2.95 & 0.00775 & 0.00359 & 0.0071 & 0.99 & 0.000178 & 0.0000000 & 0.0000082 \\
\hline 194 & 77.2 & 0.0000 & 0.0000 & 2.39 & 0.00000 & 0.00335 & 0.0030 & 1.06 & 0.000274 & 0.0000234 & 0.0000044 \\
\hline 195 & 77.6 & 0.0000 & 0.0222 & 3.10 & 0.00694 & 0.00045 & 0.0247 & 1.24 & 0.000402 & 0.0000000 & 0.0000049 \\
\hline 196 & 78.0 & 0.0152 & 0.0375 & 2.74 & 0.00000 & 0.00204 & 0.0091 & 1.05 & 0.000257 & 0.0000991 & 0.0000000 \\
\hline 197 & 78.4 & 0.0018 & 0.0112 & 2.98 & 0.00000 & 0.00504 & 0.0073 & 1.10 & 0.000298 & 0.0000415 & 0.0000000 \\
\hline 198 & 78.8 & 0.0000 & 0.0054 & 3.03 & 0.00000 & 0.00439 & 0.0057 & 1.22 & 0.000292 & 0.0000519 & 0.0000000 \\
\hline 199 & 79.2 & 0.0060 & 0.0000 & 2.34 & 0.00000 & 0.00000 & 0.0025 & 1.03 & 0.000341 & 0.0000278 & 0.0000036 \\
\hline 200 & 79.6 & 0.0062 & 0.0034 & 2.34 & 0.00000 & 0.00191 & 0.0098 & 1.35 & 0.000397 & 0.0000135 & 0.0000000 \\
\hline 201 & 80.0 & 0.0131 & 0.0118 & 2.29 & 0.00000 & 0.00227 & 0.0000 & 1.25 & 0.000406 & 0.0000338 & 0.0000015 \\
\hline 202 & 80.4 & 0.0000 & 0.0096 & 2.63 & 0.00000 & 0.00023 & 0.0000 & 1.41 & 0.000452 & 0.0000008 & 0.0000146 \\
\hline 203 & 80.8 & 0.0234 & 0.0115 & 2.05 & 0.01223 & 0.00000 & 0.0019 & 1.34 & 0.000341 & 0.0000619 & 0.0000000 \\
\hline 204 & 81.2 & 0.0080 & 0.0114 & 2.26 & 0.00666 & 0.00269 & 0.0024 & 1.34 & 0.000394 & 0.0000224 & 0.0000000 \\
\hline 205 & 81.6 & 0.0325 & 0.0049 & 2.97 & 0.00000 & 0.00353 & 0.0069 & 1.58 & 0.000533 & 0.0000107 & 0.0000117 \\
\hline 206 & 82.0 & 0.0000 & 0.0148 & 1.96 & 0.00000 & 0.00000 & 0.0114 & 1.21 & 0.000159 & 0.0000031 & 0.0000000 \\
\hline 207 & 82.4 & 0.0000 & 0.0000 & 2.31 & 0.00000 & 0.00000 & 0.0279 & 1.30 & 0.000437 & 0.0000000 & 0.0000000 \\
\hline 208 & 82.8 & 0.0048 & 0.0000 & 2.23 & 0.00468 & 0.00000 & 0.0050 & 1.34 & 0.000418 & 0.0000000 & 0.0000317 \\
\hline 209 & 83.2 & 0.0000 & 0.0380 & 2.34 & 0.00262 & 0.00000 & 0.0090 & 1.44 & 0.000561 & 0.0001364 & 0.0000042 \\
\hline
\end{tabular}




\begin{tabular}{|c|c|c|c|c|c|c|c|c|c|c|c|}
\hline \multirow{2}{*}{ Spot Number } & \multirow{2}{*}{ Distance from the foot (mm) } & \multicolumn{10}{|c|}{ RW75 100 prismatic layer transect corrected data $(\mathrm{mmol} / \mathrm{mol}$ ) continued... } \\
\hline & & $\mathrm{Li} / \mathrm{Ca}$ & $\mathrm{B} / \mathrm{Ca}$ & $\mathrm{Mg} / \mathrm{Ca}$ & $\mathrm{Al} / \mathrm{Ca}$ & $\mathrm{Mn} / \mathrm{Ca}$ & $\mathrm{Zn} / \mathrm{Ca}$ & Sr88/Ca & $\mathrm{Ba} / \mathrm{Ca}$ & $\mathrm{Pb} / \mathrm{Ca}$ & $\mathrm{U} / \mathrm{Ca}$ \\
\hline 210 & 83.6 & 0.0148 & 0.0354 & 1.79 & 0.00000 & 0.00000 & 0.0065 & 1.43 & 0.000471 & 0.0000000 & 0.0000279 \\
\hline 211 & 84.0 & 0.0107 & 0.0000 & 2.98 & 0.00560 & 0.00000 & 0.0017 & 1.25 & 0.000373 & 0.0000000 & 0.0000144 \\
\hline 212 & 84.4 & 0.0082 & 0.0378 & 1.85 & 0.00000 & 0.00000 & 0.0015 & 1.42 & 0.000099 & 0.0000000 & 0.0000000 \\
\hline 213 & 84.8 & 0.0350 & 0.0000 & 4.56 & 0.00033 & 0.00156 & 0.0046 & 1.28 & 0.000347 & 0.0000316 & 0.0000040 \\
\hline 214 & 85.2 & 0.0000 & 0.0507 & 4.61 & 0.02131 & 0.00090 & 0.0023 & 1.30 & 0.000433 & 0.0001518 & 0.0000084 \\
\hline 215 & 85.6 & 0.0064 & 0.0000 & 4.22 & 0.00000 & 0.00445 & 0.0097 & 1.18 & 0.000316 & 0.0000535 & 0.0000034 \\
\hline 216 & 86.0 & 0.0190 & 0.0644 & 4.07 & 0.00188 & 0.00000 & 0.0011 & 1.43 & 0.000342 & 0.0000213 & 0.0000197 \\
\hline 217 & 86.4 & 0.0095 & 0.0342 & 4.69 & 0.00222 & 0.00000 & 0.0074 & 1.20 & 0.000286 & 0.0000599 & 0.0000132 \\
\hline 218 & 86.8 & 0.0000 & 0.0420 & 4.83 & 0.00000 & 0.00000 & 0.0079 & 1.41 & 0.000251 & 0.0000000 & 0.0000000 \\
\hline 219 & 87.2 & 0.0000 & 0.0062 & 4.09 & 0.00685 & 0.00411 & 0.0000 & 1.26 & 0.000385 & 0.0000284 & 0.0000172 \\
\hline 220 & 87.6 & 0.0121 & 0.0101 & 3.35 & 0.00000 & 0.00072 & 0.0023 & 1.25 & 0.000407 & 0.0000763 & 0.0000000 \\
\hline 221 & 88.0 & 0.0126 & 0.0136 & 3.27 & 0.00959 & 0.00110 & 0.0000 & 1.25 & 0.000414 & 0.0000374 & 0.0000000 \\
\hline 222 & 88.4 & 0.0019 & 0.0081 & 4.24 & 0.00124 & 0.00205 & 0.0027 & 1.16 & 0.000416 & 0.0000197 & 0.0000000 \\
\hline 223 & 88.8 & 0.0046 & 0.0000 & 3.21 & 0.00593 & 0.00226 & 0.0046 & 1.42 & 0.000382 & 0.0000000 & 0.0000000 \\
\hline 224 & 89.2 & 0.0000 & 0.0000 & 5.11 & 0.00000 & 0.00028 & 0.0000 & 1.44 & 0.000274 & 0.0000504 & 0.0000000 \\
\hline 225 & 89.6 & 0.0090 & 0.0000 & 3.44 & 0.00000 & 0.00402 & 0.0034 & 1.21 & 0.000300 & 0.0001162 & 0.0000000 \\
\hline 226 & 90.0 & 0.0396 & 0.0334 & 4.51 & 0.00597 & 0.00000 & 0.0043 & 1.18 & 0.000353 & 0.0000096 & 0.0000080 \\
\hline 227 & 90.4 & 0.0000 & 0.0000 & 3.92 & 0.00000 & 0.00023 & 0.0080 & 1.06 & 0.000333 & 0.0000000 & 0.0000032 \\
\hline 228 & 90.8 & 0.0043 & 0.0008 & 5.92 & 0.00392 & 0.00000 & 0.0007 & 1.32 & 0.000399 & 0.0000000 & 0.0000332 \\
\hline 229 & 91.2 & 0.0000 & 0.0000 & 4.00 & 0.00246 & 0.00000 & 0.0000 & 1.21 & 0.000369 & 0.0000034 & 0.0000000 \\
\hline 230 & 91.6 & 0.0054 & 0.0000 & 2.79 & 0.00000 & 0.00000 & 0.0041 & 1.22 & 0.000047 & 0.0000000 & 0.0000000 \\
\hline 231 & 92.0 & 0.0027 & 0.0121 & 2.52 & 0.00000 & 0.00415 & 0.0000 & 1.32 & 0.000191 & 0.0000243 & 0.0000000 \\
\hline 232 & 92.4 & 0.0019 & 0.0000 & 6.47 & 0.00000 & 0.00481 & 0.0068 & 1.20 & 0.000459 & 0.0000000 & 0.0000092 \\
\hline 233 & 92.8 & 0.0285 & 0.0000 & 3.46 & 0.00000 & 0.00002 & 0.0012 & 1.33 & 0.000306 & 0.0000000 & 0.0000301 \\
\hline 234 & 93.2 & 0.0145 & 0.0168 & 3.96 & 0.01365 & 0.00265 & 0.0022 & 1.26 & 0.000357 & 0.0000172 & 0.0000000 \\
\hline 235 & 93.6 & 0.0000 & 0.0447 & 4.35 & 0.00099 & 0.00000 & 0.0019 & 1.09 & 0.000251 & 0.0000034 & 0.0000000 \\
\hline 236 & 94.0 & 0.0084 & 0.0000 & 4.41 & 0.00000 & 0.00354 & 0.0044 & 1.06 & 0.000078 & 0.0000000 & 0.0000000 \\
\hline 237 & 94.4 & 0.0176 & 0.0163 & 4.18 & 0.00563 & 0.00228 & 0.0014 & 1.04 & 0.000305 & 0.0000000 & 0.0000000 \\
\hline 238 & 94.8 & 0.0274 & 0.0000 & 4.77 & 0.01220 & 0.00782 & 0.0000 & 1.15 & 0.000245 & 0.0000000 & 0.0000000 \\
\hline 239 & 95.2 & 0.0138 & 0.0321 & 19.06 & 0.00421 & 0.00513 & 0.0038 & 1.03 & 0.000338 & 0.0000087 & 0.0000000 \\
\hline
\end{tabular}




\begin{tabular}{|c|c|c|c|c|c|c|c|c|c|c|c|}
\hline \multirow{2}{*}{ Spot Number } & \multirow{2}{*}{ Distance from the foot $(\mathrm{mm})$} & \multicolumn{10}{|c|}{ RW75 100 prismatic layer transect corrected data $(\mathrm{mmol} / \mathrm{mol})$ continued... } \\
\hline & & $\mathrm{Li} / \mathrm{Ca}$ & $\mathrm{B} / \mathrm{Ca}$ & $\mathrm{Mg} / \mathrm{Ca}$ & $\mathrm{Al} / \mathrm{Ca}$ & $\mathrm{Mn} / \mathrm{Ca}$ & $\mathrm{Zn} / \mathrm{Ca}$ & Sr88/Ca & $\mathrm{Ba} / \mathrm{Ca}$ & $\mathrm{Pb} / \mathrm{Ca}$ & $\mathrm{U} / \mathrm{Ca}$ \\
\hline 240 & 95.6 & 0.0280 & 0.0185 & 7.36 & 0.00127 & 0.00146 & 0.0000 & 0.93 & 0.000263 & 0.0000517 & 0.0000317 \\
\hline 241 & 96.0 & 0.0000 & 0.0000 & 7.87 & 0.00253 & 0.00412 & 0.0000 & 0.95 & 0.000267 & 0.0000579 & 0.0000000 \\
\hline 242 & 96.4 & 0.0000 & 0.0134 & 3.29 & 0.00000 & 0.00229 & 0.0000 & 0.95 & 0.000000 & 0.0000000 & 0.0000000 \\
\hline 243 & 96.8 & 0.0102 & 0.0267 & 4.11 & 0.00000 & 0.00000 & 0.0087 & 0.91 & 0.000204 & 0.0001189 & 0.0000000 \\
\hline 244 & 97.2 & 0.0000 & 0.0000 & 4.65 & 0.01259 & 0.00102 & 0.0000 & 0.83 & 0.000112 & 0.0000348 & 0.0000000 \\
\hline 245 & 97.6 & 0.0327 & 0.0000 & 5.36 & 0.00322 & 0.00233 & 0.0045 & 0.93 & 0.000221 & 0.0000000 & 0.0000105 \\
\hline 246 & 98.0 & 0.0000 & 0.0456 & 5.25 & 0.00222 & 0.00449 & 0.0000 & 0.94 & 0.000230 & 0.0000000 & 0.0000000 \\
\hline 247 & 98.4 & 0.0205 & 0.0000 & 2.99 & 0.00000 & 0.00000 & 0.0000 & 0.99 & 0.000191 & 0.0000000 & 0.0000089 \\
\hline 248 & 98.8 & 0.0122 & 0.0058 & 3.21 & 0.00000 & 0.00000 & 0.0039 & 1.04 & 0.000002 & 0.0000000 & 0.0000000 \\
\hline 249 & 99.2 & 0.0000 & 0.0055 & 2.63 & 0.00000 & 0.00062 & 0.0083 & 1.01 & 0.000173 & 0.0001321 & 0.0000000 \\
\hline 250 & 99.6 & 0.0000 & 0.0000 & 3.67 & 0.00596 & 0.00000 & 0.0013 & 0.97 & 0.000213 & 0.0000000 & 0.0000000 \\
\hline 251 & 100.0 & 0.0088 & 0.0014 & 2.60 & 0.00000 & 0.00000 & 0.0026 & 1.06 & 0.000154 & 0.0000000 & 0.0000000 \\
\hline 252 & 100.4 & 0.0000 & 0.0000 & 2.73 & 0.01286 & 0.00000 & 0.0087 & 1.19 & 0.000278 & 0.0000587 & 0.0000251 \\
\hline 253 & 100.8 & 0.0000 & 0.0410 & 2.36 & 0.00343 & 0.00000 & 0.0034 & 1.49 & 0.000401 & 0.0000844 & 0.0000000 \\
\hline 254 & 101.2 & 0.0156 & 0.0122 & 2.37 & 0.00000 & 0.00000 & 0.0000 & 1.28 & 0.000119 & 0.0000000 & 0.0000000 \\
\hline 255 & 101.6 & 0.0258 & 0.0000 & 2.55 & 0.00000 & 0.00411 & 0.0082 & 1.36 & 0.000374 & 0.0000530 & 0.0000607 \\
\hline 256 & 102.0 & 0.0016 & 0.0175 & 2.68 & 0.00759 & 0.00641 & 0.0000 & 1.15 & 0.000216 & 0.0000000 & 0.0000000 \\
\hline 257 & 102.4 & 0.0000 & 0.0000 & 2.19 & 0.01905 & 0.00355 & 0.0071 & 1.25 & 0.000085 & 0.0000262 & 0.0000000 \\
\hline 258 & 102.8 & 0.0000 & 0.0102 & 3.13 & 0.00244 & 0.00393 & 0.0081 & 1.02 & 0.000177 & 0.0000000 & 0.0000000 \\
\hline 259 & 103.2 & 0.0078 & 0.0000 & 2.17 & 0.01864 & 0.00000 & 0.0000 & 1.34 & 0.000328 & 0.0000020 & 0.0000000 \\
\hline 260 & 103.6 & 0.0344 & 0.0000 & 2.39 & 0.00000 & 0.00248 & 0.0001 & 1.35 & 0.000000 & 0.0000000 & 0.0000000 \\
\hline 261 & 104.0 & 0.0081 & 0.0357 & 2.57 & 0.00015 & 0.00000 & 0.0091 & 1.53 & 0.000345 & 0.0000000 & 0.0000000 \\
\hline 262 & 104.4 & 0.0122 & 0.0000 & 2.73 & 0.00538 & 0.00000 & 0.0116 & 1.42 & 0.000449 & 0.0000202 & 0.0000000 \\
\hline 263 & 104.8 & 0.0082 & 0.0031 & 3.38 & 0.00000 & 0.00137 & 0.0000 & 1.34 & 0.000385 & 0.0000696 & 0.0000141 \\
\hline 264 & 105.2 & 0.0132 & 0.0000 & 3.08 & 0.00000 & 0.00114 & 0.0055 & 1.24 & 0.000377 & 0.0000000 & 0.0002636 \\
\hline 265 & 105.6 & 0.0095 & 0.0000 & 2.79 & 0.03286 & 0.00108 & 0.0030 & 1.24 & 0.000393 & 0.0000000 & 0.0000000 \\
\hline 266 & 106.0 & 0.0000 & 0.0000 & 3.74 & 0.00000 & 0.00087 & 0.0000 & 1.26 & 0.000000 & 0.0000000 & 0.0000000 \\
\hline 267 & 106.4 & 0.0431 & 0.0019 & 6.07 & 0.00000 & 0.00037 & 0.0101 & 1.08 & 0.000299 & 0.0000000 & 0.0000048 \\
\hline 268 & 106.8 & 0.0170 & 0.0465 & 0.51 & 0.00000 & 0.00000 & 0.0051 & 2.41 & 0.001049 & 0.0001708 & 0.0002451 \\
\hline 269 & 107.2 & 0.0091 & 0.0389 & 0.27 & 0.00000 & 0.00084 & 0.0019 & 1.98 & 0.000621 & 0.0001175 & 0.0000379 \\
\hline
\end{tabular}




\begin{tabular}{|c|c|c|c|c|c|c|c|c|c|c|c|}
\hline \multirow{2}{*}{ Spot Number } & \multirow{2}{*}{ Distance from the foot $(\mathrm{mm})$} & \multicolumn{10}{|c|}{ RW75 100 prismatic layer transect corrected data $(\mathrm{mmol} / \mathrm{mol})$ continued... } \\
\hline & & $\mathrm{Li} / \mathrm{Ca}$ & $\mathrm{B} / \mathrm{Ca}$ & $\mathrm{Mg} / \mathrm{Ca}$ & $\mathrm{Al} / \mathrm{Ca}$ & $\mathrm{Mn} / \mathrm{Ca}$ & $\mathrm{Zn} / \mathrm{Ca}$ & Sr88/Ca & $\mathrm{Ba} / \mathrm{Ca}$ & $\mathrm{Pb} / \mathrm{Ca}$ & $\mathrm{U} / \mathrm{Ca}$ \\
\hline 270 & 107.6 & 0.0000 & 0.0000 & 0.44 & 0.00658 & 0.00235 & 0.0030 & 1.58 & 0.000413 & 0.0001342 & 0.0000000 \\
\hline 271 & 108.0 & 0.0120 & 0.0166 & 0.33 & 0.00000 & 0.00191 & 0.0040 & 1.98 & 0.001696 & 0.0000157 & 0.0000000 \\
\hline 272 & 108.4 & 0.0088 & 0.0277 & 0.33 & 0.00000 & 0.00000 & 0.0022 & 2.00 & 0.001577 & 0.0000000 & 0.0000000 \\
\hline 273 & 108.8 & 0.0000 & 0.0157 & 1.08 & 0.00271 & 0.00000 & 0.0100 & 1.84 & 0.002019 & 0.0000000 & 0.0000000 \\
\hline 274 & 109.2 & 0.0185 & 0.0524 & 0.55 & 0.00000 & 0.00176 & 0.0073 & 1.67 & 0.002195 & 0.0000174 & 0.0000000 \\
\hline 275 & 109.6 & 0.0000 & 0.0538 & 0.46 & 0.00000 & 0.00157 & 0.0071 & 1.75 & 0.001998 & 0.0001712 & 0.0000290 \\
\hline 276 & 110.0 & 0.0077 & 0.0470 & 0.34 & 0.00000 & 0.00715 & 0.0096 & 1.91 & 0.002354 & 0.0001049 & 0.0000218 \\
\hline 277 & 110.4 & 0.0000 & 0.0490 & 0.97 & 0.00000 & 0.00000 & 0.0081 & 2.42 & 0.002503 & 0.0000132 & 0.0000000 \\
\hline 278 & 110.8 & 0.0000 & 0.0430 & 6.23 & 0.00000 & 0.00376 & 0.0078 & 1.47 & 0.000970 & 0.0000000 & 0.0000000 \\
\hline 279 & 111.2 & 0.0000 & 0.0213 & 33.08 & 0.00000 & 0.00821 & 0.0019 & 0.90 & 0.000221 & 0.0000000 & 0.0000000 \\
\hline 280 & 111.6 & 0.0000 & 0.0332 & 12.57 & 0.00000 & 0.00311 & 0.0086 & 1.03 & 0.000375 & 0.0000000 & 0.0000000 \\
\hline 281 & 112.0 & 0.0286 & 0.0281 & 11.32 & 0.00000 & 0.00576 & 0.0048 & 0.93 & 0.000362 & 0.0000750 & 0.0000231 \\
\hline 282 & 112.4 & 0.0000 & 0.0181 & 4.62 & 0.00000 & 0.00474 & 0.0180 & 0.89 & 0.000348 & 0.0000000 & 0.0000000 \\
\hline 283 & 112.8 & 0.0186 & 0.0124 & 3.21 & 0.02359 & 0.00453 & 0.0095 & 0.91 & 0.000201 & 0.0000952 & 0.0000000 \\
\hline 284 & 113.2 & 0.0000 & 0.0000 & 4.55 & 0.00000 & 0.00105 & 0.0193 & 1.06 & 0.000190 & 0.0000000 & 0.0000000 \\
\hline 285 & 113.6 & 0.0209 & 0.0208 & 5.42 & 0.01120 & 0.00254 & 0.0210 & 1.09 & 0.000427 & 0.0000617 & 0.0002294 \\
\hline 286 & 114.0 & 0.0000 & 0.0026 & 5.54 & 0.00498 & 0.00337 & 0.0274 & 1.04 & 0.000384 & 0.0000396 & 0.0000000 \\
\hline 287 & 114.4 & 0.0000 & 0.0082 & 4.29 & 0.03444 & 0.00292 & 0.0037 & 1.13 & 0.000246 & 0.0000434 & 0.0000304 \\
\hline 288 & 114.8 & 0.0000 & 0.0000 & 4.90 & 0.00000 & 0.00620 & 0.0117 & 1.00 & 0.000308 & 0.0000825 & 0.0000188 \\
\hline 289 & 115.2 & 0.0273 & 0.0000 & 4.69 & 0.02963 & 0.00051 & 0.0090 & 1.16 & 0.000403 & 0.0000000 & 0.0000303 \\
\hline 290 & 115.6 & 0.0099 & 0.1009 & 4.36 & 0.00000 & 0.00258 & 0.0028 & 1.14 & 0.000223 & 0.0000020 & 0.0000000 \\
\hline 291 & 116.0 & 0.0000 & 0.0222 & 3.84 & 0.00000 & 0.00266 & 0.0126 & 1.12 & 0.000320 & 0.0000000 & 0.0000000 \\
\hline 292 & 116.4 & 0.0000 & 0.0019 & 3.95 & 0.00000 & 0.00089 & 0.0044 & 1.07 & 0.000319 & 0.0000000 & 0.0000468 \\
\hline 293 & 116.8 & 0.0258 & 0.0000 & 4.00 & 0.00798 & 0.00221 & 0.0025 & 1.01 & 0.000220 & 0.0000531 & 0.0000142 \\
\hline 294 & 117.2 & 0.0000 & 0.0299 & 4.66 & 0.00013 & 0.00067 & 0.0047 & 1.02 & 0.000260 & 0.0000749 & 0.0000038 \\
\hline 295 & 117.6 & 0.0000 & 0.0000 & 4.58 & 0.02850 & 0.00346 & 0.0105 & 1.10 & 0.000261 & 0.0001074 & 0.0000000 \\
\hline 296 & 118.0 & 0.0000 & 0.0000 & 4.43 & 0.00000 & 0.00242 & 0.0102 & 1.12 & 0.000000 & 0.0000000 & 0.0000000 \\
\hline 297 & 118.4 & 0.0430 & 0.0277 & 3.94 & 0.01226 & 0.00076 & 0.0137 & 1.22 & 0.000259 & 0.0000962 & 0.0000000 \\
\hline 298 & 118.8 & 0.0480 & 0.0125 & 3.83 & 0.00000 & 0.00144 & 0.0187 & 1.16 & 0.000401 & 0.0001201 & 0.0000245 \\
\hline 299 & 119.2 & 0.0211 & 0.0186 & 3.48 & 0.00000 & 0.00565 & 0.0096 & 1.22 & 0.000305 & 0.0000261 & 0.0000000 \\
\hline
\end{tabular}




\begin{tabular}{|c|c|c|c|c|c|c|c|c|c|c|c|}
\hline \multirow{2}{*}{ Spot Number } & \multirow{2}{*}{ Distance from the foot $(\mathrm{mm})$} & \multicolumn{10}{|c|}{ RW75 100 prismatic layer transect corrected data $(\mathrm{mmol} / \mathrm{mol}$ ) continued... } \\
\hline & & $\mathrm{Li} / \mathrm{Ca}$ & $\mathrm{B} / \mathrm{Ca}$ & $\mathrm{Mg} / \mathrm{Ca}$ & $\mathbf{A l} / \mathbf{C a}$ & $\mathrm{Mn} / \mathrm{Ca}$ & $\mathrm{Zn} / \mathrm{Ca}$ & $\mathrm{Sr} 88 / \mathrm{Ca}$ & $\mathrm{Ba} / \mathrm{Ca}$ & $\mathrm{Pb} / \mathrm{Ca}$ & $\mathrm{U} / \mathrm{Ca}$ \\
\hline 300 & 119.6 & 0.0044 & 0.0000 & 3.03 & 0.00000 & 0.00378 & 0.0065 & 1.04 & 0.000298 & 0.0000000 & 0.0000416 \\
\hline 301 & 120.0 & 0.0000 & 0.0000 & 3.40 & 0.02042 & 0.00846 & 0.0135 & 1.34 & 0.000307 & 0.0000649 & 0.0000227 \\
\hline 302 & 120.4 & 0.0283 & 0.0359 & 4.77 & 0.00000 & 0.00385 & 0.0058 & 1.18 & 0.000000 & 0.0000000 & 0.0000000 \\
\hline 303 & 120.8 & 0.0000 & 0.0248 & 3.63 & 0.00000 & 0.00481 & 0.0000 & 1.17 & 0.000352 & 0.0000091 & 0.0000274 \\
\hline 304 & 121.2 & 0.0160 & 0.0000 & 4.48 & 0.00000 & 0.00261 & 0.0020 & 1.11 & 0.000374 & 0.0001748 & 0.0000116 \\
\hline 305 & 121.6 & 0.0000 & 0.0057 & 3.85 & 0.00000 & 0.00308 & 0.0000 & 1.26 & 0.000252 & 0.0001085 & 0.0000000 \\
\hline 306 & 122.0 & 0.0000 & 0.0151 & 5.63 & 0.00435 & 0.00475 & 0.0058 & 1.20 & 0.000392 & 0.0000793 & 0.0000000 \\
\hline 307 & 122.4 & 0.0126 & 0.0000 & 4.72 & 0.00877 & 0.00362 & 0.0116 & 1.13 & 0.000294 & 0.0000000 & 0.0000107 \\
\hline 308 & 122.8 & 0.0000 & 0.0135 & 4.88 & 0.00208 & 0.00000 & 0.0087 & 1.07 & 0.000039 & 0.0000000 & 0.0000000 \\
\hline 309 & 123.2 & 0.0109 & 0.0116 & 5.81 & 0.00000 & 0.00693 & 0.0112 & 1.24 & 0.000466 & 0.0000579 & 0.0000018 \\
\hline 310 & 123.6 & 0.0000 & 0.0253 & 5.31 & 0.00000 & 0.00375 & 0.0000 & 1.22 & 0.000367 & 0.0000000 & 0.0000000 \\
\hline 311 & 124.0 & 0.0436 & 0.0000 & 3.95 & 0.01380 & 0.00012 & 0.0128 & 1.17 & 0.000298 & 0.0000963 & 0.0000229 \\
\hline 312 & 124.4 & 0.0000 & 0.0000 & 3.87 & 0.01060 & 0.00272 & 0.0051 & 1.07 & 0.000333 & 0.0000000 & 0.0000000 \\
\hline 313 & 124.8 & 0.0398 & 0.0110 & 4.79 & 0.00000 & 0.00311 & 0.0078 & 1.18 & 0.000363 & 0.0000597 & 0.0000000 \\
\hline 314 & 125.2 & 0.0147 & 0.0218 & 3.19 & 0.00000 & 0.00387 & 0.0070 & 1.26 & 0.000368 & 0.0000491 & 0.0000000 \\
\hline 315 & 125.6 & 0.0251 & 0.0000 & 3.91 & 0.00000 & 0.00377 & 0.0219 & 1.31 & 0.000550 & 0.0000706 & 0.0000000 \\
\hline 316 & 126.0 & 0.0000 & 0.0000 & 2.76 & 0.00000 & 0.00441 & 0.0133 & 1.11 & 0.000394 & 0.0000000 & 0.0000000 \\
\hline 317 & 126.4 & 0.0000 & 0.0000 & 3.06 & 0.01329 & 0.00000 & 0.0076 & 1.21 & 0.000404 & 0.0000068 & 0.0000140 \\
\hline 318 & 126.8 & 0.0075 & 0.0143 & 3.58 & 0.00263 & 0.00617 & 0.0000 & 1.08 & 0.000446 & 0.0000021 & 0.0000055 \\
\hline 319 & 127.2 & 0.0092 & 0.0069 & 3.98 & 0.00000 & 0.00585 & 0.0075 & 1.33 & 0.000613 & 0.0000041 & 0.0000000 \\
\hline 320 & 127.6 & 0.0074 & 0.0246 & 3.70 & 0.00000 & 0.00301 & 0.0065 & 1.31 & 0.000465 & 0.0000000 & 0.0000000 \\
\hline 321 & 128.0 & 0.0000 & 0.0000 & 3.78 & 0.00864 & 0.00203 & 0.0188 & 1.31 & 0.000614 & 0.0000718 & 0.0000000 \\
\hline 322 & 128.4 & 0.0000 & 0.0110 & 2.74 & 0.02914 & 0.00231 & 0.0094 & 1.26 & 0.000407 & 0.0000000 & 0.0000000 \\
\hline 323 & 128.8 & 0.0126 & 0.0014 & 2.68 & 0.02733 & 0.00103 & 0.0223 & 1.22 & 0.000522 & 0.0000000 & 0.0000000 \\
\hline 324 & 129.2 & 0.0215 & 0.0000 & 2.83 & 0.00000 & 0.00048 & 0.0152 & 1.25 & 0.000461 & 0.0001718 & 0.0000086 \\
\hline 325 & 129.6 & 0.0000 & 0.0193 & 2.74 & 0.01219 & 0.00223 & 0.0174 & 1.28 & 0.000468 & 0.0001170 & 0.0000000 \\
\hline 326 & 130.0 & 0.0089 & 0.0214 & 2.30 & 0.00447 & 0.00023 & 0.0045 & 1.26 & 0.000312 & 0.0000000 & 0.0000000 \\
\hline 327 & 130.4 & 0.0209 & 0.0000 & 3.39 & 0.00798 & 0.00686 & 0.0283 & 1.35 & 0.000553 & 0.0000778 & 0.0000000 \\
\hline 328 & 130.8 & 0.0000 & 0.0000 & 2.62 & 0.00000 & 0.00447 & 0.0144 & 1.20 & 0.000481 & 0.0000000 & 0.0000054 \\
\hline 329 & 131.2 & 0.0044 & 0.0000 & 2.66 & 0.00000 & 0.00000 & 0.0194 & 1.20 & 0.000338 & 0.0000610 & 0.0000424 \\
\hline
\end{tabular}




\begin{tabular}{|c|c|c|c|c|c|c|c|c|c|c|c|}
\hline \multirow{2}{*}{ Spot Number } & \multirow{2}{*}{ Distance from the foot (mm) } & \multicolumn{10}{|c|}{ RW75 100 prismatic layer transect corrected data $(\mathrm{mmol} / \mathrm{mol})$ continued... } \\
\hline & & $\mathrm{Li} / \mathrm{Ca}$ & $\mathrm{B} / \mathrm{Ca}$ & $\mathrm{Mg} / \mathrm{Ca}$ & $\mathrm{Al} / \mathrm{Ca}$ & $\mathrm{Mn} / \mathrm{Ca}$ & $\mathrm{Zn} / \mathrm{Ca}$ & $\mathrm{Sr} 88 / \mathrm{Ca}$ & $\mathrm{Ba} / \mathrm{Ca}$ & $\mathrm{Pb} / \mathrm{Ca}$ & $\mathrm{U} / \mathbf{C a}$ \\
\hline 330 & 131.6 & 0.0105 & 0.0340 & 2.46 & 0.01677 & 0.00000 & 0.0085 & 1.33 & 0.000353 & 0.0000313 & 0.0000000 \\
\hline 331 & 132.0 & 0.0138 & 0.0000 & 3.05 & 0.00000 & 0.00586 & 0.0044 & 1.27 & 0.000470 & 0.0000284 & 0.0000425 \\
\hline 332 & 132.4 & 0.0000 & 0.0000 & 3.25 & 0.00261 & 0.00000 & 0.0072 & 1.30 & 0.000352 & 0.0000979 & 0.0000000 \\
\hline 333 & 132.8 & 0.0353 & 0.0253 & 4.30 & 0.00000 & 0.00235 & 0.0083 & 1.19 & 0.000421 & 0.0000000 & 0.0000000 \\
\hline 334 & 133.2 & 0.0000 & 0.0200 & 3.16 & 0.00851 & 0.00594 & 0.0246 & 1.15 & 0.000420 & 0.0000000 & 0.0000181 \\
\hline 335 & 133.6 & 0.0172 & 0.0116 & 2.86 & 0.00316 & 0.00147 & 0.0083 & 1.43 & 0.000557 & 0.0000950 & 0.0000000 \\
\hline 336 & 134.0 & 0.0360 & 0.0241 & 1.79 & 0.00000 & 0.00274 & 0.0035 & 1.22 & 0.000439 & 0.0000489 & 0.0000165 \\
\hline 337 & 134.4 & 0.0000 & 0.0000 & 2.74 & 0.00330 & 0.00273 & 0.0028 & 1.37 & 0.000475 & 0.0000540 & 0.0000000 \\
\hline 338 & 134.8 & 0.0000 & 0.0000 & 2.51 & 0.00000 & 0.00393 & 0.0060 & 1.27 & 0.000381 & 0.0000436 & 0.0000000 \\
\hline 339 & 135.2 & 0.0000 & 0.0386 & 3.30 & 0.00000 & 0.00204 & 0.0111 & 1.43 & 0.000399 & 0.0000801 & 0.0000000 \\
\hline 340 & 135.6 & 0.0148 & 0.0030 & 2.69 & 0.04680 & 0.00133 & 0.0058 & 1.55 & 0.000484 & 0.0000541 & 0.0000000 \\
\hline 341 & 136.0 & 0.0240 & 0.0000 & 2.00 & 0.00395 & 0.00284 & 0.0099 & 1.44 & 0.000313 & 0.0000000 & 0.0000000 \\
\hline
\end{tabular}


APPENDIX 5.1c $\quad$ A740 (1) Prismatic layer data

\begin{tabular}{|c|c|c|c|c|c|c|c|}
\hline \multirow{2}{*}{ Spot Number } & \multirow{2}{*}{ Distance from the foot $(\mathrm{mm})$} & \multicolumn{6}{|c|}{ A740 1 prismatic layer transect corrected data $(\mathrm{mmol} / \mathrm{mol})$} \\
\hline & & $\mathrm{Mg} / \mathrm{Ca}$ & $\mathbf{A l} / \mathbf{C a}$ & $\mathrm{Mn} / \mathrm{Ca}$ & $\mathrm{Zn} / \mathrm{Ca}$ & $\mathrm{Sr} / \mathrm{Ca}$ & $\mathrm{Ba} / \mathrm{Ca}$ \\
\hline 1 & 0.0 & 4.65 & 0.00000 & 0.00604 & 0.00000 & 1.51 & 0.0005459 \\
\hline 2 & 0.4 & 5.49 & 0.00000 & 0.00000 & 0.00360 & 1.27 & 0.0004191 \\
\hline 3 & 0.8 & 6.80 & 0.00000 & 0.00219 & 0.00000 & 1.32 & 0.0003962 \\
\hline 4 & 1.2 & 6.20 & 0.00000 & 0.00054 & 0.00000 & 1.36 & 0.0005238 \\
\hline 5 & 1.6 & 5.95 & 0.01354 & 0.00000 & 0.00000 & 1.13 & 0.000122 \\
\hline 6 & 2.0 & 6.73 & 0.00725 & 0.00692 & 0.00000 & 1.38 & 0.0003471 \\
\hline 7 & 2.4 & 6.15 & 0.00000 & 0.00218 & 0.00000 & 1.50 & 0.0004478 \\
\hline 8 & 2.8 & 9.79 & 0.00000 & 0.00164 & 0.00413 & 1.32 & 0.0003692 \\
\hline 9 & 3.2 & 6.89 & 0.00000 & 0.00305 & 0.00259 & 1.01 & 0.0001759 \\
\hline 10 & 3.6 & 29.13 & 0.00000 & 0.00000 & 0.00000 & 1.14 & 0.0003965 \\
\hline 11 & 4.0 & 14.27 & 0.00462 & 0.00257 & 0.00000 & 0.87 & 0.0002514 \\
\hline 12 & 4.4 & 5.75 & 0.00000 & 0.00112 & 0.00000 & 1.14 & 0.0003356 \\
\hline 13 & 4.8 & 6.15 & 0.00264 & 0.00000 & 0.00000 & 1.12 & 0.0001975 \\
\hline 14 & 5.2 & 7.34 & 0.00051 & 0.00351 & 0.00326 & 1.52 & 0.0007032 \\
\hline 15 & 5.6 & 4.98 & 0.00315 & 0.00307 & 0.00000 & 1.43 & 0.0005622 \\
\hline 16 & 6.0 & 5.69 & 0.00099 & 0.00000 & 0.00031 & 1.15 & 0.0003537 \\
\hline 17 & 6.4 & 4.86 & 0.00000 & 0.00000 & 0.00000 & 1.36 & 0.0003788 \\
\hline 18 & 6.8 & 7.17 & 0.00379 & 0.00014 & 0.00269 & 1.13 & 0.0005443 \\
\hline 19 & 7.2 & 5.23 & 0.00000 & 0.00251 & 0.00428 & 1.34 & 0.0004321 \\
\hline 20 & 7.6 & 3.99 & 0.00000 & 0.00000 & 0.00000 & 1.33 & 0.0004383 \\
\hline 21 & 8.0 & 4.93 & 0.00000 & 0.00139 & 0.00007 & 1.30 & 0.0004937 \\
\hline 22 & 8.4 & 8.82 & 0.00000 & 0.00536 & 0.00413 & 1.47 & 0.0005541 \\
\hline 23 & 8.8 & 4.64 & 0.00000 & 0.00139 & 0.00000 & 1.23 & 0.0003465 \\
\hline 24 & 9.2 & 4.72 & 0.00000 & 0.00000 & 0.00236 & 1.16 & 0.0003243 \\
\hline 25 & 9.6 & 4.75 & 0.00000 & 0.00343 & 0.00244 & 1.13 & 0.0002089 \\
\hline 26 & 10.0 & 5.24 & 0.00248 & 0.00291 & 0.00372 & 1.28 & 0.0004085 \\
\hline 27 & 10.4 & 4.19 & 0.00000 & 0.00438 & 0.00000 & 1.32 & 0.0003833 \\
\hline 28 & 10.8 & 4.53 & 0.00000 & 0.00381 & 0.00000 & 1.37 & 0.0004329 \\
\hline 29 & 11.2 & 4.60 & 0.01395 & 0.00425 & 0.00000 & 1.40 & 0.0003185 \\
\hline
\end{tabular}




\begin{tabular}{|c|c|c|c|c|c|c|c|}
\hline \multirow{2}{*}{ Spot Number } & \multirow{2}{*}{ Distance from the foot (mm) } & \multicolumn{6}{|c|}{ A740 1 prismatic layer transect corrected data $(\mathrm{mmol} / \mathrm{mol})$ continued... } \\
\hline & & $\mathrm{Mg} / \mathrm{Ca}$ & $\mathbf{A l} / \mathbf{C a}$ & $\mathrm{Mn} / \mathrm{Ca}$ & $\mathrm{Zn} / \mathrm{Ca}$ & $\mathrm{Sr} / \mathrm{Ca}$ & $\mathrm{Ba} / \mathrm{Ca}$ \\
\hline 30 & 11.6 & 4.57 & 0.00000 & 0.00000 & 0.00225 & 1.33 & 0.0004224 \\
\hline 31 & 12.0 & 4.75 & 0.00000 & 0.00635 & 0.00000 & 1.56 & 0.00058209 \\
\hline 32 & 12.4 & 4.69 & 0.00022 & 0.00000 & 0.00000 & 1.39 & 0.00062853 \\
\hline 33 & 12.8 & 4.63 & 0.00515 & 0.00412 & 0.00429 & 1.37 & 0.00040738 \\
\hline 34 & 13.2 & 5.32 & 0.00000 & 0.00310 & 0.00668 & 1.13 & 0.00034522 \\
\hline 35 & 13.6 & 4.43 & 0.00000 & 0.00000 & 0.00000 & 1.08 & 0.00034295 \\
\hline 36 & 14.0 & 5.22 & 0.00000 & 0.00004 & 0.00525 & 1.25 & 0.00027799 \\
\hline 37 & 14.4 & 6.00 & 0.00537 & 0.00151 & 0.00374 & 1.33 & 0.00040268 \\
\hline 38 & 14.8 & 4.49 & 0.00000 & 0.00282 & 0.00000 & 1.36 & 0.00044345 \\
\hline 39 & 15.2 & 5.35 & 0.00000 & 0.00429 & 0.00000 & 1.37 & 0.00045623 \\
\hline 40 & 15.6 & 5.34 & 0.00488 & 0.00371 & 0.00410 & 1.33 & 0.000505 \\
\hline 41 & 16.0 & 4.06 & 0.00000 & 0.00450 & 0.00618 & 1.08 & 0.00027394 \\
\hline 42 & 16.4 & 4.38 & 0.00000 & 0.00000 & 0.00000 & 1.26 & 0.00032522 \\
\hline 43 & 16.8 & 5.60 & 0.00049 & 0.00000 & 0.00366 & 1.13 & 0.00024128 \\
\hline 44 & 17.2 & 5.34 & 0.00000 & 0.00807 & 0.00000 & 1.26 & 0.00042615 \\
\hline 45 & 17.6 & 5.04 & 0.00000 & 0.00000 & 0.00000 & 1.42 & 0.00060473 \\
\hline 46 & 18.0 & 3.93 & 0.00040 & 0.00567 & 0.00021 & 1.47 & 0.00086909 \\
\hline 47 & 18.4 & 3.54 & 0.00539 & 0.00000 & 0.00000 & 1.38 & 0.00051035 \\
\hline 48 & 18.8 & 4.24 & 0.00350 & 0.00157 & 0.00000 & 1.56 & 0.00067609 \\
\hline 49 & 19.2 & 4.60 & 0.00000 & 0.00635 & 0.00000 & 1.52 & 0.00066663 \\
\hline 50 & 19.6 & 4.04 & 0.00158 & 0.00454 & 0.00745 & 1.41 & 0.00041938 \\
\hline 51 & 20.0 & 3.75 & 0.00005 & 0.00034 & 0.00000 & 1.47 & 0.00044104 \\
\hline 52 & 20.4 & 4.23 & 0.00000 & 0.00000 & 0.00645 & 1.15 & 0.00031057 \\
\hline 53 & 20.8 & 3.67 & 0.00705 & 0.00196 & 0.00000 & 1.39 & 0.00050079 \\
\hline 54 & 21.2 & 5.44 & 0.00000 & 0.00341 & 0.01705 & 1.24 & 0.00052943 \\
\hline 55 & 21.6 & 7.07 & 0.00000 & 0.00569 & 0.00000 & 1.65 & 0.00064976 \\
\hline 56 & 22.0 & 3.76 & 0.00068 & 0.00000 & 0.00254 & 1.56 & 0.00052012 \\
\hline 57 & 22.4 & 4.97 & 0.00204 & 0.00358 & 0.00000 & 1.51 & 0.00063698 \\
\hline 58 & 22.8 & 4.27 & 0.00000 & 0.00356 & 0.00056 & 1.55 & 0.00061621 \\
\hline 59 & 23.2 & 6.68 & 0.00270 & 0.00622 & 0.00102 & 1.36 & 0.000384 \\
\hline 60 & 23.6 & 4.03 & 0.00000 & 0.00133 & 0.00000 & 1.49 & 0.00058556 \\
\hline
\end{tabular}




\begin{tabular}{|c|c|c|c|c|c|c|c|}
\hline \multirow{2}{*}{ Spot Number } & \multirow{2}{*}{ Distance from the foot $(\mathrm{mm})$} & \multicolumn{6}{|c|}{ A740 1 prismatic layer transect corrected data $(\mathrm{mmol} / \mathrm{mol})$ continued... } \\
\hline & & $\mathrm{Mg} / \mathrm{Ca}$ & $\mathrm{Al} / \mathrm{Ca}$ & $\mathrm{Mn} / \mathrm{Ca}$ & $\mathrm{Zn} / \mathrm{Ca}$ & $\mathrm{Sr} / \mathrm{Ca}$ & $\mathrm{Ba} / \mathrm{Ca}$ \\
\hline 61 & 24.0 & 4.52 & 0.00000 & 0.00501 & 0.00000 & 1.58 & 0.0005433 \\
\hline 62 & 24.4 & 5.01 & 0.00081 & 0.00462 & 0.00377 & 1.36 & 0.00057756 \\
\hline 63 & 24.8 & 5.13 & 0.00000 & 0.00264 & 0.00000 & 1.32 & 0.00049099 \\
\hline 64 & 25.2 & 5.81 & 0.00108 & 0.00195 & 0.00000 & 1.43 & 0.00049349 \\
\hline 65 & 25.6 & 3.81 & 0.00254 & 0.00318 & 0.00308 & 1.52 & 0.00067157 \\
\hline 66 & 26.0 & 9.85 & 0.00000 & 0.00921 & 0.00000 & 1.50 & 0.00038309 \\
\hline 67 & 26.4 & 5.00 & 0.01604 & 0.00161 & 0.00416 & 1.41 & 0.00064035 \\
\hline 68 & 26.8 & 5.88 & 0.00748 & 0.00413 & 0.00562 & 1.56 & 0.00055547 \\
\hline 69 & 27.2 & 16.45 & 0.00000 & 0.00233 & 0.00075 & 1.67 & 0.00056942 \\
\hline 70 & 27.6 & 3.82 & 0.00083 & 0.00481 & 0.00046 & 1.38 & 0.00038261 \\
\hline 71 & 28.0 & 3.90 & 0.00921 & 0.00557 & 0.00000 & 1.40 & 0.00037987 \\
\hline 72 & 28.4 & 4.09 & 0.00000 & 0.00291 & 0.00658 & 1.41 & 0.00044948 \\
\hline 73 & 28.8 & 6.58 & 0.00000 & 0.00040 & 0.00852 & 1.34 & 0.00037003 \\
\hline 74 & 29.2 & 13.26 & 0.00589 & 0.00902 & 0.00000 & 1.39 & 0.00061868 \\
\hline 75 & 29.6 & 7.64 & 0.01546 & 0.00241 & 0.00434 & 1.22 & 0.00067377 \\
\hline 76 & 30.0 & 3.35 & 0.00000 & 0.00025 & 0.00514 & 1.42 & 0.00053987 \\
\hline 77 & 30.4 & 6.48 & 0.00000 & 0.00755 & 0.00376 & 1.48 & 0.00045426 \\
\hline 78 & 30.8 & 1.21 & 0.00000 & 0.00229 & 0.01684 & 1.49 & 0.00239995 \\
\hline 79 & 31.2 & 3.34 & 0.00000 & 0.00405 & 0.00087 & 1.49 & 0.00025472 \\
\hline 80 & 31.6 & 3.23 & 0.00419 & 0.00007 & 0.00000 & 1.52 & 0.00039319 \\
\hline 81 & 32.0 & 3.52 & 0.01204 & 0.00165 & 0.00000 & 1.31 & 0.00024349 \\
\hline 82 & 32.4 & 3.51 & 0.00000 & 0.00219 & 0.00106 & 1.37 & 0.00047924 \\
\hline 83 & 32.8 & 4.08 & 0.00512 & 0.00000 & 0.00000 & 1.55 & 0.00040249 \\
\hline 84 & 33.2 & 4.38 & 0.00000 & 0.00080 & 0.00396 & 1.28 & 0.0006958 \\
\hline 85 & 33.6 & 3.87 & 0.00000 & 0.00214 & 0.00000 & 1.50 & 0.00054927 \\
\hline 86 & 34.0 & 4.41 & 0.00000 & 0.00165 & 0.00000 & 1.41 & 0.00027719 \\
\hline 87 & 34.4 & 4.69 & 0.00000 & 0.00115 & 0.00000 & 1.34 & 0.00031733 \\
\hline 88 & 34.8 & 4.16 & 0.00000 & 0.00683 & 0.00064 & 1.34 & 0.00051093 \\
\hline 89 & 35.2 & 3.18 & 0.01025 & 0.00014 & 0.00000 & 1.59 & 0.00043268 \\
\hline 90 & 35.6 & 4.46 & 0.00708 & 0.00526 & 0.00414 & 1.29 & 0.00037802 \\
\hline
\end{tabular}




\begin{tabular}{|c|c|c|c|c|c|c|c|}
\hline \multirow{2}{*}{ Spot Number } & \multirow{2}{*}{ Distance from the foot $(\mathrm{mm})$} & \multicolumn{6}{|c|}{ A740 1 prismatic layer transect corrected data $(\mathrm{mmol} / \mathrm{mol})$ continued... } \\
\hline & & $\mathrm{Mg} / \mathrm{Ca}$ & $\mathrm{Al} / \mathrm{Ca}$ & $\mathrm{Mn} / \mathrm{Ca}$ & $\mathrm{Zn} / \mathrm{Ca}$ & $\mathrm{Sr} / \mathrm{Ca}$ & $\mathrm{Ba} / \mathrm{Ca}$ \\
\hline 91 & 36.0 & 3.45 & 0.00000 & 0.00117 & 0.00504 & 1.40 & 0.00032836 \\
\hline 92 & 36.4 & 4.36 & 0.00000 & 0.00000 & 0.00000 & 1.19 & 0.00034675 \\
\hline 93 & 36.8 & 5.02 & 0.00000 & 0.00156 & 0.00527 & 1.51 & 0.00043373 \\
\hline 94 & 37.2 & 2.11 & 0.00000 & 0.00427 & 0.01319 & 1.51 & 0.00186443 \\
\hline 95 & 37.6 & 3.87 & 0.00000 & 0.00492 & 0.00190 & 1.50 & 0.00061101 \\
\hline 96 & 38.0 & 4.06 & 0.00323 & 0.00028 & 0.00000 & 1.56 & 0.00039622 \\
\hline 97 & 38.4 & 6.55 & 0.00640 & 0.00575 & 0.00383 & 1.64 & 0.00063259 \\
\hline 98 & 38.8 & 5.20 & 0.00000 & 0.00390 & 0.00000 & 1.42 & 0.00052849 \\
\hline 99 & 39.2 & 5.17 & 0.00000 & 0.00328 & 0.00000 & 1.35 & 0.00051103 \\
\hline 100 & 39.6 & 5.30 & 0.00000 & 0.00121 & 0.00000 & 1.21 & $8.0132 \mathrm{E}-05$ \\
\hline 101 & 40.0 & 3.51 & 0.00784 & 0.00000 & 0.00090 & 1.27 & 0.00026032 \\
\hline 102 & 40.4 & 4.61 & 0.00000 & 0.00221 & 0.00282 & 1.23 & 0.00039561 \\
\hline 103 & 40.8 & 6.06 & 0.00207 & 0.00283 & 0.00000 & 1.42 & 0.00057584 \\
\hline 104 & 41.2 & 4.58 & 0.00846 & 0.00126 & 0.00441 & 1.38 & 0.00020996 \\
\hline 105 & 41.6 & 6.79 & 0.00746 & 0.00244 & 0.00876 & 1.24 & 0.00052634 \\
\hline 106 & 42.0 & 5.76 & 0.00000 & 0.00140 & 0.00150 & 1.26 & 0.00043475 \\
\hline 107 & 42.4 & 6.89 & 0.00000 & 0.00404 & 0.00000 & 1.06 & 0.00031613 \\
\hline 108 & 42.8 & 14.44 & 0.00000 & 0.00134 & 0.00000 & 0.96 & 0.00016905 \\
\hline 109 & 43.2 & 3.43 & 0.00000 & 0.00242 & 0.00023 & 1.16 & 0.00041105 \\
\hline 110 & 43.6 & 4.89 & 0.06412 & 0.00637 & 0.01281 & 1.34 & 0.00060026 \\
\hline 111 & 44.0 & 3.77 & 0.00657 & 0.00363 & 0.00345 & 1.42 & 0.00063234 \\
\hline 112 & 44.4 & 3.69 & 0.00532 & 0.00079 & 0.00036 & 1.13 & 0.00021114 \\
\hline 113 & 44.8 & 4.34 & 0.00475 & 0.00000 & 0.00440 & 1.32 & 0.00036622 \\
\hline 114 & 45.2 & 4.15 & 0.00075 & 0.00061 & 0.00000 & 1.42 & 0.00046385 \\
\hline 115 & 45.6 & 5.21 & 0.00142 & 0.00370 & 0.00369 & 1.33 & 0.00038149 \\
\hline 116 & 46.0 & 6.49 & 0.00000 & 0.00624 & 0.00227 & 1.21 & 0.00049623 \\
\hline 117 & 46.4 & 4.25 & 0.00000 & 0.00000 & 0.00000 & 1.36 & 0.0005053 \\
\hline 118 & 46.8 & 4.09 & 0.00000 & 0.00280 & 0.01073 & 1.25 & 0.00034221 \\
\hline 119 & 47.2 & 4.17 & 0.00056 & 0.00000 & 0.00379 & 1.45 & 0.00035125 \\
\hline 120 & 47.6 & 4.42 & 0.00000 & 0.00164 & 0.00000 & 1.55 & 0.00054064 \\
\hline 121 & 48.0 & 4.39 & 0.00000 & 0.00000 & 0.00230 & 1.20 & 0.00023953 \\
\hline 122 & 48.4 & 3.33 & 0.00000 & 0.00000 & 0.00000 & 1.31 & 0.00047883 \\
\hline
\end{tabular}


APPENDIX 5.1d $\quad$ A740 (2) prismatic layer transect data

\begin{tabular}{|c|c|c|c|c|c|c|c|c|c|c|c|}
\hline \multirow{2}{*}{$\begin{array}{c}\text { Spot } \\
\text { Number }\end{array}$} & \multirow{2}{*}{ Distance from the foot (mm) } & \multicolumn{10}{|c|}{ A740 2 prismatic layer transect corrected data $(\mathrm{mmol} / \mathrm{mol})$} \\
\hline & & $\mathrm{Li} / \mathrm{Ca}$ & $\mathrm{B} / \mathrm{Ca}$ & $\mathrm{Mg} / \mathrm{Ca}$ & $\mathrm{Al} / \mathrm{Ca}$ & $\mathrm{Mn} / \mathrm{Ca}$ & $\mathrm{Zn} / \mathrm{Ca}$ & $\mathrm{Sr} / \mathrm{Ca}$ & $\mathrm{Ba} / \mathrm{Ca}$ & $\mathrm{Pb} / \mathrm{Ca}$ & $\mathrm{U} / \mathrm{Ca}$ \\
\hline 1 & 0.0 & 0.0039 & 0.0000 & 4.93 & 0.0000 & 0.00000 & 0.00836 & 1.42 & 0.000463 & 0.000000 & 0.0000000 \\
\hline 2 & 0.4 & 0.0119 & 0.0000 & 7.37 & 0.0000 & 0.00000 & 0.00000 & 1.27 & 0.000410 & 0.000000 & 0.0000000 \\
\hline 3 & 0.8 & 0.0172 & 0.0000 & 6.04 & 0.0000 & 0.00000 & 0.01191 & 1.28 & 0.000299 & 0.000226 & 0.0000268 \\
\hline 4 & 1.2 & 0.0002 & 0.0000 & 6.45 & 0.0000 & 0.00000 & 0.01359 & 1.25 & 0.000232 & 0.000333 & 0.0000498 \\
\hline 5 & 1.6 & 0.0181 & 0.0000 & 7.16 & 0.0000 & 0.00040 & 0.00844 & 1.33 & 0.000287 & 0.000000 & 0.0000000 \\
\hline 6 & 2.0 & 0.0013 & 0.0000 & 5.70 & 0.0000 & 0.00163 & 0.00669 & 1.39 & 0.000612 & 0.000175 & 0.0000289 \\
\hline 7 & 2.4 & 0.0057 & 0.0000 & 10.18 & 0.0013 & 0.00000 & 0.00000 & 1.32 & 0.000150 & 0.000188 & 0.0000820 \\
\hline 8 & 2.8 & 0.0000 & 0.0000 & 7.81 & 0.0000 & 0.00000 & 0.00000 & 1.22 & 0.000306 & 0.000266 & 0.0000000 \\
\hline 9 & 3.2 & 0.0144 & 0.0000 & 18.76 & 0.0000 & 0.00000 & 0.00000 & 1.14 & 0.000489 & 0.000352 & 0.0000000 \\
\hline 10 & 3.6 & 0.0011 & 0.0000 & 5.76 & 0.0103 & 0.00000 & 0.01205 & 1.02 & 0.000386 & 0.000085 & 0.0000000 \\
\hline 11 & 4.0 & 0.0149 & 0.0000 & 7.82 & 0.0000 & 0.00213 & 0.00029 & 1.02 & 0.000000 & 0.000000 & 0.0000000 \\
\hline 12 & 4.4 & 0.0000 & 0.0000 & 5.08 & 0.0000 & 0.00000 & 0.00414 & 1.53 & 0.000897 & 0.000506 & 0.0000000 \\
\hline 13 & 4.8 & 0.0033 & 0.0000 & 4.44 & 0.0000 & 0.00000 & 0.00000 & 1.26 & 0.000326 & 0.000057 & 0.0000000 \\
\hline 14 & 5.2 & 0.0131 & 0.0288 & 6.17 & 0.0000 & 0.00579 & 0.00000 & 1.24 & 0.000298 & 0.000000 & 0.0000000 \\
\hline 15 & 5.6 & 0.0000 & 0.1321 & 9.86 & 0.0000 & 0.00000 & 0.04430 & 1.48 & 0.000687 & 0.000011 & 0.0000000 \\
\hline 16 & 6.0 & 0.0047 & 0.0020 & 4.72 & 0.0069 & 0.00512 & 0.00000 & 1.48 & 0.000413 & 0.000000 & 0.0000000 \\
\hline 17 & 6.4 & 0.0085 & 0.0000 & 4.95 & 0.0184 & 0.00002 & 0.00000 & 1.28 & 0.000586 & 0.000254 & 0.0000000 \\
\hline 18 & 6.8 & 0.0077 & 0.0000 & 6.95 & 0.0000 & 0.00072 & 0.00000 & 1.46 & 0.000538 & 0.000259 & 0.0000000 \\
\hline 19 & 7.2 & 0.0000 & 0.0975 & 5.48 & 0.0000 & 0.00000 & 0.00036 & 1.43 & 0.000324 & 0.000093 & 0.0000000 \\
\hline 20 & 7.6 & 0.0161 & 0.0309 & 5.47 & 0.0094 & 0.00188 & 0.00317 & 1.25 & 0.000427 & 0.000069 & 0.0000790 \\
\hline 21 & 8.0 & 0.0017 & 0.0000 & 5.18 & 0.0022 & 0.00000 & 0.00326 & 1.09 & 0.000397 & 0.000336 & 0.0000000 \\
\hline 22 & 8.4 & 0.0097 & 0.0000 & 5.28 & 0.0000 & 0.00065 & 0.00000 & 1.29 & 0.000560 & 0.000000 & 0.0000000 \\
\hline 23 & 8.8 & 0.0050 & 0.0351 & 4.41 & 0.0008 & 0.00060 & 0.00000 & 1.33 & 0.000412 & 0.000000 & 0.0000000 \\
\hline 24 & 9.2 & 0.0201 & 0.0944 & 4.41 & 0.0000 & 0.00040 & 0.00000 & 1.29 & 0.000399 & 0.000398 & 0.0000000 \\
\hline 25 & 9.6 & 0.0000 & 0.0000 & 4.14 & 0.0000 & 0.00319 & 0.01130 & 1.26 & 0.000342 & 0.000202 & 0.0000000 \\
\hline 26 & 10.0 & 0.0149 & 0.0353 & 4.73 & 0.0105 & 0.00334 & 0.00000 & 1.52 & 0.000612 & 0.000340 & 0.0000000 \\
\hline 27 & 10.4 & 0.0067 & 0.0679 & 5.18 & 0.0100 & 0.00513 & 0.00000 & 1.43 & 0.000702 & 0.000000 & 0.0000165 \\
\hline 28 & 10.8 & 0.0190 & 0.0000 & 5.89 & 0.0060 & 0.00132 & 0.00000 & 1.46 & 0.000559 & 0.000000 & 0.0000000 \\
\hline 29 & 11.2 & 0.0143 & 0.0011 & 6.58 & 0.0006 & 0.00052 & 0.00378 & 1.41 & 0.000413 & 0.000185 & 0.0000888 \\
\hline
\end{tabular}




\begin{tabular}{|c|c|c|c|c|c|c|c|c|c|c|c|}
\hline \multirow{2}{*}{ Spot Number } & \multirow{2}{*}{ Distance from the foot $(\mathrm{mm})$} & \multicolumn{10}{|c|}{ A740 2 prismatic layer transect corrected data $(\mathrm{mmol} / \mathrm{mol})$ continued... } \\
\hline & & $\mathrm{Li} / \mathrm{Ca}$ & $\mathrm{B} / \mathrm{Ca}$ & $\mathrm{Mg} / \mathrm{Ca}$ & $\mathbf{A l} / \mathbf{C a}$ & $\mathrm{Mn} / \mathrm{Ca}$ & $\mathrm{Zn} / \mathrm{Ca}$ & $\mathrm{Sr} / \mathrm{Ca}$ & $\mathrm{Ba} / \mathrm{Ca}$ & $\mathrm{Pb} / \mathrm{Ca}$ & $\mathrm{U} / \mathrm{Ca}$ \\
\hline 30 & 11.6 & 0.0101 & 0.1064 & 5.72 & 0.0053 & 0.00306 & 0.00000 & 1.20 & 0.000540 & 0.000000 & 0.0000000 \\
\hline 31 & 12.0 & 0.0102 & 0.1791 & 6.34 & 0.0000 & 0.00354 & 0.00849 & 1.23 & 0.000821 & 0.000131 & 0.0000000 \\
\hline 32 & 12.4 & 0.0102 & 0.1684 & 6.39 & 0.0025 & 0.00108 & 0.00894 & 1.27 & 0.000775 & 0.000000 & 0.0000000 \\
\hline 33 & 12.8 & 0.0072 & 0.0852 & 4.59 & 0.0000 & 0.00293 & 0.00121 & 1.34 & 0.000743 & 0.000000 & 0.0000000 \\
\hline 34 & 13.2 & 0.0118 & 0.0295 & 5.17 & 0.0102 & 0.00365 & 0.00181 & 1.31 & 0.000589 & 0.000098 & 0.0000802 \\
\hline 35 & 13.6 & 0.0159 & 0.0293 & 4.56 & 0.0000 & 0.00388 & 0.00358 & 1.19 & 0.000617 & 0.000265 & 0.0000737 \\
\hline 36 & 14.0 & 0.0019 & 0.0633 & 4.50 & 0.0016 & 0.00307 & 0.00466 & 1.13 & 0.000593 & 0.000020 & 0.0000000 \\
\hline 37 & 14.4 & 0.0185 & 0.0965 & 5.53 & 0.0141 & 0.00321 & 0.00000 & 1.26 & 0.000451 & 0.000517 & 0.0000000 \\
\hline 38 & 14.8 & 0.0000 & 0.1598 & 5.74 & 0.0037 & 0.00235 & 0.00000 & 1.38 & 0.000445 & 0.000176 & 0.0000000 \\
\hline 39 & 15.2 & 0.0000 & 0.0000 & 5.58 & 0.0000 & 0.00069 & 0.00000 & 1.36 & 0.000622 & 0.000044 & 0.0000000 \\
\hline 40 & 15.6 & 0.0146 & 0.1639 & 4.27 & 0.0177 & 0.00149 & 0.02359 & 1.41 & 0.000441 & 0.000161 & 0.0000000 \\
\hline 41 & 16.0 & 0.0000 & 0.0108 & 4.19 & 0.0000 & 0.00456 & 0.00000 & 1.41 & 0.000519 & 0.000078 & 0.0000767 \\
\hline 42 & 16.4 & 0.0000 & 0.0000 & 3.92 & 0.0132 & 0.00880 & 0.00654 & 1.38 & 0.000830 & 0.000018 & 0.0000914 \\
\hline 43 & 16.8 & 0.0076 & 0.2373 & 4.86 & 0.0183 & 0.00488 & 0.01104 & 1.18 & 0.000625 & 0.000052 & 0.0000000 \\
\hline 44 & 17.2 & 0.0133 & 0.0214 & 20.42 & 0.0156 & 0.00370 & 0.01116 & 1.34 & 0.000807 & 0.000000 & 0.0000503 \\
\hline 45 & 17.6 & 0.0080 & 0.0007 & 4.32 & 0.0000 & 0.00533 & 0.00357 & 1.19 & 0.000248 & 0.000122 & 0.0000000 \\
\hline 46 & 18.0 & 0.0142 & 0.0961 & 4.62 & 0.0041 & 0.00000 & 0.00000 & 1.43 & 0.000684 & 0.000006 & 0.0000558 \\
\hline 47 & 18.4 & 0.0000 & 0.0000 & 4.37 & 0.0064 & 0.00355 & 0.00000 & 1.55 & 0.000660 & 0.000310 & 0.0000125 \\
\hline 48 & 18.8 & 0.0144 & 0.1307 & 4.55 & 0.0051 & 0.00587 & 0.01038 & 1.31 & 0.000479 & 0.000000 & 0.0000498 \\
\hline 49 & 19.2 & 0.0135 & 0.0784 & 5.42 & 0.0117 & 0.00353 & 0.00000 & 1.34 & 0.000526 & 0.000000 & 0.0000091 \\
\hline 50 & 19.6 & 0.0150 & 0.0150 & 5.84 & 0.0000 & 0.00819 & 0.01549 & 1.45 & 0.000644 & 0.000000 & 0.0001046 \\
\hline 51 & 20.0 & 0.0147 & 0.0839 & 4.78 & 0.0000 & 0.00000 & 0.00000 & 1.50 & 0.000283 & 0.000073 & 0.0000000 \\
\hline 52 & 20.4 & 0.0064 & 0.0000 & 4.05 & 0.0075 & 0.00135 & 0.00792 & 1.36 & 0.000000 & 0.000000 & 0.0000000 \\
\hline 53 & 20.8 & 0.0022 & 0.0177 & 4.66 & 0.0018 & 0.00336 & 0.00000 & 1.30 & 0.000542 & 0.000000 & 0.0000817 \\
\hline 54 & 21.2 & 0.0000 & 0.0939 & 3.77 & 0.0010 & 0.00503 & 0.00000 & 1.37 & 0.000592 & 0.000249 & 0.0000000 \\
\hline 55 & 21.6 & 0.0026 & 0.0000 & 3.94 & 0.0255 & 0.01154 & 0.00000 & 1.38 & 0.000221 & 0.000139 & 0.0001980 \\
\hline 56 & 22.0 & 0.0082 & 0.0069 & 4.01 & 0.0000 & 0.00000 & 0.00609 & 1.54 & 0.000695 & 0.000000 & 0.0000000 \\
\hline 57 & 22.4 & 0.0104 & 0.0000 & 5.33 & 0.0009 & 0.00213 & 0.00000 & 1.48 & 0.000444 & 0.000000 & 0.0000000 \\
\hline 58 & 22.8 & 0.0118 & 0.0642 & 7.78 & 0.0044 & 0.00887 & 0.00000 & 1.70 & 0.000928 & 0.000352 & 0.0000000 \\
\hline 59 & 23.2 & 0.0213 & 0.0000 & 4.83 & 0.0036 & 0.00149 & 0.00806 & 1.54 & 0.000749 & 0.000027 & 0.0000587 \\
\hline
\end{tabular}




\begin{tabular}{|c|c|c|c|c|c|c|c|c|c|c|c|}
\hline \multirow{2}{*}{ Spot Number } & \multirow{2}{*}{ Distance from the foot (mm) } & \multicolumn{10}{|c|}{ A740 2 prismatic layer transect corrected data $(\mathrm{mmol} / \mathrm{mol})$ continued... } \\
\hline & & $\mathrm{Li} / \mathrm{Ca}$ & $\mathrm{B} / \mathrm{Ca}$ & $\mathrm{Mg} / \mathrm{Ca}$ & $\mathrm{Al} / \mathrm{Ca}$ & $\mathrm{Mn} / \mathrm{Ca}$ & $\mathrm{Zn} / \mathrm{Ca}$ & $\mathrm{Sr} / \mathrm{Ca}$ & $\mathrm{Ba} / \mathrm{Ca}$ & $\mathrm{Pb} / \mathrm{Ca}$ & $\mathrm{U} / \mathrm{Ca}$ \\
\hline 60 & 23.6 & 0.0108 & 0.1300 & 5.16 & 0.0022 & 0.00850 & 0.00229 & 1.51 & 0.000482 & 0.000190 & 0.0001033 \\
\hline 61 & 24.0 & 0.0083 & 0.0000 & 4.29 & 0.0011 & 0.00162 & 0.00791 & 1.54 & 0.000607 & 0.000111 & 0.0000000 \\
\hline 62 & 24.4 & 0.0000 & 0.0899 & 4.40 & 0.0000 & 0.00198 & 0.00944 & 1.40 & 0.000221 & 0.000000 & 0.0000508 \\
\hline 63 & 24.8 & 0.0071 & 0.0092 & 5.27 & 0.0000 & 0.00397 & 0.01079 & 1.44 & 0.000187 & 0.000000 & 0.0000572 \\
\hline 64 & 25.2 & 0.0134 & 0.0903 & 2.84 & 0.0107 & 0.00000 & 0.00773 & 1.58 & 0.000614 & 0.000132 & 0.0001949 \\
\hline 65 & 25.6 & 0.0130 & 0.1344 & 3.30 & 0.0039 & 0.00019 & 0.00177 & 1.54 & 0.000909 & 0.000120 & 0.0000830 \\
\hline 66 & 26.0 & 0.0122 & 0.1620 & 10.61 & 0.0000 & 0.00270 & 0.00806 & 1.27 & 0.000458 & 0.000240 & 0.0000901 \\
\hline 67 & 26.4 & 0.0088 & 0.0867 & 4.35 & 0.0000 & 0.00814 & 0.00404 & 1.41 & 0.000543 & 0.000000 & 0.0000000 \\
\hline 68 & 26.8 & 0.0152 & 0.0900 & 3.93 & 0.0002 & 0.00449 & 0.00000 & 1.38 & 0.000528 & 0.000000 & 0.0001217 \\
\hline 69 & 27.2 & 0.0077 & 0.0774 & 6.00 & 0.0000 & 0.00000 & 0.00939 & 1.21 & 0.000590 & 0.000292 & 0.0000000 \\
\hline 70 & 27.6 & 0.0111 & 0.0938 & 5.99 & 0.0069 & 0.00009 & 0.00080 & 1.23 & 0.000581 & 0.000085 & 0.0001039 \\
\hline 71 & 28.0 & 0.0168 & 0.0017 & 10.47 & 0.0000 & 0.00712 & 0.00000 & 1.68 & 0.000635 & 0.000193 & 0.0000000 \\
\hline 72 & 28.4 & 0.0146 & 0.0587 & 4.83 & 0.0128 & 0.00114 & 0.00303 & 1.39 & 0.000448 & 0.000156 & 0.0000000 \\
\hline 73 & 28.8 & 0.0059 & 0.0000 & 5.47 & 0.0050 & 0.00178 & 0.00000 & 1.30 & 0.000545 & 0.000152 & 0.0000000 \\
\hline 74 & 29.2 & 0.0097 & 0.0000 & 5.21 & 0.0016 & 0.00565 & 0.01459 & 1.22 & 0.000588 & 0.000000 & 0.0001321 \\
\hline 75 & 29.6 & 0.0100 & 0.0343 & 5.41 & 0.0000 & 0.00206 & 0.00109 & 1.25 & 0.000269 & 0.000077 & 0.0001072 \\
\hline 76 & 30.0 & 0.0159 & 0.1463 & 3.83 & 0.0193 & 0.00455 & 0.00121 & 1.50 & 0.000528 & 0.000000 & 0.0000524 \\
\hline 77 & 30.4 & 0.0105 & 0.0447 & 3.43 & 0.0000 & 0.00658 & 0.00041 & 1.42 & 0.000360 & 0.000000 & 0.0000000 \\
\hline 78 & 30.8 & 0.0160 & 0.0500 & 5.74 & 0.0072 & 0.00074 & 0.00000 & 1.56 & 0.000652 & 0.000000 & 0.0000000 \\
\hline 79 & 31.2 & 0.0121 & 0.0594 & 3.50 & 0.0000 & 0.00347 & 0.00448 & 1.49 & 0.000827 & 0.000290 & 0.0000000 \\
\hline 80 & 31.6 & 0.0143 & 0.0000 & 4.87 & 0.0063 & 0.00142 & 0.00000 & 1.66 & 0.000698 & 0.000000 & 0.0000000 \\
\hline 81 & 32.0 & 0.0070 & 0.1195 & 4.98 & 0.0000 & 0.00211 & 0.00000 & 1.75 & 0.000299 & 0.000000 & 0.0000126 \\
\hline 82 & 32.4 & 0.0132 & 0.0379 & 5.01 & 0.0000 & 0.00000 & 0.00000 & 1.52 & 0.000402 & 0.000000 & 0.0000000 \\
\hline 83 & 32.8 & 0.0000 & 0.0233 & 5.96 & 0.0044 & 0.00407 & 0.01743 & 1.41 & 0.000700 & 0.000080 & 0.0000000 \\
\hline 84 & 33.2 & 0.0044 & 0.0000 & 6.29 & 0.0051 & 0.00337 & 0.00000 & 1.23 & 0.000140 & 0.000000 & 0.0000000 \\
\hline 85 & 33.6 & 0.0147 & 0.1415 & 4.87 & 0.0000 & 0.00320 & 0.00218 & 1.16 & 0.000630 & 0.000104 & 0.0000000 \\
\hline 86 & 34.0 & 0.0038 & 0.0232 & 3.97 & 0.0000 & 0.00130 & 0.00000 & 1.50 & 0.000478 & 0.000229 & 0.0000293 \\
\hline 87 & 34.4 & 0.0000 & 0.0935 & 5.06 & 0.0039 & 0.00002 & 0.00000 & 1.52 & 0.000195 & 0.000000 & 0.0000021 \\
\hline 88 & 34.8 & 0.0121 & 0.0377 & 4.39 & 0.0000 & 0.00000 & 0.00039 & 1.15 & 0.000265 & 0.000000 & 0.0000051 \\
\hline 89 & 35.2 & 0.0021 & 0.0856 & 6.14 & 0.0017 & 0.00150 & 0.00155 & 1.47 & 0.000359 & 0.000112 & 0.0000315 \\
\hline
\end{tabular}




\begin{tabular}{|c|c|c|c|c|c|c|c|c|c|c|c|}
\hline \multirow{2}{*}{ Spot Number } & \multirow{2}{*}{ Distance from the foot $(\mathrm{mm})$} & \multicolumn{10}{|c|}{ A740 2 prismatic layer transect corrected data $(\mathrm{mmol} / \mathrm{mol})$ continued... } \\
\hline & & $\mathrm{Li} / \mathrm{Ca}$ & $\mathrm{B} / \mathrm{Ca}$ & $\mathrm{Mg} / \mathrm{Ca}$ & $\mathbf{A l} / \mathbf{C a}$ & $\mathrm{Mn} / \mathrm{Ca}$ & $\mathrm{Zn} / \mathrm{Ca}$ & $\mathrm{Sr} / \mathrm{Ca}$ & $\mathrm{Ba} / \mathrm{Ca}$ & $\mathrm{Pb} / \mathrm{Ca}$ & $\mathrm{U} / \mathrm{Ca}$ \\
\hline 90 & 35.6 & 0.0089 & 0.0349 & 6.42 & 0.0091 & 0.00268 & 0.00000 & 1.20 & 0.000312 & 0.000220 & 0.0000000 \\
\hline 91 & 36.0 & 0.0059 & 0.0684 & 16.18 & 0.0010 & 0.00176 & 0.00000 & 0.90 & 0.000166 & 0.000000 & 0.0001241 \\
\hline 92 & 36.4 & 0.0149 & 0.0379 & 4.26 & 0.0000 & 0.00396 & 0.01408 & 1.18 & 0.000467 & 0.000489 & 0.0000000 \\
\hline 93 & 36.8 & 0.0160 & 0.0000 & 5.66 & 0.0000 & 0.00309 & 0.00000 & 1.54 & 0.000553 & 0.000000 & 0.0000000 \\
\hline 94 & 37.2 & 0.0177 & 0.0000 & 5.32 & 0.0000 & 0.00521 & 0.00020 & 1.43 & 0.000141 & 0.000000 & 0.0000000 \\
\hline 95 & 37.6 & 0.0121 & 0.0000 & 5.51 & 0.0050 & 0.00451 & 0.00000 & 1.33 & 0.000212 & 0.000000 & 0.0000000 \\
\hline 96 & 38.0 & 0.0000 & 0.0602 & 5.18 & 0.0026 & 0.00314 & 0.00666 & 1.23 & 0.000563 & 0.000108 & 0.0000092 \\
\hline 97 & 38.4 & 0.0064 & 0.0431 & 5.42 & 0.0000 & 0.00516 & 0.01827 & 1.29 & 0.000674 & 0.000000 & 0.0000283 \\
\hline 98 & 38.8 & 0.0120 & 0.0555 & 4.86 & 0.0161 & 0.00332 & 0.00000 & 1.43 & 0.000330 & 0.000000 & 0.0000000 \\
\hline 99 & 39.2 & 0.0200 & 0.0820 & 5.41 & 0.0057 & 0.00195 & 0.00314 & 1.67 & 0.000972 & 0.000021 & 0.0000000 \\
\hline 100 & 39.6 & 0.0062 & 0.0385 & 4.63 & 0.0000 & 0.00352 & 0.01126 & 1.27 & 0.000349 & 0.000000 & 0.0000000 \\
\hline 101 & 40.0 & 0.0072 & 0.0000 & 7.37 & 0.0000 & 0.00061 & 0.00000 & 0.97 & 0.000171 & 0.000258 & 0.0000165 \\
\hline 102 & 40.4 & 0.0000 & 0.0083 & 3.35 & 0.0000 & 0.00354 & 0.00703 & 1.38 & 0.000483 & 0.000014 & 0.0001071 \\
\hline
\end{tabular}


APPENDIX 5.1e $\quad$ P1B prismatic layer transect data

\begin{tabular}{|c|c|c|c|c|c|c|c|c|c|c|c|}
\hline \multirow{2}{*}{$\begin{array}{c}\text { Spot } \\
\text { Number }\end{array}$} & \multirow{2}{*}{ Distance from the foot $(\mathrm{mm})$} & \multicolumn{10}{|c|}{ P1B prismatic layer transect corrected data $(\mathrm{mmol} / \mathrm{mol})$} \\
\hline & & $\mathrm{Li} / \mathrm{Ca}$ & $\mathrm{B} / \mathrm{Ca}$ & $\mathrm{Mg} / \mathrm{Ca}$ & $\mathbf{A l} / \mathbf{C a}$ & $\mathrm{Mn} / \mathrm{Ca}$ & $\mathrm{Zn} / \mathrm{Ca}$ & $\mathrm{Sr} / \mathrm{Ca}$ & $\mathrm{Ba} / \mathrm{Ca}$ & $\mathrm{Pb} / \mathrm{Ca}$ & $\mathrm{U} / \mathrm{Ca}$ \\
\hline 1 & 0.0 & 0.0202 & 0.0000 & 13.41 & 0.013 & 0.00090 & 0.00436 & 1.38 & 0.000180 & 0.000000 & 0.0000000 \\
\hline 2 & 0.4 & 0.0112 & 0.0000 & 5.72 & 0.009 & 0.00300 & 0.00141 & 1.29 & 0.000425 & 0.000096 & 0.0000058 \\
\hline 3 & 0.8 & 0.0352 & 0.0000 & 2.91 & 0.000 & 0.00000 & 0.00104 & 1.23 & 0.000424 & 0.000026 & 0.0000000 \\
\hline 4 & 1.2 & 0.0157 & 0.0000 & 6.80 & 0.001 & 0.00137 & 0.00000 & 1.37 & 0.000533 & 0.000026 & 0.0000082 \\
\hline 5 & 1.6 & 0.0000 & 0.0572 & 7.51 & 0.816 & 0.00000 & 0.00249 & 1.42 & 0.001322 & 0.000086 & 0.000013 \\
\hline 6 & 2.0 & 0.0319 & 0.0000 & 10.81 & 0.878 & 0.00101 & 0.00291 & 1.85 & 0.001735 & 0.000091 & 0.0000952 \\
\hline 7 & 2.4 & 0.0074 & 0.0143 & 13.06 & 0.418 & 0.00514 & 0.00000 & 1.39 & 0.000917 & 0.000000 & 0.0000000 \\
\hline 8 & 2.8 & 0.0046 & 0.0737 & 5.97 & 0.229 & 0.01045 & 0.00325 & 2.99 & 0.002304 & 0.000000 & 0.0003274 \\
\hline 9 & 3.2 & 0.0056 & 0.0026 & 6.66 & 0.000 & 0.00000 & 0.00049 & 1.03 & 0.000244 & 0.000000 & 0.0000000 \\
\hline 10 & 3.6 & 0.0211 & 0.0000 & 3.79 & 0.001 & 0.00260 & 0.00000 & 1.29 & 0.000441 & 0.000000 & 0.0000057 \\
\hline 11 & 4.0 & 0.0256 & 0.0000 & 1.76 & 0.000 & 0.00042 & 0.00170 & 1.24 & 0.000281 & 0.000045 & 0.0000185 \\
\hline 12 & 4.4 & 0.0073 & 0.0094 & 5.88 & 0.008 & 0.00065 & 0.00057 & 1.29 & 0.000374 & 0.000006 & 0.0000064 \\
\hline 13 & 4.8 & 0.0242 & 0.0027 & 4.64 & 0.000 & 0.00000 & 0.00000 & 1.36 & 0.000087 & 0.000000 & 0.0000000 \\
\hline 14 & 5.2 & 0.0224 & 0.0272 & 3.11 & 0.000 & 0.00065 & 0.00199 & 1.45 & 0.000396 & 0.000090 & 0.0000000 \\
\hline 15 & 5.6 & 0.0198 & 0.0086 & 2.21 & 0.000 & 0.00525 & 0.00254 & 1.35 & 0.000406 & 0.000049 & 0.0000195 \\
\hline 16 & 6.0 & 0.0040 & 0.0000 & 3.59 & 0.000 & 0.00283 & 0.00466 & 1.17 & 0.000378 & 0.000104 & 0.0000350 \\
\hline 17 & 6.4 & 0.0189 & 0.0046 & 4.89 & 0.041 & 0.00700 & 0.00315 & 1.20 & 0.000345 & 0.000000 & 0.0000088 \\
\hline 18 & 6.8 & 0.0131 & 0.0000 & 6.11 & 0.283 & 0.00497 & 0.00000 & 1.27 & 0.000520 & 0.000000 & 0.0000083 \\
\hline 19 & 7.2 & 0.0057 & 0.0124 & 11.52 & 0.206 & 0.00189 & 0.00000 & 1.32 & 0.000594 & 0.000210 & $0.000005 \mathrm{~s}$ \\
\hline 20 & 7.6 & 0.0130 & 0.0000 & 8.19 & 0.000 & 0.00296 & 0.00000 & 1.23 & 0.000348 & 0.000079 & 0.0000000 \\
\hline 21 & 8.0 & 0.0273 & 0.0454 & 21.87 & 3.033 & 0.00850 & 0.00616 & 1.56 & 0.003996 & 0.000170 & 0.0000612 \\
\hline 22 & 8.4 & 0.0102 & 0.0000 & 3.04 & 0.000 & 0.00000 & 0.00000 & 1.30 & 0.000393 & 0.000485 & 0.0000153 \\
\hline 23 & 8.8 & 0.0265 & 0.0132 & 3.18 & 0.007 & 0.00000 & 0.00000 & 1.13 & 0.000309 & 0.000127 & 0.0000000 \\
\hline 24 & 9.2 & 0.0075 & 0.0000 & 3.30 & 0.001 & 0.00282 & 0.00112 & 1.19 & 0.000342 & 0.000073 & 0.0000011 \\
\hline 25 & 9.6 & 0.0247 & 0.0048 & 1.98 & 0.000 & 0.00000 & 0.00005 & 1.31 & 0.000274 & 0.000017 & 0.0000000 \\
\hline 26 & 10.0 & 0.0087 & 0.0493 & 2.86 & 0.003 & 0.00119 & 0.00488 & 1.29 & 0.000343 & 0.000071 & 0.0000041 \\
\hline 27 & 10.4 & 0.0331 & 0.0225 & 3.82 & 0.000 & 0.00000 & 0.00646 & 1.35 & 0.000378 & 0.000039 & 0.0000000 \\
\hline 28 & 10.8 & 0.0000 & 0.0365 & 5.67 & 1.715 & 0.00239 & 0.00022 & 1.33 & 0.001023 & 0.000127 & 0.0000226 \\
\hline 29 & 11.2 & 0.0010 & 0.0000 & 2.81 & 0.010 & 0.00000 & 0.00289 & 1.31 & 0.000362 & 0.000166 & 0.0000233 \\
\hline
\end{tabular}




\begin{tabular}{|c|c|c|c|c|c|c|c|c|c|c|c|}
\hline \multirow{2}{*}{ Spot Number } & \multirow{2}{*}{ Distance from the foot ( $\mathrm{mm})$} & \multicolumn{10}{|c|}{ P1B prismatic layer transect corrected data $(\mathrm{mmol} / \mathrm{mol})$} \\
\hline & & $\mathrm{Li} / \mathbf{C a}$ & $\mathbf{B} / \mathbf{C a}$ & $\mathrm{Mg} / \mathrm{Ca}$ & $\mathbf{A l} / \mathbf{C a}$ & $\mathrm{Mn} / \mathrm{Ca}$ & $\mathrm{Zn} / \mathrm{Ca}$ & $\mathrm{Sr} / \mathrm{Ca}$ & $\mathrm{Ba} / \mathrm{Ca}$ & $\mathrm{Pb} / \mathrm{Ca}$ & $\mathbf{U} / \mathbf{C a}$ \\
\hline 30 & 11.6 & 0.0436 & 0.0054 & 2.99 & 0.000 & 0.00243 & 0.00000 & 1.32 & 0.000371 & 0.000235 & 0.0000000 \\
\hline 31 & 12.0 & 0.0092 & 0.0016 & 3.29 & 0.000 & 0.00014 & 0.00000 & 1.39 & 0.000477 & 0.000168 & 0.0000156 \\
\hline 32 & 12.4 & 0.0000 & 0.0349 & 3.08 & 0.000 & 0.00427 & 0.00328 & 1.39 & 0.000536 & 0.000093 & 0.0000000 \\
\hline 33 & 12.8 & 0.0000 & 0.0096 & 9.41 & 0.000 & 0.00597 & 0.00616 & 1.38 & 0.000536 & 0.000167 & 0.0000096 \\
\hline 34 & 13.2 & 0.0229 & 0.0000 & 2.85 & 0.000 & 0.00516 & 0.00698 & 1.36 & 0.000369 & 0.000053 & 0.0000000 \\
\hline 35 & 13.6 & 0.0124 & 0.0378 & 9.17 & 0.325 & 0.00703 & 0.00249 & 1.78 & 0.001123 & 0.000124 & 0.0000333 \\
\hline 36 & 14.0 & 0.0000 & 0.0342 & 3.50 & 0.002 & 0.00000 & 0.00000 & 1.27 & 0.000317 & 0.000063 & 0.0000313 \\
\hline 37 & 14.4 & 0.0010 & 0.0280 & 4.71 & 0.000 & 0.00723 & 0.00934 & 1.35 & 0.000441 & 0.000013 & 0.0000000 \\
\hline 38 & 14.8 & 0.0162 & 0.0000 & 8.04 & 0.364 & 0.01254 & 0.00727 & 1.52 & 0.000921 & 0.000190 & 0.0000000 \\
\hline 39 & 15.2 & 0.0090 & 0.0000 & 9.24 & 0.000 & 0.00923 & 0.00745 & 1.47 & 0.000631 & 0.000142 & 0.0000396 \\
\hline 40 & 15.6 & 0.0420 & 0.2066 & 3.01 & 1.735 & 0.05611 & 0.01162 & 6.97 & 0.012180 & 0.000387 & 0.0020442 \\
\hline 41 & 16.0 & 0.0307 & 0.1297 & 1.65 & 0.000 & 0.02726 & 0.00745 & 4.60 & 0.004621 & 0.000528 & 0.0009662 \\
\hline 42 & 16.4 & 0.0065 & 0.0363 & 2.75 & 0.038 & 0.00367 & 0.00472 & 1.32 & 0.000385 & 0.000070 & 0.0000000 \\
\hline 43 & 16.8 & 0.0205 & 0.0074 & 7.59 & 0.000 & 0.01583 & 0.00206 & 1.46 & 0.000513 & 0.000108 & 0.0000000 \\
\hline 44 & 17.2 & 0.0142 & 0.0104 & 9.96 & 0.000 & 0.01233 & 0.00159 & 1.52 & 0.000595 & 0.000144 & 0.0000000 \\
\hline 45 & 17.6 & 0.0000 & 0.0084 & 9.28 & 0.017 & 0.00336 & 0.00170 & 1.57 & 0.000660 & 0.000071 & 0.0000000 \\
\hline 46 & 18.0 & 0.0106 & 0.0294 & 12.86 & 0.251 & 0.00399 & 0.00406 & 1.32 & 0.000699 & 0.000076 & 0.0000347 \\
\hline 47 & 18.4 & 0.0116 & 0.0000 & 7.00 & 0.000 & 0.00152 & 0.00590 & 1.14 & 0.000373 & 0.000071 & 0.0000090 \\
\hline 48 & 18.8 & 0.0045 & 0.0090 & 4.87 & 0.000 & 0.00239 & 0.00216 & 1.22 & 0.000484 & 0.000156 & 0.0000075 \\
\hline 49 & 19.2 & 0.0182 & 0.0105 & 14.43 & 1.388 & 0.00696 & 0.00722 & 1.40 & 0.002101 & 0.000111 & 0.0000235 \\
\hline 50 & 19.6 & 0.0307 & 0.0036 & 8.50 & 1.522 & 0.02322 & 0.00336 & 1.23 & 0.001619 & 0.000289 & 0.0000260 \\
\hline 51 & 20.0 & 0.0073 & 0.0134 & 3.89 & 0.007 & 0.01004 & 0.00984 & 1.22 & 0.000508 & 0.000346 & 0.0000000 \\
\hline 52 & 20.4 & 0.0420 & 0.0365 & 11.17 & 0.108 & 0.02025 & 0.00137 & 2.45 & 0.001680 & 0.000043 & 0.0002151 \\
\hline 53 & 20.8 & 0.0202 & 0.0023 & 1.86 & 0.002 & 0.00000 & 0.00195 & 1.15 & 0.000203 & 0.000185 & 0.0000000 \\
\hline 54 & 21.2 & 0.0000 & 0.0278 & 3.92 & 0.001 & 0.00416 & 0.00273 & 1.07 & 0.000323 & 0.000145 & 0.0000000 \\
\hline 55 & 21.6 & 0.0000 & 0.0150 & 3.77 & 0.000 & 0.00364 & 0.00016 & 1.12 & 0.000436 & 0.000158 & 0.0000000 \\
\hline 56 & 22.0 & 0.0033 & 0.0325 & 8.62 & 0.000 & 0.00954 & 0.00200 & 1.52 & 0.000573 & 0.000063 & 0.0000057 \\
\hline 57 & 22.4 & 0.0180 & 0.0213 & 21.68 & 0.013 & 0.02798 & 0.00025 & 1.75 & 0.001179 & 0.000143 & 0.0000568 \\
\hline 58 & 22.8 & 0.0043 & 0.0289 & 4.86 & 0.002 & 0.00782 & 0.00000 & 1.58 & 0.000591 & 0.000123 & 0.0000029 \\
\hline 59 & 23.2 & 0.0868 & 0.1632 & 8.76 & 17.634 & 0.17811 & 0.01101 & 5.43 & 0.020799 & 0.001042 & 0.0020242 \\
\hline
\end{tabular}




\begin{tabular}{|c|c|c|c|c|c|c|c|c|c|c|c|}
\hline \multirow{2}{*}{ Spot Number } & \multirow{2}{*}{ Distance from the foot $(\mathrm{mm})$} & \multicolumn{10}{|c|}{ P1B prismatic layer transect corrected data $(\mathrm{mmol} / \mathrm{mol})$} \\
\hline & & $\mathrm{Li} / \mathrm{Ca}$ & $\mathrm{B} / \mathrm{Ca}$ & $\mathrm{Mg} / \mathrm{Ca}$ & $\mathrm{Al} / \mathrm{Ca}$ & $\mathrm{Mn} / \mathrm{Ca}$ & $\mathrm{Zn} / \mathrm{Ca}$ & $\mathrm{Sr} / \mathrm{Ca}$ & $\mathrm{Ba} / \mathrm{Ca}$ & $\mathrm{Pb} / \mathrm{Ca}$ & $\mathrm{U} / \mathrm{Ca}$ \\
\hline 60 & 23.6 & 0.0090 & 0.0274 & 4.69 & 0.004 & 0.01794 & 0.00345 & 1.35 & 0.000473 & 0.000000 & 0.0000000 \\
\hline 61 & 24.0 & 0.0300 & 0.0000 & 11.70 & 0.015 & 0.00273 & 0.00216 & 1.49 & 0.000678 & 0.000508 & 0.0000305 \\
\hline 62 & 24.4 & 0.0004 & 0.0000 & 5.81 & 0.002 & 0.01077 & 0.00000 & 1.43 & 0.000557 & 0.000188 & 0.0000035 \\
\hline 63 & 24.8 & 0.0242 & 0.0332 & 4.25 & 0.000 & 0.00694 & 0.00749 & 1.32 & 0.000620 & 0.000200 & 0.0000104 \\
\hline 64 & 25.2 & 0.0068 & 0.0028 & 5.65 & 0.000 & 0.00594 & 0.00000 & 1.40 & 0.000315 & 0.000127 & 0.0000057 \\
\hline 65 & 25.6 & 0.0092 & 0.0228 & 4.62 & 0.000 & 0.00329 & 0.00000 & 1.35 & 0.000352 & 0.000217 & 0.0000053 \\
\hline 66 & 26.0 & 0.0112 & 0.0240 & 1.56 & 0.000 & 0.00104 & 0.00589 & 1.25 & 0.000297 & 0.000143 & 0.0000116 \\
\hline 67 & 26.4 & 0.0096 & 0.0069 & 1.72 & 0.002 & 0.00814 & 0.00391 & 0.99 & 0.000233 & 0.000150 & 0.0000000 \\
\hline 68 & 26.8 & 0.0000 & 0.0062 & 2.17 & 0.000 & 0.00290 & 0.00000 & 1.14 & 0.000428 & 0.000000 & 0.0000101 \\
\hline 69 & 27.2 & 0.0000 & 0.0146 & 2.35 & 0.002 & 0.01617 & 0.00457 & 1.46 & 0.000477 & 0.000060 & 0.0000000 \\
\hline 70 & 27.6 & 0.0435 & 0.0174 & 3.07 & 0.000 & 0.01809 & 0.00275 & 1.47 & 0.000412 & 0.000064 & 0.0000034 \\
\hline 71 & 28.0 & 0.0167 & 0.0000 & 1.82 & 0.033 & 0.00888 & 0.00196 & 1.20 & 0.000329 & 0.000206 & 0.0000216 \\
\hline 72 & 28.4 & 0.0000 & 0.0000 & 2.06 & 0.000 & 0.00288 & 0.00955 & 1.12 & 0.000240 & 0.000188 & 0.0000000 \\
\hline 73 & 28.8 & 0.0000 & 0.0027 & 3.18 & 0.000 & 0.00000 & 0.00059 & 1.11 & 0.000356 & 0.000133 & 0.0000056 \\
\hline 74 & 29.2 & 0.0273 & 0.0000 & 1.76 & 0.000 & 0.00011 & 0.00000 & 1.32 & 0.000412 & 0.000082 & 0.0000000 \\
\hline 75 & 29.6 & 0.0000 & 0.0430 & 2.23 & 0.011 & 0.00737 & 0.00567 & 1.44 & 0.000451 & 0.000184 & 0.0000000 \\
\hline 76 & 30.0 & 0.0000 & 0.0337 & 1.96 & 0.000 & 0.00361 & 0.00170 & 1.12 & 0.000298 & 0.000128 & 0.0000000 \\
\hline 77 & 30.4 & 0.0000 & 0.0183 & 2.12 & 0.011 & 0.00678 & 0.00713 & 1.30 & 0.000228 & 0.000234 & 0.0000000 \\
\hline 78 & 30.8 & 0.0228 & 0.0019 & 2.46 & 0.018 & 0.01508 & 0.00521 & 1.35 & 0.000486 & 0.000249 & 0.0000095 \\
\hline 79 & 31.2 & 0.0184 & 0.0045 & 2.06 & 0.000 & 0.00876 & 0.00276 & 1.29 & 0.000402 & 0.000302 & 0.0000000 \\
\hline 80 & 31.6 & 0.0330 & 0.0039 & 2.10 & 0.003 & 0.00058 & 0.00000 & 1.53 & 0.000423 & 0.000000 & 0.0000000 \\
\hline 81 & 32.0 & 0.0267 & 0.0094 & 4.57 & 0.001 & 0.00865 & 0.00000 & 1.35 & 0.000416 & 0.000101 & 0.0000163 \\
\hline 82 & 32.4 & 0.0348 & 0.0000 & 3.07 & 0.002 & 0.00349 & 0.00000 & 1.33 & 0.000260 & 0.000198 & 0.0000549 \\
\hline 83 & 32.8 & 0.0227 & 0.0221 & 2.76 & 0.000 & 0.00530 & 0.00230 & 1.16 & 0.000474 & 0.000234 & 0.0000000 \\
\hline 84 & 33.2 & 0.0000 & 0.0017 & 1.91 & 0.000 & 0.01191 & 0.00078 & 1.38 & 0.000415 & 0.000108 & 0.0000040 \\
\hline 85 & 33.6 & 0.0000 & 0.0115 & 11.24 & 0.000 & 0.00204 & 0.00750 & 1.28 & 0.000288 & 0.000081 & 0.0000010 \\
\hline 86 & 34.0 & 0.0000 & 0.0205 & 4.82 & 0.014 & 0.02620 & 0.00058 & 1.44 & 0.000569 & 0.000152 & 0.0000360 \\
\hline 87 & 34.4 & 0.0297 & 0.0237 & 13.51 & 0.005 & 0.00295 & 0.00000 & 1.37 & 0.000420 & 0.000174 & 0.0000000 \\
\hline 88 & 34.8 & 0.0000 & 0.0042 & 11.47 & 0.392 & 0.01709 & 0.00369 & 1.32 & 0.001082 & 0.000165 & 0.0000000 \\
\hline 89 & 35.2 & 0.0030 & 0.0153 & 13.63 & 0.099 & 0.00978 & 0.00000 & 1.55 & 0.000826 & 0.000120 & 0.0000254 \\
\hline
\end{tabular}




\begin{tabular}{|c|c|c|c|c|c|c|c|c|c|c|c|}
\hline \multirow{2}{*}{ Spot Number } & \multirow{2}{*}{ Distance from the foot $(\mathrm{mm})$} & \multicolumn{10}{|c|}{ P1B prismatic layer transect corrected data ( $\mathrm{mmol} / \mathrm{mol})$} \\
\hline & & $\mathrm{Li} / \mathrm{Ca}$ & $\mathrm{B} / \mathrm{Ca}$ & $\mathrm{Mg} / \mathrm{Ca}$ & $\mathbf{A l} / \mathbf{C a}$ & $\mathrm{Mn} / \mathrm{Ca}$ & $\mathrm{Zn} / \mathrm{Ca}$ & $\mathrm{Sr} / \mathrm{Ca}$ & $\mathrm{Ba} / \mathrm{Ca}$ & $\mathrm{Pb} / \mathrm{Ca}$ & $\mathrm{U} / \mathrm{Ca}$ \\
\hline 90 & 35.6 & 0.0245 & 0.0654 & 21.44 & 5.215 & 0.03556 & 0.00117 & 1.92 & 0.005976 & 0.000253 & 0.0002609 \\
\hline 91 & 36.0 & 0.0000 & 0.0192 & 3.89 & 0.000 & 0.00824 & 0.00061 & 1.15 & 0.000413 & 0.000158 & 0.0000039 \\
\hline 92 & 36.4 & 0.0000 & 0.0977 & 14.62 & 0.002 & 0.03870 & 0.00859 & 3.67 & 0.003782 & 0.000162 & 0.0006917 \\
\hline 93 & 36.8 & 0.0006 & 0.0132 & 2.63 & 0.019 & 0.00629 & 0.00000 & 1.50 & 0.000467 & 0.000255 & 0.0000238 \\
\hline 94 & 37.2 & 0.0234 & 0.0000 & 5.50 & 0.005 & 0.00408 & 0.00223 & 1.41 & 0.000432 & 0.000131 & 0.0000000 \\
\hline 95 & 37.6 & 0.0359 & 0.0630 & 15.01 & 10.562 & 0.07908 & 0.00151 & 2.15 & 0.012339 & 0.000483 & 0.0001391 \\
\hline 96 & 38.0 & 0.0263 & 0.0143 & 2.25 & 0.000 & 0.00484 & 0.00000 & 1.21 & 0.000297 & 0.000110 & 0.0000000 \\
\hline 97 & 38.4 & 0.0183 & 0.0044 & 2.31 & 0.000 & 0.00322 & 0.00374 & 0.96 & 0.000225 & 0.000105 & 0.0000000 \\
\hline 98 & 38.8 & 0.0539 & 0.0414 & 9.61 & 6.587 & 0.06008 & 0.00719 & 1.45 & 0.003410 & 0.000173 & 0.0000562 \\
\hline 99 & 39.2 & 0.0000 & 0.0018 & 2.29 & 0.000 & 0.00841 & 0.00155 & 1.09 & 0.000402 & 0.000123 & 0.0000107 \\
\hline 100 & 39.6 & 0.0000 & 0.0007 & 3.46 & 0.000 & 0.00213 & 0.00000 & 1.13 & 0.000402 & 0.000059 & 0.0000086 \\
\hline 101 & 40.0 & 0.0229 & 0.0177 & 3.08 & 0.004 & 0.01577 & 0.00036 & 1.31 & 0.000479 & 0.000198 & 0.0000094 \\
\hline 102 & 40.4 & 0.0182 & 0.0219 & 10.69 & 1.348 & 0.02665 & 0.00479 & 1.45 & 0.001684 & 0.000155 & 0.0000436 \\
\hline 103 & 40.8 & 0.0001 & 0.0103 & 6.39 & 0.000 & 0.00000 & 0.00000 & 1.28 & 0.000574 & 0.000225 & 0.0000054 \\
\hline 104 & 41.2 & 0.0271 & 0.0342 & 6.56 & 0.027 & 0.00879 & 0.00292 & 1.40 & 0.000443 & 0.000225 & 0.0000000 \\
\hline 105 & 41.6 & 0.0311 & 0.0000 & 1.88 & 0.007 & 0.00459 & 0.00573 & 1.26 & 0.000367 & 0.000137 & 0.0000000 \\
\hline 106 & 42.0 & 0.0088 & 0.0009 & 1.50 & 0.018 & 0.00183 & 0.00089 & 1.33 & 0.000306 & 0.000304 & 0.0000055 \\
\hline 107 & 42.4 & 0.0124 & 0.0248 & 2.58 & 0.014 & 0.00670 & 0.00000 & 1.21 & 0.000395 & 0.000144 & 0.0000002 \\
\hline 108 & 42.8 & 0.0000 & 0.0098 & 1.97 & 0.000 & 0.01635 & 0.01019 & 1.07 & 0.000341 & 0.000195 & 0.0000309 \\
\hline 109 & 43.2 & 0.0000 & 0.0030 & 2.18 & 0.002 & 0.00356 & 0.00795 & 1.28 & 0.000307 & 0.000154 & 0.0000000 \\
\hline 110 & 43.6 & 0.0166 & 0.0000 & 3.51 & 0.005 & 0.00319 & 0.00047 & 1.08 & 0.000365 & 0.000258 & 0.0000000 \\
\hline 111 & 44.0 & 0.0029 & 0.0239 & 6.84 & 0.000 & 0.00557 & 0.00120 & 1.40 & 0.000707 & 0.000328 & 0.0000000 \\
\hline 112 & 44.4 & 0.0000 & 0.0000 & 6.10 & 0.000 & 0.00647 & 0.00380 & 1.39 & 0.001755 & 0.000221 & 0.0000000 \\
\hline 113 & 44.8 & 0.0213 & 0.0038 & 9.61 & 0.004 & 0.02942 & 0.00475 & 1.28 & 0.000507 & 0.000407 & 0.0000086 \\
\hline 114 & 45.2 & 0.0000 & 0.0000 & 17.55 & 0.644 & 0.00251 & 0.00233 & 1.20 & 0.000876 & 0.000395 & 0.0000000 \\
\hline 115 & 45.6 & 0.0104 & 0.0469 & 14.56 & 0.714 & 0.01228 & 0.00588 & 1.35 & 0.002156 & 0.000716 & 0.0000679 \\
\hline 116 & 46.0 & 0.0505 & 0.0429 & 8.62 & 0.007 & 0.00161 & 0.00474 & 1.37 & 0.000489 & 0.000530 & 0.0000000 \\
\hline
\end{tabular}


APPENDIX 5.1f P04A prismatic layer transects data

\begin{tabular}{|c|c|c|c|c|c|c|c|c|c|c|c|}
\hline \multirow{2}{*}{ Spot Number } & \multirow{2}{*}{ Distance from the foot $(\mathrm{mm})$} & \multicolumn{10}{|c|}{ P04A prismatic layer transect corrected data $(\mathrm{mmol} / \mathrm{mol})$} \\
\hline & & $\mathrm{Li} / \mathrm{Ca}$ & $\mathrm{B} / \mathrm{Ca}$ & $\mathrm{Mg} / \mathrm{Ca}$ & $\mathrm{Al} / \mathrm{Ca}$ & $\mathrm{Mn} / \mathrm{Ca}$ & $\mathrm{Zn} / \mathrm{Ca}$ & $\mathrm{Sr} / \mathrm{Ca}$ & $\mathrm{Ba} / \mathrm{Ca}$ & $\mathrm{Pb} / \mathrm{Ca}$ & $\mathrm{U} / \mathrm{Ca}$ \\
\hline 1 & 0.0 & 0.0093 & 0.0111 & 2.26 & 0.003 & 0.00000 & 0.00648 & 1.26 & 0.000274 & 0.000076 & 0.0000054 \\
\hline 2 & 0.4 & 0.0066 & 0.0000 & 2.37 & 0.000 & 0.00000 & 0.00654 & 1.39 & 0.000446 & 0.000156 & 0.0000000 \\
\hline 3 & 0.8 & 0.0087 & 0.0000 & 7.92 & 0.075 & 0.00679 & 0.00779 & 1.17 & 0.000605 & 0.000000 & 0.0000273 \\
\hline 4 & 1.2 & 0.0141 & 0.0000 & 2.53 & 0.002 & 0.00336 & 0.00179 & 1.20 & 0.000306 & 0.000000 & 0.0000000 \\
\hline 5 & 1.6 & 0.0076 & 0.0075 & 3.06 & 0.004 & 0.00000 & 0.00098 & 1.13 & 0.000461 & 0.000186 & 0.0000000 \\
\hline 6 & 2.0 & 0.0194 & 0.0000 & 17.13 & 0.000 & 0.00000 & 0.00038 & 1.48 & 0.000587 & 0.000285 & 0.0000009 \\
\hline 7 & 2.4 & 0.0216 & 0.0000 & 8.97 & 0.000 & 0.00000 & 0.00226 & 1.49 & 0.000395 & 0.000030 & 0.0000000 \\
\hline 8 & 2.8 & 0.0119 & 0.0253 & 18.40 & 0.340 & 0.00547 & 0.00000 & 1.64 & 0.001323 & 0.000000 & 0.0000511 \\
\hline 9 & 3.2 & 0.0090 & 0.0091 & 5.10 & 0.002 & 0.00189 & 0.00366 & 1.44 & 0.000630 & 0.000162 & 0.0000019 \\
\hline 10 & 3.6 & 0.0079 & 0.0000 & 3.37 & 0.029 & 0.00000 & 0.00074 & 1.16 & 0.000378 & 0.000247 & 0.0000000 \\
\hline 11 & 4.0 & 0.0337 & 0.0946 & 18.76 & 4.393 & 0.01479 & 0.00470 & 3.09 & 0.005989 & 0.000047 & 0.0000855 \\
\hline 12 & 4.4 & 0.0237 & 0.0319 & 8.55 & 2.158 & 0.00311 & 0.00507 & 2.25 & 0.002542 & 0.000058 & 0.0000973 \\
\hline 13 & 4.8 & 0.0152 & 0.0052 & 6.18 & 0.047 & 0.00179 & 0.00742 & 1.52 & 0.000755 & 0.000000 & 0.0000108 \\
\hline 14 & 5.2 & 0.0742 & 0.0246 & 12.17 & 7.185 & 0.01496 & 0.00351 & 1.44 & 0.010829 & 0.000060 & 0.0000000 \\
\hline 15 & 5.6 & 0.0112 & 0.0216 & 7.84 & 0.000 & 0.00000 & 0.00204 & 1.22 & 0.000465 & 0.000000 & 0.0000255 \\
\hline 16 & 6.0 & 0.0286 & 0.0351 & 17.08 & 2.836 & 0.01434 & 0.00829 & 1.38 & 0.003450 & 0.000618 & 0.0000552 \\
\hline 17 & 6.4 & 0.0163 & 0.0000 & 14.26 & 0.002 & 0.00220 & 0.00089 & 1.37 & 0.000520 & 0.000009 & 0.0000000 \\
\hline 18 & 6.8 & 0.0202 & 0.0000 & 19.05 & 0.001 & 0.00213 & 0.00000 & 1.13 & 0.000419 & 0.000104 & 0.0000004 \\
\hline 19 & 7.2 & 0.0061 & 0.0626 & 0.90 & 0.002 & 0.00000 & 0.00277 & 2.65 & 0.001052 & 0.000056 & 0.0000000 \\
\hline 20 & 7.6 & 0.0082 & 0.0000 & 8.95 & 0.001 & 0.00038 & 0.00489 & 1.38 & 0.000590 & 0.000128 & 0.0000000 \\
\hline 21 & 8.0 & 0.0070 & 0.0000 & 5.27 & 0.000 & 0.00000 & 0.00465 & 0.98 & 0.000269 & 0.000000 & 0.0000283 \\
\hline 22 & 8.4 & 0.0082 & 0.0037 & 4.52 & 0.003 & 0.00311 & 0.00072 & 1.16 & 0.000385 & 0.000000 & 0.0000000 \\
\hline 23 & 8.8 & 0.0162 & 0.0094 & 3.63 & 0.000 & 0.00000 & 0.00144 & 1.22 & 0.000308 & 0.000000 & 0.0000000 \\
\hline 24 & 9.2 & 0.0080 & 0.0020 & 3.06 & 0.000 & 0.00000 & 0.00646 & 1.22 & 0.000383 & 0.000044 & 0.0000000 \\
\hline 25 & 9.6 & 0.0108 & 0.0174 & 8.04 & 0.000 & 0.00397 & 0.00395 & 1.06 & 0.000340 & 0.000000 & 0.0000014 \\
\hline 26 & 10.0 & 0.0216 & 0.0523 & 14.01 & 0.980 & 0.01713 & 0.01611 & 1.66 & 0.002354 & 0.000094 & 0.0000118 \\
\hline 27 & 10.4 & 0.0109 & 0.0154 & 4.04 & 0.143 & 0.00000 & 0.00803 & 1.42 & 0.000800 & 0.000037 & 0.0000000 \\
\hline 28 & 10.8 & 0.0085 & 0.0193 & 5.17 & 0.001 & 0.00439 & 0.00468 & 1.41 & 0.000415 & 0.000037 & 0.0000115 \\
\hline 29 & 11.2 & 0.0085 & 0.0197 & 3.83 & 0.005 & 0.00000 & 0.00261 & 1.09 & 0.000320 & 0.000078 & 0.0000000 \\
\hline
\end{tabular}




\begin{tabular}{|c|c|c|c|c|c|c|c|c|c|c|c|}
\hline \multirow{2}{*}{ Spot Number } & \multirow{2}{*}{ Distance from the foot $(\mathrm{mm})$} & \multicolumn{10}{|c|}{ P04A prismatic layer transect corrected data $(\mathrm{mmol} / \mathrm{mol})$ continued... } \\
\hline & & $\mathrm{Li} / \mathrm{Ca}$ & $\mathrm{B} / \mathrm{Ca}$ & $\mathrm{Mg} / \mathrm{Ca}$ & $\mathrm{Al} / \mathrm{Ca}$ & $\mathrm{Mn} / \mathrm{Ca}$ & $\mathrm{Zn} / \mathrm{Ca}$ & $\mathrm{Sr} / \mathrm{Ca}$ & $\mathrm{Ba} / \mathrm{Ca}$ & $\mathrm{Pb} / \mathrm{Ca}$ & $\mathrm{U} / \mathbf{C a}$ \\
\hline 30 & 11.6 & 0.0110 & 0.0047 & 7.61 & 0.004 & 0.00083 & 0.00000 & 1.21 & 0.000305 & 0.000010 & 0.0000000 \\
\hline 31 & 12.0 & 0.0060 & 0.0206 & 3.40 & 0.002 & 0.00000 & 0.00225 & 1.19 & 0.000509 & 0.000004 & 0.0000488 \\
\hline 32 & 12.4 & 0.0084 & 0.0095 & 7.03 & 0.011 & 0.00652 & 0.00000 & 1.45 & 0.000797 & 0.000000 & 0.0000272 \\
\hline 33 & 12.8 & 0.0285 & 0.0331 & 31.11 & 0.236 & 0.00967 & 0.00018 & 1.41 & 0.016772 & 0.000000 & 0.0000241 \\
\hline 34 & 13.2 & 0.0255 & 0.0000 & 24.74 & 0.006 & 0.00630 & 0.00290 & 1.22 & 0.000328 & 0.000060 & 0.0000104 \\
\hline 35 & 13.6 & 0.0244 & 0.0923 & 17.06 & 1.242 & 0.02066 & 0.01485 & 3.04 & 0.006289 & 0.000322 & 0.0002370 \\
\hline 36 & 14.0 & 0.0215 & 0.0155 & 6.95 & 0.667 & 0.00715 & 0.00574 & 1.43 & 0.001401 & 0.000119 & 0.0000365 \\
\hline 37 & 14.4 & 0.0160 & 0.0351 & 12.67 & 0.263 & 0.00378 & 0.01083 & 1.53 & 0.000957 & 0.000000 & 0.0000001 \\
\hline 38 & 14.8 & 0.0228 & 0.0149 & 24.09 & 0.143 & 0.00000 & 0.00037 & 1.75 & 0.001422 & 0.000000 & 0.0000570 \\
\hline 39 & 15.2 & 0.0087 & 0.0000 & 2.59 & 0.003 & 0.00000 & 0.00346 & 1.36 & 0.000484 & 0.000000 & 0.0000000 \\
\hline 40 & 15.6 & 0.0093 & 0.0000 & 6.67 & 0.000 & 0.00000 & 0.00325 & 1.46 & 0.000602 & 0.000000 & 0.0000434 \\
\hline 41 & 16.0 & 0.0065 & 0.0000 & 6.38 & 0.000 & 0.00472 & 0.00047 & 1.37 & 0.000472 & 0.000048 & 0.0000122 \\
\hline 42 & 16.4 & 0.0111 & 0.0266 & 7.09 & 0.000 & 0.00072 & 0.00294 & 1.25 & 0.000621 & 0.000130 & 0.0000089 \\
\hline 43 & 16.8 & 0.0069 & 0.0044 & 6.03 & 0.000 & 0.00081 & 0.00691 & 1.25 & 0.000489 & 0.000108 & 0.0000009 \\
\hline 44 & 17.2 & 0.0162 & 0.0283 & 7.16 & 0.720 & 0.00285 & 0.01086 & 1.36 & 0.001630 & 0.000000 & 0.0000254 \\
\hline 45 & 17.6 & 0.0167 & 0.0158 & 11.61 & 0.153 & 0.00440 & 0.00701 & 1.42 & 0.000796 & 0.000000 & 0.0000267 \\
\hline 46 & 18.0 & 0.0165 & 0.0069 & 9.82 & 0.002 & 0.00068 & 0.00000 & 1.41 & 0.000421 & 0.000171 & 0.0000000 \\
\hline 47 & 18.4 & 0.0143 & 0.0212 & 11.12 & 0.005 & 0.00254 & 0.00254 & 1.31 & 0.000570 & 0.000014 & 0.0000259 \\
\hline 48 & 18.8 & 0.0194 & 0.0260 & 19.10 & 0.087 & 0.00161 & 0.00239 & 1.49 & 0.000916 & 0.000000 & 0.0000634 \\
\hline 49 & 19.2 & 0.0406 & 0.0789 & 13.77 & 9.832 & 0.02674 & 0.00288 & 1.29 & 0.016772 & 0.000369 & 0.0004307 \\
\hline 50 & 19.6 & 0.0054 & 0.0017 & 4.32 & 0.015 & 0.01308 & 0.01265 & 1.31 & 0.000577 & 0.000049 & 0.0000000 \\
\hline 51 & 20.0 & 0.0147 & 0.0000 & 15.66 & 0.000 & 0.00000 & 0.00588 & 1.15 & 0.000440 & 0.000000 & 0.0000000 \\
\hline 52 & 20.4 & 0.0123 & 0.0000 & 7.88 & 0.004 & 0.00393 & 0.01104 & 1.03 & 0.000370 & 0.000134 & 0.0000000 \\
\hline 53 & 20.8 & 0.0169 & 0.0000 & 14.67 & 0.028 & 0.00373 & 0.00000 & 1.12 & 0.000615 & 0.000000 & 0.0000255 \\
\hline 54 & 21.2 & 0.0128 & 0.0160 & 3.11 & 0.001 & 0.00094 & 0.00857 & 1.28 & 0.000326 & 0.000069 & 0.0000041 \\
\hline 55 & 21.6 & 0.0031 & 0.0181 & 2.60 & 0.000 & 0.00153 & 0.00055 & 1.09 & 0.000305 & 0.000161 & 0.0000000 \\
\hline 56 & 22.0 & 0.0092 & 0.0247 & 6.64 & 0.003 & 0.00115 & 0.00000 & 1.10 & 0.000155 & 0.000098 & 0.0000107 \\
\hline 57 & 22.4 & 0.0134 & 0.0271 & 6.91 & 0.004 & 0.00044 & 0.00000 & 1.07 & 0.000465 & 0.000018 & 0.0000000 \\
\hline 58 & 22.8 & 0.0051 & 0.0035 & 2.84 & 0.000 & 0.00000 & 0.00103 & 1.08 & 0.000257 & 0.000009 & 0.0000000 \\
\hline 59 & 23.2 & 0.0043 & 0.0008 & 3.69 & 0.001 & 0.00095 & 0.00917 & 1.27 & 0.000241 & 0.000068 & 0.0000000 \\
\hline
\end{tabular}




\begin{tabular}{|c|c|c|c|c|c|c|c|c|c|c|c|}
\hline \multirow{2}{*}{ Spot Number } & \multirow{2}{*}{ Distance from the foot $(\mathrm{mm})$} & \multicolumn{10}{|c|}{ P04A prismatic layer transect corrected data $(\mathrm{mmol} / \mathrm{mol})$ continued... } \\
\hline & & $\mathrm{Li} / \mathrm{Ca}$ & $\mathrm{B} / \mathrm{Ca}$ & $\mathrm{Mg} / \mathrm{Ca}$ & $\mathrm{Al} / \mathrm{Ca}$ & $\mathrm{Mn} / \mathrm{Ca}$ & $\mathrm{Zn} / \mathrm{Ca}$ & $\mathrm{Sr} / \mathrm{Ca}$ & $\mathrm{Ba} / \mathrm{Ca}$ & $\mathrm{Pb} / \mathrm{Ca}$ & $\mathrm{U} / \mathbf{C a}$ \\
\hline 60 & 23.6 & 0.0065 & 0.0000 & 3.11 & 0.004 & 0.00000 & 0.00876 & 1.25 & 0.000346 & 0.000095 & 0.0000005 \\
\hline 61 & 24.0 & 0.0099 & 0.0080 & 3.37 & 0.001 & 0.00000 & 0.00477 & 1.01 & 0.000252 & 0.000044 & 0.0000000 \\
\hline 62 & 24.4 & 0.0068 & 0.0000 & 3.04 & 0.006 & 0.00121 & 0.00609 & 1.27 & 0.000491 & 0.000046 & 0.0000000 \\
\hline 63 & 24.8 & 0.0084 & 0.0000 & 1.81 & 0.000 & 0.00000 & 0.00000 & 1.44 & 0.000226 & 0.000162 & 0.0000000 \\
\hline 64 & 25.2 & 0.0081 & 0.0000 & 2.26 & 0.001 & 0.00223 & 0.00000 & 1.23 & 0.000415 & 0.000000 & 0.0000004 \\
\hline 65 & 25.6 & 0.0090 & 0.0008 & 3.20 & 0.001 & 0.00129 & 0.00568 & 1.11 & 0.000121 & 0.000126 & 0.0000633 \\
\hline 66 & 26.0 & 0.0137 & 0.0231 & 3.44 & 0.000 & 0.00240 & 0.01094 & 1.25 & 0.000415 & 0.000103 & 0.0000000 \\
\hline 67 & 26.4 & 0.0172 & 0.0180 & 3.40 & 0.051 & 0.00670 & 0.02320 & 1.43 & 0.000499 & 0.000070 & 0.0000153 \\
\hline 68 & 26.8 & 0.0089 & 0.0153 & 2.86 & 0.001 & 0.00712 & 0.00244 & 1.15 & 0.000319 & 0.000038 & 0.0000384 \\
\hline 69 & 27.2 & 0.0105 & 0.0201 & 1.61 & 0.008 & 0.00000 & 0.00248 & 1.70 & 0.000444 & 0.000158 & 0.0000019 \\
\hline 70 & 27.6 & 0.0103 & 0.0137 & 2.88 & 0.000 & 0.00126 & 0.00000 & 1.25 & 0.000435 & 0.000105 & 0.0000015 \\
\hline 71 & 28.0 & 0.0173 & 0.0298 & 2.64 & 0.002 & 0.00251 & 0.00000 & 1.22 & 0.000371 & 0.000091 & 0.0000000 \\
\hline 72 & 28.4 & 0.0125 & 0.0000 & 2.86 & 0.009 & 0.00194 & 0.00611 & 1.27 & 0.000475 & 0.000257 & 0.0000315 \\
\hline 73 & 28.8 & 0.0115 & 0.0000 & 3.54 & 0.007 & 0.00000 & 0.01093 & 1.37 & 0.000386 & 0.000137 & 0.0000000 \\
\hline 74 & 29.2 & 0.0091 & 0.0118 & 2.20 & 0.003 & 0.00000 & 0.01129 & 1.25 & 0.000348 & 0.000143 & 0.0000165 \\
\hline 75 & 29.6 & 0.0152 & 0.0081 & 9.71 & 0.001 & 0.00544 & 0.00035 & 1.45 & 0.000549 & 0.000040 & 0.0000759 \\
\hline 76 & 30.0 & 0.0116 & 0.0093 & 8.45 & 0.000 & 0.00202 & 0.00000 & 1.09 & 0.000344 & 0.000000 & 0.0000000 \\
\hline 77 & 30.4 & 0.0128 & 0.0184 & 4.49 & 0.005 & 0.01510 & 0.00685 & 1.35 & 0.000576 & 0.000071 & 0.0000315 \\
\hline 78 & 30.8 & 0.0125 & 0.0153 & 3.20 & 0.000 & 0.00159 & 0.00146 & 1.47 & 0.000220 & 0.000000 & 0.0000450 \\
\hline 79 & 31.2 & 0.0104 & 0.0151 & 3.43 & 0.004 & 0.00234 & 0.00000 & 1.37 & 0.000418 & 0.000000 & 0.0000000 \\
\hline 80 & 31.6 & 0.0135 & 0.0000 & 3.93 & 0.000 & 0.00859 & 0.00795 & 1.30 & 0.000398 & 0.000043 & 0.0000000 \\
\hline 81 & 32.0 & 0.0199 & 0.0000 & 4.31 & 0.002 & 0.01094 & 0.00087 & 1.59 & 0.000482 & 0.000189 & 0.0000236 \\
\hline 82 & 32.4 & 0.0120 & 0.0210 & 2.41 & 0.006 & 0.00000 & 0.00280 & 1.38 & 0.000337 & 0.000014 & 0.0000099 \\
\hline 83 & 32.8 & 0.0126 & 0.0087 & 2.65 & 0.012 & 0.01650 & 0.01546 & 1.26 & 0.000540 & 0.000130 & 0.0000000 \\
\hline 84 & 33.2 & 0.0155 & 0.0101 & 3.17 & 0.008 & 0.00340 & 0.00375 & 1.39 & 0.000416 & 0.000050 & 0.0000000 \\
\hline 85 & 33.6 & 0.0108 & 0.0073 & 3.76 & 0.000 & 0.00000 & 0.00270 & 1.28 & 0.000372 & 0.000030 & 0.0000000 \\
\hline 86 & 34.0 & 0.0116 & 0.0169 & 4.48 & 0.003 & 0.00000 & 0.00058 & 1.30 & 0.000438 & 0.000063 & 0.0000451 \\
\hline 87 & 34.4 & 0.0156 & 0.0041 & 5.67 & 0.038 & 0.00538 & 0.00750 & 1.43 & 0.000987 & 0.000093 & 0.0000258 \\
\hline 88 & 34.8 & 0.0142 & 0.0072 & 3.92 & 0.000 & 0.00393 & 0.00374 & 1.23 & 0.000446 & 0.000000 & 0.0000000 \\
\hline 89 & 35.2 & 0.0143 & 0.0250 & 11.64 & 0.143 & 0.00431 & 0.00478 & 1.53 & 0.000919 & 0.000000 & 0.0000000 \\
\hline
\end{tabular}




\begin{tabular}{|c|c|c|c|c|c|c|c|c|c|c|c|}
\hline \multirow{2}{*}{ Spot Number } & \multirow{2}{*}{ Distance from the foot $(\mathrm{mm})$} & \multicolumn{10}{|c|}{ P04A prismatic layer transect corrected data $(\mathrm{mmol} / \mathrm{mol})$ continued... } \\
\hline & & $\mathrm{Li} / \mathrm{Ca}$ & $\mathrm{B} / \mathrm{Ca}$ & $\mathrm{Mg} / \mathrm{Ca}$ & $\mathrm{Al} / \mathrm{Ca}$ & $\mathrm{Mn} / \mathrm{Ca}$ & $\mathrm{Zn} / \mathrm{Ca}$ & $\mathrm{Sr} / \mathrm{Ca}$ & $\mathrm{Ba} / \mathrm{Ca}$ & $\mathrm{Pb} / \mathrm{Ca}$ & $\mathrm{U} / \mathrm{Ca}$ \\
\hline 90 & 35.6 & 0.0155 & 0.0546 & 14.83 & 0.844 & 0.11925 & 0.28091 & 1.44 & 0.023307 & 0.003946 & 0.0002104 \\
\hline 91 & 36.0 & 0.0230 & 0.0299 & 17.07 & 0.102 & 0.00875 & 0.00000 & 2.00 & 0.001578 & 0.000118 & 0.0001896 \\
\hline 92 & 36.4 & 0.0181 & 0.0658 & 37.26 & 1.105 & 0.00930 & 0.00000 & 1.86 & 0.003000 & 0.000181 & 0.0001222 \\
\hline 93 & 36.8 & 0.0076 & 0.0118 & 4.16 & 0.005 & 0.00503 & 0.00882 & 1.09 & 0.000499 & 0.000198 & 0.0000000 \\
\hline 94 & 37.2 & 0.0000 & 0.0000 & 3.35 & 0.000 & 0.05852 & 0.00000 & 1.35 & 0.003420 & 0.000000 & 0.0000943 \\
\hline 95 & 37.6 & 0.0195 & 0.0190 & 2.68 & 0.001 & 0.00386 & 0.00787 & 1.28 & 0.000355 & 0.000102 & 0.0000000 \\
\hline 96 & 38.0 & 0.0104 & 0.0336 & 4.30 & 0.042 & 0.01683 & 0.06104 & 1.34 & 0.001022 & 0.000135 & 0.0000643 \\
\hline
\end{tabular}


APPENDIX 5.1g $\quad$ SC2 prismatic layer transect data

\begin{tabular}{|c|c|c|c|c|c|c|c|c|c|c|c|}
\hline \multirow{2}{*}{ Spot Number } & \multirow{2}{*}{ Distance from the foot $(\mathrm{mm})$} & \multicolumn{10}{|c|}{ SC2 prismatic layer transect corrected data $(\mathrm{mmol} / \mathrm{mol})$} \\
\hline & & $\mathrm{Li} / \mathrm{Ca}$ & $\mathrm{B} / \mathrm{Ca}$ & $\mathrm{Mg} / \mathrm{Ca}$ & $\mathbf{A l} / \mathbf{C a}$ & $\mathrm{Mn} / \mathrm{Ca}$ & $\mathrm{Zn} / \mathrm{Ca}$ & $\mathrm{Sr} / \mathrm{Ca}$ & $\mathrm{Ba} / \mathrm{Ca}$ & $\mathrm{Pb} / \mathrm{Ca}$ & $\mathrm{U} / \mathrm{Ca}$ \\
\hline 1 & 0.0 & 0.0076 & 0.0144 & 4.12 & 0.0000 & 0.00028 & 0.00000 & 1.31 & 0.000319 & 0.0000000 & 0.0000000 \\
\hline 2 & 0.4 & 0.0113 & 0.0136 & 5.76 & 0.0016 & 0.00000 & 0.00187 & 1.33 & 0.000415 & 0.0000000 & 0.0000120 \\
\hline 3 & 0.8 & 0.0118 & 0.0000 & 6.16 & 0.0000 & 0.00000 & 0.00162 & 1.07 & 0.000366 & 0.0000168 & 0.0000142 \\
\hline 4 & 1.2 & 0.0058 & 0.0334 & 2.50 & 0.0000 & 0.00000 & 0.00025 & 1.25 & 0.000247 & 0.0000000 & 0.0000000 \\
\hline 5 & 1.6 & 0.0118 & 0.0165 & 3.07 & 0.0008 & 0.00233 & 0.00000 & 1.20 & 0.000198 & 0.0000286 & 0.0000211 \\
\hline 6 & 2.0 & 0.0036 & 0.0092 & 3.10 & 0.0000 & 0.00000 & 0.00000 & 1.15 & 0.000330 & 0.0000005 & 0.0000208 \\
\hline 7 & 2.4 & 0.0036 & 0.0079 & 3.55 & 0.0000 & 0.00043 & 0.00183 & 1.17 & 0.000304 & 0.0000559 & 0.0000035 \\
\hline 8 & 2.8 & 0.0133 & 0.0000 & 4.16 & 0.0006 & 0.00197 & 0.00069 & 0.98 & 0.000261 & 0.0000000 & 0.0000132 \\
\hline 9 & 3.2 & 0.0124 & 0.0076 & 3.27 & 0.0039 & 0.00099 & 0.00199 & 0.96 & 0.000186 & 0.0000000 & 0.0000332 \\
\hline 10 & 3.6 & 0.0065 & 0.0506 & 2.82 & 0.0000 & 0.00000 & 0.00002 & 0.98 & 0.000248 & 0.0000458 & 0.0000000 \\
\hline 11 & 4.0 & 0.0055 & 0.0140 & 3.53 & 0.0034 & 0.00000 & 0.00459 & 1.02 & 0.000235 & 0.0000180 & 0.0000000 \\
\hline 12 & 4.4 & 0.0107 & 0.0356 & 4.60 & 0.0000 & 0.00084 & 0.00075 & 1.03 & 0.000342 & 0.0000178 & 0.0000000 \\
\hline 13 & 4.8 & 0.0090 & 0.0000 & 3.56 & 0.0000 & 0.00000 & 0.00000 & 1.08 & 0.000107 & 0.0000535 & 0.0000000 \\
\hline 14 & 5.2 & 0.0133 & 0.0059 & 3.65 & 0.0050 & 0.00095 & 0.00143 & 0.96 & 0.000232 & 0.0000000 & 0.0000075 \\
\hline 15 & 5.6 & 0.0076 & 0.0000 & 4.94 & 0.0000 & 0.00343 & 0.00282 & 1.04 & 0.000197 & 0.0000000 & 0.0000025 \\
\hline 16 & 6.0 & 0.0061 & 0.0000 & 4.44 & 0.0004 & 0.00031 & 0.00000 & 1.01 & 0.000241 & 0.0000140 & 0.0000000 \\
\hline 17 & 6.4 & 0.0144 & 0.0097 & 6.09 & 0.0037 & 0.00110 & 0.00429 & 0.98 & 0.000249 & 0.0000366 & 0.0000000 \\
\hline 18 & 6.8 & 0.0120 & 0.0310 & 4.88 & 0.0000 & 0.00378 & 0.00585 & 1.19 & 0.000303 & 0.0000000 & 0.0000000 \\
\hline 19 & 7.2 & 0.0199 & 0.1198 & 5.35 & 0.2046 & 0.00013 & 0.00000 & 1.47 & 0.000762 & 0.0000000 & 0.0000186 \\
\hline 20 & 7.6 & 0.0111 & 0.0279 & 4.41 & 0.0161 & 0.00380 & 0.00258 & 1.18 & 0.000344 & 0.0000054 & 0.0000101 \\
\hline 21 & 8.0 & 0.0112 & 0.0000 & 6.83 & 0.3584 & 0.00267 & 0.00622 & 1.52 & 0.000663 & 0.0000000 & 0.0000153 \\
\hline 22 & 8.4 & 0.0125 & 0.0000 & 7.98 & 0.0030 & 0.00379 & 0.00472 & 1.38 & 0.000474 & 0.0000386 & 0.0000143 \\
\hline 23 & 8.8 & 0.0112 & 0.0000 & 7.10 & 0.0341 & 0.00152 & 0.00068 & 1.42 & 0.000449 & 0.0000290 & 0.0000108 \\
\hline 24 & 9.2 & 0.0127 & 0.0047 & 9.93 & 0.0000 & 0.00364 & 0.00073 & 1.60 & 0.000562 & 0.0000000 & 0.0000000 \\
\hline 25 & 9.6 & 0.0153 & 0.0000 & 11.98 & 0.0071 & 0.00339 & 0.00000 & 1.33 & 0.000547 & 0.0000181 & 0.0000000 \\
\hline 26 & 10.0 & 0.0083 & 0.0232 & 4.62 & 0.0000 & 0.00151 & 0.00030 & 1.37 & 0.000433 & 0.0000028 & 0.0000000 \\
\hline 27 & 10.4 & 0.0147 & 0.0000 & 7.39 & 0.0003 & 0.00204 & 0.00000 & 1.22 & 0.000485 & 0.0000000 & 0.0000222 \\
\hline 28 & 10.8 & 0.0158 & 0.0113 & 6.39 & 0.0000 & 0.00193 & 0.00000 & 1.14 & 0.000344 & 0.0000332 & 0.0000285 \\
\hline 29 & 11.2 & 0.0103 & 0.0034 & 7.60 & 0.0000 & 0.00077 & 0.00115 & 1.40 & 0.000439 & 0.0000073 & 0.0000145 \\
\hline
\end{tabular}




\begin{tabular}{|c|c|c|c|c|c|c|c|c|c|c|c|}
\hline \multirow{2}{*}{ Spot Number } & \multirow{2}{*}{ Distance from the foot $(\mathrm{mm})$} & \multicolumn{10}{|c|}{$\mathrm{SC} 2$ prismatic layer transect corrected data $(\mathrm{mmol} / \mathrm{mol})$} \\
\hline & & $\mathrm{Li} / \mathrm{Ca}$ & $\mathrm{B} / \mathrm{Ca}$ & $\mathrm{Mg} / \mathrm{Ca}$ & $\mathrm{Al} / \mathrm{Ca}$ & $\mathrm{Mn} / \mathrm{Ca}$ & $\mathrm{Zn} / \mathrm{Ca}$ & $\mathrm{Sr} / \mathrm{Ca}$ & $\mathrm{Ba} / \mathrm{Ca}$ & $\mathrm{Pb} / \mathrm{Ca}$ & $\mathrm{U} / \mathrm{Ca}$ \\
\hline 30 & 11.6 & 0.0112 & 0.0063 & 4.93 & 0.0000 & 0.00241 & 0.00000 & 1.23 & 0.000449 & 0.0000224 & 0.0000000 \\
\hline 31 & 12.0 & 0.0127 & 0.0012 & 8.86 & 0.0000 & 0.00337 & 0.00232 & 1.32 & 0.000525 & 0.0000000 & 0.0000000 \\
\hline 32 & 12.4 & 0.0110 & 0.0000 & 7.27 & 0.0000 & 0.00617 & 0.00000 & 1.16 & 0.000322 & 0.0000000 & 0.0000000 \\
\hline 33 & 12.8 & 0.0062 & 0.0161 & 6.86 & 0.0045 & 0.00000 & 0.00000 & 1.12 & 0.000351 & 0.0000000 & 0.0000016 \\
\hline 34 & 13.2 & 0.0092 & 0.0281 & 10.38 & 0.0000 & 0.00000 & 0.00045 & 1.31 & 0.000299 & 0.0000747 & 0.0000270 \\
\hline 35 & 13.6 & 0.0167 & 0.0203 & 4.84 & 0.0000 & 0.00000 & 0.00000 & 1.16 & 0.000385 & 0.0000000 & 0.0000234 \\
\hline 36 & 14.0 & 0.0158 & 0.0264 & 8.11 & 0.0096 & 0.00246 & 0.00000 & 1.53 & 0.000568 & 0.0000000 & 0.0000013 \\
\hline 37 & 14.4 & 0.0125 & 0.0212 & 4.47 & 0.0045 & 0.00296 & 0.00359 & 1.14 & 0.000321 & 0.0000000 & 0.0000000 \\
\hline 38 & 14.8 & 0.0161 & 0.0000 & 5.66 & 0.0055 & 0.00000 & 0.00261 & 1.35 & 0.000454 & 0.0000146 & 0.0000014 \\
\hline 39 & 15.2 & 0.0130 & 0.0164 & 10.93 & 0.0157 & 0.00135 & 0.00258 & 1.59 & 0.000707 & 0.0000308 & 0.0000184 \\
\hline 40 & 15.6 & 0.0061 & 0.0000 & 3.47 & 0.0044 & 0.00217 & 0.00101 & 1.26 & 0.000351 & 0.0000030 & 0.0000000 \\
\hline 41 & 16.0 & 0.0053 & 0.0000 & 2.75 & 0.0000 & 0.00050 & 0.00000 & 1.27 & 0.000306 & 0.0000233 & 0.0000086 \\
\hline 42 & 16.4 & 0.0100 & 0.0112 & 2.97 & 0.0000 & 0.00000 & 0.00000 & 1.23 & 0.000330 & 0.0000103 & 0.0000000 \\
\hline 43 & 16.8 & 0.0161 & 0.0034 & 9.74 & 0.1482 & 0.00357 & 0.00000 & 1.69 & 0.001124 & 0.0000396 & 0.0000000 \\
\hline 44 & 17.2 & 0.0078 & 0.0285 & 5.49 & 0.0000 & 0.00000 & 0.00026 & 1.12 & 0.000258 & 0.0000114 & 0.0000000 \\
\hline 45 & 17.6 & 0.0119 & 0.0170 & 3.43 & 0.0016 & 0.00219 & 0.00000 & 1.27 & 0.000348 & 0.0000051 & 0.0000000 \\
\hline 46 & 18.0 & 0.0088 & 0.0000 & 5.61 & 0.0000 & 0.00355 & 0.00097 & 1.13 & 0.000340 & 0.0000000 & 0.0000061 \\
\hline 47 & 18.4 & 0.0105 & 0.0000 & 4.42 & 0.0037 & 0.00228 & 0.00104 & 1.14 & 0.000278 & 0.0000377 & 0.0000000 \\
\hline 48 & 18.8 & 0.0076 & 0.0000 & 5.58 & 0.0035 & 0.00299 & 0.00252 & 1.14 & 0.000313 & 0.0000227 & 0.0000000 \\
\hline 49 & 19.2 & 0.0095 & 0.0000 & 4.24 & 0.0038 & 0.00089 & 0.00000 & 1.25 & 0.000231 & 0.0000000 & 0.0000000 \\
\hline 50 & 19.6 & 0.0104 & 0.0097 & 3.83 & 0.0012 & 0.00442 & 0.00224 & 1.46 & 0.000412 & 0.0000000 & 0.0000014 \\
\hline 51 & 20.0 & 0.0081 & 0.0000 & 5.42 & 0.0057 & 0.00277 & 0.00000 & 1.27 & 0.000438 & 0.0000000 & 0.0000132 \\
\hline 52 & 20.4 & 0.0189 & 0.0078 & 9.06 & 0.0000 & 0.00230 & 0.00393 & 1.06 & 0.000364 & 0.0000000 & 0.0000234 \\
\hline 53 & 20.8 & 0.0152 & 0.0000 & 5.57 & 0.0062 & 0.00038 & 0.00237 & 1.28 & 0.000408 & 0.0000000 & 0.0000000 \\
\hline 54 & 21.2 & 0.0135 & 0.0000 & 7.62 & 0.0102 & 0.00160 & 0.00287 & 1.04 & 0.000271 & 0.0000000 & 0.0000126 \\
\hline 55 & 21.6 & 0.0177 & 0.0008 & 7.37 & 0.0000 & 0.00195 & 0.00000 & 1.73 & 0.000703 & 0.0000000 & 0.0000016 \\
\hline 56 & 22.0 & 0.0102 & 0.0000 & 6.29 & 0.0047 & 0.00350 & 0.00000 & 1.13 & 0.000388 & 0.0000197 & 0.0000000 \\
\hline 57 & 22.4 & 0.0064 & 0.0033 & 9.10 & 0.0240 & 0.00174 & 0.00070 & 1.12 & 0.000417 & 0.0000000 & 0.0000000 \\
\hline 58 & 22.8 & 0.0114 & 0.0000 & 9.57 & 0.0001 & 0.00421 & 0.00156 & 1.17 & 0.000396 & 0.0000000 & 0.0000183 \\
\hline 59 & 23.2 & 0.0120 & 0.0212 & 7.67 & 0.0000 & 0.00032 & 0.00378 & 1.09 & 0.000314 & 0.0000000 & 0.0000017 \\
\hline
\end{tabular}




\begin{tabular}{|c|c|c|c|c|c|c|c|c|c|c|c|}
\hline \multirow{2}{*}{ Spot Number } & \multirow{2}{*}{ Distance from the foot $(\mathrm{mm})$} & \multicolumn{10}{|c|}{$\mathrm{SC} 2$ prismatic layer transect corrected data $(\mathrm{mmol} / \mathrm{mol})$} \\
\hline & & $\mathrm{Li} / \mathrm{Ca}$ & $\mathrm{B} / \mathrm{Ca}$ & $\mathrm{Mg} / \mathrm{Ca}$ & $\mathrm{Al} / \mathrm{Ca}$ & $\mathrm{Mn} / \mathrm{Ca}$ & $\mathrm{Zn} / \mathrm{Ca}$ & $\mathrm{Sr} / \mathrm{Ca}$ & $\mathrm{Ba} / \mathrm{Ca}$ & $\mathrm{Pb} / \mathrm{Ca}$ & $\mathrm{U} / \mathrm{Ca}$ \\
\hline 60 & 23.6 & 0.0070 & 0.0169 & 7.57 & 0.0010 & 0.00299 & 0.00000 & 1.09 & 0.000218 & 0.0000000 & 0.0000000 \\
\hline 61 & 24.0 & 0.0126 & 0.0079 & 7.56 & 0.0000 & 0.00330 & 0.00037 & 1.11 & 0.000281 & 0.0000000 & 0.0000160 \\
\hline 62 & 24.4 & 0.0135 & 0.0000 & 7.04 & 0.0000 & 0.00000 & 0.00000 & 1.08 & 0.000173 & 0.0000048 & 0.0000217 \\
\hline 63 & 24.8 & 0.0161 & 0.0258 & 7.00 & 0.0032 & 0.00292 & 0.00478 & 0.93 & 0.000223 & 0.0000173 & 0.0000197 \\
\hline 64 & 25.2 & 0.0071 & 0.0045 & 3.93 & 0.0017 & 0.00294 & 0.00029 & 1.07 & 0.000248 & 0.0000551 & 0.0000008 \\
\hline 65 & 25.6 & 0.0085 & 0.0201 & 2.84 & 0.0000 & 0.00114 & 0.00000 & 1.16 & 0.000282 & 0.0000000 & 0.0000000 \\
\hline 66 & 26.0 & 0.0121 & 0.0000 & 4.38 & 0.0006 & 0.00220 & 0.00324 & 1.08 & 0.000324 & 0.0000005 & 0.0000000 \\
\hline 67 & 26.4 & 0.0083 & 0.0074 & 3.42 & 0.0025 & 0.00370 & 0.00199 & 0.94 & 0.000234 & 0.0000255 & 0.0000000 \\
\hline 68 & 26.8 & 0.0106 & 0.0060 & 4.08 & 0.0010 & 0.00267 & 0.00201 & 1.21 & 0.000342 & 0.0000000 & 0.0000087 \\
\hline 69 & 27.2 & 0.0220 & 0.0179 & 11.28 & 0.0234 & 0.00245 & 0.00375 & 1.71 & 0.001031 & 0.0000027 & 0.0000024 \\
\hline 70 & 27.6 & 0.0099 & 0.0044 & 3.18 & 0.0000 & 0.00210 & 0.00378 & 1.26 & 0.000283 & 0.0000000 & 0.0000000 \\
\hline 71 & 28.0 & 0.0077 & 0.0356 & 4.55 & 0.0000 & 0.00051 & 0.00000 & 1.30 & 0.000340 & 0.0000000 & 0.0000000 \\
\hline 72 & 28.4 & 0.0120 & 0.0017 & 5.05 & 0.0018 & 0.00208 & 0.00440 & 1.32 & 0.000448 & 0.0000000 & 0.0000004 \\
\hline 73 & 28.8 & 0.0084 & 0.0142 & 4.82 & 0.0014 & 0.00330 & 0.00000 & 1.06 & 0.000296 & 0.0000000 & 0.0000000 \\
\hline 74 & 29.2 & 0.0111 & 0.0260 & 4.14 & 0.0018 & 0.00116 & 0.00221 & 1.10 & 0.000355 & 0.0000086 & 0.0000164 \\
\hline 75 & 29.6 & 0.0108 & 0.0000 & 3.45 & 0.0017 & 0.00000 & 0.00000 & 1.03 & 0.000203 & 0.0000000 & 0.0000000 \\
\hline 76 & 30.0 & 0.0096 & 0.0000 & 3.23 & 0.0000 & 0.00225 & 0.00305 & 1.16 & 0.000268 & 0.0000000 & 0.0000000 \\
\hline 77 & 30.4 & 0.0133 & 0.0000 & 4.65 & 0.0037 & 0.00000 & 0.00290 & 1.44 & 0.000353 & 0.0000813 & 0.0000000 \\
\hline 78 & 30.8 & 0.0140 & 0.0146 & 3.45 & 0.0000 & 0.00177 & 0.00000 & 1.34 & 0.000446 & 0.0000000 & 0.0000000 \\
\hline 79 & 31.2 & 0.0095 & 0.0223 & 3.29 & 0.0021 & 0.00034 & 0.00418 & 1.39 & 0.000448 & 0.0000142 & 0.0000089 \\
\hline 80 & 31.6 & 0.0085 & 0.0048 & 2.67 & 0.0010 & 0.00073 & 0.00238 & 1.26 & 0.000209 & 0.0000554 & 0.0000121 \\
\hline 81 & 32.0 & 0.0135 & 0.0159 & 3.01 & 0.0031 & 0.00082 & 0.00252 & 1.37 & 0.000332 & 0.0000000 & 0.0000000 \\
\hline 82 & 32.4 & 0.0127 & 0.0011 & 3.29 & 0.0000 & 0.00106 & 0.00526 & 1.38 & 0.000416 & 0.0000000 & 0.0000000 \\
\hline 83 & 32.8 & 0.0166 & 0.0000 & 3.03 & 0.0003 & 0.00033 & 0.00170 & 1.22 & 0.000262 & 0.0000000 & 0.0000139 \\
\hline 84 & 33.2 & 0.0120 & 0.0000 & 2.92 & 0.0000 & 0.00039 & 0.00000 & 1.10 & 0.000296 & 0.0000263 & 0.0000018 \\
\hline 85 & 33.6 & 0.0174 & 0.0251 & 3.25 & 0.0000 & 0.00307 & 0.00000 & 1.16 & 0.000346 & 0.0000000 & 0.0000254 \\
\hline 86 & 34.0 & 0.0066 & 0.0045 & 3.42 & 0.0000 & 0.00444 & 0.00824 & 1.14 & 0.000421 & 0.0000602 & 0.0000050 \\
\hline 87 & 34.4 & 0.0072 & 0.0047 & 3.30 & 0.0009 & 0.00204 & 0.00117 & 1.14 & 0.000275 & 0.0000511 & 0.0000000 \\
\hline 88 & 34.8 & 0.0068 & 0.0080 & 3.14 & 0.0000 & 0.00178 & 0.00083 & 1.20 & 0.000275 & 0.0000212 & 0.0000000 \\
\hline 89 & 35.2 & 0.0090 & 0.0185 & 4.15 & 0.0063 & 0.00336 & 0.00018 & 1.36 & 0.000411 & 0.0000000 & 0.0000000 \\
\hline
\end{tabular}




\begin{tabular}{|c|c|c|c|c|c|c|c|c|c|c|c|}
\hline \multirow{2}{*}{ Spot Number } & \multirow{2}{*}{ Distance from the foot $(\mathrm{mm})$} & \multicolumn{10}{|c|}{ SC2 prismatic layer transect corrected data $(\mathrm{mmol} / \mathrm{mol})$} \\
\hline & & $\mathrm{Li} / \mathrm{Ca}$ & $\mathrm{B} / \mathrm{Ca}$ & $\mathrm{Mg} / \mathrm{Ca}$ & $\mathrm{Al} / \mathrm{Ca}$ & $\mathrm{Mn} / \mathrm{Ca}$ & $\mathrm{Zn} / \mathrm{Ca}$ & $\mathrm{Sr} / \mathrm{Ca}$ & $\mathrm{Ba} / \mathrm{Ca}$ & $\mathrm{Pb} / \mathrm{Ca}$ & $\mathrm{U} / \mathrm{Ca}$ \\
\hline 90 & 35.6 & 0.0156 & 0.0080 & 8.75 & 0.1076 & 0.00122 & 0.00198 & 1.46 & 0.000839 & 0.0000317 & 0.0000219 \\
\hline 91 & 36.0 & 0.0089 & 0.0000 & 3.80 & 0.0000 & 0.00277 & 0.00000 & 1.21 & 0.000307 & 0.0000000 & 0.0000170 \\
\hline 92 & 36.4 & 0.0075 & 0.0087 & 3.45 & 0.0000 & 0.00264 & 0.00219 & 1.10 & 0.000328 & 0.0000000 & 0.0000000 \\
\hline 93 & 36.8 & 0.0079 & 0.0136 & 3.04 & 0.0019 & 0.00148 & 0.00000 & 1.27 & 0.000380 & 0.0000000 & 0.0000007 \\
\hline 94 & 37.2 & 0.0051 & 0.0047 & 2.76 & 0.0000 & 0.00193 & 0.00000 & 1.01 & 0.000233 & 0.0000000 & 0.0000000 \\
\hline 95 & 37.6 & 0.0113 & 0.0000 & 3.84 & 0.0043 & 0.00000 & 0.00104 & 1.35 & 0.000356 & 0.0000000 & 0.0000000 \\
\hline 96 & 38.0 & 0.0142 & 0.0000 & 4.87 & 0.0000 & 0.00370 & 0.00000 & 1.14 & 0.000300 & 0.0000097 & 0.0000000 \\
\hline 97 & 38.4 & 0.0061 & 0.0000 & 3.25 & 0.0000 & 0.00009 & 0.00271 & 1.24 & 0.000214 & 0.0000000 & 0.0000132 \\
\hline 98 & 38.8 & 0.0076 & 0.0108 & 3.71 & 0.0044 & 0.00407 & 0.00084 & 1.21 & 0.000304 & 0.0000000 & 0.0000011 \\
\hline 99 & 39.2 & 0.0069 & 0.0000 & 3.49 & 0.0000 & 0.00010 & 0.00145 & 1.06 & 0.000199 & 0.0000000 & 0.0000002 \\
\hline 100 & 39.6 & 0.0066 & 0.0000 & 4.16 & 0.0000 & 0.00143 & 0.00340 & 1.13 & 0.000287 & 0.0000000 & 0.0000089 \\
\hline 101 & 40.0 & 0.0138 & 0.0000 & 5.23 & 0.0008 & 0.00126 & 0.00251 & 1.36 & 0.000379 & 0.0000006 & 0.0000000 \\
\hline 102 & 40.4 & 0.0152 & 0.0083 & 7.24 & 0.0005 & 0.00140 & 0.00000 & 1.14 & 0.000275 & 0.0000000 & 0.0000048 \\
\hline 103 & 40.8 & 0.0053 & 0.0107 & 4.77 & 0.0000 & 0.00000 & 0.00182 & 1.03 & 0.000221 & 0.0000000 & 0.0000000 \\
\hline 104 & 41.2 & 0.0144 & 0.0000 & 7.66 & 0.0000 & 0.00139 & 0.00028 & 1.30 & 0.000540 & 0.0000162 & 0.0000248 \\
\hline 105 & 41.6 & 0.0104 & 0.0102 & 8.96 & 0.0000 & 0.00231 & 0.00079 & 1.13 & 0.000406 & 0.0000000 & 0.0000000 \\
\hline 106 & 42.0 & 0.0068 & 0.0109 & 4.55 & 0.0000 & 0.00085 & 0.00065 & 0.99 & 0.000123 & 0.0000056 & 0.0000000 \\
\hline 107 & 42.4 & 0.0060 & 0.0069 & 3.15 & 0.0067 & 0.00203 & 0.00096 & 0.98 & 0.000276 & 0.0000000 & 0.0000000 \\
\hline 108 & 42.8 & 0.0118 & 0.0218 & 4.58 & 0.0000 & 0.00208 & 0.00000 & 1.02 & 0.000293 & 0.0000000 & 0.0000043 \\
\hline 109 & 43.2 & 0.0121 & 0.0261 & 6.38 & 0.0021 & 0.00186 & 0.00000 & 1.10 & 0.000336 & 0.0000000 & 0.0000000 \\
\hline 110 & 43.6 & 0.0068 & 0.0187 & 5.36 & 0.0259 & 0.00427 & 0.00815 & 1.05 & 0.000290 & 0.0001358 & 0.0000000 \\
\hline 111 & 44.0 & 0.0036 & 0.0285 & 4.90 & 0.0000 & 0.00180 & 0.00000 & 1.13 & 0.000264 & 0.0000085 & 0.0000000 \\
\hline 112 & 44.4 & 0.0067 & 0.0000 & 3.37 & 0.0000 & 0.00000 & 0.00166 & 1.12 & 0.000192 & 0.0000000 & 0.0000000 \\
\hline 113 & 44.8 & 0.0101 & 0.0132 & 3.11 & 0.0000 & 0.00330 & 0.00342 & 1.14 & 0.000333 & 0.0000000 & 0.0000095 \\
\hline 114 & 45.2 & 0.0122 & 0.0000 & 3.55 & 0.0004 & 0.00134 & 0.00208 & 1.10 & 0.000235 & 0.0000000 & 0.0000099 \\
\hline 115 & 45.6 & 0.0067 & 0.0250 & 2.58 & 0.0038 & 0.00101 & 0.00344 & 1.09 & 0.000260 & 0.0000000 & 0.0000000 \\
\hline 116 & 46.0 & 0.0099 & 0.0747 & 5.85 & 0.0075 & 0.00146 & 0.00510 & 1.28 & 0.000393 & 0.0000353 & 0.0000000 \\
\hline
\end{tabular}


APPENDIX 5.1h $\quad$ SC1A prismatic layer transect data

\begin{tabular}{|c|c|c|c|c|c|c|c|c|c|c|c|}
\hline \multirow{2}{*}{ Spot Number } & \multirow{2}{*}{ Distance from the foot $(\mathrm{mm})$} & \multicolumn{10}{|c|}{$\mathrm{SC} 1 \mathrm{~A}$ prismatic layer transect corrected data $(\mathrm{mmol} / \mathrm{mol})$} \\
\hline & & $\mathrm{Li} / \mathrm{Ca}$ & $\mathrm{B} / \mathrm{Ca}$ & $\mathrm{Mg} / \mathrm{Ca}$ & $\mathbf{A l} / \mathbf{C a}$ & $\mathrm{Mn} / \mathrm{Ca}$ & $\mathrm{Zn} / \mathrm{Ca}$ & $\mathrm{Sr} 88 / \mathrm{Ca}$ & $\mathrm{Ba} / \mathrm{Ca}$ & $\mathrm{Pb} / \mathrm{Ca}$ & $\mathrm{U} / \mathrm{Ca}$ \\
\hline 1 & 0.0 & 0.0000 & 0.391 & 4.72 & 0.0267 & 0.00159 & 0.01361 & 1.37 & 0.000334 & 0.000000 & 0.0000000 \\
\hline 2 & 0.4 & 0.0109 & 0.043 & 5.53 & 0.0000 & 0.00534 & 0.00000 & 1.37 & 0.000279 & 0.000294 & 0.0000223 \\
\hline 3 & 0.8 & 0.0267 & 0.068 & 2.64 & 0.0052 & 0.00033 & 0.00000 & 1.33 & 0.000000 & 0.000384 & 0.0000013 \\
\hline 4 & 1.2 & 0.0000 & 0.011 & 1.89 & 0.0127 & 0.00225 & 0.00845 & 1.28 & 0.000378 & 0.000248 & 0.0000331 \\
\hline 5 & 1.6 & 0.0000 & 0.000 & 2.36 & 0.0338 & 0.00000 & 0.00142 & 1.18 & 0.000316 & 0.000034 & 0.0000392 \\
\hline 6 & 2.0 & 0.0000 & 0.453 & 2.81 & 0.0000 & 0.00125 & 0.00781 & 1.09 & 0.000109 & 0.000074 & 0.0000000 \\
\hline 7 & 2.4 & 0.0000 & 0.000 & 3.11 & 0.0000 & 0.00056 & 0.00000 & 1.12 & 0.000211 & 0.000000 & 0.0000167 \\
\hline 8 & 2.8 & 0.0633 & 0.000 & 2.88 & 0.0000 & 0.00000 & 0.00000 & 1.12 & 0.000506 & 0.000200 & 0.0000681 \\
\hline 9 & 3.2 & 0.0295 & 0.000 & 2.75 & 0.0000 & 0.00000 & 0.00883 & 1.15 & 0.000368 & 0.000000 & 0.0000000 \\
\hline 10 & 3.6 & 0.0020 & 0.000 & 3.31 & 0.0123 & 0.00082 & 0.00851 & 0.79 & 0.000479 & 0.000038 & 0.0000000 \\
\hline 11 & 4.0 & 0.0881 & 0.000 & 3.75 & 0.0000 & 0.00090 & 0.00796 & 1.40 & 0.000357 & 0.000042 & 0.0000604 \\
\hline 12 & 4.4 & 0.0000 & 0.055 & 2.13 & 0.0142 & 0.00087 & 0.00000 & 1.28 & 0.000206 & 0.000321 & 0.0000000 \\
\hline 13 & 4.8 & 0.0000 & 0.173 & 2.98 & 0.0028 & 0.00000 & 0.00000 & 1.24 & 0.000193 & 0.000000 & 0.0000000 \\
\hline 14 & 5.2 & 0.0000 & 0.000 & 2.84 & 0.0000 & 0.00139 & 0.01192 & 1.39 & 0.000719 & 0.000048 & 0.0000000 \\
\hline 15 & 5.6 & 0.0000 & 0.000 & 1.90 & 0.0010 & 0.00000 & 0.00000 & 1.27 & 0.000178 & 0.000008 & 0.0000436 \\
\hline 16 & 6.0 & 0.0000 & 0.019 & 2.17 & 0.0000 & 0.00110 & 0.01224 & 1.36 & 0.000241 & 0.000000 & 0.0000616 \\
\hline 17 & 6.4 & 0.0903 & 0.133 & 2.86 & 0.0000 & 0.00000 & 0.00406 & 1.51 & 0.000461 & 0.000117 & 0.0000293 \\
\hline 18 & 6.8 & 0.0000 & 0.000 & 3.46 & 0.0500 & 0.00167 & 0.00379 & 1.42 & 0.000217 & 0.000014 & 0.0000562 \\
\hline 19 & 7.2 & 0.0000 & 0.329 & 4.32 & 0.0047 & 0.00000 & 0.00000 & 1.29 & 0.000407 & 0.000000 & 0.0000000 \\
\hline 20 & 7.6 & 0.0000 & 0.000 & 1.54 & 0.0000 & 0.00214 & 0.00342 & 1.39 & 0.000627 & 0.000171 & 0.0000017 \\
\hline 21 & 8.0 & 0.0999 & 0.361 & 1.98 & 0.0000 & 0.00251 & 0.00000 & 4.29 & 0.002339 & 0.000181 & 0.0004285 \\
\hline 22 & 8.4 & 0.0000 & 0.000 & 2.83 & 0.0228 & 0.00029 & 0.00415 & 1.46 & 0.000788 & 0.000432 & 0.0000000 \\
\hline 23 & 8.8 & 0.0000 & 0.000 & 8.17 & 0.0000 & 0.00000 & 0.00563 & 1.63 & 0.000224 & 0.000385 & 0.0000000 \\
\hline 24 & 9.2 & 0.0000 & 0.000 & 2.48 & 0.0393 & 0.00000 & 0.01319 & 1.50 & 0.000179 & 0.000109 & 0.0000000 \\
\hline 25 & 9.6 & 0.0000 & 0.059 & 3.14 & 0.0000 & 0.00289 & 0.00413 & 1.36 & 0.000415 & 0.000149 & 0.0000000 \\
\hline 26 & 10.0 & 0.1358 & 0.019 & 4.77 & 0.0144 & 0.00243 & 0.00843 & 1.48 & 0.000305 & 0.000451 & 0.0000000 \\
\hline 27 & 10.4 & 0.0134 & 0.000 & 2.49 & 0.0000 & 0.00000 & 0.00856 & 1.23 & 0.000648 & 0.000180 & 0.0000044 \\
\hline 28 & 10.8 & 0.0000 & 0.262 & 1.83 & 0.0000 & 0.00186 & 0.00626 & 1.29 & 0.000358 & 0.000317 & 0.0000000 \\
\hline 29 & 11.2 & 0.2136 & 0.081 & 2.22 & 0.0000 & 0.00021 & 0.00000 & 1.46 & 0.000157 & 0.000000 & 0.0000054 \\
\hline
\end{tabular}




\begin{tabular}{|c|c|c|c|c|c|c|c|c|c|c|c|}
\hline \multirow{2}{*}{$\begin{array}{c}\text { Spot } \\
\text { Number }\end{array}$} & \multirow{2}{*}{$\begin{array}{l}\text { Distance } \\
\text { from the } \\
\text { foot (mm) }\end{array}$} & \multicolumn{10}{|c|}{ SC1A prismatic layer transect corrected data $(\mathrm{mmol} / \mathrm{mol})$} \\
\hline & & $\mathrm{Li} / \mathrm{Ca}$ & $\mathrm{B} / \mathrm{Ca}$ & $\mathrm{Mg} / \mathrm{Ca}$ & $\mathrm{Al} / \mathrm{Ca}$ & $\mathrm{Mn} / \mathrm{Ca}$ & $\mathrm{Zn} / \mathrm{Ca}$ & Sr88/Ca & $\mathrm{Ba} / \mathrm{Ca}$ & $\mathrm{Pb} / \mathrm{Ca}$ & $\mathrm{U} / \mathrm{Ca}$ \\
\hline 30 & 11.6 & 0.0088 & 0.020 & 2.73 & 0.0543 & 0.00039 & 0.01494 & 1.28 & 0.000475 & 0.000259 & 0.0000443 \\
\hline 31 & 12.0 & 0.0000 & 0.002 & 2.57 & 0.0000 & 0.00000 & 0.00696 & 1.13 & 0.000321 & 0.000000 & 0.0000000 \\
\hline 32 & 12.4 & 0.0000 & 0.000 & 2.19 & 0.0000 & 0.00373 & 0.00514 & 1.11 & 0.000279 & 0.000360 & 0.0000190 \\
\hline 33 & 12.8 & 0.0125 & 0.000 & 1.78 & 0.0000 & 0.00232 & 0.00355 & 1.12 & 0.000410 & 0.000181 & 0.0000000 \\
\hline 34 & 13.2 & 0.0000 & 0.148 & 3.79 & 0.0000 & 0.00216 & 0.00546 & 1.25 & 0.000215 & 0.000000 & 0.0000260 \\
\hline 35 & 13.6 & 0.0000 & 0.048 & 3.42 & 0.0000 & 0.00000 & 0.00000 & 1.21 & 0.000543 & 0.000287 & 0.0000582 \\
\hline 36 & 14.0 & 0.0000 & 0.000 & 4.32 & 0.0000 & 0.00405 & 0.00430 & 0.95 & 0.000332 & 0.000232 & 0.0000000 \\
\hline 37 & 14.4 & 0.0538 & 0.006 & 7.24 & 0.0000 & 0.00297 & 0.00000 & 1.23 & 0.000295 & 0.000503 & 0.0000000 \\
\hline 38 & 14.8 & 0.1219 & 0.000 & 7.20 & 0.0685 & 0.00347 & 0.01090 & 1.35 & 0.000497 & 0.000039 & 0.0000657 \\
\hline 39 & 15.2 & 0.2489 & 0.000 & 1.67 & 0.0000 & 0.00151 & 0.00000 & 1.15 & 0.000280 & 0.000110 & 0.0000358 \\
\hline 40 & 15.6 & 0.1005 & 0.245 & 2.34 & 0.0412 & 0.00349 & 0.00000 & 1.17 & 0.000390 & 0.000325 & 0.0000244 \\
\hline 41 & 16.0 & 0.0000 & 0.252 & 4.56 & 0.0047 & 0.00389 & 0.00388 & 1.31 & 0.000427 & 0.000291 & 0.0000054 \\
\hline 42 & 16.4 & 0.0695 & 0.004 & 7.16 & 0.2629 & 0.00480 & 0.00865 & 1.41 & 0.001175 & 0.000147 & 0.0000002 \\
\hline 43 & 16.8 & 0.0000 & 0.000 & 3.77 & 0.0000 & 0.00297 & 0.00594 & 1.30 & 0.000236 & 0.000213 & 0.0000000 \\
\hline 44 & 17.2 & 0.0000 & 0.000 & 3.07 & 0.0268 & 0.00102 & 0.01551 & 1.37 & 0.000162 & 0.000642 & 0.0000016 \\
\hline 45 & 17.6 & 0.0898 & 0.000 & 2.06 & 0.0000 & 0.00000 & 0.01485 & 1.34 & 0.000243 & 0.000244 & 0.0000000 \\
\hline 46 & 18.0 & 0.1062 & 0.059 & 4.51 & 0.0950 & 0.00180 & 0.00504 & 1.40 & 0.000345 & 0.000376 & 0.0000203 \\
\hline 47 & 18.4 & 0.1011 & 0.150 & 4.08 & 0.0000 & 0.00106 & 0.00000 & 1.51 & 0.000271 & 0.000166 & 0.0000553 \\
\hline 48 & 18.8 & 0.1980 & 0.263 & 2.29 & 0.0524 & 0.00000 & 0.00323 & 1.40 & 0.000559 & 0.000400 & 0.0000000 \\
\hline 49 & 19.2 & 0.0000 & 0.000 & 2.78 & 0.0000 & 0.00159 & 0.00000 & 1.34 & 0.000316 & 0.000432 & 0.0000000 \\
\hline 50 & 19.6 & 0.0000 & 0.115 & 3.76 & 0.0000 & 0.00241 & 0.00913 & 1.39 & 0.000228 & 0.000066 & 0.0000000 \\
\hline 51 & 20.0 & 0.0000 & 0.000 & 2.19 & 0.0000 & 0.00372 & 0.00000 & 1.33 & 0.000000 & 0.000121 & 0.0000047 \\
\hline 52 & 20.4 & 0.0060 & 0.000 & 3.32 & 0.0000 & 0.00297 & 0.02030 & 1.27 & 0.000393 & 0.000162 & 0.0000000 \\
\hline 53 & 20.8 & 0.0000 & 0.000 & 5.97 & 0.0000 & 0.00123 & 0.00000 & 1.39 & 0.000101 & 0.000643 & 0.0000633 \\
\hline 54 & 21.2 & 0.0000 & 0.000 & 2.62 & 0.0000 & 0.00000 & 0.01689 & 1.28 & 0.000932 & 0.000337 & 0.0000334 \\
\hline 55 & 21.6 & 0.0000 & 0.000 & 2.93 & 0.0005 & 0.00201 & 0.00000 & 1.32 & 0.000358 & 0.000537 & 0.0000000 \\
\hline 56 & 22.0 & 0.0761 & 0.141 & 2.80 & 0.0138 & 0.00000 & 0.00807 & 1.63 & 0.000677 & 0.000495 & 0.0000035 \\
\hline 57 & 22.4 & 0.0000 & 0.111 & 4.58 & 0.0000 & 0.00097 & 0.01290 & 1.57 & 0.000415 & 0.000227 & 0.0000463 \\
\hline 58 & 22.8 & 0.0298 & 0.000 & 5.42 & 0.0890 & 0.00000 & 0.00272 & 1.38 & 0.000316 & 0.000369 & 0.0000187 \\
\hline 59 & 23.2 & 0.0992 & 0.108 & 6.06 & 0.0238 & 0.00000 & 0.00868 & 1.68 & 0.000676 & 0.000215 & 0.0000000 \\
\hline
\end{tabular}




\begin{tabular}{|c|c|c|c|c|c|c|c|c|c|c|c|}
\hline \multirow{2}{*}{$\begin{array}{c}\text { Spot } \\
\text { Number }\end{array}$} & \multirow{2}{*}{$\begin{array}{l}\text { Distance } \\
\text { from the } \\
\text { foot (mm) }\end{array}$} & \multicolumn{10}{|c|}{ SC1A prismatic layer transect corrected data $(\mathrm{mmol} / \mathrm{mol})$} \\
\hline & & $\mathrm{Li} / \mathrm{Ca}$ & $\mathrm{B} / \mathrm{Ca}$ & $\mathrm{Mg} / \mathrm{Ca}$ & $\mathrm{Al} / \mathrm{Ca}$ & $\mathrm{Mn} / \mathrm{Ca}$ & $\mathrm{Zn} / \mathrm{Ca}$ & Sr88/Ca & $\mathrm{Ba} / \mathrm{Ca}$ & $\mathrm{Pb} / \mathrm{Ca}$ & $\mathrm{U} / \mathrm{Ca}$ \\
\hline 60 & 23.6 & 0.0613 & 0.131 & 3.58 & 0.0263 & 0.00231 & 0.01840 & 1.49 & 0.000454 & 0.000000 & 0.0000271 \\
\hline 61 & 24.0 & 0.0000 & 0.229 & 4.51 & 0.0000 & 0.00000 & 0.02950 & 1.52 & 0.000648 & 0.000000 & 0.0000017 \\
\hline 62 & 24.4 & 0.0153 & 0.039 & 3.96 & 0.0169 & 0.00245 & 0.00000 & 1.43 & 0.000553 & 0.000094 & 0.0000093 \\
\hline 63 & 24.8 & 0.0000 & 0.024 & 3.98 & 0.0000 & 0.00000 & 0.00582 & 1.61 & 0.000492 & 0.000046 & 0.0000646 \\
\hline 64 & 25.2 & 0.0000 & 0.297 & 2.98 & 0.0000 & 0.00304 & 0.00714 & 1.29 & 0.000447 & 0.000304 & 0.0000567 \\
\hline 65 & 25.6 & 0.0000 & 0.020 & 3.06 & 0.0000 & 0.00026 & 0.00000 & 1.57 & 0.000659 & 0.000175 & 0.0001278 \\
\hline 66 & 26.0 & 0.0341 & 0.151 & 4.05 & 0.0139 & 0.00250 & 0.01120 & 1.44 & 0.000512 & 0.000078 & 0.0000000 \\
\hline 67 & 26.4 & 0.0396 & 0.000 & 3.18 & 0.0256 & 0.00256 & 0.00519 & 1.47 & 0.000300 & 0.000175 & 0.0000000 \\
\hline 68 & 26.8 & 0.0424 & 0.000 & 2.05 & 0.0511 & 0.00235 & 0.00000 & 1.31 & 0.000358 & 0.000181 & 0.0000000 \\
\hline 69 & 27.2 & 0.0000 & 0.109 & 3.34 & 0.0698 & 0.00192 & 0.00546 & 1.44 & 0.000057 & 0.000547 & 0.0000522 \\
\hline 70 & 27.6 & 0.0000 & 0.133 & 2.64 & 0.0000 & 0.00066 & 0.00846 & 1.30 & 0.000234 & 0.000640 & 0.0000000 \\
\hline 71 & 28.0 & 0.0672 & 0.000 & 2.93 & 0.0000 & 0.00050 & 0.00362 & 1.36 & 0.000016 & 0.000259 & 0.0000489 \\
\hline 72 & 28.4 & 0.0000 & 0.045 & 2.58 & 0.0000 & 0.00000 & 0.00000 & 1.15 & 0.000544 & 0.000089 & 0.0000078 \\
\hline 73 & 28.8 & 0.0000 & 0.290 & 2.57 & 0.0776 & 0.00245 & 0.00597 & 1.30 & 0.000399 & 0.000355 & 0.0000000 \\
\hline 74 & 29.2 & 0.1236 & 0.000 & 2.99 & 0.0656 & 0.00000 & 0.01267 & 1.19 & 0.000650 & 0.000365 & 0.0000000 \\
\hline 75 & 29.6 & 0.2374 & 0.068 & 2.40 & 0.0717 & 0.00684 & 0.00413 & 1.24 & 0.000354 & 0.000353 & 0.0000525 \\
\hline 76 & 30.0 & 0.0596 & 0.106 & 3.46 & 0.0000 & 0.00000 & 0.00452 & 1.27 & 0.000211 & 0.000204 & 0.0000000 \\
\hline 77 & 30.4 & 0.0229 & 0.099 & 2.74 & 0.0393 & 0.00000 & 0.00000 & 1.18 & 0.000191 & 0.000544 & 0.0000000 \\
\hline 78 & 30.8 & 0.1799 & 0.288 & 2.91 & 0.0000 & 0.00455 & 0.00077 & 1.32 & 0.000608 & 0.000228 & 0.0000332 \\
\hline 79 & 31.2 & 0.0000 & 0.000 & 3.14 & 0.0000 & 0.00317 & 0.01124 & 1.21 & 0.000347 & 0.000634 & 0.0000164 \\
\hline 80 & 31.6 & 0.0000 & 0.000 & 4.32 & 1.4457 & 0.00000 & 0.00973 & 1.56 & 0.000551 & 0.000869 & 0.0000125 \\
\hline 81 & 32.0 & 0.0398 & 0.485 & 3.04 & 0.0335 & 0.00482 & 0.01463 & 1.36 & 0.000324 & 0.000550 & 0.0000060 \\
\hline 82 & 32.4 & 0.1113 & 0.000 & 2.57 & 0.0000 & 0.00427 & 0.00000 & 1.38 & 0.000730 & 0.000412 & 0.0000000 \\
\hline 83 & 32.8 & 0.0146 & 0.217 & 7.58 & 0.0749 & 0.00394 & 0.03356 & 1.60 & 0.000852 & 0.000243 & 0.0000066 \\
\hline 84 & 33.2 & 0.0299 & 0.000 & 3.96 & 0.0520 & 0.00099 & 0.00658 & 1.60 & 0.000597 & 0.000310 & 0.0000410 \\
\hline 85 & 33.6 & 0.0030 & 0.168 & 3.42 & 0.0000 & 0.00000 & 0.00137 & 1.53 & 0.000223 & 0.000137 & 0.0000000 \\
\hline 86 & 34.0 & 0.0000 & 0.000 & 3.92 & 0.0252 & 0.00311 & 0.00000 & 1.23 & 0.000388 & 0.000166 & 0.0000000 \\
\hline 87 & 34.4 & 0.0713 & 0.000 & 2.63 & 0.0000 & 0.00000 & 0.01375 & 1.33 & 0.000226 & 0.000349 & 0.0000067 \\
\hline 88 & 34.8 & 0.0000 & 0.039 & 7.39 & 0.0000 & 0.00105 & 0.00178 & 1.67 & 0.000397 & 0.000390 & 0.0000114 \\
\hline 89 & 35.2 & 0.0000 & 0.000 & 9.75 & 0.0512 & 0.00265 & 0.00000 & 1.87 & 0.000388 & 0.000249 & 0.0000227 \\
\hline
\end{tabular}




\begin{tabular}{|c|c|c|c|c|c|c|c|c|c|c|c|}
\hline \multirow{2}{*}{$\begin{array}{c}\text { Spot } \\
\text { Number }\end{array}$} & \multirow{2}{*}{$\begin{array}{l}\text { Distance } \\
\text { from the } \\
\text { foot (mm) }\end{array}$} & \multicolumn{10}{|c|}{ SC1A prismatic layer transect corrected data $(\mathrm{mmol} / \mathrm{mol})$} \\
\hline & & $\mathrm{Li} / \mathrm{Ca}$ & $\mathrm{B} / \mathrm{Ca}$ & $\mathrm{Mg} / \mathrm{Ca}$ & $\mathrm{Al} / \mathrm{Ca}$ & $\mathrm{Mn} / \mathrm{Ca}$ & $\mathrm{Zn} / \mathrm{Ca}$ & $\mathrm{Sr} 88 / \mathrm{Ca}$ & $\mathrm{Ba} / \mathrm{Ca}$ & $\mathrm{Pb} / \mathrm{Ca}$ & $\mathrm{U} / \mathrm{Ca}$ \\
\hline 90 & 35.6 & 0.0000 & 0.110 & 3.82 & 0.0378 & 0.00110 & 0.00000 & 1.61 & 0.000307 & 0.000000 & 0.0000654 \\
\hline 91 & 36.0 & 0.0000 & 0.183 & 2.91 & 0.0294 & 0.00199 & 0.00803 & 1.43 & 0.000050 & 0.000095 & 0.0000000 \\
\hline 92 & 36.4 & 0.0000 & 0.004 & 5.14 & 0.9345 & 0.00484 & 0.01078 & 1.64 & 0.002793 & 0.000032 & 0.0000000 \\
\hline 93 & 36.8 & 0.0625 & 0.140 & 4.94 & 0.0219 & 0.00044 & 0.00000 & 1.64 & 0.000386 & 0.000295 & 0.0000000 \\
\hline 94 & 37.2 & 0.0000 & 0.022 & 8.16 & 0.0000 & 0.00000 & 0.00761 & 1.73 & 0.000396 & 0.000070 & 0.0000125 \\
\hline 95 & 37.6 & 0.1394 & 0.040 & 2.88 & 0.0000 & 0.00341 & 0.00494 & 1.46 & 0.000762 & 0.000279 & 0.0000598 \\
\hline 96 & 38.0 & 0.1434 & 0.000 & 3.16 & 0.0000 & 0.00000 & 0.00252 & 1.33 & 0.000447 & 0.000444 & 0.0000928 \\
\hline 97 & 38.4 & 0.2065 & 0.000 & 4.83 & 0.0000 & 0.00203 & 0.00000 & 1.36 & 0.000486 & 0.000330 & 0.0000000 \\
\hline 98 & 38.8 & 0.0832 & 0.300 & 4.39 & 0.0758 & 0.00041 & 0.01732 & 1.40 & 0.000489 & 0.000323 & 0.0000000 \\
\hline 99 & 39.2 & 0.2083 & 0.111 & 17.13 & 0.0000 & 0.00179 & 0.00003 & 1.46 & 0.000423 & 0.000025 & 0.0000000 \\
\hline
\end{tabular}


APPENDIX 5.1i MP02A prismatic layer transect data

\begin{tabular}{|c|c|c|c|c|c|c|c|c|c|c|c|}
\hline \multirow{2}{*}{ Spot Number } & \multirow{2}{*}{ Distance from the foot (mm) } & \multicolumn{10}{|c|}{ MP02A prismatic layer transect corrected data $(\mathrm{mmol} / \mathrm{mol})$} \\
\hline & & $\mathrm{Li} / \mathrm{Ca}$ & $\mathrm{B} / \mathrm{Ca}$ & $\mathrm{Mg} / \mathrm{Ca}$ & $\mathrm{Al} / \mathrm{Ca}$ & $\mathrm{Mn} / \mathrm{Ca}$ & $\mathrm{Zn} / \mathrm{Ca}$ & $\mathrm{Sr} / \mathrm{Ca}$ & $\mathrm{Ba} / \mathrm{Ca}$ & $\mathrm{Pb} / \mathrm{Ca}$ & $\mathrm{U} / \mathrm{Ca}$ \\
\hline 1 & 0.0 & 0.0462 & 0.0316 & 5.96 & 0.050 & 0.00000 & 0.0000 & 1.38 & 0.00039 & 0.000000 & 0.0000902 \\
\hline 2 & 0.4 & 0.0115 & 0.0000 & 7.71 & 0.016 & 0.00152 & 0.0246 & 1.25 & 0.00057 & 0.000154 & 0.0000000 \\
\hline 3 & 0.8 & 0.0331 & 0.0696 & 21.27 & 0.120 & 0.00118 & 0.0000 & 2.30 & 0.00106 & 0.000031 & 0.0002184 \\
\hline 4 & 1.2 & 0.0727 & 0.0504 & 16.33 & 2.906 & 0.00484 & 0.0033 & 2.39 & 0.00423 & 0.000076 & 0.0002492 \\
\hline 5 & 1.6 & 0.0000 & 0.0474 & 9.89 & 0.049 & 0.00000 & 0.0048 & 1.46 & 0.00043 & 0.000000 & 0.0000652 \\
\hline 6 & 2.0 & 0.0196 & 0.0000 & 8.66 & 0.000 & 0.00338 & 0.0048 & 1.24 & 0.00051 & 0.000122 & 0.0000967 \\
\hline 7 & 2.4 & 0.0231 & 0.0250 & 15.85 & 1.737 & 0.01111 & 0.0000 & 1.24 & 0.00165 & 0.000084 & 0.0000000 \\
\hline 8 & 2.8 & 0.0711 & 0.0800 & 6.54 & 0.392 & 0.00000 & 0.0027 & 1.44 & 0.00089 & 0.000326 & 0.0000426 \\
\hline 9 & 3.2 & 0.0088 & 0.0245 & 9.38 & 0.316 & 0.00680 & 0.0129 & 1.61 & 0.00125 & 0.000121 & 0.0000526 \\
\hline 10 & 3.6 & 0.0766 & 0.0870 & 15.56 & 19.871 & 0.06430 & 0.0256 & 1.53 & 0.01620 & 0.000616 & 0.0001179 \\
\hline 11 & 4.0 & 0.0416 & 0.1183 & 10.37 & 1.033 & 0.00167 & 0.0009 & 1.69 & 0.00415 & 0.000000 & 0.0000739 \\
\hline 12 & 4.4 & 0.0000 & 0.1017 & 8.89 & 0.000 & 0.00186 & 0.0022 & 1.08 & 0.00043 & 0.000028 & 0.0000000 \\
\hline 13 & 4.8 & 0.0516 & 0.0000 & 22.98 & 0.000 & 0.00000 & 0.0000 & 1.22 & 0.00065 & 0.000026 & 0.0000760 \\
\hline 14 & 5.2 & 0.0681 & 0.0504 & 6.28 & 0.046 & 0.00990 & 0.0034 & 1.31 & 0.00045 & 0.000046 & 0.0000000 \\
\hline 15 & 5.6 & 0.0000 & 0.0000 & 6.29 & 0.020 & 0.00226 & 0.0000 & 1.23 & 0.00020 & 0.000000 & 0.0000125 \\
\hline 16 & 6.0 & 0.0235 & 0.0820 & 11.54 & 0.834 & 0.01171 & 0.0024 & 1.51 & 0.00230 & 0.000152 & 0.0000435 \\
\hline 17 & 6.4 & 0.0084 & 0.0699 & 14.66 & 2.397 & 0.03937 & 0.0153 & 1.50 & 0.00273 & 0.000625 & 0.0000000 \\
\hline 18 & 6.8 & 0.0244 & 0.0333 & 4.84 & 0.000 & 0.00000 & 0.0000 & 1.41 & 0.00038 & 0.000242 & 0.0000000 \\
\hline 19 & 7.2 & 0.0047 & 0.0000 & 7.14 & 0.052 & 0.00341 & 0.0101 & 1.40 & 0.00042 & 0.000159 & 0.0000000 \\
\hline 20 & 7.6 & 0.0713 & 0.0017 & 9.76 & 0.058 & 0.00125 & 0.0090 & 1.48 & 0.00082 & 0.000005 & 0.0000000 \\
\hline 21 & 8.0 & 0.0016 & 0.0162 & 4.15 & 0.021 & 0.00000 & 0.0015 & 1.38 & 0.00051 & 0.000000 & 0.0000031 \\
\hline 22 & 8.4 & 0.0000 & 0.0222 & 2.30 & 0.007 & 0.00000 & 0.0158 & 1.19 & 0.00019 & 0.000000 & 0.0000320 \\
\hline 23 & 8.8 & 0.0000 & 0.0220 & 4.86 & 0.000 & 0.00092 & 0.0000 & 1.27 & 0.00050 & 0.000122 & 0.0000000 \\
\hline 24 & 9.2 & 0.0196 & 0.0230 & 4.35 & 0.335 & 0.00000 & 0.0000 & 1.33 & 0.00082 & 0.000000 & 0.0000000 \\
\hline 25 & 9.6 & 0.0000 & 0.0046 & 4.89 & 0.000 & 0.00357 & 0.0000 & 1.20 & 0.00032 & 0.000000 & 0.0000000 \\
\hline 26 & 10.0 & 0.0401 & 0.0138 & 3.91 & 0.011 & 0.00575 & 0.0000 & 1.14 & 0.00028 & 0.000107 & 0.0000798 \\
\hline 27 & 10.4 & 0.0571 & 0.0403 & 4.72 & 0.002 & 0.00000 & 0.0120 & 1.21 & 0.00039 & 0.000095 & 0.0000000 \\
\hline 28 & 10.8 & 0.0000 & 0.0128 & 3.79 & 0.000 & 0.00000 & 0.0000 & 1.13 & 0.00047 & 0.000022 & 0.0000002 \\
\hline 29 & 11.2 & 0.0644 & 0.0000 & 4.66 & 0.015 & 0.00187 & 0.0041 & 1.18 & 0.00027 & 0.000075 & 0.0000000 \\
\hline
\end{tabular}




\begin{tabular}{|c|c|c|c|c|c|c|c|c|c|c|c|}
\hline \multirow{2}{*}{$\begin{array}{c}\text { Spot } \\
\text { Number }\end{array}$} & \multirow{2}{*}{ Distance from the foot $(\mathrm{mm})$} & \multicolumn{10}{|c|}{ MP02A prismatic layer transect corrected data $(\mathrm{mmol} / \mathrm{mol})$ continued... } \\
\hline & & $\mathrm{Li} / \mathrm{Ca}$ & $\mathrm{B} / \mathrm{Ca}$ & $\mathrm{Mg} / \mathrm{Ca}$ & $\mathrm{Al} / \mathrm{Ca}$ & $\mathrm{Mn} / \mathrm{Ca}$ & $\mathrm{Zn} / \mathrm{Ca}$ & $\mathrm{Sr} / \mathrm{Ca}$ & $\mathrm{Ba} / \mathrm{Ca}$ & $\mathrm{Pb} / \mathrm{Ca}$ & $\mathrm{U} / \mathrm{Ca}$ \\
\hline 30 & 11.6 & 0.0323 & 0.0000 & 2.18 & 0.000 & 0.00268 & 0.0008 & 1.14 & 0.00019 & 0.000000 & 0.0000000 \\
\hline 31 & 12.0 & 0.0000 & 0.0014 & 2.24 & 0.000 & 0.00336 & 0.0007 & 1.18 & 0.00017 & 0.000034 & 0.0000430 \\
\hline 32 & 12.4 & 0.0299 & 0.0551 & 4.75 & 0.013 & 0.00155 & 0.0000 & 1.34 & 0.00040 & 0.000047 & 0.0000066 \\
\hline 33 & 12.8 & 0.0193 & 0.0000 & 5.24 & 0.041 & 0.00686 & 0.0032 & 1.44 & 0.00026 & 0.000060 & 0.0000172 \\
\hline 34 & 13.2 & 0.0513 & 0.0384 & 10.03 & 0.001 & 0.00000 & 0.0034 & 1.30 & 0.00025 & 0.000316 & 0.0000078 \\
\hline 35 & 13.6 & 0.0055 & 0.0000 & 9.75 & 0.080 & 0.00000 & 0.0081 & 1.29 & 0.00052 & 0.000000 & 0.0000000 \\
\hline 36 & 14.0 & 0.0318 & 0.0000 & 12.47 & 0.000 & 0.00170 & 0.0013 & 1.37 & 0.00057 & 0.000001 & 0.0000000 \\
\hline 38 & 14.8 & 0.0000 & 0.0000 & 5.82 & 0.580 & 0.00630 & 0.0017 & 1.17 & 0.00066 & 0.000100 & 0.0000483 \\
\hline 39 & 15.2 & 0.0192 & 0.0176 & 15.20 & 0.015 & 0.00470 & 0.0033 & 1.56 & 0.00055 & 0.000036 & 0.0000293 \\
\hline 40 & 15.6 & 0.0000 & 0.0000 & 5.74 & 0.221 & 0.35373 & 0.0000 & 1.50 & 0.00072 & 0.015897 & 0.0004891 \\
\hline 41 & 16.0 & 0.0194 & 0.0343 & 5.01 & 0.003 & 0.00432 & 0.0029 & 1.06 & 0.00029 & 0.000044 & 0.0000198 \\
\hline 42 & 16.4 & 0.0514 & 0.0232 & 9.69 & 0.164 & 0.01940 & 0.0000 & 2.64 & 0.00235 & 0.000034 & 0.0002422 \\
\hline 43 & 16.8 & 0.0085 & 0.0236 & 3.87 & 0.000 & 0.00614 & 0.0034 & 1.43 & 0.00059 & 0.000000 & 0.0000000 \\
\hline 44 & 17.2 & 0.0218 & 0.0000 & 4.65 & 0.040 & 0.00251 & 0.0000 & 0.94 & 0.00027 & 0.000000 & 0.0000000 \\
\hline 45 & 17.6 & 0.0512 & 0.0149 & 5.87 & 0.000 & 0.00621 & 0.0000 & 1.25 & 0.00042 & 0.000000 & 0.0000000 \\
\hline 46 & 18.0 & 0.0000 & 0.0297 & 8.13 & 0.013 & 0.03702 & 0.0038 & 1.27 & 0.00077 & 0.000148 & 0.0000283 \\
\hline 48 & 18.8 & 0.0042 & 0.0056 & 3.76 & 0.000 & 0.02933 & 0.0055 & 1.09 & 0.00051 & 0.000225 & 0.0000000 \\
\hline 49 & 19.2 & 0.0321 & 0.0157 & 2.41 & 0.036 & 0.00936 & 0.0015 & 1.29 & 0.00033 & 0.000000 & 0.0000000 \\
\hline 50 & 19.6 & 0.0000 & 0.0000 & 2.26 & 0.012 & 0.01729 & 0.0165 & 1.09 & 0.00119 & 0.000116 & 0.0000263 \\
\hline 51 & 20.0 & 0.0000 & 0.0171 & 2.13 & 0.000 & 0.00000 & 0.0000 & 1.00 & 0.00012 & 0.000092 & 0.0000470 \\
\hline 52 & 20.4 & 0.0000 & 0.0347 & 2.02 & 0.021 & 0.01035 & 0.0045 & 1.07 & 0.00027 & 0.000078 & 0.0000213 \\
\hline 53 & 20.8 & 0.0367 & 0.0866 & 15.30 & 0.000 & 0.01264 & 0.0013 & 1.68 & 0.00083 & 0.000190 & 0.0000186 \\
\hline 54 & 21.2 & 0.0181 & 0.0398 & 12.49 & 0.028 & 0.00512 & 0.0099 & 1.21 & 0.00037 & 0.000018 & 0.0000232 \\
\hline 55 & 21.6 & 0.0454 & 0.0000 & 5.55 & 0.000 & 0.00592 & 0.0046 & 1.36 & 0.00039 & 0.000000 & 0.0000000 \\
\hline 56 & 22.0 & 0.0045 & 0.0000 & 3.24 & 0.000 & 0.02014 & 0.0217 & 1.25 & 0.00036 & 0.000055 & 0.0000000 \\
\hline 57 & 22.4 & 0.0052 & 0.0000 & 10.08 & 0.000 & 0.00126 & 0.0132 & 1.41 & 0.00069 & 0.000000 & 0.0000220 \\
\hline 58 & 22.8 & 0.0241 & 0.0686 & 2.72 & 0.044 & 0.00973 & 0.0096 & 1.21 & 0.00082 & 0.000114 & 0.0002164 \\
\hline 59 & 23.2 & 0.0302 & 0.0000 & 6.02 & 0.280 & 0.00000 & 0.0031 & 1.32 & 0.00064 & 0.000072 & 0.0000110 \\
\hline
\end{tabular}




\begin{tabular}{|c|c|c|c|c|c|c|c|c|c|c|c|}
\hline \multirow{2}{*}{ Spot Number } & \multirow{2}{*}{ Distance from the foot $(\mathrm{mm})$} & \multicolumn{10}{|c|}{ MP02A prismatic layer transect corrected data $(\mathrm{mmol} / \mathrm{mol})$ continued... } \\
\hline & & $\mathrm{Li} / \mathrm{Ca}$ & $\mathrm{B} / \mathrm{Ca}$ & $\mathrm{Mg} / \mathrm{Ca}$ & $\mathbf{A l} / \mathbf{C a}$ & $\mathrm{Mn} / \mathrm{Ca}$ & $\mathrm{Zn} / \mathrm{Ca}$ & $\mathrm{Sr} / \mathrm{Ca}$ & $\mathrm{Ba} / \mathrm{Ca}$ & $\mathrm{Pb} / \mathrm{Ca}$ & $\mathrm{U} / \mathrm{Ca}$ \\
\hline 60 & 23.6 & 0.0886 & 0.0000 & 3.14 & 0.000 & 0.01188 & 0.0038 & 1.30 & 0.00036 & 0.000097 & 0.0000000 \\
\hline 61 & 24.0 & 0.0371 & 0.0000 & 2.56 & 0.000 & 0.02282 & 0.0226 & 1.43 & 0.00047 & 0.000205 & 0.0000000 \\
\hline 62 & 24.4 & 0.0271 & 0.0000 & 8.39 & 0.021 & 0.00476 & 0.0000 & 1.39 & 0.00040 & 0.000250 & 0.0000328 \\
\hline 63 & 24.8 & 0.0076 & 0.0459 & 2.88 & 0.000 & 0.05752 & 0.0000 & 1.35 & 0.00066 & 0.000197 & 0.0000490 \\
\hline 64 & 25.2 & 0.0132 & 0.0000 & 9.54 & 0.000 & 0.00000 & 0.0053 & 1.44 & 0.00026 & 0.000060 & 0.0000190 \\
\hline 65 & 25.6 & 0.0023 & 0.0046 & 6.92 & 0.000 & 0.01585 & 0.0010 & 1.37 & 0.00045 & 0.000000 & 0.0000217 \\
\hline 66 & 26.0 & 0.0489 & 0.0422 & 4.53 & 1.262 & 0.00129 & 0.0041 & 1.17 & 0.00119 & 0.000007 & 0.0000388 \\
\hline 67 & 26.4 & 0.0000 & 0.0000 & 5.07 & 0.000 & 0.00000 & 0.0000 & 0.90 & 0.00025 & 0.000049 & 0.0000000 \\
\hline 68 & 26.8 & 0.0089 & 0.0000 & 6.89 & 0.001 & 0.00000 & 0.0000 & 0.82 & 0.00023 & 0.000000 & 0.0000000 \\
\hline 69 & 27.2 & 0.0145 & 0.0000 & 3.27 & 0.000 & 0.00118 & 0.0059 & 1.11 & 0.00047 & 0.000124 & 0.0000341 \\
\hline 70 & 27.6 & 0.0173 & 0.0063 & 2.94 & 0.000 & 0.00446 & 0.0000 & 1.08 & 0.00032 & 0.000000 & 0.0000045 \\
\hline 71 & 28.0 & 0.0000 & 0.0000 & 2.70 & 0.000 & 0.00123 & 0.0042 & 1.08 & 0.00027 & 0.000000 & 0.0000063 \\
\hline 72 & 28.4 & 0.0214 & 0.0014 & 2.07 & 0.000 & 0.00028 & 0.0022 & 1.16 & 0.00032 & 0.000000 & 0.0000000 \\
\hline 73 & 28.8 & 0.0399 & 0.0546 & 3.60 & 0.007 & 0.00457 & 0.0120 & 1.14 & 0.00020 & 0.000060 & 0.0000000 \\
\hline 74 & 29.2 & 0.0243 & 0.0048 & 2.90 & 0.021 & 0.00157 & 0.0012 & 1.16 & 0.00033 & 0.000028 & 0.0000290 \\
\hline 75 & 29.6 & 0.0113 & 0.0000 & 3.37 & 0.014 & 0.02452 & 0.0069 & 1.31 & 0.00075 & 0.000123 & 0.0000196 \\
\hline 76 & 30.0 & 0.0088 & 0.0034 & 3.65 & 0.002 & 0.03970 & 0.0034 & 1.31 & 0.00098 & 0.000211 & 0.0000004 \\
\hline 77 & 30.4 & 0.0055 & 0.0142 & 3.50 & 0.001 & 0.01040 & 0.0024 & 1.34 & 0.00042 & 0.000021 & 0.0000061 \\
\hline 78 & 30.8 & 0.0069 & 0.0122 & 4.16 & 0.000 & 0.00445 & 0.0000 & 1.17 & 0.00038 & 0.000009 & 0.0000070 \\
\hline 79 & 31.2 & 0.0047 & 0.0059 & 2.45 & 0.000 & 0.02625 & 0.0020 & 1.21 & 0.00041 & 0.000048 & 0.0000112 \\
\hline 80 & 31.6 & 0.0092 & 0.0052 & 2.68 & 0.001 & 0.00921 & 0.0004 & 1.24 & 0.00034 & 0.000005 & 0.0000054 \\
\hline 81 & 32.0 & 0.0086 & 0.0052 & 3.43 & 0.000 & 0.01071 & 0.0005 & 1.30 & 0.00038 & 0.000002 & 0.0000050 \\
\hline 82 & 32.4 & 0.0000 & 0.0000 & 3.76 & 0.000 & 0.01955 & 0.0067 & 1.11 & 0.00064 & 0.000000 & 0.0000000 \\
\hline 83 & 32.8 & 0.0169 & 0.0000 & 2.91 & 0.000 & 0.00981 & 0.0000 & 1.20 & 0.00034 & 0.000000 & 0.0000000 \\
\hline 84 & 33.2 & 0.0050 & 0.0197 & 3.97 & 0.017 & 0.00154 & 0.0000 & 1.16 & 0.00036 & 0.000000 & 0.0000051 \\
\hline 85 & 33.6 & 0.0000 & 0.0000 & 3.32 & 0.009 & 0.02676 & 0.0131 & 1.32 & 0.00025 & 0.000138 & 0.0000000 \\
\hline 86 & 34.0 & 0.0173 & 0.0000 & 5.13 & 0.000 & 0.02055 & 0.0079 & 1.33 & 0.00046 & 0.000100 & 0.0000267 \\
\hline 87 & 34.4 & 0.0000 & 0.0000 & 2.71 & 0.000 & 0.00000 & 0.0059 & 1.27 & 0.00031 & 0.000138 & 0.0000000 \\
\hline 88 & 34.8 & 0.0000 & 0.0000 & 2.33 & 0.000 & 0.00024 & 0.0092 & 1.22 & 0.00000 & 0.000000 & 0.0000000 \\
\hline 89 & 35.2 & 0.0000 & 0.0106 & 2.80 & 0.000 & 0.00261 & 0.0000 & 1.14 & 0.00020 & 0.000000 & 0.0000000 \\
\hline
\end{tabular}




\begin{tabular}{|c|c|c|c|c|c|c|c|c|c|c|c|}
\hline \multirow{2}{*}{ Spot Number } & \multirow{2}{*}{ Distance from the foot $(\mathrm{mm})$} & \multicolumn{10}{|c|}{ MP02A prismatic layer transect corrected data $(\mathrm{mmol} / \mathrm{mol})$ continued... } \\
\hline & & $\mathrm{Li} / \mathrm{Ca}$ & $\mathrm{B} / \mathrm{Ca}$ & $\mathrm{Mg} / \mathrm{Ca}$ & $\mathbf{A l} / \mathbf{C a}$ & $\mathrm{Mn} / \mathrm{Ca}$ & $\mathrm{Zn} / \mathrm{Ca}$ & $\mathrm{Sr} / \mathrm{Ca}$ & $\mathrm{Ba} / \mathrm{Ca}$ & $\mathrm{Pb} / \mathrm{Ca}$ & $\mathrm{U} / \mathrm{Ca}$ \\
\hline 90 & 35.6 & 0.0212 & 0.0682 & 1.35 & 0.047 & 0.05381 & 0.0052 & 2.62 & 0.00262 & 0.000111 & 0.0002542 \\
\hline 91 & 36.0 & 0.0548 & 0.0162 & 4.78 & 0.010 & 0.00323 & 0.0093 & 0.99 & 0.00024 & 0.000000 & 0.0000624 \\
\hline 92 & 36.4 & 0.0489 & 0.0234 & 2.61 & 0.000 & 0.01158 & 0.0046 & 1.15 & 0.00055 & 0.000000 & 0.0000000 \\
\hline 93 & 36.8 & 0.0000 & 0.0584 & 2.10 & 0.000 & 0.00619 & 0.0117 & 1.20 & 0.00031 & 0.000037 & 0.0000087 \\
\hline 94 & 37.2 & 0.0000 & 0.0248 & 2.67 & 0.000 & 0.01867 & 0.0000 & 1.07 & 0.00000 & 0.000026 & 0.0000000 \\
\hline 95 & 37.6 & 0.0264 & 0.0075 & 4.61 & 0.019 & 0.03240 & 0.0000 & 1.40 & 0.00048 & 0.000089 & 0.0000098 \\
\hline 96 & 38.0 & 0.0000 & 0.0187 & 3.74 & 0.035 & 0.01047 & 0.0000 & 1.12 & 0.00022 & 0.000076 & 0.0000000 \\
\hline 97 & 38.4 & 0.0078 & 0.0000 & 2.56 & 0.017 & 0.00216 & 0.0000 & 1.25 & 0.00024 & 0.000233 & 0.0000000 \\
\hline 98 & 38.8 & 0.0000 & 0.0086 & 12.16 & 0.066 & 0.00912 & 0.0075 & 1.50 & 0.00082 & 0.000000 & 0.0000000 \\
\hline 99 & 39.2 & 0.0000 & 0.0254 & 7.50 & 0.044 & 0.00874 & 0.0021 & 1.56 & 0.00041 & 0.000198 & 0.0000000 \\
\hline 100 & 39.6 & 0.0000 & 0.0520 & 2.73 & 0.000 & 0.00348 & 0.0030 & 1.46 & 0.00026 & 0.000019 & 0.0000000 \\
\hline 101 & 40.0 & 0.0198 & 0.0037 & 5.78 & 0.000 & 0.01727 & 0.0000 & 1.26 & 0.00031 & 0.000032 & 0.0000000 \\
\hline 102 & 40.4 & 0.0182 & 0.0000 & 3.51 & 0.005 & 0.01540 & 0.0025 & 1.73 & 0.00053 & 0.000148 & 0.0000000 \\
\hline 103 & 40.8 & 0.0211 & 0.0013 & 2.99 & 0.025 & 0.00755 & 0.0001 & 1.41 & 0.00038 & 0.000027 & 0.0000297 \\
\hline 104 & 41.2 & 0.0178 & 0.0000 & 1.76 & 0.007 & 0.00460 & 0.0053 & 1.38 & 0.00034 & 0.000000 & 0.0000000 \\
\hline 105 & 41.6 & 0.0000 & 0.0135 & 1.86 & 0.000 & 0.00475 & 0.0002 & 1.22 & 0.00028 & 0.000000 & 0.0000000 \\
\hline 106 & 42.0 & 0.0075 & 0.0174 & 2.08 & 0.009 & 0.00100 & 0.0022 & 1.20 & 0.00024 & 0.000000 & 0.0000000 \\
\hline 107 & 42.4 & 0.0000 & 0.0000 & 3.19 & 0.000 & 0.01170 & 0.0000 & 1.09 & 0.00028 & 0.000000 & 0.0000126 \\
\hline 108 & 42.8 & 0.0000 & 0.0106 & 3.29 & 0.023 & 0.00459 & 0.0000 & 1.19 & 0.00056 & 0.000000 & 0.0000000 \\
\hline 109 & 43.2 & 0.0000 & 0.0000 & 3.22 & 0.011 & 0.01270 & 0.0039 & 1.23 & 0.00044 & 0.000018 & 0.0000787 \\
\hline 110 & 43.6 & 0.0000 & 0.0143 & 2.09 & 0.002 & 0.00537 & 0.0007 & 1.28 & 0.00036 & 0.000066 & 0.0000048 \\
\hline 111 & 44.0 & 0.0000 & 0.0305 & 15.12 & 0.214 & 0.00075 & 0.0000 & 1.42 & 0.00072 & 0.000000 & 0.0000000 \\
\hline 112 & 44.4 & 0.0158 & 0.0177 & 14.15 & 11.205 & 0.09814 & 0.0209 & 1.47 & 0.01338 & 0.000539 & 0.0000000 \\
\hline 113 & 44.8 & 0.0030 & 0.0148 & 2.91 & 0.000 & 0.00209 & 0.0012 & 1.14 & 0.00032 & 0.000035 & 0.0000144 \\
\hline 114 & 45.2 & 0.0112 & 0.0362 & 9.34 & 3.120 & 0.00936 & 0.0024 & 1.37 & 0.00265 & 0.000247 & 0.0000117 \\
\hline 115 & 45.6 & 0.0136 & 0.0273 & 6.68 & 0.165 & 0.00000 & 0.0000 & 1.10 & 0.00058 & 0.000037 & 0.0000000 \\
\hline 116 & 46.0 & 0.0150 & 0.0000 & 10.95 & 0.065 & 0.01308 & 0.0107 & 1.50 & 0.00099 & 0.000000 & 0.0000221 \\
\hline
\end{tabular}


APPENDIX 5.1j KD1B prismatic layer transect data

\begin{tabular}{|c|c|c|c|c|c|c|c|c|c|c|c|}
\hline \multirow{2}{*}{ Spot Number } & \multirow{2}{*}{ Distance from the foot $(\mathrm{mm})$} & \multicolumn{10}{|c|}{ KD1B prismatic layer transect corrected data $(\mathrm{mmol} / \mathrm{mol})$} \\
\hline & & $\mathrm{Li} / \mathrm{Ca}$ & $\mathrm{B} / \mathrm{Ca}$ & $\mathrm{Mg} / \mathrm{Ca}$ & $\mathrm{Al} / \mathrm{Ca}$ & $\mathrm{Mn} / \mathrm{Ca}$ & $\mathrm{Zn} / \mathrm{Ca}$ & $\mathrm{Sr} 8 / \mathrm{Ca}$ & $\mathrm{Ba} / \mathrm{Ca}$ & $\mathrm{Pb} / \mathrm{Ca}$ & $\mathrm{U} / \mathbf{C a}$ \\
\hline 1 & 0.0 & 0.0102 & 0.0549 & 11.60 & 0.3835 & 0.00000 & 0.00000 & 1.72 & 0.001184 & 0.0000000 & 0.0000000 \\
\hline 2 & 0.4 & 0.0000 & 0.0006 & 14.74 & 0.0175 & 0.00000 & 0.00329 & 1.29 & 0.000657 & 0.0000183 & 0.0000000 \\
\hline 3 & 0.8 & 0.0213 & 0.0576 & 12.23 & 5.6329 & 0.02065 & 0.00000 & 1.19 & 0.007106 & 0.0000554 & 0.0000454 \\
\hline 4 & 1.2 & 0.0185 & 0.0000 & 3.40 & 0.0000 & 0.00000 & 0.00000 & 1.17 & 0.000436 & 0.0000000 & 0.0000352 \\
\hline 5 & 1.6 & 0.0009 & 0.0000 & 4.65 & 0.0000 & 0.00000 & 0.00548 & 0.94 & 0.000335 & 0.0000000 & 0.0000167 \\
\hline 6 & 2.0 & 0.0072 & 0.0019 & 7.29 & 0.0046 & 0.00095 & 0.00769 & 1.25 & 0.001169 & 0.0000000 & 0.0000017 \\
\hline 7 & 2.4 & 0.0225 & 0.0151 & 6.96 & 0.0000 & 0.00259 & 0.00287 & 1.19 & 0.000730 & 0.0001188 & 0.0000000 \\
\hline 8 & 2.8 & 0.0078 & 0.0000 & 5.91 & 0.0002 & 0.00098 & 0.00000 & 1.36 & 0.000680 & 0.0000493 & 0.0000139 \\
\hline 9 & 3.2 & 0.0000 & 0.0284 & 1.84 & 0.0078 & 0.00000 & 0.00710 & 1.32 & 0.000480 & 0.0000000 & 0.0000197 \\
\hline 10 & 3.6 & 0.0000 & 0.0365 & 4.85 & 0.0000 & 0.00064 & 0.00111 & 1.21 & 0.000474 & 0.0001135 & 0.0000013 \\
\hline 11 & 4.0 & 0.0191 & 0.0000 & 2.76 & 0.0032 & 0.00134 & 0.00000 & 1.15 & 0.000389 & 0.0000000 & 0.0000055 \\
\hline 12 & 4.4 & 0.0009 & 0.0255 & 3.71 & 0.0050 & 0.00000 & 0.00000 & 1.20 & 0.000426 & 0.0000000 & 0.0000182 \\
\hline 13 & 4.8 & 0.0129 & 0.0160 & 4.15 & 0.0055 & 0.00091 & 0.00000 & 1.28 & 0.000444 & 0.0000151 & 0.0000026 \\
\hline 14 & 5.2 & 0.0307 & 0.0000 & 6.97 & 0.0010 & 0.00000 & 0.00149 & 1.06 & 0.000376 & 0.0000000 & 0.0000205 \\
\hline 15 & 5.6 & 0.0253 & 0.0015 & 9.61 & 0.0017 & 0.00000 & 0.00376 & 1.06 & 0.000310 & 0.0000000 & 0.0000000 \\
\hline 16 & 6.0 & 0.0069 & 0.0000 & 7.59 & 0.0000 & 0.00042 & 0.00509 & 1.25 & 0.000552 & 0.0000455 & 0.0000128 \\
\hline 17 & 6.4 & 0.0235 & 0.0000 & 5.60 & 0.0000 & 0.00178 & 0.00520 & 1.44 & 0.000598 & 0.0000300 & 0.0000000 \\
\hline 18 & 6.8 & 0.0225 & 0.0000 & 13.90 & 0.0055 & 0.00188 & 0.00106 & 1.42 & 0.000467 & 0.0000000 & 0.0000080 \\
\hline 19 & 7.2 & 0.0242 & 0.0090 & 6.38 & 0.0067 & 0.00461 & 0.00248 & 1.32 & 0.000534 & 0.0000000 & 0.0000216 \\
\hline 20 & 7.6 & 0.0077 & 0.0305 & 3.67 & 0.0000 & 0.00076 & 0.00240 & 1.23 & 0.000508 & 0.0000122 & 0.0000000 \\
\hline 21 & 8.0 & 0.0186 & 0.0313 & 14.01 & 0.1789 & 0.00306 & 0.00000 & 1.62 & 0.001004 & 0.0001004 & 0.0000107 \\
\hline 22 & 8.4 & 0.0151 & 0.1780 & 5.35 & 0.1858 & 0.00444 & 0.00710 & 4.41 & 0.004161 & 0.0000890 & 0.0004747 \\
\hline 23 & 8.8 & 0.0000 & 0.0392 & 12.42 & 0.0059 & 0.00008 & 0.01019 & 1.55 & 0.000654 & 0.0000144 & 0.0000000 \\
\hline 24 & 9.2 & 0.0275 & 0.0200 & 3.47 & 0.0000 & 0.00000 & 0.00060 & 1.28 & 0.000406 & 0.0000000 & 0.0000000 \\
\hline 25 & 9.6 & 0.0111 & 0.0000 & 2.49 & 0.0032 & 0.00272 & 0.00000 & 1.03 & 0.000343 & 0.0000509 & 0.0000146 \\
\hline 26 & 10.0 & 0.0000 & 0.0000 & 2.82 & 0.0000 & 0.00101 & 0.00078 & 1.00 & 0.000335 & 0.0000000 & 0.0000000 \\
\hline 27 & 10.4 & 0.0117 & 0.0000 & 3.21 & 0.0033 & 0.00000 & 0.00000 & 0.91 & 0.000237 & 0.0000000 & 0.0000000 \\
\hline 28 & 10.8 & 0.0000 & 0.0204 & 2.74 & 0.0000 & 0.00380 & 0.00506 & 1.06 & 0.000405 & 0.0000196 & 0.0000000 \\
\hline 29 & 11.2 & 0.0000 & 0.0183 & 2.35 & 0.0000 & 0.00150 & 0.00721 & 1.20 & 0.000343 & 0.0001198 & 0.0000000 \\
\hline
\end{tabular}




\begin{tabular}{|c|c|c|c|c|c|c|c|c|c|c|c|}
\hline \multirow{2}{*}{ Spot Number } & \multirow{2}{*}{ Distance from the foot $(\mathrm{mm})$} & \multicolumn{10}{|c|}{ KD1B prismatic layer transect corrected data $(\mathrm{mmol} / \mathrm{mol})$ continued... } \\
\hline & & $\mathrm{Li} / \mathrm{Ca}$ & $\mathrm{B} / \mathrm{Ca}$ & $\mathrm{Mg} / \mathrm{Ca}$ & $\mathrm{Al} / \mathrm{Ca}$ & $\mathrm{Mn} / \mathrm{Ca}$ & $\mathrm{Zn} / \mathrm{Ca}$ & $\mathrm{Sr} 8 / \mathrm{Ca}$ & $\mathrm{Ba} / \mathrm{Ca}$ & $\mathrm{Pb} / \mathrm{Ca}$ & $\mathrm{U} / \mathbf{C a}$ \\
\hline 30 & 11.6 & 0.0100 & 0.0316 & 7.25 & 0.0058 & 0.00103 & 0.00488 & 1.34 & 0.000622 & 0.0000583 & 0.0000000 \\
\hline 31 & 12.0 & 0.0150 & 0.0325 & 2.32 & 0.0072 & 0.00134 & 0.00428 & 1.17 & 0.000474 & 0.0000000 & 0.0000064 \\
\hline 32 & 12.4 & 0.0251 & 0.0227 & 2.04 & 0.0000 & 0.00604 & 0.00477 & 1.14 & 0.000251 & 0.0000112 & 0.0000000 \\
\hline 33 & 12.8 & 0.0123 & 0.0081 & 3.11 & 0.0014 & 0.00056 & 0.00220 & 0.96 & 0.000323 & 0.0000000 & 0.0000113 \\
\hline 34 & 13.2 & 0.0000 & 0.0000 & 3.47 & 0.0000 & 0.00077 & 0.00144 & 1.30 & 0.000343 & 0.0000000 & 0.0000000 \\
\hline 35 & 13.6 & 0.0311 & 0.0107 & 3.94 & 0.0001 & 0.00259 & 0.00217 & 1.27 & 0.000449 & 0.0001274 & 0.0000000 \\
\hline 36 & 14.0 & 0.0190 & 0.0254 & 2.44 & 0.0000 & 0.00126 & 0.00204 & 0.99 & 0.000265 & 0.0001024 & 0.0000000 \\
\hline 37 & 14.4 & 0.0099 & 0.0173 & 2.24 & 0.0008 & 0.00273 & 0.00000 & 1.13 & 0.000361 & 0.0000306 & 0.0000000 \\
\hline 38 & 14.8 & 0.0389 & 0.0520 & 5.39 & 0.0005 & 0.00376 & 0.00178 & 1.46 & 0.000527 & 0.0000000 & 0.0000186 \\
\hline 39 & 15.2 & 0.0215 & 0.0215 & 5.62 & 0.0068 & 0.00279 & 0.00193 & 1.26 & 0.000357 & 0.0000166 & 0.0000000 \\
\hline 40 & 15.6 & 0.0089 & 0.0000 & 6.89 & 0.0096 & 0.00000 & 0.00000 & 1.33 & 0.000458 & 0.0000755 & 0.0000194 \\
\hline 41 & 16.0 & 0.0136 & 0.0248 & 4.76 & 0.0032 & 0.00193 & 0.00156 & 1.14 & 0.000396 & 0.0000153 & 0.0000060 \\
\hline 42 & 16.4 & 0.0097 & 0.0273 & 4.22 & 0.0000 & 0.00221 & 0.00000 & 1.10 & 0.000624 & 0.0000000 & 0.0000000 \\
\hline 43 & 16.8 & 0.0447 & 0.0377 & 16.70 & 8.9357 & 0.04311 & 0.01063 & 1.33 & 0.010851 & 0.0001414 & 0.0000282 \\
\hline 44 & 17.2 & 0.0000 & 0.0120 & 5.33 & 0.0000 & 0.00233 & 0.00000 & 1.03 & 0.000319 & 0.0000182 & 0.0000000 \\
\hline 45 & 17.6 & 0.0230 & 0.0083 & 6.02 & 0.0018 & 0.00007 & 0.00109 & 1.04 & 0.000500 & 0.0000366 & 0.0000042 \\
\hline 46 & 18.0 & 0.0056 & 0.0000 & 5.40 & 0.0000 & 0.00104 & 0.00494 & 0.97 & 0.000348 & 0.0000298 & 0.0000047 \\
\hline 47 & 18.4 & 0.0136 & 0.0093 & 4.45 & 0.0017 & 0.00195 & 0.00774 & 1.27 & 0.000399 & 0.0000099 & 0.0000239 \\
\hline 48 & 18.8 & 0.0000 & 0.0305 & 5.30 & 0.0000 & 0.00375 & 0.00065 & 1.27 & 0.000465 & 0.0000213 & 0.0000124 \\
\hline 49 & 19.2 & 0.0003 & 0.0163 & 11.91 & 0.0506 & 0.00628 & 0.00000 & 1.32 & 0.000834 & 0.0000000 & 0.0000000 \\
\hline 50 & 19.6 & 0.0317 & 0.0249 & 9.32 & 0.4056 & 0.00156 & 0.00364 & 1.40 & 0.001401 & 0.0000876 & 0.0000150 \\
\hline 51 & 20.0 & 0.0333 & 0.0036 & 4.99 & 0.0147 & 0.00073 & 0.00230 & 1.30 & 0.000582 & 0.0000170 & 0.0000258 \\
\hline 52 & 20.4 & 0.0164 & 0.0496 & 6.84 & 2.1834 & 0.00578 & 0.00284 & 1.25 & 0.005260 & 0.0000947 & 0.0000000 \\
\hline 53 & 20.8 & 0.0000 & 0.0098 & 3.66 & 0.0083 & 0.00128 & 0.00542 & 1.16 & 0.000421 & 0.0000376 & 0.0000121 \\
\hline 54 & 21.2 & 0.0000 & 0.0000 & 2.81 & 0.0007 & 0.00244 & 0.00000 & 1.27 & 0.000552 & 0.0000000 & 0.0000137 \\
\hline 55 & 21.6 & 0.0105 & 0.0088 & 2.06 & 0.0035 & 0.00000 & 0.00000 & 1.29 & 0.000477 & 0.0000116 & 0.0000000 \\
\hline 56 & 22.0 & 0.0399 & 0.0000 & 2.52 & 0.0000 & 0.00469 & 0.00727 & 1.20 & 0.000399 & 0.0000237 & 0.0000000 \\
\hline 57 & 22.4 & 0.0040 & 0.0271 & 2.06 & 0.0028 & 0.00101 & 0.00000 & 1.24 & 0.000473 & 0.0000000 & 0.0000067 \\
\hline 58 & 22.8 & 0.0063 & 0.0000 & 2.40 & 0.0037 & 0.00545 & 0.00000 & 1.21 & 0.000540 & 0.0000109 & 0.0000000 \\
\hline 59 & 23.2 & 0.0090 & 0.0069 & 4.17 & 0.0056 & 0.00149 & 0.00067 & 1.27 & 0.000530 & 0.0000000 & 0.0000185 \\
\hline
\end{tabular}




\begin{tabular}{|c|c|c|c|c|c|c|c|c|c|c|c|}
\hline \multirow{2}{*}{ Spot Number } & \multirow{2}{*}{ Distance from the foot $(\mathrm{mm})$} & \multicolumn{10}{|c|}{ KD1B prismatic layer transect corrected data $(\mathrm{mmol} / \mathrm{mol})$ continued... } \\
\hline & & $\mathrm{Li} / \mathrm{Ca}$ & $\mathrm{B} / \mathrm{Ca}$ & $\mathrm{Mg} / \mathrm{Ca}$ & $\mathrm{Al} / \mathrm{Ca}$ & $\mathrm{Mn} / \mathrm{Ca}$ & $\mathrm{Zn} / \mathrm{Ca}$ & $\mathrm{Sr} 8 / \mathrm{Ca}$ & $\mathrm{Ba} / \mathrm{Ca}$ & $\mathrm{Pb} / \mathrm{Ca}$ & $\mathrm{U} / \mathbf{C a}$ \\
\hline 60 & 23.6 & 0.0174 & 0.0000 & 2.58 & 0.0010 & 0.00000 & 0.00251 & 1.53 & 0.000553 & 0.0000000 & 0.0000209 \\
\hline 61 & 24.0 & 0.0226 & 0.0000 & 3.47 & 0.0000 & 0.00000 & 0.00538 & 1.37 & 0.000318 & 0.0000616 & 0.0000000 \\
\hline 62 & 24.4 & 0.0000 & 0.0387 & 2.78 & 0.0000 & 0.00182 & 0.00337 & 1.40 & 0.000497 & 0.0000000 & 0.0000184 \\
\hline 63 & 24.8 & 0.0219 & 0.0265 & 16.42 & 0.0086 & 0.00305 & 0.00785 & 1.58 & 0.001618 & 0.0000159 & 0.0000061 \\
\hline 64 & 25.2 & 0.0266 & 0.0120 & 3.78 & 0.0113 & 0.00451 & 0.00000 & 1.25 & 0.000495 & 0.0000213 & 0.0000104 \\
\hline 65 & 25.6 & 0.0136 & 0.0093 & 1.94 & 0.0053 & 0.00000 & 0.00100 & 1.15 & 0.000312 & 0.0000039 & 0.0000000 \\
\hline 66 & 26.0 & 0.0150 & 0.0000 & 5.42 & 0.0112 & 0.00077 & 0.00507 & 1.54 & 0.000682 & 0.0000039 & 0.0000000 \\
\hline 67 & 26.4 & 0.0129 & 0.0110 & 2.73 & 0.0000 & 0.00389 & 0.00078 & 1.30 & 0.000453 & 0.0000087 & 0.0000000 \\
\hline 68 & 26.8 & 0.0130 & 0.0209 & 5.23 & 0.1423 & 0.00187 & 0.00268 & 1.14 & 0.001425 & 0.0000169 & 0.0000613 \\
\hline 69 & 27.2 & 0.0154 & 0.0000 & 2.84 & 0.0000 & 0.00000 & 0.00265 & 1.13 & 0.000446 & 0.0000000 & 0.0000008 \\
\hline 70 & 27.6 & 0.0125 & 0.0185 & 4.16 & 0.0074 & 0.00204 & 0.00144 & 1.10 & 0.000312 & 0.0000000 & 0.0000326 \\
\hline 71 & 28.0 & 0.0000 & 0.0094 & 2.49 & 0.0039 & 0.00293 & 0.00000 & 1.06 & 0.000298 & 0.0000154 & 0.0000047 \\
\hline 72 & 28.4 & 0.0000 & 0.0202 & 2.10 & 0.0000 & 0.00000 & 0.00028 & 1.37 & 0.000387 & 0.0000000 & 0.0000000 \\
\hline 73 & 28.8 & 0.0116 & 0.0064 & 2.82 & 0.0035 & 0.00110 & 0.00146 & 1.24 & 0.000483 & 0.0000283 & 0.0000193 \\
\hline 74 & 29.2 & 0.0026 & 0.0000 & 2.42 & 0.0020 & 0.00000 & 0.00000 & 1.24 & 0.000452 & 0.0000640 & 0.0000000 \\
\hline 75 & 29.6 & 0.0030 & 0.0007 & 2.00 & 0.0043 & 0.00079 & 0.00630 & 1.15 & 0.000356 & 0.0000000 & 0.0000000 \\
\hline 76 & 30.0 & 0.0252 & 0.0000 & 5.34 & 0.0086 & 0.00330 & 0.00918 & 1.45 & 0.000577 & 0.0000186 & 0.0000047 \\
\hline 77 & 30.4 & 0.0000 & 0.0175 & 3.13 & 0.0038 & 0.00853 & 0.00186 & 1.42 & 0.001525 & 0.0000000 & 0.0000000 \\
\hline 78 & 30.8 & 0.0079 & 0.0343 & 3.19 & 0.0000 & 0.00366 & 0.00347 & 1.49 & 0.001134 & 0.0000000 & 0.0000092 \\
\hline 79 & 31.2 & 0.0243 & 0.0096 & 2.30 & 0.0086 & 0.00157 & 0.00363 & 1.29 & 0.000479 & 0.0000135 & 0.0000000 \\
\hline 80 & 31.6 & 0.0182 & 0.0604 & 3.87 & 0.0000 & 0.00000 & 0.00433 & 1.27 & 0.000401 & 0.0000147 & 0.0000000 \\
\hline 81 & 32.0 & 0.0000 & 0.0000 & 2.52 & 0.0000 & 0.00000 & 0.00585 & 1.40 & 0.000657 & 0.0000000 & 0.0000011 \\
\hline 82 & 32.4 & 0.1804 & 0.1150 & 17.30 & 29.0871 & 0.17113 & 0.02190 & 1.61 & 0.044943 & 0.0004403 & 0.0000497 \\
\hline 83 & 32.8 & 0.0221 & 0.0359 & 2.93 & 0.0058 & 0.00396 & 0.00000 & 1.35 & 0.000341 & 0.0000650 & 0.0000000 \\
\hline 84 & 33.2 & 0.0357 & 0.0000 & 1.86 & 0.0097 & 0.00015 & 0.00736 & 1.39 & 0.000701 & 0.0000000 & 0.0000000 \\
\hline 85 & 33.6 & 0.0082 & 0.0000 & 4.93 & 0.0000 & 0.01262 & 0.00000 & 1.36 & 0.000432 & 0.0000000 & 0.0000228 \\
\hline 86 & 34.0 & 0.0000 & 0.0180 & 3.02 & 0.0050 & 0.00260 & 0.00277 & 1.37 & 0.000550 & 0.0000000 & 0.0000000 \\
\hline 87 & 34.4 & 0.0000 & 0.0181 & 2.06 & 0.0061 & 0.00243 & 0.00429 & 1.21 & 0.000327 & 0.0000000 & 0.0000053 \\
\hline 88 & 34.8 & 0.0238 & 0.0135 & 2.79 & 0.0128 & 0.00112 & 0.00066 & 1.31 & 0.000402 & 0.0000096 & 0.0000148 \\
\hline 89 & 35.2 & 0.0067 & 0.0293 & 2.35 & 0.0014 & 0.00205 & 0.00578 & 1.32 & 0.000434 & 0.0000029 & 0.0000060 \\
\hline
\end{tabular}




\begin{tabular}{|c|c|c|c|c|c|c|c|c|c|c|c|}
\hline \multirow{2}{*}{ Spot Number } & \multirow{2}{*}{ Distance from the foot $(\mathrm{mm})$} & \multicolumn{10}{|c|}{ KD1B prismatic layer transect corrected data $(\mathrm{mmol} / \mathrm{mol})$ continued... } \\
\hline & & $\mathrm{Li} / \mathrm{Ca}$ & $\mathrm{B} / \mathrm{Ca}$ & $\mathrm{Mg} / \mathrm{Ca}$ & $\mathrm{Al} / \mathrm{Ca}$ & $\mathrm{Mn} / \mathrm{Ca}$ & $\mathrm{Zn} / \mathrm{Ca}$ & $\mathrm{Sr} 8 / \mathrm{Ca}$ & $\mathrm{Ba} / \mathrm{Ca}$ & $\mathrm{Pb} / \mathrm{Ca}$ & $\mathrm{U} / \mathbf{C a}$ \\
\hline 90 & 35.6 & 0.0037 & 0.0054 & 2.97 & 0.0000 & 0.00906 & 0.00364 & 1.37 & 0.000637 & 0.0000298 & 0.0000048 \\
\hline 91 & 36.0 & 0.0416 & 0.0080 & 2.74 & 0.0242 & 0.06589 & 0.00503 & 1.56 & 0.001351 & 0.0000250 & 0.0000000 \\
\hline 92 & 36.4 & 0.0153 & 0.0089 & 2.14 & 0.0000 & 0.00292 & 0.00999 & 1.40 & 0.000694 & 0.0000000 & 0.0000053 \\
\hline 93 & 36.8 & 0.0071 & 0.0344 & 4.71 & 0.0000 & 0.00196 & 0.00857 & 1.90 & 0.000577 & 0.0000000 & 0.0000000 \\
\hline 94 & 37.2 & 0.0184 & 0.0180 & 4.21 & 0.0000 & 0.00864 & 0.00200 & 1.18 & 0.000932 & 0.0000445 & 0.0000276 \\
\hline 95 & 37.6 & 0.0383 & 0.0000 & 2.82 & 0.0004 & 0.00237 & 0.00000 & 1.26 & 0.000648 & 0.0000063 & 0.0000213 \\
\hline 96 & 38.0 & 0.0218 & 0.0034 & 2.05 & 0.0000 & 0.00494 & 0.00074 & 1.15 & 0.000472 & 0.0000000 & 0.0000149 \\
\hline 97 & 38.4 & 0.0200 & 0.0176 & 3.23 & 0.0000 & 0.00304 & 0.00081 & 1.25 & 0.000527 & 0.0000670 & 0.0000000 \\
\hline 98 & 38.8 & 0.0203 & 0.0166 & 2.49 & 0.0000 & 0.00000 & 0.00000 & 1.26 & 0.000442 & 0.0000378 & 0.0000030 \\
\hline 99 & 39.2 & 0.0000 & 0.0035 & 3.22 & 0.0000 & 0.00262 & 0.00303 & 1.22 & 0.000511 & 0.0000400 & 0.0000115 \\
\hline 100 & 39.6 & 0.0210 & 0.0086 & 2.10 & 0.0000 & 0.00269 & 0.00368 & 1.07 & 0.000339 & 0.0000193 & 0.0000000 \\
\hline 101 & 40.0 & 0.0114 & 0.0000 & 1.85 & 0.0000 & 0.00350 & 0.00424 & 1.25 & 0.000449 & 0.0000605 & 0.0000000 \\
\hline 102 & 40.4 & 0.0165 & 0.0072 & 2.21 & 0.0081 & 0.00332 & 0.00517 & 1.15 & 0.000301 & 0.0000369 & 0.0000000 \\
\hline 103 & 40.8 & 0.0000 & 0.0104 & 2.20 & 0.0000 & 0.00000 & 0.00323 & 1.14 & 0.000356 & 0.0000079 & 0.0000124 \\
\hline 104 & 41.2 & 0.0133 & 0.0000 & 1.52 & 0.0019 & 0.00000 & 0.00373 & 1.29 & 0.000390 & 0.0000235 & 0.0000000 \\
\hline 105 & 41.6 & 0.0000 & 0.0128 & 2.36 & 0.0071 & 0.00000 & 0.00000 & 1.37 & 0.000646 & 0.0000282 & 0.0000000 \\
\hline 106 & 42.0 & 0.0000 & 0.0179 & 3.83 & 0.0000 & 0.00308 & 0.00486 & 1.35 & 0.000493 & 0.0000952 & 0.0000138 \\
\hline 107 & 42.4 & 0.0222 & 0.0304 & 7.92 & 0.0101 & 0.00281 & 0.00613 & 1.46 & 0.000584 & 0.0000730 & 0.0000000 \\
\hline 108 & 42.8 & 0.0000 & 0.0173 & 2.81 & 0.0091 & 0.00131 & 0.00861 & 1.19 & 0.000520 & 0.0000000 & 0.0000000 \\
\hline 109 & 43.2 & 0.0000 & 0.0018 & 1.95 & 0.0005 & 0.00257 & 0.00119 & 1.22 & 0.000355 & 0.0000000 & 0.0000000 \\
\hline 110 & 43.6 & 0.0002 & 0.0025 & 2.58 & 0.0000 & 0.00311 & 0.00000 & 1.41 & 0.000436 & 0.0000000 & 0.0000000 \\
\hline 111 & 44.0 & 0.0206 & 0.0000 & 2.94 & 0.0000 & 0.00078 & 0.00000 & 1.17 & 0.000408 & 0.0000000 & 0.0000068 \\
\hline 112 & 44.4 & 0.0317 & 0.0154 & 2.98 & 0.0000 & 0.00076 & 0.00686 & 1.08 & 0.000276 & 0.0000000 & 0.0000000 \\
\hline 113 & 44.8 & 0.0367 & 0.0110 & 3.88 & 0.0069 & 0.00061 & 0.00224 & 1.19 & 0.000347 & 0.0000496 & 0.0000061 \\
\hline 114 & 45.2 & 0.0194 & 0.0000 & 2.46 & 0.0000 & 0.00054 & 0.00287 & 1.14 & 0.000418 & 0.0000000 & 0.0000000 \\
\hline 115 & 45.6 & 0.0000 & 0.0049 & 2.59 & 0.0000 & 0.00000 & 0.00039 & 1.29 & 0.000432 & 0.0000000 & 0.0000000 \\
\hline 116 & 46.0 & 0.0192 & 0.0000 & 2.52 & 0.0047 & 0.00000 & 0.00065 & 1.20 & 0.000457 & 0.0000000 & 0.0000000 \\
\hline 117 & 46.4 & 0.0036 & 0.0112 & 3.07 & 0.0033 & 0.00141 & 0.00891 & 1.16 & 0.000517 & 0.0000000 & 0.0000208 \\
\hline 118 & 46.8 & 0.0000 & 0.0120 & 2.25 & 0.0041 & 0.00000 & 0.00305 & 1.18 & 0.000441 & 0.0000000 & 0.0000000 \\
\hline 119 & 47.2 & 0.0146 & 0.0000 & 2.42 & 0.0049 & 0.00282 & 0.00000 & 1.17 & 0.000377 & 0.0000000 & 0.0000000 \\
\hline
\end{tabular}




\begin{tabular}{|c|c|c|c|c|c|c|c|c|c|c|c|}
\hline \multirow{2}{*}{ Spot Number } & \multirow{2}{*}{ Distance from the foot $(\mathrm{mm})$} & \multicolumn{10}{|c|}{ KD1B prismatic layer transect corrected data $(\mathrm{mmol} / \mathrm{mol})$ continued... } \\
\hline & & $\mathrm{Li} / \mathrm{Ca}$ & $\mathrm{B} / \mathrm{Ca}$ & $\mathrm{Mg} / \mathrm{Ca}$ & $\mathrm{Al} / \mathrm{Ca}$ & $\mathrm{Mn} / \mathrm{Ca}$ & $\mathrm{Zn} / \mathrm{Ca}$ & $\mathrm{Sr} 8 / \mathrm{Ca}$ & $\mathrm{Ba} / \mathrm{Ca}$ & $\mathrm{Pb} / \mathrm{Ca}$ & $\mathrm{U} / \mathbf{C a}$ \\
\hline 120 & 47.6 & 0.0091 & 0.0251 & 2.49 & 0.0010 & 0.01953 & 0.00590 & 1.08 & 0.000590 & 0.0001742 & 0.0000200 \\
\hline 121 & 48.0 & 0.0126 & 0.0202 & 3.07 & 0.0194 & 0.00000 & 0.00073 & 1.08 & 0.000367 & 0.0000000 & 0.0000000 \\
\hline 122 & 48.4 & 0.0040 & 0.0000 & 2.67 & 0.0000 & 0.00078 & 0.00000 & 1.10 & 0.000286 & 0.0000000 & 0.0000120 \\
\hline 123 & 48.8 & 0.0093 & 0.0000 & 2.85 & 0.0000 & 0.00324 & 0.00000 & 1.18 & 0.000423 & 0.0000751 & 0.0000266 \\
\hline 124 & 49.2 & 0.0461 & 0.0038 & 2.59 & 0.0000 & 0.00452 & 0.00003 & 1.16 & 0.000335 & 0.0000190 & 0.0000000 \\
\hline 125 & 49.6 & 0.0191 & 0.0080 & 2.46 & 0.0000 & 0.00000 & 0.00020 & 1.07 & 0.000368 & 0.0000000 & 0.0000000 \\
\hline 126 & 50.0 & 0.0055 & 0.0350 & 1.61 & 0.0093 & 0.00419 & 0.00733 & 1.45 & 0.000615 & 0.0000265 & 0.0000000 \\
\hline 127 & 50.4 & 0.0308 & 0.0077 & 2.10 & 0.0010 & 0.00364 & 0.00097 & 1.15 & 0.000461 & 0.0000312 & 0.0000000 \\
\hline 128 & 50.8 & 0.0188 & 0.0000 & 2.13 & 0.0000 & 0.00000 & 0.00199 & 1.06 & 0.000336 & 0.0000822 & 0.0000178 \\
\hline 129 & 51.2 & 0.0000 & 0.0183 & 2.88 & 0.0071 & 0.00362 & 0.00588 & 1.41 & 0.000445 & 0.0000000 & 0.0000119 \\
\hline 130 & 51.6 & 0.0031 & 0.0030 & 1.87 & 0.0019 & 0.00378 & 0.00420 & 1.34 & 0.000371 & 0.0000956 & 0.0000000 \\
\hline 131 & 52.0 & 0.0088 & 0.0044 & 1.82 & 0.0099 & 0.00228 & 0.00000 & 1.48 & 0.000518 & 0.0000193 & 0.0000024 \\
\hline 132 & 52.4 & 0.0000 & 0.0061 & 2.65 & 0.0064 & 0.00392 & 0.00000 & 1.36 & 0.000582 & 0.0000400 & 0.0000161 \\
\hline 133 & 52.8 & 0.0101 & 0.0000 & 4.04 & 0.0003 & 0.00556 & 0.00409 & 1.18 & 0.000400 & 0.0000000 & 0.0000200 \\
\hline 134 & 53.2 & 0.0546 & 0.0182 & 2.40 & 0.0167 & 0.00000 & 0.01364 & 1.20 & 0.000558 & 0.0000991 & 0.0000002 \\
\hline 135 & 53.6 & 0.0195 & 0.0035 & 2.83 & 0.0000 & 0.00000 & 0.00649 & 1.17 & 0.000505 & 0.0000000 & 0.0000000 \\
\hline 136 & 54.0 & 0.0090 & 0.0025 & 4.70 & 0.0000 & 0.00000 & 0.01130 & 1.45 & 0.000629 & 0.0000000 & 0.0000126 \\
\hline 137 & 54.4 & 0.0050 & 0.0000 & 1.85 & 0.0042 & 0.00269 & 0.00312 & 1.18 & 0.000479 & 0.0000000 & 0.0000000 \\
\hline 138 & 54.8 & 0.0073 & 0.0000 & 2.48 & 0.0000 & 0.00210 & 0.00490 & 1.19 & 0.000595 & 0.0001165 & 0.0000115 \\
\hline 139 & 55.2 & 0.0000 & 0.0000 & 2.07 & 0.0000 & 0.00479 & 0.00180 & 1.46 & 0.000635 & 0.0000000 & 0.0000192 \\
\hline 140 & 55.6 & 0.0000 & 0.0285 & 3.83 & 0.0000 & 0.00014 & 0.00146 & 1.41 & 0.000436 & 0.0000046 & 0.0000000 \\
\hline 141 & 56.0 & 0.0211 & 0.0271 & 7.90 & 0.0000 & 0.00412 & 0.00696 & 1.48 & 0.000750 & 0.0000273 & 0.0000000 \\
\hline 142 & 56.4 & 0.0150 & 0.0000 & 2.77 & 0.0151 & 0.00209 & 0.00000 & 1.30 & 0.000386 & 0.0000000 & 0.0000000 \\
\hline 143 & 56.8 & 0.0000 & 0.0016 & 2.83 & 0.0000 & 0.00543 & 0.00467 & 1.49 & 0.000578 & 0.0000000 & 0.0000000 \\
\hline 144 & 57.2 & 0.0156 & 0.0125 & 2.32 & 0.0052 & 0.00042 & 0.00000 & 1.40 & 0.000558 & 0.0000000 & 0.0000161 \\
\hline 145 & 57.6 & 0.0000 & 0.0136 & 6.31 & 0.1085 & 0.00276 & 0.00000 & 1.30 & 0.000847 & 0.0000000 & 0.0000000 \\
\hline 146 & 58.0 & 0.0368 & 0.0259 & 2.15 & 0.0087 & 0.00328 & 0.00295 & 1.46 & 0.000537 & 0.0000000 & 0.0000043 \\
\hline 147 & 58.4 & 0.0391 & 0.0058 & 2.65 & 0.0092 & 0.00410 & 0.00250 & 1.47 & 0.000642 & 0.0000274 & 0.0000000 \\
\hline 148 & 58.8 & 0.0136 & 0.0196 & 2.61 & 0.0076 & 0.00000 & 0.00288 & 1.49 & 0.000583 & 0.0000456 & 0.0000000 \\
\hline 149 & 59.2 & 0.0019 & 0.0313 & 2.01 & 0.0158 & 0.00000 & 0.00104 & 1.54 & 0.000639 & 0.0000883 & 0.0000374 \\
\hline
\end{tabular}




\begin{tabular}{|c|c|c|c|c|c|c|c|c|c|c|c|}
\hline \multirow{2}{*}{ Spot Number } & \multirow{2}{*}{ Distance from the foot $(\mathrm{mm})$} & \multicolumn{10}{|c|}{ KD1B prismatic layer transect corrected data $(\mathrm{mmol} / \mathrm{mol})$ continued... } \\
\hline & & $\mathrm{Li} / \mathrm{Ca}$ & $\mathrm{B} / \mathrm{Ca}$ & $\mathrm{Mg} / \mathrm{Ca}$ & $\mathrm{Al} / \mathrm{Ca}$ & $\mathrm{Mn} / \mathrm{Ca}$ & $\mathrm{Zn} / \mathrm{Ca}$ & $\mathrm{Sr} 8 / \mathrm{Ca}$ & $\mathrm{Ba} / \mathrm{Ca}$ & $\mathrm{Pb} / \mathrm{Ca}$ & $\mathrm{U} / \mathbf{C a}$ \\
\hline 150 & 59.6 & 0.0076 & 0.0160 & 2.20 & 0.0081 & 0.00000 & 0.00195 & 1.33 & 0.000469 & 0.0000394 & 0.0000000 \\
\hline 151 & 60.0 & 0.0155 & 0.0174 & 3.30 & 0.0208 & 0.00110 & 0.00000 & 1.34 & 0.000497 & 0.0000307 & 0.0000152 \\
\hline 152 & 60.4 & 0.0000 & 0.0000 & 6.77 & 0.0012 & 0.00083 & 0.00000 & 1.34 & 0.000473 & 0.0000000 & 0.0000245 \\
\hline 153 & 60.8 & 0.0232 & 0.0053 & 1.71 & 0.0000 & 0.00119 & 0.00303 & 1.44 & 0.000549 & 0.0000000 & 0.0000000 \\
\hline 154 & 61.2 & 0.0273 & 0.0000 & 2.73 & 0.0000 & 0.00465 & 0.00000 & 1.38 & 0.000352 & 0.0000161 & 0.0000000 \\
\hline 155 & 61.6 & 0.0026 & 0.0180 & 2.12 & 0.0075 & 0.00262 & 0.00654 & 1.25 & 0.000282 & 0.0000000 & 0.0000000 \\
\hline 156 & 62.0 & 0.0269 & 0.0220 & 6.13 & 0.0203 & 0.00641 & 0.00685 & 1.47 & 0.000733 & 0.0000577 & 0.0000000 \\
\hline 157 & 62.4 & 0.0358 & 0.0000 & 5.72 & 0.0031 & 0.00695 & 0.00021 & 1.53 & 0.000849 & 0.0000000 & 0.0000000 \\
\hline 158 & 62.8 & 0.0010 & 0.0321 & 3.64 & 0.0063 & 0.00515 & 0.00922 & 1.32 & 0.000512 & 0.0000000 & 0.0000000 \\
\hline 159 & 63.2 & 0.0000 & 0.0005 & 3.96 & 0.0000 & 0.00000 & 0.00240 & 1.59 & 0.000511 & 0.0001330 & 0.0000000 \\
\hline 160 & 63.6 & 0.0243 & 0.0000 & 3.67 & 0.0311 & 0.00275 & 0.00672 & 1.59 & 0.000854 & 0.0001794 & 0.0000075 \\
\hline 161 & 64.0 & 0.0000 & 0.0000 & 4.42 & 0.0000 & 0.00057 & 0.00602 & 1.37 & 0.000675 & 0.0000000 & 0.0000000 \\
\hline 162 & 64.4 & 0.0090 & 0.0100 & 4.42 & 0.0000 & 0.00112 & 0.00000 & 1.20 & 0.000488 & 0.0000696 & 0.0000106 \\
\hline 163 & 64.8 & 0.0169 & 0.0071 & 2.89 & 0.0060 & 0.00165 & 0.00669 & 1.48 & 0.000408 & 0.0000192 & 0.0000065 \\
\hline 164 & 65.2 & 0.0141 & 0.0000 & 2.51 & 0.0000 & 0.00501 & 0.00380 & 1.34 & 0.000484 & 0.0000000 & 0.0000098 \\
\hline 165 & 65.6 & 0.0000 & 0.0000 & 2.02 & 0.0005 & 0.00115 & 0.00264 & 1.34 & 0.000428 & 0.0000323 & 0.0000110 \\
\hline 166 & 66.0 & 0.0043 & 0.0169 & 1.74 & 0.0000 & 0.00000 & 0.00090 & 1.22 & 0.000340 & 0.0000000 & 0.0000000 \\
\hline 167 & 66.4 & 0.0349 & 0.0000 & 2.48 & 0.0074 & 0.00036 & 0.00348 & 1.43 & 0.000448 & 0.0000317 & 0.0000029 \\
\hline 168 & 66.8 & 0.0168 & 0.0000 & 2.27 & 0.0055 & 0.00038 & 0.00110 & 1.31 & 0.000457 & 0.0000000 & 0.0000000 \\
\hline 169 & 67.2 & 0.0091 & 0.0089 & 1.82 & 0.0000 & 0.00000 & 0.00000 & 1.24 & 0.000333 & 0.0000180 & 0.0000036 \\
\hline 170 & 67.6 & 0.0192 & 0.0000 & 1.89 & 0.0076 & 0.00000 & 0.00339 & 1.29 & 0.000392 & 0.0000197 & 0.0000000 \\
\hline 171 & 68.0 & 0.0241 & 0.0238 & 1.52 & 0.0049 & 0.00082 & 0.00000 & 1.58 & 0.000608 & 0.0000577 & 0.0000076 \\
\hline 172 & 68.4 & 0.0355 & 0.0000 & 2.02 & 0.0075 & 0.00627 & 0.00278 & 1.39 & 0.000620 & 0.0000000 & 0.0000223 \\
\hline 173 & 68.8 & 0.0111 & 0.0000 & 1.64 & 0.0268 & 0.00000 & 0.00982 & 1.26 & 0.000422 & 0.0000231 & 0.0000000 \\
\hline 174 & 69.2 & 0.0814 & 0.0429 & 6.37 & 16.9871 & 0.03965 & 0.01581 & 1.43 & 0.038405 & 0.0001054 & 0.0000007 \\
\hline 175 & 69.6 & 0.0151 & 0.0136 & 1.63 & 0.0021 & 0.00143 & 0.00376 & 1.37 & 0.000374 & 0.0000081 & 0.0000089 \\
\hline 176 & 70.0 & 0.0000 & 0.0000 & 2.38 & 0.0160 & 0.00000 & 0.00992 & 1.52 & 0.000518 & 0.0000476 & 0.0000047 \\
\hline 177 & 70.4 & 0.0261 & 0.0326 & 8.25 & 0.1918 & 0.00508 & 0.00762 & 3.45 & 0.003454 & 0.0000515 & 0.0005306 \\
\hline 178 & 70.8 & 0.0025 & 0.0000 & 8.10 & 0.0145 & 0.00360 & 0.00043 & 1.29 & 0.000507 & 0.0000467 & 0.0000137 \\
\hline 179 & 71.2 & 0.0048 & 0.0157 & 3.17 & 0.0045 & 0.00274 & 0.00000 & 1.48 & 0.000532 & 0.0000238 & 0.0000000 \\
\hline
\end{tabular}




\begin{tabular}{|c|c|c|c|c|c|c|c|c|c|c|c|}
\hline \multirow{2}{*}{ Spot Number } & \multirow{2}{*}{ Distance from the foot $(\mathrm{mm})$} & \multicolumn{10}{|c|}{ KD1B prismatic layer transect corrected data $(\mathrm{mmol} / \mathrm{mol})$ continued... } \\
\hline & & $\mathrm{Li} / \mathrm{Ca}$ & $\mathrm{B} / \mathrm{Ca}$ & $\mathrm{Mg} / \mathrm{Ca}$ & $\mathrm{Al} / \mathrm{Ca}$ & $\mathrm{Mn} / \mathrm{Ca}$ & $\mathrm{Zn} / \mathrm{Ca}$ & $\mathrm{Sr} 8 / \mathrm{Ca}$ & $\mathrm{Ba} / \mathrm{Ca}$ & $\mathrm{Pb} / \mathrm{Ca}$ & $\mathrm{U} / \mathrm{Ca}$ \\
\hline 180 & 71.6 & 0.0180 & 0.0000 & 2.89 & 0.0022 & 0.00321 & 0.00098 & 1.28 & 0.000390 & 0.0000493 & 0.0000184 \\
\hline 181 & 72.0 & 0.0175 & 0.0254 & 2.47 & 0.0000 & 0.00000 & 0.00144 & 1.31 & 0.000381 & 0.0000000 & 0.0000329 \\
\hline 182 & 72.4 & 0.0423 & 0.0186 & 4.22 & 0.0000 & 0.00000 & 0.00337 & 1.38 & 0.000561 & 0.0000000 & 0.0000000 \\
\hline 183 & 72.8 & 0.0374 & 0.0322 & 2.82 & 0.0000 & 0.00000 & 0.00117 & 1.52 & 0.000674 & 0.0000853 & 0.0000184 \\
\hline 184 & 73.2 & 0.0068 & 0.0032 & 2.50 & 0.0123 & 0.00000 & 0.00512 & 1.54 & 0.001043 & 0.0000559 & 0.0000072 \\
\hline 185 & 73.6 & 0.0058 & 0.0224 & 2.08 & 0.0163 & 0.00438 & 0.00537 & 1.58 & 0.000688 & 0.0000415 & 0.0000094 \\
\hline 186 & 74.0 & 0.0206 & 0.0000 & 2.00 & 0.0000 & 0.00080 & 0.00000 & 1.25 & 0.000867 & 0.0000242 & 0.0000000 \\
\hline 187 & 74.4 & 0.0406 & 0.0313 & 3.54 & 0.0109 & 0.00260 & 0.00639 & 1.41 & 0.000957 & 0.0000000 & 0.0000214 \\
\hline 188 & 74.8 & 0.0000 & 0.0000 & 3.31 & 0.0000 & 0.00181 & 0.00304 & 1.60 & 0.000600 & 0.0000603 & 0.0000000 \\
\hline 189 & 75.2 & 0.0117 & 0.0312 & 9.14 & 0.0271 & 0.00036 & 0.03303 & 1.67 & 0.001208 & 0.0001875 & 0.0000000 \\
\hline 190 & 75.6 & 0.0104 & 0.0000 & 4.13 & 0.0000 & 0.00309 & 0.00241 & 1.35 & 0.000419 & 0.0000000 & 0.0000000 \\
\hline 191 & 76.0 & 0.0000 & 0.0160 & 3.46 & 0.0000 & 0.00149 & 0.00409 & 1.22 & 0.000417 & 0.0000000 & 0.0000284 \\
\hline 192 & 76.4 & 0.0057 & 0.0000 & 2.45 & 0.0311 & 0.00473 & 0.00000 & 1.39 & 0.000408 & 0.0000000 & 0.0000038 \\
\hline 193 & 76.8 & 0.0000 & 0.0000 & 4.54 & 0.0097 & 0.00551 & 0.00241 & 1.33 & 0.000500 & 0.0000741 & 0.0000000 \\
\hline 194 & 77.2 & 0.0387 & 0.0000 & 9.67 & 0.0113 & 0.01033 & 0.00087 & 1.26 & 0.000639 & 0.0000483 & 0.0000000 \\
\hline 195 & 77.6 & 0.0148 & 0.0140 & 3.93 & 0.0000 & 0.00274 & 0.00409 & 1.34 & 0.000282 & 0.0000000 & 0.0000209 \\
\hline 196 & 78.0 & 0.0156 & 0.0000 & 2.16 & 0.0036 & 0.00030 & 0.00456 & 1.54 & 0.000530 & 0.0000000 & 0.0000000 \\
\hline 197 & 78.4 & 0.0187 & 0.0138 & 1.82 & 0.0052 & 0.00173 & 0.00833 & 1.35 & 0.000615 & 0.0000139 & 0.0000000 \\
\hline 198 & 78.8 & 0.0184 & 0.0076 & 4.54 & 0.0108 & 0.00238 & 0.00529 & 1.49 & 0.000415 & 0.0000217 & 0.0000000 \\
\hline 199 & 79.2 & 0.0140 & 0.0000 & 2.21 & 0.0215 & 0.00011 & 0.00119 & 1.23 & 0.000380 & 0.0000411 & 0.0000084 \\
\hline 200 & 79.6 & 0.0070 & 0.0355 & 2.79 & 0.0361 & 0.00183 & 0.00503 & 3.42 & 0.004081 & 0.0000826 & 0.0007646 \\
\hline
\end{tabular}


APPENDIX 5.1k K3A prismatic layer transect data

\begin{tabular}{|c|c|c|c|c|c|c|c|c|c|c|c|}
\hline \multirow{2}{*}{ Spot Number } & \multirow{2}{*}{ Distance from the foot $(\mathrm{mm})$} & \multicolumn{10}{|c|}{ K3A prismatic layer transect corrected data $(\mathrm{mmol} / \mathrm{mol})$} \\
\hline & & $\mathrm{Li} / \mathrm{Ca}$ & $\mathrm{B} / \mathrm{Ca}$ & $\mathrm{Mg} / \mathrm{Ca}$ & $\mathrm{Al} / \mathrm{Ca}$ & $\mathrm{Mn} / \mathrm{Ca}$ & $\mathrm{Zn} / \mathrm{Ca}$ & $\mathrm{Sr} / \mathrm{Ca}$ & $\mathrm{Ba} / \mathrm{Ca}$ & $\mathrm{Pb} / \mathrm{Ca}$ & $\mathrm{U} / \mathbf{C a}$ \\
\hline 1 & 0.0 & 0.0247 & 0.0095 & 11.90 & 0.0507 & 0.0028088 & 0.0046680 & 1.19 & 0.000389 & 0.0003151 & 0.0000000 \\
\hline 2 & 0.4 & 0.0000 & 0.0708 & 4.32 & 0.0122 & 0.0000000 & 0.0018997 & 2.73 & 0.001453 & 0.0000872 & 0.0001110 \\
\hline 3 & 0.8 & 0.0312 & 0.0728 & 3.28 & 0.3388 & 0.0030973 & 0.0059630 & 2.87 & 0.001637 & 0.0000608 & 0.0000919 \\
\hline 4 & 1.2 & 0.0188 & 0.0393 & 2.42 & 0.4599 & 0.0019760 & 0.0053686 & 2.66 & 0.001746 & 0.0000939 & 0.0001948 \\
\hline 5 & 1.6 & 0.0283 & 0.0000 & 18.65 & 0.0035 & 0.0018763 & 0.0061604 & 1.54 & 0.000936 & 0.0000377 & 0.0000185 \\
\hline 6 & 2.0 & 0.0099 & 0.0072 & 17.67 & 0.0055 & 0.0028722 & 0.0007268 & 1.90 & 0.000962 & 0.0000104 & $0.000025 \mathrm{c}$ \\
\hline 7 & 2.4 & 0.0173 & 0.0107 & 17.94 & 0.0684 & 0.0044535 & 0.0011079 & 1.96 & 0.001321 & 0.0000279 & 0.0000034 \\
\hline 8 & 2.8 & 0.0155 & 0.0121 & 7.81 & 0.0000 & 0.0068846 & 0.0027374 & 1.69 & 0.000632 & 0.0001047 & $0.000002 s$ \\
\hline 9 & 3.2 & 0.0355 & 0.0000 & 4.10 & 0.0000 & 0.0041217 & 0.0000000 & 1.45 & 0.000505 & 0.0001112 & 0.0000137 \\
\hline 10 & 3.6 & 0.0287 & 0.0814 & 28.15 & 0.0896 & 0.0067975 & 0.0002802 & 2.50 & 0.001250 & 0.0000787 & 0.0001191 \\
\hline 11 & 4.0 & 0.0000 & 0.0000 & 7.61 & 0.0133 & 0.0003729 & 0.0021782 & 1.53 & 0.000540 & 0.0000984 & 0.0000000 \\
\hline 12 & 4.4 & 0.0463 & 0.0157 & 4.84 & 0.0038 & 0.0009627 & 0.0039591 & 1.89 & 0.000814 & 0.0000938 & 0.0000280 \\
\hline 13 & 4.8 & 0.0186 & 0.0189 & 4.81 & 0.0000 & 0.0029679 & 0.0035880 & 1.89 & 0.000832 & 0.0000000 & 0.0000000 \\
\hline 14 & 5.2 & 0.0000 & 0.0000 & 7.61 & 0.0053 & 0.0044503 & 0.0000000 & 2.04 & 0.000785 & 0.0000452 & 0.0000000 \\
\hline 15 & 5.6 & 0.0000 & 0.0027 & 4.10 & 0.0000 & 0.0032768 & 0.0014751 & 1.89 & 0.000665 & 0.0000000 & 0.0000000 \\
\hline 16 & 6.0 & 0.0106 & 0.0088 & 8.22 & 0.0000 & 0.0037511 & 0.0059641 & 1.56 & 0.000748 & 0.0000352 & 0.0000134 \\
\hline 17 & 6.4 & 0.0248 & 0.0317 & 8.06 & 0.0028 & 0.0059853 & 0.0045887 & 1.80 & 0.000703 & 0.0000000 & 0.0000138 \\
\hline 18 & 6.8 & 0.0000 & 0.0000 & 7.35 & 0.0010 & 0.0040641 & 0.0044041 & 1.58 & 0.000675 & 0.0000722 & 0.0000035 \\
\hline 19 & 7.2 & 0.0093 & 0.0035 & 8.41 & 0.0000 & 0.0044277 & 0.0052113 & 1.47 & 0.000624 & 0.0000440 & 0.0000000 \\
\hline 20 & 7.6 & 0.0044 & 0.0024 & 7.87 & 0.0000 & 0.0025368 & 0.0029242 & 1.55 & 0.000632 & 0.0000224 & 0.0000000 \\
\hline 21 & 8.0 & 0.0000 & 0.0264 & 10.84 & 0.0255 & 0.0055001 & 0.0060253 & 1.49 & 0.000665 & 0.0000997 & 0.0000000 \\
\hline 22 & 8.4 & 0.0154 & 0.0832 & 2.20 & 0.0798 & 0.0031434 & 0.0060780 & 3.08 & 0.001972 & 0.0001830 & 0.0003613 \\
\hline 23 & 8.8 & 0.0261 & 0.0737 & 22.40 & 0.0135 & 0.0048035 & 0.0116884 & 1.55 & 0.000900 & 0.0000292 & 0.0000311 \\
\hline 24 & 9.2 & 0.0092 & 0.0087 & 6.36 & 0.3141 & 0.0054903 & 0.0093022 & 1.59 & 0.001806 & 0.0000677 & 0.0000084 \\
\hline 25 & 9.6 & 0.0187 & 0.0354 & 8.87 & 0.2687 & 0.0059874 & 0.0049201 & 1.77 & 0.001175 & 0.0000000 & 0.0000000 \\
\hline 26 & 10.0 & 0.0100 & 0.0102 & 5.70 & 0.0068 & 0.0014985 & 0.0036104 & 1.33 & 0.000452 & 0.0001496 & 0.0000000 \\
\hline 27 & 10.4 & 0.0252 & 0.1005 & 8.31 & 0.6501 & 0.0054408 & 0.0106815 & 3.82 & 0.004694 & 0.0001277 & 0.0005256 \\
\hline 28 & 10.8 & 0.0218 & 0.0000 & 11.23 & 0.1393 & 0.0020829 & 0.0053249 & 1.71 & 0.000753 & 0.0000898 & 0.0000107 \\
\hline 29 & 11.2 & 0.0098 & 0.0094 & 13.30 & 0.2018 & 0.0075655 & 0.0089772 & 2.34 & 0.001729 & 0.0000566 & 0.0001178 \\
\hline
\end{tabular}




\begin{tabular}{|c|c|c|c|c|c|c|c|c|c|c|c|}
\hline \multirow{2}{*}{$\begin{array}{c}\text { Spot } \\
\text { Number }\end{array}$} & \multirow{2}{*}{ Distance from the foot (mm) } & \multicolumn{10}{|c|}{ K3A prismatic layer transect corrected data $(\mathrm{mmol} / \mathrm{mol})$ continued... } \\
\hline & & $\mathrm{Li} / \mathrm{Ca}$ & $\mathrm{B} / \mathrm{Ca}$ & $\mathrm{Mg} / \mathrm{Ca}$ & $\mathrm{Al} / \mathrm{Ca}$ & $\mathrm{Mn} / \mathrm{Ca}$ & $\mathrm{Zn} / \mathrm{Ca}$ & $\mathrm{Sr} / \mathrm{Ca}$ & $\mathrm{Ba} / \mathrm{Ca}$ & $\mathrm{Pb} / \mathrm{Ca}$ & $\mathrm{U} / \mathrm{Ca}$ \\
\hline 30 & 11.6 & 0.0054 & 0.0000 & 11.09 & 0.0000 & 0.0054145 & 0.0093685 & 1.97 & 0.000834 & 0.0001230 & 0.0000000 \\
\hline 31 & 12.0 & 0.0172 & 0.0207 & 5.90 & 0.0000 & 0.0020528 & 0.0035536 & 1.88 & 0.000612 & 0.0000000 & 0.0000000 \\
\hline 32 & 12.4 & 0.0156 & 0.0151 & 14.20 & 0.0000 & 0.0015723 & 0.0073700 & 1.64 & 0.000680 & 0.0000281 & 0.0000089 \\
\hline 33 & 12.8 & 0.0148 & 0.0028 & 3.64 & 0.0005 & 0.0034410 & 0.0065330 & 1.39 & 0.000533 & 0.0001538 & 0.0000000 \\
\hline 34 & 13.2 & 0.0073 & 0.0011 & 2.93 & 0.0024 & 0.0005659 & 0.0021985 & 1.42 & 0.000373 & 0.0000493 & 0.0000000 \\
\hline 35 & 13.6 & 0.0248 & 0.0197 & 7.30 & 0.0087 & 0.0041824 & 0.0021439 & 1.77 & 0.000596 & 0.0000000 & 0.0000134 \\
\hline 36 & 14.0 & 0.0102 & 0.0075 & 5.39 & 0.0049 & 0.0062936 & 0.0027299 & 1.45 & 0.000707 & 0.0000582 & 0.0000000 \\
\hline 37 & 14.4 & 0.0000 & 0.0000 & 4.86 & 0.0000 & 0.0048704 & 0.0007515 & 1.24 & 0.000362 & 0.0000258 & 0.0000000 \\
\hline 38 & 14.8 & 0.0016 & 0.0277 & 3.07 & 0.0000 & 0.0077872 & 0.0047573 & 1.42 & 0.000469 & 0.0000091 & 0.0000036 \\
\hline 39 & 15.2 & 0.0078 & 0.0071 & 2.99 & 0.0000 & 0.0017141 & 0.0019585 & 1.43 & 0.000519 & 0.0000558 & 0.0000000 \\
\hline 40 & 15.6 & 0.0183 & 0.0058 & 5.06 & 0.0038 & 0.0050099 & 0.0054666 & 1.29 & 0.000416 & 0.0000334 & 0.0000018 \\
\hline 41 & 16.0 & 0.0127 & 0.0263 & 4.16 & 0.0035 & 0.0017669 & 0.0000000 & 1.36 & 0.000443 & 0.0000654 & 0.0000033 \\
\hline 42 & 16.4 & 0.0145 & 0.0000 & 3.59 & 0.0000 & 0.0000000 & 0.0000000 & 1.51 & 0.000431 & 0.0000334 & 0.0000000 \\
\hline 43 & 16.8 & 0.0239 & 0.0000 & 4.20 & 0.0002 & 0.0064121 & 0.0027995 & 1.64 & 0.000694 & 0.0000674 & 0.0000000 \\
\hline 44 & 17.2 & 0.0110 & 0.0051 & 4.26 & 0.0021 & 0.0052116 & 0.0074371 & 1.46 & 0.000604 & 0.0000971 & 0.0000002 \\
\hline 45 & 17.6 & 0.0000 & 0.0191 & 8.24 & 0.0000 & 0.0070195 & 0.0074341 & 1.83 & 0.000805 & 0.0001263 & 0.0000000 \\
\hline 46 & 18.0 & 0.0196 & 0.0079 & 10.26 & 0.0076 & 0.0008884 & 0.0025125 & 1.67 & 0.000759 & 0.0001495 & 0.0000211 \\
\hline 47 & 18.4 & 0.0054 & 0.0063 & 8.07 & 0.0009 & 0.0023730 & 0.0002630 & 1.77 & 0.000738 & 0.0001533 & 0.0000291 \\
\hline 48 & 18.8 & 0.0074 & 0.0000 & 5.28 & 0.0000 & 0.0068226 & 0.0072751 & 1.91 & 0.000731 & 0.0001340 & 0.0000000 \\
\hline 49 & 19.2 & 0.0378 & 0.0260 & 17.24 & 0.0328 & 0.0070265 & 0.0020600 & 1.82 & 0.000958 & 0.0000637 & 0.0000180 \\
\hline 50 & 19.6 & 0.0025 & 0.0139 & 9.88 & 0.0201 & 0.0054837 & 0.0012820 & 1.60 & 0.000708 & 0.0000777 & 0.0000219 \\
\hline 51 & 20.0 & 0.0001 & 0.0158 & 8.87 & 0.0177 & 0.0056816 & 0.0042375 & 1.53 & 0.000789 & 0.0000228 & 0.0000000 \\
\hline 52 & 20.4 & 0.0015 & 0.0000 & 9.96 & 0.1289 & 0.0012981 & 0.0018210 & 1.36 & 0.000672 & 0.0000298 & 0.0000133 \\
\hline 53 & 20.8 & 0.0367 & 0.0014 & 8.76 & 0.1086 & 0.0093195 & 0.0091277 & 1.56 & 0.000983 & 0.0000322 & 0.0000000 \\
\hline 54 & 21.2 & 0.0188 & 0.0000 & 7.90 & 0.0058 & 0.0021152 & 0.0026612 & 1.76 & 0.000541 & 0.0001038 & 0.0000016 \\
\hline 55 & 21.6 & 0.0000 & 0.0167 & 6.38 & 0.0131 & 0.0057334 & 0.0027679 & 1.71 & 0.000655 & 0.0001089 & 0.0000000 \\
\hline 56 & 22.0 & 0.0120 & 0.0000 & 10.57 & 0.0000 & 0.0019387 & 0.0062425 & 1.55 & 0.000536 & 0.0002082 & 0.0000122 \\
\hline 57 & 22.4 & 0.0232 & 0.0000 & 6.66 & 0.0000 & 0.0036279 & 0.0062523 & 1.45 & 0.000576 & 0.0000696 & 0.0000000 \\
\hline 58 & 22.8 & 0.0000 & 0.0000 & 3.25 & 0.0159 & 0.0054004 & 0.0045385 & 1.49 & 0.000450 & 0.0001117 & 0.0000000 \\
\hline 59 & 23.2 & 0.0422 & 0.0066 & 11.17 & 0.8283 & 0.0088102 & 0.0077375 & 1.80 & 0.001603 & 0.0002703 & 0.0000000 \\
\hline
\end{tabular}




\begin{tabular}{|c|c|c|c|c|c|c|c|c|c|c|c|}
\hline \multirow{2}{*}{ Spot Number } & \multirow{2}{*}{ Distance from the foot $(\mathrm{mm})$} & \multicolumn{10}{|c|}{ K3A prismatic layer transect corrected data $(\mathrm{mmol} / \mathrm{mol})$ continued... } \\
\hline & & $\mathrm{Li} / \mathrm{Ca}$ & $\mathrm{B} / \mathrm{Ca}$ & $\mathrm{Mg} / \mathrm{Ca}$ & $\mathrm{Al} / \mathrm{Ca}$ & $\mathrm{Mn} / \mathrm{Ca}$ & $\mathrm{Zn} / \mathrm{Ca}$ & $\mathrm{Sr} / \mathrm{Ca}$ & $\mathrm{Ba} / \mathrm{Ca}$ & $\mathrm{Pb} / \mathrm{Ca}$ & $\mathrm{U} / \mathbf{C a}$ \\
\hline 60 & 23.6 & 0.0026 & 0.0282 & 15.56 & 0.0134 & 0.0028642 & 0.0044512 & 2.02 & 0.000635 & 0.0001256 & 0.0000167 \\
\hline 61 & 24.0 & 0.0474 & 0.0000 & 6.55 & 0.0020 & 0.0057633 & 0.0022519 & 1.65 & 0.000666 & 0.0001446 & 0.0000000 \\
\hline 62 & 24.4 & 0.0000 & 0.0000 & 3.63 & 0.0000 & 0.0000000 & 0.0051775 & 1.75 & 0.000580 & 0.0001643 & 0.0000000 \\
\hline 63 & 24.8 & 0.0076 & 0.0016 & 3.37 & 0.0353 & 0.0031236 & 0.0112702 & 1.88 & 0.001509 & 0.0002477 & 0.0000143 \\
\hline 64 & 25.2 & 0.0007 & 0.0131 & 4.14 & 0.0011 & 0.0007421 & 0.0108357 & 1.57 & 0.000598 & 0.0001642 & 0.0000000 \\
\hline 65 & 25.6 & 0.0241 & 0.0161 & 6.89 & 0.0000 & 0.0013649 & 0.0077401 & 1.85 & 0.000596 & 0.0001482 & 0.0000016 \\
\hline 66 & 26.0 & 0.0215 & 0.0231 & 7.46 & 0.3853 & 0.0086110 & 0.0041125 & 1.77 & 0.000936 & 0.0001003 & 0.0000132 \\
\hline 67 & 26.4 & 0.0101 & 0.0000 & 4.93 & 0.0043 & 0.0022003 & 0.0063593 & 1.62 & 0.000654 & 0.0000707 & 0.0000233 \\
\hline 68 & 26.8 & 0.0338 & 0.0002 & 7.16 & 0.0117 & 0.0009490 & 0.0033819 & 1.59 & 0.000682 & 0.0000669 & 0.0000023 \\
\hline 69 & 27.2 & 0.0000 & 0.0054 & 5.62 & 0.0113 & 0.0054174 & 0.0062204 & 1.70 & 0.000697 & 0.0001374 & 0.0000033 \\
\hline 70 & 27.6 & 0.0225 & 0.0262 & 8.99 & 0.0135 & 0.0021257 & 0.0041956 & 1.81 & 0.000812 & 0.0000000 & 0.0000000 \\
\hline 71 & 28.0 & 0.0128 & 0.0000 & 2.95 & 0.0081 & 0.0000000 & 0.0067231 & 1.29 & 0.000358 & 0.0001100 & 0.0000054 \\
\hline 72 & 28.4 & 0.0065 & 0.0089 & 3.61 & 0.0000 & 0.0012539 & 0.0021120 & 1.73 & 0.000585 & 0.0001349 & 0.0000121 \\
\hline 73 & 28.8 & 0.0197 & 0.0104 & 3.24 & 0.0000 & 0.0022761 & 0.0037665 & 1.48 & 0.000468 & 0.0000008 & 0.0000165 \\
\hline 74 & 29.2 & 0.0102 & 0.0120 & 4.73 & 0.0000 & 0.0032262 & 0.0030531 & 1.35 & 0.000422 & 0.0000589 & 0.0000056 \\
\hline 75 & 29.6 & 0.0184 & 0.0223 & 7.39 & 0.1639 & 0.0025935 & 0.0032539 & 1.63 & 0.000853 & 0.0000515 & 0.0000121 \\
\hline 76 & 30.0 & 0.0258 & 0.0231 & 9.41 & 0.1092 & 0.0020128 & 0.0028132 & 1.72 & 0.000757 & 0.0000182 & 0.0000000 \\
\hline 77 & 30.4 & 0.0000 & 0.0000 & 4.44 & 0.0000 & 0.0036245 & 0.0068509 & 1.48 & 0.000508 & 0.0000778 & 0.0000037 \\
\hline 78 & 30.8 & 0.0044 & 0.0245 & 5.85 & 0.0000 & 0.0040976 & 0.0029392 & 1.21 & 0.000446 & 0.0000611 & 0.0000000 \\
\hline 79 & 31.2 & 0.0192 & 0.0000 & 4.54 & 0.0000 & 0.0026950 & 0.0041161 & 1.35 & 0.000577 & 0.0000475 & 0.0000112 \\
\hline 80 & 31.6 & 0.0158 & 0.0009 & 5.65 & 0.0000 & 0.0032790 & 0.0036794 & 1.11 & 0.000313 & 0.0000796 & 0.0000057 \\
\hline 81 & 32.0 & 0.0000 & 0.0000 & 4.67 & 0.0000 & 0.0012545 & 0.0060341 & 1.09 & 0.000406 & 0.0000574 & 0.0000000 \\
\hline 82 & 32.4 & 0.0101 & 0.0000 & 5.80 & 0.0000 & 0.0048216 & 0.0105566 & 1.56 & 0.000731 & 0.0000000 & 0.0000000 \\
\hline 83 & 32.8 & 0.0000 & 0.0000 & 3.22 & 0.0130 & 0.0112641 & 0.0080010 & 1.15 & 0.000426 & 0.0000898 & 0.0000168 \\
\hline 84 & 33.2 & 0.0163 & 0.0137 & 6.91 & 0.0054 & 0.0032174 & 0.0091824 & 1.83 & 0.000637 & 0.0000603 & 0.0000000 \\
\hline 85 & 33.6 & 0.0325 & 0.0629 & 19.48 & 0.2516 & 0.0226376 & 0.0054861 & 2.00 & 0.001798 & 0.0001502 & 0.0000724 \\
\hline 86 & 34.0 & 0.0110 & 0.0184 & 9.66 & 0.0000 & 0.0026033 & 0.0043748 & 1.62 & 0.000629 & 0.0001250 & 0.0000046 \\
\hline 87 & 34.4 & 0.0135 & 0.0246 & 16.09 & 0.0000 & 0.0060117 & 0.0043717 & 1.58 & 0.000723 & 0.0001193 & 0.0000023 \\
\hline 88 & 34.8 & 0.0159 & 0.0317 & 11.54 & 0.0080 & 0.0052893 & 0.0080119 & 1.49 & 0.000707 & 0.0000460 & 0.0000010 \\
\hline 89 & 35.2 & 0.0256 & 0.0287 & 16.06 & 0.0000 & 0.0117428 & 0.0073096 & 2.22 & 0.001489 & 0.0001811 & 0.0001543 \\
\hline
\end{tabular}




\begin{tabular}{|c|c|c|c|c|c|c|c|c|c|c|c|}
\hline \multirow{2}{*}{ Spot Number } & \multirow{2}{*}{ Distance from the foot $(\mathrm{mm})$} & \multicolumn{10}{|c|}{ K3A prismatic layer transect corrected data ( $\mathrm{mmol} / \mathrm{mol})$ continued... } \\
\hline & & $\mathrm{Li} / \mathrm{Ca}$ & $\mathrm{B} / \mathrm{Ca}$ & $\mathrm{Mg} / \mathrm{Ca}$ & $\mathrm{Al} / \mathrm{Ca}$ & $\mathrm{Mn} / \mathrm{Ca}$ & $\mathrm{Zn} / \mathrm{Ca}$ & $\mathrm{Sr} / \mathrm{Ca}$ & $\mathrm{Ba} / \mathrm{Ca}$ & $\mathrm{Pb} / \mathrm{Ca}$ & $\mathrm{U} / \mathrm{Ca}$ \\
\hline 90 & 35.6 & 0.0050 & 0.0032 & 5.65 & 0.0021 & 0.0016187 & 0.0075558 & 1.45 & 0.000531 & 0.0001432 & 0.0000000 \\
\hline 91 & 36.0 & 0.0137 & 0.0000 & 5.64 & 0.0000 & 0.0138902 & 0.0033318 & 1.24 & 0.000487 & 0.0001802 & 0.0000014 \\
\hline 92 & 36.4 & 0.0008 & 0.0170 & 2.94 & 0.0012 & 0.0045923 & 0.0077707 & 1.56 & 0.000582 & 0.0001044 & 0.0000000 \\
\hline 93 & 36.8 & 0.0319 & 0.0410 & 9.55 & 0.0226 & 0.0055465 & 0.0037813 & 2.29 & 0.001163 & 0.0000373 & 0.0000176 \\
\hline 94 & 37.2 & 0.0111 & 0.0104 & 6.38 & 0.0000 & 0.0022946 & 0.0021786 & 1.36 & 0.000529 & 0.0000654 & 0.0000000 \\
\hline 95 & 37.6 & 0.0174 & 0.0146 & 2.92 & 0.0011 & 0.0087976 & 0.0061584 & 1.44 & 0.000462 & 0.0001161 & 0.0000000 \\
\hline 96 & 38.0 & 0.0165 & 0.0000 & 3.53 & 0.0116 & 0.0121678 & 0.0008882 & 1.80 & 0.000666 & 0.0002093 & 0.0000000 \\
\hline
\end{tabular}


APPENDIX 5.11 K1A1 prismatic layer transect data

\begin{tabular}{|c|c|c|c|c|c|c|c|c|c|c|c|}
\hline \multirow{2}{*}{ spot number } & \multirow{2}{*}{ Distance from the foot (mm) } & \multicolumn{10}{|c|}{ K1A1 prismatic layer transect corrected data $(\mathrm{mmol} / \mathrm{mol})$} \\
\hline & & $\mathrm{Li} / \mathrm{Ca}$ & $\mathrm{B} / \mathrm{Ca}$ & $\mathrm{Mg} / \mathrm{Ca}$ & $\mathrm{Al} / \mathrm{Ca}$ & $\mathrm{Mn} / \mathrm{Ca}$ & $\mathrm{Zn} / \mathrm{Ca}$ & $\mathrm{Sr} / \mathrm{Ca}$ & $\mathrm{Ba} / \mathrm{Ca}$ & $\mathrm{Pb} / \mathrm{Ca}$ & $\mathrm{U} / \mathrm{Ca}$ \\
\hline 1 & 0.0 & 0.0270 & 0.0028 & 13.54 & 0.1063 & 0.00900 & 0.00873 & 1.96 & 0.001265 & 0.000160 & 0.0000000 \\
\hline 2 & 0.4 & 0.0000 & 0.0063 & 7.29 & 0.0043 & 0.00049 & 0.00633 & 1.83 & 0.000814 & 0.000051 & 0.0000000 \\
\hline 3 & 0.8 & 0.0147 & 0.0282 & 11.12 & 0.0260 & 0.00259 & 0.01495 & 1.95 & 0.001177 & 0.000000 & 0.0000416 \\
\hline 4 & 1.2 & 0.0119 & 0.0128 & 7.84 & 0.0000 & 0.00060 & 0.01146 & 1.77 & 0.000853 & 0.000235 & 0.0000114 \\
\hline 5 & 1.6 & 0.0131 & 0.0319 & 12.82 & 0.0000 & 0.00379 & 0.00182 & 1.70 & 0.001049 & 0.000185 & 0.0000000 \\
\hline 6 & 2.0 & 0.0051 & 0.0134 & 6.31 & 0.0000 & 0.00149 & 0.00000 & 1.49 & 0.000584 & 0.000061 & 0.0000129 \\
\hline 7 & 2.4 & 0.0007 & 0.0000 & 6.77 & 0.0423 & 0.00250 & 0.00564 & 1.57 & 0.000846 & 0.000144 & 0.0000140 \\
\hline 8 & 2.8 & 0.0333 & 0.0163 & 31.17 & 0.0472 & 0.00671 & 0.00793 & 1.60 & 0.001260 & 0.000321 & 0.0000305 \\
\hline 9 & 3.2 & 0.0157 & 0.0000 & 6.46 & 0.0129 & 0.00107 & 0.00904 & 1.41 & 0.000716 & 0.000236 & 0.0000301 \\
\hline 10 & 3.6 & 0.0248 & 0.0169 & 5.26 & 0.0000 & 0.00172 & 0.00303 & 1.18 & 0.000456 & 0.000114 & 0.0000000 \\
\hline 11 & 4.0 & 0.0070 & 0.0099 & 5.72 & 0.0027 & 0.01057 & 0.00013 & 1.45 & 0.000504 & 0.000258 & 0.0000313 \\
\hline 12 & 4.4 & 0.0000 & 0.0194 & 5.36 & 0.0139 & 0.00260 & 0.00246 & 1.56 & 0.000583 & 0.000295 & 0.0000025 \\
\hline 13 & 4.8 & 0.0348 & 0.0224 & 5.74 & 0.0684 & 0.00411 & 0.00307 & 1.91 & 0.000980 & 0.000191 & 0.0000000 \\
\hline 14 & 5.2 & 0.0000 & 0.0118 & 8.29 & 0.0074 & 0.00173 & 0.00551 & 1.77 & 0.000743 & 0.000322 & 0.0000003 \\
\hline 15 & 5.6 & 0.0136 & 0.0000 & 5.89 & 0.0216 & 0.00439 & 0.00945 & 1.65 & 0.000711 & 0.000132 & 0.0000000 \\
\hline 16 & 6.0 & 0.0000 & 0.0037 & 7.11 & 0.0031 & 0.00513 & 0.00636 & 1.70 & 0.000849 & 0.000181 & 0.0000000 \\
\hline 17 & 6.4 & 0.0037 & 0.0000 & 8.30 & 0.0006 & 0.00000 & 0.00696 & 1.39 & 0.000427 & 0.000144 & 0.0000000 \\
\hline 18 & 6.8 & 0.0000 & 0.0173 & 3.62 & 0.0000 & 0.00322 & 0.00000 & 1.68 & 0.000663 & 0.000129 & 0.0000146 \\
\hline 19 & 7.2 & 0.0000 & 0.0074 & 6.75 & 0.0000 & 0.00142 & 0.00149 & 1.51 & 0.000446 & 0.000141 & 0.0000015 \\
\hline 20 & 7.6 & 0.0000 & 0.0168 & 3.39 & 0.0000 & 0.00116 & 0.00907 & 1.64 & 0.000519 & 0.000017 & 0.0000156 \\
\hline 21 & 8.0 & 0.0243 & 0.0027 & 7.11 & 0.0000 & 0.00000 & 0.01122 & 1.63 & 0.000631 & 0.000150 & 0.0000005 \\
\hline 22 & 8.4 & 0.0054 & 0.0000 & 5.56 & 0.0000 & 0.00428 & 0.00421 & 1.59 & 0.000626 & 0.000338 & 0.0000000 \\
\hline 23 & 8.8 & 0.0000 & 0.0205 & 6.71 & 0.0000 & 0.00198 & 0.00494 & 1.75 & 0.000856 & 0.000281 & 0.0000000 \\
\hline 24 & 9.2 & 0.0000 & 0.0052 & 4.17 & 0.0263 & 0.00338 & 0.00294 & 1.84 & 0.000840 & 0.000336 & 0.0000225 \\
\hline 25 & 9.6 & 0.0000 & 0.0000 & 6.18 & 0.0000 & 0.00266 & 0.01203 & 1.89 & 0.000878 & 0.000209 & 0.0000000 \\
\hline 26 & 10.0 & 0.0442 & 0.0122 & 3.73 & 0.0197 & 0.00177 & 0.00155 & 1.52 & 0.000479 & 0.000122 & 0.0000000 \\
\hline 27 & 10.4 & 0.0333 & 0.0338 & 4.97 & 0.0000 & 0.00124 & 0.00465 & 1.56 & 0.000505 & 0.000240 & 0.0000071 \\
\hline 28 & 10.8 & 0.0321 & 0.0000 & 3.33 & 0.0000 & 0.00363 & 0.01207 & 1.49 & 0.000504 & 0.000345 & 0.0000000 \\
\hline 29 & 11.2 & 0.0073 & 0.0000 & 8.81 & 0.0000 & 0.00321 & 0.00000 & 1.55 & 0.000672 & 0.000251 & 0.0000000 \\
\hline
\end{tabular}




\begin{tabular}{|c|c|c|c|c|c|c|c|c|c|c|c|}
\hline \multirow{2}{*}{ spot number } & \multirow{2}{*}{ Distance from the foot $(\mathrm{mm})$} & \multicolumn{10}{|c|}{ K1A1 prismatic layer transect corrected data $(\mathrm{mmol} / \mathrm{mol})$ continued... } \\
\hline & & $\mathrm{Li} / \mathrm{Ca}$ & $\mathrm{B} / \mathrm{Ca}$ & $\mathrm{Mg} / \mathrm{Ca}$ & $\mathbf{A l} / \mathbf{C a}$ & $\mathrm{Mn} / \mathrm{Ca}$ & $\mathrm{Zn} / \mathrm{Ca}$ & $\mathrm{Sr} / \mathrm{Ca}$ & $\mathrm{Ba} / \mathrm{Ca}$ & $\mathrm{Pb} / \mathrm{Ca}$ & $\mathrm{U} / \mathbf{C a}$ \\
\hline 30 & 11.6 & 0.0353 & 0.0199 & 10.29 & 0.0161 & 0.00308 & 0.00000 & 1.74 & 0.000983 & 0.000072 & 0.0000256 \\
\hline 31 & 12.0 & 0.0203 & 0.0466 & 15.97 & 0.0182 & 0.00727 & 0.01221 & 1.70 & 0.001611 & 0.000091 & 0.0000041 \\
\hline 32 & 12.4 & 0.0061 & 0.0000 & 7.25 & 0.0071 & 0.00422 & 0.00614 & 1.53 & 0.000561 & 0.000111 & 0.0000000 \\
\hline 33 & 12.8 & 0.0000 & 0.0174 & 10.68 & 0.0195 & 0.00000 & 0.00441 & 1.71 & 0.002501 & 0.000091 & 0.0000320 \\
\hline 34 & 13.2 & 0.0209 & 0.0000 & 7.07 & 0.0000 & 0.00246 & 0.01068 & 1.55 & 0.001352 & 0.000148 & 0.0000455 \\
\hline 35 & 13.6 & 0.0000 & 0.0021 & 7.85 & 0.0000 & 0.00651 & 0.01093 & 1.19 & 0.000441 & 0.000249 & 0.0000000 \\
\hline 36 & 14.0 & 0.0267 & 0.0000 & 4.77 & 0.0000 & 0.00373 & 0.00277 & 1.34 & 0.000513 & 0.000325 & 0.0000199 \\
\hline 37 & 14.4 & 0.0047 & 0.0193 & 6.76 & 0.0093 & 0.00000 & 0.01100 & 1.52 & 0.000719 & 0.000229 & 0.0000333 \\
\hline 38 & 14.8 & 0.0162 & 0.0193 & 12.35 & 0.0000 & 0.00403 & 0.00133 & 1.86 & 0.000882 & 0.000343 & 0.0000000 \\
\hline 39 & 15.2 & 0.0000 & 0.0124 & 4.73 & 0.0000 & 0.00188 & 0.00527 & 1.53 & 0.000590 & 0.000331 & 0.0000000 \\
\hline 40 & 15.6 & 0.0000 & 0.0000 & 9.16 & 0.0000 & 0.00611 & 0.00364 & 1.35 & 0.000487 & 0.000340 & 0.0000000 \\
\hline 41 & 16.0 & 0.0000 & 0.0119 & 12.92 & 0.0000 & 0.00496 & 0.00652 & 1.71 & 0.000905 & 0.000314 & 0.0000000 \\
\hline 42 & 16.4 & 0.0242 & 0.0134 & 3.76 & 0.0000 & 0.00468 & 0.00000 & 1.47 & 0.000481 & 0.000262 & 0.0000000 \\
\hline 43 & 16.8 & 0.0155 & 0.0000 & 18.31 & 0.3477 & 0.00746 & 0.00115 & 1.93 & 0.001286 & 0.000381 & 0.0000095 \\
\hline 44 & 17.2 & 0.0310 & 0.0209 & 11.07 & 0.3176 & 0.00426 & 0.00706 & 1.95 & 0.001110 & 0.000282 & 0.0000000 \\
\hline 45 & 17.6 & 0.0085 & 0.0080 & 5.29 & 0.0000 & 0.00148 & 0.00397 & 1.48 & 0.000538 & 0.000345 & 0.0000026 \\
\hline 46 & 18.0 & 0.0301 & 0.0050 & 7.51 & 0.0175 & 0.00491 & 0.00622 & 1.75 & 0.000889 & 0.000423 & 0.0000000 \\
\hline 47 & 18.4 & 0.0023 & 0.0082 & 4.33 & 0.0000 & 0.00316 & 0.00000 & 1.68 & 0.000545 & 0.000486 & 0.0000324 \\
\hline 48 & 18.8 & 0.0079 & 0.0098 & 9.97 & 0.0000 & 0.00163 & 0.00903 & 1.77 & 0.000643 & 0.000428 & 0.0000000 \\
\hline 49 & 19.2 & 0.0259 & 0.0156 & 5.35 & 0.0022 & 0.00217 & 0.00743 & 1.44 & 0.000532 & 0.000505 & 0.0000000 \\
\hline 50 & 19.6 & 0.0174 & 0.0014 & 8.26 & 0.0000 & 0.00251 & 0.01119 & 1.31 & 0.000741 & 0.000494 & 0.0000130 \\
\hline 51 & 20.0 & 0.0035 & 0.0108 & 11.83 & 0.0000 & 0.00468 & 0.01727 & 1.45 & 0.000752 & 0.000443 & 0.0000086 \\
\hline 52 & 20.4 & 0.0053 & 0.0051 & 6.10 & 0.0000 & 0.00000 & 0.00441 & 1.29 & 0.000637 & 0.000365 & 0.0000120 \\
\hline 53 & 20.8 & 0.0209 & 0.0282 & 7.42 & 0.0155 & 0.00350 & 0.00977 & 1.20 & 0.000475 & 0.000366 & 0.0000144 \\
\hline 54 & 21.2 & 0.0000 & 0.0187 & 6.53 & 0.0065 & 0.00481 & 0.00657 & 1.28 & 0.000529 & 0.000389 & 0.0000000 \\
\hline 55 & 21.6 & 0.0237 & 0.0298 & 5.77 & 0.0000 & 0.00480 & 0.00910 & 1.36 & 0.000568 & 0.000528 & 0.0000101 \\
\hline 56 & 22.0 & 0.0103 & 0.0000 & 7.23 & 0.0000 & 0.00354 & 0.00443 & 1.61 & 0.000785 & 0.000422 & 0.0000035 \\
\hline 57 & 22.4 & 0.0091 & 0.0087 & 16.76 & 0.0000 & 0.00432 & 0.00516 & 1.88 & 0.001155 & 0.000292 & 0.0000000 \\
\hline 58 & 22.8 & 0.0100 & 0.0148 & 9.93 & 0.0067 & 0.00110 & 0.00000 & 1.93 & 0.000989 & 0.000319 & 0.0000068 \\
\hline 59 & 23.2 & 0.0070 & 0.0042 & 5.60 & 0.0000 & 0.00001 & 0.00295 & 1.54 & 0.000568 & 0.000238 & 0.0000000 \\
\hline
\end{tabular}




\begin{tabular}{|c|c|c|c|c|c|c|c|c|c|c|c|}
\hline \multirow{2}{*}{ spot number } & \multirow{2}{*}{ Distance from the foot $(\mathrm{mm})$} & \multicolumn{10}{|c|}{ K1A1 prismatic layer transect corrected data $(\mathrm{mmol} / \mathrm{mol})$ continued... } \\
\hline & & $\mathrm{Li} / \mathrm{Ca}$ & $\mathbf{B} / \mathbf{C a}$ & $\mathrm{Mg} / \mathrm{Ca}$ & $\mathbf{A l} / \mathbf{C a}$ & $\mathrm{Mn} / \mathrm{Ca}$ & $\mathrm{Zn} / \mathrm{Ca}$ & $\mathrm{Sr} / \mathrm{Ca}$ & $\mathrm{Ba} / \mathrm{Ca}$ & $\mathrm{Pb} / \mathrm{Ca}$ & $\mathbf{U} / \mathbf{C a}$ \\
\hline 60 & 23.6 & 0.0000 & 0.0250 & 6.94 & 0.0000 & 0.00000 & 0.00553 & 1.53 & 0.000564 & 0.000332 & 0.0000229 \\
\hline 61 & 24.0 & 0.0000 & 0.0000 & 7.29 & 0.0000 & 0.01146 & 0.00668 & 1.82 & 0.000938 & 0.000483 & 0.0000000 \\
\hline 62 & 24.4 & 0.0397 & 0.0123 & 7.20 & 0.0000 & 0.00928 & 0.00790 & 1.68 & 0.000712 & 0.000394 & 0.0000000 \\
\hline 63 & 24.8 & 0.0240 & 0.0027 & 4.43 & 0.0006 & 0.00400 & 0.00523 & 1.31 & 0.000388 & 0.000381 & 0.0000000 \\
\hline 64 & 25.2 & 0.0000 & 0.0082 & 5.70 & 0.0000 & 0.00000 & 0.00462 & 1.44 & 0.000495 & 0.000390 & 0.0000000 \\
\hline 65 & 25.6 & 0.0000 & 0.0000 & 5.84 & 0.0000 & 0.00454 & 0.01628 & 1.37 & 0.000524 & 0.000537 & 0.0000000 \\
\hline 66 & 26.0 & 0.0000 & 0.0000 & 6.48 & 0.0000 & 0.00255 & 0.00514 & 1.49 & 0.000470 & 0.000427 & 0.0000000 \\
\hline 67 & 26.4 & 0.0224 & 0.0000 & 9.50 & 0.0016 & 0.00290 & 0.00050 & 1.12 & 0.000372 & 0.000277 & 0.0000000 \\
\hline 68 & 26.8 & 0.0095 & 0.0000 & 6.78 & 0.0063 & 0.00144 & 0.00487 & 1.43 & 0.000549 & 0.000327 & 0.0000000 \\
\hline 69 & 27.2 & 0.0003 & 0.0196 & 23.26 & 0.0000 & 0.00452 & 0.00827 & 1.56 & 0.000908 & 0.000334 & 0.0000000 \\
\hline 70 & 27.6 & 0.0218 & 0.0150 & 13.62 & 0.0000 & 0.00000 & 0.00593 & 1.45 & 0.000731 & 0.000201 & 0.0000000 \\
\hline 71 & 28.0 & 0.0218 & 0.0177 & 10.88 & 0.0159 & 0.00886 & 0.01870 & 1.88 & 0.001548 & 0.000169 & 0.0000274 \\
\hline 72 & 28.4 & 0.0054 & 0.0000 & 6.18 & 0.0000 & 0.00447 & 0.00130 & 1.40 & 0.000576 & 0.000176 & 0.0000000 \\
\hline 73 & 28.8 & 0.0161 & 0.0295 & 5.94 & 0.0000 & 0.00099 & 0.00430 & 1.46 & 0.000629 & 0.000116 & 0.0000000 \\
\hline 74 & 29.2 & 0.0116 & 0.0000 & 8.04 & 0.0000 & 0.00647 & 0.00670 & 1.35 & 0.000527 & 0.000259 & 0.0000000 \\
\hline 75 & 29.6 & 0.0000 & 0.0000 & 3.69 & 0.0000 & 0.00635 & 0.00462 & 1.40 & 0.000534 & 0.000350 & 0.0000006 \\
\hline 76 & 30.0 & 0.0310 & 0.0214 & 7.20 & 0.0000 & 0.00340 & 0.00743 & 1.62 & 0.000693 & 0.000500 & 0.0000161 \\
\hline 77 & 30.4 & 0.0000 & 0.0000 & 6.41 & 0.0000 & 0.00077 & 0.00421 & 1.54 & 0.000502 & 0.000424 & 0.0000000 \\
\hline 78 & 30.8 & 0.0000 & 0.0000 & 6.82 & 0.0025 & 0.00214 & 0.00828 & 1.62 & 0.000563 & 0.000246 & 0.0000065 \\
\hline 79 & 31.2 & 0.0502 & 0.0000 & 8.65 & 0.0000 & 0.00666 & 0.00515 & 1.40 & 0.000542 & 0.000574 & 0.0000628 \\
\hline 80 & 31.6 & 0.0000 & 0.0228 & 5.16 & 0.0234 & 0.00575 & 0.01036 & 1.44 & 0.000639 & 0.000647 & 0.0000035 \\
\hline 81 & 32.0 & 0.0375 & 0.0003 & 3.89 & 0.0124 & 0.00168 & 0.00351 & 1.49 & 0.000556 & 0.000295 & 0.0000040 \\
\hline 82 & 32.4 & 0.0383 & 0.0000 & 7.67 & 0.0000 & 0.00216 & 0.00308 & 1.49 & 0.000570 & 0.000203 & 0.0000000 \\
\hline 83 & 32.8 & 0.0116 & 0.0000 & 10.37 & 0.0052 & 0.00425 & 0.01164 & 1.16 & 0.000423 & 0.000150 & 0.0000050 \\
\hline 84 & 33.2 & 0.0263 & 0.0200 & 10.87 & 0.0000 & 0.00614 & 0.01106 & 1.23 & 0.000579 & 0.000194 & 0.0000000 \\
\hline 85 & 33.6 & 0.0261 & 0.0079 & 4.92 & 0.0000 & 0.00255 & 0.00170 & 1.25 & 0.000422 & 0.000151 & 0.0000280 \\
\hline 86 & 34.0 & 0.0150 & 0.0139 & 4.40 & 0.0000 & 0.00417 & 0.00787 & 1.41 & 0.000682 & 0.000139 & 0.0000000 \\
\hline 87 & 34.4 & 0.0052 & 0.0244 & 4.32 & 0.0168 & 0.02028 & 0.01037 & 1.15 & 0.000570 & 0.000199 & 0.0000000 \\
\hline 88 & 34.8 & 0.0000 & 0.0002 & 3.65 & 0.0000 & 0.00423 & 0.00972 & 1.27 & 0.000475 & 0.000144 & 0.0000107 \\
\hline 89 & 35.2 & 0.0191 & 0.0000 & 2.86 & 0.0000 & 0.00197 & 0.01256 & 1.44 & 0.000475 & 0.000371 & 0.0000000 \\
\hline
\end{tabular}




\begin{tabular}{|c|c|c|c|c|c|c|c|c|c|c|c|}
\hline \multirow{2}{*}{ spot number } & \multirow{2}{*}{ Distance from the foot $(\mathrm{mm})$} & \multicolumn{10}{|c|}{ K1A1 prismatic layer transect corrected data $(\mathrm{mmol} / \mathrm{mol})$ continued... } \\
\hline & & $\mathrm{Li} / \mathrm{Ca}$ & $\mathrm{B} / \mathrm{Ca}$ & $\mathrm{Mg} / \mathrm{Ca}$ & $\mathrm{Al} / \mathrm{Ca}$ & $\mathrm{Mn} / \mathrm{Ca}$ & $\mathrm{Zn} / \mathrm{Ca}$ & $\mathrm{Sr} / \mathrm{Ca}$ & $\mathrm{Ba} / \mathrm{Ca}$ & $\mathrm{Pb} / \mathrm{Ca}$ & $\mathrm{U} / \mathrm{Ca}$ \\
\hline 91 & 36.0 & 0.0192 & 0.0097 & 4.81 & 0.0000 & 0.00908 & 0.00402 & 1.63 & 0.000632 & 0.000200 & 0.0000034 \\
\hline 92 & 36.4 & 0.0000 & 0.0136 & 3.46 & 0.0000 & 0.00968 & 0.00191 & 1.68 & 0.000608 & 0.000202 & 0.0000000 \\
\hline 93 & 36.8 & 0.0297 & 0.0217 & 2.80 & 0.0000 & 0.00759 & 0.00652 & 1.32 & 0.000460 & 0.000214 & 0.0000171 \\
\hline 94 & 37.2 & 0.0405 & 0.0088 & 3.34 & 0.0073 & 0.00481 & 0.00259 & 1.39 & 0.000466 & 0.000392 & 0.0000105 \\
\hline 95 & 37.6 & 0.0000 & 0.0033 & 3.47 & 0.0000 & 0.00008 & 0.00228 & 1.40 & 0.000505 & 0.000315 & 0.0000000 \\
\hline 96 & 38.0 & 0.0004 & 0.0177 & 3.00 & 0.0000 & 0.00000 & 0.00566 & 1.51 & 0.000456 & 0.000357 & 0.0000000 \\
\hline 97 & 38.4 & 0.0005 & 0.0045 & 4.80 & 0.0163 & 0.00888 & 0.00809 & 1.41 & 0.000472 & 0.000227 & 0.0000167 \\
\hline 98 & 38.8 & 0.0000 & 0.0000 & 4.36 & 0.0000 & 0.00527 & 0.00729 & 1.61 & 0.000580 & 0.000293 & 0.0000000 \\
\hline 99 & 39.2 & 0.0207 & 0.0000 & 5.74 & 0.0000 & 0.00856 & 0.00571 & 1.58 & 0.000592 & 0.000259 & 0.0000107 \\
\hline 100 & 39.6 & 0.0132 & 0.0000 & 5.69 & 0.0000 & 0.00571 & 0.00467 & 1.50 & 0.000457 & 0.000242 & 0.0000038 \\
\hline 101 & 40.0 & 0.0286 & 0.0154 & 8.87 & 0.0000 & 0.00433 & 0.00492 & 1.52 & 0.000565 & 0.000171 & 0.0000105 \\
\hline 102 & 40.4 & 0.0130 & 0.0009 & 11.49 & 0.0000 & 0.01240 & 0.01334 & 1.45 & 0.000587 & 0.000136 & 0.0000000 \\
\hline 103 & 40.8 & 0.0141 & 0.0092 & 6.20 & 0.0000 & 0.02106 & 0.02417 & 1.69 & 0.000773 & 0.000144 & 0.0000286 \\
\hline 104 & 41.2 & 0.0096 & 0.0134 & 3.39 & 0.0000 & 0.01321 & 0.01440 & 1.67 & 0.000694 & 0.000339 & 0.0000013 \\
\hline 105 & 41.6 & 0.0370 & 0.0000 & 3.00 & 0.0000 & 0.00290 & 0.01159 & 1.56 & 0.000485 & 0.000429 & 0.0000089 \\
\hline 106 & 42.0 & 0.0000 & 0.0136 & 5.29 & 0.0000 & 0.01738 & 0.02069 & 1.51 & 0.000713 & 0.000298 & 0.0000000 \\
\hline 107 & 42.4 & 0.0000 & 0.0000 & 3.70 & 0.0000 & 0.01100 & 0.01399 & 1.66 & 0.000681 & 0.000146 & 0.0000118 \\
\hline 108 & 42.8 & 0.0196 & 0.0000 & 4.88 & 0.0128 & 0.01311 & 0.01596 & 1.64 & 0.000659 & 0.000325 & 0.0000224 \\
\hline 109 & 43.2 & 0.0181 & 0.0220 & 4.57 & 0.0000 & 0.00929 & 0.01318 & 1.86 & 0.000739 & 0.000486 & 0.0000198 \\
\hline 110 & 43.6 & 0.0224 & 0.0008 & 4.69 & 0.0000 & 0.00294 & 0.00788 & 1.75 & 0.000507 & 0.000221 & 0.0000136 \\
\hline 111 & 44.0 & 0.0000 & 0.0209 & 4.57 & 0.0028 & 0.00097 & 0.00429 & 1.56 & 0.000431 & 0.000378 & 0.0000092 \\
\hline 112 & 44.4 & 0.0373 & 0.0000 & 6.95 & 0.0000 & 0.00670 & 0.01553 & 1.85 & 0.000731 & 0.000429 & 0.0000129 \\
\hline
\end{tabular}


APPENDIX 5.1m AR1 prismatic layer transect data

\begin{tabular}{|c|c|c|c|c|c|c|c|c|c|c|c|}
\hline \multirow{2}{*}{$\begin{array}{l}\text { Spot } \\
\text { Number }\end{array}$} & \multirow{2}{*}{ Distance from the foot $(\mathrm{mm})$} & \multicolumn{10}{|c|}{ AR1 prismatic layer transect corrected data $(\mathrm{mmol} / \mathrm{mol})$} \\
\hline & & $\mathrm{Li} / \mathrm{Ca}$ & $\mathrm{B} / \mathrm{Ca}$ & $\mathrm{Mg} / \mathrm{Ca}$ & $\mathrm{Al} / \mathrm{Ca}$ & $\mathrm{Mn} / \mathrm{Ca}$ & $\mathrm{Zn} / \mathrm{Ca}$ & $\mathrm{Sr} / \mathrm{Ca}$ & $\mathrm{Ba} / \mathrm{Ca}$ & $\mathrm{Pb} / \mathrm{Ca}$ & $\mathrm{U} / \mathrm{Ca}$ \\
\hline 1 & 0.0 & 0.0182 & 0.0413 & 11.64 & 0.0120 & 0.00000 & 0.00683 & 1.64 & 0.000826 & 0.0000237 & 0.0000173 \\
\hline 2 & 0.4 & 0.0000 & 0.0000 & 2.60 & 0.0000 & 0.00066 & 0.00783 & 1.28 & 0.000528 & 0.0000496 & 0.0000000 \\
\hline 3 & 0.8 & 0.0000 & 0.0000 & 4.39 & 0.0000 & 0.00000 & 0.00535 & 1.31 & 0.000771 & 0.0000709 & 0.0000008 \\
\hline 4 & 1.2 & 0.0416 & 0.0000 & 10.29 & 0.0063 & 0.00000 & 0.00733 & 1.33 & 0.000629 & 0.0001459 & 0.0000000 \\
\hline 5 & 1.6 & 0.0124 & 0.0000 & 13.31 & 0.0481 & 0.00322 & 0.01272 & 1.34 & 0.000962 & 0.0000807 & 0.0000198 \\
\hline 6 & 2.0 & 0.0000 & 0.0274 & 10.90 & 0.0075 & 0.00000 & 0.00000 & 1.29 & 0.000648 & 0.0000758 & 0.0000130 \\
\hline 7 & 2.4 & 0.0371 & 0.0065 & 7.26 & 0.0000 & 0.00000 & 0.00267 & 1.21 & 0.000548 & 0.0000879 & 0.0000000 \\
\hline 8 & 2.8 & 0.0202 & 0.0067 & 8.77 & 0.0180 & 0.00091 & 0.01767 & 1.23 & 0.000806 & 0.0001098 & 0.0000031 \\
\hline 9 & 3.2 & 0.0064 & 0.0000 & 3.32 & 0.0000 & 0.00179 & 0.00420 & 1.26 & 0.000468 & 0.0000784 & 0.0000000 \\
\hline 10 & 3.6 & 0.0144 & 0.0151 & 2.85 & 0.0167 & 0.00000 & 0.01127 & 1.40 & 0.000523 & 0.0000428 & 0.0000407 \\
\hline 11 & 4.0 & 0.0000 & 0.0000 & 4.34 & 0.0013 & 0.00000 & 0.00190 & 1.45 & 0.000398 & 0.0000000 & 0.0000000 \\
\hline 12 & 4.4 & 0.0000 & 0.0126 & 5.00 & 0.0058 & 0.00003 & 0.00141 & 1.36 & 0.000451 & 0.0000000 & 0.0000000 \\
\hline 13 & 4.8 & 0.0155 & 0.0485 & 6.32 & 0.0000 & 0.00000 & 0.00000 & 1.33 & 0.000471 & 0.0000000 & 0.0000117 \\
\hline 14 & 5.2 & 0.0565 & 0.0287 & 3.86 & 0.0126 & 0.00086 & 0.00772 & 1.57 & 0.000698 & 0.0000522 & 0.0000000 \\
\hline 15 & 5.6 & 0.0000 & 0.0253 & 13.78 & 0.0186 & 0.00000 & 0.01302 & 1.30 & 0.000519 & 0.0000818 & 0.0000320 \\
\hline 16 & 6.0 & 0.0558 & 0.0043 & 5.63 & 0.0000 & 0.00321 & 0.00454 & 1.48 & 0.000571 & 0.0000000 & 0.0000000 \\
\hline 17 & 6.4 & 0.0483 & 0.0000 & 13.75 & 0.0088 & 0.00739 & 0.00523 & 1.31 & 0.000458 & 0.0000102 & 0.0000000 \\
\hline 18 & 6.8 & 0.0460 & 0.0065 & 10.55 & 0.0000 & 0.00394 & 0.01158 & 1.16 & 0.000451 & 0.0000000 & 0.0000072 \\
\hline 19 & 7.2 & 0.0124 & 0.0448 & 12.48 & 0.0164 & 0.00474 & 0.00176 & 1.31 & 0.000642 & 0.0000000 & $0.000025 s$ \\
\hline 20 & 7.6 & 0.0314 & 0.0092 & 9.14 & 0.0133 & 0.00384 & 0.01045 & 1.51 & 0.000721 & 0.0001052 & 0.0000000 \\
\hline 21 & 8.0 & 0.0000 & 0.0013 & 8.30 & 0.0000 & 0.00421 & 0.00000 & 1.40 & 0.000492 & 0.0000404 & 0.0000000 \\
\hline 22 & 8.4 & 0.0164 & 0.0080 & 4.87 & 0.0064 & 0.00318 & 0.00920 & 1.55 & 0.000982 & 0.0001235 & 0.0000000 \\
\hline 23 & 8.8 & 0.0000 & 0.0000 & 4.37 & 0.0172 & 0.00118 & 0.00273 & 1.41 & 0.001754 & 0.0000630 & 0.0000104 \\
\hline 24 & 9.2 & 0.0058 & 0.0127 & 9.20 & 0.0000 & 0.00263 & 0.00208 & 1.27 & 0.000835 & 0.0000000 & 0.0000000 \\
\hline 25 & 9.6 & 0.0085 & 0.0000 & 6.07 & 0.0227 & 0.00372 & 0.00669 & 1.28 & 0.000466 & 0.0000794 & 0.0000268 \\
\hline 26 & 10.0 & 0.0194 & 0.0107 & 5.26 & 0.0268 & 0.00000 & 0.00291 & 1.34 & 0.001010 & 0.0000237 & 0.0000001 \\
\hline 27 & 10.4 & 0.0193 & 0.0158 & 4.71 & 0.0042 & 0.00297 & 0.01607 & 1.38 & 0.000408 & 0.0000000 & 0.0000000 \\
\hline 28 & 10.8 & 0.0159 & 0.0000 & 5.68 & 0.0000 & 0.00299 & 0.02180 & 1.30 & 0.001265 & 0.0000105 & 0.0000000 \\
\hline 29 & 11.2 & 0.0000 & 0.0650 & 14.67 & 0.0271 & 0.00320 & 0.00482 & 1.30 & 0.000922 & 0.0000548 & 0.0000000 \\
\hline
\end{tabular}




\begin{tabular}{|c|c|c|c|c|c|c|c|c|c|c|c|}
\hline \multirow{2}{*}{ Spot Number } & \multirow{2}{*}{ Distance from the foot $(\mathrm{mm})$} & \multicolumn{10}{|c|}{ AR1 prismatic layer transect corrected data $(\mathrm{mmol} / \mathrm{mol})$ continued... } \\
\hline & & $\mathrm{Li} / \mathrm{Ca}$ & $\mathrm{B} / \mathrm{Ca}$ & $\mathrm{Mg} / \mathrm{Ca}$ & $\mathrm{Al} / \mathrm{Ca}$ & $\mathrm{Mn} / \mathrm{Ca}$ & $\mathrm{Zn} / \mathrm{Ca}$ & $\mathrm{Sr} / \mathrm{Ca}$ & $\mathrm{Ba} / \mathrm{Ca}$ & $\mathrm{Pb} / \mathrm{Ca}$ & $\mathrm{U} / \mathrm{Ca}$ \\
\hline 30 & 11.6 & 0.0242 & 0.0318 & 6.99 & 0.0123 & 0.00000 & 0.00346 & 1.40 & 0.000542 & 0.0000572 & 0.0000000 \\
\hline 31 & 12.0 & 0.0074 & 0.0000 & 5.09 & 0.0164 & 0.00325 & 0.00408 & 1.53 & 0.000715 & 0.0000116 & 0.0000014 \\
\hline 32 & 12.4 & 0.0217 & 0.0090 & 6.44 & 0.0134 & 0.00000 & 0.01354 & 1.16 & 0.000241 & 0.0000032 & 0.0000241 \\
\hline 33 & 12.8 & 0.0000 & 0.0373 & 6.87 & 0.0032 & 0.00294 & 0.00830 & 1.10 & 0.000487 & 0.0000000 & 0.0000000 \\
\hline 34 & 13.2 & 0.0329 & 0.0161 & 4.54 & 0.0144 & 0.00000 & 0.00554 & 1.02 & 0.000488 & 0.0000741 & 0.0000000 \\
\hline 35 & 13.6 & 0.0234 & 0.0000 & 4.14 & 0.0186 & 0.00339 & 0.00188 & 1.05 & 0.000369 & 0.0000304 & 0.0000000 \\
\hline 36 & 14.0 & 0.0000 & 0.0213 & 5.43 & 0.0122 & 0.00253 & 0.00677 & 1.17 & 0.000356 & 0.0000000 & 0.0000000 \\
\hline 37 & 14.4 & 0.0397 & 0.0000 & 5.87 & 0.0002 & 0.00135 & 0.00606 & 1.03 & 0.000325 & 0.0000000 & 0.0000000 \\
\hline 38 & 14.8 & 0.0000 & 0.0331 & 5.31 & 0.0118 & 0.00000 & 0.00763 & 1.11 & 0.000217 & 0.0000000 & 0.0000307 \\
\hline 39 & 15.2 & 0.0000 & 0.0444 & 7.12 & 0.0078 & 0.00090 & 0.00325 & 1.35 & 0.000498 & 0.0000062 & 0.0000000 \\
\hline 40 & 15.6 & 0.0144 & 0.0000 & 5.30 & 0.0000 & 0.00000 & 0.00326 & 1.27 & 0.000351 & 0.0000111 & 0.0000000 \\
\hline 41 & 16.0 & 0.0000 & 0.0260 & 4.62 & 0.0000 & 0.00177 & 0.00585 & 1.08 & 0.000327 & 0.0000778 & 0.0000000 \\
\hline 42 & 16.4 & 0.0000 & 0.0073 & 4.83 & 0.0030 & 0.00022 & 0.00777 & 1.21 & 0.000678 & 0.0000549 & 0.0000157 \\
\hline 43 & 16.8 & 0.0038 & 0.0188 & 2.89 & 0.0192 & 0.00301 & 0.01070 & 1.11 & 0.000344 & 0.0000234 & 0.0000000 \\
\hline 44 & 17.2 & 0.0251 & 0.0226 & 3.08 & 0.0057 & 0.00556 & 0.00402 & 1.18 & 0.000330 & 0.0000000 & 0.0000114 \\
\hline 45 & 17.6 & 0.0000 & 0.0312 & 2.73 & 0.0033 & 0.00000 & 0.00566 & 1.20 & 0.000325 & 0.0001122 & 0.0000000 \\
\hline 46 & 18.0 & 0.0404 & 0.0000 & 4.22 & 0.0030 & 0.00280 & 0.00994 & 1.19 & 0.000298 & 0.0000575 & 0.0000000 \\
\hline 47 & 18.4 & 0.0233 & 0.0133 & 3.45 & 0.0009 & 0.00000 & 0.01083 & 1.17 & 0.000348 & 0.0000110 & 0.0000190 \\
\hline 48 & 18.8 & 0.0000 & 0.0160 & 5.65 & 0.0099 & 0.00000 & 0.01927 & 1.24 & 0.000507 & 0.0000000 & 0.0000000 \\
\hline 49 & 19.2 & 0.0163 & 0.0033 & 3.76 & 0.0155 & 0.00000 & 0.01105 & 1.24 & 0.000551 & 0.0000000 & 0.0000000 \\
\hline 50 & 19.6 & 0.0426 & 0.0000 & 4.24 & 0.0036 & 0.00052 & 0.01192 & 1.15 & 0.000555 & 0.0000799 & 0.0000000 \\
\hline 51 & 20.0 & 0.0061 & 0.0005 & 3.75 & 0.0079 & 0.00033 & 0.00695 & 1.35 & 0.000352 & 0.0001243 & 0.0000113 \\
\hline 52 & 20.4 & 0.0467 & 0.0435 & 8.55 & 0.0000 & 0.00102 & 0.01091 & 1.13 & 0.000535 & 0.0000164 & 0.0000000 \\
\hline 53 & 20.8 & 0.0044 & 0.0081 & 3.58 & 0.0089 & 0.00000 & 0.00666 & 1.22 & 0.000319 & 0.0000000 & 0.0000301 \\
\hline 54 & 21.2 & 0.0311 & 0.0046 & 4.32 & 0.0085 & 0.00299 & 0.00223 & 1.16 & 0.000347 & 0.0000876 & 0.0000000 \\
\hline 55 & 21.6 & 0.0329 & 0.0501 & 5.73 & 0.0080 & 0.00381 & 0.00310 & 1.13 & 0.000615 & 0.0000000 & 0.0000000 \\
\hline 56 & 22.0 & 0.0300 & 0.0071 & 5.28 & 0.0000 & 0.00097 & 0.00765 & 1.08 & 0.000369 & 0.0001161 & 0.0000086 \\
\hline 57 & 22.4 & 0.0000 & 0.0204 & 5.98 & 0.0000 & 0.00000 & 0.00536 & 1.15 & 0.000352 & 0.0000340 & 0.0000000 \\
\hline 58 & 22.8 & 0.0259 & 0.0157 & 10.46 & 0.0189 & 0.00155 & 0.00845 & 1.07 & 0.000417 & 0.0000527 & 0.0000000 \\
\hline 59 & 23.2 & 0.0205 & 0.0000 & 7.27 & 0.0217 & 0.00183 & 0.00822 & 1.21 & 0.000304 & 0.0001135 & 0.0000000 \\
\hline
\end{tabular}




\begin{tabular}{|c|c|c|c|c|c|c|c|c|c|c|c|}
\hline \multirow{2}{*}{ Spot Number } & \multirow{2}{*}{ Distance from the foot $(\mathrm{mm})$} & \multicolumn{10}{|c|}{ AR1 prismatic layer transect corrected data $(\mathrm{mmol} / \mathrm{mol})$ continued... } \\
\hline & & $\mathrm{Li} / \mathrm{Ca}$ & $\mathrm{B} / \mathrm{Ca}$ & $\mathrm{Mg} / \mathrm{Ca}$ & $\mathrm{Al} / \mathrm{Ca}$ & $\mathrm{Mn} / \mathrm{Ca}$ & $\mathrm{Zn} / \mathrm{Ca}$ & $\mathrm{Sr} / \mathrm{Ca}$ & $\mathrm{Ba} / \mathrm{Ca}$ & $\mathrm{Pb} / \mathrm{Ca}$ & $\mathrm{U} / \mathrm{Ca}$ \\
\hline 60 & 23.6 & 0.0000 & 0.0167 & 5.64 & 0.0478 & 0.00579 & 0.01157 & 1.39 & 0.000657 & 0.0000970 & 0.0000093 \\
\hline 61 & 24.0 & 0.0000 & 0.0062 & 6.70 & 0.0292 & 0.00558 & 0.00593 & 1.38 & 0.000623 & 0.0000000 & 0.0000064 \\
\hline 62 & 24.4 & 0.0094 & 0.0291 & 4.61 & 0.0000 & 0.00000 & 0.00093 & 1.39 & 0.000539 & 0.0000450 & 0.0000000 \\
\hline 63 & 24.8 & 0.0327 & 0.0360 & 7.33 & 0.0038 & 0.00582 & 0.00861 & 1.66 & 0.000707 & 0.0000167 & 0.0000177 \\
\hline 64 & 25.2 & 0.0092 & 0.0106 & 4.44 & 0.0000 & 0.00318 & 0.00420 & 1.37 & 0.000561 & 0.0000113 & 0.0000027 \\
\hline 65 & 25.6 & 0.0063 & 0.0307 & 3.33 & 0.0000 & 0.00320 & 0.00000 & 1.50 & 0.000469 & 0.0000404 & 0.0000417 \\
\hline 66 & 26.0 & 0.0077 & 0.0042 & 3.63 & 0.0117 & 0.00443 & 0.00480 & 1.59 & 0.000457 & 0.0000249 & 0.0000057 \\
\hline 67 & 26.4 & 0.0184 & 0.0220 & 3.94 & 0.0000 & 0.00375 & 0.00576 & 1.57 & 0.000556 & 0.0000222 & 0.0000007 \\
\hline 68 & 26.8 & 0.0354 & 0.0317 & 8.78 & 0.0000 & 0.00417 & 0.00371 & 1.72 & 0.000642 & 0.0000239 & 0.0000137 \\
\hline 69 & 27.2 & 0.0084 & 0.0016 & 13.56 & 0.0002 & 0.00000 & 0.00218 & 1.77 & 0.000599 & 0.0000738 & 0.0000544 \\
\hline 70 & 27.6 & 0.0000 & 0.0061 & 4.10 & 0.0111 & 0.00386 & 0.00361 & 1.20 & 0.000516 & 0.0000785 & 0.0000224 \\
\hline 71 & 28.0 & 0.0062 & 0.0206 & 3.35 & 0.0049 & 0.00711 & 0.00551 & 1.75 & 0.001157 & 0.0000000 & 0.0000000 \\
\hline 72 & 28.4 & 0.0159 & 0.0281 & 7.54 & 0.0139 & 0.00430 & 0.00000 & 1.57 & 0.000564 & 0.0000000 & 0.0000188 \\
\hline 73 & 28.8 & 0.0131 & 0.0088 & 5.61 & 0.0000 & 0.00430 & 0.00611 & 1.47 & 0.000880 & 0.0000000 & 0.0000324 \\
\hline 74 & 29.2 & 0.0238 & 0.0000 & 2.86 & 0.0000 & 0.00138 & 0.00725 & 1.41 & 0.000525 & 0.0000299 & 0.0000000 \\
\hline 75 & 29.6 & 0.0587 & 0.0110 & 2.87 & 0.0054 & 0.00080 & 0.00778 & 1.22 & 0.000379 & 0.0000041 & 0.0000113 \\
\hline 76 & 30.0 & 0.0170 & 0.0228 & 3.55 & 0.0000 & 0.00513 & 0.00597 & 1.44 & 0.000696 & 0.0000587 & 0.0000000 \\
\hline 77 & 30.4 & 0.0270 & 0.0214 & 3.41 & 0.0105 & 0.00141 & 0.00269 & 1.10 & 0.000366 & 0.0000958 & 0.0000304 \\
\hline 78 & 30.8 & 0.0000 & 0.0062 & 4.30 & 0.0003 & 0.00034 & 0.01587 & 1.20 & 0.000448 & 0.0000000 & 0.0000361 \\
\hline 79 & 31.2 & 0.0109 & 0.0294 & 3.68 & 0.0000 & 0.00253 & 0.00041 & 1.13 & 0.000257 & 0.0000649 & 0.0000000 \\
\hline 80 & 31.6 & 0.0000 & 0.0043 & 4.05 & 0.0278 & 0.00845 & 0.00000 & 1.04 & 0.000425 & 0.0000000 & 0.0000000 \\
\hline 81 & 32.0 & 0.0503 & 0.0509 & 4.66 & 0.0092 & 0.00448 & 0.00937 & 1.09 & 0.000350 & 0.0000000 & 0.0000134 \\
\hline 82 & 32.4 & 0.0270 & 0.0000 & 6.01 & 0.0353 & 0.00410 & 0.00222 & 1.21 & 0.000560 & 0.0000353 & 0.0000000 \\
\hline 83 & 32.8 & 0.0081 & 0.0387 & 3.86 & 0.0106 & 0.00014 & 0.01136 & 1.23 & 0.000478 & 0.0000352 & 0.0000000 \\
\hline 84 & 33.2 & 0.0058 & 0.0273 & 3.50 & 0.0000 & 0.00214 & 0.00647 & 1.16 & 0.000276 & 0.0000000 & 0.0000112 \\
\hline 85 & 33.6 & 0.0000 & 0.0000 & 4.53 & 0.0100 & 0.00080 & 0.00999 & 1.25 & 0.000373 & 0.0000435 & 0.0000000 \\
\hline 86 & 34.0 & 0.0188 & 0.0000 & 4.98 & 0.0268 & 0.00401 & 0.00206 & 1.13 & 0.000375 & 0.0001210 & 0.0000000 \\
\hline 87 & 34.4 & 0.0249 & 0.0475 & 4.79 & 0.0000 & 0.00152 & 0.01221 & 1.08 & 0.000609 & 0.0001547 & 0.0000149 \\
\hline 88 & 34.8 & 0.0000 & 0.0246 & 3.73 & 0.0325 & 0.00463 & 0.01583 & 1.00 & 0.000440 & 0.0000000 & 0.0000000 \\
\hline 89 & 35.2 & 0.0000 & 0.0074 & 3.82 & 0.0019 & 0.00000 & 0.00878 & 1.20 & 0.000606 & 0.0001130 & 0.0000000 \\
\hline 90 & 35.6 & 0.0179 & 0.0000 & 4.57 & 0.0014 & 0.00463 & 0.02033 & 1.46 & 0.001215 & 0.0001184 & 0.0000132 \\
\hline
\end{tabular}


APPENDIX 5.1n MR2 prismatic layer transect corrected data

\begin{tabular}{|c|c|c|c|c|c|c|c|c|c|c|c|}
\hline \multirow{2}{*}{$\begin{array}{c}\text { Spot } \\
\text { Number }\end{array}$} & \multirow{2}{*}{ Distance from the foot $(\mathrm{mm})$} & \multicolumn{10}{|c|}{ MR2 prismatic layer transect corrected data $(\mathrm{mmol} / \mathrm{mol})$} \\
\hline & & $\mathrm{Li} / \mathrm{Ca}$ & $\mathrm{B} / \mathrm{Ca}$ & $\mathrm{Mg} / \mathrm{Ca}$ & $\mathbf{A l} / \mathbf{C a}$ & $\mathrm{Mn} / \mathrm{Ca}$ & $\mathrm{Zn} / \mathrm{Ca}$ & $\mathrm{Sr} / \mathrm{Ca}$ & $\mathrm{Ba} / \mathrm{Ca}$ & $\mathrm{Pb} / \mathrm{Ca}$ & $\mathrm{U} / \mathrm{Ca}$ \\
\hline 1 & 0.0 & 0.0339 & 0.0000 & 11.47 & 0.0000 & 0.0000 & 0.0092 & 1.46 & 0.00076 & 0.000000 & 0.000108 \\
\hline 2 & 0.4 & 0.0000 & 0.0000 & 6.14 & 0.0000 & 0.0000 & 0.0079 & 1.36 & 0.00056 & 0.000000 & 0.000000 \\
\hline 3 & 0.8 & 0.0280 & 0.0000 & 16.61 & 0.0000 & 0.0000 & 0.0130 & 1.72 & 0.00132 & 0.000191 & 0.000074 \\
\hline 4 & 1.2 & 0.0071 & 0.0000 & 16.93 & 0.4090 & 0.0023 & 0.0129 & 2.43 & 0.00234 & 0.000185 & 0.000265 \\
\hline 5 & 1.6 & 0.0237 & 0.0000 & 12.49 & 0.0000 & 0.0000 & 0.0000 & 1.33 & 0.00069 & 0.000057 & 0.000000 \\
\hline 6 & 2.0 & 0.0034 & 0.0000 & 3.55 & 0.0000 & 0.0000 & 0.0025 & 4.38 & 0.00437 & 0.000000 & 0.000672 \\
\hline 7 & 2.4 & 0.0388 & 0.0000 & 17.86 & 0.0000 & 0.0000 & 0.0000 & 2.86 & 0.00194 & 0.000000 & 0.000104 \\
\hline 8 & 2.8 & 0.0064 & 0.0000 & 5.71 & 0.0000 & 0.0054 & 0.0012 & 1.28 & 0.00109 & 0.000127 & 0.000000 \\
\hline 9 & 3.2 & 0.0380 & 0.0000 & 17.18 & 0.0076 & 0.0000 & 0.0093 & 1.43 & 0.00101 & 0.000000 & 0.000000 \\
\hline 10 & 3.6 & 0.0172 & 0.0000 & 8.92 & 0.6361 & 0.0121 & 0.0000 & 1.39 & 0.00418 & 0.000108 & 0.000046 \\
\hline 11 & 4.0 & 0.0000 & 0.0000 & 13.79 & 0.0000 & 0.0054 & 0.0354 & 1.11 & 0.00221 & 0.000482 & 0.000241 \\
\hline 12 & 4.4 & 0.0000 & 0.0000 & 4.16 & 0.0000 & 0.0129 & 0.0092 & 1.09 & 0.00158 & 0.000677 & 0.000310 \\
\hline 13 & 4.8 & 0.0000 & 0.0036 & 3.96 & 0.0034 & 0.0054 & 0.0031 & 1.27 & 0.00122 & 0.000176 & 0.000000 \\
\hline 14 & 5.2 & 0.0031 & 0.0000 & 8.66 & 0.0026 & 0.0015 & 0.0081 & 1.25 & 0.00048 & 0.000000 & 0.000000 \\
\hline 15 & 5.6 & 0.0149 & 0.2560 & 4.90 & 0.0366 & 0.0018 & 0.0000 & 1.22 & 0.00034 & 0.000159 & 0.000000 \\
\hline 16 & 6.0 & 0.0042 & 0.4867 & 14.40 & 0.0000 & 0.0000 & 0.0099 & 1.28 & 0.00066 & 0.000009 & 0.000082 \\
\hline 17 & 6.4 & 0.0000 & 0.0160 & 3.79 & 0.0100 & 0.0000 & 0.0038 & 1.04 & 0.00057 & 0.000000 & 0.000037 \\
\hline 18 & 6.8 & 0.0257 & 0.1440 & 20.27 & 0.0097 & 0.0088 & 0.0134 & 2.09 & 0.00448 & 0.000158 & 0.000000 \\
\hline 19 & 7.2 & 0.0238 & 0.0000 & 4.08 & 0.0175 & 0.0112 & 0.0041 & 1.36 & 0.00125 & 0.000033 & 0.000000 \\
\hline 20 & 7.6 & 0.0172 & 0.3932 & 7.05 & 0.0091 & 0.0005 & 0.0000 & 1.43 & 0.00156 & 0.000051 & 0.000000 \\
\hline 21 & 8.0 & 0.0178 & 0.0000 & 11.09 & 0.1282 & 0.0095 & 0.0048 & 1.64 & 0.00182 & 0.000191 & 0.000069 \\
\hline 22 & 8.4 & 0.0000 & 0.3784 & 7.68 & 0.1157 & 0.0000 & 0.0125 & 1.40 & 0.00046 & 0.000089 & 0.000101 \\
\hline 23 & 8.8 & 0.0448 & 0.2788 & 8.57 & 0.2490 & 0.0043 & 0.0082 & 1.59 & 0.00101 & 0.000057 & 0.000073 \\
\hline 24 & 9.2 & 0.0342 & 0.0450 & 9.27 & 0.0347 & 0.0007 & 0.0020 & 1.35 & 0.00054 & 0.000127 & 0.000123 \\
\hline 25 & 9.6 & 0.0291 & 0.4143 & 4.88 & 0.0000 & 0.0079 & 0.0154 & 1.68 & 0.00138 & 0.000000 & 0.000106 \\
\hline 26 & 10.0 & 0.0107 & 0.5426 & 4.16 & 0.0000 & 0.0074 & 0.0122 & 1.57 & 0.00071 & 0.000000 & 0.000000 \\
\hline 27 & 10.4 & 0.0115 & 0.5083 & 6.85 & 0.0039 & 0.0024 & 0.0037 & 1.44 & 0.00135 & 0.000442 & 0.000060 \\
\hline 28 & 10.8 & 0.0000 & 0.3832 & 5.02 & 0.0000 & 0.0000 & 0.0112 & 1.51 & 0.00117 & 0.000043 & 0.000000 \\
\hline 29 & 11.2 & 0.0500 & 0.0718 & 10.84 & 0.0000 & 0.0132 & 0.0000 & 1.68 & 0.00145 & 0.000000 & 0.000005 \\
\hline
\end{tabular}




\begin{tabular}{|c|c|c|c|c|c|c|c|c|c|c|c|}
\hline \multirow{2}{*}{ Spot Number } & \multirow{2}{*}{ Distance from the foot $(\mathrm{mm})$} & \multicolumn{10}{|c|}{ MR2 prismatic layer transect corrected data $(\mathrm{mmol} / \mathrm{mol})$ continued... } \\
\hline & & $\mathrm{Li} / \mathrm{Ca}$ & $\mathrm{B} / \mathrm{Ca}$ & $\mathrm{Mg} / \mathrm{Ca}$ & $\mathrm{Al} / \mathrm{Ca}$ & $\mathrm{Mn} / \mathrm{Ca}$ & $\mathrm{Zn} / \mathrm{Ca}$ & $\mathrm{Sr} / \mathrm{Ca}$ & $\mathrm{Ba} / \mathrm{Ca}$ & $\mathrm{Pb} / \mathrm{Ca}$ & $\mathrm{U} / \mathrm{Ca}$ \\
\hline 30 & 11.6 & 0.0075 & 0.0618 & 6.16 & 0.0123 & 0.0003 & 0.0000 & 1.51 & 0.00108 & 0.000002 & 0.000039 \\
\hline 31 & 12.0 & 0.0000 & 0.0984 & 22.27 & 0.0070 & 0.0004 & 0.0000 & 1.62 & 0.00106 & 0.000312 & 0.000052 \\
\hline 32 & 12.4 & 0.0000 & 0.4794 & 6.38 & 0.0164 & 0.0013 & 0.0106 & 1.31 & 0.00122 & 0.000069 & 0.000108 \\
\hline 33 & 12.8 & 0.0000 & 0.0742 & 12.05 & 0.0206 & 0.0071 & 0.0059 & 1.41 & 0.00210 & 0.000000 & 0.000000 \\
\hline 34 & 13.2 & 0.0186 & 0.3117 & 4.90 & 0.0303 & 0.0036 & 0.0004 & 1.07 & 0.00074 & 0.000118 & 0.000058 \\
\hline 35 & 13.6 & 0.0173 & 0.0677 & 3.77 & 0.0000 & 0.0036 & 0.0014 & 1.41 & 0.00165 & 0.000012 & 0.000000 \\
\hline 36 & 14.0 & 0.0062 & 0.1005 & 5.31 & 0.0146 & 0.0000 & 0.0000 & 1.78 & 0.00124 & 0.000156 & 0.000000 \\
\hline 37 & 14.4 & 0.0148 & 0.5761 & 24.40 & 0.0263 & 0.0130 & 0.0183 & 1.79 & 0.00609 & 0.000000 & 0.000030 \\
\hline 38 & 14.8 & 0.0264 & 0.1578 & 2.86 & 0.0146 & 0.0000 & 0.0012 & 4.21 & 0.00328 & 0.000000 & 0.000355 \\
\hline 39 & 15.2 & 0.0000 & 0.1688 & 4.14 & 0.0122 & 0.0047 & 0.0008 & 4.02 & 0.00283 & 0.000000 & 0.000139 \\
\hline 40 & 15.6 & 0.0209 & 0.0000 & 3.69 & 0.0014 & 0.0030 & 0.0108 & 4.60 & 0.00250 & 0.000048 & 0.000166 \\
\hline 41 & 16.0 & 0.0210 & 0.2752 & 5.65 & 0.0000 & 0.0040 & 0.0000 & 4.51 & 0.00363 & 0.000115 & 0.000087 \\
\hline 42 & 16.4 & 0.0017 & 0.3102 & 4.38 & 0.0000 & 0.0021 & 0.0000 & 4.47 & 0.00339 & 0.000487 & 0.000276 \\
\hline 43 & 16.8 & 0.0000 & 0.0000 & 33.59 & 0.0018 & 0.0069 & 0.0000 & 1.57 & 0.00218 & 0.000186 & 0.000000 \\
\hline 44 & 17.2 & 0.0086 & 0.3116 & 8.99 & 0.0000 & 0.0009 & 0.0000 & 1.66 & 0.00096 & 0.000116 & 0.000000 \\
\hline 45 & 17.6 & 0.0397 & 0.0524 & 24.91 & 0.0012 & 0.0009 & 0.0036 & 1.72 & 0.00141 & 0.000323 & 0.000039 \\
\hline 46 & 18.0 & 0.0189 & 0.4329 & 28.74 & 0.0338 & 0.0108 & 0.0066 & 1.78 & 0.00114 & 0.000000 & 0.000005 \\
\hline 47 & 18.4 & 0.0306 & 0.0000 & 6.23 & 0.0000 & 0.0041 & 0.0090 & 1.63 & 0.00076 & 0.000000 & 0.000000 \\
\hline 48 & 18.8 & 0.0478 & 0.0000 & 10.47 & 0.0000 & 0.0070 & 0.0067 & 1.55 & 0.00090 & 0.000019 & 0.000000 \\
\hline 49 & 19.2 & 0.0109 & 0.0343 & 18.54 & 0.0306 & 0.0057 & 0.0031 & 1.59 & 0.00064 & 0.000000 & 0.000000 \\
\hline 50 & 19.6 & 0.0536 & 0.3113 & 19.50 & 0.0504 & 0.0038 & 0.0194 & 1.78 & 0.00143 & 0.000048 & 0.000026 \\
\hline 51 & 20.0 & 0.0110 & 0.0986 & 9.80 & 0.0033 & 0.0019 & 0.0107 & 1.67 & 0.00102 & 0.000066 & 0.000108 \\
\hline 52 & 20.4 & 0.0179 & 0.1878 & 8.56 & 0.0069 & 0.0094 & 0.0087 & 1.66 & 0.00094 & 0.000122 & 0.000072 \\
\hline 53 & 20.8 & 0.0049 & 0.1122 & 11.89 & 0.0676 & 0.0091 & 0.0154 & 1.62 & 0.00097 & 0.000114 & 0.000000 \\
\hline 54 & 21.2 & 0.0112 & 0.2102 & 6.79 & 0.0073 & 0.0000 & 0.0055 & 1.30 & 0.00105 & 0.000000 & 0.000000 \\
\hline 55 & 21.6 & 0.0411 & 0.5367 & 43.04 & 0.0417 & 0.0000 & 0.0043 & 2.34 & 0.00454 & 0.000000 & 0.000077 \\
\hline 56 & 22.0 & 0.0409 & 0.3669 & 36.82 & 0.0000 & 0.0041 & 0.0116 & 1.90 & 0.00275 & 0.000077 & 0.000000 \\
\hline 57 & 22.4 & 0.0572 & 0.1800 & 15.10 & 0.0000 & 0.0076 & 0.0001 & 4.55 & 0.00451 & 0.000242 & 0.000493 \\
\hline 58 & 22.8 & 0.0402 & 0.1304 & 6.27 & 0.0301 & 0.0018 & 0.0023 & 1.52 & 0.00085 & 0.000000 & 0.000154 \\
\hline 59 & 23.2 & 0.0226 & 0.4078 & 4.68 & 0.0000 & 0.0063 & 0.0185 & 1.45 & 0.00023 & 0.000000 & 0.000000 \\
\hline
\end{tabular}




\begin{tabular}{|c|c|c|c|c|c|c|c|c|c|c|c|}
\hline \multirow{2}{*}{ Spot Number } & \multirow{2}{*}{ Distance from the foot $(\mathrm{mm})$} & \multicolumn{10}{|c|}{ MR2 prismatic layer transect corrected data $(\mathrm{mmol} / \mathrm{mol})$ continued... } \\
\hline & & $\mathrm{Li} / \mathrm{Ca}$ & $\mathrm{B} / \mathrm{Ca}$ & $\mathrm{Mg} / \mathrm{Ca}$ & $\mathrm{Al} / \mathrm{Ca}$ & $\mathrm{Mn} / \mathrm{Ca}$ & $\mathrm{Zn} / \mathrm{Ca}$ & $\mathrm{Sr} / \mathrm{Ca}$ & $\mathrm{Ba} / \mathrm{Ca}$ & $\mathrm{Pb} / \mathrm{Ca}$ & $\mathrm{U} / \mathrm{Ca}$ \\
\hline 60 & 23.6 & 0.0196 & 0.4409 & 7.50 & 0.0221 & 0.0058 & 0.0126 & 1.71 & 0.00044 & 0.000000 & 0.000000 \\
\hline 61 & 24.0 & 0.0135 & 0.1290 & 2.30 & 0.0055 & 0.0014 & 0.0026 & 5.02 & 0.00467 & 0.000000 & 0.000534 \\
\hline 62 & 24.4 & 0.9830 & 94.9266 & 361.75 & 14.8474 & 0.0578 & 0.0954 & 2.06 & 0.00000 & 0.008198 & 0.007424 \\
\hline 63 & 24.8 & 0.0139 & 0.0999 & 12.86 & 0.0000 & 0.0000 & 0.0090 & 1.30 & 0.00050 & 0.000000 & 0.000002 \\
\hline 64 & 25.2 & 0.0000 & 0.0042 & 13.21 & 0.0068 & 0.0041 & 0.0010 & 1.60 & 0.00350 & 0.000000 & 0.000160 \\
\hline 65 & 25.6 & 0.0252 & 0.7103 & 3.13 & 0.0000 & 0.0005 & 0.0028 & 1.40 & 0.00111 & 0.000000 & 0.000163 \\
\hline 66 & 26.0 & 0.0000 & 0.2313 & 3.90 & 0.0000 & 0.0018 & 0.0188 & 1.44 & 0.00038 & 0.000000 & 0.000007 \\
\hline 67 & 26.4 & 0.0000 & 0.0000 & 3.48 & 0.0385 & 0.0030 & 0.0197 & 1.34 & 0.00082 & 0.000000 & 0.000000 \\
\hline 68 & 26.8 & 0.0000 & 0.1836 & 2.81 & 0.0379 & 0.0010 & 0.0204 & 1.41 & 0.00239 & 0.000210 & 0.000069 \\
\hline 69 & 27.2 & 0.0000 & 0.1267 & 3.14 & 0.0413 & 0.0086 & 0.0109 & 1.65 & 0.00178 & 0.000032 & 0.000000 \\
\hline 70 & 27.6 & 0.0165 & 0.1246 & 4.65 & 0.0005 & 0.0056 & 0.0101 & 1.44 & 0.00129 & 0.000000 & 0.000000 \\
\hline 71 & 28.0 & 0.0740 & 0.0000 & 3.36 & 0.0189 & 0.0083 & 0.0000 & 1.38 & 0.00103 & 0.000260 & 0.000044 \\
\hline 72 & 28.4 & 0.0002 & 0.2994 & 6.93 & 0.0329 & 0.0030 & 0.0077 & 1.45 & 0.00107 & 0.000000 & 0.000000 \\
\hline 73 & 28.8 & 0.0050 & 0.5308 & 5.12 & 0.0000 & 0.0011 & 0.0064 & 1.48 & 0.00092 & 0.000064 & 0.000008 \\
\hline 74 & 29.2 & 0.0194 & 0.0000 & 3.81 & 0.0051 & 0.0080 & 0.0111 & 1.46 & 0.00127 & 0.000192 & 0.000013 \\
\hline 75 & 29.6 & 0.0059 & 0.1981 & 3.40 & 0.0035 & 0.0000 & 0.0000 & 1.42 & 0.00076 & 0.000186 & 0.000000 \\
\hline 76 & 30.0 & 0.0792 & 0.0954 & 5.87 & 0.0218 & 0.0024 & 0.0090 & 1.78 & 0.00167 & 0.000071 & 0.000000 \\
\hline 77 & 30.4 & 0.0000 & 0.3019 & 10.62 & 0.0068 & 0.0066 & 0.0000 & 1.92 & 0.00149 & 0.000000 & 0.000000 \\
\hline 78 & 30.8 & 0.0245 & 0.3359 & 14.76 & 0.0131 & 0.0000 & 0.0027 & 1.69 & 0.00114 & 0.000000 & 0.000039 \\
\hline 79 & 31.2 & 0.0000 & 0.2335 & 4.90 & 0.0000 & 0.0079 & 0.0098 & 1.44 & 0.00108 & 0.000180 & 0.000000 \\
\hline 80 & 31.6 & 0.0270 & 0.2430 & 6.90 & 0.0239 & 0.0055 & 0.0037 & 1.57 & 0.00123 & 0.000052 & 0.000000 \\
\hline 81 & 32.0 & 0.0187 & 0.0187 & 5.03 & 0.0342 & 0.0000 & 0.0096 & 1.71 & 0.00163 & 0.000086 & 0.000009 \\
\hline 82 & 32.4 & 0.0252 & 0.0734 & 11.24 & 0.0567 & 0.0045 & 0.0113 & 1.26 & 0.00100 & 0.000398 & 0.000113 \\
\hline 83 & 32.8 & 0.0186 & 0.3220 & 7.17 & 0.0000 & 0.0077 & 0.0188 & 1.25 & 0.00089 & 0.000115 & 0.000000 \\
\hline 84 & 33.2 & 0.0000 & 0.2239 & 4.48 & 0.0165 & 0.0000 & 0.0074 & 1.30 & 0.00132 & 0.000000 & 0.000000 \\
\hline 85 & 33.6 & 0.0456 & 0.2810 & 4.41 & 0.0000 & 0.0042 & 0.0084 & 1.55 & 0.00111 & 0.000237 & 0.000006 \\
\hline 86 & 34.0 & 0.0631 & 0.2598 & 5.58 & 0.0478 & 0.0044 & 0.0044 & 1.27 & 0.00055 & 0.000275 & 0.000098 \\
\hline 87 & 34.4 & 0.0032 & 0.2715 & 5.97 & 0.0000 & 0.0006 & 0.0000 & 1.19 & 0.00058 & 0.000095 & 0.000068 \\
\hline 88 & 34.8 & 0.0400 & 0.2708 & 3.49 & 0.0082 & 0.0082 & 0.0000 & 1.05 & 0.00065 & 0.000021 & 0.000077 \\
\hline
\end{tabular}


APPENDIX 5.10 MD1 prismatic layer transect data

\begin{tabular}{|c|c|c|c|c|c|c|c|c|c|c|c|}
\hline \multirow{2}{*}{ Spot Number } & \multirow{2}{*}{ Distance from the foot $(\mathrm{mm})$} & \multicolumn{10}{|c|}{ MD1 prismatic layer transect corrected data $(\mathrm{mmol} / \mathrm{mol})$} \\
\hline & & $\mathrm{Li} / \mathrm{Ca}$ & $\mathrm{B} / \mathrm{Ca}$ & $\mathrm{Mg} / \mathrm{Ca}$ & $\mathbf{A l} / \mathbf{C a}$ & $\mathrm{Mn} / \mathrm{Ca}$ & $\mathrm{Zn} / \mathrm{Ca}$ & $\mathrm{Sr} / \mathrm{Ca}$ & $\mathrm{Ba} / \mathrm{Ca}$ & $\mathrm{Pb} / \mathrm{Ca}$ & $\mathrm{U} / \mathrm{Ca}$ \\
\hline 1 & 0.0 & 0.0161 & 0.000 & 9.97 & 0.033 & 0.00269 & 0.0080 & 1.49 & 0.001327 & 0.0000000 & 0.0000717 \\
\hline 2 & 0.4 & 0.0122 & 0.000 & 3.52 & 0.000 & 0.00475 & 0.0000 & 1.29 & 0.000472 & 0.0000000 & 0.0000000 \\
\hline 3 & 0.8 & 0.0146 & 0.000 & 4.18 & 0.000 & 0.00000 & 0.0000 & 1.82 & 0.000536 & 0.0002286 & 0.0000000 \\
\hline 4 & 1.2 & 0.0126 & 0.000 & 17.76 & 0.145 & 0.00166 & 0.0034 & 1.85 & 0.000668 & 0.0001160 & 0.0000656 \\
\hline 5 & 1.6 & 0.0064 & 0.000 & 6.83 & 0.123 & 0.00000 & 0.0000 & 1.46 & 0.000512 & 0.0000000 & 0.0000314 \\
\hline 6 & 2.0 & 0.0001 & 0.000 & 11.37 & 0.079 & 0.00000 & 0.0016 & 1.70 & 0.000905 & 0.0001554 & 0.0000000 \\
\hline 7 & 2.4 & 0.0267 & 0.000 & 12.69 & 0.054 & 0.00000 & 0.0062 & 1.87 & 0.000896 & 0.0002297 & 0.0000863 \\
\hline 8 & 2.8 & 0.0000 & 0.317 & 5.14 & 0.004 & 0.00000 & 0.0018 & 1.58 & 0.000353 & 0.0000000 & 0.0000000 \\
\hline 9 & 3.2 & 0.0318 & 0.034 & 5.35 & 0.000 & 0.00000 & 0.0123 & 1.48 & 0.000414 & 0.0000129 & 0.0000000 \\
\hline 10 & 3.6 & 0.0040 & 0.000 & 17.59 & 0.197 & 0.00000 & 0.0069 & 1.70 & 0.000873 & 0.0000680 & 0.0000237 \\
\hline 11 & 4.0 & 0.0244 & 0.000 & 7.82 & 0.006 & 0.01011 & 0.0112 & 1.33 & 0.000334 & 0.0000000 & 0.0000000 \\
\hline 12 & 4.4 & 0.0132 & 0.256 & 4.70 & 0.029 & 0.00449 & 0.0049 & 1.51 & 0.000512 & 0.0002485 & 0.0000000 \\
\hline 13 & 4.8 & 0.0000 & 0.000 & 12.40 & 2.309 & 0.00187 & 0.0065 & 1.63 & 0.003495 & 0.0000000 & 0.0000251 \\
\hline 14 & 5.2 & 0.0285 & 0.064 & 2.25 & 0.004 & 0.00050 & 0.0104 & 1.27 & 0.000466 & 0.0000364 & 0.0000000 \\
\hline 15 & 5.6 & 0.0158 & 0.160 & 6.45 & 0.002 & 0.00633 & 0.0000 & 1.20 & 0.000484 & 0.0001267 & 0.0000104 \\
\hline 16 & 6.0 & 0.0000 & 0.695 & 8.01 & 0.338 & 0.00389 & 0.0007 & 1.33 & 0.000785 & 0.0002397 & 0.0000000 \\
\hline 17 & 6.4 & 0.0000 & 0.204 & 11.33 & 0.026 & 0.00000 & 0.0064 & 1.43 & 0.000658 & 0.0003057 & 0.0000000 \\
\hline 18 & 6.8 & 0.0000 & 0.025 & 25.60 & 0.003 & 0.00309 & 0.0000 & 1.24 & 0.000881 & 0.0000000 & 0.0000602 \\
\hline 19 & 7.2 & 0.0251 & 0.751 & 10.04 & 0.121 & 0.00941 & 0.0000 & 1.50 & 0.001051 & 0.0000000 & 0.0000527 \\
\hline 20 & 7.6 & 0.0000 & 0.268 & 9.82 & 0.128 & 0.00258 & 0.0037 & 1.56 & 0.000999 & 0.0002977 & 0.0000466 \\
\hline 21 & 8.0 & 0.0053 & 0.000 & 12.27 & 0.035 & 0.00221 & 0.0000 & 1.37 & 0.000676 & 0.0002824 & 0.0000650 \\
\hline 22 & 8.4 & 0.0585 & 0.590 & 21.48 & 4.652 & 0.01612 & 0.0000 & 1.82 & 0.005108 & 0.0001894 & 0.0001865 \\
\hline 23 & 8.8 & 0.0072 & 0.047 & 2.50 & 0.299 & 0.00000 & 0.0114 & 1.29 & 0.000700 & 0.0000619 & 0.0000000 \\
\hline 24 & 9.2 & 0.0208 & 0.535 & 13.19 & 0.082 & 0.00242 & 0.0081 & 1.52 & 0.000726 & 0.0000000 & 0.0000000 \\
\hline 25 & 9.6 & 0.0097 & 0.273 & 5.08 & 0.000 & 0.00031 & 0.0000 & 1.41 & 0.000745 & 0.0000000 & 0.0000624 \\
\hline 26 & 10.0 & 0.0092 & 0.023 & 9.41 & 0.017 & 0.00585 & 0.0027 & 1.37 & 0.000689 & 0.0000622 & 0.0000000 \\
\hline 27 & 10.4 & 0.0131 & 0.000 & 4.40 & 0.000 & 0.00601 & 0.0080 & 1.49 & 0.000461 & 0.0000076 & 0.0000000 \\
\hline 28 & 10.8 & 0.0077 & 0.059 & 6.07 & 0.024 & 0.00370 & 0.0000 & 1.34 & 0.000470 & 0.0001034 & 0.0000000 \\
\hline 29 & 11.2 & 0.0420 & 0.000 & 4.77 & 0.000 & 0.00327 & 0.0000 & 1.39 & 0.000646 & 0.0000000 & 0.0000000 \\
\hline
\end{tabular}




\begin{tabular}{|c|c|c|c|c|c|c|c|c|c|c|c|}
\hline \multirow{2}{*}{ Spot Number } & \multirow{2}{*}{ Distance from the foot $(\mathrm{mm})$} & \multicolumn{10}{|c|}{ MD1 prismatic layer transect corrected data $(\mathrm{mmol} / \mathrm{mol})$ continued... } \\
\hline & & $\mathrm{Li} / \mathrm{Ca}$ & $\mathrm{B} / \mathrm{Ca}$ & $\mathrm{Mg} / \mathrm{Ca}$ & $\mathrm{Al} / \mathrm{Ca}$ & $\mathrm{Mn} / \mathrm{Ca}$ & $\mathrm{Zn} / \mathrm{Ca}$ & $\mathrm{Sr} / \mathrm{Ca}$ & $\mathrm{Ba} / \mathrm{Ca}$ & $\mathrm{Pb} / \mathrm{Ca}$ & $\mathrm{U} / \mathbf{C a}$ \\
\hline 30 & 11.6 & 0.0041 & 0.119 & 21.80 & 0.000 & 0.00827 & 0.0100 & 1.57 & 0.000871 & 0.0000000 & 0.0000212 \\
\hline 31 & 12.0 & 0.0268 & 0.161 & 2.90 & 0.000 & 0.00100 & 0.0074 & 1.32 & 0.000901 & 0.0000000 & 0.0000000 \\
\hline 32 & 12.4 & 0.0000 & 0.111 & 2.71 & 0.018 & 0.00030 & 0.0028 & 0.97 & 0.000580 & 0.0002770 & 0.0000046 \\
\hline 33 & 12.8 & 0.0000 & 0.372 & 6.28 & 0.023 & 0.00000 & 0.0030 & 1.21 & 0.000472 & 0.0000901 & 0.0000000 \\
\hline 34 & 13.2 & 0.0340 & 1.566 & 3.12 & 0.000 & 0.00384 & 0.0000 & 6.55 & 0.005225 & 0.0000000 & 0.0005987 \\
\hline 35 & 13.6 & 0.0445 & 0.460 & 8.58 & 0.000 & 0.00000 & 0.0000 & 1.35 & 0.000385 & 0.0000407 & 0.0000191 \\
\hline 36 & 14.0 & 0.0217 & 0.198 & 5.49 & 0.000 & 0.00451 & 0.0109 & 1.08 & 0.000080 & 0.0003627 & 0.0000030 \\
\hline 37 & 14.4 & 0.0307 & 0.268 & 10.40 & 0.000 & 0.00835 & 0.0078 & 1.38 & 0.000288 & 0.0000000 & 0.0000000 \\
\hline 38 & 14.8 & 0.0205 & 0.272 & 4.70 & 0.008 & 0.00160 & 0.0000 & 1.28 & 0.000141 & 0.0000000 & 0.0000435 \\
\hline 39 & 15.2 & 0.0144 & 0.000 & 8.38 & 0.000 & 0.00722 & 0.0099 & 1.12 & 0.000388 & 0.0000985 & 0.0000649 \\
\hline 40 & 15.6 & 0.0184 & 0.000 & 12.04 & 2.365 & 0.00468 & 0.0075 & 1.37 & 0.002281 & 0.0001006 & 0.0000352 \\
\hline 41 & 16.0 & 0.0382 & 0.000 & 14.67 & 0.020 & 0.00380 & 0.0000 & 1.34 & 0.000748 & 0.0000000 & 0.0000496 \\
\hline 42 & 16.4 & 0.0275 & 0.051 & 6.82 & 0.017 & 0.00354 & 0.0000 & 1.52 & 0.001152 & 0.0001393 & 0.0000000 \\
\hline 43 & 16.8 & 0.0000 & 0.555 & 1.96 & 0.011 & 0.00972 & 0.0101 & 1.10 & 0.000388 & 0.0000000 & 0.0000000 \\
\hline 44 & 17.2 & 0.0246 & 0.421 & 2.30 & 0.043 & 0.00947 & 0.0074 & 1.30 & 0.000355 & 0.0000054 & 0.0000000 \\
\hline 45 & 17.6 & 0.0110 & 0.009 & 2.78 & 0.000 & 0.00269 & 0.0093 & 1.21 & 0.000451 & 0.0000498 & 0.0000377 \\
\hline 46 & 18.0 & 0.0034 & 0.230 & 3.09 & 0.044 & 0.00836 & 0.0034 & 1.13 & 0.000000 & 0.0000000 & 0.0000326 \\
\hline 47 & 18.4 & 0.0000 & 0.000 & 3.03 & 0.000 & 0.00698 & 0.0076 & 1.25 & 0.000395 & 0.0003225 & 0.0000311 \\
\hline 48 & 18.8 & 0.0000 & 0.524 & 1.81 & 0.018 & 0.00281 & 0.0258 & 1.29 & 0.000447 & 0.0000540 & 0.0000000 \\
\hline 49 & 19.2 & 0.0063 & 0.131 & 3.00 & 0.000 & 0.00350 & 0.0000 & 1.31 & 0.000813 & 0.0000196 & 0.0000132 \\
\hline 50 & 19.6 & 0.0000 & 0.162 & 2.58 & 0.473 & 0.00733 & 0.0000 & 1.17 & 0.001005 & 0.0000000 & 0.0000000 \\
\hline 51 & 20.0 & 0.0152 & 0.089 & 3.23 & 0.000 & 0.00829 & 0.0157 & 1.23 & 0.000537 & 0.0000000 & 0.0000072 \\
\hline 52 & 20.4 & 0.0000 & 0.398 & 5.21 & 0.006 & 0.00000 & 0.0050 & 1.19 & 0.000568 & 0.0000000 & 0.0000000 \\
\hline 53 & 20.8 & 0.0000 & 0.109 & 20.83 & 0.021 & 0.01654 & 0.0122 & 1.52 & 0.001153 & 0.0000000 & 0.0000373 \\
\hline 54 & 21.2 & 0.0470 & 0.163 & 18.57 & 0.188 & 0.00517 & 0.0108 & 1.49 & 0.001415 & 0.0000740 & 0.0000637 \\
\hline 55 & 21.6 & 0.0547 & 0.181 & 7.53 & 0.000 & 0.00000 & 0.0059 & 1.28 & 0.000442 & 0.0000000 & 0.0000000 \\
\hline 56 & 22.0 & 0.0073 & 0.000 & 6.22 & 0.025 & 0.00565 & 0.0239 & 1.33 & 0.000781 & 0.0000793 & 0.0000765 \\
\hline 57 & 22.4 & 0.0540 & 0.000 & 14.13 & 0.032 & 0.02935 & 0.0050 & 1.58 & 0.000731 & 0.0000000 & 0.0000576 \\
\hline 58 & 22.8 & 0.0106 & 0.050 & 12.88 & 0.038 & 0.00640 & 0.0000 & 1.53 & 0.000334 & 0.0000000 & 0.0000000 \\
\hline 59 & 23.2 & 0.0271 & 0.000 & 3.39 & 0.000 & 0.01602 & 0.0060 & 1.47 & 0.000645 & 0.0000000 & 0.0000273 \\
\hline
\end{tabular}




\begin{tabular}{|c|c|c|c|c|c|c|c|c|c|c|c|}
\hline \multirow{2}{*}{ Spot Number } & \multirow{2}{*}{ Distance from the foot $(\mathrm{mm})$} & \multicolumn{10}{|c|}{ MD1 prismatic layer transect corrected data $(\mathrm{mmol} / \mathrm{mol})$ continued... } \\
\hline & & $\mathrm{Li} / \mathrm{Ca}$ & $\mathrm{B} / \mathrm{Ca}$ & $\mathrm{Mg} / \mathrm{Ca}$ & $\mathrm{Al} / \mathrm{Ca}$ & $\mathrm{Mn} / \mathrm{Ca}$ & $\mathrm{Zn} / \mathrm{Ca}$ & $\mathrm{Sr} / \mathrm{Ca}$ & $\mathrm{Ba} / \mathrm{Ca}$ & $\mathrm{Pb} / \mathrm{Ca}$ & $\mathrm{U} / \mathrm{Ca}$ \\
\hline 60 & 23.6 & 0.0585 & 0.145 & 3.03 & 0.006 & 0.02294 & 0.0070 & 4.86 & 0.004638 & 0.0002041 & 0.0010382 \\
\hline 61 & 24.0 & 0.0000 & 0.000 & 8.75 & 0.000 & 0.00882 & 0.0146 & 1.46 & 0.000609 & 0.0001914 & 0.0000000 \\
\hline 62 & 24.4 & 0.0000 & 0.195 & 3.20 & 0.003 & 0.00385 & 0.0000 & 1.43 & 0.000550 & 0.0000000 & 0.0000000 \\
\hline 63 & 24.8 & 0.0001 & 0.255 & 3.61 & 0.000 & 0.00000 & 0.0069 & 1.45 & 0.000529 & 0.0000164 & 0.0000028 \\
\hline 64 & 25.2 & 0.0000 & 0.273 & 3.29 & 0.013 & 0.00718 & 0.0114 & 1.31 & 0.000450 & 0.0001987 & 0.0000000 \\
\hline 65 & 25.6 & 0.0342 & 0.453 & 4.81 & 0.000 & 0.00893 & 0.0000 & 1.39 & 0.000059 & 0.0000890 & 0.0000000 \\
\hline 66 & 26.0 & 0.0112 & 0.085 & 6.43 & 0.000 & 0.00294 & 0.0050 & 1.44 & 0.000190 & 0.0000000 & 0.0000000 \\
\hline 67 & 26.4 & 0.0000 & 0.504 & 2.47 & 0.004 & 0.00616 & 0.0071 & 1.06 & 0.000372 & 0.0003578 & 0.0000000 \\
\hline 68 & 26.8 & 0.0361 & 0.360 & 2.22 & 0.018 & 0.00821 & 0.0150 & 1.15 & 0.000456 & 0.0000000 & 0.0000050 \\
\hline 69 & 27.2 & 0.0379 & 0.110 & 3.71 & 0.028 & 0.00918 & 0.0009 & 1.20 & 0.000499 & 0.0002057 & 0.0000000 \\
\hline 70 & 27.6 & 0.0000 & 0.462 & 4.62 & 0.109 & 0.00000 & 0.0071 & 1.50 & 0.000801 & 0.0000000 & 0.0000000 \\
\hline 71 & 28.0 & 0.0064 & 0.629 & 11.29 & 0.000 & 0.00012 & 0.0091 & 1.24 & 0.000533 & 0.0000000 & 0.0000064 \\
\hline 72 & 28.4 & 0.0440 & 0.288 & 8.23 & 0.000 & 0.00816 & 0.0000 & 1.40 & 0.000634 & 0.0000045 & 0.0001223 \\
\hline 73 & 28.8 & 0.0251 & 0.000 & 12.06 & 0.000 & 0.00188 & 0.0036 & 1.73 & 0.000902 & 0.0000930 & 0.0000460 \\
\hline 74 & 29.2 & 0.0965 & 0.180 & 9.35 & 0.020 & 0.01264 & 0.0000 & 1.41 & 0.000753 & 0.0003296 & 0.0000000 \\
\hline 75 & 29.6 & 0.0178 & 0.595 & 3.28 & 0.000 & 0.00854 & 0.0030 & 1.44 & 0.000307 & 0.0000000 & 0.0001539 \\
\hline 76 & 30.0 & 0.0585 & 0.350 & 3.09 & 0.040 & 0.01624 & 0.0100 & 1.36 & 0.000321 & 0.0001198 & 0.0000354 \\
\hline 77 & 30.4 & 0.0095 & 0.032 & 6.23 & 0.000 & 0.00074 & 0.0111 & 1.47 & 0.000578 & 0.0000537 & 0.0000016 \\
\hline 78 & 30.8 & 0.0346 & 0.110 & 5.85 & 0.000 & 0.00804 & 0.0072 & 1.20 & 0.000207 & 0.0002393 & 0.0000000 \\
\hline 79 & 31.2 & 0.0076 & 0.131 & 17.42 & 0.216 & 0.00696 & 0.0000 & 2.75 & 0.002306 & 0.0000000 & 0.0001797 \\
\hline 80 & 31.6 & 0.0208 & 0.227 & 9.44 & 0.022 & 0.02298 & 0.0172 & 1.93 & 0.000717 & 0.0003370 & 0.0000000 \\
\hline 81 & 32.0 & 0.0000 & 0.397 & 2.99 & 0.004 & 0.01376 & 0.0000 & 1.40 & 0.000533 & 0.0002322 & 0.0000401 \\
\hline 82 & 32.4 & 0.0482 & 0.000 & 5.50 & 0.005 & 0.01678 & 0.0262 & 1.58 & 0.000412 & 0.0001652 & 0.0000459 \\
\hline 83 & 32.8 & 0.0218 & 0.000 & 2.78 & 0.046 & 0.00000 & 0.0293 & 1.07 & 0.000633 & 0.0000000 & 0.0000000 \\
\hline 84 & 33.2 & 0.0209 & 0.240 & 2.83 & 0.000 & 0.00305 & 0.0385 & 1.45 & 0.000802 & 0.0000555 & 0.0000505 \\
\hline 85 & 33.6 & 0.0010 & 0.416 & 2.20 & 0.021 & 0.00514 & 0.0337 & 1.55 & 0.000525 & 0.0000000 & 0.0000000 \\
\hline 86 & 34.0 & 0.0109 & 0.030 & 2.46 & 0.034 & 0.00338 & 0.0000 & 1.52 & 0.000571 & 0.0000000 & 0.0001310 \\
\hline 87 & 34.4 & 0.0000 & 0.000 & 2.53 & 0.000 & 0.00444 & 0.0067 & 1.30 & 0.000642 & 0.0000000 & 0.0000913 \\
\hline 88 & 34.8 & 0.0716 & 1.305 & 2.80 & 0.154 & 0.02099 & 0.0342 & 1.37 & 0.000780 & 0.0003332 & 0.0001257 \\
\hline 89 & 35.2 & 0.0181 & 0.084 & 2.27 & 0.000 & 0.00920 & 0.0013 & 1.22 & 0.000287 & 0.0001408 & 0.0001020 \\
\hline
\end{tabular}




\begin{tabular}{|c|c|c|c|c|c|c|c|c|c|c|c|}
\hline \multirow{2}{*}{ Spot Number } & \multirow{2}{*}{ Distance from the foot $(\mathrm{mm})$} & \multicolumn{10}{|c|}{ MD1 prismatic layer transect corrected data ( $\mathrm{mmol} / \mathrm{mol})$ continued... } \\
\hline & & $\mathrm{Li} / \mathrm{Ca}$ & $\mathrm{B} / \mathrm{Ca}$ & $\mathrm{Mg} / \mathrm{Ca}$ & $\mathrm{Al} / \mathrm{Ca}$ & $\mathrm{Mn} / \mathrm{Ca}$ & $\mathrm{Zn} / \mathrm{Ca}$ & $\mathrm{Sr} / \mathrm{Ca}$ & $\mathrm{Ba} / \mathrm{Ca}$ & $\mathrm{Pb} / \mathrm{Ca}$ & $\mathrm{U} / \mathrm{Ca}$ \\
\hline 90 & 35.6 & 0.0498 & 0.386 & 3.62 & 0.000 & 0.00109 & 0.0000 & 1.51 & 0.000517 & 0.0000800 & 0.0000173 \\
\hline 91 & 36.0 & 0.0000 & 0.243 & 1.99 & 0.008 & 0.00278 & 0.0012 & 1.12 & 0.000291 & 0.0002236 & 0.0000000 \\
\hline 92 & 36.4 & 0.0188 & 0.177 & 2.74 & 0.033 & 0.00000 & 0.0001 & 1.13 & 0.000631 & 0.0001002 & 0.0000000 \\
\hline 93 & 36.8 & 0.0000 & 0.000 & 2.06 & 0.003 & 0.00000 & 0.0000 & 1.17 & 0.000140 & 0.0003906 & 0.0001187 \\
\hline 94 & 37.2 & 0.0649 & 0.501 & 2.47 & 0.033 & 0.00677 & 0.0100 & 1.14 & 0.000333 & 0.0004188 & 0.0000105 \\
\hline 95 & 37.6 & 0.0247 & 0.263 & 3.79 & 0.014 & 0.00000 & 0.0000 & 1.25 & 0.000851 & 0.0002787 & 0.0000000 \\
\hline 96 & 38.0 & 0.0392 & 0.070 & 10.31 & 0.000 & 0.00655 & 0.0048 & 1.57 & 0.000622 & 0.0002720 & 0.0002570 \\
\hline 97 & 38.4 & 0.0000 & 0.409 & 10.64 & 0.008 & 0.05084 & 0.0168 & 1.17 & 0.000626 & 0.0000000 & 0.0000727 \\
\hline
\end{tabular}


APPENDIX 5.1p $\quad$ MD3 prismatic layer transect data

\begin{tabular}{|c|c|c|c|c|c|c|c|c|c|c|c|}
\hline \multirow{2}{*}{ Spot Number } & \multirow{2}{*}{ Distance from the foot $(\mathrm{mm})$} & \multicolumn{10}{|c|}{ MD3 prismatic layer transect corrected data $(\mathrm{mmol} / \mathrm{mol})$} \\
\hline & & $\mathrm{Li} / \mathrm{Ca}$ & $\mathrm{B} / \mathrm{Ca}$ & $\mathrm{Mg} / \mathrm{Ca}$ & $\mathrm{Al} / \mathrm{Ca}$ & $\mathrm{Mn} / \mathrm{Ca}$ & $\mathrm{Zn} / \mathrm{Ca}$ & $\mathrm{Sr} / \mathrm{Ca}$ & $\mathrm{Ba} / \mathrm{Ca}$ & $\mathrm{Pb} / \mathrm{Ca}$ & $\mathrm{U} / \mathrm{Ca}$ \\
\hline 1 & 0.0 & 0.0190 & 0.0336 & 28.55 & 0.075 & 0.00505 & 0.0055 & 1.58 & 0.001026 & 0.0000000 & 0.0000000 \\
\hline 2 & 0.4 & 0.0050 & 0.0218 & 3.92 & 0.002 & 0.00000 & 0.0099 & 1.43 & 0.000634 & 0.0000950 & 0.0000000 \\
\hline 3 & 0.8 & 0.0095 & 0.0000 & 5.98 & 0.263 & 0.00148 & 0.0208 & 1.36 & 0.000515 & 0.0000000 & 0.0000053 \\
\hline 4 & 1.2 & 0.0318 & 0.0000 & 9.39 & 0.124 & 0.00012 & 0.0136 & 1.39 & 0.000665 & 0.0000000 & 0.0000283 \\
\hline 5 & 1.6 & 0.0288 & 0.0140 & 19.39 & 0.337 & 0.00231 & 0.0187 & 1.86 & 0.001875 & 0.0001812 & 0.0001014 \\
\hline 6 & 2.0 & 0.0000 & 0.0182 & 10.17 & 0.008 & 0.00339 & 0.0000 & 1.26 & 0.000496 & 0.0000177 & 0.0000004 \\
\hline 7 & 2.4 & 0.0112 & 0.0000 & 6.45 & 0.001 & 0.00167 & 0.0106 & 1.24 & 0.000427 & 0.0000000 & 0.0000143 \\
\hline 8 & 2.8 & 0.0123 & 0.0031 & 4.94 & 0.005 & 0.00076 & 0.0100 & 1.49 & 0.000542 & 0.0000598 & 0.0000000 \\
\hline 9 & 3.2 & 0.0151 & 0.0000 & 3.26 & 0.000 & 0.00144 & 0.0141 & 1.47 & 0.000472 & 0.0000742 & 0.0000196 \\
\hline 10 & 3.6 & 0.0137 & 0.0118 & 3.22 & 0.003 & 0.00000 & 0.0081 & 1.22 & 0.000311 & 0.0000000 & 0.0000150 \\
\hline 11 & 4.0 & 0.0253 & 0.0081 & 4.94 & 0.000 & 0.00365 & 0.0160 & 1.39 & 0.000550 & 0.0000000 & 0.0000000 \\
\hline 12 & 4.4 & 0.0163 & 0.0260 & 5.68 & 0.950 & 0.00287 & 0.0087 & 1.59 & 0.001998 & 0.0000141 & 0.0000047 \\
\hline 13 & 4.8 & 0.0237 & 0.0000 & 3.67 & 0.002 & 0.00195 & 0.0095 & 1.29 & 0.000363 & 0.0000308 & 0.0000000 \\
\hline 14 & 5.2 & 0.0057 & 0.0000 & 9.68 & 0.001 & 0.00001 & 0.0094 & 1.47 & 0.000393 & 0.0000000 & 0.0000127 \\
\hline 15 & 5.6 & 0.0150 & 0.0730 & 13.10 & 0.151 & 0.00358 & 0.0045 & 3.32 & 0.001606 & 0.0000619 & 0.0001739 \\
\hline 16 & 6.0 & 0.0246 & 0.0496 & 24.68 & 1.302 & 0.00138 & 0.0000 & 1.55 & 0.001590 & 0.0000000 & 0.0000417 \\
\hline 17 & 6.4 & 0.0000 & 0.0249 & 5.13 & 0.006 & 0.00232 & 0.0045 & 1.40 & 0.000427 & 0.0000000 & 0.0000204 \\
\hline 18 & 6.8 & 0.0079 & 0.0239 & 5.26 & 0.000 & 0.00570 & 0.0090 & 1.48 & 0.000685 & 0.0000343 & 0.0000000 \\
\hline 19 & 7.2 & 0.0202 & 0.0190 & 4.57 & 0.000 & 0.00376 & 0.0048 & 1.37 & 0.000372 & 0.0000000 & 0.0000000 \\
\hline 20 & 7.6 & 0.0012 & 0.0024 & 3.17 & 0.005 & 0.00260 & 0.0117 & 1.15 & 0.000378 & 0.0000443 & 0.0000123 \\
\hline 21 & 8.0 & 0.0255 & 0.0356 & 12.81 & 0.345 & 0.00488 & 0.0116 & 1.59 & 0.000891 & 0.0000000 & 0.0000339 \\
\hline 22 & 8.4 & 0.0050 & 0.0657 & 16.98 & 0.012 & 0.00203 & 0.0097 & 1.44 & 0.000675 & 0.0001519 & 0.0000000 \\
\hline 23 & 8.8 & 0.0127 & 0.0047 & 13.90 & 0.004 & 0.00337 & 0.0010 & 1.49 & 0.000735 & 0.0000114 & 0.0000075 \\
\hline 24 & 9.2 & 0.0012 & 0.0166 & 11.12 & 1.240 & 0.00518 & 0.0011 & 1.54 & 0.001011 & 0.0000609 & 0.0000000 \\
\hline 25 & 9.6 & 0.0000 & 0.0090 & 4.37 & 0.000 & 0.00098 & 0.0081 & 1.40 & 0.000419 & 0.0000000 & 0.0000000 \\
\hline 26 & 10.0 & 0.0000 & 0.0441 & 11.12 & 0.013 & 0.00274 & 0.0102 & 1.36 & 0.000680 & 0.0000757 & 0.0000000 \\
\hline 27 & 10.4 & 0.0119 & 0.0163 & 3.21 & 0.001 & 0.00327 & 0.0000 & 1.35 & 0.000512 & 0.0000108 & 0.0000278 \\
\hline 28 & 10.8 & 0.0111 & 0.0115 & 5.35 & 0.001 & 0.00000 & 0.0097 & 1.32 & 0.000824 & 0.0000784 & 0.0000000 \\
\hline 29 & 11.2 & 0.0145 & 0.0000 & 3.67 & 0.000 & 0.00081 & 0.0126 & 1.40 & 0.000239 & 0.0000000 & 0.0000000 \\
\hline
\end{tabular}




\begin{tabular}{|c|c|c|c|c|c|c|c|c|c|c|c|}
\hline \multirow{2}{*}{ Spot Number } & \multirow{2}{*}{ Distance from the foot (mm) } & \multicolumn{10}{|c|}{ MD3 prismatic layer transect corrected data $(\mathrm{mmol} / \mathrm{mol})$ continued... } \\
\hline & & $\mathrm{Li} / \mathrm{Ca}$ & $\mathrm{B} / \mathrm{Ca}$ & $\mathrm{Mg} / \mathrm{Ca}$ & $\mathrm{Al} / \mathrm{Ca}$ & $\mathrm{Mn} / \mathrm{Ca}$ & $\mathrm{Zn} / \mathrm{Ca}$ & $\mathrm{Sr} / \mathrm{Ca}$ & $\mathrm{Ba} / \mathrm{Ca}$ & $\mathrm{Pb} / \mathrm{Ca}$ & $\mathrm{U} / \mathrm{Ca}$ \\
\hline 30 & 11.6 & 0.0000 & 0.0051 & 2.84 & 0.000 & 0.00000 & 0.0113 & 1.18 & 0.000330 & 0.0000803 & 0.0000000 \\
\hline 31 & 12.0 & 0.0000 & 0.0000 & 3.47 & 0.000 & 0.00073 & 0.0085 & 0.98 & 0.000382 & 0.0000845 & 0.0000271 \\
\hline 32 & 12.4 & 0.0137 & 0.0000 & 4.97 & 0.004 & 0.00344 & 0.0116 & 1.38 & 0.000463 & 0.0000775 & 0.0000232 \\
\hline 33 & 12.8 & 0.0126 & 0.0093 & 5.88 & 0.009 & 0.00000 & 0.0087 & 1.28 & 0.000505 & 0.0000071 & 0.0000000 \\
\hline 34 & 13.2 & 0.0161 & 0.0156 & 9.59 & 0.000 & 0.00216 & 0.0074 & 1.25 & 0.000568 & 0.0000313 & 0.0000000 \\
\hline 35 & 13.6 & 0.0069 & 0.0120 & 3.71 & 0.000 & 0.00488 & 0.0052 & 1.37 & 0.000285 & 0.0000137 & 0.0000000 \\
\hline 36 & 14.0 & 0.0060 & 0.0242 & 3.41 & 0.000 & 0.00289 & 0.0068 & 1.62 & 0.000500 & 0.0000000 & 0.0000000 \\
\hline 37 & 14.4 & 0.0382 & 0.1404 & 21.53 & 2.565 & 0.00872 & 0.0119 & 3.88 & 0.008295 & 0.0002025 & 0.0005845 \\
\hline 38 & 14.8 & 0.0161 & 0.0514 & 8.87 & 0.000 & 0.00349 & 0.0047 & 1.30 & 0.000553 & 0.0000000 & 0.0000000 \\
\hline 39 & 15.2 & 0.0000 & 0.0000 & 4.42 & 0.000 & 0.00225 & 0.0057 & 1.46 & 0.000533 & 0.0000867 & 0.0000073 \\
\hline 40 & 15.6 & 0.0346 & 0.0399 & 4.03 & 0.000 & 0.00241 & 0.0041 & 1.39 & 0.000437 & 0.0000087 & 0.0000054 \\
\hline 41 & 16.0 & 0.0001 & 0.0012 & 3.66 & 0.000 & 0.00436 & 0.0082 & 1.45 & 0.000222 & 0.0000000 & 0.0000000 \\
\hline 42 & 16.4 & 0.0126 & 0.0051 & 12.05 & 0.011 & 0.00512 & 0.0126 & 1.52 & 0.000557 & 0.0000974 & 0.0000243 \\
\hline 43 & 16.8 & 0.0245 & 0.1466 & 3.26 & 0.777 & 0.00419 & 0.0095 & 4.11 & 0.002733 & 0.0001408 & 0.0006332 \\
\hline 44 & 17.2 & 0.0000 & 0.0034 & 6.72 & 0.000 & 0.00035 & 0.0144 & 1.51 & 0.000689 & 0.0000328 & 0.0000083 \\
\hline 45 & 17.6 & 0.0092 & 0.0000 & 12.57 & 0.006 & 0.00442 & 0.0163 & 1.69 & 0.000913 & 0.0000248 & 0.0000000 \\
\hline 46 & 18.0 & 0.0000 & 0.1129 & 18.03 & 0.011 & 0.01219 & 0.0248 & 2.04 & 0.001608 & 0.0001279 & 0.0000682 \\
\hline 47 & 18.4 & 0.0034 & 0.0187 & 6.63 & 0.000 & 0.00170 & 0.0096 & 1.46 & 0.000382 & 0.0000000 & 0.0000000 \\
\hline 48 & 18.8 & 0.0130 & 0.0005 & 4.58 & 0.045 & 0.00311 & 0.0069 & 1.25 & 0.000537 & 0.0000000 & 0.0000000 \\
\hline 49 & 19.2 & 0.0000 & 0.0000 & 3.46 & 0.000 & 0.00142 & 0.0129 & 1.19 & 0.000739 & 0.0000477 & 0.0000000 \\
\hline 50 & 19.6 & 0.0032 & 0.0675 & 6.22 & 0.188 & 0.00162 & 0.0158 & 1.46 & 0.000490 & 0.0001082 & 0.0000244 \\
\hline 51 & 20.0 & 0.0078 & 0.0176 & 4.59 & 0.000 & 0.00673 & 0.0139 & 1.44 & 0.000494 & 0.0000047 & 0.0000183 \\
\hline 52 & 20.4 & 0.0000 & 0.0000 & 5.20 & 0.012 & 0.00428 & 0.0164 & 1.36 & 0.000460 & 0.0000057 & 0.0000000 \\
\hline 53 & 20.8 & 0.0000 & 0.0000 & 4.23 & 0.000 & 0.00204 & 0.0125 & 1.31 & 0.000311 & 0.0000000 & 0.0000000 \\
\hline 54 & 21.2 & 0.0270 & 0.0000 & 5.92 & 0.009 & 0.00372 & 0.0175 & 1.47 & 0.000675 & 0.0000000 & 0.0000177 \\
\hline 55 & 21.6 & 0.0378 & 0.0602 & 3.49 & 0.000 & 0.00438 & 0.0252 & 1.26 & 0.001003 & 0.0000000 & 0.0000000 \\
\hline 56 & 22.0 & 0.0050 & 0.0118 & 4.57 & 0.015 & 0.00111 & 0.0178 & 1.00 & 0.000651 & 0.0000869 & 0.0000000 \\
\hline 57 & 22.4 & 0.0249 & 0.0000 & 5.44 & 0.003 & 0.00134 & 0.0170 & 1.02 & 0.000383 & 0.0000106 & 0.0000000 \\
\hline 58 & 22.8 & 0.0246 & 0.0032 & 5.91 & 0.001 & 0.00329 & 0.0097 & 1.00 & 0.000308 & 0.0000421 & 0.0000000 \\
\hline 59 & 23.2 & 0.0094 & 0.0000 & 7.22 & 0.000 & 0.00406 & 0.0089 & 1.17 & 0.000596 & 0.0000551 & 0.0000000 \\
\hline
\end{tabular}




\begin{tabular}{|c|c|c|c|c|c|c|c|c|c|c|c|}
\hline \multirow{2}{*}{ Spot Number } & \multirow{2}{*}{ Distance from the foot (mm) } & \multicolumn{10}{|c|}{ MD3 prismatic layer transect corrected data $(\mathrm{mmol} / \mathrm{mol})$ continued... } \\
\hline & & $\mathrm{Li} / \mathrm{Ca}$ & $\mathrm{B} / \mathrm{Ca}$ & $\mathrm{Mg} / \mathrm{Ca}$ & $\mathrm{Al} / \mathrm{Ca}$ & $\mathrm{Mn} / \mathrm{Ca}$ & $\mathrm{Zn} / \mathrm{Ca}$ & $\mathrm{Sr} / \mathrm{Ca}$ & $\mathrm{Ba} / \mathrm{Ca}$ & $\mathrm{Pb} / \mathrm{Ca}$ & $\mathrm{U} / \mathrm{Ca}$ \\
\hline 60 & 23.6 & 0.0355 & 0.0317 & 6.91 & 0.019 & 0.00000 & 0.0099 & 1.19 & 0.000286 & 0.0000000 & 0.0000000 \\
\hline 61 & 24.0 & 0.0000 & 0.0000 & 3.97 & 0.000 & 0.00115 & 0.0039 & 0.99 & 0.000000 & 0.0000000 & 0.0000000 \\
\hline 62 & 24.4 & 0.0348 & 0.0430 & 2.74 & 0.019 & 0.00036 & 0.0112 & 1.37 & 0.000474 & 0.0000435 & 0.0000000 \\
\hline 63 & 24.8 & 0.0000 & 0.0317 & 4.76 & 0.033 & 0.00000 & 0.0053 & 1.39 & 0.000602 & 0.0000219 & 0.0000113 \\
\hline 64 & 25.2 & 0.0037 & 0.0000 & 3.17 & 0.000 & 0.00244 & 0.0055 & 1.22 & 0.000379 & 0.0000655 & 0.0000000 \\
\hline 65 & 25.6 & 0.0064 & 0.0000 & 8.23 & 0.004 & 0.00380 & 0.0029 & 1.50 & 0.000522 & 0.0000309 & 0.0000254 \\
\hline 66 & 26.0 & 0.0075 & 0.0033 & 9.33 & 0.358 & 0.00688 & 0.0165 & 1.63 & 0.001085 & 0.0000249 & 0.0000446 \\
\hline 67 & 26.4 & 0.0000 & 0.0000 & 18.23 & 0.939 & 0.00823 & 0.0218 & 1.74 & 0.001335 & 0.0000000 & 0.0000000 \\
\hline 68 & 26.8 & 0.0000 & 0.0000 & 4.87 & 0.107 & 0.00460 & 0.0120 & 1.05 & 0.000473 & 0.0000506 & 0.0000000 \\
\hline 69 & 27.2 & 0.0109 & 0.0025 & 5.17 & 0.000 & 0.00255 & 0.0143 & 1.03 & 0.000457 & 0.0000905 & 0.0000050 \\
\hline 70 & 27.6 & 0.0169 & 0.0000 & 10.35 & 0.017 & 0.00063 & 0.0135 & 1.07 & 0.000312 & 0.0001200 & 0.0000153 \\
\hline 71 & 28.0 & 0.0248 & 0.0033 & 4.80 & 0.011 & 0.00184 & 0.0205 & 1.25 & 0.000481 & 0.0001499 & 0.0000000 \\
\hline 72 & 28.4 & 0.0030 & 0.0000 & 3.03 & 0.000 & 0.00082 & 0.0182 & 1.29 & 0.000375 & 0.0000000 & 0.0000021 \\
\hline 73 & 28.8 & 0.0000 & 0.0084 & 3.76 & 0.000 & 0.00000 & 0.0040 & 1.44 & 0.000238 & 0.0000000 & 0.0000000 \\
\hline 74 & 29.2 & 0.0111 & 0.0124 & 5.13 & 0.004 & 0.00167 & 0.0154 & 1.37 & 0.000543 & 0.0001568 & 0.0000039 \\
\hline 75 & 29.6 & 0.0198 & 0.0097 & 13.27 & 0.001 & 0.00300 & 0.0082 & 1.45 & 0.000642 & 0.0000000 & 0.0000000 \\
\hline 76 & 30.0 & 0.0247 & 0.0257 & 16.81 & 0.298 & 0.00288 & 0.0184 & 1.80 & 0.001358 & 0.0000074 & 0.0000288 \\
\hline 77 & 30.4 & 0.0136 & 0.0000 & 8.96 & 0.013 & 0.00433 & 0.0184 & 1.46 & 0.000535 & 0.0001071 & 0.0000180 \\
\hline 78 & 30.8 & 0.0000 & 0.0124 & 9.43 & 0.000 & 0.00001 & 0.0129 & 1.42 & 0.000781 & 0.0000771 & 0.0000000 \\
\hline 79 & 31.2 & 0.0138 & 0.0000 & 6.87 & 0.000 & 0.00503 & 0.0128 & 1.49 & 0.000490 & 0.0000000 & 0.0000000 \\
\hline 80 & 31.6 & 0.0183 & 0.0186 & 7.65 & 0.264 & 0.00593 & 0.0118 & 1.74 & 0.000954 & 0.0000719 & 0.0000111 \\
\hline 81 & 32.0 & 0.0108 & 0.0000 & 5.50 & 0.001 & 0.00712 & 0.0151 & 1.36 & 0.000517 & 0.0001430 & 0.0000000 \\
\hline 82 & 32.4 & 0.0000 & 0.0000 & 7.03 & 0.168 & 0.00254 & 0.0121 & 1.33 & 0.000701 & 0.0001128 & 0.0000085 \\
\hline 83 & 32.8 & 0.0152 & 0.0147 & 4.90 & 0.000 & 0.00020 & 0.0152 & 1.08 & 0.000348 & 0.0000000 & 0.0000000 \\
\hline 84 & 33.2 & 0.0341 & 0.0038 & 5.07 & 0.001 & 0.00174 & 0.0028 & 1.04 & 0.000247 & 0.0000000 & 0.0000126 \\
\hline 85 & 33.6 & 0.0000 & 0.0055 & 7.63 & 0.796 & 0.00579 & 0.0194 & 1.42 & 0.000687 & 0.0000000 & 0.0000000 \\
\hline 86 & 34.0 & 0.0000 & 0.0163 & 6.63 & 0.000 & 0.00305 & 0.0146 & 1.12 & 0.000515 & 0.0001532 & 0.0000134 \\
\hline 87 & 34.4 & 0.0296 & 0.0000 & 5.53 & 0.030 & 0.01364 & 0.0158 & 1.46 & 0.000741 & 0.0000370 & 0.0000205 \\
\hline 88 & 34.8 & 0.0191 & 0.0000 & 3.67 & 0.015 & 0.00129 & 0.0188 & 1.35 & 0.000357 & 0.0001029 & 0.0000000 \\
\hline 89 & 35.2 & 0.0195 & 0.0105 & 7.19 & 0.017 & 0.00924 & 0.0014 & 1.50 & 0.000668 & 0.0000509 & 0.0000000 \\
\hline
\end{tabular}


APPENDIX 5.2a $\quad$ RW75 nacreous layer data

\begin{tabular}{|c|c|c|c|c|c|c|c|}
\hline \multirow{2}{*}{ Spot Number } & \multirow{2}{*}{ Distance from inner shell $(\mathrm{mm})$} & \multicolumn{6}{|c|}{ RW75 nacreous layer transect $\mathrm{N} 1$ corrected data $(\mathrm{mmol} / \mathrm{mol})$} \\
\hline & & $\mathrm{Mg} / \mathrm{Ca}$ & $\mathrm{Al} / \mathrm{Ca}$ & $\mathrm{Mn} / \mathrm{Ca}$ & $\mathrm{Zn} / \mathrm{Ca}$ & $\mathrm{Sr} / \mathrm{Ca}$ & $\mathrm{Ba} / \mathrm{Ca}$ \\
\hline 1 & 0.05 & 0.275 & 0.000171 & 0.00149 & 0.00391 & 1.57 & 0.00239 \\
\hline 2 & 0.10 & 0.256 & 0.000713 & 0.00182 & 0.00358 & 1.66 & 0.00296 \\
\hline 3 & 0.15 & 6.833 & 0.000000 & 0.00145 & 0.00570 & 2.97 & 0.00123 \\
\hline 4 & 0.20 & 0.201 & 0.000000 & 0.00026 & 0.00658 & 1.58 & 0.00219 \\
\hline 5 & 0.25 & 0.185 & 0.000000 & 0.00157 & 0.00408 & 1.64 & 0.00214 \\
\hline 6 & 0.30 & 0.176 & 0.000107 & 0.00237 & 0.00306 & 1.78 & 0.00216 \\
\hline 7 & 0.35 & 0.176 & 0.000000 & 0.00321 & 0.00168 & 1.77 & 0.00202 \\
\hline 8 & 0.40 & 0.188 & 0.000000 & 0.00065 & 0.00715 & 1.90 & 0.00243 \\
\hline 9 & 0.45 & 0.233 & 0.000575 & 0.00137 & 0.01722 & 1.85 & 0.00274 \\
\hline 10 & 0.50 & 0.191 & 0.000079 & 0.00126 & 0.00379 & 1.54 & 0.00189 \\
\hline 11 & 0.55 & 0.161 & 0.000152 & 0.00202 & 0.00150 & 1.63 & 0.00208 \\
\hline 12 & 0.60 & 0.179 & 0.000272 & 0.00221 & 0.00177 & 1.53 & 0.00180 \\
\hline 13 & 0.65 & 0.156 & 0.000000 & 0.00010 & 0.00378 & 1.59 & 0.00181 \\
\hline
\end{tabular}




\begin{tabular}{|c|c|c|c|c|c|c|c|}
\hline \multirow{2}{*}{ Spot Number } & \multirow{2}{*}{ Distance from inner shell (mm) } & \multicolumn{6}{|c|}{ RW75 nacreous layer transect N2 corrected data $(\mathrm{mmol} / \mathrm{mol})$} \\
\hline & & $\mathrm{Mg} / \mathrm{Ca}$ & $\mathrm{Al} / \mathrm{Ca}$ & $\mathrm{Mn} / \mathrm{Ca}$ & $\mathrm{Zn} / \mathrm{Ca}$ & $\mathrm{Sr} / \mathrm{Ca}$ & $\mathrm{Ba} / \mathrm{Ca}$ \\
\hline 1 & 0.00 & 0.278 & 0.000495 & 0.00397 & 0.00359 & 1.68 & 0.00217 \\
\hline 2 & 0.05 & 0.287 & 0.000161 & 0.00164 & 0.00378 & 1.60 & 0.00217 \\
\hline 3 & 0.10 & 0.357 & 0.000181 & 0.00480 & 0.00695 & 1.72 & 0.00270 \\
\hline 4 & 0.15 & 14.442 & 0.014564 & 0.00892 & 0.03345 & 4.30 & 0.00367 \\
\hline 5 & 0.20 & 0.214 & 0.000393 & 0.00169 & 0.00884 & 1.60 & 0.00216 \\
\hline 6 & 0.25 & 0.227 & 0.000130 & 0.00268 & 0.00454 & 1.71 & 0.00213 \\
\hline 7 & 0.30 & 0.196 & 0.000256 & 0.00447 & 0.00569 & 1.53 & 0.00201 \\
\hline 8 & 0.35 & 0.185 & 0.000201 & 0.00073 & 0.00373 & 1.61 & 0.00164 \\
\hline 9 & 0.40 & 0.152 & 0.000088 & 0.00237 & 0.00420 & 1.45 & 0.00140 \\
\hline 10 & 0.45 & 0.157 & 0.000260 & 0.00092 & 0.00328 & 1.43 & 0.00149 \\
\hline 11 & 0.50 & 0.150 & 0.000127 & 0.00073 & 0.00374 & 1.49 & 0.00157 \\
\hline 12 & 0.55 & 0.175 & 0.000009 & 0.00373 & 0.00550 & 1.56 & 0.00170 \\
\hline 13 & 0.60 & 0.197 & 0.000294 & 0.00400 & 0.00276 & 1.52 & 0.00168 \\
\hline 14 & 0.65 & 0.173 & 0.000000 & 0.00164 & 0.00860 & 1.62 & 0.00178 \\
\hline 15 & 0.70 & 0.178 & 0.000000 & 0.00023 & 0.00254 & 1.76 & 0.00182 \\
\hline 16 & 0.75 & 0.218 & 0.000000 & 0.00336 & 0.00182 & 1.68 & 0.00178 \\
\hline 17 & 0.80 & 0.285 & 0.000301 & 0.00082 & 0.00685 & 1.76 & 0.00197 \\
\hline 18 & 0.85 & 0.233 & 0.000000 & 0.00157 & 0.00766 & 1.95 & 0.00214 \\
\hline
\end{tabular}




\begin{tabular}{|c|c|c|c|c|c|c|c|}
\hline \multirow{2}{*}{ Spot Number } & \multirow{2}{*}{ Distance from inner shell (mm) } & \multicolumn{6}{|c|}{ RW75 nacreous layer transect N3 corrected data $(\mathrm{mmol} / \mathrm{mol})$} \\
\hline & & $\mathrm{Mg} / \mathrm{Ca}$ & $\mathrm{Al} / \mathrm{Ca}$ & $\mathrm{Mn} / \mathrm{Ca}$ & $\mathrm{Zn} / \mathrm{Ca}$ & $\mathrm{Sr} / \mathrm{Ca}$ & $\mathrm{Ba} / \mathrm{Ca}$ \\
\hline 1 & 0 & 0.289 & 0.000250 & 0.00287 & 0.00191 & 1.67 & 0.00232 \\
\hline 2 & 0.05 & 0.270 & 0.000000 & 0.00353 & 0.00859 & 1.63 & 0.00204 \\
\hline 3 & 0.1 & 1.368 & 0.000180 & 0.00146 & 0.00466 & 2.96 & 0.00197 \\
\hline 4 & 0.15 & 0.551 & 0.000866 & 0.00204 & 0.01292 & 2.45 & 0.00244 \\
\hline 5 & 0.2 & 0.254 & 0.000079 & 0.00382 & 0.01023 & 1.81 & 0.00245 \\
\hline 6 & 0.25 & 0.293 & 0.000054 & 0.00448 & 0.00707 & 1.60 & 0.00189 \\
\hline 7 & 0.3 & 0.000 & 0.000985 & 0.00431 & 0.00572 & 1.92 & 0.00232 \\
\hline 8 & 0.35 & 0.244 & 0.000599 & 0.00158 & 0.00381 & 1.46 & 0.00177 \\
\hline 9 & 0.4 & 3.771 & 0.000601 & 0.00448 & 0.00858 & 3.82 & 0.00178 \\
\hline 10 & 0.45 & 0.386 & 0.000825 & 0.00413 & 0.00747 & 1.47 & 0.00165 \\
\hline 11 & 0.5 & 0.270 & 0.000000 & 0.00120 & 0.00302 & 1.54 & 0.00152 \\
\hline 12 & 0.55 & 0.234 & 0.000000 & 0.00285 & 0.01237 & 1.52 & 0.00182 \\
\hline 13 & 0.6 & 0.190 & 0.000479 & 0.00076 & 0.00215 & 1.66 & 0.00190 \\
\hline 14 & 0.65 & 0.234 & 0.000000 & 0.00296 & 0.00332 & 1.44 & 0.00153 \\
\hline 15 & 0.7 & 0.195 & 0.000720 & 0.00356 & 0.00438 & 1.43 & 0.00136 \\
\hline 16 & 0.75 & 0.179 & 0.000297 & 0.00062 & 0.00310 & 1.52 & 0.00151 \\
\hline 17 & 0.8 & 0.157 & 0.001137 & 0.00000 & 0.01098 & 1.77 & 0.00188 \\
\hline 18 & 0.85 & 0.155 & 0.000000 & 0.00000 & 0.00837 & 1.71 & 0.00176 \\
\hline 19 & 0.9 & 0.142 & 0.000000 & 0.00191 & 0.00562 & 1.66 & 0.00176 \\
\hline 20 & 0.95 & 0.160 & 0.000471 & 0.00299 & 0.00707 & 1.70 & 0.00197 \\
\hline
\end{tabular}




\begin{tabular}{|c|c|c|c|c|c|c|c|c|c|c|c|}
\hline \multirow{2}{*}{ Spot Number } & \multirow{2}{*}{ Distance from inner shell $(\mathrm{mm})$} & \multicolumn{10}{|c|}{ RW75 nacreous layer transect $\mathrm{N} 4$ corrected data $(\mathrm{mmol} / \mathrm{mol})$} \\
\hline & & $\mathrm{Li} / \mathrm{Ca}$ & $\mathrm{B} / \mathrm{Ca}$ & $\mathrm{Mg} / \mathrm{Ca}$ & $\mathbf{A l} / \mathbf{C a}$ & $\mathrm{Mn} / \mathrm{Ca}$ & $\mathrm{Zn} / \mathrm{Ca}$ & $\mathrm{Sr} / \mathrm{Ca}$ & $\mathrm{Ba} / \mathrm{Ca}$ & $\mathrm{Pb} / \mathrm{Ca}$ & $\mathrm{U} / \mathrm{Ca}$ \\
\hline 1 & 0.00 & 0.0190 & 0.0228 & 0.239 & 0.00366 & 0.00239 & 0.0057 & 1.53 & 0.00252 & 0.0000823 & 0.0000014 \\
\hline 2 & 0.05 & 0.0061 & 0.0452 & 0.248 & 0.00000 & 0.00041 & 0.0058 & 1.48 & 0.00223 & 0.0000569 & 0.0000000 \\
\hline 3 & 0.10 & 0.0095 & 0.0464 & 0.283 & 0.00249 & 0.00214 & 0.0123 & 1.91 & 0.00239 & 0.0000000 & 0.0000176 \\
\hline 4 & 0.15 & 0.0106 & 0.0232 & 0.250 & 0.00273 & 0.00020 & 0.0014 & 1.76 & 0.00202 & 0.0000324 & 0.0000146 \\
\hline 5 & 0.20 & 0.0130 & 0.0372 & 0.282 & 0.00000 & 0.00018 & 0.0073 & 1.59 & 0.00217 & 0.0000771 & 0.0000201 \\
\hline 6 & 0.25 & 0.0000 & 0.0264 & 0.176 & 0.00082 & 0.00155 & 0.0068 & 1.67 & 0.00177 & 0.0000491 & 0.0000000 \\
\hline 7 & 0.30 & 0.0000 & 0.0248 & 0.175 & 0.00101 & 0.00094 & 0.0118 & 1.69 & 0.00198 & 0.0000179 & 0.0000000 \\
\hline 8 & 0.35 & 0.0000 & 0.0141 & 0.177 & 0.00000 & 0.00000 & 0.0101 & 1.60 & 0.00171 & 0.0000261 & 0.0000014 \\
\hline 9 & 0.40 & 0.0000 & 0.0285 & 0.182 & 0.00408 & 0.00291 & 0.0057 & 1.67 & 0.00176 & 0.0000467 & 0.0000000 \\
\hline 10 & 0.45 & 0.0000 & 0.0166 & 0.152 & 0.00206 & 0.00066 & 0.0063 & 1.76 & 0.00178 & 0.0000431 & 0.0000000 \\
\hline 11 & 0.50 & 0.0183 & 0.0437 & 0.161 & 0.00000 & 0.00063 & 0.0056 & 1.77 & 0.00177 & 0.0000600 & 0.0000000 \\
\hline 12 & 0.55 & 0.0000 & 0.0342 & 0.179 & 0.00044 & 0.00137 & 0.0060 & 1.64 & 0.00168 & 0.0000557 & 0.0000002 \\
\hline 13 & 0.60 & 0.0019 & 0.0266 & 0.169 & 0.00000 & 0.00136 & 0.0021 & 1.57 & 0.00153 & 0.0001517 & 0.0000117 \\
\hline 14 & 0.65 & 0.0071 & 0.0420 & 0.193 & 0.00255 & 0.00030 & 0.0084 & 1.60 & 0.00169 & 0.0002788 & 0.0000015 \\
\hline 15 & 0.70 & 0.0139 & 0.0313 & 0.201 & 0.00723 & 0.00126 & 0.0087 & 1.63 & 0.00185 & 0.0001634 & 0.0000000 \\
\hline 16 & 0.75 & 0.0105 & 0.0467 & 0.223 & 0.00643 & 0.00068 & 0.0083 & 1.68 & 0.00215 & 0.0000577 & 0.0000000 \\
\hline 17 & 0.80 & 0.0000 & 0.0499 & 0.277 & 0.00302 & 0.00000 & 0.0133 & 2.13 & 0.00286 & 0.0000832 & 0.0000000 \\
\hline
\end{tabular}




\begin{tabular}{|c|c|c|c|c|c|c|c|c|c|c|c|}
\hline \multirow{2}{*}{ Spot Number } & \multirow{2}{*}{ Distance from the foot $(\mathrm{mm})$} & \multicolumn{10}{|c|}{ RW75 nacreous layer transect N5 corrected data (mmol/mol) } \\
\hline & & $\mathrm{Li} / \mathrm{Ca}$ & $\mathrm{B} / \mathrm{Ca}$ & $\mathrm{Mg} / \mathrm{Ca}$ & $\mathrm{Al} / \mathrm{Ca}$ & $\mathrm{Mn} / \mathrm{Ca}$ & $\mathrm{Zn} / \mathrm{Ca}$ & $\mathrm{Sr} / \mathrm{Ca}$ & $\mathrm{Ba} / \mathrm{Ca}$ & $\mathrm{Pb} / \mathrm{Ca}$ & $\mathrm{U} / \mathrm{Ca}$ \\
\hline 1 & 0.00 & 0.0143 & 0.0321 & 0.401 & 0.00000 & 0.00425 & 0.0047 & 1.75 & 0.00278 & 0.0000586 & 0.0000048 \\
\hline 2 & 0.05 & 0.0266 & 0.0096 & 0.170 & 0.00000 & 0.00288 & 0.0036 & 1.50 & 0.00146 & 0.0000205 & 0.0000163 \\
\hline 3 & 0.10 & 0.0139 & 0.0216 & 0.132 & 0.00336 & 0.00000 & 0.0022 & 1.65 & 0.00159 & 0.0000222 & 0.0000000 \\
\hline 4 & 0.15 & 0.0000 & 0.0416 & 0.128 & 0.00000 & 0.00453 & 0.0079 & 1.85 & 0.00164 & 0.0000134 & 0.0000000 \\
\hline 5 & 0.20 & 0.0000 & 0.0101 & 0.138 & 0.01383 & 0.00243 & 0.0026 & 1.47 & 0.00143 & 0.0000872 & 0.0000000 \\
\hline 6 & 0.25 & 0.0062 & 0.0366 & 0.206 & 0.00000 & 0.00298 & 0.0070 & 1.85 & 0.00218 & 0.0000163 & 0.0000171 \\
\hline 7 & 0.30 & 0.0000 & 0.0384 & 0.704 & 0.01500 & 0.00289 & 0.0035 & 1.92 & 0.00217 & 0.0000239 & 0.0000214 \\
\hline 8 & 0.35 & 0.0158 & 0.0136 & 0.259 & 0.00000 & 0.00555 & 0.0036 & 1.91 & 0.00202 & 0.0000233 & 0.0000000 \\
\hline 9 & 0.40 & 0.0032 & 0.0000 & 0.218 & 0.00041 & 0.00285 & 0.0037 & 1.85 & 0.00186 & 0.0000725 & 0.0000000 \\
\hline 10 & 0.45 & 0.0000 & 0.0512 & 0.201 & 0.01116 & 0.00000 & 0.0064 & 1.89 & 0.00176 & 0.0000460 & 0.0000000 \\
\hline 11 & 0.50 & 0.0146 & 0.0178 & 0.210 & 0.00650 & 0.00121 & 0.0048 & 1.91 & 0.00180 & 0.0000000 & 0.0000071 \\
\hline 12 & 0.55 & 0.0067 & 0.0360 & 0.227 & 0.00000 & 0.00168 & 0.0033 & 2.11 & 0.00155 & 0.0000416 & 0.0000000 \\
\hline
\end{tabular}


APPENDIX 5.2b

A740 nacreous layer data

\begin{tabular}{|c|c|c|c|c|c|c|c|}
\hline \multirow{2}{*}{ Spot Number } & \multirow{2}{*}{ Distance from inner shell (mm) } & \multicolumn{6}{|c|}{ A740 nacreous layer transect $\mathrm{N} 1$ corrected data $(\mathrm{mmol} / \mathrm{mol})$} \\
\hline & & $\mathrm{Mg} / \mathrm{Ca}$ & $\mathrm{Al} / \mathrm{Ca}$ & $\mathrm{Mn} / \mathrm{Ca}$ & $\mathrm{Zn} / \mathrm{Ca}$ & $\mathrm{Sr} / \mathrm{Ca}$ & $\mathrm{Ba} / \mathrm{Ca}$ \\
\hline 1 & 0.00 & 0.284 & 0.00000 & 0.00000 & 0.00177 & 1.82 & 0.00223 \\
\hline 2 & 0.05 & 0.231 & 0.00015 & 0.00000 & 0.00000 & 1.57 & 0.00145 \\
\hline 3 & 0.10 & 0.234 & 0.00313 & 0.00000 & 0.00431 & 1.66 & 0.00148 \\
\hline 4 & 0.15 & 0.204 & 0.00734 & 0.00307 & 0.00000 & 1.67 & 0.00123 \\
\hline 5 & 0.20 & 0.191 & 0.00000 & 0.00000 & 0.00241 & 1.62 & 0.00120 \\
\hline 6 & 0.25 & 0.203 & 0.00164 & 0.00000 & 0.00000 & 1.82 & 0.00117 \\
\hline 7 & 0.30 & 0.163 & 0.00910 & 0.00605 & 0.00000 & 2.10 & 0.00242 \\
\hline 8 & 0.35 & 0.199 & 0.00545 & 0.00016 & 0.00574 & 2.27 & 0.00307 \\
\hline 9 & 0.40 & 0.177 & 0.00000 & 0.00213 & 0.00000 & 2.18 & 0.00310 \\
\hline 10 & 0.45 & 0.170 & 0.00000 & 0.00347 & 0.00368 & 2.32 & 0.00341 \\
\hline 11 & 0.50 & 0.207 & 0.00000 & 0.00000 & 0.00000 & 2.13 & 0.00361 \\
\hline 12 & 0.55 & 0.248 & 0.00000 & 0.00239 & 0.00000 & 2.26 & 0.00417 \\
\hline 13 & 0.60 & 0.321 & 0.01688 & 0.00000 & 0.00638 & 2.46 & 0.00378 \\
\hline 14 & 0.65 & 0.176 & 0.00000 & 0.00334 & 0.00449 & 2.68 & 0.00452 \\
\hline
\end{tabular}




\begin{tabular}{|c|c|c|c|c|c|c|c|}
\hline \multirow{2}{*}{ Spot Number } & \multirow{2}{*}{ Distance from inner shell (mm) } & \multicolumn{6}{|c|}{ A740 nacreous layer transect $\mathrm{N} 2$ corrected data $(\mathrm{mmol} / \mathrm{mol})$} \\
\hline & & $\mathrm{Mg} / \mathrm{Ca}$ & $\mathrm{Al} / \mathrm{Ca}$ & $\mathrm{Mn} / \mathrm{Ca}$ & $\mathrm{Zn} / \mathrm{Ca}$ & $\mathrm{Sr} / \mathrm{Ca}$ & $\mathrm{Ba} / \mathrm{Ca}$ \\
\hline 1 & 0.00 & 0.175 & 0.00755 & 0.00027 & 0.00154 & 1.67 & 0.00249 \\
\hline 2 & 0.05 & 0.145 & 0.00000 & 0.00482 & 0.00000 & 1.56 & 0.00214 \\
\hline 3 & 0.10 & 0.141 & 0.00000 & 0.00028 & 0.00329 & 1.67 & 0.00216 \\
\hline 4 & 0.15 & 0.133 & 0.00419 & 0.00000 & 0.00000 & 1.72 & 0.00194 \\
\hline 5 & 0.20 & 0.148 & 0.00000 & 0.00000 & 0.00000 & 1.71 & 0.00221 \\
\hline 6 & 0.25 & 0.133 & 0.00652 & 0.00000 & 0.00350 & 1.65 & 0.00185 \\
\hline 7 & 0.30 & 0.128 & 0.00372 & 0.00092 & 0.00358 & 1.91 & 0.00227 \\
\hline 8 & 0.35 & 0.125 & 0.00454 & 0.00000 & 0.00025 & 2.02 & 0.00209 \\
\hline 9 & 0.40 & 0.157 & 0.00979 & 0.00117 & 0.00000 & 2.13 & 0.00250 \\
\hline 10 & 0.45 & 0.156 & 0.00712 & 0.00309 & 0.00000 & 1.79 & 0.00200 \\
\hline 11 & 0.50 & 0.162 & 0.00000 & 0.00148 & 0.00037 & 1.76 & 0.00196 \\
\hline 12 & 0.55 & 0.146 & 0.00000 & 0.00000 & 0.00051 & 2.05 & 0.00227 \\
\hline 13 & 0.60 & 0.151 & 0.00000 & 0.00080 & 0.00075 & 2.16 & 0.00256 \\
\hline 14 & 0.65 & 0.161 & 0.01168 & 0.00104 & 0.00345 & 2.12 & 0.00264 \\
\hline 15 & 0.70 & 0.146 & 0.00000 & 0.00285 & 0.00401 & 2.27 & 0.00265 \\
\hline 16 & 0.75 & 0.157 & 0.00000 & 0.00251 & 0.00198 & 2.36 & 0.00279 \\
\hline
\end{tabular}




\begin{tabular}{|c|c|c|c|c|c|c|c|}
\hline \multirow{2}{*}{ Spot Number } & \multirow{2}{*}{ Distance from inner shell $(\mathrm{mm})$} & \multicolumn{6}{|c|}{ A740 nacreous layer transect $\mathrm{N} 3$ corrected data $(\mathrm{mmol} / \mathrm{mol})$} \\
\hline & & $\mathrm{Mg} / \mathrm{Ca}$ & $\mathrm{Al} / \mathrm{Ca}$ & $\mathrm{Mn} / \mathrm{Ca}$ & $\mathrm{Zn} / \mathrm{Ca}$ & $\mathrm{Sr} / \mathrm{Ca}$ & $\mathrm{Ba} / \mathrm{Ca}$ \\
\hline 1 & 0.00 & 0.352 & 0.00000 & 0.00360 & 0.00663 & 2.02 & 0.00348 \\
\hline 2 & 0.05 & 0.407 & 0.00000 & 0.00295 & 0.00345 & 2.81 & 0.00266 \\
\hline 3 & 0.10 & 0.178 & 0.00000 & 0.00343 & 0.01629 & 1.71 & 0.00464 \\
\hline 4 & 0.15 & 0.252 & 0.00000 & 0.00406 & 0.02024 & 1.63 & 0.00411 \\
\hline 5 & 0.20 & 0.182 & 0.00000 & 0.00146 & 0.02924 & 2.01 & 0.00462 \\
\hline 6 & 0.25 & 0.160 & 0.00000 & 0.00174 & 0.02657 & 1.94 & 0.00402 \\
\hline 7 & 0.30 & 0.145 & 0.00000 & 0.00340 & 0.02135 & 1.94 & 0.00386 \\
\hline 8 & 0.35 & 0.157 & 0.00536 & 0.00556 & 0.01808 & 1.76 & 0.00379 \\
\hline 9 & 0.40 & 0.147 & 0.00000 & 0.00095 & 0.01955 & 1.98 & 0.00374 \\
\hline 10 & 0.45 & 0.170 & 0.00100 & 0.00126 & 0.01569 & 1.76 & 0.00340 \\
\hline 11 & 0.50 & 0.154 & 0.00000 & 0.00005 & 0.01256 & 1.77 & 0.00333 \\
\hline 12 & 0.55 & 0.167 & 0.00000 & 0.00119 & 0.01381 & 1.75 & 0.00339 \\
\hline 13 & 0.60 & 0.154 & 0.00000 & 0.00441 & 0.01155 & 2.00 & 0.00356 \\
\hline 14 & 0.65 & 0.173 & 0.00000 & 0.00334 & 0.00740 & 2.03 & 0.00390 \\
\hline 15 & 0.70 & 0.184 & 0.00679 & 0.00111 & 0.00920 & 1.78 & 0.00394 \\
\hline 16 & 0.75 & 0.318 & 0.00324 & 0.00000 & 0.00880 & 2.29 & 0.00382 \\
\hline 17 & 0.80 & 0.215 & 0.00395 & 0.00498 & 0.00202 & 2.51 & 0.00412 \\
\hline
\end{tabular}




\begin{tabular}{|c|c|c|c|c|c|c|c|}
\hline \multirow{2}{*}{ Spot Number } & \multirow{2}{*}{ Distance from inner shell (mm) } & \multicolumn{6}{|c|}{ A740 nacreous layer transect $\mathrm{N} 4$ corrected data $(\mathrm{mmol} / \mathrm{mol})$} \\
\hline & & $\mathrm{Mg} / \mathrm{Ca}$ & $\mathrm{Al} / \mathrm{Ca}$ & $\mathrm{Mn} / \mathrm{Ca}$ & $\mathrm{Zn} / \mathrm{Ca}$ & $\mathrm{Sr} / \mathrm{Ca}$ & $\mathrm{Ba} / \mathrm{Ca}$ \\
\hline 1 & 0.00 & 0.621 & 0.01099 & 0.00460 & 0.00000 & 2.40 & 0.00225 \\
\hline 2 & 0.05 & 0.186 & 0.01381 & 0.00194 & 0.01701 & 1.86 & 0.00492 \\
\hline 3 & 0.10 & 0.151 & 0.00000 & 0.00050 & 0.01491 & 1.84 & 0.00438 \\
\hline 4 & 0.15 & 0.155 & 0.00000 & 0.00374 & 0.00658 & 1.75 & 0.00428 \\
\hline 5 & 0.20 & 0.158 & 0.00000 & 0.00180 & 0.01763 & 1.73 & 0.00409 \\
\hline 6 & 0.25 & 0.161 & 0.00000 & 0.00428 & 0.01067 & 1.63 & 0.00352 \\
\hline 7 & 0.30 & 0.185 & 0.01892 & 0.00151 & 0.00809 & 1.58 & 0.00349 \\
\hline 8 & 0.35 & 0.195 & 0.00623 & 0.00529 & 0.01267 & 1.90 & 0.00377 \\
\hline 9 & 0.40 & 0.175 & 0.00000 & 0.00255 & 0.00950 & 1.94 & 0.00361 \\
\hline 10 & 0.45 & 0.141 & 0.00101 & 0.00155 & 0.01711 & 2.01 & 0.00385 \\
\hline 11 & 0.50 & 0.147 & 0.00000 & 0.00305 & 0.01445 & 2.23 & 0.00424 \\
\hline 12 & 0.55 & 0.154 & 0.00000 & 0.00029 & 0.00996 & 2.14 & 0.00366 \\
\hline 13 & 0.60 & 0.166 & 0.00293 & 0.00131 & 0.01784 & 2.08 & 0.00411 \\
\hline 14 & 0.65 & 0.195 & 0.00000 & 0.00453 & 0.01669 & 2.18 & 0.00482 \\
\hline 15 & 0.70 & 0.474 & 0.00580 & 0.00280 & 0.00628 & 2.78 & 0.00466 \\
\hline 16 & 0.75 & 0.183 & 0.00764 & 0.00206 & 0.01446 & 2.25 & 0.00410 \\
\hline 17 & 0.80 & 5.167 & 0.00415 & 0.00401 & 0.00000 & 1.58 & 0.00097 \\
\hline
\end{tabular}




\begin{tabular}{|c|c|c|c|c|c|c|c|}
\hline \multirow{2}{*}{ Spot Number } & \multirow{2}{*}{ Distance from inner shell (mm) } & \multicolumn{6}{|c|}{ A740 nacreous layer transect $\mathrm{N} 5$ corrected data $(\mathrm{mmol} / \mathrm{mol})$} \\
\hline & & $\mathrm{Mg} / \mathrm{Ca}$ & $\mathrm{Al} / \mathrm{Ca}$ & $\mathrm{Mn} / \mathrm{Ca}$ & $\mathrm{Zn} / \mathrm{Ca}$ & $\mathrm{Sr} / \mathrm{Ca}$ & $\mathrm{Ba} / \mathrm{Ca}$ \\
\hline 1 & 0.00 & 0.352 & 0.00000 & 0.0051 & 0.00767 & 1.98 & 0.00116 \\
\hline 2 & 0.05 & 0.653 & 0.00000 & 0.0026 & 0.00216 & 2.44 & 0.00162 \\
\hline 3 & 0.10 & 0.422 & 0.00000 & 0.0000 & 0.01219 & 2.21 & 0.00269 \\
\hline 4 & 0.15 & 0.229 & 0.00000 & 0.0074 & 0.01939 & 1.74 & 0.00385 \\
\hline 5 & 0.20 & 0.082 & 0.06029 & 0.0000 & 0.03140 & 1.80 & 0.00408 \\
\hline 6 & 0.25 & 0.292 & 0.00000 & 0.0000 & 0.00868 & 1.92 & 0.00308 \\
\hline 7 & 0.30 & 0.194 & 0.00000 & 0.0088 & 0.00000 & 1.55 & 0.00345 \\
\hline 8 & 0.35 & 0.038 & 0.15809 & 0.0000 & 0.00000 & 1.47 & 0.00290 \\
\hline 9 & 0.40 & 0.046 & 0.00000 & 0.0279 & 0.00000 & 1.72 & 0.00312 \\
\hline 10 & 0.45 & 0.440 & 0.23329 & 0.0000 & 0.03346 & 2.03 & 0.00422 \\
\hline 11 & 0.50 & 0.171 & 0.53019 & 0.0315 & 0.04726 & 2.34 & 0.00648 \\
\hline 12 & 0.55 & 0.000 & 0.16931 & 0.0964 & 0.11083 & 1.84 & 0.00139 \\
\hline 13 & 0.60 & 0.468 & 0.84181 & 0.0277 & 0.00000 & 2.19 & 0.00172 \\
\hline 14 & 0.65 & 0.227 & 0.00000 & 0.0000 & 0.00000 & 1.72 & 0.00502 \\
\hline 15 & 0.70 & 0.427 & 0.00000 & 0.0177 & 0.10789 & 1.63 & 0.00346 \\
\hline 16 & 0.75 & 0.214 & 0.43278 & 0.0000 & 0.00000 & 2.12 & 0.00417 \\
\hline 17 & 0.80 & 0.284 & 0.00000 & 0.0000 & 0.01513 & 2.29 & 0.00434 \\
\hline 18 & 0.85 & 0.667 & 0.00134 & 0.0000 & 0.00000 & 3.10 & 0.00200 \\
\hline
\end{tabular}




\begin{tabular}{|c|c|c|c|c|c|c|c|c|c|c|}
\hline \multirow{2}{*}{ Spot Number } & \multirow{2}{*}{ Distance from inner shell $(\mathrm{mm})$} & \multicolumn{9}{|c|}{ A740 nacreous layer transect $\mathrm{N} 6$ corrected data $(\mathrm{mmol} / \mathrm{mol})$} \\
\hline & & $\mathrm{Li} / \mathrm{Ca}$ & $\mathrm{B} / \mathrm{Ca}$ & $\mathrm{Mg} / \mathrm{Ca}$ & $\mathrm{Al} / \mathrm{Ca}$ & $\mathrm{Mn} / \mathrm{Ca}$ & $\mathrm{Zn} / \mathrm{Ca}$ & $\mathrm{Sr} / \mathrm{Ca}$ & $\mathrm{Ba} / \mathrm{Ca}$ & $\mathrm{U} / \mathrm{Ca}$ \\
\hline 1 & 0.00 & 0.0096 & 0.0415 & 0.351 & 0.00190 & 0.00000 & 0.0050 & 1.67 & 0.00195 & 0.0000000 \\
\hline 2 & 0.05 & 0.0067 & 0.0376 & 0.425 & 0.00000 & 0.00122 & 0.0025 & 1.99 & 0.00243 & 0.0000256 \\
\hline 3 & 0.10 & 0.0134 & 1.1410 & 7.402 & 0.00305 & 0.00373 & 0.0401 & 4.91 & 0.00278 & 0.0000784 \\
\hline 4 & 0.15 & 0.0065 & 0.0083 & 0.162 & 0.00000 & 0.00367 & 0.0067 & 1.68 & 0.00386 & 0.0000537 \\
\hline 5 & 0.20 & 0.0054 & 0.0427 & 0.147 & 0.00435 & 0.00302 & 0.0110 & 1.84 & 0.00399 & 0.0000336 \\
\hline 6 & 0.25 & 0.0079 & 0.0122 & 0.166 & 0.00766 & 0.00333 & 0.0070 & 1.82 & 0.00362 & 0.0000520 \\
\hline 7 & 0.30 & 0.0075 & 0.0399 & 0.167 & 0.00482 & 0.00312 & 0.0138 & 1.80 & 0.00346 & 0.0000000 \\
\hline 8 & 0.35 & 0.0103 & 0.0216 & 0.148 & 0.00823 & 0.00357 & 0.0124 & 1.75 & 0.00344 & 0.0000281 \\
\hline 9 & 0.40 & 0.0101 & 0.0191 & 0.157 & 0.00000 & 0.00247 & 0.0123 & 1.72 & 0.00341 & 0.0000983 \\
\hline 10 & 0.45 & 0.0139 & 0.0195 & 0.172 & 0.00000 & 0.00277 & 0.0038 & 1.90 & 0.00345 & 0.0000280 \\
\hline 11 & 0.50 & 0.0114 & 0.0490 & 0.168 & 0.00464 & 0.00191 & 0.0081 & 2.01 & 0.00390 & 0.0000000 \\
\hline 12 & 0.55 & 0.0099 & 0.0218 & 0.150 & 0.00070 & 0.00232 & 0.0051 & 1.85 & 0.00348 & 0.0000717 \\
\hline 13 & 0.60 & 0.0084 & 0.0159 & 0.152 & 0.00000 & 0.00196 & 0.0115 & 2.03 & 0.00386 & 0.0000000 \\
\hline 14 & 0.65 & 0.0085 & 0.0151 & 0.152 & 0.00143 & 0.00312 & 0.0010 & 2.11 & 0.00369 & 0.0000583 \\
\hline 15 & 0.70 & 0.0077 & 0.0381 & 0.154 & 0.00187 & 0.00355 & 0.0151 & 2.09 & 0.00405 & 0.0000213 \\
\hline 16 & 0.75 & 0.0000 & 0.0435 & 0.162 & 0.00295 & 0.00403 & 0.0085 & 2.16 & 0.00411 & $0.000025 \mathrm{~s}$ \\
\hline 17 & 0.80 & 0.0077 & 0.0341 & 0.175 & 0.00086 & 0.00366 & 0.0069 & 2.13 & 0.00439 & 0.0000115 \\
\hline 18 & 0.85 & 0.0051 & 0.0553 & 0.209 & 0.00000 & 0.00182 & 0.0093 & 2.26 & 0.00348 & 0.0000613 \\
\hline
\end{tabular}


APPENDIX 5.2c $\quad$ PIB nacreous layer data

\begin{tabular}{|c|c|c|c|c|c|c|c|c|c|c|c|}
\hline \multirow{2}{*}{ Spot Number } & \multirow{2}{*}{ Distance from inner shell ( $\mathrm{mm})$} & \multicolumn{10}{|c|}{ P1B nacreous layer transect $\mathrm{N} 1$ corrected data $(\mathrm{mmol} / \mathrm{mol})$} \\
\hline & & $\mathrm{Li} / \mathrm{Ca}$ & $\mathrm{B} / \mathrm{Ca}$ & $\mathrm{Mg} / \mathrm{Ca}$ & $\mathrm{Al} / \mathrm{Ca}$ & $\mathrm{Mn} / \mathrm{Ca}$ & $\mathrm{Zn} / \mathrm{Ca}$ & $\mathrm{Sr} / \mathrm{Ca}$ & $\mathrm{Ba} / \mathrm{Ca}$ & $\mathrm{Pb} / \mathrm{Ca}$ & $\mathrm{U} / \mathrm{Ca}$ \\
\hline 1 & 0.00 & 0.0000 & 0.0000 & 0.282 & 0.0000 & 0.00000 & 0.01694 & 2.19 & 0.000683 & 0.000067 & 0.0000000 \\
\hline 2 & 0.05 & 0.0006 & 0.0000 & 0.234 & 0.0219 & 0.00000 & 0.00000 & 1.73 & 0.000404 & 0.000012 & 0.0000119 \\
\hline 3 & 0.10 & 0.0000 & 0.0000 & 0.222 & 0.0000 & 0.00000 & 0.00062 & 1.78 & 0.000431 & 0.000055 & 0.0000313 \\
\hline 4 & 0.15 & 0.0295 & 0.0000 & 0.236 & 0.0000 & 0.00000 & 0.00243 & 1.71 & 0.000467 & 0.000134 & 0.0000450 \\
\hline 5 & 0.20 & 0.0000 & 0.0176 & 0.343 & 0.0000 & 0.00000 & 0.00021 & 1.85 & 0.000537 & 0.000041 & 0.0000379 \\
\hline 6 & 0.25 & 0.0000 & 1.2510 & 6.983 & 0.0256 & 0.00000 & 0.00000 & 2.88 & 0.001372 & 0.000224 & 0.0000114 \\
\hline 7 & 0.30 & 0.0742 & 5.8058 & 44.410 & 0.0522 & 0.00486 & 0.01675 & 5.84 & 0.003228 & 0.000000 & 0.0001076 \\
\hline 8 & 0.35 & 0.0000 & 0.0424 & 0.486 & 0.0023 & 0.00000 & 0.00000 & 1.75 & 0.000415 & 0.000000 & 0.0000146 \\
\hline 9 & 0.40 & 0.0000 & 0.0608 & 0.804 & 0.0000 & 0.00000 & 0.00000 & 2.10 & 0.000618 & 0.000130 & 0.0000000 \\
\hline 10 & 0.45 & 0.0152 & 0.0858 & 0.855 & 0.0000 & 0.00000 & 0.00000 & 2.38 & 0.000700 & 0.000090 & 0.0000080 \\
\hline 11 & 0.50 & 0.0127 & 0.0552 & 0.714 & 0.0035 & 0.00007 & 0.00000 & 2.39 & 0.000584 & 0.000036 & 0.0000000 \\
\hline 12 & 0.55 & 0.0000 & 0.0374 & 0.484 & 0.0016 & 0.00157 & 0.00000 & 2.15 & 0.000487 & 0.000043 & 0.0000132 \\
\hline 13 & 0.60 & 0.0008 & 0.0417 & 0.366 & 0.0053 & 0.00675 & 0.00241 & 1.62 & 0.000351 & 0.000156 & 0.0000364 \\
\hline 14 & 0.65 & 0.0063 & 0.0264 & 0.338 & 0.0000 & 0.00046 & 0.00000 & 1.53 & 0.000381 & 0.000208 & 0.0000268 \\
\hline 15 & 0.70 & 0.0000 & 0.0000 & 0.349 & 0.0000 & 0.00327 & 0.00314 & 1.76 & 0.000408 & 0.000073 & 0.0000000 \\
\hline 16 & 0.75 & 0.0000 & 0.0749 & 0.357 & 0.0063 & 0.00000 & 0.00160 & 1.66 & 0.000335 & 0.000113 & 0.0000000 \\
\hline 17 & 0.80 & 0.0000 & 0.0382 & 0.366 & 0.0146 & 0.00000 & 0.00000 & 1.67 & 0.000359 & 0.000055 & 0.0000000 \\
\hline 18 & 0.85 & 0.0000 & 0.0616 & 0.399 & 0.0000 & 0.00000 & 0.00000 & 1.80 & 0.000536 & 0.000148 & 0.0000245 \\
\hline 19 & 0.90 & 0.0027 & 0.0029 & 0.413 & 0.0000 & 0.00202 & 0.00000 & 1.59 & 0.000447 & 0.000000 & 0.0000000 \\
\hline 20 & 0.95 & 0.0105 & 0.0408 & 0.471 & 0.0000 & 0.00000 & 0.00000 & 1.88 & 0.000514 & 0.000067 & 0.0000000 \\
\hline 21 & 1.00 & 0.0333 & 0.0691 & 0.496 & 0.0009 & 0.00000 & 0.00356 & 2.15 & 0.000787 & 0.000015 & 0.0000000 \\
\hline 22 & 1.05 & 0.0065 & 0.0214 & 0.421 & 0.0082 & 0.00215 & 0.00305 & 2.20 & 0.000736 & 0.000069 & 0.0000282 \\
\hline
\end{tabular}




\begin{tabular}{|c|c|c|c|c|c|c|c|c|c|c|c|}
\hline \multirow{2}{*}{ Spot Number } & \multirow{2}{*}{ Distance from inner Shell $(\mathrm{mm})$} & \multicolumn{10}{|c|}{ P1B nacreous layer transect $\mathrm{N} 2$ corrected data $(\mathrm{mmol} / \mathrm{mol})$} \\
\hline & & $\mathrm{Li} / \mathrm{Ca}$ & $\mathrm{B} / \mathrm{Ca}$ & $\mathrm{Mg} / \mathrm{Ca}$ & $\mathrm{Al} / \mathrm{Ca}$ & $\mathrm{Mn} / \mathrm{Ca}$ & $\mathrm{Zn} / \mathrm{Ca}$ & $\mathrm{Sr} / \mathrm{Ca}$ & $\mathrm{Ba} / \mathrm{Ca}$ & $\mathrm{Pb} / \mathrm{Ca}$ & $\mathrm{U} / \mathrm{Ca}$ \\
\hline 1 & 0.00 & 0.0000 & 0.0759 & 0.167 & 0.0100 & 0.00421 & 0.00000 & 1.69 & 0.000605 & 0.000255 & 0.0000000 \\
\hline 2 & 0.05 & 0.0367 & 0.1829 & 0.692 & 0.0000 & 0.00000 & 0.00288 & 1.86 & 0.000558 & 0.000093 & 0.0000000 \\
\hline 3 & 0.10 & 0.0264 & 0.6163 & 3.047 & 0.0066 & 0.00456 & 0.00000 & 2.67 & 0.000818 & 0.000195 & 0.0000000 \\
\hline 4 & 0.15 & 0.0041 & 0.0323 & 0.361 & 0.0090 & 0.00054 & 0.00312 & 1.57 & 0.000514 & 0.000230 & 0.0000099 \\
\hline 5 & 0.20 & 0.0060 & 0.0717 & 0.360 & 0.0000 & 0.00000 & 0.00871 & 1.74 & 0.000475 & 0.000272 & 0.0000105 \\
\hline 6 & 0.25 & 0.0000 & 0.0743 & 0.548 & 0.0013 & 0.00000 & 0.00267 & 2.02 & 0.000495 & 0.000360 & 0.0000284 \\
\hline 7 & 0.30 & 0.0071 & 7.9105 & 57.220 & 0.0000 & 0.02420 & 0.00203 & 3.39 & 0.001276 & 0.000093 & 0.0000000 \\
\hline 8 & 0.35 & 0.0000 & 0.0204 & 0.598 & 0.0132 & 0.00000 & 0.00506 & 1.66 & 0.000402 & 0.000229 & 0.0000413 \\
\hline 9 & 0.40 & 0.0000 & 0.0218 & 0.571 & 0.0000 & 0.00004 & 0.00359 & 1.73 & 0.000431 & 0.000210 & 0.0000000 \\
\hline 10 & 0.45 & 0.0065 & 0.0369 & 0.711 & 0.0155 & 0.00000 & 0.00226 & 2.22 & 0.000499 & 0.000065 & 0.0000067 \\
\hline 11 & 0.50 & 0.0249 & 0.1060 & 0.579 & 0.0000 & 0.00110 & 0.00083 & 2.66 & 0.000712 & 0.000170 & 0.0000023 \\
\hline 12 & 0.55 & 0.0154 & 0.0428 & 0.402 & 0.0000 & 0.00071 & 0.00684 & 1.87 & 0.000422 & 0.000051 & 0.0000081 \\
\hline 13 & 0.60 & 0.0000 & 0.0509 & 0.445 & 0.0000 & 0.00307 & 0.00000 & 1.81 & 0.000405 & 0.000023 & 0.0000102 \\
\hline 14 & 0.65 & 0.0135 & 0.0582 & 0.383 & 0.0161 & 0.00000 & 0.00815 & 1.77 & 0.000433 & 0.000127 & 0.0000000 \\
\hline 15 & 0.70 & 0.0160 & 0.0702 & 0.518 & 0.0059 & 0.00000 & 0.00219 & 2.11 & 0.000725 & 0.000110 & 0.0000000 \\
\hline 16 & 0.75 & 0.0000 & 0.0581 & 0.403 & 0.0136 & 0.00099 & 0.00000 & 1.84 & 0.000607 & 0.000128 & 0.0000141 \\
\hline 17 & 0.80 & 0.0078 & 0.0899 & 0.367 & 0.0213 & 0.00000 & 0.00194 & 1.73 & 0.000477 & 0.000118 & 0.0000000 \\
\hline 18 & 0.85 & 0.0332 & 0.0741 & 0.342 & 0.0145 & 0.00000 & 0.00182 & 1.82 & 0.000592 & 0.000000 & 0.0000000 \\
\hline 19 & 0.90 & 0.0109 & 0.0596 & 0.435 & 0.0000 & 0.00000 & 0.00051 & 1.78 & 0.000605 & 0.000000 & 0.0000000 \\
\hline 20 & 0.95 & 0.0000 & 0.0390 & 0.416 & 0.0008 & 0.00293 & 0.00867 & 2.01 & 0.000814 & 0.000048 & 0.0000000 \\
\hline 21 & 1.00 & 0.0000 & 0.0683 & 0.434 & 0.0136 & 0.00091 & 0.00568 & 1.75 & 0.000554 & 0.000046 & 0.0000000 \\
\hline 22 & 1.05 & 0.0376 & 0.0751 & 0.442 & 0.0021 & 0.00448 & 0.00000 & 2.35 & 0.000858 & 0.000112 & 0.0000000 \\
\hline
\end{tabular}




\begin{tabular}{|c|c|c|c|c|c|c|c|c|c|c|c|}
\hline \multirow{2}{*}{ Spot Number } & \multirow{2}{*}{ Distance from inner Shell $(\mathrm{mm})$} & \multicolumn{10}{|c|}{ P1B nacreous layer transect N3 corrected data $(\mathrm{mmol} / \mathrm{mol})$} \\
\hline & & $\mathrm{Li} / \mathrm{Ca}$ & $\mathrm{B} / \mathrm{Ca}$ & $\mathrm{Mg} / \mathrm{Ca}$ & $\mathrm{Al} / \mathrm{Ca}$ & $\mathrm{Mn} / \mathrm{Ca}$ & $\mathrm{Zn} / \mathrm{Ca}$ & $\mathrm{Sr} / \mathrm{Ca}$ & $\mathrm{Ba} / \mathrm{Ca}$ & $\mathrm{Pb} / \mathrm{Ca}$ & $\mathrm{U} / \mathrm{Ca}$ \\
\hline 1 & 0.00 & 0.0108 & 0.0141 & 0.336 & 0.0104 & 0.00000 & 0.00542 & 1.34 & 0.000346 & 0.000243 & 0.0000000 \\
\hline 2 & 0.05 & 0.0150 & 0.0604 & 0.481 & 0.0000 & 0.00000 & 0.00081 & 2.23 & 0.000647 & 0.000040 & 0.0000000 \\
\hline 3 & 0.10 & 0.0029 & 0.0491 & 0.434 & 0.0086 & 0.00335 & 0.00515 & 1.54 & 0.000427 & 0.000246 & 0.0000000 \\
\hline 4 & 0.15 & 0.0001 & 0.4949 & 1.457 & 0.0028 & 0.00086 & 0.00338 & 2.15 & 0.000648 & 0.000107 & 0.0000172 \\
\hline 5 & 0.20 & 0.0071 & 4.2678 & 19.795 & 0.0085 & 0.00605 & 0.00000 & 3.30 & 0.001488 & 0.000484 & 0.0000404 \\
\hline 6 & 0.25 & 0.0000 & 0.0480 & 0.464 & 0.0179 & 0.00233 & 0.00388 & 1.59 & 0.000403 & 0.000257 & 0.0000000 \\
\hline 7 & 0.30 & 0.0236 & 0.0530 & 0.474 & 0.0044 & 0.00037 & 0.00216 & 2.00 & 0.000461 & 0.000000 & 0.0000000 \\
\hline 8 & 0.35 & 0.0357 & 22.0627 & 74.182 & 0.0474 & 0.02154 & 0.01773 & 3.69 & 0.001532 & 0.000555 & 0.0001278 \\
\hline 9 & 0.40 & 0.0113 & 0.0747 & 0.422 & 0.0000 & 0.00000 & 0.01205 & 1.68 & 0.000525 & 0.000507 & 0.0000000 \\
\hline 10 & 0.45 & 0.0218 & 0.0902 & 0.680 & 0.0286 & 0.00000 & 0.00000 & 1.73 & 0.000458 & 0.000360 & 0.0000000 \\
\hline 11 & 0.50 & 0.0000 & 0.1051 & 0.773 & 0.0000 & 0.00000 & 0.00435 & 2.21 & 0.000395 & 0.000450 & 0.0000241 \\
\hline 12 & 0.55 & 0.0082 & 0.0775 & 0.491 & 0.0072 & 0.00152 & 0.01124 & 1.53 & 0.000425 & 0.000479 & 0.0000000 \\
\hline 13 & 0.60 & 0.0000 & 0.0000 & 0.474 & 0.0000 & 0.00029 & 0.00637 & 1.55 & 0.000228 & 0.000222 & 0.0000000 \\
\hline 14 & 0.65 & 0.0000 & 0.0890 & 0.390 & 0.0000 & 0.00000 & 0.00699 & 1.39 & 0.000206 & 0.000622 & 0.0000000 \\
\hline 15 & 0.70 & 0.0895 & 0.0017 & 0.437 & 0.0000 & 0.00000 & 0.01060 & 1.58 & 0.000629 & 0.000770 & 0.0000000 \\
\hline 16 & 0.75 & 0.0064 & 0.0765 & 0.526 & 0.0049 & 0.00070 & 0.00802 & 1.68 & 0.000227 & 0.000278 & 0.0000000 \\
\hline 17 & 0.80 & 0.0551 & 0.2163 & 0.668 & 0.0446 & 0.00619 & 0.00000 & 1.91 & 0.000554 & 0.000583 & 0.0000000 \\
\hline 18 & 0.85 & 0.0293 & 0.8484 & 2.551 & 0.0320 & 0.00400 & 0.00295 & 2.69 & 0.000772 & 0.000276 & 0.0000000 \\
\hline 19 & 0.90 & 0.0199 & 0.0663 & 0.560 & 0.0230 & 0.00068 & 0.00000 & 1.72 & 0.000248 & 0.000000 & 0.0000000 \\
\hline 20 & 0.95 & 0.0191 & 0.0497 & 0.440 & 0.0358 & 0.00216 & 0.00136 & 1.65 & 0.000471 & 0.000363 & 0.0000680 \\
\hline 21 & 1.00 & 0.0000 & 0.0650 & 0.548 & 0.0081 & 0.00000 & 0.00026 & 1.87 & 0.000654 & 0.000287 & 0.0000037 \\
\hline 22 & 1.05 & 0.0000 & 0.0165 & 0.439 & 0.0337 & 0.00000 & 0.00638 & 1.61 & 0.000373 & 0.000461 & 0.0000336 \\
\hline 23 & 1.10 & 0.0000 & 0.0683 & 0.484 & 0.0000 & 0.00103 & 0.00752 & 1.90 & 0.000758 & 0.000363 & 0.0000000 \\
\hline 24 & 1.15 & 0.0000 & 0.0854 & 0.595 & 0.0090 & 0.00530 & 0.00000 & 1.78 & 0.000777 & 0.000490 & 0.0000197 \\
\hline 25 & 1.20 & 0.0073 & 0.0686 & 0.526 & 0.0000 & 0.00456 & 0.00096 & 2.00 & 0.000771 & 0.000063 & 0.0000000 \\
\hline 26 & 1.25 & 0.0000 & 0.0653 & 0.425 & 0.0020 & 0.00063 & 0.00000 & 1.80 & 0.000524 & 0.000224 & 0.0000000 \\
\hline 27 & 1.30 & 0.0303 & 0.0597 & 0.478 & 0.0067 & 0.00421 & 0.00603 & 1.79 & 0.000574 & 0.000247 & 0.0000478 \\
\hline 28 & 1.35 & 0.0136 & 0.0582 & 0.515 & 0.0000 & 0.00189 & 0.00230 & 1.87 & 0.000450 & 0.000104 & 0.0000044 \\
\hline 29 & 1.40 & 0.0153 & 0.0569 & 0.495 & 0.0198 & 0.00516 & 0.00276 & 1.73 & 0.000496 & 0.000077 & 0.0000000 \\
\hline 30 & 1.45 & 0.0128 & 0.0609 & 0.575 & 0.0000 & 0.00607 & 0.00000 & 1.94 & 0.000694 & 0.000252 & 0.0000000 \\
\hline 31 & 1.50 & 0.0066 & 0.0504 & 0.498 & 0.0000 & 0.00686 & 0.00014 & 2.12 & 0.000661 & 0.000008 & 0.0000000 \\
\hline 32 & 1.55 & 0.0000 & 0.0308 & 0.424 & 0.0010 & 0.00413 & 0.00134 & 2.11 & 0.000756 & 0.000246 & 0.0000000 \\
\hline 33 & 1.60 & 0.0216 & 0.0477 & 0.472 & 0.0000 & 0.00470 & 0.00560 & 2.43 & 0.001035 & 0.000293 & 0.0000205 \\
\hline
\end{tabular}




\begin{tabular}{|c|c|c|c|c|c|c|c|c|c|c|c|}
\hline \multirow{2}{*}{ Spot Number } & \multirow{2}{*}{ Distance from inner Shell (mm) } & \multicolumn{10}{|c|}{ P1B nacreous layer transect $\mathrm{N} 4$ corrected data $(\mathrm{mmol} / \mathrm{mol})$} \\
\hline & & $\mathrm{Li} / \mathrm{Ca}$ & $\mathrm{B} / \mathrm{Ca}$ & $\mathrm{Mg} / \mathrm{Ca}$ & $\mathrm{Al} / \mathrm{Ca}$ & $\mathrm{Mn} / \mathrm{Ca}$ & $\mathrm{Zn} / \mathrm{Ca}$ & $\mathrm{Sr} / \mathrm{Ca}$ & $\mathrm{Ba} / \mathrm{Ca}$ & $\mathrm{Pb} / \mathrm{Ca}$ & $\mathrm{U} / \mathrm{Ca}$ \\
\hline 1 & 0.00 & 0.0000 & 0.0240 & 0.348 & 0.0000 & 0.00424 & 0.00000 & 1.52 & 0.000359 & 0.000106 & 0.0000000 \\
\hline 2 & 0.50 & 0.0243 & 0.0378 & 0.433 & 0.0064 & 0.00178 & 0.00000 & 1.59 & 0.000402 & 0.000184 & 0.0000107 \\
\hline 3 & 0.10 & 0.0000 & 0.1099 & 0.821 & 0.0000 & 0.00351 & 0.00000 & 2.35 & 0.000827 & 0.000054 & 0.0000000 \\
\hline 4 & 0.30 & 0.0057 & 0.0186 & 0.361 & 0.0000 & 0.00000 & 0.00234 & 1.80 & 0.000539 & 0.000071 & 0.0000227 \\
\hline 5 & 0.35 & 0.0179 & 1.4601 & 5.350 & 0.0103 & 0.00081 & 0.00378 & 2.82 & 0.000855 & 0.000052 & 0.0000168 \\
\hline 6 & 0.40 & 0.0024 & 0.0557 & 0.762 & 0.0058 & 0.00120 & 0.00179 & 1.68 & 0.000469 & 0.000165 & 0.0000000 \\
\hline 7 & 0.45 & 0.0189 & 0.0763 & 0.472 & 0.0131 & 0.00000 & 0.00378 & 1.40 & 0.000485 & 0.000011 & 0.0000000 \\
\hline 8 & 0.50 & 0.0000 & 0.0600 & 0.428 & 0.0000 & 0.00000 & 0.00000 & 1.52 & 0.000399 & 0.000157 & 0.0000000 \\
\hline 9 & 0.55 & 0.0054 & 11.6918 & 38.433 & 0.0000 & 0.01199 & 0.00768 & 4.27 & 0.001981 & 0.000117 & 0.0000000 \\
\hline 10 & 0.60 & 0.0051 & 0.0414 & 0.450 & 0.0000 & 0.00000 & 0.00139 & 1.70 & 0.000545 & 0.000145 & 0.0000000 \\
\hline 11 & 0.65 & 0.0000 & 0.0596 & 0.455 & 0.0022 & 0.00076 & 0.00000 & 1.75 & 0.000635 & 0.000071 & 0.0000009 \\
\hline 12 & 0.70 & 0.0000 & 0.0334 & 0.373 & 0.0112 & 0.00161 & 0.00000 & 1.73 & 0.000486 & 0.000066 & 0.0000201 \\
\hline 13 & 0.75 & 0.0000 & 0.0327 & 0.541 & 0.0189 & 0.00222 & 0.00445 & 2.27 & 0.000674 & 0.000038 & 0.0000000 \\
\hline 14 & 0.80 & 0.0038 & 0.0527 & 0.677 & 0.0000 & 0.00000 & 0.00000 & 2.14 & 0.000671 & 0.000203 & 0.0000224 \\
\hline 15 & 0.85 & 0.0132 & 0.0737 & 0.420 & 0.0020 & 0.00057 & 0.00000 & 1.65 & 0.000462 & 0.000065 & 0.0000011 \\
\hline 16 & 0.90 & 0.0143 & 0.0505 & 0.503 & 0.0000 & 0.00266 & 0.00000 & 1.60 & 0.000507 & 0.000059 & 0.0000000 \\
\hline 17 & 0.95 & 0.0020 & 0.0395 & 0.410 & 0.0000 & 0.00000 & 0.00048 & 1.67 & 0.000446 & 0.000084 & 0.0000089 \\
\hline 18 & 1.00 & 0.0032 & 0.0615 & 0.452 & 0.0006 & 0.00000 & 0.00163 & 1.68 & 0.000458 & 0.000134 & 0.0000000 \\
\hline 19 & 1.05 & 0.0068 & 0.0685 & 0.386 & 0.0000 & 0.00256 & 0.00095 & 1.64 & 0.000319 & 0.000079 & 0.0000000 \\
\hline 20 & 1.10 & 0.0232 & 0.0497 & 0.416 & 0.0000 & 0.00269 & 0.00150 & 1.47 & 0.000303 & 0.000029 & 0.0000000 \\
\hline 21 & 1.15 & 0.0176 & 0.0401 & 0.448 & 0.0000 & 0.00258 & 0.00000 & 1.54 & 0.000367 & 0.000109 & 0.0000081 \\
\hline 22 & 1.20 & 0.0319 & 0.0394 & 0.389 & 0.0000 & 0.00184 & 0.00258 & 1.65 & 0.000471 & 0.000137 & 0.0000037 \\
\hline 23 & 1.25 & 0.0183 & 0.0590 & 0.369 & 0.0000 & 0.00204 & 0.00374 & 1.54 & 0.000408 & 0.000141 & 0.0000000 \\
\hline 24 & 1.30 & 0.0047 & 0.0353 & 0.376 & 0.0000 & 0.00000 & 0.00136 & 1.52 & 0.000416 & 0.000126 & 0.0000166 \\
\hline 25 & 1.35 & 0.0000 & 0.0670 & 0.329 & 0.0051 & 0.00005 & 0.00097 & 1.57 & 0.000379 & 0.000050 & 0.0000000 \\
\hline 26 & 1.40 & 0.0208 & 0.0302 & 0.345 & 0.0000 & 0.00000 & 0.00408 & 1.68 & 0.000555 & 0.000080 & 0.0000000 \\
\hline 27 & 1.45 & 0.0247 & 0.0709 & 0.340 & 0.0000 & 0.00177 & 0.00000 & 1.76 & 0.000546 & 0.000054 & 0.0000298 \\
\hline 28 & 1.50 & 0.0025 & 0.0593 & 0.442 & 0.0064 & 0.00311 & 0.00555 & 1.82 & 0.000549 & 0.000064 & 0.0000401 \\
\hline 29 & 1.55 & 0.0000 & 0.0137 & 0.486 & 0.0000 & 0.00824 & 0.00000 & 2.00 & 0.000731 & 0.000049 & 0.0000111 \\
\hline
\end{tabular}


APPENDIX 5.2d P04A nacreous layer transects data

\begin{tabular}{|c|c|c|c|c|c|c|c|c|c|c|c|}
\hline \multirow{2}{*}{$\begin{array}{c}\text { Spot } \\
\text { Number }\end{array}$} & \multirow{2}{*}{ Distance from inner shell (mm) } & \multicolumn{10}{|c|}{ P04A nacreous layer transect $\mathrm{N} 1$ corrected data $(\mathrm{mmol} / \mathrm{mol})$} \\
\hline & & $\mathrm{Li} / \mathrm{Ca}$ & $\mathrm{B} / \mathrm{Ca}$ & $\mathrm{Mg} / \mathrm{Ca}$ & $\mathrm{Al} / \mathrm{Ca}$ & $\mathrm{Mn} / \mathrm{Ca}$ & $\mathrm{Zn} / \mathrm{Ca}$ & $\mathrm{Sr} / \mathrm{Ca}$ & $\mathrm{Ba} / \mathrm{Ca}$ & $\mathrm{Pb} / \mathrm{Ca}$ & $\mathrm{U} / \mathrm{Ca}$ \\
\hline 1 & 0.00 & 0.00252 & 0.055 & 0.279 & 0.0344 & 0.0043 & 0.01866 & 1.56 & 0.000282 & 0.000000 & 0.0001801 \\
\hline 2 & 0.05 & 0.00000 & 0.108 & 0.124 & 0.0000 & 0.0117 & 0.00000 & 1.78 & 0.001080 & 0.000000 & 0.0000000 \\
\hline 3 & 0.10 & 0.01719 & 0.125 & 0.118 & 0.0405 & 0.0000 & 0.00188 & 1.65 & 0.000082 & 0.000000 & 0.0000000 \\
\hline 4 & 0.15 & 0.00818 & 0.018 & 0.113 & 0.0145 & 0.0000 & 0.00125 & 1.62 & 0.000724 & 0.000248 & 0.0000000 \\
\hline 5 & 0.20 & 0.00506 & 0.000 & 0.147 & 0.0000 & 0.0091 & 0.00206 & 1.51 & 0.000462 & 0.000434 & 0.0000000 \\
\hline 6 & 0.25 & 0.00000 & 0.155 & 0.200 & 0.0002 & 0.0000 & 0.00647 & 1.61 & 0.000191 & 0.000146 & 0.0000000 \\
\hline 7 & 0.30 & 0.00093 & 0.000 & 0.170 & 0.0000 & 0.0108 & 0.00360 & 1.63 & 0.000781 & 0.000294 & 0.0000000 \\
\hline 8 & 0.35 & 0.00000 & 0.066 & 0.195 & 0.0068 & 0.0128 & 0.00000 & 1.58 & 0.000000 & 0.000125 & 0.0000000 \\
\hline 9 & 0.40 & 0.01956 & 0.000 & 0.282 & 0.0044 & 0.0001 & 0.00069 & 1.90 & 0.000579 & 0.000000 & 0.0000911 \\
\hline 10 & 0.45 & 0.00000 & 0.099 & 0.339 & 0.0000 & 0.0002 & 0.00000 & 1.80 & 0.000911 & 0.000409 & 0.0001559 \\
\hline 11 & 0.50 & 0.01956 & 0.019 & 4.535 & 0.0000 & 0.0098 & 0.00000 & 2.11 & 0.000858 & 0.000000 & 0.0000000 \\
\hline
\end{tabular}




\begin{tabular}{|c|c|c|c|c|c|c|c|c|c|c|c|}
\hline \multirow{2}{*}{ Spot Number } & \multirow{2}{*}{ Distance from inner shell (mm) } & \multicolumn{10}{|c|}{ P04A nacreous layer transect $\mathrm{N} 2$ corrected data $(\mathrm{mmol} / \mathrm{mol})$} \\
\hline & & $\mathrm{Li} / \mathrm{Ca}$ & $\mathrm{B} / \mathrm{Ca}$ & $\mathrm{Mg} / \mathrm{Ca}$ & $\mathbf{A l} / \mathbf{C a}$ & $\mathrm{Mn} / \mathrm{Ca}$ & $\mathrm{Zn} / \mathrm{Ca}$ & $\mathrm{Sr} / \mathrm{Ca}$ & $\mathrm{Ba} / \mathrm{Ca}$ & $\mathrm{Pb} / \mathrm{Ca}$ & $\mathrm{U} / \mathrm{Ca}$ \\
\hline 1 & 0.00 & 0.00236 & 0.059 & 0.304 & 0.0060 & 0.0024 & 0.01174 & 1.68 & 0.000475 & 0.000378 & 0.0000584 \\
\hline 2 & 0.05 & 0.00926 & 0.000 & 0.166 & 0.0000 & 0.0000 & 0.00988 & 1.63 & 0.000584 & 0.000000 & 0.0000000 \\
\hline 3 & 0.10 & 0.00000 & 0.067 & 0.195 & 0.0222 & 0.0001 & 0.00043 & 1.63 & 0.000535 & 0.000068 & 0.0000000 \\
\hline 4 & 0.15 & 0.01446 & 0.091 & 0.204 & 0.0156 & 0.0012 & 0.00329 & 1.60 & 0.000688 & 0.000525 & 0.0000333 \\
\hline 5 & 0.20 & 0.01715 & 0.101 & 0.307 & 0.0004 & 0.0028 & 0.00215 & 1.74 & 0.000722 & 0.000000 & 0.0000671 \\
\hline 6 & 0.25 & 0.00576 & 0.012 & 0.293 & 0.0000 & 0.0027 & 0.00568 & 1.91 & 0.000644 & 0.000000 & 0.0000000 \\
\hline 7 & 0.30 & 0.00282 & 0.045 & 0.370 & 0.0000 & 0.0011 & 0.00000 & 1.83 & 0.000693 & 0.000006 & 0.0000000 \\
\hline 8 & 0.35 & 0.01559 & 0.044 & 0.636 & 0.0077 & 0.0000 & 0.00084 & 2.29 & 0.001028 & 0.000090 & 0.0000956 \\
\hline 9 & 0.40 & 0.01042 & 0.115 & 0.490 & 0.0050 & 0.0000 & 0.00596 & 2.02 & 0.001138 & 0.000000 & 0.0000075 \\
\hline 10 & 0.45 & 0.00380 & 0.061 & 0.528 & 0.0084 & 0.0014 & 0.00000 & 2.18 & 0.001038 & 0.000000 & 0.0000480 \\
\hline 11 & 0.50 & 0.00654 & 0.032 & 1.075 & 0.0000 & 0.0000 & 0.00180 & 2.53 & 0.001239 & 0.000061 & 0.0000105 \\
\hline 12 & 0.55 & 0.00220 & 0.104 & 0.879 & 0.0000 & 0.0000 & 0.00246 & 2.55 & 0.001356 & 0.000297 & 0.0000000 \\
\hline 13 & 0.60 & 0.00000 & 0.080 & 0.726 & 0.0025 & 0.0057 & 0.01160 & 2.00 & 0.001048 & 0.000268 & 0.0000000 \\
\hline 14 & 0.65 & 0.01858 & 0.068 & 0.698 & 0.0000 & 0.0082 & 0.00382 & 1.94 & 0.000797 & 0.000317 & 0.0000000 \\
\hline 15 & 0.70 & 0.00284 & 0.000 & 0.847 & 0.0093 & 0.0006 & 0.00600 & 2.07 & 0.000644 & 0.000000 & 0.0000000 \\
\hline
\end{tabular}




\begin{tabular}{|c|c|c|c|c|c|c|c|c|c|c|c|}
\hline \multirow{2}{*}{ Spot Number } & \multirow{2}{*}{ Distance from inner shell $(\mathrm{mm})$} & \multicolumn{10}{|c|}{ P04A nacreous layer transect N3 corrected data $(\mathrm{mmol} / \mathrm{mol})$} \\
\hline & & $\mathrm{Li} / \mathrm{Ca}$ & $\mathrm{B} / \mathrm{Ca}$ & $\mathrm{Mg} / \mathrm{Ca}$ & $\mathrm{Al} / \mathrm{Ca}$ & $\mathrm{Mn} / \mathrm{Ca}$ & $\mathrm{Zn} / \mathrm{Ca}$ & $\mathrm{Sr} / \mathrm{Ca}$ & $\mathrm{Ba} / \mathrm{Ca}$ & $\mathrm{Pb} / \mathrm{Ca}$ & $\mathrm{U} / \mathrm{Ca}$ \\
\hline 1 & 0.00 & 0.01607 & 0.134 & 0.266 & 0.0120 & 0.0138 & 0.01496 & 1.80 & 0.001327 & 0.000362 & 0.000000 \\
\hline 2 & 0.05 & 0.00000 & 10.695 & 42.750 & 0.0000 & 0.0268 & 0.00376 & 4.00 & 0.000989 & 0.000000 & 0.000000 \\
\hline 3 & 0.10 & 0.01002 & 0.095 & 0.364 & 0.0000 & 0.0000 & 0.01771 & 1.77 & 0.000894 & 0.000000 & 0.000000 \\
\hline 4 & 0.15 & 0.00622 & 17.976 & 73.396 & 0.0000 & 0.0626 & 0.03297 & 3.48 & 0.004062 & 0.000622 & 0.000000 \\
\hline 5 & 0.20 & 0.02194 & 0.075 & 0.278 & 0.0000 & 0.0000 & 0.00000 & 1.54 & 0.000751 & 0.000578 & 0.000188 \\
\hline 6 & 0.25 & 0.00284 & 0.064 & 0.409 & 0.0000 & 0.0000 & 0.00000 & 1.45 & 0.000523 & 0.000063 & 0.000103 \\
\hline 7 & 0.30 & 0.01065 & 0.000 & 0.360 & 0.0000 & 0.0010 & 0.00648 & 1.75 & 0.000329 & 0.000163 & 0.000115 \\
\hline 8 & 0.35 & 0.00000 & 3.005 & 8.648 & 0.0305 & 0.0038 & 0.00000 & 2.84 & 0.000824 & 0.000000 & 0.00003 \\
\hline 9 & 0.40 & 0.01056 & 0.242 & 0.548 & 0.0054 & 0.0012 & 0.00000 & 2.06 & 0.000314 & 0.000283 & 0.000208 \\
\hline 10 & 0.45 & 0.01406 & 0.000 & 0.621 & 0.0000 & 0.0071 & 0.00000 & 2.11 & 0.001168 & 0.000000 & 0.000000 \\
\hline 11 & 0.50 & 0.01107 & 0.070 & 0.543 & 0.0010 & 0.0000 & 0.01709 & 1.81 & 0.000000 & 0.000617 & 0.000546 \\
\hline 12 & 0.55 & 0.00000 & 4.021 & 21.404 & 0.0000 & 0.0409 & 0.01409 & 3.36 & 0.000867 & 0.000758 & 0.000285 \\
\hline 13 & 0.60 & 0.00000 & 0.040 & 1.433 & 0.0000 & 0.0000 & 0.01594 & 2.01 & 0.001159 & 0.000000 & 0.000000 \\
\hline 14 & 0.65 & 0.01549 & 0.018 & 0.808 & 0.0100 & 0.0062 & 0.01310 & 1.76 & 0.000075 & 0.000000 & 0.000123 \\
\hline 15 & 0.70 & 0.01759 & 0.142 & 0.761 & 0.0305 & 0.0077 & 0.00000 & 1.94 & 0.000457 & 0.000251 & 0.000000 \\
\hline 16 & 0.75 & 0.00526 & 0.251 & 2.151 & 0.0000 & 0.0100 & 0.01248 & 3.01 & 0.000943 & 0.000000 & 0.000000 \\
\hline 17 & 0.80 & 0.00000 & 0.000 & 0.910 & 0.0285 & 0.0000 & 0.00000 & 2.16 & 0.000717 & 0.000532 & 0.000000 \\
\hline 18 & 0.85 & 0.01644 & 0.132 & 1.186 & 0.0000 & 0.0000 & 0.02008 & 2.62 & 0.001007 & 0.000667 & 0.000000 \\
\hline 19 & 0.90 & 0.00511 & 0.052 & 0.753 & 0.0000 & 0.0000 & 0.01847 & 2.29 & 0.001039 & 0.000000 & 0.000412 \\
\hline
\end{tabular}




\begin{tabular}{|c|c|c|c|c|c|c|c|c|c|c|c|}
\hline \multirow{2}{*}{$\begin{array}{c}\text { Spot } \\
\text { Number }\end{array}$} & \multirow{2}{*}{ Distance from the foot $(\mathrm{mm})$} & \multicolumn{10}{|c|}{ P04A nacreous layer transect N5 corrected data $(\mathrm{mmol} / \mathrm{mol})$} \\
\hline & & $\mathrm{Li} / \mathrm{Ca}$ & $\mathrm{B} / \mathrm{Ca}$ & $\mathrm{Mg} / \mathrm{Ca}$ & $\mathrm{Al} / \mathrm{Ca}$ & $\mathrm{Mn} / \mathrm{Ca}$ & $\mathrm{Zn} / \mathrm{Ca}$ & $\mathrm{Sr} / \mathrm{Ca}$ & $\mathrm{Ba} / \mathrm{Ca}$ & $\mathrm{Pb} / \mathrm{Ca}$ & $\mathrm{U} / \mathrm{Ca}$ \\
\hline 1 & 0.00 & 0.00094 & 0.054 & 0.269 & 0.0000 & 0.0000 & 0.00000 & 1.80 & 0.000946 & 0.000000 & 0.0000405 \\
\hline 2 & 0.05 & 0.01277 & 0.085 & 0.340 & 0.0000 & 0.0000 & 0.00049 & 1.75 & 0.000692 & 0.000001 & 0.0000000 \\
\hline 3 & 0.10 & 0.00000 & 0.000 & 0.785 & 0.0105 & 0.0000 & 0.03030 & 2.12 & 0.000000 & 0.000000 & 0.0001938 \\
\hline 4 & 0.15 & 0.00279 & 2.083 & 9.692 & 0.0000 & 0.0164 & 0.00391 & 2.64 & 0.001006 & 0.000000 & 0.0005585 \\
\hline 5 & 0.20 & 0.02635 & 0.000 & 0.328 & 0.0047 & 0.0033 & 0.00000 & 1.74 & 0.000805 & 0.000000 & 0.0003407 \\
\hline 6 & 0.25 & 0.00920 & 0.124 & 0.355 & 0.0000 & 0.0000 & 0.00000 & 1.63 & 0.000564 & 0.000000 & 0.0001113 \\
\hline 7 & 0.30 & 0.02236 & 2.657 & 12.083 & 0.0098 & 0.0000 & 0.01243 & 3.33 & 0.001275 & 0.001134 & 0.0000000 \\
\hline 8 & 0.35 & 0.00000 & 1.944 & 8.594 & 0.0000 & 0.0048 & 0.02739 & 2.33 & 0.001495 & 0.001117 & 0.0000000 \\
\hline 9 & 0.40 & 0.01006 & 0.096 & 0.426 & 0.0302 & 0.0000 & 0.00000 & 1.74 & 0.000794 & 0.000000 & 0.0000000 \\
\hline 10 & 0.45 & 0.00000 & 0.227 & 1.113 & 0.0000 & 0.0009 & 0.00749 & 2.29 & 0.000743 & 0.000388 & 0.0000660 \\
\hline 11 & 0.50 & 0.00000 & 0.011 & 0.661 & 0.0099 & 0.0000 & 0.00000 & 1.71 & 0.001166 & 0.000000 & 0.0000000 \\
\hline 12 & 0.55 & 0.01390 & 0.072 & 0.697 & 0.0216 & 0.0000 & 0.00218 & 1.62 & 0.000091 & 0.000000 & 0.0000000 \\
\hline 13 & 0.60 & 0.00000 & 0.086 & 0.654 & 0.0000 & 0.0000 & 0.00000 & 1.54 & 0.000000 & 0.000000 & 0.0001465 \\
\hline 14 & 0.65 & 0.00000 & 0.145 & 0.636 & 0.0215 & 0.0000 & 0.00000 & 1.52 & 0.000058 & 0.000000 & 0.0000000 \\
\hline 15 & 0.70 & 0.00913 & 0.010 & 0.597 & 0.0149 & 0.0115 & 0.02175 & 1.57 & 0.000500 & 0.000213 & 0.0000308 \\
\hline 16 & 0.75 & 0.00097 & 0.009 & 0.533 & 0.0000 & 0.0007 & 0.01104 & 1.63 & 0.000826 & 0.000000 & 0.0000999 \\
\hline 17 & 0.80 & 0.00000 & 0.144 & 0.548 & 0.0000 & 0.0080 & 0.00000 & 1.67 & 0.000692 & 0.000058 & 0.0000000 \\
\hline 18 & 0.85 & 0.00000 & 0.111 & 0.571 & 0.0000 & 0.0122 & 0.00000 & 1.80 & 0.000810 & 0.001125 & 0.0000000 \\
\hline 19 & 0.90 & 0.02219 & 0.000 & 0.490 & 0.0000 & 0.0216 & 0.01607 & 1.67 & 0.000803 & 0.000000 & 0.0000025 \\
\hline 20 & 0.95 & 0.01070 & 0.038 & 0.468 & 0.0000 & 0.0070 & 0.00000 & 1.51 & 0.000512 & 0.000000 & 0.0001334 \\
\hline 21 & 1.00 & 0.00000 & 0.063 & 0.515 & 0.0085 & 0.0000 & 0.00000 & 1.50 & 0.000593 & 0.000000 & 0.0000000 \\
\hline
\end{tabular}


APPENDIX 5.2e $\quad$ SC2 nacreous layer transect data

\begin{tabular}{|c|c|c|c|c|c|c|c|c|c|c|c|}
\hline \multirow{2}{*}{ Spot Number } & \multirow{2}{*}{ Distance from inner shell (mm) } & \multicolumn{10}{|c|}{$\mathrm{SC} 2$ nacreous layer transect $\mathrm{N} 1$ corrected data $(\mathrm{mmol} / \mathrm{mol})$} \\
\hline & & $\mathrm{Li} / \mathrm{Ca}$ & $\mathrm{B} / \mathrm{Ca}$ & $\mathrm{Mg} / \mathrm{Ca}$ & $\mathbf{A l} / \mathbf{C a}$ & $\mathrm{Mn} / \mathrm{Ca}$ & $\mathrm{Zn} / \mathrm{Ca}$ & $\mathrm{Sr} / \mathrm{Ca}$ & $\mathrm{Ba} / \mathrm{Ca}$ & $\mathrm{Pb} / \mathrm{Ca}$ & $\mathrm{U} / \mathrm{Ca}$ \\
\hline 1 & 0.00 & 0.0096 & 0.0406 & 0.386 & 0.00305 & 0.0000 & 0.00322 & 1.73 & 0.000291 & 0.0000659 & 0.0000000 \\
\hline 2 & 0.05 & 0.0130 & 0.0473 & 0.190 & 0.00000 & 0.0000 & 0.00000 & 1.66 & 0.000640 & 0.0001122 & 0.0000555 \\
\hline 3 & 0.10 & 0.0118 & 0.0034 & 0.216 & 0.00101 & 0.0037 & 0.00351 & 1.69 & 0.000527 & 0.0000179 & 0.0000008 \\
\hline 4 & 0.15 & 0.0075 & 0.3326 & 1.539 & 0.00000 & 0.0035 & 0.00000 & 1.98 & 0.000534 & 0.0000937 & 0.0000000 \\
\hline 5 & 0.20 & 0.0182 & 5.3652 & 30.488 & 0.00464 & 0.0172 & 0.01497 & 4.86 & 0.002250 & 0.0000751 & 0.0000548 \\
\hline 6 & 0.25 & 0.0065 & 0.0083 & 0.247 & 0.00232 & 0.0000 & 0.00041 & 1.81 & 0.000622 & 0.0000693 & 0.0000000 \\
\hline 7 & 0.30 & 0.0079 & 0.0149 & 0.249 & 0.00246 & 0.0000 & 0.00639 & 1.83 & 0.000692 & 0.0000332 & 0.0000000 \\
\hline 8 & 0.35 & 0.0035 & 0.0398 & 0.275 & 0.00000 & 0.0000 & 0.00228 & 1.84 & 0.000561 & 0.0000000 & 0.0000000 \\
\hline 9 & 0.40 & 0.0120 & 0.0819 & 0.319 & 0.00000 & 0.0020 & 0.00049 & 1.89 & 0.000667 & 0.0000000 & 0.0000000 \\
\hline 10 & 0.45 & 0.0158 & 0.0283 & 0.255 & 0.00317 & 0.0007 & 0.00000 & 1.75 & 0.000756 & 0.0000000 & 0.0000000 \\
\hline 11 & 0.50 & 0.0054 & 0.0374 & 0.337 & 0.00000 & 0.0000 & 0.00110 & 1.72 & 0.000721 & 0.0000000 & 0.0000000 \\
\hline 12 & 0.55 & 0.0075 & 0.0586 & 0.329 & 0.00232 & 0.0012 & 0.00000 & 1.72 & 0.000512 & 0.0000058 & 0.0000156 \\
\hline 13 & 0.60 & 0.0109 & 2.0398 & 7.929 & 0.00000 & 0.0060 & 0.00326 & 5.96 & 0.003160 & 0.0000000 & 0.0000121 \\
\hline 14 & 0.65 & 0.0067 & 0.0166 & 0.532 & 0.00332 & 0.0012 & 0.00000 & 1.94 & 0.000687 & 0.0001326 & 0.0000543 \\
\hline 15 & 0.70 & 0.0066 & 0.0750 & 0.600 & 0.00000 & 0.0025 & 0.00000 & 2.28 & 0.000991 & 0.0000000 & 0.0000264 \\
\hline 16 & 0.75 & 0.0113 & 0.0511 & 0.752 & 0.00000 & 0.0000 & 0.00004 & 2.55 & 0.000985 & 0.0000670 & 0.0000584 \\
\hline 17 & 0.80 & 0.0139 & 0.0681 & 0.525 & 0.00000 & 0.0024 & 0.01090 & 2.07 & 0.000973 & 0.0000000 & 0.0000139 \\
\hline 18 & 0.85 & 0.0093 & 0.0057 & 0.581 & 0.00000 & 0.0000 & 0.00000 & 2.10 & 0.000931 & 0.0000000 & 0.0000675 \\
\hline 19 & 0.90 & 0.0058 & 0.0805 & 0.937 & 0.00164 & 0.0022 & 0.00054 & 2.62 & 0.000866 & 0.0001697 & 0.0000339 \\
\hline 20 & 0.95 & 0.0108 & 0.0336 & 1.008 & 0.00000 & 0.0012 & 0.00307 & 2.75 & 0.001182 & 0.0000233 & 0.0000447 \\
\hline
\end{tabular}




\begin{tabular}{|c|c|c|c|c|c|c|c|c|c|c|c|}
\hline \multirow{2}{*}{ Spot Number } & \multirow{2}{*}{ Distance from inner shell (mm) } & \multicolumn{10}{|c|}{$\mathrm{SC} 2$ nacreous layer transect $\mathrm{N} 2$ corrected data $(\mathrm{mmol} / \mathrm{mol})$} \\
\hline & & $\mathrm{Li} / \mathrm{Ca}$ & $\mathrm{B} / \mathrm{Ca}$ & $\mathrm{Mg} / \mathrm{Ca}$ & $\mathrm{Al} / \mathrm{Ca}$ & $\mathrm{Mn} / \mathrm{Ca}$ & $\mathrm{Zn} / \mathrm{Ca}$ & $\mathrm{Sr} / \mathrm{Ca}$ & $\mathrm{Ba} / \mathrm{Ca}$ & $\mathrm{Pb} / \mathrm{Ca}$ & $\mathrm{U} / \mathrm{Ca}$ \\
\hline 1 & 0.00 & 0.0000 & 221.0092 & 2524.069 & 0.00000 & 0.1231 & 0.28555 & 1.77 & 0.003588 & 0.0000000 & 0.0001969 \\
\hline 2 & 0.05 & 0.0075 & 0.0256 & 0.336 & 0.00265 & 0.0059 & 0.00000 & 1.82 & 0.000311 & 0.0000000 & 0.0000086 \\
\hline 3 & 0.10 & 0.0098 & 0.0574 & 0.464 & 0.00000 & 0.0000 & 0.00019 & 1.69 & 0.000282 & 0.0000113 & 0.0000000 \\
\hline 4 & 0.15 & 0.0140 & 7.8813 & 41.971 & 0.00000 & 0.0146 & 0.00243 & 4.58 & 0.001865 & 0.0000000 & 0.0000000 \\
\hline 5 & 0.20 & 0.0086 & 2.8131 & 15.142 & 0.00000 & 0.0000 & 0.00600 & 4.46 & 0.001846 & 0.0000000 & 0.0000000 \\
\hline 6 & 0.25 & 0.0109 & 0.0231 & 0.350 & 0.00092 & 0.0000 & 0.00107 & 1.85 & 0.000777 & 0.0000000 & 0.0000000 \\
\hline 7 & 0.30 & 0.0122 & 0.0770 & 0.388 & 0.00020 & 0.0010 & 0.00000 & 1.81 & 0.000519 & 0.0001474 & 0.0000000 \\
\hline 8 & 0.35 & 0.0281 & 7.8311 & 30.716 & 0.00013 & 0.0073 & 0.00000 & 4.72 & 0.001976 & 0.0000000 & 0.0000533 \\
\hline 9 & 0.40 & 0.0113 & 0.0736 & 0.368 & 0.00000 & 0.0000 & 0.00000 & 1.73 & 0.000692 & 0.0000000 & 0.0000000 \\
\hline 10 & 0.45 & 0.0036 & 0.0227 & 0.347 & 0.00288 & 0.0000 & 0.00000 & 1.70 & 0.000680 & 0.0000248 & 0.0000000 \\
\hline 11 & 0.50 & 0.0038 & 0.0572 & 0.468 & 0.00000 & 0.0000 & 0.00517 & 1.73 & 0.000671 & 0.0000958 & 0.0000000 \\
\hline 12 & 0.55 & 0.0210 & 7.0188 & 34.988 & 0.00815 & 0.0093 & 0.00512 & 5.30 & 0.002376 & 0.0000364 & 0.0000474 \\
\hline 13 & 0.60 & 0.0063 & 0.0084 & 0.525 & 0.00246 & 0.0033 & 0.00232 & 1.70 & 0.000394 & 0.0000489 & 0.0000505 \\
\hline 14 & 0.65 & 0.0080 & 0.0326 & 0.538 & 0.00257 & 0.0000 & 0.00531 & 1.79 & 0.000669 & 0.0000014 & 0.0000762 \\
\hline 15 & 0.70 & 0.0090 & 0.0410 & 0.438 & 0.00013 & 0.0028 & 0.00339 & 1.71 & 0.000611 & 0.0000000 & 0.0000020 \\
\hline 16 & 0.75 & 0.0090 & 0.0484 & 0.412 & 0.00000 & 0.0007 & 0.00505 & 1.74 & 0.000438 & 0.0001107 & 0.0000625 \\
\hline 17 & 0.80 & 0.0099 & 3.2235 & 15.241 & 0.00000 & 0.0024 & 0.00481 & 2.97 & 0.000776 & 0.0000000 & 0.0000345 \\
\hline 18 & 0.85 & 0.0067 & 1.3245 & 8.269 & 0.00324 & 0.0017 & 0.01086 & 4.76 & 0.001950 & 0.0000000 & 0.0000000 \\
\hline 19 & 0.90 & 0.0097 & 0.0521 & 0.400 & 0.00000 & 0.0076 & 0.00689 & 1.76 & 0.000531 & 0.0000998 & 0.0000287 \\
\hline 20 & 0.95 & 0.0092 & 0.0476 & 0.459 & 0.00000 & 0.0000 & 0.00027 & 1.75 & 0.000695 & 0.0000532 & 0.0000000 \\
\hline 21 & 1.00 & 0.0074 & 0.0756 & 0.473 & 0.00170 & 0.0050 & 0.00000 & 1.69 & 0.000543 & 0.0000000 & 0.0000000 \\
\hline 22 & 1.05 & 0.0034 & 0.0668 & 0.371 & 0.00613 & 0.0031 & 0.00000 & 1.76 & 0.000672 & 0.0000000 & 0.0000000 \\
\hline 23 & 1.10 & 0.0083 & 0.0479 & 0.379 & 0.00000 & 0.0003 & 0.00000 & 1.78 & 0.000605 & 0.0000000 & 0.0000000 \\
\hline 24 & 1.15 & 0.0082 & 0.0630 & 0.405 & 0.00000 & 0.0029 & 0.00000 & 1.79 & 0.000673 & 0.0000546 & 0.0000007 \\
\hline 25 & 1.20 & 0.0104 & 0.0555 & 0.391 & 0.00000 & 0.0049 & 0.00233 & 1.77 & 0.000944 & 0.0000000 & 0.0000243 \\
\hline 26 & 1.25 & 0.0047 & 0.0739 & 0.437 & 0.00172 & 0.0016 & 0.00106 & 1.68 & 0.000803 & 0.0000000 & 0.0000000 \\
\hline 27 & 1.30 & 0.0082 & 0.0854 & 0.418 & 0.00419 & 0.0045 & 0.00210 & 1.77 & 0.000523 & 0.0001725 & 0.0000031 \\
\hline 28 & 1.35 & 0.0066 & 0.0733 & 0.387 & 0.00000 & 0.0000 & 0.00317 & 1.81 & 0.000725 & 0.0000000 & 0.0000000 \\
\hline 29 & 1.40 & 0.0116 & 0.0461 & 0.563 & 0.00000 & 0.0024 & 0.00587 & 1.92 & 0.000759 & 0.0000015 & 0.0000000 \\
\hline 30 & 1.45 & 0.0086 & 0.0831 & 0.445 & 0.00000 & 0.0053 & 0.00000 & 1.91 & 0.000651 & 0.0001440 & 0.0000000 \\
\hline 31 & 1.50 & 0.0070 & 0.0676 & 0.505 & 0.00333 & 0.0000 & 0.00206 & 2.08 & 0.000994 & 0.0000000 & 0.0000000 \\
\hline 32 & 1.55 & 0.0106 & 0.0744 & 0.496 & 0.00501 & 0.0000 & 0.00089 & 1.89 & 0.000737 & 0.0000044 & 0.0000000 \\
\hline
\end{tabular}




\begin{tabular}{|c|c|c|c|c|c|c|c|c|c|c|c|}
\hline \multirow{2}{*}{$\begin{array}{c}\text { Spot } \\
\text { Number }\end{array}$} & \multirow{2}{*}{ Distance from inner shell (mm) } & \multicolumn{10}{|c|}{$\mathrm{SC} 2$ nacreous layer transect $\mathrm{N} 3$ corrected data $(\mathrm{mmol} / \mathrm{mol})$} \\
\hline & & $\mathrm{Li} / \mathrm{Ca}$ & $\mathrm{B} / \mathrm{Ca}$ & $\mathrm{Mg} / \mathrm{Ca}$ & $\mathbf{A l} / \mathbf{C a}$ & $\mathrm{Mn} / \mathrm{Ca}$ & $\mathrm{Zn} / \mathrm{Ca}$ & $\mathrm{Sr} / \mathrm{Ca}$ & $\mathrm{Ba} / \mathrm{Ca}$ & $\mathrm{Pb} / \mathrm{Ca}$ & $\mathrm{U} / \mathbf{C a}$ \\
\hline 1 & 0.00 & 0.0025 & 0.0565 & 0.223 & 0.0000 & 0.0011 & 0.00000 & 1.60 & 0.000182 & 0.0000000 & 0.0000000 \\
\hline 2 & 0.05 & 0.0117 & 0.0406 & 0.266 & 0.0065 & 0.0000 & 0.00000 & 1.56 & 0.000441 & 0.0000000 & 0.0000000 \\
\hline 3 & 0.10 & 0.0154 & 5.2883 & 31.601 & 0.0006 & 0.0000 & 0.00846 & 3.13 & 0.001100 & 0.0000000 & 0.0000365 \\
\hline 4 & 0.15 & 0.0094 & 0.3972 & 2.135 & 0.0000 & 0.0058 & 0.00314 & 2.94 & 0.001230 & 0.0001379 & 0.0000023 \\
\hline 5 & 0.20 & 0.0090 & 0.0405 & 0.260 & 0.0055 & 0.0039 & 0.00587 & 1.46 & 0.000640 & 0.0000000 & 0.0000200 \\
\hline 6 & 0.25 & 0.0044 & 0.0340 & 0.343 & 0.0000 & 0.0040 & 0.00000 & 1.84 & 0.000769 & 0.0000000 & 0.0000000 \\
\hline 7 & 0.30 & 0.0059 & 0.0565 & 0.352 & 0.0029 & 0.0000 & 0.00000 & 1.74 & 0.000599 & 0.0001460 & 0.0000559 \\
\hline 8 & 0.35 & 0.0115 & 0.1903 & 1.613 & 0.0000 & 0.0000 & 0.00580 & 2.10 & 0.000546 & 0.0001766 & 0.0000000 \\
\hline 9 & 0.40 & 0.0343 & 25.9166 & 179.821 & 0.0117 & 0.0003 & 0.02707 & 5.48 & 0.002738 & 0.0009499 & 0.0000000 \\
\hline 10 & 0.45 & 0.0013 & 0.0640 & 0.269 & 0.0000 & 0.0016 & 0.00234 & 1.50 & 0.000776 & 0.0001809 & 0.0000000 \\
\hline 11 & 0.50 & 0.0140 & 0.0165 & 0.220 & 0.0000 & 0.0000 & 0.00195 & 1.34 & 0.000577 & 0.0000000 & 0.0000216 \\
\hline 12 & 0.55 & 0.0054 & 0.0699 & 0.418 & 0.0000 & 0.0000 & 0.00006 & 1.65 & 0.000582 & 0.0000689 & 0.0000000 \\
\hline 13 & 0.60 & 0.0077 & 0.0730 & 0.364 & 0.0000 & 0.0000 & 0.00341 & 1.57 & 0.000610 & 0.0000000 & 0.0000000 \\
\hline 14 & 0.65 & 0.0017 & 0.0740 & 0.396 & 0.0000 & 0.0028 & 0.00272 & 1.64 & 0.000476 & 0.0000000 & 0.0000069 \\
\hline 15 & 0.70 & 0.0141 & 0.0392 & 0.571 & 0.0171 & 0.0018 & 0.00000 & 1.57 & 0.000700 & 0.0000465 & 0.0000590 \\
\hline 16 & 0.75 & 0.0191 & 6.6903 & 36.090 & 0.0000 & 0.0029 & 0.00440 & 3.91 & 0.001563 & 0.0000000 & 0.0000222 \\
\hline 17 & 0.80 & 0.0003 & 0.2611 & 1.712 & 0.0169 & 0.0000 & 0.00714 & 2.40 & 0.001420 & 0.0000025 & 0.0000217 \\
\hline 18 & 0.85 & 0.0116 & 0.0469 & 0.401 & 0.0037 & 0.0000 & 0.00000 & 1.72 & 0.000732 & 0.0000000 & 0.0000000 \\
\hline 19 & 0.90 & 0.0081 & 0.0086 & 0.392 & 0.0000 & 0.0018 & 0.00000 & 1.58 & 0.000569 & 0.0000000 & 0.0000611 \\
\hline 20 & 0.95 & 0.0182 & 4.6343 & 22.826 & 0.0000 & 0.0051 & 0.00497 & 3.76 & 0.001370 & 0.0001781 & 0.0000331 \\
\hline 21 & 1.00 & 0.0006 & 0.6426 & 3.718 & 0.0063 & 0.0023 & 0.00140 & 2.97 & 0.001240 & 0.0001161 & 0.0000000 \\
\hline 22 & 1.05 & 0.0061 & 0.0603 & 0.511 & 0.0000 & 0.0000 & 0.00446 & 1.69 & 0.000621 & 0.0000000 & 0.0000022 \\
\hline 23 & 1.10 & 0.0042 & 0.0266 & 0.517 & 0.0107 & 0.0000 & 0.00000 & 1.83 & 0.000669 & 0.0000369 & 0.0000000 \\
\hline 24 & 1.15 & 0.0080 & 0.0777 & 0.478 & 0.0000 & 0.0000 & 0.00523 & 1.71 & 0.000450 & 0.0000000 & 0.0000151 \\
\hline 25 & 1.20 & 0.0069 & 0.0850 & 0.444 & 0.0000 & 0.0000 & 0.00912 & 1.80 & 0.000478 & 0.0001900 & 0.0000000 \\
\hline 26 & 1.25 & 0.0044 & 0.0552 & 0.382 & 0.0000 & 0.0044 & 0.00530 & 1.77 & 0.000606 & 0.0000000 & 0.0000000 \\
\hline 27 & 1.30 & 0.0066 & 0.0599 & 0.403 & 0.0007 & 0.0005 & 0.00000 & 1.64 & 0.000618 & 0.0000357 & 0.0000000 \\
\hline 28 & 1.35 & 0.0083 & 0.0654 & 0.437 & 0.0003 & 0.0023 & 0.00240 & 1.75 & 0.000621 & 0.0001550 & 0.0000109 \\
\hline 29 & 1.40 & 0.0043 & 0.0629 & 0.368 & 0.0028 & 0.0000 & 0.00000 & 1.53 & 0.000671 & 0.0000000 & 0.0000000 \\
\hline
\end{tabular}




\begin{tabular}{|c|c|c|c|c|c|c|c|c|c|c|c|}
\hline \multirow{2}{*}{ Spot Number } & \multirow{2}{*}{ Distance from inner shell $(\mathrm{mm})$} & \multicolumn{10}{|c|}{ SC2 nacreous layer transect $\mathrm{N} 3$ corrected data $(\mathrm{mmol} / \mathrm{mol})$ continued... } \\
\hline & & $\mathrm{Li} / \mathrm{Ca}$ & $\mathrm{B} / \mathrm{Ca}$ & $\mathrm{Mg} / \mathrm{Ca}$ & $\mathrm{Al} / \mathrm{Ca}$ & $\mathrm{Mn} / \mathrm{Ca}$ & $\mathrm{Zn} / \mathrm{Ca}$ & $\mathrm{Sr} / \mathrm{Ca}$ & $\mathrm{Ba} / \mathrm{Ca}$ & $\mathrm{Pb} / \mathrm{Ca}$ & $\mathrm{U} / \mathrm{Ca}$ \\
\hline 30 & 1.45 & 0.0018 & 0.0401 & 0.359 & 0.0006 & 0.0000 & 0.00000 & 1.62 & 0.000491 & 0.0000000 & 0.0000258 \\
\hline 31 & 1.50 & 0.0129 & 0.0692 & 0.574 & 0.0055 & 0.0003 & 0.00103 & 1.75 & 0.000680 & 0.0000000 & 0.0000529 \\
\hline 32 & 1.55 & 0.0029 & 0.1053 & 0.721 & 0.0000 & 0.0017 & 0.00188 & 2.82 & 0.000964 & 0.0000000 & 0.0000210 \\
\hline 33 & 1.60 & 0.0056 & 0.0392 & 0.388 & 0.0165 & 0.0000 & 0.00000 & 1.77 & 0.000487 & 0.0002061 & 0.0000000 \\
\hline 34 & 1.65 & 0.0017 & 0.0598 & 0.345 & 0.0000 & 0.0000 & 0.00976 & 1.75 & 0.000532 & 0.0000000 & 0.0000023 \\
\hline
\end{tabular}

\begin{tabular}{|c|c|c|c|c|c|c|c|c|c|c|c|}
\hline \multirow{2}{*}{ Spot Number } & \multirow{2}{*}{ Distance from inner shell (mm) } & \multicolumn{10}{|c|}{$\mathrm{SC} 2$ nacreous layer transect $\mathrm{N} 4$ corrected data $(\mathrm{mmol} / \mathrm{mol})$} \\
\hline & & $\mathrm{Li} / \mathrm{Ca}$ & $\mathrm{B} / \mathrm{Ca}$ & $\mathrm{Mg} / \mathrm{Ca}$ & $\mathrm{Al} / \mathrm{Ca}$ & $\mathrm{Mn} / \mathrm{Ca}$ & $\mathrm{Zn} / \mathrm{Ca}$ & $\mathrm{Sr} / \mathrm{Ca}$ & $\mathrm{Ba} / \mathrm{Ca}$ & $\mathrm{Pb} / \mathrm{Ca}$ & $\mathrm{U} / \mathrm{Ca}$ \\
\hline 1 & 0.00 & 0.0084 & 0.0890 & 0.334 & 0.00000 & 0.0003 & 0.00000 & 1.79 & 0.000781 & 0.0000334 & 0.0000000 \\
\hline 2 & 0.05 & 0.0076 & 0.0802 & 0.347 & 0.00000 & 0.0012 & 0.00150 & 1.71 & 0.000792 & 0.0000000 & 0.0000000 \\
\hline 3 & 0.10 & 0.0133 & 0.0667 & 0.377 & 0.00493 & 0.0025 & 0.00393 & 1.74 & 0.000686 & 0.0000000 & 0.0000000 \\
\hline 4 & 0.15 & 0.0086 & 0.0876 & 0.362 & 0.00000 & 0.0015 & 0.00863 & 1.71 & 0.000626 & 0.0000000 & 0.0000000 \\
\hline 5 & 0.20 & 0.0096 & 0.0652 & 0.337 & 0.00000 & 0.0000 & 0.00000 & 1.65 & 0.000661 & 0.0000000 & 0.0000000 \\
\hline 6 & 0.25 & 0.0078 & 0.0672 & 0.380 & 0.00000 & 0.0000 & 0.00248 & 1.71 & 0.000731 & 0.0000067 & 0.0000041 \\
\hline 7 & 0.30 & 0.0080 & 0.0609 & 0.390 & 0.00000 & 0.0000 & 0.00561 & 1.72 & 0.000861 & 0.0000000 & 0.0000000 \\
\hline 8 & 0.35 & 0.0033 & 0.0914 & 0.379 & 0.00000 & 0.0000 & 0.00000 & 1.79 & 0.000685 & 0.0000000 & 0.0000000 \\
\hline 9 & 0.40 & 0.0068 & 0.0307 & 0.401 & 0.00000 & 0.0016 & 0.00091 & 1.84 & 0.000747 & 0.0000879 & 0.0000144 \\
\hline 10 & 0.45 & 0.0024 & 0.0791 & 0.462 & 0.00000 & 0.0021 & 0.00000 & 2.04 & 0.000882 & 0.0001294 & 0.0000008 \\
\hline
\end{tabular}


APPENDIX 5.2f $\quad$ SC1A necrous layer transect data

\begin{tabular}{|c|c|c|c|c|c|c|c|c|c|c|c|}
\hline \multirow{2}{*}{ Spot Number } & \multirow{2}{*}{ Distance from inner shell (mm) } & \multicolumn{10}{|c|}{$\mathrm{SC} 1 \mathrm{~A}$ nacreous layer transect $\mathrm{N} 1$ corrected data $(\mathrm{mmol} / \mathrm{mol})$} \\
\hline & & $\mathrm{Li} / \mathrm{Ca}$ & $\mathrm{B} / \mathrm{Ca}$ & $\mathrm{Mg} / \mathrm{Ca}$ & $\mathbf{A l} / \mathbf{C a}$ & $\mathrm{Mn} / \mathrm{Ca}$ & $\mathrm{Zn} / \mathrm{Ca}$ & $\mathrm{Sr} / \mathrm{Ca}$ & $\mathrm{Ba} / \mathrm{Ca}$ & $\mathrm{Pb} / \mathrm{Ca}$ & $\mathrm{U} / \mathrm{Ca}$ \\
\hline 1 & 0.00 & 0.0789 & 0.0000 & 0.399 & 0.0000 & 0.00671 & 0.00000 & 1.64 & 0.000000 & 0.000000 & 0.0000000 \\
\hline 2 & 0.05 & 0.0331 & 0.0380 & 0.231 & 0.0415 & 0.00135 & 0.00499 & 1.53 & 0.000069 & 0.000132 & 0.0000000 \\
\hline 3 & 0.10 & 0.0000 & 0.0920 & 0.290 & 0.0000 & 0.00058 & 0.00000 & 1.71 & 0.000066 & 0.000048 & 0.0000000 \\
\hline 4 & 0.15 & 0.0000 & 0.1522 & 0.263 & 0.0000 & 0.00000 & 0.00000 & 1.84 & 0.000572 & 0.000100 & 0.0000000 \\
\hline 5 & 0.20 & 0.0000 & 0.0000 & 0.258 & 0.0554 & 0.00279 & 0.00381 & 2.04 & 0.000711 & 0.000000 & 0.0000250 \\
\hline 6 & 0.25 & 0.0143 & 0.2672 & 0.403 & 0.0128 & 0.00000 & 0.00000 & 1.90 & 0.000519 & 0.000000 & 0.0000000 \\
\hline 7 & 0.30 & 0.0000 & 0.0539 & 0.271 & 0.0000 & 0.00147 & 0.00304 & 1.73 & 0.000170 & 0.000000 & 0.0000000 \\
\hline 8 & 0.35 & 0.0800 & 0.0387 & 0.279 & 0.0630 & 0.00000 & 0.00136 & 1.89 & 0.000252 & 0.000126 & 0.0000000 \\
\hline 9 & 0.40 & 0.0000 & 0.0000 & 0.299 & 0.0000 & 0.00163 & 0.00996 & 1.82 & 0.000323 & 0.000000 & 0.0000143 \\
\hline 10 & 0.45 & 0.0000 & 0.0191 & 0.454 & 0.0000 & 0.00203 & 0.00000 & 1.92 & 0.000655 & 0.000119 & 0.0000000 \\
\hline 11 & 0.50 & 0.0000 & 0.0000 & 0.350 & 0.0000 & 0.00566 & 0.00132 & 1.95 & 0.000642 & 0.000069 & 0.0000197 \\
\hline 12 & 0.55 & 0.0621 & 0.0000 & 0.259 & 0.0000 & 0.00000 & 0.00000 & 1.98 & 0.000392 & 0.000068 & 0.0000000 \\
\hline 13 & 0.60 & 0.0338 & 0.0706 & 0.409 & 0.0000 & 0.00000 & 0.00000 & 2.03 & 0.000477 & 0.000000 & 0.0000000 \\
\hline 14 & 0.65 & 0.0556 & 0.0544 & 0.515 & 0.0058 & 0.00073 & 0.00000 & 2.17 & 0.000656 & 0.000082 & 0.0000000 \\
\hline
\end{tabular}




\begin{tabular}{|c|c|c|c|c|c|c|c|c|c|c|c|}
\hline \multirow{2}{*}{ Spot Number } & \multirow{2}{*}{ Distance from inner shell $(\mathrm{mm})$} & \multicolumn{10}{|c|}{ SC1A nacreous layer transect $\mathrm{N} 2$ corrected data $(\mathrm{mmol} / \mathrm{mol})$} \\
\hline & & $\mathrm{Li} / \mathrm{Ca}$ & $\mathrm{B} / \mathrm{Ca}$ & $\mathrm{Mg} / \mathrm{Ca}$ & $\mathbf{A l} / \mathbf{C a}$ & $\mathrm{Mn} / \mathrm{Ca}$ & $\mathrm{Zn} / \mathrm{Ca}$ & $\mathrm{Sr} / \mathrm{Ca}$ & $\mathrm{Ba} / \mathrm{Ca}$ & $\mathrm{Pb} / \mathrm{Ca}$ & $\mathrm{U} / \mathrm{Ca}$ \\
\hline 1 & 0.00 & 0.0000 & 0.0000 & 0.272 & 0.0000 & 0.00000 & 0.00000 & 1.80 & 0.000079 & 0.000021 & 0.0000612 \\
\hline 2 & 0.05 & 0.0000 & 0.1611 & 0.300 & 0.0230 & 0.00695 & 0.00861 & 1.73 & 0.000240 & 0.000026 & 0.0000110 \\
\hline 3 & 0.10 & 0.0816 & 0.0000 & 0.397 & 0.0063 & 0.00016 & 0.00673 & 1.94 & 0.000467 & 0.000000 & 0.0000645 \\
\hline 4 & 0.15 & 0.0863 & 0.3628 & 0.696 & 0.0000 & 0.00151 & 0.00580 & 2.35 & 0.000836 & 0.000000 & 0.0000365 \\
\hline 5 & 0.20 & 0.0000 & 1.9056 & 10.212 & 0.0000 & 0.00337 & 0.00000 & 4.01 & 0.001516 & 0.000024 & 0.0000227 \\
\hline 6 & 0.25 & 0.0818 & 0.0000 & 0.290 & 0.0070 & 0.00224 & 0.00797 & 1.86 & 0.000134 & 0.000040 & 0.0000000 \\
\hline 7 & 0.30 & 0.0000 & 0.0388 & 0.336 & 0.0000 & 0.00000 & 0.00000 & 1.55 & 0.000530 & 0.000119 & 0.0000000 \\
\hline 8 & 0.35 & 0.0496 & 0.0000 & 0.389 & 0.0495 & 0.00000 & 0.00508 & 1.47 & 0.000376 & 0.000055 & 0.0000088 \\
\hline 9 & 0.40 & 0.0836 & 0.2591 & 0.409 & 0.0000 & 0.00000 & 0.00393 & 1.56 & 0.000387 & 0.000086 & 0.0000081 \\
\hline 10 & 0.45 & 0.0000 & 0.0000 & 0.442 & 0.0000 & 0.00016 & 0.00633 & 1.62 & 0.000647 & 0.000152 & 0.0000222 \\
\hline 11 & 0.50 & 0.1572 & 0.1443 & 0.501 & 0.0000 & 0.00752 & 0.00992 & 1.77 & 0.000433 & 0.000085 & 0.0000028 \\
\hline 12 & 0.55 & 0.0078 & 0.0000 & 0.392 & 0.0000 & 0.00277 & 0.00659 & 1.82 & 0.000280 & 0.000104 & 0.0000083 \\
\hline 13 & 0.60 & 0.0000 & 0.0000 & 0.451 & 0.0000 & 0.00223 & 0.00024 & 1.80 & 0.000269 & 0.000036 & 0.0000013 \\
\hline 14 & 0.65 & 0.0000 & 0.1289 & 0.397 & 0.0000 & 0.00000 & 0.00000 & 1.71 & 0.000547 & 0.000089 & 0.0000159 \\
\hline 15 & 0.70 & 0.0387 & 0.0000 & 0.416 & 0.0000 & 0.00000 & 0.00000 & 1.70 & 0.000315 & 0.000073 & 0.0000000 \\
\hline 16 & 0.75 & 0.0313 & 0.1463 & 0.485 & 0.0000 & 0.00000 & 0.00520 & 1.72 & 0.000287 & 0.000032 & 0.0000079 \\
\hline 17 & 0.80 & 0.0000 & 0.0173 & 0.420 & 0.0000 & 0.00060 & 0.00849 & 1.91 & 0.000572 & 0.000070 & 0.0000062 \\
\hline 18 & 0.85 & 0.0529 & 0.0708 & 0.422 & 0.0000 & 0.00579 & 0.00411 & 1.91 & 0.000486 & 0.000044 & 0.0000025 \\
\hline 19 & 0.90 & 0.0000 & 0.0000 & 0.488 & 0.0124 & 0.00045 & 0.00248 & 1.90 & 0.000459 & 0.000000 & 0.0000000 \\
\hline 20 & 0.95 & 0.0514 & 0.0384 & 0.498 & 0.0246 & 0.00015 & 0.01321 & 2.17 & 0.000668 & 0.000060 & 0.0000134 \\
\hline 21 & 1.00 & 0.0077 & 0.1213 & 0.437 & 0.0000 & 0.00440 & 0.00000 & 1.83 & 0.000398 & 0.000000 & 0.0000141 \\
\hline 22 & 1.05 & 0.0213 & 0.0185 & 0.654 & 0.0357 & 0.00000 & 0.00000 & 2.18 & 0.000543 & 0.000039 & 0.0000012 \\
\hline 23 & 1.10 & 0.1208 & 0.0000 & 0.408 & 0.0507 & 0.00291 & 0.00644 & 2.18 & 0.000816 & 0.000017 & 0.0000000 \\
\hline 24 & 1.15 & 0.0201 & 0.0000 & 0.642 & 0.0112 & 0.00327 & 0.00225 & 2.39 & 0.000521 & 0.000034 & 0.0000244 \\
\hline
\end{tabular}




\begin{tabular}{|c|c|c|c|c|c|c|c|c|c|c|c|}
\hline \multirow{2}{*}{ Spot Number } & \multirow{2}{*}{ Distance from inner shell (mm) } & \multicolumn{10}{|c|}{ SC1A nacreous layer transect $\mathrm{N} 3$ corrected data $(\mathrm{mmol} / \mathrm{mol})$} \\
\hline & & $\mathrm{Li} / \mathrm{Ca}$ & $\mathrm{B} / \mathrm{Ca}$ & $\mathrm{Mg} / \mathrm{Ca}$ & $\mathbf{A l} / \mathbf{C a}$ & $\mathrm{Mn} / \mathrm{Ca}$ & $\mathrm{Zn} / \mathrm{Ca}$ & $\mathrm{Sr} / \mathrm{Ca}$ & $\mathrm{Ba} / \mathrm{Ca}$ & $\mathrm{Pb} / \mathrm{Ca}$ & $\mathrm{U} / \mathrm{Ca}$ \\
\hline 1 & 0.00 & 0.1221 & 0.0000 & 0.493 & 0.0000 & 0.00000 & 0.00427 & 1.73 & 0.000327 & 0.000051 & 0.0000670 \\
\hline 2 & 0.05 & 0.0449 & 0.0000 & 0.990 & 0.0289 & 0.00319 & 0.00000 & 2.47 & 0.000360 & 0.000164 & 0.0000000 \\
\hline 3 & 0.10 & 0.0590 & 0.1470 & 0.669 & 0.0264 & 0.00552 & 0.00374 & 2.06 & 0.000739 & 0.000217 & 0.0000000 \\
\hline 4 & 0.15 & 0.0000 & 0.0000 & 0.463 & 0.1414 & 0.00280 & 0.00000 & 2.01 & 0.000681 & 0.000089 & 0.0000000 \\
\hline 5 & 0.20 & 0.0610 & 0.0464 & 0.321 & 0.0000 & 0.00092 & 0.01323 & 1.75 & 0.000348 & 0.000305 & 0.0000136 \\
\hline 6 & 0.25 & 0.0000 & 0.0000 & 0.415 & 0.0000 & 0.00226 & 0.00586 & 1.79 & 0.000250 & 0.000026 & 0.0000110 \\
\hline 7 & 0.30 & 0.0000 & 0.0000 & 0.353 & 0.0000 & 0.00217 & 0.01054 & 1.88 & 0.000319 & 0.000074 & 0.0000000 \\
\hline 8 & 0.35 & 0.0599 & 0.0132 & 0.343 & 0.0000 & 0.00234 & 0.00000 & 1.86 & 0.000596 & 0.000084 & 0.0000000 \\
\hline 9 & 0.40 & 0.0000 & 0.2233 & 0.337 & 0.0497 & 0.00191 & 0.00000 & 1.95 & 0.000204 & 0.000139 & 0.0000270 \\
\hline 10 & 0.45 & 0.0000 & 0.0000 & 0.348 & 0.0000 & 0.00067 & 0.00000 & 2.03 & 0.000624 & 0.000096 & 0.0000212 \\
\hline 11 & 0.50 & 0.0178 & 0.2031 & 0.513 & 0.0000 & 0.00000 & 0.01334 & 2.34 & 0.000655 & 0.000000 & 0.0000000 \\
\hline
\end{tabular}


APPENDIX 5.2g MP02A nacreous layer data

\begin{tabular}{|c|c|c|c|c|c|c|c|c|c|c|c|}
\hline \multirow{2}{*}{ Spot Number } & \multirow{2}{*}{ Distance from inner shell $(\mathrm{mm})$} & \multicolumn{10}{|c|}{ MP02A nacreous layer transect $\mathrm{N} 1$ corrected data $(\mathrm{mmol} / \mathrm{mol})$} \\
\hline & & $\mathrm{Li} / \mathrm{Ca}$ & $\mathrm{B} / \mathrm{Ca}$ & $\mathrm{Mg} / \mathrm{Ca}$ & $\mathbf{A l} / \mathbf{C a}$ & $\mathrm{Mn} / \mathrm{Ca}$ & $\mathrm{Zn} / \mathrm{Ca}$ & $\mathrm{Sr} / \mathrm{Ca}$ & $\mathrm{Ba} / \mathrm{Ca}$ & $\mathrm{Pb} / \mathrm{Ca}$ & $\mathrm{U} / \mathrm{Ca}$ \\
\hline 1 & 0.00 & 0.0000 & 0.0291 & 0.337 & 0.0054 & 0.00352 & 0.00890 & 1.34 & 0.001091 & 0.0000476 & 0.0000000 \\
\hline 2 & 0.05 & 0.0000 & 0.0495 & 0.288 & 0.0000 & 0.00000 & 0.00670 & 1.44 & 0.000696 & 0.0000000 & 0.0000000 \\
\hline 3 & 0.10 & 0.0000 & 0.0360 & 0.356 & 0.0000 & 0.00000 & 0.00262 & 1.65 & 0.000516 & 0.0000439 & 0.0000157 \\
\hline 4 & 0.15 & 0.0510 & 2.4152 & 13.548 & 0.0000 & 0.00128 & 0.00000 & 3.26 & 0.001050 & 0.0000293 & 0.0000000 \\
\hline 5 & 0.20 & 0.0033 & 0.0587 & 0.442 & 0.0067 & 0.00000 & 0.00213 & 1.49 & 0.000413 & 0.0000504 & 0.0000000 \\
\hline 6 & 0.25 & 0.0006 & 0.0418 & 0.418 & 0.0048 & 0.00210 & 0.00000 & 1.54 & 0.000415 & 0.0000000 & 0.0000064 \\
\hline 7 & 0.30 & 0.0000 & 0.0689 & 0.525 & 0.0000 & 0.00589 & 0.00121 & 1.70 & 0.000203 & 0.0000000 & 0.0000000 \\
\hline 8 & 0.35 & 0.0000 & 0.0517 & 0.423 & 0.0064 & 0.00000 & 0.00000 & 1.52 & 0.000462 & 0.0000263 & 0.0000000 \\
\hline 9 & 0.40 & 0.0037 & 0.0604 & 0.406 & 0.0080 & 0.00079 & 0.00160 & 1.55 & 0.000497 & 0.0000000 & 0.0000000 \\
\hline 10 & 0.45 & 0.0279 & 0.0250 & 0.406 & 0.0148 & 0.00439 & 0.00000 & 1.69 & 0.000391 & 0.0000000 & 0.0000115 \\
\hline 11 & 0.50 & 0.0000 & 0.0604 & 0.574 & 0.0000 & 0.00024 & 0.00334 & 1.94 & 0.000601 & 0.0000239 & 0.0000029 \\
\hline 12 & 0.55 & 0.0000 & 8.2161 & 50.333 & 0.0357 & 0.00846 & 0.01100 & 4.11 & 0.001955 & 0.0001538 & 0.0000300 \\
\hline 13 & 0.60 & 0.0000 & 0.0738 & 0.617 & 0.0000 & 0.00000 & 0.00416 & 1.87 & 0.000267 & 0.0000000 & 0.0000000 \\
\hline 14 & 0.65 & 0.0196 & 0.0810 & 0.569 & 0.0125 & 0.00506 & 0.00693 & 1.77 & 0.000465 & 0.0000000 & 0.0000000 \\
\hline 15 & 0.70 & 0.0000 & 0.0898 & 0.588 & 0.0000 & 0.00241 & 0.00236 & 1.74 & 0.000620 & 0.0000000 & 0.0000172 \\
\hline 16 & 0.75 & 0.0006 & 0.0557 & 0.601 & 0.0000 & 0.00395 & 0.00476 & 1.66 & 0.000405 & 0.0000000 & 0.0000000 \\
\hline 17 & 0.80 & 0.0155 & 0.0729 & 0.599 & 0.0000 & 0.00002 & 0.00000 & 1.66 & 0.000372 & 0.0000043 & 0.0000000 \\
\hline 18 & 0.85 & 0.0000 & 0.0812 & 0.596 & 0.0159 & 0.00000 & 0.00439 & 1.75 & 0.000616 & 0.0000000 & 0.0000073 \\
\hline 19 & 0.90 & 0.0000 & 0.0918 & 0.503 & 0.0000 & 0.00000 & 0.00000 & 1.45 & 0.000246 & 0.0000000 & 0.0000000 \\
\hline 20 & 0.95 & 0.0309 & 0.0493 & 0.470 & 0.0280 & 0.00000 & 0.00226 & 1.61 & 0.000441 & 0.0000455 & 0.0000219 \\
\hline 21 & 1.00 & 0.0283 & 0.0611 & 0.531 & 0.0124 & 0.00119 & 0.00534 & 1.62 & 0.000460 & 0.0000000 & 0.0000191 \\
\hline 22 & 1.05 & 0.0136 & 0.0096 & 0.587 & 0.0005 & 0.00114 & 0.00000 & 1.63 & 0.000431 & 0.0000241 & 0.0000084 \\
\hline 23 & 1.10 & 0.0000 & 0.0621 & 0.626 & 0.0000 & 0.00000 & 0.00000 & 1.76 & 0.000571 & 0.0000000 & 0.0000000 \\
\hline 24 & 1.15 & 0.0000 & 0.0652 & 0.819 & 0.0000 & 0.00052 & 0.00000 & 1.86 & 0.000605 & 0.0000623 & 0.0000000 \\
\hline 25 & 1.20 & 0.0000 & 0.0926 & 0.927 & 0.0000 & 0.00667 & 0.00153 & 1.98 & 0.000377 & 0.0000000 & 0.0000000 \\
\hline 26 & 1.25 & 0.0198 & 0.0604 & 0.881 & 0.0038 & 0.00311 & 0.00132 & 1.79 & 0.000688 & 0.0000000 & 0.0000608 \\
\hline 27 & 1.30 & 0.0296 & 0.0472 & 0.771 & 0.0174 & 0.00237 & 0.01141 & 1.76 & 0.000595 & 0.0000000 & 0.0000648 \\
\hline 28 & 1.35 & 0.0000 & 0.0697 & 1.117 & 0.0000 & 0.00102 & 0.00299 & 1.88 & 0.000740 & 0.0000533 & 0.0000138 \\
\hline 29 & 1.40 & 0.0345 & 0.0803 & 1.907 & 0.0000 & 0.00000 & 0.00468 & 2.58 & 0.001000 & 0.0000000 & 0.0000680 \\
\hline
\end{tabular}




\begin{tabular}{|c|c|c|c|c|c|c|c|c|c|c|c|}
\hline \multirow{2}{*}{$\begin{array}{c}\text { Spot } \\
\text { Number }\end{array}$} & \multirow{2}{*}{ Distance from inner shell (mm) } & \multicolumn{10}{|c|}{ MP02A nacreous layer transect $\mathrm{N} 2$ corrected data $(\mathrm{mmol} / \mathrm{mol})$} \\
\hline & & $\mathrm{Li} / \mathrm{Ca}$ & $\mathrm{B} / \mathrm{Ca}$ & $\mathrm{Mg} / \mathrm{Ca}$ & $\mathbf{A l} / \mathbf{C a}$ & $\mathrm{Mn} / \mathrm{Ca}$ & $\mathrm{Zn} / \mathrm{Ca}$ & $\mathrm{Sr} / \mathrm{Ca}$ & $\mathrm{Ba} / \mathrm{Ca}$ & $\mathrm{Pb} / \mathrm{Ca}$ & $\mathrm{U} / \mathrm{Ca}$ \\
\hline 1 & 0.00 & 0.0045 & 0.0564 & 0.283 & 0.0000 & 0.00147 & 0.00922 & 1.36 & 0.000107 & 0.0000277 & 0.0000000 \\
\hline 2 & 0.05 & 0.0022 & 0.2815 & 1.179 & 0.0161 & 0.00242 & 0.00000 & 2.00 & 0.000488 & 0.0000632 & 0.0000079 \\
\hline 3 & 0.10 & 0.0179 & 0.0627 & 0.301 & 0.0000 & 0.00103 & 0.00139 & 1.40 & 0.000319 & 0.0001150 & 0.0000092 \\
\hline 4 & 0.15 & 0.0000 & 0.0259 & 0.338 & 0.0140 & 0.00123 & 0.00000 & 1.41 & 0.000419 & 0.0000047 & 0.0000038 \\
\hline 5 & 0.20 & 0.0283 & 4.1552 & 16.291 & 0.0167 & 0.00974 & 0.00000 & 3.63 & 0.001226 & 0.0001418 & 0.0000107 \\
\hline 6 & 0.25 & 0.0229 & 0.0208 & 0.405 & 0.0000 & 0.00000 & 0.00000 & 1.46 & 0.000429 & 0.0000532 & 0.0000135 \\
\hline 7 & 0.30 & 0.0000 & 0.0476 & 0.326 & 0.0000 & 0.00399 & 0.00000 & 1.38 & 0.000000 & 0.0000000 & 0.0000000 \\
\hline 8 & 0.35 & 0.0111 & 0.0748 & 0.293 & 0.0000 & 0.00276 & 0.00304 & 1.39 & 0.000387 & 0.0001143 & 0.0000000 \\
\hline 9 & 0.40 & 0.0050 & 0.0952 & 0.489 & 0.0146 & 0.00070 & 0.00000 & 1.63 & 0.000409 & 0.0000727 & 0.0000168 \\
\hline 10 & 0.45 & 0.0000 & 15.7149 & 96.957 & 0.0000 & 0.01564 & 0.01324 & 4.84 & 0.002272 & 0.0002518 & 0.0000000 \\
\hline 11 & 0.50 & 0.0402 & 0.0313 & 0.567 & 0.0000 & 0.00000 & 0.00000 & 1.80 & 0.000531 & 0.0000639 & 0.0000000 \\
\hline 12 & 0.55 & 0.0000 & 0.0523 & 0.411 & 0.0333 & 0.00414 & 0.00387 & 1.60 & 0.000139 & 0.0000000 & 0.0000000 \\
\hline 13 & 0.60 & 0.0000 & 0.0689 & 0.447 & 0.0000 & 0.00000 & 0.00042 & 1.68 & 0.000000 & 0.0000000 & 0.0000000 \\
\hline 14 & 0.65 & 0.0303 & 0.1256 & 0.542 & 0.0000 & 0.00361 & 0.00614 & 1.63 & 0.000441 & 0.0000000 & 0.0000000 \\
\hline 15 & 0.70 & 0.0272 & 0.0415 & 0.430 & 0.0088 & 0.00000 & 0.00169 & 1.56 & 0.000476 & 0.0000436 & 0.0000000 \\
\hline 16 & 0.75 & 0.0000 & 0.0366 & 0.446 & 0.0849 & 0.00776 & 0.00000 & 1.67 & 0.000445 & 0.0000000 & 0.0000022 \\
\hline 17 & 0.80 & 0.0000 & 0.0890 & 0.393 & 0.0000 & 0.00168 & 0.00000 & 1.58 & 0.000419 & 0.0000000 & 0.0000135 \\
\hline 18 & 0.85 & 0.0031 & 0.0592 & 0.500 & 0.0108 & 0.00000 & 0.00365 & 1.60 & 0.000432 & 0.0000000 & 0.0000000 \\
\hline 19 & 0.90 & 0.0315 & 0.0742 & 0.460 & 0.0000 & 0.00581 & 0.00240 & 1.57 & 0.000000 & 0.0000000 & 0.0000000 \\
\hline 20 & 0.95 & 0.0000 & 0.1326 & 0.477 & 0.0000 & 0.00235 & 0.00000 & 1.91 & 0.000387 & 0.0000000 & 0.0000000 \\
\hline 21 & 1.00 & 0.0218 & 0.0072 & 0.396 & 0.0000 & 0.00065 & 0.00948 & 1.73 & 0.000518 & 0.0000341 & 0.0000105 \\
\hline 22 & 1.05 & 0.0000 & 0.0972 & 0.471 & 0.0130 & 0.00000 & 0.00522 & 1.76 & 0.000435 & 0.0001507 & 0.0000313 \\
\hline 23 & 1.10 & 0.0395 & 0.0498 & 0.408 & 0.0000 & 0.00000 & 0.00511 & 1.81 & 0.000505 & 0.0000223 & 0.0000000 \\
\hline 24 & 1.15 & 0.0000 & 0.0342 & 0.426 & 0.0000 & 0.00000 & 0.00000 & 1.76 & 0.000605 & 0.0001019 & 0.0000281 \\
\hline 25 & 1.20 & 0.0000 & 0.0097 & 0.761 & 0.0000 & 0.00846 & 0.00000 & 2.60 & 0.001330 & 0.0000000 & 0.0000522 \\
\hline
\end{tabular}




\begin{tabular}{|c|c|c|c|c|c|c|c|c|c|c|c|}
\hline \multirow{2}{*}{$\begin{array}{c}\text { Spot } \\
\text { Number }\end{array}$} & \multirow{2}{*}{ Distance from inner shell $(\mathrm{mm})$} & \multicolumn{10}{|c|}{ MP02A nacreous layer transect N3 corrected data $(\mathrm{mmol} / \mathrm{mol})$} \\
\hline & & $\mathrm{Li} / \mathrm{Ca}$ & $\mathrm{B} / \mathrm{Ca}$ & $\mathrm{Mg} / \mathrm{Ca}$ & $\mathbf{A l} / \mathbf{C a}$ & $\mathrm{Mn} / \mathrm{Ca}$ & $\mathrm{Zn} / \mathrm{Ca}$ & $\mathrm{Sr} / \mathrm{Ca}$ & $\mathrm{Ba} / \mathrm{Ca}$ & $\mathrm{Pb} / \mathrm{Ca}$ & $\mathrm{U} / \mathrm{Ca}$ \\
\hline 1 & 0.00 & 0.0000 & 0.0587 & 0.431 & 0.0000 & 0.00038 & 0.00000 & 2.73 & 0.000394 & 0.0000000 & 0.0000000 \\
\hline 2 & 0.05 & 0.0202 & 0.0365 & 0.380 & 0.0009 & 0.00000 & 0.00038 & 1.54 & 0.000572 & 0.0000237 & 0.0000000 \\
\hline 3 & 0.10 & 0.0445 & 5.0129 & 21.351 & 0.0053 & 0.01550 & 0.01035 & 3.74 & 0.001465 & 0.0000000 & 0.0000000 \\
\hline 4 & 0.15 & 0.0049 & 1.0574 & 6.061 & 0.0201 & 0.00298 & 0.00080 & 2.04 & 0.000708 & 0.0000805 & 0.0000542 \\
\hline 5 & 0.20 & 0.0123 & 0.0737 & 0.630 & 0.0000 & 0.00000 & 0.00000 & 2.33 & 0.000723 & 0.0000000 & 0.0000000 \\
\hline 6 & 0.25 & 0.0000 & 0.0767 & 0.565 & 0.0000 & 0.00100 & 0.00483 & 2.37 & 0.000735 & 0.0001212 & 0.0000031 \\
\hline 7 & 0.30 & 0.0000 & 0.0455 & 0.406 & 0.0000 & 0.00184 & 0.00809 & 1.67 & 0.000078 & 0.0000000 & 0.0000000 \\
\hline 8 & 0.35 & 0.0117 & 0.0376 & 0.380 & 0.0076 & 0.00018 & 0.00000 & 1.69 & 0.000412 & 0.0001676 & 0.0000000 \\
\hline 9 & 0.40 & 0.0000 & 0.0772 & 0.376 & 0.0052 & 0.00018 & 0.00000 & 1.59 & 0.000367 & 0.0000856 & 0.0000142 \\
\hline 10 & 0.45 & 0.0000 & 0.0294 & 0.374 & 0.0109 & 0.00063 & 0.00118 & 1.77 & 0.000503 & 0.0000508 & 0.0000143 \\
\hline 11 & 0.50 & 0.0000 & 0.0715 & 0.372 & 0.0000 & 0.00000 & 0.00246 & 1.71 & 0.000432 & 0.0000237 & 0.0000000 \\
\hline 12 & 0.55 & 0.0000 & 0.0735 & 0.410 & 0.0154 & 0.00126 & 0.00503 & 1.81 & 0.000443 & 0.0000000 & 0.0000064 \\
\hline 13 & 0.60 & 0.0000 & 0.0309 & 0.529 & 0.0000 & 0.00000 & 0.00551 & 2.04 & 0.000000 & 0.0000000 & 0.0000000 \\
\hline 14 & 0.65 & 0.0000 & 0.0389 & 0.404 & 0.0000 & 0.00000 & 0.00113 & 1.64 & 0.000445 & 0.0000000 & 0.0000000 \\
\hline 15 & 0.70 & 0.0146 & 0.0313 & 0.398 & 0.0032 & 0.00250 & 0.00096 & 1.66 & 0.000449 & 0.0000000 & 0.0000000 \\
\hline 16 & 0.75 & 0.0090 & 0.0376 & 0.431 & 0.0000 & 0.00000 & 0.00468 & 1.62 & 0.000501 & 0.0000000 & 0.0000000 \\
\hline 17 & 0.80 & 0.0005 & 0.0469 & 0.334 & 0.0049 & 0.00315 & 0.00000 & 1.67 & 0.000455 & 0.0000121 & 0.0000000 \\
\hline 18 & 0.85 & 0.0000 & 0.0348 & 0.447 & 0.0144 & 0.00288 & 0.00442 & 1.72 & 0.000493 & 0.0000000 & 0.0000373 \\
\hline 19 & 0.90 & 0.0000 & 0.0309 & 0.434 & 0.0000 & 0.00000 & 0.00235 & 1.73 & 0.000048 & 0.0000000 & 0.0000000 \\
\hline 20 & 0.95 & 0.0000 & 0.0753 & 0.486 & 0.0000 & 0.00292 & 0.00194 & 1.92 & 0.000838 & 0.0000000 & 0.0000354 \\
\hline 21 & 1.00 & 0.0173 & 0.0584 & 1.270 & 0.0007 & 0.00544 & 0.01367 & 2.16 & 0.001372 & 0.0000000 & 0.0001201 \\
\hline
\end{tabular}




\begin{tabular}{|c|c|c|c|c|c|c|c|c|c|c|c|}
\hline \multirow{2}{*}{$\begin{array}{c}\text { Spot } \\
\text { Number }\end{array}$} & \multirow{2}{*}{ Distance from inner shell (mm) } & \multicolumn{10}{|c|}{ MP02A nacreous layer transect $\mathrm{N} 4$ corrected data $(\mathrm{mmol} / \mathrm{mol})$} \\
\hline & & $\mathrm{Li} / \mathrm{Ca}$ & $\mathrm{B} / \mathrm{Ca}$ & $\mathrm{Mg} / \mathrm{Ca}$ & $\mathrm{Al} / \mathrm{Ca}$ & $\mathrm{Mn} / \mathrm{Ca}$ & $\mathrm{Zn} / \mathrm{Ca}$ & $\mathrm{Sr} / \mathrm{Ca}$ & $\mathrm{Ba} / \mathrm{Ca}$ & $\mathrm{Pb} / \mathrm{Ca}$ & $\mathrm{U} / \mathrm{Ca}$ \\
\hline 1 & 0.00 & 0.0000 & 0.0347 & 0.346 & 0.0000 & 0.00114 & 0.00403 & 1.63 & 0.000100 & 0.0000000 & 0.0000000 \\
\hline 2 & 0.05 & 0.0000 & 1.5544 & 9.566 & 0.0080 & 0.00482 & 0.00612 & 3.32 & 0.000778 & 0.0000537 & 0.0000000 \\
\hline 3 & 0.10 & 0.0000 & 0.0256 & 0.452 & 0.0000 & 0.00000 & 0.00090 & 1.45 & 0.000453 & 0.0001244 & 0.0000000 \\
\hline 4 & 0.15 & 0.0000 & 0.5428 & 1.916 & 0.0199 & 0.00000 & 0.00248 & 2.63 & 0.000800 & 0.0000000 & 0.0000000 \\
\hline 5 & 0.20 & 0.0353 & 5.1308 & 19.952 & 0.0355 & 0.00386 & 0.00308 & 2.78 & 0.000770 & 0.0000830 & 0.0000000 \\
\hline 6 & 0.25 & 0.0000 & 0.0612 & 0.422 & 0.0068 & 0.00106 & 0.00000 & 1.49 & 0.000271 & 0.0000000 & 0.0000000 \\
\hline 7 & 0.30 & 0.0000 & 0.0824 & 0.501 & 0.0000 & 0.00000 & 0.00368 & 1.44 & 0.000000 & 0.0000000 & 0.0000000 \\
\hline 8 & 0.35 & 0.0050 & 0.0346 & 0.363 & 0.0098 & 0.00170 & 0.00119 & 1.49 & 0.000243 & 0.0000907 & 0.0000000 \\
\hline 9 & 0.40 & 0.0104 & 0.0649 & 0.366 & 0.0000 & 0.00266 & 0.00000 & 1.52 & 0.000466 & 0.0000160 & 0.0000135 \\
\hline 10 & 0.45 & 0.0303 & 0.0739 & 0.341 & 0.0000 & 0.00000 & 0.00457 & 1.45 & 0.000379 & 0.0000000 & 0.0000000 \\
\hline 11 & 0.50 & 0.0082 & 0.0525 & 0.352 & 0.0089 & 0.00000 & 0.00471 & 1.44 & 0.000332 & 0.0000000 & 0.0000082 \\
\hline 12 & 0.55 & 0.0102 & 0.0693 & 0.375 & 0.0122 & 0.00248 & 0.00000 & 1.58 & 0.000407 & 0.0000453 & 0.0000490 \\
\hline 13 & 0.60 & 0.0000 & 0.0526 & 0.337 & 0.0000 & 0.00506 & 0.00000 & 1.63 & 0.000000 & 0.0000000 & 0.0000000 \\
\hline 14 & 0.65 & 0.0000 & 0.0442 & 0.356 & 0.0281 & 0.00000 & 0.00086 & 1.63 & 0.000452 & 0.0000000 & 0.0000000 \\
\hline 15 & 0.70 & 0.0000 & 0.0396 & 0.384 & 0.0000 & 0.00000 & 0.00327 & 1.55 & 0.000319 & 0.0000176 & 0.0000286 \\
\hline 16 & 0.75 & 0.0000 & 0.0897 & 0.358 & 0.0081 & 0.00162 & 0.00000 & 1.64 & 0.000343 & 0.0000000 & 0.0000398 \\
\hline 17 & 0.80 & 0.0151 & 0.0851 & 0.351 & 0.0000 & 0.00133 & 0.00648 & 1.58 & 0.000358 & 0.0000350 & 0.0000044 \\
\hline 18 & 0.85 & 0.0107 & 0.0986 & 0.469 & 0.0000 & 0.00085 & 0.00414 & 1.76 & 0.000634 & 0.0000000 & 0.0000000 \\
\hline 19 & 0.90 & 0.0000 & 0.0399 & 0.468 & 0.0000 & 0.00373 & 0.00000 & 2.16 & 0.000835 & 0.0000252 & 0.0000000 \\
\hline
\end{tabular}


APPENDIX 5.2h KD1B nacreous layer transect data

\begin{tabular}{|c|c|c|c|c|c|c|c|c|c|c|c|}
\hline \multirow{2}{*}{$\begin{array}{l}\text { Spot } \\
\text { Number }\end{array}$} & \multirow{2}{*}{ Distance from inner shell (mm) } & \multicolumn{10}{|c|}{ KD1B nacreous layer transect N1 corrected data $(\mathrm{mmol} / \mathrm{mol})$} \\
\hline & & $\mathrm{Li} / \mathrm{Ca}$ & $\mathrm{B} / \mathrm{Ca}$ & $\mathrm{Mg} / \mathrm{Ca}$ & $\mathbf{A l} / \mathbf{C a}$ & $\mathrm{Mn} / \mathrm{Ca}$ & $\mathrm{Zn} / \mathrm{Ca}$ & $\mathrm{Sr} / \mathrm{Ca}$ & $\mathrm{Ba} / \mathrm{Ca}$ & $\mathrm{Pb} / \mathrm{Ca}$ & $\mathrm{U} / \mathrm{Ca}$ \\
\hline 1 & 0.00 & 0.0000 & 0.0510 & 0.39 & 0.00000 & 0.00129 & 0.00000 & 1.91 & 0.00081 & 0.0000566 & 0.0000000 \\
\hline 2 & 0.05 & 0.0035 & 0.1375 & 0.76 & 0.00000 & 0.00108 & 0.00369 & 1.91 & 0.00068 & 0.0010296 & 0.0000814 \\
\hline 3 & 0.10 & 0.0144 & 0.0635 & 0.81 & 0.00275 & 0.00000 & 0.00370 & 2.20 & 0.00104 & 0.0000406 & 0.0000056 \\
\hline 4 & 0.15 & 0.0357 & 0.0690 & 0.67 & 0.00000 & 0.00000 & 0.00309 & 1.95 & 0.00087 & 0.0000536 & 0.0000000 \\
\hline 5 & 0.20 & 0.0004 & 0.0519 & 0.64 & 0.01202 & 0.00180 & 0.00425 & 2.05 & 0.00081 & 0.0000699 & 0.0000087 \\
\hline 6 & 0.25 & 0.0351 & 15.3125 & 91.16 & 0.00000 & 0.02923 & 0.03155 & 3.09 & 0.00219 & 0.0000274 & 0.0000086 \\
\hline 7 & 0.30 & 0.0000 & 0.0567 & 0.69 & 0.00194 & 0.00000 & 0.00000 & 1.85 & 0.00068 & 0.0000000 & 0.0000000 \\
\hline 8 & 0.35 & 0.0217 & 0.0563 & 0.53 & 0.00000 & 0.00000 & 0.00049 & 1.69 & 0.00055 & 0.0000194 & 0.0000000 \\
\hline 9 & 0.40 & 0.0151 & 0.0381 & 0.49 & 0.00524 & 0.00056 & 0.00000 & 1.72 & 0.00060 & 0.0000208 & 0.0000209 \\
\hline 10 & 0.45 & 0.0004 & 0.0452 & 0.46 & 0.00000 & 0.00000 & 0.00101 & 1.58 & 0.00061 & 0.0000000 & 0.0000141 \\
\hline 11 & 0.50 & 0.0000 & 0.0356 & 0.41 & 0.00000 & 0.00001 & 0.00287 & 1.57 & 0.00055 & 0.0000680 & 0.0000083 \\
\hline 12 & 0.55 & 0.0000 & 0.0466 & 0.35 & 0.00399 & 0.00008 & 0.00378 & 1.63 & 0.00066 & 0.0000362 & 0.0000152 \\
\hline 13 & 0.60 & 0.0000 & 0.0478 & 0.35 & 0.00000 & 0.00000 & 0.00000 & 1.64 & 0.00054 & 0.0000345 & 0.0000000 \\
\hline 14 & 0.65 & 0.0112 & 0.0366 & 0.38 & 0.00000 & 0.00000 & 0.00518 & 1.71 & 0.00056 & 0.0000297 & 0.0000042 \\
\hline 15 & 0.70 & 0.0108 & 0.0296 & 0.30 & 0.00000 & 0.00193 & 0.00763 & 1.66 & 0.00054 & 0.0000410 & 0.0000000 \\
\hline 16 & 0.75 & 0.0087 & 0.0278 & 0.28 & 0.00102 & 0.00060 & 0.00576 & 1.76 & 0.00079 & 0.0000473 & 0.0000106 \\
\hline 17 & 0.80 & 0.0200 & 0.0636 & 0.23 & 0.00264 & 0.00000 & 0.00133 & 1.62 & 0.00068 & 0.0000013 & 0.0000010 \\
\hline 18 & 0.85 & 0.0111 & 0.0075 & 0.27 & 0.00000 & 0.00000 & 0.00000 & 1.66 & 0.00061 & 0.0000000 & 0.0000000 \\
\hline 19 & 0.90 & 0.0233 & 0.0480 & 0.33 & 0.00495 & 0.00080 & 0.00256 & 1.68 & 0.00071 & 0.0000000 & 0.0000019 \\
\hline 20 & 0.95 & 0.0136 & 0.0459 & 0.30 & 0.00350 & 0.00077 & 0.00008 & 1.70 & 0.00081 & 0.0000000 & 0.0000004 \\
\hline 21 & 1.00 & 0.0120 & 0.0367 & 0.30 & 0.00000 & 0.00075 & 0.00000 & 1.83 & 0.00088 & 0.0000000 & 0.0000231 \\
\hline 22 & 1.05 & 0.0249 & 0.0062 & 0.31 & 0.00000 & 0.00000 & 0.00399 & 1.85 & 0.00089 & 0.0000000 & 0.0000059 \\
\hline 23 & 1.10 & 0.0045 & 0.0295 & 0.41 & 0.00118 & 0.00000 & 0.00370 & 1.85 & 0.00079 & 0.0000000 & 0.0000239 \\
\hline 24 & 1.15 & 0.0105 & 0.0242 & 0.50 & 0.01128 & 0.00086 & 0.00379 & 1.80 & 0.00121 & 0.0000692 & 0.0000000 \\
\hline 25 & 1.20 & 0.0065 & 0.0606 & 0.67 & 0.00308 & 0.00249 & 0.00701 & 2.24 & 0.00161 & 0.0000000 & 0.0000041 \\
\hline
\end{tabular}




\begin{tabular}{|c|c|c|c|c|c|c|c|c|c|c|c|}
\hline \multirow{2}{*}{$\begin{array}{c}\text { Spot } \\
\text { Number }\end{array}$} & \multirow{2}{*}{ Distance from inner shell $(\mathrm{mm})$} & \multicolumn{10}{|c|}{ KD1B nacreous layer transect $\mathrm{N} 2$ corrected data $(\mathrm{mmol} / \mathrm{mol})$} \\
\hline & & $\mathrm{Li} / \mathrm{Ca}$ & $\mathrm{B} / \mathrm{Ca}$ & $\mathrm{Mg} / \mathrm{Ca}$ & $\mathbf{A l} / \mathbf{C a}$ & $\mathrm{Mn} / \mathrm{Ca}$ & $\mathrm{Zn} / \mathrm{Ca}$ & $\mathrm{Sr} / \mathrm{Ca}$ & $\mathrm{Ba} / \mathrm{Ca}$ & $\mathrm{Pb} / \mathrm{Ca}$ & $\mathrm{U} / \mathrm{Ca}$ \\
\hline 1 & 0.00 & 0.0011 & 0.0612 & 0.41 & 0.00000 & 0.00100 & 0.00440 & 1.76 & 0.00090 & 0.0000441 & 0.0000000 \\
\hline 2 & 0.05 & 0.0060 & 0.0631 & 0.44 & 0.00000 & 0.00276 & 0.00257 & 1.88 & 0.00095 & 0.0000000 & 0.0000000 \\
\hline 3 & 0.10 & 0.0000 & 0.0338 & 0.45 & 0.00000 & 0.00295 & 0.00672 & 1.68 & 0.00090 & 0.0000840 & 0.0000000 \\
\hline 4 & 0.15 & 0.0082 & 1.6841 & 11.17 & 0.00185 & 0.00420 & 0.00324 & 2.56 & 0.00105 & 0.0000043 & 0.0000000 \\
\hline 5 & 0.20 & 0.0051 & 0.0533 & 0.58 & 0.00819 & 0.00000 & 0.00310 & 1.82 & 0.00076 & 0.0000357 & 0.0000000 \\
\hline 6 & 0.25 & 0.0014 & 0.0410 & 0.35 & 0.00000 & 0.00526 & 0.00287 & 1.82 & 0.00098 & 0.0000435 & 0.0000000 \\
\hline 7 & 0.30 & 0.0069 & 0.0320 & 0.37 & 0.00000 & 0.00306 & 0.00600 & 2.02 & 0.00128 & 0.0000324 & 0.0000015 \\
\hline 8 & 0.35 & 0.0000 & 0.0444 & 0.60 & 0.01131 & 0.00195 & 0.00153 & 2.18 & 0.00096 & 0.0000000 & 0.0000000 \\
\hline 9 & 0.40 & 0.0226 & 0.0070 & 0.67 & 0.00698 & 0.00000 & 0.00536 & 2.04 & 0.00183 & 0.0000476 & 0.0000000 \\
\hline 10 & 0.45 & 0.0092 & 0.7719 & 3.25 & 0.01892 & 0.00269 & 0.00037 & 2.11 & 0.00105 & 0.0000300 & 0.0000000 \\
\hline 11 & 0.50 & 0.0000 & 2.4298 & 13.96 & 0.00000 & 0.00606 & 0.00656 & 3.85 & 0.00195 & 0.0000252 & 0.0000000 \\
\hline 12 & 0.55 & 0.0118 & 0.0300 & 0.62 & 0.00119 & 0.00176 & 0.00127 & 1.82 & 0.00083 & 0.0000000 & 0.0000000 \\
\hline 13 & 0.60 & 0.0000 & 0.0734 & 0.52 & 0.00000 & 0.00272 & 0.00000 & 1.65 & 0.00073 & 0.0000205 & 0.0000210 \\
\hline 14 & 0.65 & 0.0102 & 0.0330 & 0.58 & 0.01929 & 0.00205 & 0.00132 & 1.94 & 0.00072 & 0.0001100 & 0.0000000 \\
\hline 15 & 0.70 & 0.0096 & 0.0783 & 0.61 & 0.00323 & 0.00409 & 0.00000 & 1.87 & 0.00068 & 0.0000000 & 0.0000000 \\
\hline 16 & 0.75 & 0.0000 & 0.0558 & 0.56 & 0.00000 & 0.00028 & 0.00000 & 1.58 & 0.00065 & 0.0000765 & 0.0000000 \\
\hline 17 & 0.80 & 0.0150 & 0.0529 & 0.59 & 0.00489 & 0.00000 & 0.00683 & 1.66 & 0.00050 & 0.0000000 & 0.0000000 \\
\hline 18 & 0.85 & 0.0000 & 7.8759 & 37.76 & 0.00000 & 0.00539 & 0.01189 & 2.53 & 0.00111 & 0.0000000 & 0.0000000 \\
\hline 19 & 0.90 & 0.0055 & 0.0732 & 0.58 & 0.00000 & 0.00207 & 0.00391 & 2.01 & 0.00075 & 0.0000000 & 0.0000151 \\
\hline 20 & 0.95 & 0.0000 & 0.0377 & 0.46 & 0.00000 & 0.00000 & 0.00000 & 1.73 & 0.00069 & 0.0000000 & 0.0000084 \\
\hline 21 & 1.00 & 0.0000 & 0.0550 & 0.45 & 0.00000 & 0.00000 & 0.00000 & 1.74 & 0.00084 & 0.0000574 & 0.0000000 \\
\hline 22 & 1.05 & 0.0204 & 0.0705 & 0.42 & 0.01455 & 0.00000 & 0.00039 & 1.65 & 0.00052 & 0.0000179 & 0.0000234 \\
\hline 23 & 1.10 & 0.0089 & 0.0936 & 0.43 & 0.00000 & 0.00000 & 0.00485 & 1.62 & 0.00090 & 0.0000000 & 0.0000182 \\
\hline 24 & 1.15 & 0.0000 & 0.0952 & 0.41 & 0.00000 & 0.00193 & 0.00654 & 1.54 & 0.00075 & 0.0000000 & 0.0000067 \\
\hline 25 & 1.20 & 0.0000 & 0.1133 & 0.64 & 0.00420 & 0.00000 & 0.00652 & 2.12 & 0.00143 & 0.0000316 & 0.0000107 \\
\hline 26 & 1.25 & 0.0397 & 0.0883 & 0.40 & 0.01010 & 0.00039 & 0.00000 & 1.79 & 0.00132 & 0.0000000 & 0.0000109 \\
\hline 27 & 1.30 & 0.0258 & 0.1097 & 0.39 & 0.00000 & 0.00000 & 0.00354 & 1.74 & 0.00085 & 0.0000000 & 0.0000141 \\
\hline 28 & 1.35 & 0.0000 & 0.0782 & 0.38 & 0.00189 & 0.00048 & 0.00218 & 1.75 & 0.00071 & 0.0000000 & 0.0000000 \\
\hline 29 & 1.40 & 0.0000 & 0.1138 & 0.43 & 0.00260 & 0.00000 & 0.00450 & 1.69 & 0.00059 & 0.0000408 & 0.0000000 \\
\hline 30 & 1.45 & 0.0017 & 0.0780 & 0.46 & 0.01305 & 0.00157 & 0.00223 & 2.05 & 0.00066 & 0.0000000 & 0.0000000 \\
\hline 31 & 1.50 & 0.0011 & 0.0885 & 0.50 & 0.00000 & 0.00000 & 0.00354 & 2.25 & 0.00128 & 0.0000000 & 0.0000000 \\
\hline
\end{tabular}




\begin{tabular}{|c|c|c|c|c|c|c|c|c|c|c|c|}
\hline \multirow{2}{*}{$\begin{array}{c}\text { Spot } \\
\text { Number }\end{array}$} & \multirow{2}{*}{ Distance from inner shell $(\mathrm{mm})$} & \multicolumn{10}{|c|}{ KD1B nacreous layer transect N3 corrected data $(\mathrm{mmol} / \mathrm{mol})$} \\
\hline & & $\mathrm{Li} / \mathrm{Ca}$ & $\mathrm{B} / \mathrm{Ca}$ & $\mathrm{Mg} / \mathrm{Ca}$ & $\mathbf{A l} / \mathbf{C a}$ & $\mathrm{Mn} / \mathrm{Ca}$ & $\mathrm{Zn} / \mathrm{Ca}$ & $\mathrm{Sr} / \mathrm{Ca}$ & $\mathrm{Ba} / \mathrm{Ca}$ & $\mathrm{Pb} / \mathrm{Ca}$ & $\mathrm{U} / \mathrm{Ca}$ \\
\hline 1 & 0.00 & 0.0000 & 0.0597 & 0.53 & 0.01239 & 0.00000 & 0.00193 & 1.80 & 0.00091 & 0.0016615 & 0.0000000 \\
\hline 2 & 0.05 & 0.0110 & 0.0330 & 0.56 & 0.00000 & 0.00000 & 0.00326 & 1.79 & 0.00076 & 0.0000000 & 0.0000004 \\
\hline 3 & 0.10 & 0.0171 & 0.0526 & 0.51 & 0.00000 & 0.00178 & 0.00000 & 1.50 & 0.00055 & 0.0000552 & 0.0001324 \\
\hline 4 & 0.15 & 0.0092 & 0.0626 & 0.51 & 0.00000 & 0.00039 & 0.00362 & 1.65 & 0.00073 & 0.0000343 & 0.0000000 \\
\hline 5 & 0.20 & 0.0298 & 0.0985 & 0.59 & 0.00000 & 0.00324 & 0.00292 & 1.81 & 0.00096 & 0.0000581 & 0.0000239 \\
\hline 6 & 0.25 & 0.0000 & 0.0631 & 0.57 & 0.00000 & 0.00000 & 0.00135 & 1.80 & 0.00066 & 0.0000413 & 0.0000026 \\
\hline 7 & 0.30 & 0.0092 & 0.0565 & 0.52 & 0.00000 & 0.00372 & 0.00355 & 1.74 & 0.00075 & 0.0000930 & 0.0000388 \\
\hline 8 & 0.35 & 0.0000 & 0.0651 & 0.53 & 0.00000 & 0.00117 & 0.00205 & 1.69 & 0.00081 & 0.0000000 & 0.0000000 \\
\hline 9 & 0.40 & 0.0051 & 0.0780 & 0.48 & 0.00000 & 0.00138 & 0.00180 & 1.72 & 0.00089 & 0.0003819 & 0.0000257 \\
\hline 10 & 0.45 & 0.0000 & 0.0479 & 0.50 & 0.02306 & 0.00101 & 0.00162 & 1.61 & 0.00077 & 0.0000000 & 0.0000163 \\
\hline 11 & 0.50 & 0.0262 & 0.0505 & 0.49 & 0.00326 & 0.00000 & 0.00774 & 1.50 & 0.00070 & 0.0012022 & 0.0000000 \\
\hline 12 & 0.55 & 0.0019 & 0.0569 & 0.53 & 0.00000 & 0.00000 & 0.00075 & 1.58 & 0.00071 & 0.0000000 & 0.0001823 \\
\hline 13 & 0.60 & 0.0000 & 0.0728 & 0.49 & 0.01107 & 0.00211 & 0.00467 & 1.72 & 0.00062 & 0.0000000 & 0.0000893 \\
\hline 14 & 0.65 & 0.0116 & 0.0572 & 0.44 & 0.00000 & 0.00000 & 0.00849 & 1.66 & 0.00064 & 0.0000242 & 0.0000000 \\
\hline 15 & 0.70 & 0.0000 & 0.0489 & 0.47 & 0.00000 & 0.00003 & 0.00000 & 1.63 & 0.00065 & 0.0000000 & 0.0001018 \\
\hline 16 & 0.75 & 0.0082 & 0.0851 & 0.42 & 0.00382 & 0.00000 & 0.00574 & 1.86 & 0.00070 & 0.0000386 & 0.0000000 \\
\hline 17 & 0.80 & 0.0476 & 0.0746 & 0.46 & 0.00000 & 0.00203 & 0.00275 & 1.89 & 0.00086 & 0.0014102 & 0.0000000 \\
\hline 18 & 0.85 & 0.0088 & 0.1085 & 0.41 & 0.01091 & 0.00000 & 0.00566 & 1.97 & 0.00092 & 0.0000159 & 0.0000000 \\
\hline 19 & 0.90 & 0.0162 & 0.0619 & 0.46 & 0.00000 & 0.00170 & 0.00020 & 1.98 & 0.00108 & 0.0000000 & 0.0000000 \\
\hline 20 & 0.95 & 0.0099 & 0.0685 & 0.51 & 0.00348 & 0.00000 & 0.00296 & 1.89 & 0.00116 & 0.0000000 & 0.0000000 \\
\hline
\end{tabular}


APPENDIX 5.2i $\quad$ K3A nacreous layer transect data

\begin{tabular}{|c|c|c|c|c|c|c|c|c|c|c|c|}
\hline \multirow{2}{*}{ Spot Number } & \multirow{2}{*}{ Distance from inner shell $(\mathrm{mm})$} & \multicolumn{10}{|c|}{$\mathrm{K} 3 \mathrm{~A}$ nacreous layer transect $\mathrm{N} 1$ corrected data $(\mathrm{mmol} / \mathrm{mol})$} \\
\hline & & $\mathrm{Li} / \mathrm{Ca}$ & $\mathrm{B} / \mathrm{Ca}$ & $\mathrm{Mg} / \mathrm{Ca}$ & $\mathbf{A l} / \mathbf{C a}$ & $\mathrm{Mn} / \mathrm{Ca}$ & $\mathrm{Zn} / \mathrm{Ca}$ & $\mathrm{Sr} / \mathrm{Ca}$ & $\mathrm{Ba} / \mathrm{Ca}$ & $\mathrm{Pb} / \mathrm{Ca}$ & $\mathrm{U} / \mathrm{Ca}$ \\
\hline 1 & 0.00 & 0.0000 & 0.0524 & 0.25 & 0.00000 & 0.00188 & 0.00947 & 1.68 & 0.00061 & 0.000275 & 0.0000000 \\
\hline 2 & 0.05 & 0.0000 & 0.0610 & 0.51 & 0.00000 & 0.00000 & 0.00300 & 2.13 & 0.00072 & 0.000396 & 0.0000000 \\
\hline 3 & 0.10 & 0.0360 & 0.0407 & 0.39 & 0.00166 & 0.00398 & 0.00628 & 1.80 & 0.00056 & 0.000438 & 0.0000087 \\
\hline 4 & 0.15 & 0.0016 & 0.0578 & 0.48 & 0.00000 & 0.00000 & 0.00668 & 1.90 & 0.00071 & 0.000395 & 0.0000000 \\
\hline 5 & 0.20 & 0.0014 & 0.1313 & 3.90 & 0.00000 & 0.00020 & 0.00562 & 2.65 & 0.00106 & 0.000278 & 0.0000252 \\
\hline 6 & 0.25 & 0.0124 & 0.2640 & 8.34 & 0.00615 & 0.00512 & 0.02749 & 4.12 & 0.00348 & 0.000540 & 0.0000004 \\
\hline 7 & 0.30 & 0.0178 & 1.9727 & 19.72 & 0.00976 & 0.02311 & 0.02968 & 4.49 & 0.00730 & 0.000314 & 0.0000000 \\
\hline 8 & 0.35 & 0.0006 & 0.0232 & 0.87 & 0.00129 & 0.00145 & 0.00489 & 2.72 & 0.00119 & 0.000300 & 0.0000012 \\
\hline 9 & 0.40 & 0.0151 & 0.0344 & 0.86 & 0.00000 & 0.00000 & 0.00805 & 1.79 & 0.00081 & 0.000220 & 0.0000029 \\
\hline 10 & 0.45 & 0.0204 & 0.0182 & 0.76 & 0.00078 & 0.00241 & 0.00320 & 1.70 & 0.00067 & 0.000219 & 0.0000004 \\
\hline 11 & 0.50 & 0.0000 & 0.0589 & 1.06 & 0.00000 & 0.00082 & 0.00270 & 1.83 & 0.00068 & 0.000126 & 0.0000000 \\
\hline 12 & 0.55 & 0.0072 & 0.0333 & 0.61 & 0.00000 & 0.00335 & 0.00272 & 1.60 & 0.00056 & 0.000222 & 0.0000090 \\
\hline 13 & 0.60 & 0.0000 & 0.0309 & 0.70 & 0.00000 & 0.00179 & 0.00000 & 1.87 & 0.00047 & 0.000041 & 0.0000000 \\
\hline 14 & 0.65 & 0.0090 & 0.0189 & 0.73 & 0.00412 & 0.00051 & 0.00583 & 1.81 & 0.00060 & 0.000149 & 0.0000058 \\
\hline 15 & 0.70 & 0.0087 & 0.0607 & 0.82 & 0.00256 & 0.00356 & 0.00156 & 2.03 & 0.00065 & 0.000058 & 0.0000000 \\
\hline 16 & 0.75 & 0.0000 & 0.0408 & 0.79 & 0.00000 & 0.00087 & 0.00438 & 2.03 & 0.00063 & 0.000137 & 0.0000000 \\
\hline 17 & 0.80 & 0.0000 & 0.0367 & 0.61 & 0.00000 & 0.00286 & 0.00341 & 2.20 & 0.00071 & 0.000016 & 0.0000035 \\
\hline 18 & 0.85 & 0.0105 & 0.0461 & 0.72 & 0.01125 & 0.00021 & 0.00192 & 2.04 & 0.00067 & 0.000092 & 0.0000000 \\
\hline 19 & 0.90 & 33.2205 & 15.1640 & 9.17 & 194.65587 & 4.28961 & 3.35728 & 2.85 & 1.52752 & 0.951116 & 0.8994688 \\
\hline 20 & 0.95 & 0.0173 & 0.0611 & 0.59 & 0.00000 & 0.00074 & 0.00840 & 2.17 & 0.00070 & 0.000008 & 0.0000000 \\
\hline 21 & 1.00 & 0.0036 & 0.0469 & 0.67 & 0.00000 & 0.00088 & 0.00324 & 1.91 & 0.00075 & 0.000074 & 0.0000001 \\
\hline 22 & 1.05 & 0.0269 & 0.0540 & 2.26 & 0.00559 & 0.00095 & 0.00658 & 2.66 & 0.00097 & 0.000100 & 0.0000076 \\
\hline 23 & 1.10 & 0.0159 & 0.0223 & 1.04 & 0.00000 & 0.00000 & 0.00296 & 2.07 & 0.00068 & 0.000085 & 0.0000000 \\
\hline 24 & 1.15 & 0.0086 & 0.0400 & 1.12 & 0.00628 & 0.00129 & 0.00429 & 2.69 & 0.00098 & 0.000088 & 0.0000183 \\
\hline 25 & 1.20 & 0.0005 & 0.0518 & 12.72 & 0.00903 & 0.00700 & 0.00960 & 2.06 & 0.00091 & 0.000037 & 0.0000085 \\
\hline 26 & 1.25 & 0.0252 & 0.0089 & 7.15 & 0.00000 & 0.00469 & 0.00494 & 1.88 & 0.00064 & 0.000000 & 0.0000000 \\
\hline 27 & 1.30 & 0.0370 & 0.0000 & 8.10 & 0.01080 & 0.00497 & 0.00159 & 1.69 & 0.00060 & 0.000067 & 0.0000112 \\
\hline 28 & 1.35 & 0.0000 & 0.0000 & 8.29 & 0.00459 & 0.00020 & 0.00620 & 2.47 & 0.00085 & 0.000068 & 0.0000094 \\
\hline 29 & 1.40 & 0.0000 & 0.0497 & 0.86 & 0.00000 & 0.00287 & 0.00676 & 3.66 & 0.00136 & 0.000102 & 0.0000353 \\
\hline 30 & 1.45 & 0.0112 & 0.0625 & 1.77 & 0.01814 & 0.00010 & 0.00522 & 3.03 & 0.00134 & 0.000023 & 0.0000671 \\
\hline
\end{tabular}




\begin{tabular}{|c|c|c|c|c|c|c|c|c|c|c|c|}
\hline \multirow{2}{*}{ Spot Number } & \multirow{2}{*}{ Distance from inner shell (mm) } & \multicolumn{10}{|c|}{$\mathrm{K} 3 \mathrm{~A}$ nacreous layer transect $\mathrm{N} 2$ corrected data $(\mathrm{mmol} / \mathrm{mol})$} \\
\hline & & $\mathrm{Li} / \mathrm{Ca}$ & $\mathrm{B} / \mathrm{Ca}$ & $\mathrm{Mg} / \mathrm{Ca}$ & $\mathbf{A l} / \mathbf{C a}$ & $\mathrm{Mn} / \mathrm{Ca}$ & $\mathrm{Zn} / \mathrm{Ca}$ & $\mathrm{Sr} / \mathrm{Ca}$ & $\mathrm{Ba} / \mathrm{Ca}$ & $\mathrm{Pb} / \mathrm{Ca}$ & $\mathrm{U} / \mathrm{Ca}$ \\
\hline 1 & 0.00 & 0.0092 & 0.0622 & 0.36 & 0.00000 & 0.00431 & 0.00619 & 1.78 & 0.00171 & 0.000060 & 0.0000000 \\
\hline 2 & 0.05 & 0.0254 & 0.0574 & 0.30 & 0.00000 & 0.00031 & 0.00091 & 1.71 & 0.00081 & 0.000018 & 0.0000000 \\
\hline 3 & 0.10 & 0.0150 & 0.0526 & 0.31 & 0.00000 & 0.00022 & 0.00000 & 1.54 & 0.00052 & 0.000102 & 0.0000035 \\
\hline 4 & 0.15 & 0.0000 & 0.0518 & 0.30 & 0.00000 & 0.00000 & 0.00369 & 1.73 & 0.00059 & 0.000000 & 0.0000000 \\
\hline 5 & 0.20 & 0.0134 & 0.0360 & 0.32 & 0.00320 & 0.00100 & 0.00000 & 1.53 & 0.00050 & 0.000012 & 0.0000080 \\
\hline 6 & 0.25 & 0.0095 & 0.0371 & 0.39 & 0.00000 & 0.00070 & 0.00174 & 1.50 & 0.00047 & 0.000108 & 0.0000000 \\
\hline 7 & 0.30 & 0.0152 & 0.0275 & 0.43 & 0.00180 & 0.00329 & 0.00357 & 1.57 & 0.00045 & 0.000000 & 0.0000000 \\
\hline 8 & 0.35 & 0.0021 & 0.0644 & 0.54 & 0.00000 & 0.00242 & 0.00322 & 1.64 & 0.00052 & 0.000000 & 0.0000000 \\
\hline 9 & 0.40 & 0.0068 & 3.5386 & 28.60 & 0.00000 & 0.02498 & 0.01152 & 4.22 & 0.00278 & 0.000044 & 0.0000000 \\
\hline 10 & 0.45 & 0.0134 & 7.3680 & 43.85 & 0.00000 & 0.02853 & 0.01275 & 4.69 & 0.00277 & 0.000111 & 0.0000060 \\
\hline 11 & 0.50 & 0.0106 & 0.0472 & 1.06 & 0.00000 & 0.00175 & 0.00053 & 2.06 & 0.00057 & 0.000051 & 0.0000242 \\
\hline 12 & 0.55 & 0.0324 & 0.0913 & 1.30 & 0.00000 & 0.00000 & 0.00706 & 2.34 & 0.00075 & 0.000092 & 0.0000041 \\
\hline 13 & 0.60 & 0.0155 & 0.0587 & 0.66 & 0.00845 & 0.00018 & 0.00106 & 1.49 & 0.00040 & 0.000000 & 0.0000000 \\
\hline 14 & 0.65 & 0.0053 & 0.0529 & 0.60 & 0.00000 & 0.00160 & 0.00325 & 1.51 & 0.00044 & 0.000000 & 0.0000000 \\
\hline 15 & 0.70 & 0.0167 & 0.0635 & 0.64 & 0.00208 & 0.00222 & 0.00045 & 1.60 & 0.00041 & 0.000029 & 0.0000112 \\
\hline 16 & 0.75 & 0.0000 & 0.0468 & 0.65 & 0.00334 & 0.00000 & 0.00505 & 1.50 & 0.00034 & 0.000056 & 0.0000000 \\
\hline 17 & 0.80 & 0.0083 & 0.0386 & 0.54 & 0.00000 & 0.00029 & 0.00165 & 1.61 & 0.00043 & 0.000078 & 0.0000000 \\
\hline 18 & 0.85 & 0.0179 & 0.0566 & 0.65 & 0.00516 & 0.00335 & 0.00359 & 1.50 & 0.00038 & 0.000082 & 0.0000000 \\
\hline 19 & 0.90 & 0.0000 & 0.0353 & 0.65 & 0.00000 & 0.00373 & 0.00000 & 1.71 & 0.00018 & 0.000000 & 0.0000000 \\
\hline 20 & 0.95 & 0.0175 & 0.0534 & 0.67 & 0.00093 & 0.00000 & 0.00072 & 1.64 & 0.00038 & 0.000081 & 0.0000136 \\
\hline 21 & 1.00 & 0.0030 & 0.0581 & 0.68 & 0.00000 & 0.00256 & 0.00000 & 1.68 & 0.00046 & 0.000000 & 0.0000000 \\
\hline 22 & 1.05 & 0.0000 & 0.0653 & 0.60 & 0.00000 & 0.00000 & 0.00216 & 1.79 & 0.00052 & 0.000000 & 0.0000031 \\
\hline 23 & 1.10 & 0.0166 & 0.0627 & 0.56 & 0.00340 & 0.00000 & 0.00000 & 1.83 & 0.00045 & 0.000027 & 0.0000000 \\
\hline 24 & 1.15 & 0.0140 & 0.0452 & 0.51 & 0.00000 & 0.00019 & 0.00406 & 1.55 & 0.00038 & 0.000065 & 0.0000036 \\
\hline 25 & 1.20 & 0.0092 & 0.0578 & 0.54 & 0.00000 & 0.00105 & 0.00227 & 1.65 & 0.00033 & 0.000000 & 0.0000000 \\
\hline 26 & 1.25 & 0.0037 & 0.0518 & 0.46 & 0.00147 & 0.00297 & 0.00363 & 1.87 & 0.00046 & 0.000004 & 0.0000000 \\
\hline 27 & 1.30 & 0.0163 & 0.0505 & 0.48 & 0.00000 & 0.00057 & 0.00392 & 1.88 & 0.00050 & 0.000132 & 0.0000000 \\
\hline 28 & 1.35 & 0.0328 & 0.0463 & 0.44 & 0.00246 & 0.00014 & 0.00000 & 1.88 & 0.00048 & 0.000000 & 0.0000177 \\
\hline 29 & 1.40 & 0.0074 & 0.0539 & 0.35 & 0.00000 & 0.00022 & 0.00629 & 1.80 & 0.00051 & 0.000011 & 0.0000055 \\
\hline 30 & 1.45 & 0.0180 & 0.0517 & 0.53 & 0.00062 & 0.00000 & 0.00261 & 1.84 & 0.00058 & 0.000030 & 0.0000000 \\
\hline 31 & 1.50 & 0.0000 & 0.0488 & 0.53 & 0.00000 & 0.00170 & 0.00236 & 2.08 & 0.00038 & 0.000000 & 0.0000000 \\
\hline 32 & 1.55 & 0.0223 & 0.1060 & 0.88 & 0.00000 & 0.00177 & 0.00209 & 2.56 & 0.00084 & 0.000000 & 0.0000000 \\
\hline
\end{tabular}




\begin{tabular}{|c|c|c|c|c|c|c|c|c|c|c|c|}
\hline \multirow{2}{*}{ Spot Number } & \multirow{2}{*}{ Distance from inner shell (mm) } & \multicolumn{10}{|c|}{ K3A nacreous layer transect N3corrected data $(\mathrm{mmol} / \mathrm{mol})$} \\
\hline & & $\mathrm{Li} / \mathrm{Ca}$ & $\mathrm{B} / \mathrm{Ca}$ & $\mathrm{Mg} / \mathrm{Ca}$ & $\mathbf{A l} / \mathbf{C a}$ & $\mathrm{Mn} / \mathrm{Ca}$ & $\mathrm{Zn} / \mathrm{Ca}$ & $\mathrm{Sr} / \mathrm{Ca}$ & $\mathrm{Ba} / \mathrm{Ca}$ & $\mathrm{Pb} / \mathrm{Ca}$ & $\mathrm{U} / \mathrm{Ca}$ \\
\hline 1 & 0.00 & 0.0000 & 0.0791 & 0.61 & 0.00000 & 0.00291 & 0.00455 & 1.96 & 0.00069 & 0.000000 & 0.0000000 \\
\hline 2 & 0.05 & 0.0122 & 0.0865 & 0.73 & 0.00800 & 0.00137 & 0.00602 & 2.02 & 0.00057 & 0.000000 & 0.0000116 \\
\hline 3 & 0.10 & 0.0129 & 0.0733 & 0.66 & 0.00188 & 0.00421 & 0.00144 & 1.73 & 0.00049 & 0.000068 & 0.0000109 \\
\hline 4 & 0.15 & 0.0000 & 0.0298 & 0.67 & 0.00967 & 0.00303 & 0.00038 & 1.74 & 0.00053 & 0.000082 & 0.0000000 \\
\hline 5 & 0.20 & 0.0238 & 0.0446 & 0.49 & 0.00000 & 0.00018 & 0.00000 & 1.62 & 0.00045 & 0.000026 & 0.0000189 \\
\hline 6 & 0.25 & 0.0026 & 0.0665 & 0.62 & 0.00024 & 0.00037 & 0.00000 & 1.72 & 0.00047 & 0.000000 & 0.0000039 \\
\hline 7 & 0.30 & 0.0261 & 0.0477 & 0.60 & 0.00000 & 0.00378 & 0.00139 & 1.81 & 0.00040 & 0.000000 & 0.0000000 \\
\hline 8 & 0.35 & 0.0043 & 0.0589 & 1.06 & 0.00723 & 0.00000 & 0.00579 & 2.34 & 0.00080 & 0.000033 & 0.0000000 \\
\hline 9 & 0.40 & 0.0174 & 0.0196 & 12.92 & 0.00029 & 0.00316 & 0.00471 & 1.34 & 0.00043 & 0.000071 & 0.0000000 \\
\hline 10 & 0.45 & 0.0069 & 0.0123 & 0.31 & 0.00000 & 0.00000 & 0.00920 & 1.96 & 0.00105 & 0.000022 & 0.0000000 \\
\hline 11 & 0.50 & 0.0214 & 0.0781 & 0.22 & 0.00000 & 0.00000 & 0.00297 & 1.64 & 0.00066 & 0.000085 & 0.0000040 \\
\hline 12 & 0.55 & 0.0045 & 0.0283 & 0.32 & 0.00761 & 0.00000 & 0.00141 & 1.74 & 0.00064 & 0.000000 & 0.0000000 \\
\hline 13 & 0.60 & 0.0000 & 0.0864 & 0.71 & 0.00000 & 0.00000 & 0.00000 & 1.91 & 0.00061 & 0.000073 & 0.0000080 \\
\hline 14 & 0.65 & 0.0061 & 6.5111 & 33.49 & 0.00145 & 0.02104 & 0.01304 & 4.85 & 0.00227 & 0.000628 & 0.0000117 \\
\hline 15 & 0.70 & 0.0051 & 0.0376 & 0.40 & 0.00000 & 0.00000 & 0.00000 & 1.48 & 0.00049 & 0.000064 & 0.0000064 \\
\hline 16 & 0.75 & 0.0039 & 0.0317 & 0.28 & 0.00000 & 0.00000 & 0.00546 & 1.59 & 0.00041 & 0.000000 & 0.0000000 \\
\hline 17 & 0.80 & 0.0000 & 0.0236 & 0.56 & 0.00218 & 0.00031 & 0.00239 & 1.59 & 0.00052 & 0.000114 & 0.0000066 \\
\hline 18 & 0.85 & 0.0056 & 0.0637 & 0.53 & 0.00577 & 0.00000 & 0.00775 & 1.56 & 0.00055 & 0.000058 & 0.0000000 \\
\hline 19 & 0.90 & 0.0071 & 0.0280 & 0.49 & 0.00000 & 0.00000 & 0.00404 & 1.54 & 0.00050 & 0.000059 & 0.0000027 \\
\hline 20 & 0.95 & 0.0202 & 0.0724 & 0.90 & 0.00000 & 0.00000 & 0.00167 & 2.02 & 0.00066 & 0.000037 & 0.0000000 \\
\hline 21 & 1.00 & 0.0019 & 0.0286 & 0.55 & 0.01014 & 0.00000 & 0.00339 & 1.43 & 0.00034 & 0.000000 & 0.0000000 \\
\hline 22 & 1.05 & 0.9471 & 681.5120 & 3382.44 & 0.00000 & 1.29877 & 0.98715 & 1.82 & 0.00000 & 0.000000 & 0.0000000 \\
\hline 23 & 1.10 & 0.0019 & 0.0732 & 0.60 & 0.00745 & 0.00000 & 0.00336 & 1.66 & 0.00056 & 0.000025 & 0.0000000 \\
\hline 24 & 1.15 & 0.0146 & 0.0782 & 0.54 & 0.00000 & 0.00000 & 0.00065 & 1.74 & 0.00057 & 0.000065 & 0.0000000 \\
\hline 25 & 1.20 & 0.0031 & 0.0560 & 0.48 & 0.00872 & 0.00265 & 0.00254 & 1.58 & 0.00055 & 0.000131 & 0.0000228 \\
\hline 26 & 1.25 & 0.0000 & 0.0739 & 0.46 & 0.00239 & 0.00000 & 0.00785 & 1.81 & 0.00056 & 0.000027 & 0.0000089 \\
\hline 27 & 1.30 & 0.0000 & 0.0639 & 0.48 & 0.00000 & 0.00000 & 0.00306 & 1.79 & 0.00053 & 0.000004 & 0.0000172 \\
\hline
\end{tabular}




\begin{tabular}{|c|c|c|c|c|c|c|c|c|c|c|c|}
\hline \multirow{2}{*}{ Spot Number } & \multirow{2}{*}{ Distance from inner shell $(\mathrm{mm})$} & \multicolumn{10}{|c|}{$\mathrm{K} 3 \mathrm{~A}$ nacreous layer transect $\mathrm{N} 4$ corrected data $(\mathrm{mmol} / \mathrm{mol})$} \\
\hline & & $\mathrm{Li} / \mathrm{Ca}$ & $\mathrm{B} / \mathrm{Ca}$ & $\mathrm{Mg} / \mathrm{Ca}$ & $\mathrm{Al} / \mathrm{Ca}$ & $\mathrm{Mn} / \mathrm{Ca}$ & $\mathrm{Zn} / \mathrm{Ca}$ & $\mathrm{Sr} / \mathrm{Ca}$ & $\mathrm{Ba} / \mathrm{Ca}$ & $\mathrm{Pb} / \mathrm{Ca}$ & $\mathrm{U} / \mathrm{Ca}$ \\
\hline 1 & 0.00 & 0.0036 & 0.0425 & 0.41 & 0.00000 & 0.02801 & 0.00000 & 2.97 & 0.00398 & 0.000000 & 0.0000000 \\
\hline 2 & 0.05 & 0.0040 & 0.0338 & 0.25 & 0.00080 & 0.00431 & 0.00744 & 1.61 & 0.00061 & 0.000000 & 0.0000000 \\
\hline 3 & 0.10 & 0.0000 & 0.0337 & 0.26 & 0.00000 & 0.00000 & 0.00531 & 1.62 & 0.00057 & 0.000110 & 0.0000195 \\
\hline 4 & 0.15 & 0.0000 & 0.0389 & 0.32 & 0.00882 & 0.00021 & 0.00007 & 1.70 & 0.00055 & 0.000060 & 0.0000000 \\
\hline 5 & 0.20 & 0.0301 & 13.2470 & 83.46 & 0.00000 & 0.06245 & 0.00905 & 3.94 & 0.00212 & 0.000000 & 0.0000000 \\
\hline 6 & 0.25 & 0.0016 & 0.0609 & 0.28 & 0.00446 & 0.00000 & 0.00178 & 1.78 & 0.00066 & 0.000039 & 0.0000122 \\
\hline 7 & 0.30 & 0.0118 & 0.0515 & 0.37 & 0.00339 & 0.00125 & 0.00633 & 1.97 & 0.00046 & 0.000000 & 0.0000000 \\
\hline 8 & 0.35 & 0.0122 & 0.0694 & 0.43 & 0.00822 & 0.00223 & 0.00497 & 1.55 & 0.00044 & 0.000055 & 0.0000000 \\
\hline 9 & 0.40 & 0.0000 & 0.0534 & 0.50 & 0.00476 & 0.00038 & 0.00354 & 1.58 & 0.00045 & 0.000115 & 0.0000018 \\
\hline 10 & 0.45 & 0.0196 & 13.7553 & 59.44 & 0.00674 & 0.02645 & 0.00494 & 2.78 & 0.00107 & 0.000008 & 0.0000000 \\
\hline 11 & 0.50 & 0.0192 & 0.0757 & 0.60 & 0.00730 & 0.00398 & 0.00909 & 1.63 & 0.00056 & 0.000096 & 0.0000000 \\
\hline 12 & 0.55 & 0.0004 & 0.0878 & 0.58 & 0.00000 & 0.00368 & 0.00497 & 1.50 & 0.00046 & 0.000000 & 0.0000000 \\
\hline 13 & 0.60 & 0.0000 & 0.0787 & 0.58 & 0.00000 & 0.00025 & 0.00000 & 1.50 & 0.00030 & 0.000079 & 0.0000000 \\
\hline 14 & 0.65 & 0.0092 & 0.0784 & 0.53 & 0.00000 & 0.00485 & 0.00330 & 1.60 & 0.00039 & 0.000038 & 0.0000000 \\
\hline 15 & 0.70 & 0.0087 & 0.0541 & 0.55 & 0.00000 & 0.00356 & 0.00204 & 1.67 & 0.00055 & 0.000084 & 0.0000177 \\
\hline 16 & 0.75 & 0.0000 & 0.0215 & 0.47 & 0.00000 & 0.00000 & 0.00547 & 1.54 & 0.00041 & 0.000063 & 0.0000000 \\
\hline 17 & 0.80 & 0.0261 & 0.0968 & 0.42 & 0.00392 & 0.00107 & 0.00000 & 1.53 & 0.00042 & 0.000015 & 0.0000099 \\
\hline 18 & 0.85 & 0.0000 & 0.0718 & 0.42 & 0.00000 & 0.00107 & 0.00075 & 1.43 & 0.00041 & 0.000006 & 0.0000139 \\
\hline 19 & 0.90 & 0.0085 & 0.0520 & 0.42 & 0.00188 & 0.00000 & 0.00000 & 1.52 & 0.00042 & 0.000000 & 0.0000000 \\
\hline 20 & 0.95 & 0.0227 & 0.0533 & 0.46 & 0.01079 & 0.00181 & 0.00687 & 1.57 & 0.00035 & 0.000074 & 0.0000218 \\
\hline 21 & 1.00 & 0.0000 & 0.0498 & 0.34 & 0.00769 & 0.00000 & 0.00440 & 1.64 & 0.00046 & 0.000051 & 0.0000083 \\
\hline 22 & 1.05 & 0.0060 & 0.0683 & 0.30 & 0.01533 & 0.00069 & 0.00000 & 1.54 & 0.00040 & 0.000046 & 0.0000070 \\
\hline 23 & 1.10 & 0.0153 & 0.0506 & 0.31 & 0.00266 & 0.00414 & 0.00582 & 1.55 & 0.00052 & 0.000000 & 0.0000000 \\
\hline 24 & 1.15 & 0.0129 & 0.0393 & 0.26 & 0.00000 & 0.00114 & 0.00532 & 1.55 & 0.00037 & 0.000013 & 0.0000000 \\
\hline 25 & 1.20 & 0.0000 & 0.0572 & 0.29 & 0.00000 & 0.00000 & 0.00000 & 1.67 & 0.00051 & 0.000018 & 0.0000000 \\
\hline 26 & 1.25 & 0.0236 & 0.0500 & 0.32 & 0.00849 & 0.00225 & 0.00291 & 1.77 & 0.00050 & 0.000084 & 0.0000072 \\
\hline 27 & 1.30 & 0.0004 & 0.0550 & 0.33 & 0.00896 & 0.00069 & 0.00487 & 1.77 & 0.00048 & 0.000000 & 0.0000000 \\
\hline 28 & 1.35 & 0.0041 & 0.0471 & 0.37 & 0.00000 & 0.00203 & 0.00000 & 1.83 & 0.00051 & 0.000074 & 0.0000035 \\
\hline 29 & 1.40 & 0.0166 & 0.0545 & 0.49 & 0.00000 & 0.00401 & 0.00207 & 2.12 & 0.00074 & 0.000057 & 0.0000000 \\
\hline
\end{tabular}


APPENDIX 5.2j $\quad$ K1A1 nacreous layer transect data

\begin{tabular}{|c|c|c|c|c|c|c|c|c|c|c|c|}
\hline \multirow{2}{*}{ Spot Number } & \multirow{2}{*}{ Distance from inner shell (mm) } & \multicolumn{10}{|c|}{ K1A1 nacreous layer transect $\mathrm{N} 1$ corrected data $(\mathrm{mmol} / \mathrm{mol})$} \\
\hline & & $\mathrm{Li} / \mathrm{Ca}$ & $\mathrm{B} / \mathrm{Ca}$ & $\mathrm{Mg} / \mathrm{Ca}$ & $\mathbf{A l} / \mathbf{C a}$ & $\mathrm{Mn} / \mathrm{Ca}$ & $\mathrm{Zn} / \mathrm{Ca}$ & $\mathrm{Sr} / \mathrm{Ca}$ & $\mathrm{Ba} / \mathrm{Ca}$ & $\mathrm{Pb} / \mathrm{Ca}$ & $\mathrm{U} / \mathrm{Ca}$ \\
\hline 1 & 0.00 & 0.0342 & 0.0402 & 0.24 & 0.00000 & 0.00242 & 0.0238 & 2.41 & 0.00145 & 0.000255 & 0.0000000 \\
\hline 2 & 0.05 & 0.0000 & 0.0446 & 0.32 & 0.00000 & 0.00696 & 0.0261 & 2.54 & 0.00186 & 0.000302 & 0.0000208 \\
\hline 3 & 0.10 & 0.0000 & 0.0471 & 0.31 & 0.00000 & 0.00410 & 0.0214 & 2.21 & 0.00143 & 0.000267 & 0.0000000 \\
\hline 4 & 0.15 & 0.0000 & 0.0470 & 0.34 & 0.00000 & 0.00505 & 0.0171 & 2.38 & 0.00161 & 0.000350 & 0.0000000 \\
\hline 5 & 0.20 & 0.0103 & 0.0512 & 0.28 & 0.00000 & 0.00678 & 0.0179 & 2.28 & 0.00160 & 0.000232 & 0.0000000 \\
\hline 6 & 0.25 & 0.0000 & 0.0295 & 0.27 & 0.00000 & 0.00474 & 0.0142 & 2.05 & 0.00158 & 0.000235 & 0.0000000 \\
\hline 7 & 0.30 & 0.0141 & 0.0205 & 0.32 & 0.00000 & 0.00482 & 0.0145 & 2.27 & 0.00143 & 0.000237 & 0.0000294 \\
\hline 8 & 0.35 & 0.0376 & 0.0572 & 0.73 & 0.00000 & 0.00783 & 0.0172 & 2.51 & 0.00163 & 0.000260 & 0.0000165 \\
\hline 9 & 0.40 & 0.0150 & 0.0656 & 1.08 & 0.00000 & 0.00639 & 0.0188 & 2.57 & 0.00188 & 0.000333 & 0.0000074 \\
\hline 10 & 0.45 & 0.0000 & 0.0806 & 1.50 & 0.00144 & 0.00356 & 0.0060 & 3.26 & 0.00210 & 0.000334 & 0.0000106 \\
\hline
\end{tabular}

\begin{tabular}{|c|c|c|c|c|c|c|c|c|c|c|c|}
\hline \multirow{2}{*}{ Spot Number } & \multirow{2}{*}{ Distance from inner shell $(\mathrm{mm})$} & \multicolumn{10}{|c|}{ K1A1 nacreous layer transect $\mathrm{N} 2$ corrected data $(\mathrm{mmol} / \mathrm{mol})$} \\
\hline & & $\mathrm{Li} / \mathrm{Ca}$ & $\mathrm{B} / \mathrm{Ca}$ & $\mathrm{Mg} / \mathrm{Ca}$ & $\mathrm{Al} / \mathrm{Ca}$ & $\mathrm{Mn} / \mathrm{Ca}$ & $\mathrm{Zn} / \mathrm{Ca}$ & $\mathrm{Sr} / \mathrm{Ca}$ & $\mathrm{Ba} / \mathrm{Ca}$ & $\mathrm{Pb} / \mathrm{Ca}$ & $\mathrm{U} / \mathrm{Ca}$ \\
\hline 1 & 0.00 & 0.0000 & 0.0000 & 0.26 & 0.0007 & 0.00000 & 0.0115 & 2.08 & 0.00153 & 0.000148 & 0.0000000 \\
\hline 2 & 0.05 & 0.0022 & 2.8317 & 19.75 & 0.0125 & 0.00995 & 0.0318 & 3.29 & 0.00219 & 0.000122 & 0.0000000 \\
\hline 3 & 0.10 & 0.0000 & 11.3518 & 93.35 & 0.0000 & 0.05009 & 0.0880 & 3.29 & 0.00305 & 0.000369 & 0.0000000 \\
\hline 4 & 0.15 & 0.0000 & 0.0000 & 0.34 & 0.0000 & 0.00000 & 0.0373 & 1.90 & 0.00177 & 0.000000 & 0.0000000 \\
\hline 5 & 0.20 & 0.0140 & 0.0200 & 0.47 & 0.0000 & 0.00000 & 0.0063 & 2.66 & 0.00167 & 0.000122 & 0.0000000 \\
\hline 6 & 0.25 & 0.0000 & 0.0257 & 0.29 & 0.0029 & 0.00000 & 0.0177 & 2.12 & 0.00178 & 0.000029 & 0.0000000 \\
\hline 7 & 0.30 & 0.0092 & 0.0416 & 0.31 & 0.0101 & 0.00028 & 0.0180 & 1.89 & 0.00176 & 0.000083 & 0.0000000 \\
\hline 8 & 0.35 & 0.0000 & 0.0000 & 0.32 & 0.0058 & 0.00017 & 0.0241 & 1.96 & 0.00175 & 0.000148 & 0.0000000 \\
\hline 9 & 0.40 & 0.0000 & 0.0462 & 0.33 & 0.0118 & 0.00644 & 0.0357 & 2.05 & 0.00199 & 0.000112 & 0.0000272 \\
\hline 10 & 0.45 & 0.0258 & 0.0758 & 0.54 & 0.0092 & 0.00969 & 0.0300 & 2.09 & 0.00209 & 0.000094 & 0.0000000 \\
\hline 11 & 0.50 & 0.0000 & 5.3192 & 22.38 & 0.1233 & 0.02133 & 0.0535 & 3.21 & 0.00158 & 0.000200 & 0.0000321 \\
\hline 12 & 0.55 & 0.0000 & 1.3368 & 8.84 & 0.0000 & 0.01196 & 0.0280 & 3.44 & 0.00234 & 0.000000 & 0.0000351 \\
\hline 13 & 0.60 & 0.0146 & 0.0735 & 0.73 & 0.0310 & 0.00789 & 0.0118 & 2.35 & 0.00166 & 0.000019 & 0.0000000 \\
\hline 14 & 0.65 & 0.0000 & 0.0674 & 0.54 & 0.0161 & 0.00390 & 0.0011 & 2.12 & 0.00148 & 0.000056 & 0.0000264 \\
\hline 15 & 0.70 & 0.0123 & 0.1088 & 0.67 & 0.0000 & 0.00914 & 0.0174 & 2.55 & 0.00189 & 0.000115 & 0.0000000 \\
\hline 16 & 0.75 & 0.0232 & 0.1444 & 1.11 & 0.0245 & 0.00269 & 0.0137 & 2.68 & 0.00171 & 0.000245 & 0.0000000 \\
\hline 17 & 0.80 & 0.0000 & 0.3314 & 2.92 & 0.0000 & 0.00039 & 0.0135 & 4.41 & 0.00223 & 0.000138 & 0.0000251 \\
\hline
\end{tabular}




\begin{tabular}{|c|c|c|c|c|c|c|c|c|c|c|c|}
\hline \multirow{2}{*}{ Spot Number } & \multirow{2}{*}{ Distance from inner shell (mm) } & \multicolumn{10}{|c|}{ K1A1 nacreous layer transect $\mathrm{N} 3$ corrected data $(\mathrm{mmol} / \mathrm{mol})$} \\
\hline & & $\mathrm{Li} / \mathrm{Ca}$ & $\mathrm{B} / \mathrm{Ca}$ & $\mathrm{Mg} / \mathrm{Ca}$ & $\mathbf{A l} / \mathbf{C a}$ & $\mathrm{Mn} / \mathrm{Ca}$ & $\mathrm{Zn} / \mathrm{Ca}$ & $\mathrm{Sr} / \mathrm{Ca}$ & $\mathrm{Ba} / \mathrm{Ca}$ & $\mathrm{Pb} / \mathrm{Ca}$ & $\mathrm{U} / \mathrm{Ca}$ \\
\hline 1 & 0.00 & 0.0000 & 0.0389 & 0.34 & 0.00000 & 0.01140 & 0.0119 & 2.41 & 0.00211 & 0.000429 & 0.0000041 \\
\hline 2 & 0.05 & 0.0000 & 0.0000 & 0.44 & 0.00000 & 0.00890 & 0.0291 & 2.06 & 0.00202 & 0.000378 & 0.0000076 \\
\hline 3 & 0.10 & 0.0000 & 0.1299 & 0.98 & 0.00000 & 0.00398 & 0.0119 & 2.95 & 0.00174 & 0.000300 & 0.0000000 \\
\hline 4 & 0.15 & 0.0000 & 0.0179 & 0.48 & 0.00000 & 0.00134 & 0.0033 & 1.90 & 0.00143 & 0.000278 & 0.0000039 \\
\hline 5 & 0.20 & 0.0509 & 8.3875 & 50.75 & 0.00000 & 0.03876 & 0.0228 & 6.14 & 0.00707 & 0.000330 & 0.0000060 \\
\hline 6 & 0.25 & 0.0000 & 0.0314 & 0.60 & 0.00000 & 0.01102 & 0.0189 & 2.01 & 0.00189 & 0.000224 & 0.0000000 \\
\hline 7 & 0.30 & 0.0092 & 0.0347 & 0.53 & 0.00000 & 0.00913 & 0.0116 & 1.98 & 0.00158 & 0.000223 & 0.0000000 \\
\hline 8 & 0.35 & 0.0000 & 0.0437 & 0.63 & 0.00000 & 0.00652 & 0.0154 & 1.94 & 0.00202 & 0.000200 & 0.0000000 \\
\hline 9 & 0.40 & 0.2937 & 64.7668 & 491.55 & 0.00000 & 0.13388 & 0.2839 & 3.84 & 0.00390 & 0.000575 & 0.0000000 \\
\hline 10 & 0.45 & 0.0000 & 0.0322 & 0.74 & 0.00000 & 0.00634 & 0.0196 & 2.13 & 0.00201 & 0.000294 & 0.0000000 \\
\hline 11 & 0.50 & 0.0000 & 0.0237 & 0.56 & 0.00000 & 0.01308 & 0.0168 & 2.06 & 0.00163 & 0.000366 & 0.0000224 \\
\hline 12 & 0.55 & 0.0224 & 0.1012 & 0.97 & 0.00000 & 0.00101 & 0.0000 & 2.92 & 0.00146 & 0.000235 & 0.0000000 \\
\hline 13 & 0.60 & 0.0296 & 0.0698 & 0.53 & 0.00000 & 0.00930 & 0.0043 & 2.09 & 0.00146 & 0.000375 & 0.0000029 \\
\hline 14 & 0.65 & 0.0000 & 0.0797 & 0.48 & 0.00000 & 0.00204 & 0.0091 & 2.08 & 0.00139 & 0.000342 & 0.0000050 \\
\hline 15 & 0.70 & 0.0146 & 0.0566 & 0.77 & 0.00047 & 0.00411 & 0.0091 & 2.05 & 0.00131 & 0.000355 & 0.0000000 \\
\hline 16 & 0.75 & 0.0000 & 19.0908 & 84.35 & 0.00000 & 0.04349 & 0.0905 & 3.69 & 0.00201 & 0.000109 & 0.0000000 \\
\hline 17 & 0.80 & 0.0000 & 0.4513 & 2.92 & 0.00000 & 0.00721 & 0.0568 & 4.14 & 0.00377 & 0.000953 & 0.0000040 \\
\hline 18 & 0.85 & 0.0000 & 0.0511 & 0.56 & 0.00000 & 0.00704 & 0.0226 & 2.02 & 0.00164 & 0.000461 & 0.0000000 \\
\hline 19 & 0.90 & 0.0000 & 0.0260 & 0.44 & 0.00052 & 0.00226 & 0.0159 & 2.01 & 0.00150 & 0.000340 & 0.0000014 \\
\hline 20 & 0.95 & 0.0026 & 0.0337 & 0.46 & 0.00000 & 0.00285 & 0.0178 & 2.16 & 0.00149 & 0.000390 & 0.0000013 \\
\hline 21 & 1.00 & 0.0229 & 0.0834 & 0.50 & 0.00000 & 0.00422 & 0.0124 & 2.23 & 0.00162 & 0.000328 & 0.0000004 \\
\hline 22 & 1.05 & 0.0241 & 0.0524 & 0.61 & 0.02839 & 0.00066 & 0.0072 & 2.37 & 0.00162 & 0.000311 & 0.0000249 \\
\hline 23 & 1.10 & 0.0000 & 0.0351 & 0.48 & 0.00000 & 0.00075 & 0.0076 & 2.24 & 0.00133 & 0.000444 & 0.0000000 \\
\hline 24 & 1.15 & 0.0000 & 0.0517 & 0.67 & 0.00000 & 0.00281 & 0.0093 & 2.25 & 0.00131 & 0.000427 & 0.0000000 \\
\hline 25 & 1.20 & 0.0722 & 0.1027 & 1.02 & 0.00000 & 0.00349 & 0.0005 & 2.54 & 0.00118 & 0.000262 & 0.0000000 \\
\hline 26 & 1.25 & 0.0000 & 0.0877 & 1.00 & 0.00000 & 0.00044 & 0.0043 & 3.07 & 0.00148 & 0.000422 & 0.0000000 \\
\hline 27 & 1.30 & 0.0000 & 0.0559 & 0.84 & 0.00000 & 0.00350 & 0.0060 & 3.65 & 0.00259 & 0.000576 & 0.0000282 \\
\hline 28 & 1.35 & 0.0000 & 0.0658 & 1.28 & 0.00000 & 0.00523 & 0.0143 & 2.77 & 0.00227 & 0.000541 & 0.0000002 \\
\hline
\end{tabular}




\begin{tabular}{|c|c|c|c|c|c|c|c|c|c|c|c|}
\hline \multirow{2}{*}{$\begin{array}{c}\text { Spot } \\
\text { Number }\end{array}$} & \multirow{2}{*}{ Distance from inner shell (mm) } & \multicolumn{10}{|c|}{ K1A1 nacreous layer transect $\mathrm{N} 4$ corrected data $(\mathrm{mmol} / \mathrm{mol})$} \\
\hline & & $\mathrm{Li} / \mathrm{Ca}$ & $\mathrm{B} / \mathrm{Ca}$ & $\mathrm{Mg} / \mathrm{Ca}$ & $\mathrm{Al} / \mathrm{Ca}$ & $\mathrm{Mn} / \mathrm{Ca}$ & $\mathrm{Zn} / \mathrm{Ca}$ & $\mathrm{Sr} / \mathrm{Ca}$ & $\mathrm{Ba} / \mathrm{Ca}$ & $\mathrm{Pb} / \mathrm{Ca}$ & $\mathrm{U} / \mathrm{Ca}$ \\
\hline 1 & 0.00 & 0.0067 & 0.0509 & 0.32 & 0.0000 & 0.01209 & 0.0146 & 2.17 & 0.00235 & 0.000034 & 0.0000016 \\
\hline 2 & 0.05 & 0.0000 & 0.0852 & 0.69 & 0.0268 & 0.00344 & 0.0038 & 2.53 & 0.00163 & 0.000149 & 0.0000000 \\
\hline 3 & 0.10 & 0.0057 & 2.6338 & 19.98 & 0.0000 & 0.01205 & 0.0171 & 5.74 & 0.00397 & 0.000119 & 0.0000000 \\
\hline 4 & 0.15 & 0.0180 & 0.0636 & 0.52 & 0.0104 & 0.01145 & 0.0108 & 2.28 & 0.00191 & 0.000060 & 0.0000161 \\
\hline 5 & 0.20 & 0.0000 & 0.0187 & 0.52 & 0.0025 & 0.00206 & 0.0077 & 2.22 & 0.00142 & 0.000137 & 0.0000000 \\
\hline 6 & 0.25 & 0.0000 & 9.3506 & 49.22 & 0.0339 & 0.01425 & 0.0182 & 3.11 & 0.00120 & 0.000359 & 0.0000000 \\
\hline 7 & 0.30 & 0.0106 & 0.0668 & 0.68 & 0.0049 & 0.00408 & 0.0130 & 2.18 & 0.00164 & 0.000191 & 0.0000000 \\
\hline 8 & 0.35 & 0.0000 & 0.0404 & 0.50 & 0.0000 & 0.00648 & 0.0157 & 2.28 & 0.00193 & 0.000016 & 0.0000000 \\
\hline 9 & 0.40 & 0.0000 & 0.3428 & 1.74 & 0.0000 & 0.00402 & 0.0066 & 2.62 & 0.00089 & 0.000162 & 0.0000000 \\
\hline 10 & 0.45 & 0.0979 & 29.0603 & 206.60 & 0.0000 & 0.07473 & 0.1065 & 4.48 & 0.00198 & 0.000000 & 0.0002560 \\
\hline 11 & 0.50 & 0.0156 & 0.1010 & 0.53 & 0.0000 & 0.00367 & 0.0097 & 2.05 & 0.00160 & 0.000235 & 0.0000140 \\
\hline 12 & 0.55 & 0.0192 & 0.0654 & 0.56 & 0.0219 & 0.00651 & 0.0086 & 2.11 & 0.00154 & 0.000031 & 0.0000000 \\
\hline 13 & 0.60 & 0.0320 & 0.0711 & 0.48 & 0.0055 & 0.00456 & 0.0104 & 1.99 & 0.00149 & 0.000115 & 0.0000236 \\
\hline 14 & 0.65 & 0.0000 & 0.0816 & 0.48 & 0.0286 & 0.00878 & 0.0124 & 1.85 & 0.00132 & 0.000009 & 0.0000000 \\
\hline 15 & 0.70 & 0.0055 & 0.0814 & 0.42 & 0.0096 & 0.00271 & 0.0099 & 1.97 & 0.00121 & 0.000128 & 0.0000142 \\
\hline 16 & 0.75 & 0.0000 & 0.1246 & 0.75 & 0.0061 & 0.00148 & 0.0014 & 2.09 & 0.00128 & 0.000090 & 0.0000165 \\
\hline 17 & 0.80 & 0.0000 & 20.9977 & 64.36 & 0.0000 & 0.01910 & 0.0525 & 3.67 & 0.00202 & 0.000293 & 0.0000432 \\
\hline 18 & 0.85 & 0.0000 & 0.1808 & 1.02 & 0.0000 & 0.00141 & 0.0004 & 2.60 & 0.00144 & 0.000092 & 0.0000155 \\
\hline 19 & 0.90 & 0.0008 & 0.0817 & 0.41 & 0.0000 & 0.00659 & 0.0100 & 2.07 & 0.00160 & 0.000175 & 0.0000070 \\
\hline 20 & 0.95 & 0.0082 & 0.1040 & 0.37 & 0.0000 & 0.00540 & 0.0125 & 2.44 & 0.00203 & 0.000009 & 0.0000000 \\
\hline 21 & 1.00 & 0.0559 & 0.0393 & 0.51 & 0.0000 & 0.00480 & 0.0117 & 2.52 & 0.00220 & 0.000000 & 0.0000370 \\
\hline 22 & 1.05 & 0.0000 & 0.3488 & 1.54 & 0.0000 & 0.00000 & 0.0035 & 3.69 & 0.00152 & 0.000044 & 0.0000000 \\
\hline 23 & 1.10 & 0.0366 & 0.0928 & 0.50 & 0.0046 & 0.00060 & 0.0132 & 2.18 & 0.00131 & 0.000062 & 0.0000000 \\
\hline 24 & 1.15 & 0.0183 & 0.0934 & 0.55 & 0.0332 & 0.00188 & 0.0089 & 2.48 & 0.00154 & 0.000046 & 0.0000000 \\
\hline 25 & 1.20 & 0.0000 & 0.0856 & 0.67 & 0.0046 & 0.00660 & 0.0038 & 2.61 & 0.00158 & 0.000078 & 0.0000000 \\
\hline 26 & 1.25 & 0.0000 & 0.0679 & 0.64 & 0.0096 & 0.00241 & 0.0009 & 2.39 & 0.00153 & 0.000060 & 0.0000578 \\
\hline 27 & 1.30 & 0.0000 & 0.0646 & 0.75 & 0.0000 & 0.00598 & 0.0126 & 2.68 & 0.00220 & 0.000022 & 0.0000000 \\
\hline 28 & 1.35 & 0.0230 & 0.0973 & 0.99 & 0.0000 & 0.00641 & 0.0083 & 3.40 & 0.00258 & 0.000105 & 0.0000000 \\
\hline
\end{tabular}




\begin{tabular}{|c|c|c|c|c|c|c|c|c|c|c|c|}
\hline \multirow{2}{*}{ Spot Number } & \multirow{2}{*}{ Distance from inner shell (mm) } & \multicolumn{10}{|c|}{ K1A1 nacreous layer transect $\mathrm{N} 5$ corrected data $(\mathrm{mmol} / \mathrm{mol})$} \\
\hline & & $\mathrm{Li} / \mathrm{Ca}$ & $\mathrm{B} / \mathrm{Ca}$ & $\mathrm{Mg} / \mathrm{Ca}$ & $\mathbf{A l} / \mathbf{C a}$ & $\mathrm{Mn} / \mathrm{Ca}$ & $\mathrm{Zn} / \mathrm{Ca}$ & $\mathrm{Sr} / \mathrm{Ca}$ & $\mathrm{Ba} / \mathrm{Ca}$ & $\mathrm{Pb} / \mathrm{Ca}$ & $\mathrm{U} / \mathrm{Ca}$ \\
\hline 1 & 0.00 & 0.0116 & 0.0178 & 0.39 & 0.0152 & 0.00927 & 0.0254 & 1.99 & 0.00197 & 0.000277 & 0.0000000 \\
\hline 2 & 0.05 & 0.0069 & 0.0000 & 0.47 & 0.0000 & 0.00674 & 0.0105 & 1.98 & 0.00164 & 0.000236 & 0.0000238 \\
\hline 3 & 0.10 & 0.0069 & 0.0000 & 0.47 & 0.0000 & 0.00674 & 0.0105 & 1.98 & 0.00164 & 0.000236 & 0.0000238 \\
\hline 4 & 0.15 & 0.0373 & 0.0477 & 0.39 & 0.0000 & 0.01031 & 0.0233 & 2.13 & 0.00196 & 0.000025 & 0.0000000 \\
\hline 5 & 0.20 & 0.0000 & 0.2032 & 1.25 & 0.0000 & 0.00556 & 0.0009 & 2.07 & 0.00101 & 0.000306 & 0.0000000 \\
\hline 6 & 0.25 & 0.0087 & 0.3554 & 2.62 & 0.0149 & 0.00296 & 0.0000 & 2.56 & 0.00100 & 0.000375 & 0.0000415 \\
\hline 7 & 0.30 & 0.0000 & 0.0293 & 0.88 & 0.0000 & 0.01262 & 0.0189 & 2.25 & 0.00172 & 0.000209 & 0.0000000 \\
\hline 8 & 0.35 & 0.0000 & 0.0630 & 0.54 & 0.0000 & 0.00767 & 0.0195 & 2.22 & 0.00197 & 0.000296 & 0.0000000 \\
\hline 9 & 0.40 & 0.0392 & 0.0749 & 0.49 & 0.0000 & 0.00639 & 0.0227 & 2.11 & 0.00203 & 0.000095 & 0.0000000 \\
\hline 10 & 0.45 & 0.0030 & 0.0548 & 0.48 & 0.0000 & 0.00840 & 0.0252 & 2.12 & 0.00204 & 0.000200 & 0.0000000 \\
\hline 11 & 0.50 & 0.0000 & 0.0582 & 0.44 & 0.0000 & 0.00398 & 0.0133 & 1.89 & 0.00140 & 0.000094 & 0.0000750 \\
\hline 12 & 0.55 & 0.0390 & 4.6201 & 7.27 & 0.0000 & 0.00639 & 0.0133 & 3.42 & 0.00152 & 0.000166 & 0.0000349 \\
\hline 13 & 0.60 & 0.0000 & 2.5107 & 11.21 & 0.0000 & 0.00652 & 0.0066 & 3.77 & 0.00187 & 0.000239 & 0.0000000 \\
\hline 14 & 0.65 & 0.0035 & 0.0220 & 0.40 & 0.0372 & 0.00550 & 0.0115 & 1.84 & 0.00111 & 0.000166 & 0.0000000 \\
\hline 15 & 0.70 & 0.0019 & 0.0950 & 0.34 & 0.0000 & 0.00239 & 0.0075 & 2.01 & 0.00129 & 0.000005 & 0.0000000 \\
\hline 16 & 0.75 & 0.0609 & 0.0803 & 0.43 & 0.0000 & 0.00027 & 0.0118 & 2.11 & 0.00125 & 0.000152 & 0.0000264 \\
\hline 17 & 0.80 & 0.0000 & 13.6106 & 93.27 & 0.0000 & 0.03587 & 0.0408 & 4.58 & 0.00282 & 0.000238 & 0.0000000 \\
\hline 18 & 0.85 & 0.0000 & 0.4775 & 3.50 & 0.0202 & 0.00000 & 0.0000 & 4.13 & 0.00204 & 0.000067 & 0.0000000 \\
\hline 19 & 0.90 & 34.9370 & 17.0944 & 9.36 & 190.4312 & 4.28018 & 3.5072 & 2.89 & 1.58845 & 1.078390 & 1.0038803 \\
\hline 20 & 0.95 & 0.0000 & 8.4830 & 29.32 & 0.0000 & 0.01456 & 0.0231 & 4.81 & 0.00261 & 0.000238 & 0.0000000 \\
\hline 21 & 1.00 & 0.0514 & 0.0980 & 0.62 & 0.0293 & 0.00473 & 0.0111 & 2.37 & 0.00125 & 0.000195 & 0.0000000 \\
\hline 22 & 1.05 & 0.0000 & 0.0730 & 0.46 & 0.0002 & 0.00375 & 0.0092 & 2.08 & 0.00143 & 0.000146 & 0.0000429 \\
\hline 23 & 1.10 & 0.0128 & 0.0797 & 0.52 & 0.0006 & 0.00235 & 0.0129 & 2.24 & 0.00213 & 0.000150 & 0.0000184 \\
\hline 24 & 1.15 & 0.0054 & 0.0421 & 0.55 & 0.0000 & 0.00359 & 0.0084 & 2.01 & 0.00156 & 0.000226 & 0.0000348 \\
\hline 25 & 1.20 & 0.0000 & 0.0143 & 0.36 & 0.0205 & 0.00411 & 0.0098 & 2.04 & 0.00169 & 0.000036 & 0.0000313 \\
\hline 26 & 1.25 & 0.0130 & 0.0671 & 0.39 & 0.0000 & 0.00327 & 0.0079 & 1.89 & 0.00146 & 0.000051 & 0.0000000 \\
\hline 27 & 1.30 & 0.0056 & 0.0792 & 0.44 & 0.0000 & 0.00677 & 0.0100 & 2.01 & 0.00163 & 0.000088 & 0.0000227 \\
\hline 28 & 1.35 & 0.0103 & 0.0464 & 0.36 & 0.0000 & 0.00157 & 0.0095 & 2.06 & 0.00139 & 0.000096 & 0.0000151 \\
\hline 29 & 1.40 & 0.0000 & 0.0225 & 0.41 & 0.0000 & 0.00259 & 0.0088 & 2.10 & 0.00155 & 0.000000 & 0.0000731 \\
\hline 30 & 1.45 & 0.0000 & 0.0755 & 0.65 & 0.0000 & 0.00336 & 0.0039 & 2.07 & 0.00144 & 0.000000 & 0.0000000 \\
\hline
\end{tabular}


APPENDIX 5.2k AR1 nacreous layer data

\begin{tabular}{|c|c|c|c|c|c|c|c|c|c|c|c|}
\hline \multirow{2}{*}{ Spot Number } & \multirow{2}{*}{ Distance from inner shell (mm) } & \multicolumn{10}{|c|}{ AR1 nacreous layer transect $\mathrm{N} 1$ corrected data $(\mathrm{mmol} / \mathrm{mol})$} \\
\hline & & $\mathrm{Li} / \mathrm{Ca}$ & $\mathrm{B} / \mathrm{Ca}$ & $\mathrm{Mg} / \mathrm{Ca}$ & $\mathrm{Al} / \mathrm{Ca}$ & $\mathrm{Mn} / \mathrm{Ca}$ & $\mathrm{Zn} / \mathrm{Ca}$ & $\mathrm{Sr} / \mathrm{Ca}$ & $\mathrm{Ba} / \mathrm{Ca}$ & $\mathrm{Pb} / \mathrm{Ca}$ & $\mathrm{U} / \mathrm{Ca}$ \\
\hline 1 & 0.00 & 0.0075 & 0.0425 & 0.21 & 0.0065 & 0.00410 & 0.00574 & 1.55 & 0.00315 & 0.0000000 & 0.0000183 \\
\hline 2 & 0.05 & 0.0319 & 0.0529 & 0.21 & 0.0000 & 0.00571 & 0.00391 & 1.51 & 0.00081 & 0.0000000 & 0.0000000 \\
\hline 3 & 0.10 & 0.0076 & 0.0399 & 1.29 & 0.0237 & 0.00428 & 0.00168 & 2.35 & 0.00101 & 0.0000000 & 0.0000000 \\
\hline 4 & 0.15 & 0.0000 & 7.6680 & 78.06 & 0.0409 & 0.02634 & 0.03062 & 4.29 & 0.00170 & 0.0000000 & 0.0000000 \\
\hline 5 & 0.20 & 0.0262 & 0.1935 & 6.81 & 0.0093 & 0.00078 & 0.00701 & 3.89 & 0.00160 & 0.0000000 & 0.0000171 \\
\hline 6 & 0.25 & 0.0059 & 0.0241 & 0.39 & 0.0117 & 0.00000 & 0.00324 & 1.76 & 0.00156 & 0.0000000 & 0.0000022 \\
\hline 7 & 0.30 & 0.0000 & 0.0602 & 0.40 & 0.0103 & 0.00000 & 0.00592 & 1.80 & 0.00162 & 0.0000495 & 0.0000000 \\
\hline 8 & 0.35 & 0.0203 & 0.0498 & 0.37 & 0.0009 & 0.00210 & 0.00781 & 1.55 & 0.00186 & 0.0000000 & 0.0000170 \\
\hline 9 & 0.40 & 0.0204 & 0.0370 & 0.36 & 0.0010 & 0.00357 & 0.00000 & 1.75 & 0.00266 & 0.0000000 & 0.0000030 \\
\hline 10 & 0.45 & 0.0447 & 0.0302 & 0.46 & 0.0000 & 0.00193 & 0.00524 & 1.62 & 0.00176 & 0.0000000 & 0.0000000 \\
\hline 11 & 0.50 & 0.0000 & 0.0503 & 0.40 & 0.0068 & 0.00000 & 0.00000 & 1.61 & 0.00144 & 0.0000000 & 0.0000211 \\
\hline 12 & 0.55 & 0.0010 & 0.0213 & 0.42 & 0.0126 & 0.00385 & 0.00743 & 1.58 & 0.00149 & 0.0000016 & 0.0000000 \\
\hline 13 & 0.60 & 0.0277 & 0.0602 & 0.51 & 0.0075 & 0.00000 & 0.00126 & 1.62 & 0.00190 & 0.0000570 & 0.0000000 \\
\hline 14 & 0.65 & 0.0104 & 0.0250 & 0.41 & 0.0000 & 0.00000 & 0.00276 & 1.74 & 0.00135 & 0.0000389 & 0.0000138 \\
\hline 15 & 0.70 & 0.0000 & 0.0426 & 0.57 & 0.0101 & 0.00278 & 0.00279 & 1.69 & 0.00133 & 0.0000189 & 0.0000240 \\
\hline 16 & 0.75 & 0.0052 & 0.0454 & 0.51 & 0.0104 & 0.00325 & 0.00112 & 1.80 & 0.00091 & 0.0001005 & 0.0000058 \\
\hline 17 & 0.80 & 0.0283 & 0.0640 & 0.49 & 0.0103 & 0.00000 & 0.00287 & 1.97 & 0.00104 & 0.0000014 & 0.0000188 \\
\hline 18 & 0.85 & 0.0000 & 0.0459 & 0.54 & 0.0235 & 0.00562 & 0.00000 & 1.87 & 0.00150 & 0.0000202 & 0.0000152 \\
\hline 19 & 0.90 & 0.0205 & 0.0291 & 1.06 & 0.0045 & 0.00068 & 0.00409 & 2.01 & 0.00130 & 0.0000242 & 0.0000151 \\
\hline
\end{tabular}




\begin{tabular}{|c|c|c|c|c|c|c|c|c|c|c|c|}
\hline \multirow{2}{*}{ Spot Number } & \multirow{2}{*}{ Distance from inner shell (mm) } & \multicolumn{10}{|c|}{ AR1 nacreous layer transect $\mathrm{N} 2$ corrected data $(\mathrm{mmol} / \mathrm{mol})$} \\
\hline & & $\mathrm{Li} / \mathrm{Ca}$ & $\mathrm{B} / \mathrm{Ca}$ & $\mathrm{Mg} / \mathrm{Ca}$ & $\mathrm{Al} / \mathrm{Ca}$ & $\mathrm{Mn} / \mathrm{Ca}$ & $\mathrm{Zn} / \mathrm{Ca}$ & $\mathrm{Sr} / \mathrm{Ca}$ & $\mathrm{Ba} / \mathrm{Ca}$ & $\mathrm{Pb} / \mathrm{Ca}$ & $\mathrm{U} / \mathrm{Ca}$ \\
\hline 1 & 0.00 & 0.0000 & 0.0225 & 0.29 & 0.0000 & 0.00000 & 0.00138 & 1.65 & 0.00574 & 0.0000671 & 0.0000138 \\
\hline 2 & 0.05 & 0.0149 & 0.0593 & 0.23 & 0.0000 & 0.00000 & 0.00369 & 1.65 & 0.00371 & 0.0000777 & 0.0000000 \\
\hline 3 & 0.10 & 0.0120 & 0.0448 & 0.32 & 0.0000 & 0.00000 & 0.00124 & 1.64 & 0.00444 & 0.0000830 & 0.0000000 \\
\hline 4 & 0.15 & 0.0000 & 8.4611 & 23.75 & 0.0000 & 0.00515 & 0.00000 & 3.48 & 0.00243 & 0.0000000 & 0.0000000 \\
\hline 5 & 0.20 & 0.0190 & 0.0296 & 0.26 & 0.0000 & 0.00053 & 0.00518 & 1.69 & 0.00320 & 0.0000586 & 0.0000000 \\
\hline 6 & 0.25 & 0.0142 & 0.0539 & 0.92 & 0.0000 & 0.00000 & 0.00329 & 2.40 & 0.00286 & 0.0000000 & 0.0000000 \\
\hline 7 & 0.30 & 0.0193 & 3.9889 & 22.41 & 0.0004 & 0.01664 & 0.00004 & 3.75 & 0.00147 & 0.0000000 & 0.0000000 \\
\hline 8 & 0.35 & 0.0000 & 0.0628 & 0.71 & 0.0000 & 0.00000 & 0.01016 & 1.77 & 0.00319 & 0.0000011 & 0.0000197 \\
\hline 9 & 0.40 & 0.0200 & 0.0469 & 0.45 & 0.0000 & 0.00009 & 0.00432 & 1.79 & 0.00290 & 0.0000359 & 0.0000405 \\
\hline 10 & 0.45 & 0.0097 & 0.0364 & 0.44 & 0.0027 & 0.00304 & 0.00961 & 1.75 & 0.00299 & 0.0000661 & 0.0000000 \\
\hline 11 & 0.50 & 0.0030 & 0.0660 & 0.39 & 0.0000 & 0.00000 & 0.00296 & 1.57 & 0.00190 & 0.0000669 & 0.0000000 \\
\hline 12 & 0.55 & 0.0151 & 0.0090 & 0.42 & 0.0000 & 0.00000 & 0.00341 & 1.76 & 0.00203 & 0.0000885 & 0.0000000 \\
\hline 13 & 0.60 & 0.0200 & 0.0685 & 0.39 & 0.0075 & 0.00000 & 0.00153 & 1.70 & 0.00263 & 0.0000000 & 0.0000000 \\
\hline 14 & 0.65 & 0.0029 & 0.0343 & 0.39 & 0.0000 & 0.00000 & 0.00390 & 1.52 & 0.00236 & 0.0000000 & 0.0000008 \\
\hline 15 & 0.70 & 0.0055 & 0.0509 & 0.38 & 0.0001 & 0.00075 & 0.01021 & 1.48 & 0.00243 & 0.0000323 & 0.0000185 \\
\hline 16 & 0.75 & 0.0096 & 0.0000 & 0.43 & 0.0077 & 0.00000 & 0.00293 & 1.59 & 0.00189 & 0.0000000 & 0.0000096 \\
\hline 17 & 0.80 & 0.0004 & 0.0218 & 0.47 & 0.0000 & 0.00421 & 0.00707 & 1.58 & 0.00281 & 0.0000224 & 0.0000002 \\
\hline 18 & 0.85 & 0.0000 & 3.0594 & 6.22 & 0.0123 & 0.01053 & 0.00978 & 3.69 & 0.00381 & 0.0000103 & 0.0000000 \\
\hline 19 & 0.90 & 0.0065 & 0.0275 & 0.39 & 0.0000 & 0.00000 & 0.00764 & 1.74 & 0.00324 & 0.0000000 & 0.0000000 \\
\hline 20 & 0.95 & 0.0131 & 0.0206 & 0.36 & 0.0000 & 0.00000 & 0.00246 & 1.64 & 0.00305 & 0.0001194 & 0.0000000 \\
\hline 21 & 1.00 & 0.0000 & 0.0353 & 0.41 & 0.0066 & 0.00000 & 0.00105 & 1.71 & 0.00146 & 0.0000000 & 0.0000000 \\
\hline 22 & 1.05 & 0.0018 & 0.0319 & 0.38 & 0.0025 & 0.00235 & 0.00994 & 1.90 & 0.00220 & 0.0000000 & 0.0000244 \\
\hline 23 & 1.10 & 0.0141 & 0.0579 & 0.33 & 0.0000 & 0.00049 & 0.00573 & 1.69 & 0.00306 & 0.0000000 & 0.0000535 \\
\hline 24 & 1.15 & 0.0089 & 0.0548 & 0.35 & 0.0040 & 0.00404 & 0.00867 & 1.78 & 0.00254 & 0.0000714 & 0.0000000 \\
\hline 25 & 1.20 & 0.0000 & 0.0591 & 0.35 & 0.0000 & 0.00132 & 0.00000 & 1.79 & 0.00236 & 0.0000367 & 0.0000000 \\
\hline 26 & 1.25 & 0.0198 & 0.0283 & 0.46 & 0.0000 & 0.00000 & 0.00094 & 2.06 & 0.00239 & 0.0000000 & 0.0000000 \\
\hline 27 & 1.30 & 0.0210 & 0.0419 & 0.48 & 0.0000 & 0.00000 & 0.00957 & 1.88 & 0.00201 & 0.0001806 & 0.0000405 \\
\hline 28 & 1.35 & 0.0013 & 0.0598 & 0.37 & 0.0046 & 0.00000 & 0.00248 & 1.60 & 0.00179 & 0.0000744 & 0.0000000 \\
\hline 29 & 1.40 & 0.0000 & 0.0556 & 0.45 & 0.0000 & 0.00318 & 0.00880 & 1.76 & 0.00172 & 0.0000366 & 0.0000000 \\
\hline 30 & 1.45 & 0.0275 & 0.0188 & 0.49 & 0.0100 & 0.00000 & 0.00351 & 1.99 & 0.00194 & 0.0000000 & 0.0000000 \\
\hline 31 & 1.50 & 0.0037 & 0.0159 & 0.41 & 0.0014 & 0.00000 & 0.00013 & 1.61 & 0.00185 & 0.0001196 & 0.0000000 \\
\hline 32 & 1.55 & 0.0026 & 0.0560 & 0.70 & 0.0108 & 0.00149 & 0.00168 & 2.21 & 0.00290 & 0.0000000 & 0.0000000 \\
\hline
\end{tabular}




\begin{tabular}{|c|c|c|c|c|c|c|c|c|c|c|c|}
\hline \multirow{2}{*}{$\begin{array}{c}\text { Spot } \\
\text { Number }\end{array}$} & \multirow{2}{*}{ Distance from inner shell (mm) } & \multicolumn{10}{|c|}{ AR1 nacreous layer transect $\mathrm{N} 3$ corrected data $(\mathrm{mmol} / \mathrm{mol})$} \\
\hline & & $\mathrm{Li} / \mathrm{Ca}$ & $\mathrm{B} / \mathrm{Ca}$ & $\mathrm{Mg} / \mathrm{Ca}$ & $\mathrm{Al} / \mathrm{Ca}$ & $\mathrm{Mn} / \mathrm{Ca}$ & $\mathrm{Zn} / \mathrm{Ca}$ & $\mathrm{Sr} / \mathrm{Ca}$ & $\mathrm{Ba} / \mathrm{Ca}$ & $\mathrm{Pb} / \mathrm{Ca}$ & $\mathrm{U} / \mathrm{Ca}$ \\
\hline 1 & 0.00 & 0.0150 & 0.0000 & 0.31 & 0.0000 & 0.00127 & 0.00520 & 1.77 & 0.00441 & 0.0000000 & 0.0000028 \\
\hline 2 & 0.05 & 0.0064 & 0.0554 & 0.56 & 0.0131 & 0.00000 & 0.00687 & 1.78 & 0.00067 & 0.0000188 & 0.0000000 \\
\hline 3 & 0.10 & 0.0102 & 5.2268 & 25.59 & 0.0000 & 0.00639 & 0.00970 & 3.71 & 0.00236 & 0.0000000 & 0.0000000 \\
\hline 4 & 0.15 & 0.0067 & 0.0559 & 0.40 & 0.0070 & 0.00405 & 0.00595 & 1.65 & 0.00120 & 0.0000000 & 0.0000000 \\
\hline 5 & 0.20 & 0.0000 & 0.0525 & 0.31 & 0.0000 & 0.00231 & 0.01186 & 1.83 & 0.00178 & 0.0000072 & 0.0000214 \\
\hline 6 & 0.25 & 0.0192 & 2.2128 & 16.33 & 0.0000 & 0.01028 & 0.00573 & 2.83 & 0.00125 & 0.0000000 & 0.0000000 \\
\hline 7 & 0.30 & 0.0130 & 0.0728 & 0.29 & 0.0000 & 0.00000 & 0.00000 & 1.74 & 0.00108 & 0.0000385 & 0.0000000 \\
\hline 8 & 0.35 & 0.0222 & 0.0346 & 0.25 & 0.0077 & 0.00061 & 0.00000 & 1.57 & 0.00172 & 0.0000000 & 0.0000140 \\
\hline 9 & 0.40 & 0.0302 & 1.5154 & 8.58 & 0.0010 & 0.00908 & 0.00823 & 2.67 & 0.00113 & 0.0000208 & 0.0000000 \\
\hline 10 & 0.45 & 0.0085 & 2.0805 & 8.51 & 0.0000 & 0.00450 & 0.00379 & 2.54 & 0.00124 & 0.0000000 & 0.0000495 \\
\hline 11 & 0.50 & 0.0000 & 0.0106 & 0.46 & 0.0000 & 0.00389 & 0.00096 & 1.44 & 0.00149 & 0.0000287 & 0.0000000 \\
\hline 12 & 0.55 & 0.0061 & 0.0268 & 0.54 & 0.0000 & 0.00135 & 0.00248 & 1.48 & 0.00171 & 0.0000947 & 0.0000000 \\
\hline 13 & 0.60 & 0.0162 & 0.0575 & 0.59 & 0.0000 & 0.00259 & 0.00106 & 1.51 & 0.00212 & 0.0000700 & 0.0000262 \\
\hline 14 & 0.65 & 0.0007 & 0.0380 & 0.64 & 0.0078 & 0.00071 & 0.01160 & 1.63 & 0.00082 & 0.0000375 & 0.0000079 \\
\hline 15 & 0.70 & 0.0000 & 0.0270 & 0.54 & 0.0000 & 0.00000 & 0.01172 & 1.62 & 0.00195 & 0.0000000 & 0.0000475 \\
\hline 16 & 0.75 & 0.0071 & 0.0359 & 0.57 & 0.0000 & 0.00000 & 0.00000 & 1.70 & 0.00156 & 0.0000209 & 0.0000029 \\
\hline 17 & 0.80 & 0.0112 & 0.0295 & 0.61 & 0.0000 & 0.00153 & 0.00417 & 1.74 & 0.00162 & 0.0000405 & 0.0000000 \\
\hline 18 & 0.85 & 0.0208 & 5.1213 & 18.08 & 0.0000 & 0.00728 & 0.00885 & 3.45 & 0.00140 & 0.0000294 & 0.0000000 \\
\hline 19 & 0.90 & 0.0193 & 0.0613 & 0.56 & 0.0000 & 0.00471 & 0.00000 & 1.79 & 0.00207 & 0.0000000 & 0.0000000 \\
\hline 20 & 0.95 & 0.0000 & 0.0481 & 0.54 & 0.0000 & 0.00281 & 0.00000 & 1.56 & 0.00140 & 0.0000118 & 0.0000000 \\
\hline 21 & 1.00 & 0.0161 & 0.0422 & 0.49 & 0.0054 & 0.00118 & 0.00539 & 1.56 & 0.00049 & 0.0000106 & 0.0000000 \\
\hline 22 & 1.05 & 0.0000 & 0.0785 & 0.48 & 0.0047 & 0.00115 & 0.00000 & 1.54 & 0.00051 & 0.0000346 & 0.0000000 \\
\hline 23 & 1.10 & 0.0011 & 0.0552 & 0.42 & 0.0063 & 0.00127 & 0.00969 & 1.72 & 0.00142 & 0.0000000 & 0.0000012 \\
\hline 24 & 1.15 & 0.0264 & 0.0544 & 0.37 & 0.0042 & 0.00000 & 0.00000 & 1.55 & 0.00093 & 0.0000000 & 0.0000244 \\
\hline 25 & 1.20 & 0.0000 & 0.0516 & 0.38 & 0.0043 & 0.00105 & 0.00503 & 1.57 & 0.00063 & 0.0000000 & 0.0000000 \\
\hline 26 & 1.25 & 0.0099 & 0.0434 & 0.35 & 0.0073 & 0.00000 & 0.00289 & 1.67 & 0.00128 & 0.0000810 & 0.0000227 \\
\hline 27 & 1.30 & 0.0090 & 0.0707 & 0.36 & 0.0096 & 0.00000 & 0.00292 & 1.63 & 0.00107 & 0.0000000 & 0.0000161 \\
\hline 28 & 1.35 & 0.0054 & 0.0458 & 0.36 & 0.0000 & 0.00420 & 0.00298 & 1.71 & 0.00085 & 0.0000811 & 0.0000161 \\
\hline
\end{tabular}




\begin{tabular}{|c|c|c|c|c|c|c|c|c|c|c|c|}
\hline \multirow{2}{*}{ Spot Number } & \multirow{2}{*}{ Distance from inner shell (mm) } & \multicolumn{10}{|c|}{ AR1 nacreous layer transect N3 corrected data $(\mathrm{mmol} / \mathrm{mol})$ continued... } \\
\hline & & $\mathrm{Li} / \mathrm{Ca}$ & $\mathrm{B} / \mathrm{Ca}$ & $\mathrm{Mg} / \mathrm{Ca}$ & $\mathrm{Al} / \mathrm{Ca}$ & $\mathrm{Mn} / \mathrm{Ca}$ & $\mathrm{Zn} / \mathrm{Ca}$ & $\mathrm{Sr} / \mathrm{Ca}$ & $\mathrm{Ba} / \mathrm{Ca}$ & $\mathrm{Pb} / \mathrm{Ca}$ & $\mathrm{U} / \mathrm{Ca}$ \\
\hline 29 & 1.40 & 0.0133 & 0.0614 & 0.35 & 0.0020 & 0.00311 & 0.00000 & 1.64 & 0.00100 & 0.0000000 & 0.0000206 \\
\hline 30 & 1.45 & 0.0090 & 0.0386 & 0.40 & 0.0060 & 0.00278 & 0.00298 & 1.68 & 0.00053 & 0.0000426 & 0.0000099 \\
\hline 31 & 1.50 & 0.0000 & 0.0515 & 0.33 & 0.0000 & 0.00427 & 0.00410 & 1.51 & 0.00085 & 0.0000048 & 0.0000000 \\
\hline 32 & 1.55 & 0.0000 & 0.0372 & 0.31 & 0.0005 & 0.00166 & 0.01278 & 1.54 & 0.00168 & 0.0000589 & 0.0000217 \\
\hline 33 & 1.60 & 0.0059 & 0.0542 & 0.37 & 0.0154 & 0.00000 & 0.00221 & 1.62 & 0.00108 & 0.0000448 & 0.0000035 \\
\hline 34 & 1.65 & 0.0099 & 0.0554 & 0.56 & 0.0000 & 0.00249 & 0.01401 & 1.78 & 0.00244 & 0.0000412 & 0.0000375 \\
\hline 35 & 1.70 & 0.0089 & 0.0613 & 0.70 & 0.0000 & 0.00000 & 0.00108 & 2.29 & 0.00525 & 0.0000555 & 0.0000227 \\
\hline 36 & 1.75 & 0.0094 & 0.0592 & 0.55 & 0.0000 & 0.00000 & 0.00466 & 2.72 & 0.00669 & 0.0000000 & 0.0000142 \\
\hline
\end{tabular}




\begin{tabular}{|c|c|c|c|c|c|c|c|c|c|c|c|}
\hline \multirow{2}{*}{ Spot Number } & \multirow{2}{*}{ Distance from inner shell (mm) } & \multicolumn{10}{|c|}{ AR1 nacreous layer transect $\mathrm{N} 4$ corrected data $(\mathrm{mmol} / \mathrm{mol})$} \\
\hline & & $\mathrm{Li} / \mathrm{Ca}$ & $\mathrm{B} / \mathrm{Ca}$ & $\mathrm{Mg} / \mathrm{Ca}$ & $\mathbf{A l} / \mathbf{C a}$ & $\mathrm{Mn} / \mathrm{Ca}$ & $\mathrm{Zn} / \mathrm{Ca}$ & $\mathrm{Sr} / \mathrm{Ca}$ & $\mathrm{Ba} / \mathrm{Ca}$ & $\mathrm{Pb} / \mathrm{Ca}$ & $\mathrm{U} / \mathrm{Ca}$ \\
\hline 1 & 0.00 & 0.0206 & 0.0424 & 0.36 & 0.0000 & 0.00535 & 0.00000 & 1.68 & 0.00340 & 0.0000463 & 0.0000000 \\
\hline 2 & 0.05 & 0.0139 & 0.0490 & 0.28 & 0.0000 & 0.00108 & 0.00920 & 1.76 & 0.00367 & 0.0000632 & 0.0000000 \\
\hline 3 & 0.10 & 0.0131 & 0.1474 & 1.66 & 0.0071 & 0.00364 & 0.01269 & 2.18 & 0.00101 & 0.0000421 & 0.0000290 \\
\hline 4 & 0.15 & 0.0070 & 4.2999 & 17.40 & 0.0060 & 0.01086 & 0.00409 & 4.46 & 0.00175 & 0.0000608 & 0.0000029 \\
\hline 5 & 0.20 & 0.0177 & 0.0353 & 0.54 & 0.0006 & 0.00041 & 0.00788 & 1.56 & 0.00373 & 0.0000000 & 0.0000504 \\
\hline 6 & 0.25 & 0.0091 & 0.0290 & 0.48 & 0.0075 & 0.00000 & 0.00698 & 1.38 & 0.00231 & 0.0000000 & 0.0000000 \\
\hline 7 & 0.30 & 0.0251 & 0.0307 & 0.49 & 0.0036 & 0.00003 & 0.00506 & 1.49 & 0.00148 & 0.0000000 & 0.0000125 \\
\hline 8 & 0.35 & 0.0153 & 0.0525 & 0.46 & 0.0044 & 0.00291 & 0.00881 & 1.38 & 0.00285 & 0.0000000 & 0.0000074 \\
\hline 9 & 0.40 & 0.0129 & 0.0557 & 0.40 & 0.0001 & 0.00254 & 0.01338 & 1.43 & 0.00313 & 0.0000000 & 0.0000212 \\
\hline 10 & 0.45 & 0.0000 & 0.0649 & 0.39 & 0.0000 & 0.00000 & 0.00598 & 1.56 & 0.00313 & 0.0000837 & 0.0000345 \\
\hline 11 & 0.50 & 0.0014 & 0.0349 & 0.42 & 0.0025 & 0.00159 & 0.01210 & 1.57 & 0.00867 & 0.0000845 & 0.0000056 \\
\hline 12 & 0.55 & 0.0053 & 0.0708 & 0.42 & 0.0083 & 0.00000 & 0.00047 & 1.70 & 0.00285 & 0.0000207 & 0.0000178 \\
\hline 13 & 0.60 & 0.0000 & 0.0746 & 0.42 & 0.0000 & 0.00176 & 0.01012 & 1.57 & 0.00378 & 0.0000000 & 0.0000000 \\
\hline 14 & 0.65 & 0.0123 & 0.0738 & 0.38 & 0.0090 & 0.00000 & 0.01178 & 1.57 & 0.00272 & 0.0000447 & 0.0000000 \\
\hline 15 & 0.70 & 0.0056 & 0.0677 & 0.42 & 0.0037 & 0.00000 & 0.00000 & 1.78 & 0.00262 & 0.0000122 & 0.0000000 \\
\hline 16 & 0.75 & 0.0068 & 0.0582 & 0.40 & 0.0064 & 0.00000 & 0.01050 & 1.89 & 0.00404 & 0.0000000 & 0.0000000 \\
\hline 17 & 0.80 & 0.0000 & 0.0864 & 0.43 & 0.0000 & 0.00000 & 0.00002 & 1.77 & 0.00372 & 0.0000000 & 0.0000250 \\
\hline 18 & 0.85 & 0.0118 & 0.0964 & 0.46 & 0.0049 & 0.00480 & 0.00261 & 1.89 & 0.00319 & 0.0000185 & 0.0000000 \\
\hline 19 & 0.90 & 0.0017 & 0.0907 & 0.49 & 0.0000 & 0.00000 & 0.00177 & 2.10 & 0.00332 & 0.0000551 & 0.0000000 \\
\hline 20 & 0.95 & 0.0120 & 0.0769 & 0.44 & 0.0025 & 0.00203 & 0.00551 & 1.91 & 0.00340 & 0.0000000 & 0.0000000 \\
\hline 21 & 1.00 & 0.0031 & 0.0936 & 0.46 & 0.0000 & 0.00223 & 0.01199 & 1.88 & 0.00315 & 0.0000093 & 0.0000405 \\
\hline 22 & 1.05 & 0.0000 & 0.0752 & 0.47 & 0.0000 & 0.00111 & 0.00658 & 1.83 & 0.00418 & 0.0000000 & 0.0000036 \\
\hline 23 & 1.10 & 0.0057 & 0.0400 & 0.41 & 0.0017 & 0.00000 & 0.00567 & 1.72 & 0.00397 & 0.0000551 & 0.0000000 \\
\hline 24 & 1.15 & 0.0145 & 0.0624 & 0.43 & 0.0023 & 0.00037 & 0.01372 & 1.73 & 0.00376 & 0.0000281 & 0.0000052 \\
\hline 25 & 1.20 & 0.0243 & 0.0864 & 0.42 & 0.0000 & 0.00366 & 0.01336 & 1.78 & 0.00967 & 0.0000000 & 0.0000000 \\
\hline
\end{tabular}


APPENDIX 5.21 MR2 nacreous layer transect data

\begin{tabular}{|c|c|c|c|c|c|c|c|c|c|c|c|}
\hline \multirow{2}{*}{ Spot Number } & \multirow{2}{*}{ Distance from inner shell (mm) } & \multicolumn{10}{|c|}{ MR2 nacreous layer transect $\mathrm{N} 1$ corrected data $(\mathrm{mmol} / \mathrm{mol})$} \\
\hline & & $\mathrm{Li} / \mathrm{Ca}$ & $\mathrm{B} / \mathrm{Ca}$ & $\mathrm{Mg} / \mathrm{Ca}$ & $\mathrm{Al} / \mathrm{Ca}$ & $\mathrm{Mn} / \mathrm{Ca}$ & $\mathrm{Zn} / \mathrm{Ca}$ & $\mathrm{Sr} / \mathrm{Ca}$ & $\mathrm{Ba} / \mathrm{Ca}$ & $\mathrm{Pb} / \mathrm{Ca}$ & $\mathrm{U} / \mathrm{Ca}$ \\
\hline 1 & 0.00 & 0.0455 & 0.095 & 0.690 & 0.0076 & 0.00000 & 0.00632 & 2.10 & 0.00294 & 0.0000608 & 0.0000093 \\
\hline 2 & 0.05 & 0.0000 & 0.083 & 0.515 & 0.0408 & 0.00000 & 0.00560 & 1.96 & 0.00268 & 0.0000237 & 0.0000525 \\
\hline 3 & 0.10 & 0.0229 & 0.000 & 0.438 & 0.0242 & 0.00000 & 0.00516 & 1.83 & 0.00196 & 0.0000949 & 0.0000000 \\
\hline 4 & 0.15 & 0.0087 & 0.000 & 0.328 & 0.0200 & 0.00000 & 0.01065 & 1.87 & 0.00165 & 0.0000000 & 0.0000385 \\
\hline 5 & 0.20 & 0.0055 & 0.029 & 0.508 & 0.0000 & 0.00000 & 0.00000 & 2.05 & 0.00108 & 0.0000204 & 0.0000000 \\
\hline 6 & 0.25 & 0.0096 & 0.094 & 0.538 & 0.0203 & 0.00459 & 0.00392 & 1.80 & 0.00183 & 0.0000226 & 0.0000419 \\
\hline 7 & 0.30 & 0.0014 & 0.081 & 0.454 & 0.0131 & 0.00532 & 0.00213 & 1.72 & 0.00132 & 0.0000000 & 0.0000000 \\
\hline 8 & 0.35 & 0.0143 & 0.463 & 0.417 & 0.0000 & 0.00273 & 0.01185 & 1.76 & 0.00126 & 0.0001624 & 0.0000054 \\
\hline 9 & 0.40 & 0.0441 & 0.313 & 0.384 & 0.0201 & 0.00586 & 0.00000 & 1.75 & 0.00150 & 0.0000000 & 0.0001061 \\
\hline 10 & 0.45 & 0.0000 & 0.427 & 0.392 & 0.0000 & 0.00068 & 0.00773 & 1.79 & 0.00138 & 0.0000000 & 0.0000000 \\
\hline 11 & 0.50 & 0.0118 & 0.026 & 0.351 & 0.0000 & 0.00004 & 0.00000 & 1.69 & 0.00162 & 0.0000000 & 0.0000000 \\
\hline 12 & 0.55 & 0.0351 & 0.211 & 0.321 & 0.0292 & 0.00000 & 0.00000 & 1.82 & 0.00159 & 0.0003187 & 0.0000000 \\
\hline 13 & 0.60 & 0.0435 & 0.406 & 0.333 & 0.0220 & 0.00000 & 0.01033 & 1.97 & 0.00175 & 0.0001830 & 0.0000000 \\
\hline 14 & 0.65 & 0.0296 & 0.347 & 0.507 & 0.0000 & 0.00000 & 0.00757 & 2.36 & 0.00209 & 0.0002295 & 0.0000000 \\
\hline 15 & 0.70 & 0.0149 & 0.115 & 0.915 & 0.0086 & 0.00472 & 0.00025 & 3.09 & 0.00262 & 0.0000363 & 0.0000474 \\
\hline
\end{tabular}




\begin{tabular}{|c|c|c|c|c|c|c|c|c|c|c|c|}
\hline \multirow{2}{*}{ Spot Number } & \multirow{2}{*}{ Distance from inner shell (mm) } & \multicolumn{10}{|c|}{ MR2 nacreous layer transect $\mathrm{N} 2$ corrected data $(\mathrm{mmol} / \mathrm{mol})$} \\
\hline & & $\mathrm{Li} / \mathrm{Ca}$ & $\mathrm{B} / \mathrm{Ca}$ & $\mathrm{Mg} / \mathrm{Ca}$ & $\mathrm{Al} / \mathrm{Ca}$ & $\mathrm{Mn} / \mathrm{Ca}$ & $\mathrm{Zn} / \mathrm{Ca}$ & $\mathrm{Sr} / \mathrm{Ca}$ & $\mathrm{Ba} / \mathrm{Ca}$ & $\mathrm{Pb} / \mathrm{Ca}$ & $\mathrm{U} / \mathrm{Ca}$ \\
\hline 1 & 0.00 & 0.0000 & 0.436 & 0.310 & 0.0306 & 0.00000 & 0.00000 & 1.88 & 0.00228 & 0.0000000 & 0.0000000 \\
\hline 2 & 0.05 & 0.0201 & 0.158 & 0.285 & 0.0222 & 0.00276 & 0.01171 & 1.85 & 0.00205 & 0.0000000 & 0.0000036 \\
\hline 3 & 0.10 & 0.0000 & 0.287 & 0.484 & 0.0343 & 0.01109 & 0.01801 & 1.75 & 0.00266 & 0.0000263 & 0.0000387 \\
\hline 4 & 0.15 & 0.0061 & 0.158 & 0.433 & 0.0000 & 0.00518 & 0.00032 & 1.66 & 0.00187 & 0.0000000 & 0.0000000 \\
\hline 5 & 0.20 & 0.0318 & 0.463 & 0.572 & 0.0087 & 0.00000 & 0.00772 & 1.44 & 0.00169 & 0.0003441 & 0.0000000 \\
\hline 6 & 0.25 & 0.0320 & 0.451 & 0.427 & 0.0288 & 0.00126 & 0.00044 & 1.38 & 0.00153 & 0.0001009 & 0.0000000 \\
\hline 7 & 0.30 & 0.0000 & 0.460 & 0.788 & 0.0137 & 0.00251 & 0.01643 & 1.84 & 0.00211 & 0.0000000 & 0.0000000 \\
\hline 8 & 0.35 & 0.0151 & 0.000 & 0.901 & 0.0103 & 0.00000 & 0.01343 & 1.79 & 0.00256 & 0.0000000 & 0.0000000 \\
\hline 9 & 0.40 & 0.0220 & 0.763 & 1.040 & 0.0083 & 0.00000 & 0.00338 & 1.75 & 0.00227 & 0.0002057 & 0.0000000 \\
\hline 10 & 0.45 & 0.0000 & 0.167 & 0.856 & 0.0526 & 0.00000 & 0.00000 & 1.62 & 0.00171 & 0.0000000 & 0.0001077 \\
\hline 11 & 0.50 & 0.0171 & 0.321 & 0.960 & 0.0349 & 0.00663 & 0.00677 & 1.67 & 0.00131 & 0.0000000 & 0.0000000 \\
\hline 12 & 0.55 & 0.0705 & 0.129 & 1.055 & 0.0155 & 0.00558 & 0.00000 & 1.58 & 0.00181 & 0.0000000 & 0.0000000 \\
\hline 13 & 0.60 & 0.0384 & 0.349 & 1.366 & 0.0095 & 0.00257 & 0.00000 & 1.65 & 0.00207 & 0.0000000 & 0.0000795 \\
\hline 14 & 0.65 & 0.0187 & 0.356 & 1.420 & 0.0029 & 0.00000 & 0.00000 & 1.49 & 0.00142 & 0.0000000 & 0.0001608 \\
\hline 15 & 0.70 & 0.0273 & 0.413 & 1.529 & 0.0000 & 0.00000 & 0.01488 & 1.77 & 0.00104 & 0.0000000 & 0.0000997 \\
\hline 16 & 0.75 & 0.0422 & 0.293 & 1.550 & 0.0073 & 0.00517 & 0.00064 & 1.85 & 0.00176 & 0.0000371 & 0.0000290 \\
\hline 17 & 0.80 & 0.0246 & 0.497 & 1.550 & 0.0000 & 0.00271 & 0.00000 & 1.73 & 0.00172 & 0.0002230 & 0.0000000 \\
\hline 18 & 0.85 & 0.0055 & 0.424 & 1.573 & 0.0207 & 0.00301 & 0.00095 & 2.00 & 0.00246 & 0.0000889 & 0.0000384 \\
\hline 19 & 0.90 & 0.0511 & 0.490 & 2.142 & 0.0000 & 0.00000 & 0.00000 & 1.95 & 0.00276 & 0.0000000 & 0.0000000 \\
\hline 20 & 0.95 & 0.0265 & 0.352 & 1.419 & 0.0232 & 0.00000 & 0.00482 & 1.78 & 0.00144 & 0.0000000 & 0.0000000 \\
\hline 21 & 1.00 & 0.0000 & 0.603 & 1.873 & 0.0048 & 0.00472 & 0.00425 & 2.07 & 0.00242 & 0.0000000 & 0.0000346 \\
\hline 22 & 1.05 & 0.0078 & 0.451 & 2.049 & 0.0118 & 0.00499 & 0.01489 & 2.35 & 0.00270 & 0.0001490 & 0.0000562 \\
\hline
\end{tabular}




\begin{tabular}{|c|c|c|c|c|c|c|c|c|c|c|c|}
\hline \multirow{2}{*}{ Spot Number } & \multirow{2}{*}{ Distance from inner shell (mm) } & \multicolumn{10}{|c|}{ MR2 nacreous layer transect N3corrected data $(\mathrm{mmol} / \mathrm{mol})$} \\
\hline & & $\mathrm{Li} / \mathrm{Ca}$ & $\mathrm{B} / \mathrm{Ca}$ & $\mathrm{Mg} / \mathrm{Ca}$ & $\mathrm{Al} / \mathrm{Ca}$ & $\mathrm{Mn} / \mathrm{Ca}$ & $\mathrm{Zn} / \mathrm{Ca}$ & $\mathrm{Sr} / \mathrm{Ca}$ & $\mathrm{Ba} / \mathrm{Ca}$ & $\mathrm{Pb} / \mathrm{Ca}$ & $\mathrm{U} / \mathrm{Ca}$ \\
\hline 1 & 0.00 & 0.0000 & 0.254 & 0.343 & 0.0256 & 0.00033 & 0.00447 & 1.78 & 0.00335 & 0.0003136 & 0.0000760 \\
\hline 2 & 0.05 & 0.0421 & 0.186 & 0.742 & 0.0519 & 0.00532 & 0.03919 & 1.94 & 0.00163 & 0.0000000 & 0.0000366 \\
\hline 3 & 0.10 & 0.0000 & 0.490 & 0.314 & 0.0000 & 0.00000 & 0.02028 & 1.79 & 0.00216 & 0.0000000 & 0.0000000 \\
\hline 4 & 0.15 & 0.0000 & 0.435 & 0.289 & 0.0048 & 0.00000 & 0.01480 & 1.61 & 0.00239 & 0.0002933 & 0.0000000 \\
\hline 5 & 0.20 & 0.0351 & 0.725 & 0.436 & 0.0000 & 0.00606 & 0.00564 & 1.91 & 0.00262 & 0.0000473 & 0.0000000 \\
\hline 6 & 0.25 & 0.0000 & 0.294 & 0.379 & 0.0000 & 0.01419 & 0.00000 & 1.81 & 0.00199 & 0.0000000 & 0.0000062 \\
\hline 7 & 0.30 & 0.0495 & 0.146 & 0.702 & 0.0000 & 0.00778 & 0.00000 & 1.69 & 0.00137 & 0.0000000 & 0.0000000 \\
\hline 8 & 0.35 & 0.0190 & 0.184 & 0.520 & 0.0486 & 0.00060 & 0.00000 & 1.72 & 0.00155 & 0.0000000 & 0.0000000 \\
\hline 9 & 0.40 & 0.0000 & 1.188 & 1.828 & 0.0418 & 0.00416 & 0.01512 & 2.31 & 0.00243 & 0.0000000 & 0.0000000 \\
\hline 10 & 0.45 & 0.0000 & 0.000 & 0.584 & 0.0000 & 0.00000 & 0.01175 & 1.70 & 0.00212 & 0.0000000 & 0.0000044 \\
\hline 11 & 0.50 & 0.0397 & 0.191 & 0.496 & 0.0524 & 0.00000 & 0.00932 & 1.53 & 0.00138 & 0.0000000 & 0.0000000 \\
\hline 12 & 0.55 & 0.0280 & 0.000 & 0.606 & 0.0000 & 0.00266 & 0.00105 & 1.60 & 0.00119 & 0.0000455 & 0.0000000 \\
\hline 13 & 0.60 & 0.0210 & 0.154 & 0.539 & 0.0000 & 0.00546 & 0.00000 & 1.60 & 0.00133 & 0.0000000 & 0.0001152 \\
\hline 14 & 0.65 & 0.0000 & 0.328 & 0.480 & 0.0260 & 0.00875 & 0.01434 & 1.59 & 0.00097 & 0.0001200 & 0.0000221 \\
\hline 15 & 0.70 & 0.0310 & 0.353 & 0.506 & 0.0632 & 0.00312 & 0.01289 & 1.71 & 0.00158 & 0.0001190 & 0.0000000 \\
\hline 16 & 0.75 & 0.0000 & 0.086 & 0.536 & 0.0144 & 0.00000 & 0.00525 & 1.77 & 0.00138 & 0.0002556 & 0.0000364 \\
\hline 17 & 0.80 & 0.0626 & 0.204 & 0.480 & 0.0000 & 0.00448 & 0.00000 & 1.69 & 0.00137 & 0.0000812 & 0.0000446 \\
\hline 18 & 0.85 & 0.0000 & 0.236 & 0.575 & 0.0000 & 0.00203 & 0.00971 & 1.53 & 0.00136 & 0.0000000 & 0.0000000 \\
\hline 19 & 0.90 & 0.0263 & 0.020 & 0.583 & 0.0261 & 0.00000 & 0.00000 & 1.63 & 0.00113 & 0.0000000 & 0.0000000 \\
\hline 20 & 0.95 & 0.0018 & 0.640 & 0.597 & 0.0000 & 0.00839 & 0.00000 & 1.59 & 0.00116 & 0.0000008 & 0.0000000 \\
\hline 21 & 1.00 & 0.0013 & 0.479 & 0.582 & 0.0000 & 0.00270 & 0.00000 & 1.79 & 0.00095 & 0.0000188 & 0.0001464 \\
\hline 22 & 1.05 & 0.0000 & 0.373 & 0.579 & 0.0615 & 0.00000 & 0.01015 & 1.58 & 0.00141 & 0.0000932 & 0.0000000 \\
\hline 23 & 1.10 & 0.0165 & 0.000 & 0.609 & 0.0000 & 0.00000 & 0.00000 & 1.67 & 0.00154 & 0.0000000 & 0.0000244 \\
\hline 24 & 1.15 & 0.0140 & 0.342 & 0.638 & 0.0072 & 0.00339 & 0.00335 & 1.78 & 0.00132 & 0.0000000 & 0.0000000 \\
\hline 25 & 1.20 & 0.0336 & 0.615 & 0.619 & 0.0000 & 0.00751 & 0.01036 & 1.83 & 0.00162 & 0.0000073 & 0.0000000 \\
\hline 26 & 1.25 & 0.0429 & 0.601 & 0.723 & 0.0147 & 0.00550 & 0.01820 & 1.94 & 0.00251 & 0.0001551 & 0.0000000 \\
\hline 27 & 1.30 & 0.0288 & 0.489 & 0.977 & 0.0132 & 0.00000 & 0.00000 & 2.39 & 0.00326 & 0.0000000 & 0.0000646 \\
\hline
\end{tabular}




\begin{tabular}{|c|c|c|c|c|c|c|c|c|c|c|c|}
\hline \multirow{2}{*}{ Spot Number } & \multirow{2}{*}{ Distance from inner shell $(\mathrm{mm})$} & \multicolumn{10}{|c|}{ MR2 nacreous layer transect $\mathrm{N} 4$ corrected data $(\mathrm{mmol} / \mathrm{mol})$} \\
\hline & & $\mathrm{Li} / \mathrm{Ca}$ & $\mathrm{B} / \mathrm{Ca}$ & $\mathrm{Mg} / \mathrm{Ca}$ & $\mathrm{Al} / \mathrm{Ca}$ & $\mathrm{Mn} / \mathrm{Ca}$ & $\mathrm{Zn} / \mathrm{Ca}$ & $\mathrm{Sr} / \mathrm{Ca}$ & $\mathrm{Ba} / \mathrm{Ca}$ & $\mathrm{Pb} / \mathrm{Ca}$ & $\mathbf{U} / \mathbf{C a}$ \\
\hline 1 & 0.00 & 0.0337 & 0.284 & 0.223 & 0.0097 & 0.00000 & 0.00138 & 1.95 & 0.00299 & 0.0001287 & 0.0000000 \\
\hline 2 & 0.05 & 0.0080 & 0.694 & 0.462 & 0.0148 & 0.00010 & 0.00354 & 1.75 & 0.00243 & 0.0002030 & 0.0000352 \\
\hline 3 & 0.10 & 0.0318 & 0.141 & 0.302 & 0.0000 & 0.00873 & 0.00425 & 1.63 & 0.00195 & 0.0000000 & 0.0000000 \\
\hline 4 & 0.15 & 0.0000 & 0.246 & 0.493 & 0.0000 & 0.00000 & 0.00371 & 3.27 & 0.00262 & 0.0000000 & 0.0001177 \\
\hline 5 & 0.20 & 0.0000 & 0.326 & 0.362 & 0.0000 & 0.00136 & 0.01376 & 1.82 & 0.00199 & 0.0000002 & 0.0000162 \\
\hline 6 & 0.25 & 0.0314 & 0.427 & 0.365 & 0.0031 & 0.00855 & 0.00000 & 1.69 & 0.00206 & 0.0000000 & 0.0000000 \\
\hline 7 & 0.30 & 0.0278 & 0.401 & 0.489 & 0.0000 & 0.00227 & 0.00531 & 1.75 & 0.00216 & 0.0001982 & 0.0000709 \\
\hline 8 & 0.35 & 0.0000 & 0.221 & 0.480 & 0.0000 & 0.00000 & 0.01028 & 1.82 & 0.00192 & 0.0001425 & 0.0000000 \\
\hline 9 & 0.40 & 0.0236 & 0.519 & 0.572 & 0.0177 & 0.00190 & 0.01393 & 1.76 & 0.00164 & 0.0000000 & 0.0000370 \\
\hline 10 & 0.45 & 0.0339 & 0.189 & 0.418 & 0.0381 & 0.00314 & 0.00262 & 1.53 & 0.00201 & 0.0000000 & 0.0000000 \\
\hline 11 & 0.50 & 0.0269 & 0.247 & 0.501 & 0.0000 & 0.00000 & 0.00417 & 1.43 & 0.00161 & 0.0001725 & 0.0000785 \\
\hline 12 & 0.55 & 0.0000 & 0.179 & 0.432 & 0.0186 & 0.00000 & 0.00414 & 1.46 & 0.00224 & 0.0000000 & 0.0000114 \\
\hline 13 & 0.60 & 0.0000 & 0.000 & 0.575 & 0.0217 & 0.00000 & 0.00851 & 1.41 & 0.00213 & 0.0000308 & 0.0000153 \\
\hline 14 & 0.65 & 0.0000 & 0.284 & 0.607 & 0.0038 & 0.00060 & 0.00575 & 1.36 & 0.00110 & 0.0000000 & 0.0000000 \\
\hline 15 & 0.70 & 0.0000 & 0.683 & 0.532 & 0.0253 & 0.00193 & 0.01820 & 1.44 & 0.00195 & 0.0000000 & 0.0000571 \\
\hline 16 & 0.75 & 0.0045 & 0.477 & 0.485 & 0.0349 & 0.00000 & 0.00506 & 1.44 & 0.00129 & 0.0002184 & 0.0000000 \\
\hline 17 & 0.80 & 0.0000 & 0.000 & 0.549 & 0.0257 & 0.00974 & 0.00169 & 1.45 & 0.00160 & 0.0000000 & 0.0000662 \\
\hline 18 & 0.85 & 0.0000 & 0.186 & 0.458 & 0.0104 & 0.00000 & 0.00000 & 1.39 & 0.00139 & 0.0000000 & 0.0000355 \\
\hline 19 & 0.90 & 0.0000 & 0.000 & 0.497 & 0.0334 & 0.00606 & 0.00454 & 1.49 & 0.00128 & 0.0000000 & 0.0000000 \\
\hline 20 & 0.95 & 0.0000 & 0.239 & 0.522 & 0.0064 & 0.00146 & 0.00000 & 1.43 & 0.00175 & 0.0002552 & 0.0000448 \\
\hline 21 & 1.00 & 0.0192 & 0.552 & 0.570 & 0.0215 & 0.00000 & 0.01096 & 1.50 & 0.00195 & 0.0000000 & 0.0000209 \\
\hline 22 & 1.05 & 0.0194 & 0.400 & 0.630 & 0.0183 & 0.00000 & 0.00000 & 1.60 & 0.00096 & 0.0000958 & 0.0000157 \\
\hline 23 & 1.10 & 0.0328 & 0.666 & 0.605 & 0.0329 & 0.00000 & 0.00000 & 1.59 & 0.00164 & 0.0000289 & 0.0000564 \\
\hline 24 & 1.15 & 0.0208 & 0.000 & 0.658 & 0.0000 & 0.00000 & 0.01717 & 1.74 & 0.00166 & 0.0001596 & 0.0000658 \\
\hline 25 & 1.20 & 0.0157 & 0.000 & 0.686 & 0.0000 & 0.00000 & 0.01189 & 1.66 & 0.00193 & 0.0000000 & 0.0000481 \\
\hline 26 & 1.25 & 0.0034 & 0.595 & 1.080 & 0.0000 & 0.00064 & 0.00728 & 2.20 & 0.00360 & 0.0000961 & 0.0000910 \\
\hline
\end{tabular}


APPENDIX 5.2m MD1 nacreous layer data

\begin{tabular}{|c|c|c|c|c|c|c|c|c|c|c|c|}
\hline \multirow{2}{*}{ Spot Number } & \multirow{2}{*}{ Distance from inner shell (mm) } & \multicolumn{10}{|c|}{ MD1 nacreous layer transect $\mathrm{N} 1$ corrected data $(\mathrm{mmol} / \mathrm{mol})$} \\
\hline & & $\mathrm{Li} / \mathrm{Ca}$ & $\mathrm{B} / \mathrm{Ca}$ & $\mathrm{Mg} / \mathrm{Ca}$ & $\mathrm{Al} / \mathrm{Ca}$ & $\mathrm{Mn} / \mathrm{Ca}$ & $\mathrm{Zn} / \mathrm{Ca}$ & $\mathrm{Sr} / \mathrm{Ca}$ & $\mathrm{Ba} / \mathrm{Ca}$ & $\mathrm{Pb} / \mathrm{Ca}$ & $\mathrm{U} / \mathrm{Ca}$ \\
\hline 1 & 0.00 & 0.0239 & 0.2727 & 0.34 & 0.0000 & 0.00000 & 0.0000 & 1.50 & 0.000499 & 0.0000000 & 0.0000000 \\
\hline 2 & 0.05 & 0.0123 & 0.0000 & 0.29 & 0.0007 & 0.00000 & 0.0053 & 1.48 & 0.001571 & 0.0000719 & 0.0000000 \\
\hline 3 & 0.10 & 0.0136 & 0.1027 & 0.19 & 0.0345 & 0.00897 & 0.0081 & 1.46 & 0.001226 & 0.0000000 & 0.0000476 \\
\hline 4 & 0.15 & 0.0108 & 0.0000 & 0.16 & 0.0047 & 0.00039 & 0.0064 & 1.41 & 0.001066 & 0.0001342 & 0.0000000 \\
\hline 5 & 0.20 & 0.0000 & 0.0000 & 0.16 & 0.0112 & 0.00534 & 0.0025 & 1.32 & 0.000946 & 0.0000000 & 0.0000247 \\
\hline 6 & 0.25 & 0.0152 & 0.6889 & 0.25 & 0.0117 & 0.00513 & 0.0000 & 1.62 & 0.000646 & 0.0000000 & 0.0000000 \\
\hline 7 & 0.30 & 0.0361 & 0.2493 & 0.36 & 0.0060 & 0.00281 & 0.0063 & 1.91 & 0.001095 & 0.0000003 & 0.0000432 \\
\hline 8 & 0.35 & 0.0002 & 0.0197 & 0.28 & 0.0143 & 0.00107 & 0.0000 & 1.55 & 0.000969 & 0.0001868 & 0.0000052 \\
\hline 9 & 0.40 & 0.0000 & 0.1950 & 0.32 & 0.0134 & 0.00000 & 0.0105 & 1.49 & 0.001444 & 0.0000000 & 0.0000241 \\
\hline 10 & 0.45 & 0.0007 & 0.4010 & 0.43 & 0.0000 & 0.00228 & 0.0006 & 1.62 & 0.001227 & 0.0000000 & 0.0001155 \\
\hline 11 & 0.50 & 0.0000 & 0.4803 & 0.44 & 0.0085 & 0.00563 & 0.0118 & 1.88 & 0.001805 & 0.0000427 & 0.0000508 \\
\hline 12 & 0.55 & 0.0116 & 0.2455 & 0.41 & 0.0166 & 0.00000 & 0.0000 & 1.81 & 0.001381 & 0.0001034 & 0.0000405 \\
\hline 13 & 0.60 & 0.0241 & 0.3332 & 0.47 & 0.0123 & 0.00366 & 0.0052 & 2.04 & 0.001835 & 0.0000000 & 0.0000000 \\
\hline 14 & 0.65 & 0.0260 & 0.0937 & 0.54 & 0.0124 & 0.00425 & 0.0070 & 1.94 & 0.002022 & 0.0000000 & 0.0000418 \\
\hline 15 & 0.70 & 0.0036 & 0.3291 & 0.52 & 0.0049 & 0.00285 & 0.0000 & 1.71 & 0.001361 & 0.0000000 & 0.0000000 \\
\hline 16 & 0.75 & 0.0124 & 0.0693 & 0.43 & 0.0025 & 0.00680 & 0.0044 & 1.93 & 0.001922 & 0.0001361 & 0.0000366 \\
\hline 17 & 0.80 & 0.0271 & 0.6218 & 0.39 & 0.0080 & 0.00300 & 0.0080 & 1.74 & 0.000881 & 0.0000000 & 0.0000101 \\
\hline 18 & 0.85 & 0.0000 & 0.3914 & 0.49 & 0.0020 & 0.00000 & 0.0006 & 1.93 & 0.000901 & 0.0002800 & 0.0000365 \\
\hline 19 & 0.90 & 0.0093 & 0.2365 & 0.37 & 0.0628 & 0.00358 & 0.0127 & 1.92 & 0.001287 & 0.0000479 & 0.0000000 \\
\hline
\end{tabular}


APPENDIX 5.2n

MD3 nacreous layer transect data

\begin{tabular}{|c|c|c|c|c|c|c|c|c|c|c|c|}
\hline \multirow{2}{*}{$\begin{array}{c}\text { Spot } \\
\text { Number }\end{array}$} & \multirow{2}{*}{ Distance from inner shell $(\mathrm{mm})$} & \multicolumn{10}{|c|}{ MD3 nacreous layer transect $\mathrm{N} 1$ corrected data $(\mathrm{mmol} / \mathrm{mol})$} \\
\hline & & $\mathrm{Li} / \mathrm{Ca}$ & $\mathrm{B} / \mathrm{Ca}$ & $\mathrm{Mg} / \mathrm{Ca}$ & $\mathbf{A l} / \mathbf{C a}$ & $\mathrm{Mn} / \mathrm{Ca}$ & $\mathrm{Zn} / \mathrm{Ca}$ & $\mathrm{Sr} / \mathrm{Ca}$ & $\mathrm{Ba} / \mathrm{Ca}$ & $\mathrm{Pb} / \mathrm{Ca}$ & $\mathbf{U} / \mathbf{C a}$ \\
\hline 1 & 0.00 & 0.0000 & 0.0498 & 0.213 & 0.00000 & 0.00000 & 0.0000 & 1.50 & 0.000430 & 0.0000000 & 0.0000000 \\
\hline 2 & 0.05 & 0.0008 & 0.0333 & 0.260 & 0.00000 & 0.00000 & 0.0134 & 1.50 & 0.000555 & 0.0000374 & 0.0000000 \\
\hline 3 & 0.10 & 0.0000 & 0.0421 & 0.380 & 0.00000 & 0.00344 & 0.0076 & 1.53 & 0.000665 & 0.0001038 & 0.0000000 \\
\hline 4 & 0.15 & 0.0186 & 17.8210 & 116.078 & 0.02567 & 0.04072 & 0.0790 & 3.58 & 0.002279 & 0.0003739 & 0.0000000 \\
\hline 5 & 0.20 & 0.0085 & 0.0691 & 0.297 & 0.00000 & 0.00044 & 0.0072 & 1.66 & 0.001041 & 0.0000100 & 0.0000000 \\
\hline 6 & 0.25 & 0.0103 & 0.0376 & 0.334 & 0.00641 & 0.00000 & 0.0202 & 1.58 & 0.001009 & 0.0000078 & 0.0000000 \\
\hline 7 & 0.30 & 0.0000 & 0.0526 & 0.412 & 0.00000 & 0.00000 & 0.0134 & 1.91 & 0.000664 & 0.0000000 & 0.0000000 \\
\hline 8 & 0.35 & 0.0257 & 0.0589 & 0.269 & 0.00108 & 0.00000 & 0.0121 & 1.69 & 0.000659 & 0.0000054 & 0.0000000 \\
\hline 9 & 0.40 & 0.0190 & 0.0428 & 0.352 & 0.00000 & 0.00201 & 0.0075 & 1.73 & 0.000772 & 0.0000220 & 0.0000129 \\
\hline 10 & 0.45 & 0.0000 & 0.0271 & 0.605 & 0.00715 & 0.00142 & 0.0060 & 2.11 & 0.000735 & 0.0000466 & 0.0000000 \\
\hline 11 & 0.50 & 0.0018 & 0.0491 & 0.397 & 0.00293 & 0.00000 & 0.0029 & 1.49 & 0.000631 & 0.0001546 & 0.0000101 \\
\hline 12 & 0.55 & 0.0000 & 0.0346 & 0.375 & 0.00000 & 0.00000 & 0.0091 & 1.58 & 0.000520 & 0.0000548 & 0.0000000 \\
\hline 13 & 0.60 & 0.0000 & 0.0170 & 0.401 & 0.00000 & 0.00444 & 0.0131 & 1.44 & 0.000156 & 0.0000000 & 0.0000000 \\
\hline 14 & 0.65 & 0.0101 & 0.0528 & 0.411 & 0.00508 & 0.00230 & 0.0060 & 1.73 & 0.000589 & 0.0000840 & 0.0000203 \\
\hline 15 & 0.70 & 0.0110 & 0.0851 & 0.530 & 0.00000 & 0.00000 & 0.0077 & 1.97 & 0.000954 & 0.0000041 & 0.0000166 \\
\hline 16 & 0.75 & 0.0198 & 0.0496 & 0.425 & 0.00000 & 0.00046 & 0.0077 & 1.59 & 0.000814 & 0.0000000 & 0.0000541 \\
\hline 17 & 0.80 & 0.0150 & 0.0643 & 0.321 & 0.00000 & 0.00087 & 0.0062 & 1.49 & 0.000577 & 0.0000000 & 0.0000000 \\
\hline 18 & 0.85 & 0.0000 & 0.0430 & 0.343 & 0.00164 & 0.00221 & 0.0012 & 1.47 & 0.000721 & 0.0000319 & 0.0000000 \\
\hline 19 & 0.90 & 0.0000 & 0.0473 & 0.372 & 0.00385 & 0.00000 & 0.0041 & 1.58 & 0.000688 & 0.0000669 & 0.0000000 \\
\hline 20 & 0.95 & 0.0118 & 0.0712 & 0.339 & 0.00139 & 0.00000 & 0.0116 & 1.71 & 0.000684 & 0.0000871 & 0.0000000 \\
\hline 21 & 1.00 & 0.0095 & 0.0531 & 0.341 & 0.00000 & 0.00009 & 0.0165 & 1.72 & 0.000790 & 0.0000082 & 0.0000113 \\
\hline 22 & 1.05 & 0.0000 & 0.0652 & 0.268 & 0.00161 & 0.00000 & 0.0086 & 1.67 & 0.000716 & 0.0000000 & 0.0000088 \\
\hline 23 & 1.10 & 0.0147 & 0.0700 & 0.334 & 0.00000 & 0.00000 & 0.0148 & 1.71 & 0.000705 & 0.0000067 & 0.0000000 \\
\hline 24 & 1.15 & 0.0139 & 0.0541 & 0.257 & 0.00000 & 0.00000 & 0.0043 & 1.71 & 0.000707 & 0.0000232 & 0.0000010 \\
\hline 25 & 1.20 & 0.0000 & 0.0412 & 0.283 & 0.00000 & 0.00280 & 0.0064 & 1.71 & 0.000676 & 0.0000269 & 0.0000000 \\
\hline 26 & 1.25 & 0.0140 & 0.0677 & 0.300 & 0.00115 & 0.00303 & 0.0038 & 1.70 & 0.000782 & 0.0000081 & 0.0000000 \\
\hline 27 & 1.30 & 0.0137 & 0.0878 & 0.267 & 0.00000 & 0.00066 & 0.0086 & 1.88 & 0.000855 & 0.0000462 & 0.0000000 \\
\hline 28 & 1.35 & 0.0322 & 0.0680 & 0.366 & 0.00000 & 0.00083 & 0.0111 & 1.93 & 0.001068 & 0.0000000 & 0.0000046 \\
\hline 29 & 1.40 & 0.0028 & 0.0830 & 0.582 & 0.00200 & 0.00083 & 0.0082 & 2.06 & 0.001194 & 0.0000000 & 0.0000054 \\
\hline 30 & 1.45 & 0.0132 & 0.0655 & 0.363 & 0.00000 & 0.00033 & 0.0164 & 2.19 & 0.001102 & 0.0000000 & 0.0000122 \\
\hline
\end{tabular}




\begin{tabular}{|c|c|c|c|c|c|c|c|c|c|c|c|}
\hline \multirow{2}{*}{$\begin{array}{c}\text { Spot } \\
\text { Number }\end{array}$} & \multirow{2}{*}{ Distance from inner shell $(\mathrm{mm})$} & \multicolumn{10}{|c|}{ MD3 nacreous layer transect $\mathrm{N} 2$ corrected data $(\mathrm{mmol} / \mathrm{mol})$} \\
\hline & & $\mathrm{Li} / \mathrm{Ca}$ & $\mathrm{B} / \mathrm{Ca}$ & $\mathrm{Mg} / \mathrm{Ca}$ & $\mathrm{Al} / \mathrm{Ca}$ & $\mathrm{Mn} / \mathrm{Ca}$ & $\mathrm{Zn} / \mathrm{Ca}$ & $\mathrm{Sr} / \mathrm{Ca}$ & $\mathrm{Ba} / \mathrm{Ca}$ & $\mathrm{Pb} / \mathrm{Ca}$ & $\mathrm{U} / \mathrm{Ca}$ \\
\hline 1 & 0.00 & 0.0051 & 0.0136 & 0.247 & 0.00304 & 0.00262 & 0.0159 & 1.78 & 0.00111 & 0.0000737 & 0.0000000 \\
\hline 2 & 0.05 & 0.0000 & 0.0278 & 0.235 & 0.00061 & 0.00462 & 0.0035 & 1.65 & 0.00082 & 0.0000215 & 0.0000000 \\
\hline 3 & 0.10 & 0.0177 & 0.0096 & 0.478 & 0.00079 & 0.00000 & 0.0000 & 1.91 & 0.00083 & 0.0000771 & 0.0000057 \\
\hline 4 & 0.15 & 0.0000 & 0.0641 & 0.676 & 0.00119 & 0.00015 & 0.0085 & 2.34 & 0.00125 & 0.0000000 & 0.0000028 \\
\hline 5 & 0.20 & 0.0115 & 0.0393 & 0.299 & 0.00175 & 0.00000 & 0.0046 & 1.80 & 0.00076 & 0.0000298 & 0.0000000 \\
\hline 6 & 0.25 & 0.0008 & 0.0431 & 0.340 & 0.00335 & 0.00136 & 0.0075 & 1.60 & 0.00090 & 0.0000230 & 0.0000162 \\
\hline 7 & 0.30 & 0.0181 & 0.0188 & 0.482 & 0.00000 & 0.00026 & 0.0186 & 2.01 & 0.00277 & 0.0000989 & 0.0000000 \\
\hline 8 & 0.35 & 0.0144 & 0.0292 & 0.319 & 0.00000 & 0.00105 & 0.0084 & 1.74 & 0.00084 & 0.0002086 & 0.0000000 \\
\hline 9 & 0.40 & 0.0078 & 1.4325 & 5.229 & 0.01126 & 0.00516 & 0.0171 & 3.49 & 0.00181 & 0.0000887 & 0.0000286 \\
\hline 10 & 0.45 & 0.0153 & 0.0234 & 0.353 & 0.00000 & 0.00056 & 0.0000 & 1.43 & 0.00057 & 0.0000000 & 0.0000109 \\
\hline 11 & 0.50 & 0.0000 & 0.0747 & 0.400 & 0.00000 & 0.00408 & 0.0019 & 1.61 & 0.00070 & 0.0000000 & 0.0000000 \\
\hline 12 & 0.55 & 0.0262 & 0.0322 & 0.320 & 0.00013 & 0.00405 & 0.0167 & 1.52 & 0.00069 & 0.0001395 & 0.0000005 \\
\hline 13 & 0.60 & 0.0172 & 0.0381 & 0.346 & 0.00000 & 0.00259 & 0.0017 & 1.48 & 0.00065 & 0.0000767 & 0.0000000 \\
\hline 14 & 0.65 & 0.0003 & 0.0583 & 0.297 & 0.00118 & 0.00140 & 0.0071 & 1.50 & 0.00067 & 0.0000252 & 0.0000045 \\
\hline 15 & 0.70 & 0.0112 & 0.0285 & 0.324 & 0.00000 & 0.00106 & 0.0105 & 1.51 & 0.00078 & 0.0001172 & 0.0000139 \\
\hline 16 & 0.75 & 0.0002 & 0.0548 & 0.290 & 0.00685 & 0.00545 & 0.0026 & 1.55 & 0.00060 & 0.0000000 & 0.0000284 \\
\hline 17 & 0.80 & 0.0047 & 0.0695 & 0.294 & 0.00556 & 0.00270 & 0.0010 & 1.59 & 0.00083 & 0.0000000 & 0.0000138 \\
\hline 18 & 0.85 & 0.0099 & 0.0607 & 0.276 & 0.00294 & 0.00039 & 0.0057 & 1.55 & 0.00069 & 0.0000000 & 0.0000176 \\
\hline 19 & 0.90 & 0.0037 & 0.0673 & 0.297 & 0.00000 & 0.00096 & 0.0070 & 1.61 & 0.00062 & 0.0000000 & 0.0000000 \\
\hline 20 & 0.95 & 0.0110 & 0.1224 & 0.267 & 0.01881 & 0.00797 & 0.0045 & 1.75 & 0.00088 & 0.0000000 & 0.0000078 \\
\hline 21 & 1.00 & 0.0047 & 0.0641 & 0.346 & 0.00000 & 0.00000 & 0.0000 & 1.66 & 0.00097 & 0.0000245 & 0.0000000 \\
\hline 22 & 1.05 & 0.0165 & 0.0706 & 0.362 & 0.00199 & 0.00180 & 0.0151 & 1.97 & 0.00108 & 0.0000519 & 0.0000156 \\
\hline 23 & 1.10 & 0.0000 & 0.0809 & 0.349 & 0.00136 & 0.00060 & 0.0175 & 2.07 & 0.00118 & 0.0000000 & 0.0000000 \\
\hline 24 & 1.15 & 0.0000 & 0.1069 & 0.383 & 0.00514 & 0.00268 & 0.0157 & 2.23 & 0.00125 & 0.0000785 & 0.0000421 \\
\hline 25 & 1.20 & 0.0096 & 0.0968 & 0.460 & 0.00305 & 0.00467 & 0.0127 & 2.08 & 0.00130 & 0.0000000 & 0.0000025 \\
\hline
\end{tabular}




\begin{tabular}{|c|c|c|c|c|c|c|c|c|c|c|c|}
\hline \multirow{2}{*}{$\begin{array}{c}\text { Spot } \\
\text { Number }\end{array}$} & \multirow{2}{*}{ Distance from inner shell ( $\mathrm{mm})$} & \multicolumn{10}{|c|}{ MD3 nacreous layer transect N3 corrected data $(\mathrm{mmol} / \mathrm{mol})$} \\
\hline & & $\mathrm{Li} / \mathrm{Ca}$ & $\mathrm{B} / \mathrm{Ca}$ & $\mathrm{Mg} / \mathrm{Ca}$ & $\mathrm{Al} / \mathrm{Ca}$ & $\mathrm{Mn} / \mathrm{Ca}$ & $\mathrm{Zn} / \mathrm{Ca}$ & $\mathrm{Sr} / \mathrm{Ca}$ & $\mathrm{Ba} / \mathrm{Ca}$ & $\mathrm{Pb} / \mathrm{Ca}$ & $\mathrm{U} / \mathrm{Ca}$ \\
\hline 1 & 0.00 & 0.0192 & 0.0216 & 0.196 & 0.00395 & 0.00067 & 0.0059 & 1.72 & 0.000597 & 0.0000159 & 0.0000000 \\
\hline 2 & 0.05 & 0.0154 & 0.0453 & 0.206 & 0.00371 & 0.00241 & 0.0048 & 1.80 & 0.000831 & 0.0000060 & 0.0000254 \\
\hline 3 & 0.10 & 0.0268 & 0.0756 & 0.364 & 0.00046 & 0.00671 & 0.0106 & 1.93 & 0.000758 & 0.0000000 & 0.0000000 \\
\hline 4 & 0.15 & 0.0152 & 1.8824 & 13.492 & 0.00000 & 0.01195 & 0.0093 & 3.94 & 0.001903 & 0.0000000 & 0.0000184 \\
\hline 5 & 0.20 & 0.0000 & 0.0362 & 0.360 & 0.00392 & 0.00099 & 0.0017 & 1.63 & 0.000524 & 0.0000000 & 0.0000000 \\
\hline 6 & 0.25 & 0.0000 & 0.0304 & 0.597 & 0.00000 & 0.00173 & 0.0034 & 2.28 & 0.000674 & 0.0000696 & 0.0000000 \\
\hline 7 & 0.30 & 0.0086 & 0.0162 & 0.622 & 0.00000 & 0.00229 & 0.0018 & 1.72 & 0.000505 & 0.0000000 & 0.0000413 \\
\hline 8 & 0.35 & 0.0079 & 0.0604 & 0.441 & 0.00219 & 0.00000 & 0.0136 & 1.89 & 0.000557 & 0.0000567 & 0.0000000 \\
\hline 9 & 0.40 & 0.0118 & 0.0478 & 0.364 & 0.00000 & 0.00285 & 0.0046 & 1.68 & 0.000571 & 0.0000147 & 0.0000000 \\
\hline 10 & 0.45 & 0.0000 & 0.0387 & 0.348 & 0.00911 & 0.00161 & 0.0023 & 1.68 & 0.000510 & 0.0000664 & 0.0000283 \\
\hline 11 & 0.50 & 0.0142 & 0.0558 & 0.356 & 0.00000 & 0.00234 & 0.0065 & 1.69 & 0.000441 & 0.0000577 & 0.0000070 \\
\hline 12 & 0.55 & 0.0278 & 0.0280 & 0.348 & 0.00753 & 0.00186 & 0.0020 & 1.86 & 0.000698 & 0.0001465 & 0.0000030 \\
\hline 13 & 0.60 & 0.0004 & 0.0655 & 0.329 & 0.00726 & 0.00080 & 0.0000 & 1.71 & 0.000662 & 0.0000760 & 0.0000000 \\
\hline 14 & 0.65 & 0.0076 & 0.0485 & 0.395 & 0.00000 & 0.00137 & 0.0034 & 2.37 & 0.000806 & 0.0000000 & 0.0000271 \\
\hline 15 & 0.70 & 0.0109 & 0.0679 & 0.346 & 0.00000 & 0.00375 & 0.0127 & 1.89 & 0.000700 & 0.0000336 & 0.0000158 \\
\hline 16 & 0.75 & 0.0036 & 0.0481 & 0.315 & 0.00774 & 0.00000 & 0.0103 & 2.00 & 0.000647 & 0.0000000 & 0.0000027 \\
\hline 17 & 0.80 & 0.0001 & 0.0936 & 0.399 & 0.00066 & 0.00000 & 0.0052 & 2.26 & 0.000900 & 0.0000000 & 0.0000062 \\
\hline
\end{tabular}




\begin{tabular}{|c|c|c|c|c|c|c|c|c|c|c|c|}
\hline \multirow{2}{*}{$\begin{array}{c}\text { Spot } \\
\text { Number }\end{array}$} & \multirow{2}{*}{ Distance from inner shell ( $\mathrm{mm}$ ) } & \multicolumn{10}{|c|}{ MD3 nacreous layer transect $\mathrm{N} 4$ corrected data $(\mathrm{mmol} / \mathrm{mol})$} \\
\hline & & $\mathrm{Li} / \mathrm{Ca}$ & $\mathrm{B} / \mathrm{Ca}$ & $\mathrm{Mg} / \mathrm{Ca}$ & $\mathrm{Al} / \mathrm{Ca}$ & $\mathrm{Mn} / \mathrm{Ca}$ & $\mathrm{Zn} / \mathrm{Ca}$ & $\mathrm{Sr} / \mathrm{Ca}$ & $\mathrm{Ba} / \mathrm{Ca}$ & $\mathrm{Pb} / \mathrm{Ca}$ & $\mathrm{U} / \mathrm{Ca}$ \\
\hline 1 & 0.00 & 0.0133 & 0.0422 & 0.257 & 0.00112 & 0.00000 & 0.0150 & 1.49 & 0.001057 & 0.0000596 & 0.0000000 \\
\hline 2 & 0.05 & 0.0169 & 0.0352 & 0.212 & 0.00000 & 0.00351 & 0.0031 & 1.45 & 0.000727 & 0.0000000 & 0.0000632 \\
\hline 3 & 0.10 & 0.0011 & 0.0187 & 0.275 & 0.00000 & 0.00312 & 0.0095 & 1.57 & 0.000680 & 0.0001128 & 0.0000000 \\
\hline 4 & 0.15 & 0.0205 & 0.0313 & 0.330 & 0.00955 & 0.00000 & 0.0081 & 1.41 & 0.000535 & 0.0000676 & 0.0000184 \\
\hline 5 & 0.20 & 0.0012 & 0.0446 & 0.211 & 0.00238 & 0.00049 & 0.0074 & 1.57 & 0.000608 & 0.0000000 & 0.0000301 \\
\hline 6 & 0.25 & 0.0000 & 0.0653 & 0.221 & 0.00187 & 0.00233 & 0.0117 & 1.59 & 0.000680 & 0.0001281 & 0.0000178 \\
\hline 7 & 0.30 & 0.0169 & 0.0179 & 0.220 & 0.00000 & 0.00088 & 0.0165 & 1.54 & 0.000588 & 0.0000000 & 0.0000019 \\
\hline 8 & 0.35 & 0.0000 & 0.0940 & 0.244 & 0.00000 & 0.00618 & 0.0024 & 1.62 & 0.000585 & 0.0000789 & 0.0000000 \\
\hline 9 & 0.40 & 0.0116 & 0.0635 & 0.290 & 0.00000 & 0.00000 & 0.0120 & 1.60 & 0.000617 & 0.0001216 & 0.0000000 \\
\hline 10 & 0.45 & 0.0117 & 0.1107 & 1.356 & 0.00625 & 0.00394 & 0.0115 & 3.32 & 0.001397 & 0.0000046 & 0.0000463 \\
\hline 11 & 0.50 & 0.0065 & 0.0102 & 0.333 & 0.01234 & 0.00374 & 0.0080 & 2.04 & 0.000718 & 0.0000709 & 0.0000000 \\
\hline 12 & 0.55 & 0.0037 & 0.0482 & 0.378 & 0.00000 & 0.00000 & 0.0093 & 2.09 & 0.000934 & 0.0000000 & 0.0000152 \\
\hline 13 & 0.60 & 0.0172 & 0.0284 & 0.467 & 0.00000 & 0.00231 & 0.0039 & 2.34 & 0.001158 & 0.0000627 & 0.0000033 \\
\hline 14 & 0.65 & 0.0136 & 0.0232 & 0.701 & 0.00000 & 0.00000 & 0.0000 & 2.98 & 0.001275 & 0.0000270 & 0.0000628 \\
\hline 15 & 0.70 & 0.0171 & 0.0777 & 0.589 & 0.00305 & 0.00000 & 0.0189 & 2.69 & 0.001474 & 0.0000346 & 0.0000006 \\
\hline 16 & 0.75 & 0.0085 & 0.0247 & 0.518 & 0.00102 & 0.00460 & 0.0151 & 2.39 & 0.001314 & 0.0001768 & 0.0000442 \\
\hline 17 & 0.80 & 0.0056 & 0.0782 & 0.456 & 0.00000 & 0.00170 & 0.0172 & 2.33 & 0.001097 & 0.0000305 & 0.0000000 \\
\hline 18 & 0.85 & 0.0157 & 0.0562 & 0.480 & 0.00000 & 0.00469 & 0.0113 & 2.43 & 0.001100 & 0.0000759 & 0.0000000 \\
\hline 19 & 0.90 & 0.0188 & 0.0262 & 0.411 & 0.00000 & 0.00360 & 0.0115 & 2.42 & 0.001176 & 0.0000017 & 0.0000175 \\
\hline
\end{tabular}


APPENDIX 5.3a $\quad$ RW75 growth band data

\begin{tabular}{|c|c|c|c|c|c|c|c|c|c|c|}
\hline \multirow{2}{*}{ Spot Number } & \multirow{2}{*}{ Distance from outer shell (mm) } & \multicolumn{9}{|c|}{ RW75 growth band transect L1 corrected data $(\mathrm{mmol} / \mathrm{mol})$} \\
\hline & & $\mathrm{Li} / \mathrm{Ca}$ & $\mathrm{B} / \mathrm{Ca}$ & $\mathrm{Mg} / \mathrm{Ca}$ & $\mathrm{Al} / \mathrm{Ca}$ & $\mathrm{Mn} / \mathrm{Ca}$ & $\mathrm{Zn} / \mathrm{Ca}$ & $\mathrm{Sr} / \mathrm{Ca}$ & $\mathrm{Ba} / \mathrm{Ca}$ & $\mathrm{U} / \mathrm{Ca}$ \\
\hline 1 & 0.00 & 0.0000 & 0.0084 & 22.70 & 0.00000 & 0.00000 & 0.00000 & 1.44 & 0.000000 & 0.0000000 \\
\hline 2 & 0.05 & 0.0147 & 0.0000 & 15.02 & 0.00119 & 0.00025 & 0.00237 & 1.40 & 0.000491 & 0.0000004 \\
\hline 3 & 0.10 & 0.0101 & 0.0065 & 10.30 & 0.00168 & 0.00124 & 0.01038 & 1.38 & 0.000517 & 0.0000183 \\
\hline 4 & 0.15 & 0.0103 & 0.0000 & 8.57 & 0.00282 & 0.00121 & 0.00522 & 1.38 & 0.000434 & 0.0000000 \\
\hline 5 & 0.20 & 0.0076 & 0.0132 & 6.04 & 0.00200 & 0.00133 & 0.00185 & 1.27 & 0.000377 & 0.0000000 \\
\hline 6 & 0.25 & 0.0006 & 0.0019 & 5.20 & 0.00000 & 0.00064 & 0.00569 & 1.18 & 0.000145 & 0.0000000 \\
\hline 7 & 0.30 & 0.0058 & 0.0000 & 5.35 & 0.00000 & 0.00104 & 0.00120 & 1.18 & 0.000309 & 0.0000316 \\
\hline 8 & 0.35 & 0.0065 & 0.0197 & 5.44 & 0.00071 & 0.00043 & 0.00190 & 1.01 & 0.000352 & 0.0000000 \\
\hline 9 & 0.40 & 0.0089 & 0.0060 & 5.96 & 0.00100 & 0.00134 & 0.00112 & 0.94 & 0.000250 & 0.0000208 \\
\hline 10 & 0.45 & 0.0007 & 0.0000 & 6.03 & 0.00000 & 0.00000 & 0.00053 & 0.89 & 0.000000 & 0.0000000 \\
\hline 11 & 0.50 & 0.0107 & 0.0030 & 6.18 & 0.29391 & 0.00484 & 0.01140 & 1.28 & 0.001063 & 0.0000702 \\
\hline 12 & 0.55 & 0.0116 & 0.0000 & 4.23 & 0.00000 & 0.00074 & 0.00455 & 1.93 & 0.000681 & 0.0000000 \\
\hline 13 & 0.60 & 0.0076 & 0.0225 & 4.00 & 0.00000 & 0.00000 & 0.00402 & 1.84 & 0.000657 & 0.0000840 \\
\hline
\end{tabular}




\begin{tabular}{|c|c|c|c|c|c|c|c|c|c|c|}
\hline \multirow{2}{*}{ Spot Number } & \multirow{2}{*}{ Distance from outer shell $(\mathrm{mm})$} & \multicolumn{9}{|c|}{ RW75 growth band transect L2 corrected data $(\mathrm{mmol} / \mathrm{mol})$} \\
\hline & & $\mathrm{Li} / \mathrm{Ca}$ & $\mathrm{B} / \mathrm{Ca}$ & $\mathrm{Mg} / \mathrm{Ca}$ & $\mathrm{Al} / \mathrm{Ca}$ & $\mathrm{Mn} / \mathrm{Ca}$ & $\mathrm{Zn} / \mathrm{Ca}$ & $\mathrm{Sr} / \mathrm{Ca}$ & $\mathrm{Ba} / \mathrm{Ca}$ & $\mathrm{U} / \mathrm{Ca}$ \\
\hline 1 & 0.00 & 0.0081 & 0.0423 & 2.51 & 0.00137 & 0.00062 & 0.00810 & 3.39 & 0.001561 & 0.0000279 \\
\hline 2 & 0.05 & 0.0110 & 0.0000 & 13.44 & 0.00014 & 0.00234 & 0.00151 & 0.90 & 0.000369 & 0.0000179 \\
\hline 3 & 0.10 & 0.0062 & 0.0151 & 8.66 & 0.00204 & 0.00185 & 0.00209 & 1.01 & 0.000282 & 0.0000000 \\
\hline 4 & 0.15 & 0.0075 & 0.0000 & 5.74 & 0.00000 & 0.00111 & 0.00568 & 1.20 & 0.000381 & 0.0000097 \\
\hline 5 & 0.20 & 0.0072 & 0.0000 & 4.37 & 0.00000 & 0.00135 & 0.00259 & 1.23 & 0.000297 & 0.0000000 \\
\hline 6 & 0.25 & 0.0095 & 0.0087 & 5.82 & 0.25146 & 0.00114 & 0.00313 & 1.28 & 0.000512 & 0.0000223 \\
\hline 7 & 0.30 & 0.0095 & 0.0166 & 4.20 & 0.06200 & 0.00322 & 0.01841 & 1.46 & 0.002183 & 0.0000186 \\
\hline 8 & 0.35 & 0.0086 & 0.0010 & 5.14 & 0.02727 & 0.00178 & 0.00657 & 1.28 & 0.001110 & 0.0000009 \\
\hline 9 & 0.40 & 0.0056 & 0.0000 & 4.77 & 0.00243 & 0.00168 & 0.00398 & 1.13 & 0.000355 & $0.000016 \mathrm{~s}$ \\
\hline 10 & 0.45 & 0.0047 & 0.0006 & 5.61 & 0.00000 & 0.00327 & 0.00305 & 1.04 & 0.000299 & 0.0000330 \\
\hline 11 & 0.50 & 0.0080 & 0.0040 & 5.36 & 0.00077 & 0.00097 & 0.00115 & 1.02 & 0.000269 & 0.0000141 \\
\hline 12 & 0.55 & 0.0088 & 0.0000 & 9.57 & 0.00000 & 0.00126 & 0.00227 & 0.95 & 0.000267 & 0.0000252 \\
\hline 13 & 0.60 & 0.0111 & 0.0117 & 13.43 & 0.00011 & 0.00084 & 0.00199 & 0.97 & 0.000232 & 0.0000000 \\
\hline 14 & 0.65 & 0.0127 & 0.0104 & 12.67 & 0.00000 & 0.00340 & 0.00359 & 0.93 & 0.000226 & $0.000018 \mathrm{~s}$ \\
\hline 15 & 0.70 & 0.0153 & 0.0139 & 8.24 & 0.00000 & 0.00315 & 0.00336 & 2.09 & 0.001485 & $0.000000 s$ \\
\hline
\end{tabular}




\begin{tabular}{|c|c|c|c|c|c|c|c|c|c|c|}
\hline \multirow{2}{*}{ Spot Number } & \multirow{2}{*}{ Distance from outer shell $(\mathrm{mm})$} & \multicolumn{9}{|c|}{ RW75 growth band transect L3 corrected data $(\mathrm{mmol} / \mathrm{mol})$} \\
\hline & & $\mathrm{Li} / \mathrm{Ca}$ & $\mathrm{B} / \mathrm{Ca}$ & $\mathrm{Mg} / \mathrm{Ca}$ & $\mathrm{Al} / \mathrm{Ca}$ & $\mathrm{Mn} / \mathrm{Ca}$ & $\mathrm{Zn} / \mathrm{Ca}$ & $\mathrm{Sr} / \mathrm{Ca}$ & $\mathrm{Ba} / \mathrm{Ca}$ & $\mathrm{U} / \mathrm{Ca}$ \\
\hline 2 & 0.05 & 0.0182 & 0.0000 & 11.19 & 0.00154 & 0.00227 & 0.00517 & 1.30 & 0.000476 & 0.0000126 \\
\hline 3 & 0.10 & 0.0139 & 0.0083 & 6.17 & 0.00117 & 0.00115 & 0.00484 & 1.36 & 0.000428 & 0.0000742 \\
\hline 4 & 0.15 & 0.0142 & 0.0190 & 7.75 & 0.00254 & 0.00114 & 0.00301 & 1.46 & 0.000465 & 0.0000000 \\
\hline 5 & 0.20 & 0.0117 & 0.0087 & 4.42 & 0.00037 & 0.00098 & 0.00808 & 1.47 & 0.000478 & 0.0000000 \\
\hline 6 & 0.25 & 0.0139 & 0.0063 & 2.52 & 0.00000 & 0.00092 & 0.00093 & 1.51 & 0.000407 & 0.0000032 \\
\hline 7 & 0.30 & 0.0132 & 0.0166 & 4.85 & 0.00000 & 0.00090 & 0.00181 & 1.44 & 0.000390 & 0.0000353 \\
\hline 8 & 0.35 & 0.0092 & 0.0091 & 3.99 & 0.00026 & 0.00241 & 0.00260 & 1.37 & 0.000365 & 0.0000067 \\
\hline 9 & 0.40 & 0.0085 & 0.0103 & 3.46 & 0.00000 & 0.00257 & 0.00318 & 1.51 & 0.000505 & 0.0000209 \\
\hline 10 & 0.45 & 0.0131 & 0.0242 & 4.78 & 0.00000 & 0.00168 & 0.00548 & 1.45 & 0.000416 & 0.0000139 \\
\hline 11 & 0.50 & 0.0082 & 0.0198 & 3.34 & 0.00215 & 0.00282 & 0.00846 & 1.31 & 0.000434 & 0.0000032 \\
\hline 12 & 0.55 & 0.0096 & 0.0240 & 3.25 & 0.00281 & 0.00250 & 0.00616 & 1.32 & 0.000351 & 0.0000536 \\
\hline 13 & 0.60 & 0.0082 & 0.0080 & 3.62 & 0.00116 & 0.00295 & 0.00124 & 1.22 & 0.000333 & 0.0000000 \\
\hline 14 & 0.65 & 0.0067 & 0.0000 & 3.93 & 0.00141 & 0.00208 & 0.00331 & 1.29 & 0.000315 & 0.0000401 \\
\hline 15 & 0.70 & 0.0087 & 0.0003 & 4.78 & 0.00000 & 0.00121 & 0.00132 & 1.19 & 0.000315 & 0.0000098 \\
\hline 16 & 0.75 & 0.0085 & 0.0136 & 4.78 & 0.00309 & 0.00305 & 0.00261 & 1.15 & 0.000296 & 0.0000000 \\
\hline
\end{tabular}


APPENDIX 5.3b A740 growth band transect data

\begin{tabular}{|c|c|c|c|c|c|c|c|c|c|c|c|}
\hline \multirow{2}{*}{ Spot Number } & \multirow{2}{*}{ Distance from outer shell (mm) } & \multicolumn{10}{|c|}{ A740 growth band transect L1 corrected data $(\mathrm{mol} / \mathrm{mol})$} \\
\hline & & $\mathrm{Li} / \mathrm{Ca}$ & $\mathrm{B} / \mathrm{Ca}$ & $\mathrm{Mg} / \mathrm{Ca}$ & $\mathrm{Al} / \mathrm{Ca}$ & $\mathrm{Mn} / \mathrm{Ca}$ & $\mathrm{Zn} / \mathrm{Ca}$ & $\mathrm{Sr} / \mathrm{Ca}$ & $\mathrm{Ba} / \mathrm{Ca}$ & $\mathrm{Pb} / \mathrm{Ca}$ & $\mathrm{U} / \mathrm{Ca}$ \\
\hline 1 & 0.00 & 2.9480 & 0.3633 & 1.73 & 39.79950 & 3.99474 & 0.55214 & 7.19 & 6.361937 & 3.657352 & 9.227115 \\
\hline 2 & 0.05 & 0.0097 & 0.0769 & 2.13 & 0.01075 & 0.00000 & 0.00901 & 3.78 & 0.002236 & 0.000081 & 0.000444 \\
\hline 3 & 0.10 & 0.0059 & 0.0628 & 1.68 & 0.00638 & 0.00083 & 0.00427 & 3.35 & 0.001548 & 0.000001 & 0.000275 \\
\hline 4 & 0.15 & 0.0091 & 0.0675 & 2.08 & 0.00442 & 0.00076 & 0.00681 & 3.51 & 0.001274 & 0.000000 & 0.000132 \\
\hline 5 & 0.20 & 0.0073 & 0.0315 & 12.88 & 0.00711 & 0.00351 & 0.00414 & 2.75 & 0.001352 & 0.000105 & 0.000063 \\
\hline 6 & 0.25 & 0.0145 & 0.0073 & 16.81 & 0.00000 & 0.00079 & 0.00118 & 1.26 & 0.000360 & 0.000036 & 0.000000 \\
\hline 7 & 0.30 & 0.0052 & 0.0035 & 9.72 & 0.00000 & 0.00000 & 0.00101 & 1.41 & 0.000529 & 0.000083 & 0.000000 \\
\hline 8 & 0.35 & 2.9646 & 0.3611 & 1.74 & 39.92795 & 4.00887 & 0.55567 & 7.24 & 6.438205 & 3.706980 & 9.385571 \\
\hline 9 & 0.40 & 0.0105 & 0.0000 & 6.54 & 0.00361 & 0.00000 & 0.00203 & 1.42 & 0.000518 & 0.000000 & 0.000006 \\
\hline 10 & 0.45 & 0.0063 & 0.0000 & 6.40 & 0.00706 & 0.00000 & 0.00486 & 1.51 & 0.000535 & 0.000068 & 0.000000 \\
\hline 11 & 0.50 & 0.0172 & 0.0190 & 7.86 & 0.00038 & 0.00428 & 0.00465 & 1.47 & 0.000528 & 0.000004 & 0.000001 \\
\hline 12 & 0.55 & 0.0110 & 0.0100 & 6.58 & 0.00263 & 0.00198 & 0.00684 & 1.57 & 0.000538 & 0.000017 & 0.000002 \\
\hline 13 & 0.60 & 0.0087 & 0.0180 & 6.08 & 0.00000 & 0.00094 & 0.00068 & 1.52 & 0.000565 & 0.000000 & 0.000000 \\
\hline 14 & 0.65 & 0.0053 & 0.0000 & 5.85 & 0.00088 & 0.00293 & 0.00000 & 1.42 & 0.000339 & 0.000046 & 0.000000 \\
\hline 15 & 0.70 & 2.9284 & 0.3569 & 1.72 & 39.95397 & 4.01076 & 0.55650 & 7.25 & 6.450161 & 3.696299 & 9.397410 \\
\hline 16 & 0.75 & 0.0075 & 0.0000 & 6.06 & 0.00448 & 0.00200 & 0.00467 & 1.47 & 0.000440 & 0.000030 & 0.000000 \\
\hline 17 & 0.80 & 0.0061 & 0.0356 & 7.19 & 0.00418 & 0.00117 & 0.00159 & 1.46 & 0.000479 & 0.000055 & 0.00003 \\
\hline 18 & 0.85 & 0.0066 & 0.0345 & 8.45 & 0.00000 & 0.00378 & 0.00944 & 1.44 & 0.000548 & 0.000000 & 0.000000 \\
\hline 19 & 0.90 & 0.0031 & 0.0000 & 7.71 & 0.00000 & 0.00274 & 0.00572 & 1.38 & 0.000496 & 0.000049 & 0.000000 \\
\hline
\end{tabular}




\begin{tabular}{|c|c|c|c|c|c|c|c|c|c|c|c|}
\hline \multirow{2}{*}{$\begin{array}{c}\text { Spot } \\
\text { Number }\end{array}$} & \multirow{2}{*}{ Distance from outer shell (mm) } & \multicolumn{10}{|c|}{ A740 growth band transect $\mathrm{L} 2$ corrected data $(\mathrm{mol} / \mathrm{mol})$} \\
\hline & & $\mathrm{Li} / \mathrm{Ca}$ & $\mathrm{B} / \mathrm{Ca}$ & $\mathrm{Mg} / \mathrm{Ca}$ & $\mathrm{Al} / \mathrm{Ca}$ & $\mathrm{Mn} / \mathrm{Ca}$ & $\mathrm{Zn} / \mathrm{Ca}$ & $\mathrm{Sr} / \mathrm{Ca}$ & $\mathrm{Ba} / \mathrm{Ca}$ & $\mathrm{Pb} / \mathrm{Ca}$ & $\mathrm{U} / \mathrm{Ca}$ \\
\hline 1 & 0.00 & 0.0125 & 0.0922 & 2.62 & 0.00000 & 0.00494 & 0.01836 & 4.93 & 0.003496 & 0.000064 & 0.000969 \\
\hline 2 & 0.05 & 0.0111 & 0.0823 & 2.33 & 0.00587 & 0.00416 & 0.00971 & 3.98 & 0.002501 & 0.000069 & 0.000771 \\
\hline 3 & 0.10 & 0.0079 & 0.0765 & 1.71 & 0.00583 & 0.00282 & 0.01339 & 3.66 & 0.002254 & 0.000010 & 0.000824 \\
\hline 4 & 0.15 & 0.0078 & 0.0631 & 1.47 & 0.01087 & 0.00268 & 0.01560 & 3.85 & 0.002300 & 0.000048 & 0.000885 \\
\hline 5 & 0.20 & 0.0127 & 0.0854 & 1.25 & 0.00507 & 0.00234 & 0.01476 & 4.31 & 0.004276 & 0.000073 & 0.000780 \\
\hline 6 & 0.25 & 0.0177 & 0.0073 & 4.27 & 0.00729 & 0.00107 & 0.00255 & 1.40 & 0.000434 & 0.000152 & 0.000000 \\
\hline 7 & 0.30 & 0.0157 & 0.0000 & 3.13 & 0.00256 & 0.00000 & 0.00208 & 1.53 & 0.000493 & 0.000000 & 0.000024 \\
\hline 8 & 0.35 & 0.0119 & 0.0130 & 2.62 & 0.00603 & 0.00080 & 0.00277 & 1.41 & 0.000571 & 0.000013 & 0.000000 \\
\hline 9 & 0.40 & 0.0166 & 0.0000 & 2.77 & 0.00473 & 0.00491 & 0.00178 & 1.49 & 0.000456 & 0.000029 & 0.000000 \\
\hline 10 & 0.45 & 0.0120 & 0.0000 & 3.59 & 0.00148 & 0.00158 & 0.00065 & 1.41 & 0.000353 & 0.000000 & 0.000024 \\
\hline 11 & 0.50 & 0.0026 & 0.0187 & 3.48 & 0.00000 & 0.00000 & 0.00422 & 1.50 & 0.000476 & 0.000080 & 0.000000 \\
\hline 12 & 0.55 & 0.0081 & 0.0000 & 3.97 & 0.00482 & 0.00360 & 0.00000 & 1.46 & 0.000438 & 0.000020 & 0.000000 \\
\hline 13 & 0.60 & 0.0084 & 0.0179 & 4.51 & 0.00000 & 0.00255 & 0.00229 & 1.37 & 0.000495 & 0.000029 & 0.000000 \\
\hline 14 & 0.65 & 0.0082 & 0.0000 & 5.29 & 0.00078 & 0.00504 & 0.00000 & 1.48 & 0.000587 & 0.000000 & 0.000005 \\
\hline 15 & 0.70 & 0.0059 & 0.0000 & 5.03 & 0.00930 & 0.00201 & 0.00309 & 1.51 & 0.000459 & 0.000024 & 0.000024 \\
\hline 16 & 0.75 & 0.0067 & 0.0003 & 4.50 & 0.00320 & 0.00000 & 0.00000 & 1.23 & 0.000378 & 0.000000 & 0.000013 \\
\hline 17 & 0.80 & 0.0057 & 0.0308 & 5.13 & 0.00573 & 0.00416 & 0.00000 & 1.14 & 0.000248 & 0.000000 & 0.000007 \\
\hline 18 & 0.85 & 0.0048 & 0.0123 & 5.74 & 0.00000 & 0.00172 & 0.00434 & 1.13 & 0.000303 & 0.000006 & 0.000000 \\
\hline
\end{tabular}




\begin{tabular}{|c|c|c|c|c|c|c|c|c|c|c|c|}
\hline \multirow{2}{*}{$\begin{array}{c}\text { Spot } \\
\text { Number }\end{array}$} & \multirow{2}{*}{ Distance from outer shell (mm) } & \multicolumn{10}{|c|}{ A740 growth band transect $\mathrm{L} 3$ corrected data $(\mathrm{mol} / \mathrm{mol})$} \\
\hline & & $\mathrm{Li} / \mathrm{Ca}$ & $\mathrm{B} / \mathrm{Ca}$ & $\mathrm{Mg} / \mathrm{Ca}$ & $\mathbf{A l} / \mathbf{C a}$ & $\mathrm{Mn} / \mathrm{Ca}$ & $\mathrm{Zn} / \mathrm{Ca}$ & $\mathrm{Sr} / \mathrm{Ca}$ & $\mathrm{Ba} / \mathrm{Ca}$ & $\mathrm{Pb} / \mathrm{Ca}$ & $\mathrm{U} / \mathrm{Ca}$ \\
\hline 1 & 0.00 & 0.0095 & 0.0523 & 1.51 & 0.00000 & 0.00179 & 0.00566 & 3.96 & 0.002390 & 0.000080 & 0.000711 \\
\hline 2 & 0.05 & 0.0092 & 0.0694 & 1.58 & 0.00358 & 0.00391 & 0.01065 & 3.53 & 0.001992 & 0.000000 & 0.000788 \\
\hline 3 & 0.10 & 0.0122 & 0.0334 & 16.43 & 0.00407 & 0.00860 & 0.00091 & 1.41 & 0.000615 & 0.000000 & 0.000076 \\
\hline 4 & 0.15 & 0.0147 & 0.0289 & 11.07 & 0.00243 & 0.01100 & 0.00100 & 1.18 & 0.000449 & 0.000095 & 0.000000 \\
\hline 5 & 0.20 & 0.0087 & 0.0042 & 5.95 & 0.00312 & 0.00407 & 0.00099 & 1.49 & 0.000579 & 0.000020 & 0.000024 \\
\hline 6 & 0.25 & 0.0051 & 0.0352 & 4.18 & 0.00554 & 0.00265 & 0.00128 & 1.54 & 0.000723 & 0.000066 & 0.000040 \\
\hline 7 & 0.30 & 0.0108 & 0.0292 & 4.38 & 0.00686 & 0.00205 & 0.00356 & 1.54 & 0.000558 & 0.000000 & 0.000014 \\
\hline 8 & 0.35 & 0.0152 & 0.0180 & 3.75 & 0.00502 & 0.00386 & 0.00000 & 1.53 & 0.000494 & 0.000016 & 0.000000 \\
\hline 9 & 0.40 & 0.0079 & 0.0065 & 3.81 & 0.00494 & 0.00401 & 0.00555 & 1.54 & 0.000729 & 0.000000 & 0.000020 \\
\hline 10 & 0.45 & 0.0102 & 0.0000 & 3.95 & 0.00000 & 0.00322 & 0.00000 & 1.45 & 0.000666 & 0.000042 & 0.000014 \\
\hline 11 & 0.50 & 0.0132 & 0.0115 & 3.92 & 0.00367 & 0.00726 & 0.00045 & 1.49 & 0.000474 & 0.000000 & 0.000000 \\
\hline 12 & 0.55 & 0.0086 & 0.0000 & 3.60 & 0.00000 & 0.00340 & 0.00000 & 1.66 & 0.000678 & 0.000011 & 0.000000 \\
\hline 13 & 0.60 & 0.0082 & 0.0000 & 3.91 & 0.00131 & 0.00287 & 0.00000 & 1.61 & 0.000584 & 0.000000 & 0.000000 \\
\hline 14 & 0.65 & 0.0102 & 0.0000 & 5.43 & 0.00722 & 0.00610 & 0.00000 & 1.69 & 0.000671 & 0.000021 & 0.000000 \\
\hline 15 & 0.70 & 0.0101 & 0.0062 & 4.89 & 0.00000 & 0.00101 & 0.00117 & 1.58 & 0.000508 & 0.000000 & 0.000000 \\
\hline
\end{tabular}




\begin{tabular}{|c|c|c|c|c|c|c|c|c|c|c|c|}
\hline \multirow{2}{*}{$\begin{array}{c}\text { Spot } \\
\text { Number }\end{array}$} & \multirow{2}{*}{ Distance from outer shell (mm) } & \multicolumn{10}{|c|}{ A740 growth band transect L4 corrected data $(\mathrm{mol} / \mathrm{mol})$} \\
\hline & & $\mathrm{Li} / \mathrm{Ca}$ & $\mathrm{B} / \mathrm{Ca}$ & $\mathrm{Mg} / \mathrm{Ca}$ & $\mathrm{Al} / \mathrm{Ca}$ & $\mathrm{Mn} / \mathrm{Ca}$ & $\mathrm{Zn} / \mathrm{Ca}$ & $\mathrm{Sr} / \mathrm{Ca}$ & $\mathrm{Ba} / \mathrm{Ca}$ & $\mathrm{Pb} / \mathrm{Ca}$ & $\mathrm{U} / \mathrm{Ca}$ \\
\hline 1 & 0.00 & 0.0119 & 0.0926 & 1.22 & 0.01117 & 0.00572 & 0.01343 & 2.99 & 0.001633 & 0.000226 & 0.000419 \\
\hline 2 & 0.05 & 0.0123 & 0.0424 & 0.88 & 0.00080 & 0.00196 & 0.00739 & 3.02 & 0.001514 & 0.000127 & 0.000473 \\
\hline 3 & 0.10 & 0.0078 & 0.0485 & 0.72 & 0.01321 & 0.00000 & 0.00798 & 3.20 & 0.001488 & 0.000057 & 0.000500 \\
\hline 4 & 0.15 & 0.0125 & 0.0333 & 3.55 & 0.01007 & 0.00000 & 0.00300 & 3.20 & 0.001128 & 0.000000 & 0.000308 \\
\hline 5 & 0.20 & 0.0123 & 0.0060 & 6.74 & 0.00325 & 0.00049 & 0.00439 & 1.13 & 0.000373 & 0.000056 & 0.000020 \\
\hline 6 & 0.25 & 0.0140 & 0.0158 & 6.97 & 0.00000 & 0.00250 & 0.00000 & 1.29 & 0.000350 & 0.000000 & 0.000000 \\
\hline 7 & 0.30 & 0.0100 & 0.0104 & 4.71 & 0.00000 & 0.00448 & 0.00096 & 1.45 & 0.000548 & 0.000000 & 0.000000 \\
\hline 8 & 0.35 & 0.0097 & 0.0155 & 3.42 & 0.00174 & 0.00358 & 0.00458 & 1.62 & 0.000556 & 0.000033 & 0.000000 \\
\hline 9 & 0.40 & 0.0074 & 0.0028 & 4.71 & 0.00000 & 0.00127 & 0.00000 & 1.40 & 0.000307 & 0.000027 & 0.000000 \\
\hline 10 & 0.45 & 0.0138 & 0.0191 & 3.53 & 0.01002 & 0.00145 & 0.00137 & 1.70 & 0.000532 & 0.000000 & 0.000000 \\
\hline 11 & 0.50 & 0.0135 & 0.0237 & 3.54 & 0.00519 & 0.00000 & 0.00000 & 1.60 & 0.000525 & 0.000000 & 0.000000 \\
\hline 12 & 0.55 & 0.0153 & 0.0035 & 6.61 & 0.00422 & 0.00494 & 0.00000 & 1.53 & 0.000438 & 0.000009 & 0.000025 \\
\hline 13 & 0.60 & 0.0081 & 0.0000 & 5.26 & 0.00000 & 0.00191 & 0.00532 & 1.42 & 0.000430 & 0.000000 & 0.000000 \\
\hline 14 & 0.65 & 0.0059 & 0.0091 & 6.60 & 0.00000 & 0.00119 & 0.00204 & 1.26 & 0.000399 & 0.000000 & 0.000235 \\
\hline 15 & 0.70 & 0.0087 & 0.0697 & 2.08 & 0.00129 & 0.00000 & 0.00001 & 2.32 & 0.001553 & 0.000016 & 0.000032 \\
\hline
\end{tabular}


APPENDIX 5.3c P1B growth band transect data

\begin{tabular}{|c|c|c|c|c|c|c|c|c|c|c|c|}
\hline \multirow{2}{*}{$\begin{array}{c}\text { Spot } \\
\text { Number }\end{array}$} & \multirow{2}{*}{$\begin{array}{l}\text { Distance from the outer shell } \\
\qquad(\mathrm{mm})\end{array}$} & \multicolumn{10}{|c|}{ P1B growth band transect L1 corrected data $(\mathrm{mmol} / \mathrm{mol})$} \\
\hline & & $\mathrm{Li} / \mathrm{Ca}$ & $\mathbf{B} / \mathbf{C a}$ & $\mathrm{Mg} / \mathrm{Ca}$ & $\mathbf{A l} / \mathbf{C a}$ & $\mathrm{Mn} / \mathrm{Ca}$ & $\mathrm{Zn} / \mathrm{Ca}$ & $\mathrm{Sr} / \mathrm{Ca}$ & $\mathrm{Ba} / \mathrm{Ca}$ & $\mathrm{Pb} / \mathrm{Ca}$ & $\mathrm{U} / \mathbf{C a}$ \\
\hline 1 & 0.00 & 0.0071 & 0.211 & 2.55 & 0.249 & 0.02287 & 0.00012 & 5.41 & 0.00694 & 0.000404 & 0.0021919 \\
\hline 2 & 0.05 & 0.0278 & 0.140 & 7.78 & 2.597 & 0.02860 & 0.01120 & 4.40 & 0.00730 & 0.000408 & 0.0011359 \\
\hline 3 & 0.10 & 0.0177 & 0.094 & 14.19 & 1.999 & 0.01838 & 0.00014 & 3.93 & 0.00423 & 0.000396 & 0.0006978 \\
\hline 4 & 0.15 & 0.0158 & 0.034 & 16.80 & 1.073 & 0.01099 & 0.00448 & 1.29 & 0.00130 & 0.000340 & 0.0000372 \\
\hline 5 & 0.20 & 0.0124 & 0.000 & 12.96 & 0.215 & 0.00737 & 0.00244 & 1.35 & 0.00065 & 0.000545 & 0.0000302 \\
\hline 6 & 0.25 & 0.0334 & 0.001 & 11.33 & 0.089 & 0.00557 & 0.00256 & 1.53 & 0.00086 & 0.000369 & 0.0000692 \\
\hline 7 & 0.30 & 0.0014 & 0.007 & 20.28 & 1.582 & 0.00908 & 0.00234 & 1.83 & 0.00188 & 0.000523 & 0.0000974 \\
\hline 8 & 0.35 & 0.0381 & 0.024 & 16.07 & 0.067 & 0.00301 & 0.00378 & 1.32 & 0.00069 & 0.000415 & 0.0000000 \\
\hline 9 & 0.40 & 0.0052 & 0.019 & 16.14 & 0.155 & 0.00117 & 0.00310 & 1.34 & 0.00085 & 0.000385 & 0.0000286 \\
\hline 10 & 0.45 & 0.0352 & 0.038 & 14.74 & 1.026 & 0.00456 & 0.00000 & 1.51 & 0.00190 & 0.000484 & 0.0000450 \\
\hline 11 & 0.50 & 0.0000 & 0.020 & 9.17 & 0.184 & 0.00039 & 0.00377 & 1.50 & 0.00084 & 0.000300 & 0.0000057 \\
\hline 12 & 0.55 & 0.0169 & 0.033 & 15.11 & 1.189 & 0.00636 & 0.00470 & 1.61 & 0.00160 & 0.000388 & 0.0000549 \\
\hline 13 & 0.60 & 0.0327 & 0.011 & 13.11 & 0.201 & 0.00105 & 0.00000 & 1.60 & 0.00094 & 0.000262 & 0.0000015 \\
\hline 14 & 0.65 & 0.0365 & 0.015 & 15.42 & 0.223 & 0.00442 & 0.00002 & 1.56 & 0.00108 & 0.000231 & 0.0000341 \\
\hline 15 & 0.70 & 0.0133 & 0.000 & 12.72 & 0.248 & 0.00454 & 0.00092 & 1.57 & 0.00099 & 0.000061 & 0.0000209 \\
\hline 16 & 0.75 & 0.0011 & 0.000 & 14.09 & 1.097 & 0.00928 & 0.00536 & 1.60 & 0.00161 & 0.000092 & 0.0000141 \\
\hline 17 & 0.80 & 0.0145 & 0.008 & 6.19 & 0.162 & 0.00080 & 0.00000 & 1.17 & 0.00050 & 0.000030 & 0.0000000 \\
\hline 18 & 0.85 & 0.0122 & 0.031 & 8.42 & 2.201 & 0.00445 & 0.00000 & 1.32 & 0.00169 & 0.000062 & 0.0000100 \\
\hline
\end{tabular}




\begin{tabular}{|c|c|c|c|c|c|c|c|c|c|c|c|}
\hline \multirow{2}{*}{$\begin{array}{c}\text { Spot } \\
\text { Number }\end{array}$} & \multirow{2}{*}{$\begin{array}{l}\text { Distance from the outer shell } \\
(\mathrm{mm})\end{array}$} & \multicolumn{10}{|c|}{ P1B growth band transect L2 corrected data $(\mathrm{mmol} / \mathrm{mol})$} \\
\hline & & $\mathrm{Li} / \mathrm{Ca}$ & $\mathrm{B} / \mathrm{Ca}$ & $\mathrm{Mg} / \mathrm{Ca}$ & $\mathbf{A l} / \mathbf{C a}$ & $\mathrm{Mn} / \mathrm{Ca}$ & $\mathrm{Zn} / \mathrm{Ca}$ & $\mathrm{Sr} / \mathrm{Ca}$ & $\mathrm{Ba} / \mathrm{Ca}$ & $\mathrm{Pb} / \mathrm{Ca}$ & $\mathrm{U} / \mathrm{Ca}$ \\
\hline 1 & 0.00 & 0.0288 & 0.060 & 17.45 & 0.003 & 0.00747 & 0.00225 & 1.48 & 0.00083 & 0.000651 & 0.0000458 \\
\hline 2 & 0.05 & 0.0347 & 0.015 & 12.85 & 0.012 & 0.00491 & 0.00000 & 1.45 & 0.00064 & 0.000418 & 0.0000386 \\
\hline 3 & 0.10 & 0.0146 & 0.025 & 12.22 & 0.000 & 0.00102 & 0.00572 & 1.57 & 0.00079 & 0.000468 & 0.0000087 \\
\hline 4 & 0.15 & 0.0026 & 0.020 & 12.17 & 0.000 & 0.00709 & 0.00000 & 1.28 & 0.00050 & 0.000057 & 0.0000285 \\
\hline 5 & 0.20 & 0.0000 & 0.000 & 7.88 & 0.002 & 0.00456 & 0.00281 & 1.29 & 0.00042 & 0.000087 & 0.0000118 \\
\hline 6 & 0.25 & 0.0138 & 0.025 & 7.58 & 0.000 & 0.00623 & 0.00356 & 1.36 & 0.00051 & 0.000249 & 0.0000220 \\
\hline 7 & 0.30 & 0.0000 & 0.023 & 5.55 & 0.000 & 0.00389 & 0.00000 & 1.40 & 0.00034 & 0.000209 & 0.0000000 \\
\hline 8 & 0.35 & 0.0147 & 0.006 & 5.14 & 0.000 & 0.00741 & 0.00514 & 1.30 & 0.00038 & 0.000283 & 0.0000391 \\
\hline 9 & 0.40 & 0.0140 & 0.040 & 4.82 & 0.012 & 0.00409 & 0.00359 & 1.34 & 0.00070 & 0.000272 & 0.0000380 \\
\hline 10 & 0.45 & 0.0000 & 0.014 & 4.38 & 0.015 & 0.00172 & 0.00264 & 1.33 & 0.00053 & 0.000301 & 0.0000054 \\
\hline 11 & 0.50 & 0.0000 & 0.035 & 4.61 & 0.009 & 0.00000 & 0.00138 & 1.34 & 0.00042 & 0.000384 & 0.0000000 \\
\hline 12 & 0.55 & 0.0000 & 0.000 & 4.33 & 0.000 & 0.00011 & 0.00487 & 1.30 & 0.00036 & 0.000228 & 0.0000000 \\
\hline 13 & 0.60 & 0.0382 & 0.010 & 4.78 & 0.000 & 0.00365 & 0.00537 & 1.26 & 0.00042 & 0.000125 & 0.0000000 \\
\hline 14 & 0.65 & 0.0275 & 0.002 & 5.10 & 0.000 & 0.00000 & 0.00133 & 1.19 & 0.00038 & 0.000093 & 0.0000199 \\
\hline 15 & 0.70 & 0.0228 & 0.044 & 4.90 & 0.000 & 0.00185 & 0.00000 & 1.22 & 0.00036 & 0.000204 & 0.0000285 \\
\hline 16 & 0.75 & 0.0354 & 0.000 & 5.31 & 0.035 & 0.00000 & 0.00263 & 1.15 & 0.00040 & 0.000196 & 0.0000036 \\
\hline 17 & 0.80 & 0.0017 & 0.020 & 5.95 & 0.006 & 0.00000 & 0.00818 & 1.17 & 0.00030 & 0.000032 & 0.0000039 \\
\hline 18 & 0.85 & 0.0000 & 0.000 & 5.79 & 0.000 & 0.00352 & 0.01002 & 1.16 & 0.00017 & 0.000255 & 0.0000251 \\
\hline 19 & 0.90 & 0.0548 & 0.049 & 5.84 & 0.001 & 0.00806 & 0.00176 & 1.11 & 0.00045 & 0.000236 & 0.0000272 \\
\hline
\end{tabular}




\begin{tabular}{|c|c|c|c|c|c|c|c|c|c|c|c|}
\hline \multirow{2}{*}{$\begin{array}{c}\text { Spot } \\
\text { Number }\end{array}$} & \multirow{2}{*}{$\begin{array}{l}\text { Distance from the outer shell } \\
(\mathrm{mm})\end{array}$} & \multicolumn{10}{|c|}{ P1B growth band transect L3 corrected data $(\mathrm{mmol} / \mathrm{mol})$} \\
\hline & & $\mathrm{Li} / \mathrm{Ca}$ & $\mathrm{B} / \mathrm{Ca}$ & $\mathrm{Mg} / \mathrm{Ca}$ & $\mathrm{Al} / \mathrm{Ca}$ & $\mathrm{Mn} / \mathrm{Ca}$ & $\mathrm{Zn} / \mathrm{Ca}$ & $\mathrm{Sr} / \mathrm{Ca}$ & $\mathrm{Ba} / \mathrm{Ca}$ & $\mathrm{Pb} / \mathrm{Ca}$ & $\mathrm{U} / \mathbf{C a}$ \\
\hline 1 & 0.00 & 0.0262 & 0.024 & 13.08 & 0.494 & 0.01802 & 0.00292 & 1.47 & 0.00189 & 0.000363 & 0.0000326 \\
\hline 2 & 0.05 & 0.0385 & 0.029 & 17.97 & 0.536 & 0.01334 & 0.00000 & 1.74 & 0.00243 & 0.000531 & 0.0000974 \\
\hline 3 & 0.10 & 0.0116 & 0.026 & 5.56 & 0.000 & 0.00289 & 0.00578 & 1.20 & 0.00044 & 0.000358 & 0.0000055 \\
\hline 4 & 0.15 & 0.0229 & 0.000 & 6.09 & 0.005 & 0.00550 & 0.00113 & 1.33 & 0.00047 & 0.000328 & 0.0000000 \\
\hline 5 & 0.20 & 0.0059 & 0.001 & 5.14 & 0.000 & 0.01496 & 0.00081 & 1.37 & 0.00063 & 0.000318 & 0.0000468 \\
\hline 6 & 0.25 & 0.0299 & 0.000 & 4.24 & 0.003 & 0.00000 & 0.00313 & 1.25 & 0.00035 & 0.000304 & 0.0000205 \\
\hline 7 & 0.30 & 0.0242 & 0.030 & 3.59 & 0.000 & 0.00345 & 0.00000 & 1.14 & 0.00030 & 0.000175 & 0.0000000 \\
\hline 8 & 0.35 & 0.0000 & 0.000 & 3.22 & 0.012 & 0.00197 & 0.00396 & 1.07 & 0.00024 & 0.000125 & 0.0000108 \\
\hline 9 & 0.40 & 0.0166 & 0.006 & 5.21 & 0.023 & 0.00294 & 0.00137 & 1.13 & 0.00040 & 0.000252 & 0.0000272 \\
\hline 10 & 0.45 & 0.0007 & 0.012 & 5.09 & 0.022 & 0.00364 & 0.00401 & 1.12 & 0.00036 & 0.000237 & 0.0000000 \\
\hline 11 & 0.50 & 0.0192 & 0.012 & 5.03 & 0.006 & 0.00496 & 0.00059 & 1.12 & 0.00041 & 0.000109 & 0.0000245 \\
\hline 12 & 0.55 & 0.0143 & 0.021 & 5.92 & 0.010 & 0.00251 & 0.00206 & 1.08 & 0.00035 & 0.000312 & 0.0000133 \\
\hline 13 & 0.60 & 0.0071 & 0.002 & 5.72 & 0.000 & 0.00213 & 0.00360 & 1.15 & 0.00032 & 0.000158 & 0.0000000 \\
\hline 14 & 0.65 & 0.0023 & 0.000 & 4.71 & 0.000 & 0.00000 & 0.00016 & 1.12 & 0.00042 & 0.000266 & 0.0000027 \\
\hline 15 & 0.70 & 0.0015 & 0.014 & 5.85 & 0.014 & 0.00246 & 0.00432 & 1.05 & 0.00032 & 0.000163 & 0.0000219 \\
\hline 16 & 0.75 & 0.0036 & 0.013 & 7.97 & 0.000 & 0.00246 & 0.00541 & 1.04 & 0.00026 & 0.000217 & 0.0000000 \\
\hline 17 & 0.80 & 0.0000 & 0.008 & 8.66 & 0.000 & 0.01587 & 0.00617 & 1.21 & 0.00087 & 0.000169 & 0.0000000 \\
\hline 18 & 0.85 & 0.0010 & 0.025 & 8.25 & 0.013 & 0.02022 & 0.00596 & 1.29 & 0.00062 & 0.000253 & 0.0000000 \\
\hline 19 & 0.90 & 0.0000 & 0.003 & 7.56 & 0.000 & 0.03373 & 0.00386 & 1.13 & 0.00061 & 0.000108 & 0.0000000 \\
\hline 20 & 0.95 & 0.0275 & 0.017 & 6.22 & 0.006 & 0.03521 & 0.00896 & 1.45 & 0.00152 & 0.000288 & 0.0000011 \\
\hline
\end{tabular}




\begin{tabular}{|c|c|c|c|c|c|c|c|c|c|c|c|}
\hline \multirow{2}{*}{$\begin{array}{c}\text { Spot } \\
\text { Number }\end{array}$} & \multirow{2}{*}{$\begin{array}{l}\text { Distance from the outer shell } \\
(\mathrm{mm})\end{array}$} & \multicolumn{10}{|c|}{ P1B growth band transect L4 corrected data $(\mathrm{mmol} / \mathrm{mol})$} \\
\hline & & $\mathrm{Li} / \mathrm{Ca}$ & $\mathrm{B} / \mathrm{Ca}$ & $\mathrm{Mg} / \mathrm{Ca}$ & $\mathrm{Al} / \mathrm{Ca}$ & $\mathrm{Mn} / \mathrm{Ca}$ & $\mathrm{Zn} / \mathrm{Ca}$ & $\mathrm{Sr} / \mathrm{Ca}$ & $\mathrm{Ba} / \mathrm{Ca}$ & $\mathrm{Pb} / \mathrm{Ca}$ & $\mathrm{U} / \mathrm{Ca}$ \\
\hline 1 & 0.00 & 0.0936 & 1.133 & 9.46 & 21.865 & 0.45925 & 0.01400 & 10.49 & 0.02401 & 0.002213 & 0.0015296 \\
\hline 2 & 0.05 & 0.0327 & 0.905 & 5.28 & 9.649 & 0.13286 & 0.01090 & 9.68 & 0.01646 & 0.002103 & 0.0015888 \\
\hline 3 & 0.10 & 0.0009 & 0.079 & 1.34 & 0.000 & 0.00000 & 0.00203 & 4.19 & 0.00464 & 0.000248 & 0.0010896 \\
\hline 4 & 0.15 & 0.0412 & 0.044 & 7.00 & 0.000 & 0.00075 & 0.00377 & 1.15 & 0.00089 & 0.000113 & 0.0000734 \\
\hline 5 & 0.20 & 0.0127 & 0.000 & 7.69 & 0.000 & 0.00484 & 0.00000 & 1.10 & 0.00069 & 0.000189 & 0.0000000 \\
\hline 6 & 0.25 & 0.0387 & 0.017 & 5.49 & 0.005 & 0.00319 & 0.00131 & 1.22 & 0.00070 & 0.000172 & 0.0000000 \\
\hline 7 & 0.30 & 0.0306 & 0.000 & 3.54 & 0.000 & 0.00453 & 0.00000 & 1.15 & 0.00062 & 0.000107 & 0.0000000 \\
\hline 8 & 0.35 & 0.0157 & 0.021 & 2.33 & 0.000 & 0.00481 & 0.00012 & 1.21 & 0.00081 & 0.000074 & 0.0000000 \\
\hline 9 & 0.40 & 0.0152 & 0.000 & 2.29 & 0.000 & 0.01922 & 0.00044 & 1.20 & 0.00077 & 0.000256 & 0.0000175 \\
\hline 10 & 0.45 & 0.0000 & 0.016 & 1.95 & 0.000 & 0.00811 & 0.00639 & 1.26 & 0.00087 & 0.000260 & 0.0000000 \\
\hline 11 & 0.50 & 0.0671 & 0.018 & 2.78 & 0.532 & 0.00985 & 0.00562 & 1.30 & 0.00136 & 0.000138 & 0.0000027 \\
\hline 12 & 0.55 & 0.0000 & 0.000 & 3.61 & 0.413 & 0.01631 & 0.00309 & 1.20 & 0.00120 & 0.000022 & 0.0000000 \\
\hline 13 & 0.60 & 0.0324 & 0.019 & 5.17 & 5.499 & 0.04619 & 0.00166 & 1.25 & 0.00536 & 0.000083 & 0.0000000 \\
\hline 14 & 0.65 & 0.0655 & 0.027 & 7.63 & 10.468 & 0.06504 & 0.00882 & 1.43 & 0.00933 & 0.000614 & 0.0000000 \\
\hline 15 & 0.70 & 0.0024 & 0.059 & 9.34 & 3.387 & 0.03675 & 0.00577 & 1.59 & 0.00483 & 0.000300 & 0.0000647 \\
\hline 16 & 0.75 & 0.0252 & 0.018 & 6.36 & 1.894 & 0.02647 & 0.00861 & 2.22 & 0.00397 & 0.000259 & 0.0001669 \\
\hline 17 & 0.80 & 0.0296 & 0.144 & 6.31 & 10.529 & 0.02928 & 0.00745 & 3.99 & 0.01993 & 0.000409 & 0.0007536 \\
\hline 18 & 0.85 & 0.0068 & 0.093 & 1.85 & 0.612 & 0.00891 & 0.00378 & 3.98 & 0.00672 & 0.000218 & 0.0006927 \\
\hline 19 & 0.90 & 0.0000 & 0.084 & 10.09 & 0.141 & 0.01595 & 0.00218 & 3.79 & 0.00475 & 0.000254 & 0.0004947 \\
\hline 20 & 0.95 & 0.0137 & 0.030 & 13.73 & 1.386 & 0.00401 & 0.00000 & 1.64 & 0.00543 & 0.000130 & 0.0000304 \\
\hline 21 & 1.00 & 0.0239 & 0.014 & 6.40 & 0.607 & 0.00961 & 0.00000 & 1.29 & 0.00243 & 0.000055 & 0.0000081 \\
\hline 22 & 1.05 & 0.0232 & 0.000 & 6.41 & 0.042 & 0.00254 & 0.00015 & 1.66 & 0.00256 & 0.000097 & 0.0000373 \\
\hline 23 & 1.10 & 0.0500 & 0.029 & 6.84 & 4.200 & 0.09287 & 0.00514 & 1.59 & 0.00330 & 0.000090 & 0.0000343 \\
\hline 24 & 1.15 & 0.0226 & 0.032 & 4.52 & 1.106 & 0.00523 & 0.00500 & 1.12 & 0.00222 & 0.000213 & 0.0000291 \\
\hline 25 & 1.20 & 0.0000 & 0.000 & 3.04 & 0.037 & 0.00329 & 0.00136 & 1.28 & 0.00106 & 0.000160 & 0.0000000 \\
\hline 26 & 1.25 & 0.0188 & 0.000 & 2.74 & 0.028 & 0.00286 & 0.00000 & 1.35 & 0.00108 & 0.000191 & 0.0000053 \\
\hline 27 & 1.30 & 0.0000 & 0.000 & 3.37 & 0.005 & 0.00829 & 0.00053 & 1.23 & 0.00104 & 0.000198 & 0.0000016 \\
\hline
\end{tabular}


APPENDIX 5.3d P04A growth band transect data

\begin{tabular}{|c|c|c|c|c|c|c|c|c|c|c|c|}
\hline \multirow{2}{*}{ Spot Number } & \multirow{2}{*}{ Distance from outer shell (mm) } & \multicolumn{10}{|c|}{ P04A growth band transect L1 corrected data $(\mathrm{mmol} / \mathrm{mol})$} \\
\hline & & $\mathrm{Li} / \mathrm{Ca}$ & $\mathrm{B} / \mathrm{Ca}$ & $\mathrm{Mg} / \mathrm{Ca}$ & $\mathbf{A l} / \mathbf{C a}$ & $\mathrm{Mn} / \mathrm{Ca}$ & $\mathrm{Zn} / \mathrm{Ca}$ & $\mathrm{Sr} / \mathrm{Ca}$ & $\mathrm{Ba} / \mathrm{Ca}$ & $\mathrm{Pb} / \mathrm{Ca}$ & $\mathrm{U} / \mathrm{Ca}$ \\
\hline 1 & 0.00 & 0.0045 & 0.0000 & 6.96 & 0.128 & 0.0000 & 0.00164 & 2.16 & 0.00263 & 0.000444 & 0.000150 \\
\hline 2 & 0.05 & 0.0268 & 0.0000 & 6.81 & 0.944 & 0.0015 & 0.00000 & 2.44 & 0.00369 & 0.000528 & 0.000087 \\
\hline 3 & 0.10 & 0.0156 & 0.1312 & 4.73 & 8.190 & 0.1763 & 0.02401 & 5.71 & 0.01839 & 0.000249 & 0.001450 \\
\hline 4 & 0.15 & 0.0405 & 0.0000 & 3.16 & 2.589 & 0.0001 & 0.01961 & 3.93 & 0.00700 & 0.000325 & 0.000570 \\
\hline 5 & 0.20 & 0.0257 & 0.0000 & 4.35 & 0.166 & 0.0000 & 0.02342 & 1.38 & 0.00000 & 0.000000 & 0.000208 \\
\hline 6 & 0.25 & 0.0202 & 0.0000 & 3.10 & 0.648 & 0.0000 & 0.00386 & 1.93 & 0.00344 & 0.000768 & 0.000000 \\
\hline 7 & 0.30 & 0.0000 & 0.0591 & 4.11 & 2.220 & 0.0054 & 0.00317 & 1.53 & 0.00137 & 0.000432 & 0.000000 \\
\hline 8 & 0.35 & 0.0218 & 0.0000 & 7.53 & 1.136 & 0.0096 & 0.00320 & 1.48 & 0.00169 & 0.000000 & 0.000000 \\
\hline 9 & 0.40 & 0.0114 & 0.0000 & 5.13 & 0.961 & 0.0000 & 0.00000 & 1.27 & 0.00073 & 0.000000 & 0.000060 \\
\hline 10 & 0.45 & 0.0218 & 0.0931 & 3.11 & 0.002 & 0.0000 & 0.00180 & 1.34 & 0.00000 & 0.000000 & 0.000030 \\
\hline 11 & 0.50 & 0.0025 & 0.0000 & 3.91 & 0.007 & 0.0000 & 0.00000 & 1.36 & 0.00045 & 0.000000 & 0.000078 \\
\hline 12 & 0.55 & 0.0000 & 0.0885 & 3.63 & 0.000 & 0.0097 & 0.00000 & 1.23 & 0.00011 & 0.000000 & 0.000063 \\
\hline 13 & 0.60 & 0.0318 & 0.0000 & 4.23 & 0.000 & 0.0043 & 0.00000 & 1.17 & 0.00013 & 0.000000 & 0.000012 \\
\hline 14 & 0.65 & 0.0258 & 0.0556 & 5.34 & 1.975 & 0.0000 & 0.00575 & 1.28 & 0.00248 & 0.000920 & 0.000000 \\
\hline 15 & 0.70 & 0.0067 & 0.0598 & 5.13 & 0.000 & 0.0059 & 0.00000 & 1.32 & 0.00056 & 0.000542 & 0.000000 \\
\hline 16 & 0.75 & 0.0068 & 0.0150 & 5.04 & 0.141 & 0.0027 & 0.00229 & 1.42 & 0.00104 & 0.000000 & 0.000000 \\
\hline 17 & 0.80 & 0.0327 & 0.1162 & 4.52 & 0.017 & 0.0006 & 0.00118 & 1.45 & 0.00060 & 0.000000 & 0.000411 \\
\hline 18 & 0.85 & 0.0029 & 0.0802 & 5.01 & 0.032 & 0.0004 & 0.01001 & 1.46 & 0.00064 & 0.000100 & 0.000000 \\
\hline 19 & 0.90 & 0.0126 & 0.0000 & 5.52 & 0.004 & 0.0146 & 0.00000 & 1.30 & 0.00122 & 0.000000 & 0.000000 \\
\hline
\end{tabular}




\begin{tabular}{|c|c|c|c|c|c|c|c|c|c|c|c|}
\hline \multirow{2}{*}{ Spot Number } & \multirow{2}{*}{ Distance from outer shell (mm) } & \multicolumn{10}{|c|}{ P04A growth band transect $\mathrm{L} 2$ corrected data $(\mathrm{mmol} / \mathrm{mol})$} \\
\hline & & $\mathrm{Li} / \mathrm{Ca}$ & $\mathrm{B} / \mathrm{Ca}$ & $\mathrm{Mg} / \mathrm{Ca}$ & $\mathbf{A l} / \mathbf{C a}$ & $\mathrm{Mn} / \mathrm{Ca}$ & $\mathrm{Zn} / \mathrm{Ca}$ & $\mathrm{Sr} / \mathrm{Ca}$ & $\mathrm{Ba} / \mathrm{Ca}$ & $\mathrm{Pb} / \mathrm{Ca}$ & $\mathrm{U} / \mathrm{Ca}$ \\
\hline 1 & 0.00 & 0.0721 & 0.0000 & 5.44 & 0.956 & 0.0231 & 0.00950 & 3.62 & 0.01082 & 0.000000 & 0.000329 \\
\hline 2 & 0.05 & 0.0498 & 0.0768 & 4.24 & 4.167 & 0.0135 & 0.04413 & 3.39 & 0.01016 & 0.000271 & 0.000000 \\
\hline 3 & 0.10 & 0.0161 & 0.0000 & 10.43 & 19.362 & 0.0132 & 0.00000 & 2.44 & 0.00436 & 0.000000 & 0.000267 \\
\hline 4 & 0.15 & 0.0067 & 0.0632 & 17.86 & 2.067 & 0.0000 & 0.00000 & 1.42 & 0.00350 & 0.000633 & 0.000093 \\
\hline 5 & 0.20 & 0.0320 & 0.0285 & 18.51 & 0.284 & 0.0000 & 0.02669 & 1.39 & 0.00058 & 0.000872 & 0.000656 \\
\hline 6 & 0.25 & 0.0507 & 0.0000 & 11.07 & 0.042 & 0.0268 & 0.00000 & 1.16 & 0.00051 & 0.000606 & 0.000091 \\
\hline 7 & 0.30 & 0.0317 & 0.1933 & 12.93 & 0.410 & 0.0126 & 0.00000 & 1.38 & 0.00099 & 0.000000 & 0.000000 \\
\hline 8 & 0.35 & 0.0000 & 0.0000 & 11.58 & 0.097 & 0.0098 & 0.00000 & 1.23 & 0.00090 & 0.000046 & 0.000141 \\
\hline 9 & 0.40 & 0.0312 & 0.0000 & 11.82 & 0.037 & 0.0000 & 0.00000 & 1.19 & 0.00031 & 0.000000 & 0.000840 \\
\hline 10 & 0.45 & 0.0870 & 0.2999 & 12.55 & 0.120 & 0.0160 & 0.00000 & 1.03 & 0.00000 & 0.000000 & 0.000320 \\
\hline 11 & 0.50 & 0.0332 & 0.0481 & 4.74 & 0.011 & 0.0000 & 0.00000 & 2.03 & 0.00094 & 0.000666 & 0.000000 \\
\hline 12 & 0.55 & 0.0240 & 0.0522 & 0.53 & 0.056 & 0.0196 & 0.00000 & 2.73 & 0.00105 & 0.000000 & 0.000242 \\
\hline 13 & 0.60 & 0.0127 & 0.1258 & 0.47 & 0.000 & 0.0166 & 0.00000 & 2.38 & 0.00033 & 0.000289 & 0.000059 \\
\hline 14 & 0.65 & 0.0356 & 0.1421 & 0.38 & 0.000 & 0.0000 & 0.00000 & 2.17 & 0.00112 & 0.000000 & 0.000000 \\
\hline 15 & 0.70 & 0.0000 & 0.0199 & 0.49 & 0.000 & 0.0000 & 0.00894 & 2.39 & 0.00030 & 0.000000 & 0.000000 \\
\hline 16 & 0.75 & 0.0209 & 0.0860 & 0.37 & 0.005 & 0.0264 & 0.00287 & 2.07 & 0.00090 & 0.000000 & 0.000436 \\
\hline 17 & 0.80 & 0.0000 & 0.0000 & 0.38 & 0.032 & 0.0078 & 0.04559 & 2.18 & 0.00302 & 0.000000 & 0.000227 \\
\hline 18 & 0.85 & 0.0000 & 0.0000 & 0.70 & 0.013 & 0.0560 & 0.00000 & 2.11 & 0.00606 & 0.001572 & 0.001071 \\
\hline
\end{tabular}




\begin{tabular}{|c|c|c|c|c|c|c|c|c|c|c|c|}
\hline \multirow{2}{*}{ Spot Number } & \multirow{2}{*}{ Distance from outer shell (mm) } & \multicolumn{10}{|c|}{ P04A growth band transect L3 corrected data $(\mathrm{mmol} / \mathrm{mol})$} \\
\hline & & $\mathrm{Li} / \mathrm{Ca}$ & $\mathrm{B} / \mathrm{Ca}$ & $\mathrm{Mg} / \mathrm{Ca}$ & $\mathrm{Al} / \mathrm{Ca}$ & $\mathrm{Mn} / \mathrm{Ca}$ & $\mathrm{Zn} / \mathrm{Ca}$ & $\mathrm{Sr} / \mathrm{Ca}$ & $\mathrm{Ba} / \mathrm{Ca}$ & $\mathrm{Pb} / \mathrm{Ca}$ & $\mathrm{U} / \mathrm{Ca}$ \\
\hline 1 & 0.00 & 0.0199 & 0.0696 & 3.76 & 0.108 & 0.0262 & 0.00000 & 1.48 & 0.00065 & 0.000177 & 0.000000 \\
\hline 2 & 0.05 & 0.0000 & 0.0000 & 6.13 & 0.263 & 0.0179 & 0.00232 & 1.42 & 0.00092 & 0.000000 & 0.000000 \\
\hline 3 & 0.10 & 0.0000 & 0.0000 & 4.62 & 0.000 & 0.0022 & 0.00000 & 1.37 & 0.00038 & 0.000575 & 0.000222 \\
\hline 4 & 0.15 & 0.0290 & 0.0000 & 7.79 & 2.570 & 0.0188 & 0.02889 & 2.32 & 0.00556 & 0.000049 & 0.000151 \\
\hline 5 & 0.20 & 0.0467 & 0.1331 & 10.03 & 8.375 & 0.0247 & 0.04021 & 3.10 & 0.02466 & 0.000349 & 0.000721 \\
\hline 6 & 0.25 & 0.0161 & 0.0177 & 8.78 & 1.109 & 0.0086 & 0.00352 & 1.75 & 0.00242 & 0.001062 & 0.000000 \\
\hline 7 & 0.30 & 0.0243 & 0.0572 & 5.54 & 0.059 & 0.0018 & 0.00000 & 1.37 & 0.00038 & 0.000444 & 0.000000 \\
\hline 8 & 0.35 & 0.0161 & 0.0588 & 6.12 & 1.869 & 0.0077 & 0.02168 & 1.36 & 0.00397 & 0.000025 & 0.000000 \\
\hline 9 & 0.40 & 0.0184 & 0.0000 & 8.02 & 0.026 & 0.0000 & 0.00655 & 1.34 & 0.00084 & 0.000288 & 0.000255 \\
\hline 10 & 0.45 & 0.0132 & 0.0000 & 11.28 & 0.043 & 0.0073 & 0.01687 & 1.31 & 0.00027 & 0.000000 & 0.000000 \\
\hline 11 & 0.50 & 0.0136 & 0.0179 & 10.56 & 0.000 & 0.0000 & 0.00000 & 1.19 & 0.00026 & 0.000640 & 0.000000 \\
\hline 12 & 0.55 & 0.0126 & 0.0000 & 10.12 & 1.103 & 0.0202 & 0.03104 & 1.35 & 0.00154 & 0.000435 & 0.000162 \\
\hline 13 & 0.60 & 0.0054 & 0.0913 & 8.49 & 0.029 & 0.0000 & 0.03130 & 1.88 & 0.00205 & 0.000492 & 0.000004 \\
\hline 14 & 0.65 & 0.0061 & 0.0595 & 7.27 & 0.000 & 0.0000 & 0.00000 & 2.10 & 0.00106 & 0.000209 & 0.000429 \\
\hline 15 & 0.70 & 0.0057 & 0.0000 & 9.32 & 0.227 & 0.0186 & 0.05144 & 1.51 & 0.00063 & 0.000000 & 0.000000 \\
\hline 16 & 0.75 & 0.0436 & 0.0738 & 8.31 & 0.189 & 0.0222 & 0.00000 & 1.42 & 0.00147 & 0.000000 & 0.000071 \\
\hline 17 & 0.80 & 0.0312 & 0.0000 & 6.95 & 0.003 & 0.0000 & 0.00000 & 1.44 & 0.00094 & 0.000139 & 0.000036 \\
\hline 18 & 0.85 & 0.0000 & 0.0762 & 7.29 & 0.046 & 0.0342 & 0.00000 & 1.38 & 0.00042 & 0.000949 & 0.000294 \\
\hline
\end{tabular}


APPENDIX 5.3e $\quad$ SC2 growth band transect data

\begin{tabular}{|c|c|c|c|c|c|c|c|c|c|c|c|}
\hline \multirow{2}{*}{ Spot Number } & \multirow{2}{*}{ Distance from outer shell (mm) } & \multicolumn{10}{|c|}{$\mathrm{SC} 2$ growth band transect $\mathrm{L} 1$ corrected data $(\mathrm{mmol} / \mathrm{mol})$} \\
\hline & & $\mathrm{Li} / \mathrm{Ca}$ & $\mathrm{B} / \mathrm{Ca}$ & $\mathrm{Mg} / \mathrm{Ca}$ & $\mathrm{Al} / \mathrm{Ca}$ & $\mathrm{Mn} / \mathrm{Ca}$ & $\mathrm{Zn} / \mathrm{Ca}$ & $\mathrm{Sr} / \mathrm{Ca}$ & $\mathrm{Ba} / \mathrm{Ca}$ & $\mathrm{Pb} / \mathrm{Ca}$ & $\mathrm{U} / \mathbf{C a}$ \\
\hline 1 & 0.00 & 0.0178 & 0.0159 & 11.90 & 0.00068 & 0.00000 & 0.00337 & 1.26 & 0.000307 & 0.0000000 & 0.0000000 \\
\hline 2 & 0.05 & 0.0139 & 0.0002 & 11.13 & 0.00000 & 0.00000 & 0.00000 & 1.35 & 0.000469 & 0.0000000 & 0.0000000 \\
\hline 3 & 0.10 & 0.0168 & 0.0079 & 7.46 & 0.00558 & 0.00000 & 0.00418 & 1.40 & 0.000384 & 0.0000000 & 0.0000000 \\
\hline 4 & 0.15 & 0.0065 & 0.0202 & 8.31 & 0.00000 & 0.00000 & 0.00286 & 1.44 & 0.000495 & 0.0000334 & 0.0000071 \\
\hline 5 & 0.20 & 0.0084 & 0.0123 & 5.43 & 0.00390 & 0.00027 & 0.00079 & 1.33 & 0.000387 & 0.0000392 & 0.0000000 \\
\hline 6 & 0.25 & 0.0160 & 0.0000 & 5.54 & 0.00411 & 0.00058 & 0.00082 & 1.37 & 0.000430 & 0.0000286 & 0.0000092 \\
\hline 7 & 0.30 & 0.0144 & 0.0000 & 5.25 & 0.00000 & 0.00076 & 0.00237 & 1.35 & 0.000333 & 0.0000419 & 0.0000000 \\
\hline 8 & 0.35 & 0.0046 & 0.0000 & 4.47 & 0.00000 & 0.00230 & 0.00083 & 1.26 & 0.000420 & 0.0000158 & 0.0000000 \\
\hline 9 & 0.40 & 0.0135 & 0.0275 & 4.89 & 0.02274 & 0.00197 & 0.00368 & 1.28 & 0.000436 & 0.0000310 & 0.0000238 \\
\hline 10 & 0.45 & 0.0103 & 0.0043 & 5.26 & 0.00126 & 0.00294 & 0.00193 & 1.27 & 0.000424 & 0.0000410 & 0.0000090 \\
\hline 11 & 0.50 & 0.0149 & 0.0160 & 5.47 & 0.01629 & 0.00056 & 0.00065 & 1.31 & 0.000421 & 0.0000000 & 0.0000000 \\
\hline 12 & 0.55 & 0.0107 & 0.0000 & 4.75 & 0.00000 & 0.00137 & 0.00000 & 1.19 & 0.000332 & 0.0000000 & 0.0000029 \\
\hline 13 & 0.60 & 0.0116 & 0.0049 & 4.99 & 0.00000 & 0.00313 & 0.00090 & 1.14 & 0.000294 & 0.0000568 & 0.0000099 \\
\hline 14 & 0.65 & 0.0072 & 0.0110 & 5.18 & 0.00000 & 0.00276 & 0.00375 & 1.17 & 0.000294 & 0.0000000 & 0.0000000 \\
\hline 15 & 0.70 & 0.0105 & 0.0294 & 5.18 & 0.00000 & 0.00419 & 0.00000 & 1.17 & 0.000266 & 0.0000384 & 0.0000047 \\
\hline 16 & 0.75 & 0.0066 & 0.0076 & 5.28 & 0.00050 & 0.00033 & 0.00203 & 1.02 & 0.000335 & 0.0000041 & 0.0000000 \\
\hline 17 & 0.80 & 0.0106 & 0.0137 & 5.83 & 0.00218 & 0.00129 & 0.00115 & 1.05 & 0.000263 & 0.0000398 & 0.0000110 \\
\hline 18 & 0.85 & 0.0080 & 0.0000 & 6.06 & 0.00098 & 0.00000 & 0.00000 & 1.00 & 0.000279 & 0.0000105 & 0.0000000 \\
\hline 19 & 0.90 & 0.0101 & 0.0217 & 7.94 & 0.00000 & 0.00037 & 0.00041 & 1.00 & 0.000242 & 0.0000627 & 0.0000000 \\
\hline 20 & 0.95 & 0.0165 & 0.0000 & 7.47 & 0.00000 & 0.00004 & 0.00176 & 1.08 & 0.000304 & 0.0000240 & 0.0000056 \\
\hline 21 & 1.00 & 0.0131 & 0.0136 & 7.03 & 0.00000 & 0.00494 & 0.00208 & 1.08 & 0.000264 & 0.0000000 & 0.0000000 \\
\hline 22 & 1.05 & 0.0122 & 0.0136 & 7.31 & 0.00143 & 0.00087 & 0.00000 & 1.02 & 0.000244 & 0.0000000 & 0.0000191 \\
\hline 23 & 1.10 & 0.0161 & 0.0467 & 7.77 & 0.00015 & 0.00279 & 0.00175 & 0.97 & 0.000224 & 0.0000320 & 0.0000000 \\
\hline 24 & 1.15 & 0.0113 & 0.0000 & 8.29 & 0.00268 & 0.00029 & 0.00082 & 1.01 & 0.000227 & 0.0000000 & 0.0000000 \\
\hline 25 & 1.20 & 0.0100 & 0.0000 & 8.57 & 0.00034 & 0.00326 & 0.00102 & 0.96 & 0.000282 & 0.0000725 & 0.0000120 \\
\hline 26 & 1.25 & 0.0151 & 0.0080 & 10.36 & 0.00450 & 0.00321 & 0.00053 & 0.98 & 0.000278 & 0.0000092 & 0.0000000 \\
\hline 27 & 1.30 & 0.0132 & 0.0105 & 7.75 & 0.00000 & 0.00272 & 0.00269 & 1.08 & 0.000270 & 0.0000372 & 0.0000000 \\
\hline
\end{tabular}




\begin{tabular}{|c|c|c|c|c|c|c|c|c|c|c|c|}
\hline \multirow{2}{*}{ Spot Number } & \multirow{2}{*}{ Distance from outer shell (mm) } & \multicolumn{10}{|c|}{$\mathrm{SC} 2$ growth band transect $\mathrm{L} 1$ corrected data $(\mathrm{mmol} / \mathrm{mol})$} \\
\hline & & $\mathrm{Li} / \mathrm{Ca}$ & $\mathrm{B} / \mathrm{Ca}$ & $\mathrm{Mg} / \mathrm{Ca}$ & $\mathbf{A l} / \mathbf{C a}$ & $\mathrm{Mn} / \mathrm{Ca}$ & $\mathrm{Zn} / \mathrm{Ca}$ & $\mathrm{Sr} / \mathrm{Ca}$ & $\mathrm{Ba} / \mathrm{Ca}$ & $\mathrm{Pb} / \mathrm{Ca}$ & $\mathrm{U} / \mathrm{Ca}$ \\
\hline 1 & 0.00 & 0.0300 & 0.0021 & 20.47 & & 0.00000 & 0.00098 & 1.95 & 0.000848 & 0.0001253 & 0.0000149 \\
\hline 2 & 0.05 & 0.0202 & 0.0000 & 15.61 & 0.01419 & 0.00000 & 0.00000 & 2.32 & 0.001248 & 0.0001351 & 0.0000910 \\
\hline 3 & 0.10 & 0.0194 & 0.0000 & 12.38 & 0.07317 & 0.00000 & 0.00068 & 1.91 & 0.000743 & 0.0000000 & 0.0000376 \\
\hline 4 & 0.15 & 0.0199 & 0.0000 & 12.19 & 0.00383 & 0.00000 & 0.00000 & 1.62 & 0.000892 & 0.0000000 & 0.0000732 \\
\hline 5 & 0.20 & 0.0156 & 0.0000 & 7.81 & 0.00963 & 0.00243 & 0.00000 & 1.74 & 0.000926 & 0.0000193 & 0.0000379 \\
\hline 6 & 0.25 & 0.0113 & 0.0014 & 7.14 & 0.00000 & 0.00000 & 0.00300 & 1.60 & 0.000471 & 0.0000438 & 0.0000000 \\
\hline 7 & 0.30 & 0.0084 & 0.0027 & 5.61 & 0.00151 & 0.00177 & 0.00380 & 1.46 & 0.000654 & 0.0000685 & 0.0000126 \\
\hline 8 & 0.35 & 0.0112 & 0.0000 & 6.42 & 0.02975 & 0.00000 & 0.00000 & 1.77 & 0.000597 & 0.0000296 & 0.0000267 \\
\hline 9 & 0.40 & 0.0165 & 0.0000 & 4.67 & 0.00840 & 0.00002 & 0.00667 & 1.43 & 0.000449 & 0.0000000 & 0.0000000 \\
\hline 10 & 0.45 & 0.0124 & 0.0169 & 8.31 & 0.00676 & 0.00000 & 0.00267 & 1.47 & 0.000514 & 0.0001286 & 0.0000000 \\
\hline 11 & 0.50 & 0.0121 & 0.0000 & 10.34 & 0.00000 & 0.00078 & 0.00212 & 1.53 & 0.000626 & 0.0001179 & 0.0000568 \\
\hline 12 & 0.55 & 0.0112 & 0.0000 & 7.04 & 0.00039 & 0.00020 & 0.00101 & 1.38 & 0.000520 & 0.0000250 & 0.0000000 \\
\hline 13 & 0.60 & 0.0186 & 0.0038 & 8.76 & 0.00000 & 0.00352 & 0.00541 & 1.44 & 0.000600 & 0.0001931 & 0.0000276 \\
\hline 14 & 0.65 & 0.0021 & 0.0295 & 8.24 & 0.00098 & 0.00000 & 0.00439 & 1.44 & 0.000607 & 0.0001026 & 0.0000096 \\
\hline 15 & 0.70 & 0.0154 & 0.0191 & 8.64 & 0.00741 & 0.00114 & 0.00000 & 1.39 & 0.000429 & 0.0000181 & 0.0000586 \\
\hline 16 & 0.75 & 0.0083 & 0.0000 & 8.62 & 0.00000 & 0.00161 & 0.00000 & 1.32 & 0.000419 & 0.0000000 & 0.0000000 \\
\hline 17 & 0.80 & 0.0096 & 0.0000 & 9.42 & 0.00000 & 0.00101 & 0.00021 & 1.34 & 0.000576 & 0.0000000 & 0.0000098 \\
\hline 18 & 0.85 & 0.0157 & 0.0002 & 10.11 & 0.00000 & 0.00416 & 0.00000 & 1.31 & 0.000448 & 0.0000244 & 0.0000000 \\
\hline 19 & 0.90 & 0.0126 & 0.0026 & 9.30 & 0.00008 & 0.00252 & 0.00008 & 1.23 & 0.000418 & 0.0000003 & 0.0000000 \\
\hline 20 & 0.95 & 0.0133 & 0.0013 & 10.06 & 0.00135 & 0.00186 & 0.00085 & 1.21 & 0.000455 & 0.0000092 & 0.0000000 \\
\hline 21 & 1.00 & 0.0140 & 0.0063 & 10.96 & 0.00163 & 0.00286 & 0.00048 & 1.19 & 0.000400 & 0.0000000 & 0.0000000 \\
\hline 22 & 1.05 & 0.0129 & 0.0066 & 11.37 & 0.00000 & 0.00235 & 0.00087 & 1.13 & 0.000335 & 0.0000096 & 0.0000056 \\
\hline 23 & 1.10 & 0.0129 & 0.0066 & 11.37 & 0.00000 & 0.00235 & 0.00087 & 1.13 & 0.000335 & 0.0000096 & 0.0000056 \\
\hline 24 & 1.15 & 0.0168 & 0.0000 & 11.65 & 0.00021 & 0.00364 & 0.00003 & 1.15 & 0.000354 & 0.0000000 & 0.0000000 \\
\hline 25 & 1.20 & 0.0137 & 0.0008 & 13.87 & 0.00656 & 0.00000 & 0.00596 & 1.23 & 0.000296 & 0.0000000 & 0.0000063 \\
\hline 26 & 1.25 & 0.0128 & 0.0246 & 16.88 & 0.00344 & 0.00146 & 0.00140 & 1.27 & 0.000422 & 0.0000940 & 0.0000165 \\
\hline 27 & 1.30 & 0.0145 & 0.0179 & 17.68 & 0.00000 & 0.00464 & 0.00127 & 1.21 & 0.000323 & 0.0000304 & 0.0000203 \\
\hline 28 & 1.35 & 0.0205 & 0.0174 & 18.90 & 0.00000 & 0.00436 & 0.00000 & 1.23 & 0.000475 & 0.0000111 & 0.0000000 \\
\hline
\end{tabular}




\begin{tabular}{|c|c|c|c|c|c|c|c|c|c|c|c|}
\hline \multirow{2}{*}{ Spot Number } & \multirow{2}{*}{ Distance from outer shell (mm) } & \multicolumn{10}{|c|}{$\mathrm{SC} 2$ growth band transect $\mathrm{L} 1$ corrected data $(\mathrm{mmol} / \mathrm{mol})$} \\
\hline & & $\mathbf{L i} / \mathbf{C a}$ & $\mathrm{B} / \mathrm{Ca}$ & $\mathrm{Mg} / \mathrm{Ca}$ & $\mathbf{A l} / \mathbf{C a}$ & $\mathrm{Mn} / \mathrm{Ca}$ & $\mathrm{Zn} / \mathrm{Ca}$ & $\mathrm{Sr} / \mathrm{Ca}$ & $\mathrm{Ba} / \mathrm{Ca}$ & $\mathrm{Pb} / \mathrm{Ca}$ & $\mathrm{U} / \mathrm{Ca}$ \\
\hline 1 & 0.00 & 0.0128 & 0.0190 & 3.60 & 0.00000 & 0.00000 & 0.00026 & 1.09 & 0.000315 & 0.0000000 & 0.0000000 \\
\hline 2 & 0.05 & 0.0093 & 0.0111 & 4.06 & 0.00000 & 0.00367 & 0.00000 & 0.82 & 0.000267 & 0.0000375 & 0.0001064 \\
\hline 3 & 0.10 & 0.0127 & 0.0000 & 4.09 & 0.00000 & 0.00000 & 0.00173 & 0.89 & 0.000182 & 0.0000000 & 0.0000000 \\
\hline 4 & 0.15 & 0.0084 & 0.0000 & 3.60 & 0.00621 & 0.00170 & 0.00412 & 0.95 & 0.000213 & 0.0000000 & 0.0000000 \\
\hline 5 & 0.20 & 0.0070 & 0.0054 & 3.51 & 0.00000 & 0.00000 & 0.00000 & 1.01 & 0.000255 & 0.0000940 & 0.0000388 \\
\hline 6 & 0.25 & 0.0098 & 0.0177 & 3.29 & 0.00000 & 0.00539 & 0.00000 & 0.95 & 0.000341 & 0.0000000 & 0.0000060 \\
\hline 7 & 0.30 & 0.0118 & 0.0075 & 3.36 & 0.00000 & 0.00344 & 0.00196 & 0.97 & 0.000169 & 0.0000249 & 0.0000000 \\
\hline 8 & 0.35 & 0.0059 & 0.0000 & 3.64 & 0.00278 & 0.00076 & 0.00624 & 0.99 & 0.000178 & 0.0000000 & 0.0000000 \\
\hline 9 & 0.40 & 0.0117 & 0.0000 & 3.44 & 0.00000 & 0.00129 & 0.00167 & 1.09 & 0.000266 & 0.0000000 & 0.0000000 \\
\hline 10 & 0.45 & 0.0159 & 0.0023 & 3.28 & 0.00000 & 0.00257 & 0.00000 & 1.00 & 0.000253 & 0.0001000 & 0.0000000 \\
\hline 11 & 0.50 & 0.0069 & 0.0000 & 3.09 & 0.00660 & 0.00000 & 0.00390 & 1.08 & 0.000166 & 0.0000000 & 0.0000301 \\
\hline 12 & 0.55 & 0.0104 & 0.0309 & 2.98 & 0.00175 & 0.00369 & 0.00000 & 1.10 & 0.000333 & 0.0000000 & 0.0000000 \\
\hline 13 & 0.60 & 0.0155 & 0.0008 & 2.88 & 0.00307 & 0.00034 & 0.00780 & 1.12 & 0.000352 & 0.0000000 & 0.0000000 \\
\hline 14 & 0.65 & 0.0091 & 0.0312 & 2.83 & 0.00590 & 0.00194 & 0.00432 & 1.15 & 0.000345 & 0.0001451 & 0.0000000 \\
\hline 15 & 0.70 & 0.0103 & 0.0142 & 2.87 & 0.00303 & 0.00246 & 0.00597 & 1.19 & 0.000303 & 0.0000000 & 0.0000000 \\
\hline 16 & 0.75 & 0.0093 & 0.0000 & 2.76 & 0.00644 & 0.00000 & 0.00720 & 1.19 & 0.000262 & 0.0001134 & 0.0000369 \\
\hline 17 & 0.80 & 0.0054 & 0.0162 & 2.83 & 0.00088 & 0.00000 & 0.00000 & 1.21 & 0.000372 & 0.0000000 & 0.0000000 \\
\hline 18 & 0.85 & 0.0092 & 0.0133 & 2.85 & 0.00000 & 0.00000 & 0.00000 & 1.20 & 0.000363 & 0.0000265 & 0.0000298 \\
\hline 19 & 0.90 & 0.0085 & 0.0116 & 3.00 & 0.00021 & 0.00038 & 0.00000 & 1.32 & 0.000356 & 0.0000000 & 0.0000410 \\
\hline 20 & 0.95 & 0.0070 & 0.0135 & 3.37 & 0.00000 & 0.00221 & 0.00423 & 1.32 & 0.000391 & 0.0000000 & 0.0000006 \\
\hline 21 & 1.00 & 0.0181 & 0.0036 & 7.66 & 0.00602 & 0.00261 & 0.00000 & 1.44 & 0.000520 & 0.0000253 & 0.0000000 \\
\hline 22 & 1.05 & 0.0102 & 0.0295 & 11.60 & 0.00305 & 0.00000 & 0.00366 & 1.47 & 0.000477 & 0.0000433 & 0.0000235 \\
\hline 23 & 1.10 & 0.0146 & 0.0145 & 4.90 & 0.00000 & 0.00000 & 0.00120 & 1.34 & 0.000343 & 0.0000961 & 0.0000294 \\
\hline 24 & 1.15 & 0.0142 & 0.0000 & 5.86 & 0.00776 & 0.00000 & 0.00299 & 1.25 & 0.000358 & 0.0000000 & 0.0000041 \\
\hline 25 & 1.20 & 0.0174 & 0.0000 & 4.75 & 0.00075 & 0.00260 & 0.00928 & 1.32 & 0.000387 & 0.0000000 & 0.0000000 \\
\hline 26 & 1.25 & 0.0145 & 0.0313 & 7.58 & 0.00000 & 0.00580 & 0.00705 & 1.22 & 0.000364 & 0.0000000 & 0.0000156 \\
\hline 27 & 1.30 & 0.0073 & 0.0000 & 7.48 & 0.11099 & 0.00000 & 0.00000 & 1.17 & 0.000467 & 0.0000000 & 0.0000000 \\
\hline 28 & 1.35 & 0.0226 & 0.0141 & 9.15 & 0.00649 & 0.00000 & 0.00766 & 1.18 & 0.000340 & 0.0001198 & 0.0000191 \\
\hline
\end{tabular}


APPENDIX 5.3f $\quad$ SC1A growth band transect data

\begin{tabular}{|c|c|c|c|c|c|c|c|c|c|c|c|}
\hline \multirow{2}{*}{$\begin{array}{c}\text { Spot } \\
\text { Number }\end{array}$} & \multirow{2}{*}{ Distance from outer shell (mm) } & \multicolumn{10}{|c|}{ SC1A growth band transect $\mathrm{L} 1$ corrected data $(\mathrm{mmol} / \mathrm{mol})$} \\
\hline & & $\mathrm{Li} / \mathrm{Ca}$ & $\mathrm{B} / \mathrm{Ca}$ & $\mathrm{Mg} / \mathrm{Ca}$ & $\mathbf{A l} / \mathbf{C a}$ & $\mathrm{Mn} / \mathrm{Ca}$ & $\mathrm{Zn} / \mathrm{Ca}$ & $\mathrm{Sr} / \mathrm{Ca}$ & $\mathrm{Ba} / \mathrm{Ca}$ & $\mathrm{Pb} / \mathrm{Ca}$ & $\mathrm{U} / \mathrm{Ca}$ \\
\hline 1 & 0.00 & 0.026 & 0.000 & 20.38 & 0.000 & 0.00794 & 0.0229 & 1.93 & 0.00053 & 0.000061 & 0.0000520 \\
\hline 2 & 0.05 & 0.000 & 0.068 & 18.19 & 0.000 & 0.00000 & 0.0000 & 1.84 & 0.00166 & 0.000252 & 0.0000426 \\
\hline 3 & 0.10 & 0.000 & 0.000 & 14.57 & 0.104 & 0.00502 & 0.0000 & 1.78 & 0.00126 & 0.000000 & 0.0000816 \\
\hline 4 & 0.15 & 0.000 & 0.315 & 13.69 & 0.349 & 0.00585 & 0.0007 & 1.73 & 0.00120 & 0.000362 & 0.0000529 \\
\hline 5 & 0.20 & 0.000 & 0.000 & 10.14 & 0.491 & 0.00000 & 0.0105 & 1.71 & 0.00111 & 0.000000 & 0.0000000 \\
\hline 6 & 0.25 & 0.000 & 0.091 & 6.63 & 0.007 & 0.00000 & 0.0000 & 1.47 & 0.00056 & 0.000276 & 0.0000283 \\
\hline 7 & 0.30 & 0.279 & 0.062 & 4.93 & 0.000 & 0.00129 & 0.0090 & 1.43 & 0.00098 & 0.000000 & 0.0000000 \\
\hline 8 & 0.35 & 0.065 & 0.000 & 3.22 & 0.000 & 0.00876 & 0.0000 & 1.24 & 0.00000 & 0.000000 & 0.0000000 \\
\hline 9 & 0.40 & 0.145 & 0.476 & 2.86 & 0.044 & 0.00546 & 0.0000 & 1.14 & 0.00043 & 0.000256 & 0.0000373 \\
\hline 10 & 0.45 & 0.079 & 0.000 & 2.45 & 0.000 & 0.00857 & 0.0000 & 1.23 & 0.00059 & 0.000000 & 0.0000000 \\
\hline 11 & 0.50 & 0.039 & 0.000 & 3.36 & 0.019 & 0.00139 & 0.0059 & 1.22 & 0.00047 & 0.000273 & 0.0000000 \\
\hline 12 & 0.55 & 0.000 & 0.000 & 2.89 & 0.000 & 0.01047 & 0.0000 & 1.11 & 0.00015 & 0.000000 & 0.0000388 \\
\hline 13 & 0.60 & 0.072 & 0.000 & 5.08 & 0.038 & 0.00483 & 0.0150 & 1.21 & 0.00114 & 0.000214 & 0.0000000 \\
\hline 14 & 0.65 & 0.137 & 0.000 & 5.55 & 0.000 & 0.00000 & 0.0000 & 1.09 & 0.00047 & 0.000000 & 0.0000000 \\
\hline 15 & 0.70 & 0.066 & 0.000 & 4.30 & 0.020 & 0.00000 & 0.0049 & 1.06 & 0.00039 & 0.000000 & 0.0001062 \\
\hline 16 & 0.75 & 0.000 & 0.000 & 4.25 & 0.000 & 0.00000 & 0.0194 & 1.17 & 0.00027 & 0.000000 & 0.0000000 \\
\hline 17 & 0.80 & 0.056 & 0.000 & 3.63 & 0.000 & 0.00348 & 0.0048 & 1.27 & 0.00019 & 0.000000 & 0.0000000 \\
\hline 18 & 0.85 & 0.101 & 0.095 & 4.53 & 0.020 & 0.00464 & 0.0087 & 1.20 & 0.00040 & 0.000000 & 0.0000000 \\
\hline 19 & 0.90 & 0.059 & 0.110 & 4.61 & 0.092 & 0.00000 & 0.0244 & 1.30 & 0.00024 & 0.000000 & 0.0000000 \\
\hline 20 & 0.95 & 0.000 & 0.000 & 4.86 & 0.000 & 0.00000 & 0.0055 & 1.35 & 0.00000 & 0.000000 & 0.0000000 \\
\hline 21 & 1.00 & 0.195 & 0.081 & 4.82 & 0.011 & 0.00000 & 0.0000 & 1.47 & 0.00065 & 0.000206 & 0.0000000 \\
\hline 22 & 1.05 & 0.127 & 0.120 & 5.69 & 0.040 & 0.00325 & 0.0070 & 1.47 & 0.00000 & 0.000000 & 0.0000020 \\
\hline 23 & 1.10 & 0.000 & 0.000 & 5.90 & 0.000 & 0.00000 & 0.0163 & 1.37 & 0.00122 & 0.000062 & 0.0000562 \\
\hline 24 & 1.15 & 0.000 & 0.311 & 5.76 & 0.025 & 0.00000 & 0.0146 & 1.13 & 0.00000 & 0.000000 & 0.0000185 \\
\hline
\end{tabular}




\begin{tabular}{|c|c|c|c|c|c|c|c|c|c|c|c|}
\hline \multirow{2}{*}{$\begin{array}{c}\text { Spot } \\
\text { Number }\end{array}$} & \multirow{2}{*}{ Distance from outer shell (mm) } & \multicolumn{10}{|c|}{ SC1A growth band transect $\mathrm{L} 2$ corrected data $(\mathrm{mmol} / \mathrm{mol})$} \\
\hline & & $\mathrm{Li} / \mathrm{Ca}$ & $\mathrm{B} / \mathrm{Ca}$ & $\mathrm{Mg} / \mathrm{Ca}$ & $\mathrm{Al} / \mathrm{Ca}$ & $\mathrm{Mn} / \mathrm{Ca}$ & $\mathrm{Zn} / \mathrm{Ca}$ & $\mathrm{Sr} / \mathrm{Ca}$ & $\mathrm{Ba} / \mathrm{Ca}$ & $\mathrm{Pb} / \mathrm{Ca}$ & $\mathrm{U} / \mathrm{Ca}$ \\
\hline 1 & 0.00 & 0.057 & 0.045 & 4.88 & 0.000 & 0.00065 & 0.0000 & 1.13 & 0.00010 & 0.000000 & 0.0000000 \\
\hline 2 & 0.05 & 0.024 & 0.000 & 4.97 & 0.000 & 0.00459 & 0.0000 & 1.24 & 0.00063 & 0.000183 & 0.0000000 \\
\hline 3 & 0.10 & 0.000 & 0.000 & 3.07 & 0.000 & 0.00127 & 0.0023 & 1.01 & 0.00000 & 0.000154 & 0.0000041 \\
\hline 4 & 0.15 & 0.000 & 0.081 & 3.51 & 0.042 & 0.00000 & 0.0028 & 1.15 & 0.00037 & 0.000222 & 0.0000007 \\
\hline 5 & 0.20 & 0.000 & 0.174 & 3.50 & 0.015 & 0.00106 & 0.0108 & 1.08 & 0.00051 & 0.000158 & 0.0000099 \\
\hline 6 & 0.25 & 0.000 & 0.000 & 3.36 & 0.030 & 0.00003 & 0.0020 & 1.03 & 0.00036 & 0.000199 & 0.0000302 \\
\hline 7 & 0.30 & 0.000 & 0.000 & 4.40 & 0.000 & 0.00000 & 0.0008 & 1.15 & 0.00010 & 0.000102 & 0.0000066 \\
\hline 8 & 0.35 & 0.000 & 0.078 & 3.98 & 0.000 & 0.00961 & 0.0000 & 1.13 & 0.00035 & 0.000140 & 0.0000000 \\
\hline 9 & 0.40 & 0.000 & 0.018 & 4.62 & 0.000 & 0.00000 & 0.0114 & 1.07 & 0.00027 & 0.000056 & 0.0000374 \\
\hline 10 & 0.45 & 0.000 & 0.000 & 4.94 & 0.020 & 0.00053 & 0.0000 & 1.02 & 0.00010 & 0.000109 & 0.0000000 \\
\hline 11 & 0.50 & 0.000 & 0.202 & 5.91 & 0.037 & 0.00073 & 0.0037 & 1.15 & 0.00032 & 0.000031 & 0.0000038 \\
\hline 12 & 0.55 & 0.006 & 0.109 & 5.20 & 0.032 & 0.00589 & 0.0083 & 1.00 & 0.00003 & 0.000115 & 0.0000009 \\
\hline 13 & 0.60 & 0.000 & 0.000 & 4.48 & 0.000 & 0.00000 & 0.0000 & 1.12 & 0.00001 & 0.000000 & 0.0000000 \\
\hline 14 & 0.65 & 0.006 & 0.000 & 5.20 & 0.000 & 0.00556 & 0.0000 & 0.95 & 0.00022 & 0.000091 & 0.0000000 \\
\hline 15 & 0.70 & 0.077 & 0.000 & 5.60 & 0.000 & 0.00000 & 0.0000 & 0.93 & 0.00029 & 0.000122 & 0.0000184 \\
\hline 16 & 0.75 & 0.006 & 0.000 & 6.25 & 0.000 & 0.00000 & 0.0000 & 0.95 & 0.00017 & 0.000000 & 0.0000085 \\
\hline 17 & 0.80 & 0.068 & 0.211 & 6.55 & 0.000 & 0.00250 & 0.0084 & 0.97 & 0.00000 & 0.000000 & 0.0000058 \\
\hline 18 & 0.85 & 0.000 & 0.000 & 6.38 & 0.000 & 0.00251 & 0.0000 & 0.93 & 0.00007 & 0.000000 & 0.0000000 \\
\hline 19 & 0.90 & 0.027 & 0.000 & 6.87 & 0.029 & 0.00000 & 0.0000 & 0.99 & 0.00023 & 0.000000 & 0.0000000 \\
\hline 20 & 0.95 & 0.038 & 0.281 & 7.22 & 0.013 & 0.00193 & 0.0000 & 0.97 & 0.00015 & 0.000070 & 0.0000429 \\
\hline 21 & 1.00 & 0.000 & 0.019 & 7.38 & 0.064 & 0.00019 & 0.0088 & 0.90 & 0.00013 & 0.000125 & 0.0000106 \\
\hline 22 & 1.05 & 0.000 & 0.000 & 8.56 & 0.012 & 0.00529 & 0.0007 & 0.84 & 0.00015 & 0.000115 & 0.0000000 \\
\hline 23 & 1.10 & 0.054 & 0.000 & 9.20 & 0.051 & 0.00000 & 0.0044 & 0.91 & 0.00042 & 0.000265 & 0.0000000 \\
\hline
\end{tabular}




\begin{tabular}{|c|c|c|c|c|c|c|c|c|c|c|c|}
\hline \multirow{2}{*}{$\begin{array}{c}\text { Spot } \\
\text { Number }\end{array}$} & \multirow{2}{*}{ Distance from outer shell (mm) } & \multicolumn{10}{|c|}{ SC1A growth band transect L3 corrected data $(\mathrm{mmol} / \mathrm{mol})$} \\
\hline & & $\mathrm{Li} / \mathrm{Ca}$ & $\mathrm{B} / \mathrm{Ca}$ & $\mathrm{Mg} / \mathrm{Ca}$ & $\mathbf{A l} / \mathbf{C a}$ & $\mathrm{Mn} / \mathrm{Ca}$ & $\mathrm{Zn} / \mathrm{Ca}$ & $\mathrm{Sr} / \mathrm{Ca}$ & $\mathrm{Ba} / \mathrm{Ca}$ & $\mathrm{Pb} / \mathrm{Ca}$ & $\mathrm{U} / \mathbf{C a}$ \\
\hline 1 & 0.00 & 0.008 & 0.000 & 6.76 & 0.000 & 0.00229 & 0.0000 & 1.68 & 0.00017 & 0.000000 & 0.0000000 \\
\hline 2 & 0.05 & 0.024 & 0.161 & 6.18 & 0.000 & 0.00241 & 0.0031 & 1.76 & 0.00076 & 0.000105 & 0.0000743 \\
\hline 3 & 0.10 & 0.123 & 0.000 & 5.44 & 0.000 & 0.00523 & 0.0000 & 1.67 & 0.00056 & 0.000178 & 0.0000000 \\
\hline 4 & 0.15 & 0.008 & 0.096 & 5.00 & 0.000 & 0.00134 & 0.0000 & 1.68 & 0.00051 & 0.000185 & 0.0000238 \\
\hline 5 & 0.20 & 0.060 & 0.000 & 3.69 & 0.012 & 0.00210 & 0.0000 & 1.54 & 0.00041 & 0.000285 & 0.0000040 \\
\hline 6 & 0.25 & 0.049 & 0.093 & 3.10 & 0.052 & 0.00502 & 0.0068 & 1.62 & 0.00021 & 0.000066 & 0.0000000 \\
\hline 7 & 0.30 & 0.040 & 0.066 & 3.44 & 0.013 & 0.00381 & 0.0076 & 1.66 & 0.00031 & 0.000076 & 0.0000268 \\
\hline 8 & 0.35 & 0.000 & 0.000 & 3.72 & 0.045 & 0.00000 & 0.0085 & 1.69 & 0.00056 & 0.000159 & 0.0000000 \\
\hline 9 & 0.40 & 0.015 & 0.020 & 3.52 & 0.017 & 0.00000 & 0.0031 & 1.58 & 0.00026 & 0.000201 & 0.0000000 \\
\hline 10 & 0.45 & 0.037 & 0.000 & 4.68 & 0.000 & 0.00058 & 0.0000 & 1.61 & 0.00036 & 0.000136 & 0.0000206 \\
\hline 11 & 0.50 & 0.000 & 0.125 & 4.34 & 0.000 & 0.00000 & 0.0000 & 1.61 & 0.00041 & 0.000076 & 0.0000000 \\
\hline 12 & 0.55 & 0.000 & 0.038 & 3.60 & 0.005 & 0.00000 & 0.0047 & 1.51 & 0.00060 & 0.000199 & 0.0000000 \\
\hline 13 & 0.60 & 0.000 & 0.019 & 3.46 & 0.000 & 0.00000 & 0.0080 & 1.50 & 0.00019 & 0.000000 & 0.0000000 \\
\hline 14 & 0.65 & 0.000 & 0.113 & 3.32 & 0.000 & 0.00362 & 0.0005 & 1.44 & 0.00038 & 0.000079 & 0.0000049 \\
\hline 15 & 0.70 & 0.036 & 0.000 & 3.89 & 0.000 & 0.00142 & 0.0035 & 1.37 & 0.00034 & 0.000127 & 0.0000000 \\
\hline 16 & 0.75 & 0.098 & 0.122 & 4.34 & 0.000 & 0.00075 & 0.0117 & 1.39 & 0.00053 & 0.000000 & 0.0000000 \\
\hline 17 & 0.80 & 0.007 & 0.119 & 4.27 & 0.034 & 0.00264 & 0.0000 & 1.34 & 0.00054 & 0.000110 & 0.0000039 \\
\hline 18 & 0.85 & 0.000 & 0.019 & 5.28 & 0.000 & 0.00250 & 0.0004 & 1.31 & 0.00004 & 0.000140 & 0.0000049 \\
\hline
\end{tabular}


APPENDIX 5.3g $\quad$ MP02A growth band transect data

\begin{tabular}{|c|c|c|c|c|c|c|c|c|c|c|c|}
\hline \multirow{2}{*}{ Spot Number } & \multirow{2}{*}{ Distance from outer shell (mm) } & \multicolumn{10}{|c|}{ MP02A growth band transect $\mathrm{L} 1$ corrected data $(\mathrm{mmol} / \mathrm{mol})$} \\
\hline & & $\mathrm{Li} / \mathrm{Ca}$ & $\mathrm{B} / \mathrm{Ca}$ & $\mathrm{Mg} / \mathrm{Ca}$ & $\mathbf{A l} / \mathbf{C a}$ & $\mathrm{Mn} / \mathrm{Ca}$ & $\mathrm{Zn} / \mathrm{Ca}$ & $\mathrm{Sr} / \mathrm{Ca}$ & $\mathrm{Ba} / \mathrm{Ca}$ & $\mathrm{Pb} / \mathrm{Ca}$ & $\mathbf{U} / \mathbf{C a}$ \\
\hline 1 & 0.00 & 0.0047 & 0.0105 & 15.26 & 1.338 & 0.0020 & 0.0058 & 1.36 & 0.00092 & 0.000000 & 0.0000000 \\
\hline 2 & 0.05 & 0.0295 & 0.0000 & 13.34 & 0.811 & 0.0200 & 0.0082 & 1.35 & 0.00128 & 0.000135 & 0.0000000 \\
\hline 3 & 0.10 & 0.0555 & 0.0340 & 14.94 & 4.665 & 0.0676 & 0.0232 & 1.34 & 0.00148 & 0.000068 & 0.0000566 \\
\hline 4 & 0.15 & 0.0527 & 0.0356 & 16.78 & 14.517 & 0.1082 & 0.0223 & 1.36 & 0.01591 & 0.000201 & 0.0000011 \\
\hline 5 & 0.20 & 0.0066 & 0.0316 & 12.56 & 4.394 & 0.0300 & 0.0057 & 1.23 & 0.00726 & 0.000397 & 0.0000519 \\
\hline 6 & 0.25 & 0.0000 & 0.0000 & 9.78 & 0.204 & 0.0009 & 0.0025 & 1.24 & 0.00109 & 0.000142 & 0.0000085 \\
\hline 7 & 0.30 & 0.0116 & 0.0114 & 10.72 & 0.044 & 0.0020 & 0.0000 & 1.25 & 0.00025 & 0.000000 & 0.0000000 \\
\hline 8 & 0.35 & 0.0281 & 0.0116 & 9.96 & 0.000 & 0.0012 & 0.0000 & 1.19 & 0.00037 & 0.000000 & 0.0000000 \\
\hline 9 & 0.40 & 0.0501 & 0.0005 & 9.81 & 0.006 & 0.0050 & 0.0025 & 1.09 & 0.00025 & 0.000000 & 0.0000004 \\
\hline 10 & 0.45 & 0.0000 & 0.0000 & 10.41 & 0.023 & 0.0043 & 0.0059 & 0.97 & 0.00037 & 0.000000 & 0.0000000 \\
\hline 11 & 0.50 & 0.0109 & 0.0175 & 6.83 & 0.007 & 0.0016 & 0.0009 & 1.10 & 0.00040 & 0.000000 & 0.0000003 \\
\hline 12 & 0.55 & 0.0026 & 0.0000 & 5.03 & 0.000 & 0.0022 & 0.0021 & 0.97 & 0.00028 & 0.000003 & 0.0000000 \\
\hline
\end{tabular}


APPENDIX 5.3h $\quad$ KD1B growth band transect data

\begin{tabular}{|c|c|c|c|c|c|c|c|c|c|c|c|}
\hline \multirow{2}{*}{$\begin{array}{c}\text { Spot } \\
\text { Number }\end{array}$} & \multirow{2}{*}{ Distance from outer shell (mm) } & \multicolumn{10}{|c|}{ KD1B growth band transect L1 corrected data (mmol/mol) } \\
\hline & & $\mathrm{Li} / \mathrm{Ca}$ & $\mathrm{B} / \mathrm{Ca}$ & $\mathrm{Mg} / \mathrm{Ca}$ & $\mathrm{Al} / \mathrm{Ca}$ & $\mathrm{Mn} / \mathrm{Ca}$ & $\mathrm{Zn} / \mathrm{Ca}$ & $\mathrm{Sr} / \mathrm{Ca}$ & $\mathrm{Ba} / \mathrm{Ca}$ & $\mathrm{Pb} / \mathrm{Ca}$ & $\mathrm{U} / \mathrm{Ca}$ \\
\hline 1 & 0.00 & 0.0000 & 0.0084 & 7.66 & 0.1171 & 0.00892 & 0.00000 & 1.24 & 0.00114 & 0.0001139 & 0.0000000 \\
\hline 2 & 0.05 & 0.0519 & 0.0101 & 7.68 & 0.8466 & 0.00683 & 0.00234 & 1.52 & 0.00160 & 0.0000276 & 0.0000429 \\
\hline 3 & 0.10 & 0.0000 & 0.0406 & 10.75 & 0.0272 & 0.00601 & 0.00703 & 1.38 & 0.00091 & 0.0000848 & 0.0000000 \\
\hline 4 & 0.15 & 0.0363 & 0.0233 & 10.69 & 0.0756 & 0.00559 & 0.00000 & 1.43 & 0.00124 & 0.0001125 & 0.0000000 \\
\hline 5 & 0.20 & 0.0335 & 0.0135 & 12.16 & 1.0243 & 0.00645 & 0.00028 & 1.55 & 0.00141 & 0.0000212 & 0.0000444 \\
\hline 6 & 0.25 & 0.0000 & 0.0039 & 8.91 & 0.0110 & 0.00538 & 0.00000 & 1.41 & 0.00085 & 0.0000000 & 0.0000153 \\
\hline 7 & 0.30 & 0.0006 & 0.0026 & 6.88 & 0.0320 & 0.00298 & 0.00485 & 1.25 & 0.00062 & 0.0000000 & 0.0000323 \\
\hline 8 & 0.35 & 0.0029 & 0.0147 & 6.52 & 0.0148 & 0.00166 & 0.00748 & 1.25 & 0.00053 & 0.0000000 & 0.0000000 \\
\hline 9 & 0.40 & 0.0000 & 0.0000 & 4.69 & 0.0000 & 0.00084 & 0.00928 & 1.21 & 0.00048 & 0.0000291 & 0.0000034 \\
\hline 10 & 0.45 & 0.0067 & 0.0000 & 4.63 & 0.0169 & 0.00050 & 0.00170 & 1.27 & 0.00054 & 0.0000005 & 0.0000000 \\
\hline 11 & 0.50 & 0.0036 & 0.0198 & 4.32 & 0.0284 & 0.00308 & 0.00447 & 1.30 & 0.00054 & 0.0001289 & 0.0000000 \\
\hline 12 & 0.55 & 0.0048 & 0.0000 & 4.35 & 0.0000 & 0.00240 & 0.00862 & 1.23 & 0.00052 & 0.0000304 & 0.0000000 \\
\hline 13 & 0.60 & 0.0371 & 0.0000 & 6.02 & 0.0412 & 0.00020 & 0.00000 & 1.34 & 0.00069 & 0.0000000 & 0.0000000 \\
\hline 14 & 0.65 & 0.0041 & 0.0257 & 10.76 & 0.1082 & 0.00258 & 0.00730 & 1.38 & 0.00113 & 0.0000000 & 0.0000172 \\
\hline 15 & 0.70 & 0.0065 & 0.0666 & 10.15 & 0.0894 & 0.00000 & 0.01056 & 1.23 & 0.00062 & 0.0000000 & 0.0000063 \\
\hline 16 & 0.75 & 0.0434 & 0.0000 & 7.51 & 0.0056 & 0.00072 & 0.00250 & 1.16 & 0.00034 & 0.0000361 & 0.0000000 \\
\hline 17 & 0.80 & 0.0030 & 0.0040 & 7.36 & 0.0263 & 0.01111 & 0.00901 & 1.22 & 0.00051 & 0.0000653 & 0.0000000 \\
\hline 18 & 0.85 & 0.0023 & 0.0000 & 6.47 & 0.0000 & 0.00000 & 0.00108 & 1.16 & 0.00047 & 0.0000000 & 0.0000000 \\
\hline 19 & 0.90 & 0.0178 & 0.0034 & 6.21 & 0.0000 & 0.00676 & 0.00871 & 1.22 & 0.00066 & 0.0000438 & 0.0000000 \\
\hline 20 & 0.95 & 0.0172 & 0.0000 & 5.45 & 0.0226 & 0.00007 & 0.00261 & 1.18 & 0.00055 & 0.0000000 & 0.0000000 \\
\hline 21 & 1.00 & 0.0080 & 0.0000 & 5.22 & 0.0113 & 0.00309 & 0.00366 & 1.25 & 0.00053 & 0.0000000 & 0.0000000 \\
\hline 22 & 1.05 & 0.0098 & 0.0221 & 4.97 & 0.0000 & 0.00341 & 0.00815 & 1.25 & 0.00053 & 0.0000288 & 0.0000244 \\
\hline 23 & 1.10 & 0.0306 & 0.0067 & 4.45 & 0.0027 & 0.00000 & 0.00712 & 1.22 & 0.00050 & 0.0000000 & 0.0000028 \\
\hline
\end{tabular}


APPENDIX 5.3i K3A growth band data

\begin{tabular}{|c|c|c|c|c|c|c|c|c|c|c|c|}
\hline \multirow{2}{*}{ Spot Number } & \multirow{2}{*}{ Distance from outer shell (mm) } & \multicolumn{10}{|c|}{ K3A growth band transect $\mathrm{L} 1$ corrected data $(\mathrm{mmol} / \mathrm{mol})$} \\
\hline & & $\mathrm{Li} / \mathrm{Ca}$ & $\mathrm{B} / \mathrm{Ca}$ & $\mathrm{Mg} / \mathrm{Ca}$ & $\mathbf{A l} / \mathbf{C a}$ & $\mathrm{Mn} / \mathrm{Ca}$ & $\mathrm{Zn} / \mathrm{Ca}$ & $\mathrm{Sr} / \mathrm{Ca}$ & $\mathrm{Ba} / \mathrm{Ca}$ & $\mathrm{Pb} / \mathrm{Ca}$ & $\mathbf{U} / \mathbf{C a}$ \\
\hline 1 & 0.00 & 0.0060 & 0.1324 & 4.97 & 0.043 & 0.00392 & 0.00157 & 5.52 & 0.005120 & 0.000149 & 0.001612 \\
\hline 2 & 0.05 & 0.0009 & 0.1102 & 5.14 & 0.044 & 0.00570 & 0.00591 & 4.61 & 0.004493 & 0.000165 & 0.001152 \\
\hline 3 & 0.10 & 0.0175 & 0.1296 & 4.73 & 0.016 & 0.00576 & 0.00712 & 3.47 & 0.003237 & 0.000332 & 0.000655 \\
\hline 4 & 0.15 & 0.0107 & 0.1083 & 4.08 & 0.059 & 0.00495 & 0.00419 & 3.29 & 0.003242 & 0.000197 & 0.000477 \\
\hline 5 & 0.20 & 0.0000 & 0.1005 & 3.35 & 0.209 & 0.00170 & 0.00315 & 2.56 & 0.001793 & 0.000144 & 0.000429 \\
\hline 6 & 0.25 & 0.0197 & 0.0956 & 2.55 & 0.014 & 0.00104 & 0.00413 & 2.38 & 0.001581 & 0.000065 & 0.000304 \\
\hline 7 & 0.30 & 0.0000 & 0.0854 & 2.09 & 0.000 & 0.00132 & 0.00337 & 2.53 & 0.001508 & 0.000000 & 0.000233 \\
\hline 8 & 0.35 & 0.0000 & 0.0482 & 2.16 & 0.030 & 0.00021 & 0.00476 & 2.70 & 0.001557 & 0.000078 & 0.000113 \\
\hline 9 & 0.40 & 0.0041 & 0.0646 & 1.76 & 0.032 & 0.00303 & 0.00428 & 2.60 & 0.001323 & 0.000028 & 0.000088 \\
\hline 10 & 0.45 & 0.0152 & 0.0593 & 1.58 & 0.052 & 0.00203 & 0.00498 & 2.58 & 0.001193 & 0.000059 & 0.000081 \\
\hline 11 & 0.50 & 0.0015 & 0.0525 & 1.39 & 0.014 & 0.00147 & 0.00100 & 2.60 & 0.001027 & 0.000036 & 0.000071 \\
\hline 12 & 0.55 & 0.0199 & 0.0836 & 1.27 & 0.004 & 0.00329 & 0.00330 & 3.12 & 0.001188 & 0.000030 & 0.000035 \\
\hline 13 & 0.60 & 0.0240 & 0.0783 & 1.57 & 0.001 & 0.00000 & 0.00347 & 3.35 & 0.001251 & 0.000168 & 0.000055 \\
\hline 14 & 0.65 & 0.0000 & 0.0290 & 6.66 & 0.316 & 0.00345 & 0.00451 & 2.15 & 0.000977 & 0.000052 & 0.000020 \\
\hline 15 & 0.70 & 0.0156 & 0.0049 & 12.88 & 0.008 & 0.00466 & 0.00589 & 1.32 & 0.000491 & 0.000146 & 0.000004 \\
\hline 16 & 0.75 & 0.0310 & 0.0350 & 14.37 & 0.191 & 0.00320 & 0.00540 & 1.60 & 0.000750 & 0.000098 & 0.000000 \\
\hline 17 & 0.80 & 0.0000 & 0.0151 & 16.23 & 0.013 & 0.00282 & 0.00241 & 1.74 & 0.000712 & 0.000162 & 0.000017 \\
\hline 18 & 0.85 & 0.0258 & 0.0215 & 18.32 & 0.000 & 0.00634 & 0.01737 & 1.62 & 0.000857 & 0.000184 & 0.000000 \\
\hline
\end{tabular}




\begin{tabular}{|c|c|c|c|c|c|c|c|c|c|c|c|}
\hline \multirow{2}{*}{ Spot Number } & \multirow{2}{*}{ Distance from outer shell ( $\mathrm{mm}$ ) } & \multicolumn{10}{|c|}{ K3A growth band transect $\mathrm{L} 2$ corrected data $(\mathrm{mmol} / \mathrm{mol})$} \\
\hline & & $\mathrm{Li} / \mathrm{Ca}$ & $\mathbf{B} / \mathbf{C a}$ & $\mathrm{Mg} / \mathrm{Ca}$ & $\mathrm{Al} / \mathrm{Ca}$ & $\mathrm{Mn} / \mathrm{Ca}$ & $\mathrm{Zn} / \mathrm{Ca}$ & $\mathrm{Sr} / \mathrm{Ca}$ & $\mathrm{Ba} / \mathrm{Ca}$ & $\mathrm{Pb} / \mathrm{Ca}$ & $\mathrm{U} / \mathbf{C a}$ \\
\hline 1 & 0.00 & 0.0154 & 0.1610 & 2.98 & 0.108 & 0.00340 & 0.01854 & 4.63 & 0.005964 & 0.000000 & 0.000905 \\
\hline 2 & 0.05 & 0.0000 & 0.1340 & 11.50 & 0.322 & 0.01747 & 0.01057 & 4.52 & 0.005360 & 0.000141 & 0.000644 \\
\hline 3 & 0.10 & 0.0283 & 0.1121 & 5.39 & 0.619 & 0.00170 & 0.00725 & 4.07 & 0.005384 & 0.000065 & $0.00034 \mathrm{~s}$ \\
\hline 4 & 0.15 & 0.0000 & 0.0917 & 10.18 & 0.355 & 0.00391 & 0.00901 & 3.48 & 0.003381 & 0.000001 & $0.00016 c$ \\
\hline 5 & 0.20 & 0.0319 & 0.0273 & 21.44 & 0.096 & 0.00578 & 0.01204 & 2.25 & 0.001459 & 0.000144 & 0.000068 \\
\hline 6 & 0.25 & 0.0460 & 0.0128 & 14.44 & 0.000 & 0.00157 & 0.00368 & 1.76 & 0.000910 & 0.000026 & 0.000016 \\
\hline 7 & 0.30 & 0.0164 & 0.0131 & 16.94 & 0.005 & 0.00329 & 0.00488 & 1.87 & 0.000706 & 0.000000 & 0.000000 \\
\hline 8 & 0.35 & 0.0241 & 0.0000 & 10.74 & 0.003 & 0.00287 & 0.00449 & 1.65 & 0.000710 & 0.000003 & 0.000011 \\
\hline 9 & 0.40 & 0.0253 & 0.0139 & 8.61 & 0.014 & 0.00362 & 0.00313 & 1.51 & 0.000591 & 0.000000 & 0.000022 \\
\hline 10 & 0.45 & 0.0344 & 0.0230 & 6.99 & 0.002 & 0.00361 & 0.00972 & 1.43 & 0.000452 & 0.000000 & 0.000005 \\
\hline 11 & 0.50 & 0.0291 & 0.0117 & 8.14 & 0.000 & 0.00000 & 0.00000 & 1.33 & 0.000461 & 0.000068 & 0.000027 \\
\hline 12 & 0.55 & 0.0271 & 0.0042 & 12.80 & 0.001 & 0.00000 & 0.00979 & 1.38 & 0.000490 & 0.000072 & 0.00000 \\
\hline 13 & 0.60 & 0.0070 & 0.0000 & 19.25 & 0.005 & 0.00319 & 0.00501 & 1.27 & 0.000283 & 0.000000 & 0.000008 \\
\hline 14 & 0.65 & 0.0167 & 0.0000 & 21.28 & 0.000 & 0.00000 & 0.00450 & 1.24 & 0.000483 & 0.000046 & 0.00000 \\
\hline 15 & 0.70 & 0.0204 & 0.0000 & 24.23 & 0.000 & 0.00443 & 0.00189 & 1.15 & 0.000462 & 0.000054 & 0.000023 \\
\hline 16 & 0.75 & 0.0226 & 0.0081 & 21.37 & 0.019 & 0.00321 & 0.00697 & 1.21 & 0.000569 & 0.000072 & 0.00000 \\
\hline 17 & 0.80 & 0.0073 & 0.0174 & 3.41 & 0.000 & 0.00000 & 0.00642 & 2.76 & 0.001292 & 0.000000 & 0.000039 \\
\hline
\end{tabular}




\begin{tabular}{|c|c|c|c|c|c|c|c|c|c|c|c|}
\hline \multirow{2}{*}{ Spot Number } & \multirow{2}{*}{ Distance from outer shell ( $\mathrm{mm}$ ) } & \multicolumn{10}{|c|}{ K3A growth band transect $\mathrm{L} 3$ corrected data $(\mathrm{mmol} / \mathrm{mol})$} \\
\hline & & $\mathrm{Li} / \mathrm{Ca}$ & $\mathbf{B} / \mathbf{C a}$ & $\mathrm{Mg} / \mathrm{Ca}$ & $\mathrm{Al} / \mathrm{Ca}$ & $\mathrm{Mn} / \mathrm{Ca}$ & $\mathrm{Zn} / \mathrm{Ca}$ & $\mathrm{Sr} / \mathrm{Ca}$ & $\mathrm{Ba} / \mathrm{Ca}$ & $\mathrm{Pb} / \mathrm{Ca}$ & $\mathrm{U} / \mathbf{C a}$ \\
\hline 1 & 0.00 & 0.0249 & 0.0115 & 12.91 & 0.000 & 0.00167 & 0.01033 & 2.18 & 0.001364 & 0.000336 & 0.000024 \\
\hline 2 & 0.05 & 0.0034 & 0.0000 & 10.28 & 0.018 & 0.00475 & 0.00832 & 1.80 & 0.000680 & 0.000241 & 0.000000 \\
\hline 3 & 0.10 & 0.0237 & 0.0245 & 7.51 & 0.000 & 0.00279 & 0.00703 & 1.75 & 0.000595 & 0.000186 & 0.000000 \\
\hline 4 & 0.15 & 0.0031 & 0.0171 & 6.14 & 0.023 & 0.00094 & 0.00611 & 1.71 & 0.000595 & 0.000187 & 0.000023 \\
\hline 5 & 0.20 & 0.0000 & 0.0119 & 5.29 & 1.127 & 0.00078 & 0.00412 & 1.83 & 0.004048 & 0.000039 & 0.000000 \\
\hline 6 & 0.25 & 0.0000 & 0.0062 & 4.82 & 0.000 & 0.00226 & 0.00642 & 1.71 & 0.000653 & 0.000131 & 0.000010 \\
\hline 7 & 0.30 & 0.0114 & 0.0106 & 4.26 & 0.023 & 0.00137 & 0.00053 & 1.65 & 0.000354 & 0.000000 & 0.000000 \\
\hline 8 & 0.35 & 0.0070 & 0.0000 & 4.38 & 0.043 & 0.00081 & 0.00040 & 1.64 & 0.000632 & 0.000015 & 0.000018 \\
\hline 9 & 0.40 & 0.0219 & 0.0028 & 3.98 & 0.008 & 0.00361 & 0.00808 & 1.67 & 0.000509 & 0.000157 & $0.00000 s$ \\
\hline 10 & 0.45 & 0.0022 & 0.0194 & 3.36 & 0.000 & 0.00228 & 0.00260 & 1.56 & 0.000624 & 0.000118 & 0.000000 \\
\hline 11 & 0.50 & 0.0267 & 0.0300 & 3.36 & 0.010 & 0.00486 & 0.00322 & 1.55 & 0.000475 & 0.000035 & 0.000000 \\
\hline 12 & 0.55 & 0.0000 & 0.0064 & 3.19 & 0.000 & 0.00500 & 0.00199 & 1.45 & 0.000479 & 0.000034 & 0.00000 \\
\hline 13 & 0.60 & 0.0012 & 0.0000 & 3.58 & 0.007 & 0.00539 & 0.00174 & 1.32 & 0.000370 & 0.000057 & 0.00000 \\
\hline 14 & 0.65 & 0.0331 & 0.0062 & 3.85 & 0.012 & 0.00834 & 0.00273 & 1.21 & 0.000449 & 0.000097 & 0.00000 \\
\hline 15 & 0.70 & 0.0116 & 0.0108 & 7.37 & 0.009 & 0.00000 & 0.00509 & 1.12 & 0.000375 & 0.000054 & 0.000028 \\
\hline 16 & 0.75 & 0.0292 & 0.0200 & 15.41 & 0.008 & 0.00771 & 0.00116 & 1.27 & 0.000449 & 0.000048 & 0.000006 \\
\hline 17 & 0.80 & 0.0172 & 0.0394 & 17.61 & 0.000 & 0.00629 & 0.00569 & 2.05 & 0.001139 & 0.000110 & 0.000024 \\
\hline
\end{tabular}


APPENDIX 5.3j $\quad$ K1A1 growth band transect data

\begin{tabular}{|c|c|c|c|c|c|c|c|c|c|c|c|}
\hline \multirow{2}{*}{ Spot Number } & \multirow{2}{*}{ Distance from outer shell (mm) } & \multicolumn{10}{|c|}{ K1A1 growth band transect L1 corrected data $(\mathrm{mmol} / \mathrm{mol})$} \\
\hline & & $\mathrm{Li} / \mathrm{Ca}$ & $\mathrm{B} / \mathrm{Ca}$ & $\mathrm{Mg} / \mathrm{Ca}$ & $\mathbf{A l} / \mathbf{C a}$ & $\mathrm{Mn} / \mathrm{Ca}$ & $\mathrm{Zn} / \mathrm{Ca}$ & $\mathrm{Sr} / \mathrm{Ca}$ & $\mathrm{Ba} / \mathrm{Ca}$ & $\mathrm{Pb} / \mathrm{Ca}$ & $\mathbf{U} / \mathbf{C a}$ \\
\hline 1 & 0.00 & 0.0000 & 0.0230 & 11.99 & 0.0000 & 0.00741 & 0.00000 & 1.17 & 0.0005084 & 0.0003047 & 0.0000042 \\
\hline 2 & 0.05 & 0.0522 & 0.0000 & 11.90 & 0.0093 & 0.00707 & 0.00485 & 1.07 & 0.0004545 & 0.0003084 & 0.0000214 \\
\hline 3 & 0.10 & 0.0216 & 0.0000 & 9.99 & 0.0000 & 0.00683 & 0.00000 & 1.23 & 0.000456 & 0.0003888 & 0.0000068 \\
\hline 4 & 0.15 & 0.0470 & 0.0000 & 9.29 & 0.0000 & 0.00735 & 0.00448 & 1.29 & 0.0005331 & 0.0002594 & 0.0000000 \\
\hline 5 & 0.20 & 0.0317 & 0.0110 & 8.69 & 0.0000 & 0.00486 & 0.00198 & 1.34 & 0.0004846 & 0.0003118 & 0.0000000 \\
\hline 6 & 0.25 & 0.0000 & 0.0000 & 7.53 & 0.0266 & 0.00300 & 0.00000 & 1.37 & 0.0004745 & 0.0002398 & 0.0000000 \\
\hline 7 & 0.30 & 0.0256 & 0.0000 & 6.55 & 0.0054 & 0.00609 & 0.00449 & 1.39 & 0.0006375 & 0.0002322 & 0.0000000 \\
\hline 8 & 0.35 & 0.0088 & 0.0084 & 6.73 & 0.0000 & 0.00816 & 0.00000 & 1.48 & 0.0006547 & 0.0003885 & 0.0000000 \\
\hline 9 & 0.40 & 0.0097 & 0.0000 & 6.40 & 0.0017 & 0.01116 & 0.00918 & 1.49 & 0.0006535 & 0.0002442 & 0.0000639 \\
\hline 10 & 0.45 & 0.0000 & 0.0265 & 7.39 & 0.0120 & 0.00757 & 0.00738 & 1.53 & 0.0006565 & 0.0003046 & 0.0000000 \\
\hline 11 & 0.50 & 0.0000 & 0.0326 & 8.47 & 0.0171 & 0.00205 & 0.00000 & 1.56 & 0.0006249 & 0.0001483 & 0.0000354 \\
\hline 12 & 0.55 & 0.0291 & 0.0000 & 9.74 & 0.0326 & 0.01165 & 0.01385 & 1.67 & 0.0008855 & 0.0004596 & 0.0000015 \\
\hline 13 & 0.60 & 0.0000 & 0.0000 & 9.24 & 0.0102 & 0.00248 & 0.00000 & 1.75 & 0.0009199 & 0.0001907 & 0.0000000 \\
\hline 14 & 0.65 & 0.0000 & 0.0000 & 11.63 & 0.0289 & 0.00293 & 0.00158 & 1.88 & 0.0008039 & 0.0002439 & 0.0000200 \\
\hline 15 & 0.70 & 0.0120 & 0.0033 & 9.54 & 0.0000 & 0.00293 & 0.00000 & 1.89 & 0.0007248 & 0.0001882 & 0.0000541 \\
\hline 16 & 0.75 & 0.0341 & 0.0102 & 13.85 & 0.0000 & 0.00000 & 0.00490 & 1.86 & 0.0006934 & 0.000304 & 0.0000000 \\
\hline 17 & 0.80 & 0.0037 & 0.0384 & 13.87 & 0.0000 & 0.00283 & 0.00115 & 1.80 & 0.0006949 & 0.0003117 & 0.0000299 \\
\hline 18 & 0.85 & 0.0000 & 0.0242 & 15.48 & 0.0000 & 0.01002 & 0.00209 & 2.34 & 0.0014282 & 0.0004084 & 0.0000801 \\
\hline 19 & 0.90 & 0.0149 & 0.0054 & 18.28 & 0.0000 & 0.03607 & 0.01671 & 2.05 & 0.0013426 & 0.0004052 & 0.0001105 \\
\hline 20 & 0.95 & 0.0481 & 0.0325 & 19.19 & 1.7931 & 0.02739 & 0.01202 & 2.22 & 0.002051 & 0.0003656 & 0.0000000 \\
\hline 21 & 1.00 & 0.0441 & 0.0463 & 20.41 & 1.4172 & 0.03438 & 0.02178 & 2.02 & 0.003642 & 0.0003618 & 0.0000000 \\
\hline
\end{tabular}




\begin{tabular}{|c|c|c|c|c|c|c|c|c|c|c|c|}
\hline \multirow{2}{*}{ Spot Number } & \multirow{2}{*}{ Distance from outer shell (mm) } & \multicolumn{10}{|c|}{ K1A1 growth band transect L2 corrected data $(\mathrm{mmol} / \mathrm{mol})$} \\
\hline & & $\mathrm{Li} / \mathrm{Ca}$ & $\mathrm{B} / \mathrm{Ca}$ & $\mathrm{Mg} / \mathrm{Ca}$ & $\mathrm{Al} / \mathrm{Ca}$ & $\mathrm{Mn} / \mathrm{Ca}$ & $\mathrm{Zn} / \mathrm{Ca}$ & $\mathrm{Sr} / \mathrm{Ca}$ & $\mathrm{Ba} / \mathrm{Ca}$ & $\mathrm{Pb} / \mathrm{Ca}$ & U/Ca \\
\hline 1 & 0.00 & 0.0253 & 0.0112 & 6.44 & 0.0123 & 0.00512 & 0.00785 & 1.67 & 0.0013469 & 0.0001308 & 0.0000000 \\
\hline 2 & 0.05 & 0.0752 & 0.0271 & 7.11 & 0.0000 & 0.00000 & 0.00549 & 1.21 & 0.0005405 & 0.0001599 & 0.0000199 \\
\hline 3 & 0.10 & 0.0009 & 0.0184 & 6.94 & 0.0000 & 0.00000 & 0.01169 & 1.39 & 0.0004664 & 0.0001895 & 0.0000461 \\
\hline 4 & 0.15 & 0.0000 & 0.0079 & 5.72 & 0.0000 & 0.00417 & 0.00888 & 1.48 & 0.0006087 & $8.412 \mathrm{E}-05$ & 0.0000147 \\
\hline 5 & 0.20 & 0.0037 & 0.0000 & 5.54 & 0.0127 & 0.00644 & 0.00817 & 1.43 & 0.0006415 & 0.0002719 & 0.0000000 \\
\hline 6 & 0.25 & 0.0339 & 0.0019 & 5.82 & 0.0000 & 0.00000 & 0.00291 & 1.55 & 0.0006378 & 0.0001859 & 0.0000311 \\
\hline 7 & 0.30 & 0.0055 & 0.0000 & 6.36 & 0.0000 & 0.00113 & 0.00441 & 1.77 & 0.0008806 & 0.0002769 & 0.0000000 \\
\hline 8 & 0.35 & 0.0024 & 0.0186 & 7.06 & 0.0036 & 0.00476 & 0.01202 & 1.73 & 0.0008706 & 0.0001772 & 0.0000117 \\
\hline 9 & 0.40 & 0.0000 & 0.0000 & 9.52 & 0.0085 & 0.00239 & 0.00893 & 1.80 & 0.000991 & $8.931 \mathrm{E}-05$ & 0.0000000 \\
\hline 10 & 0.45 & 0.0000 & 0.0000 & 9.90 & 0.0000 & 0.00031 & 0.00458 & 1.88 & 0.0010049 & 0.0002838 & 0.0000149 \\
\hline 11 & 0.50 & 0.0109 & 0.0261 & 8.70 & 0.0719 & 0.00331 & 0.00374 & 1.74 & 0.0009156 & 0.0003613 & 0.0000000 \\
\hline 12 & 0.55 & 0.0154 & 0.0000 & 8.49 & 0.0000 & 0.00013 & 0.01654 & 1.79 & 0.0007909 & 0.0006827 & 0.0000000 \\
\hline 13 & 0.60 & 0.0148 & 0.0599 & 10.05 & 0.0154 & 0.00349 & 0.00921 & 1.79 & 0.0009872 & 0.0003473 & 0.0000000 \\
\hline 14 & 0.65 & 0.0422 & 0.0148 & 13.10 & 0.0205 & 0.00627 & 0.00662 & 1.85 & 0.0010123 & 0.0004058 & 0.0000000 \\
\hline 15 & 0.70 & 0.0000 & 0.0146 & 9.97 & 0.0308 & 0.00729 & 0.00193 & 2.02 & 0.0012665 & 0.0004219 & 0.0000000 \\
\hline 16 & 0.75 & 0.0867 & 0.0197 & 14.10 & 0.1021 & 0.00988 & 0.00435 & 1.80 & 0.0011952 & 0.0005403 & 0.0000438 \\
\hline 17 & 0.80 & 0.0000 & 0.0171 & 11.21 & 0.1848 & 0.00606 & 0.01260 & 2.69 & 0.0023177 & 0.0005121 & 0.0001475 \\
\hline 18 & 0.85 & 0.0491 & 0.0186 & 12.90 & 0.4604 & 0.01458 & 0.00000 & 2.10 & 0.0017372 & 0.0004021 & 0.0000659 \\
\hline 19 & 0.90 & 0.0167 & 0.0035 & 17.28 & 0.1813 & 0.02159 & 0.00685 & 2.08 & 0.0027224 & 0.0003811 & 0.0000000 \\
\hline 20 & 0.95 & 0.0563 & 0.0384 & 22.73 & 0.0219 & 0.01695 & 0.00458 & 2.34 & 0.0016945 & 0.000561 & 0.0000627 \\
\hline 21 & 1.00 & 0.0000 & 0.0546 & 18.47 & 0.1940 & 0.01617 & 0.00899 & 2.19 & 0.0023422 & 0.0003898 & 0.0000974 \\
\hline
\end{tabular}


APPENDIX 5.3k AR1 growth band data

\begin{tabular}{|c|c|c|c|c|c|c|c|c|c|c|c|}
\hline \multirow{2}{*}{$\begin{array}{c}\text { Spot } \\
\text { Number }\end{array}$} & \multirow{2}{*}{ Distance from inner shell (mm) } & \multicolumn{10}{|c|}{ AR1 growth band transect L1 corrected data $(\mathrm{mmol} / \mathrm{mol})$} \\
\hline & & $\mathrm{Li} / \mathrm{Ca}$ & $\mathrm{B} / \mathrm{Ca}$ & $\mathrm{Mg} / \mathrm{Ca}$ & $\mathbf{A l} / \mathbf{C a}$ & $\mathrm{Mn} / \mathrm{Ca}$ & $\mathrm{Zn} / \mathrm{Ca}$ & $\mathrm{Sr} / \mathrm{Ca}$ & $\mathrm{Ba} / \mathrm{Ca}$ & $\mathrm{Pb} / \mathrm{Ca}$ & $\mathrm{U} / \mathrm{Ca}$ \\
\hline 1 & 0.00 & 0.0171 & 0.0374 & 16.65 & 0.00850 & 0.00000 & 0.01447 & 1.36 & 0.001050 & 0.0001430 & 0.0000000 \\
\hline 2 & 0.05 & 0.0000 & 0.0020 & 22.09 & 0.05814 & 0.00056 & 0.01356 & 1.51 & 0.001767 & 0.0000717 & 0.0000058 \\
\hline 3 & 0.10 & 0.0000 & 0.0021 & 14.24 & 0.00399 & 0.00232 & 0.00765 & 1.28 & 0.000510 & 0.0000412 & 0.0000000 \\
\hline 4 & 0.15 & 0.0141 & 0.0000 & 11.81 & 0.00911 & 0.00369 & 0.00000 & 1.17 & 0.000641 & 0.0001260 & 0.0000291 \\
\hline 5 & 0.20 & 0.0000 & 0.0000 & 15.86 & 0.00782 & 0.00570 & 0.00867 & 1.02 & 0.000500 & 0.0001575 & 0.0000400 \\
\hline 6 & 0.25 & 0.0000 & 0.0638 & 20.76 & 0.00722 & 0.00000 & 0.00603 & 1.12 & 0.000885 & 0.0000000 & 0.0000088 \\
\hline 7 & 0.30 & 0.0200 & 0.0160 & 23.09 & 0.00000 & 0.00042 & 0.00000 & 1.10 & 0.000587 & 0.0001615 & 0.0000366 \\
\hline 8 & 0.35 & 0.0336 & 0.0264 & 21.63 & 0.00000 & 0.00043 & 0.00906 & 1.22 & 0.000682 & 0.0000987 & 0.0000166 \\
\hline 9 & 0.40 & 0.0189 & 0.0000 & 21.10 & 0.01669 & 0.00000 & 0.00441 & 1.18 & 0.000859 & 0.0001886 & 0.0000022 \\
\hline 10 & 0.45 & 0.0369 & 0.0032 & 22.20 & 0.00795 & 0.00439 & 0.00802 & 1.28 & 0.000713 & 0.0000000 & 0.0000382 \\
\hline 11 & 0.50 & 0.0356 & 0.0575 & 16.86 & 0.02632 & 0.00297 & 0.00519 & 1.27 & 0.000797 & 0.0001090 & 0.0000376 \\
\hline 12 & 0.55 & 0.0147 & 0.0127 & 18.81 & 0.00000 & 0.00456 & 0.01180 & 1.23 & 0.000880 & 0.0000438 & 0.0000048 \\
\hline 13 & 0.60 & 0.0000 & 0.0072 & 21.43 & 0.00000 & 0.00399 & 0.00614 & 1.38 & 0.000780 & 0.0000968 & 0.0000098 \\
\hline 14 & 0.65 & 0.0211 & 0.0054 & 20.11 & 0.00000 & 0.00000 & 0.00529 & 1.27 & 0.000652 & 0.0000024 & 0.0000164 \\
\hline 15 & 0.70 & 0.0267 & 0.0000 & 18.23 & 0.00000 & 0.00632 & 0.00732 & 1.17 & 0.000543 & 0.0000000 & 0.0000125 \\
\hline 16 & 0.75 & 0.0317 & 0.0271 & 18.76 & 0.01918 & 0.00149 & 0.00155 & 1.11 & 0.000500 & 0.0000728 & 0.0000352 \\
\hline 17 & 0.80 & 0.0364 & 0.0142 & 18.56 & 0.00000 & 0.00007 & 0.00899 & 1.08 & 0.000456 & 0.0000417 & 0.0000000 \\
\hline 18 & 0.85 & 0.0000 & 0.0095 & 16.88 & 0.03422 & 0.00115 & 0.00149 & 1.05 & 0.000351 & 0.0000803 & 0.0000061 \\
\hline 19 & 0.90 & 0.0007 & 0.0076 & 16.94 & 0.01144 & 0.00171 & 0.00490 & 1.02 & 0.000301 & 0.0000717 & 0.0000377 \\
\hline 20 & 0.95 & 0.0000 & 0.0453 & 18.00 & 0.01191 & 0.00237 & 0.00897 & 1.10 & 0.000409 & 0.0000000 & 0.0000408 \\
\hline 21 & 1.00 & 0.0000 & 0.0207 & 17.68 & 0.03484 & 0.00592 & 0.00832 & 1.11 & 0.000414 & 0.0001285 & 0.0000000 \\
\hline 22 & 1.05 & 0.0036 & 0.0000 & 19.00 & 0.00000 & 0.00378 & 0.00243 & 0.96 & 0.000385 & 0.0001137 & 0.0000169 \\
\hline 23 & 1.10 & 0.0456 & 0.0366 & 19.50 & 0.03319 & 0.00508 & 0.00410 & 1.03 & 0.000342 & 0.0000977 & 0.0000000 \\
\hline 24 & 1.15 & 0.0000 & 0.0288 & 18.71 & 0.00979 & 0.00557 & 0.00982 & 0.95 & 0.000456 & 0.0001172 & 0.0000087 \\
\hline
\end{tabular}


APPENDIX 5.31 MR2 growth band data

\begin{tabular}{|c|c|c|c|c|c|c|c|c|c|c|c|}
\hline \multirow{2}{*}{$\begin{array}{c}\text { Spot } \\
\text { Number }\end{array}$} & \multirow{2}{*}{ Distance from outer shell (mm) } & \multicolumn{10}{|c|}{ MR2 growth band transect L1 corrected data $(\mathrm{mmol} / \mathrm{mol})$} \\
\hline & & $\mathrm{Li} / \mathrm{Ca}$ & $\mathrm{B} / \mathrm{Ca}$ & $\mathrm{Mg} / \mathrm{Ca}$ & $\mathbf{A l} / \mathbf{C a}$ & $\mathrm{Mn} / \mathrm{Ca}$ & $\mathrm{Zn} / \mathrm{Ca}$ & $\mathrm{Sr} / \mathrm{Ca}$ & $\mathrm{Ba} / \mathrm{Ca}$ & $\mathrm{Pb} / \mathrm{Ca}$ & $\mathrm{U} / \mathrm{Ca}$ \\
\hline 1 & 0.00 & 0.0076 & 0.552 & 19.17 & 0.0000 & 0.00000 & 0.0112 & 1.27 & 0.000756 & 0.000000 & 0.0000000 \\
\hline 2 & 0.05 & 0.0000 & 0.702 & 14.63 & 0.0000 & 0.00000 & 0.0292 & 1.27 & 0.000956 & 0.000148 & 0.0000000 \\
\hline 3 & 0.10 & 0.0405 & 0.522 & 10.06 & 0.0000 & 0.00000 & 0.0259 & 1.28 & 0.000686 & 0.000134 & 0.0001452 \\
\hline 4 & 0.15 & 0.0000 & 0.656 & 8.27 & 0.0000 & 0.00260 & 0.0031 & 1.32 & 0.000596 & 0.000081 & 0.0000389 \\
\hline 5 & 0.20 & 0.0081 & 0.316 & 6.94 & 0.0282 & 0.00219 & 0.0120 & 1.25 & 0.000614 & 0.000133 & 0.0000000 \\
\hline 6 & 0.25 & 0.0000 & 0.004 & 7.92 & 0.0208 & 0.00070 & 0.0017 & 1.28 & 0.000521 & 0.000000 & 0.0000000 \\
\hline 7 & 0.30 & 0.0195 & 0.155 & 6.82 & 0.0000 & 0.00000 & 0.0177 & 1.21 & 0.000550 & 0.000268 & 0.0000592 \\
\hline 8 & 0.35 & 0.0022 & 0.000 & 6.61 & 0.0168 & 0.00000 & 0.0154 & 1.23 & 0.000574 & 0.000100 & 0.0000471 \\
\hline 9 & 0.40 & 0.0000 & 0.000 & 6.92 & 0.0126 & 0.00132 & 0.0111 & 1.23 & 0.000693 & 0.000000 & 0.0000000 \\
\hline 10 & 0.45 & 0.0000 & 0.073 & 7.56 & 0.0108 & 0.00201 & 0.0198 & 1.20 & 0.000557 & 0.000137 & 0.0000269 \\
\hline 11 & 0.50 & 0.0002 & 0.080 & 7.95 & 0.0000 & 0.00110 & 0.0163 & 1.08 & 0.000709 & 0.000000 & 0.0000000 \\
\hline 12 & 0.55 & 0.0000 & 0.441 & 8.42 & 0.0193 & 0.00000 & 0.0073 & 1.05 & 0.000141 & 0.000000 & 0.0000721 \\
\hline 13 & 0.60 & 0.0060 & 0.000 & 7.27 & 0.0000 & 0.00000 & 0.0186 & 1.02 & 0.000716 & 0.000000 & 0.0000510 \\
\hline 14 & 0.65 & 0.0288 & 0.000 & 7.61 & 0.0377 & 0.00589 & 0.0147 & 1.00 & 0.000431 & 0.000000 & 0.0000000 \\
\hline 15 & 0.70 & 0.0160 & 0.152 & 7.96 & 0.0491 & 0.00864 & 0.0000 & 1.04 & 0.000464 & 0.000000 & 0.0000648 \\
\hline 16 & 0.75 & 0.0475 & 0.210 & 8.08 & 0.0000 & 0.00943 & 0.0000 & 1.04 & 0.000635 & 0.000000 & 0.0000460 \\
\hline 17 & 0.80 & 0.0510 & 0.129 & 6.87 & 0.0026 & 0.00231 & 0.0063 & 1.09 & 0.000451 & 0.000000 & 0.0000145 \\
\hline 18 & 0.85 & 0.0505 & 0.000 & 7.95 & 0.0054 & 0.00048 & 0.0000 & 1.05 & 0.000431 & 0.000000 & 0.0000000 \\
\hline 19 & 0.90 & 0.0072 & 0.052 & 9.47 & 0.0116 & 0.00000 & 0.0049 & 1.00 & 0.000750 & 0.000161 & 0.0000816 \\
\hline 20 & 0.95 & 0.0021 & 0.000 & 8.73 & 0.0109 & 0.00000 & 0.0155 & 0.85 & 0.000340 & 0.000000 & 0.0000137 \\
\hline 21 & 1.00 & 0.0133 & 0.280 & 1.23 & 0.0000 & 0.00000 & 0.0000 & 2.88 & 0.003394 & 0.000000 & 0.0000189 \\
\hline 22 & 1.05 & 0.0288 & 0.337 & 12.71 & 0.0003 & 0.00000 & 0.0160 & 1.15 & 0.001160 & 0.000307 & 0.0000000 \\
\hline 23 & 1.10 & 0.0000 & 0.538 & 10.80 & 0.0119 & 0.00000 & 0.0044 & 1.80 & 0.001522 & 0.000000 & 0.0000085 \\
\hline
\end{tabular}


APPENDIX 5.3m MD1 growth band data

\begin{tabular}{|c|c|c|c|c|c|c|c|c|c|c|c|}
\hline \multirow{2}{*}{$\begin{array}{c}\text { Spot } \\
\text { Number }\end{array}$} & \multirow{2}{*}{ Distance from outer shell (mm) } & \multicolumn{10}{|c|}{ MD1 growth band transect L1 corrected data $(\mathrm{mmol} / \mathrm{mol})$} \\
\hline & & $\mathrm{Li} / \mathrm{Ca}$ & $\mathrm{B} / \mathrm{Ca}$ & $\mathrm{Mg} / \mathrm{Ca}$ & $\mathrm{Al} / \mathrm{Ca}$ & $\mathrm{Mn} / \mathrm{Ca}$ & $\mathrm{Zn} / \mathrm{Ca}$ & $\mathrm{Sr} / \mathrm{Ca}$ & $\mathrm{Ba} / \mathrm{Ca}$ & $\mathrm{Pb} / \mathrm{Ca}$ & $\mathrm{U} / \mathrm{Ca}$ \\
\hline 1 & 0.00 & 0.0000 & 0.0000 & 21.49 & 0.0000 & 0.00000 & 0.0281 & 1.26 & 0.001330 & 0.000035 & 0.0000138 \\
\hline 2 & 0.05 & 0.0023 & 0.0000 & 20.42 & 4.1944 & 0.01906 & 0.0108 & 1.88 & 0.013390 & 0.001104 & 0.0001527 \\
\hline 3 & 0.10 & 0.0278 & 0.0000 & 17.06 & 0.0243 & 0.00000 & 0.0018 & 1.25 & 0.000619 & 0.000250 & 0.0000386 \\
\hline 4 & 0.15 & 0.0096 & 0.0000 & 12.72 & 0.1655 & 0.00000 & 0.0180 & 1.25 & 0.001362 & 0.000014 & 0.0000000 \\
\hline 5 & 0.20 & 0.0450 & 0.0000 & 10.35 & 0.0000 & 0.00000 & 0.0000 & 1.26 & 0.000691 & 0.000000 & 0.0000240 \\
\hline 6 & 0.25 & 0.0441 & 0.0000 & 9.90 & 0.0000 & 0.00135 & 0.0035 & 1.20 & 0.000401 & 0.000000 & 0.0000000 \\
\hline 7 & 0.30 & 0.0141 & 0.0000 & 7.25 & 0.0362 & 0.00257 & 0.0044 & 1.14 & 0.000496 & 0.000000 & 0.0000011 \\
\hline 8 & 0.35 & 0.0318 & 0.0000 & 8.14 & 0.0320 & 0.00138 & 0.0051 & 1.05 & 0.000586 & 0.000085 & 0.0000632 \\
\hline 9 & 0.40 & 0.0291 & 0.0233 & 13.33 & 0.0074 & 0.00000 & 0.0000 & 1.02 & 0.000371 & 0.000000 & 0.0000015 \\
\hline 10 & 0.45 & 0.0281 & 0.0000 & 22.05 & 0.0000 & 0.00010 & 0.0103 & 1.04 & 0.000202 & 0.000164 & 0.0000615 \\
\hline 11 & 0.50 & 0.0314 & 0.0000 & 24.32 & 0.0000 & 0.00647 & 0.0072 & 1.38 & 0.000735 & 0.000000 & 0.0000000 \\
\hline 12 & 0.55 & 0.0112 & 0.0000 & 19.14 & 0.0369 & 0.00000 & 0.0024 & 1.60 & 0.000846 & 0.000242 & 0.0000151 \\
\hline 13 & 0.60 & 0.0183 & 0.2787 & 14.02 & 0.0000 & 0.00000 & 0.0000 & 1.54 & 0.000621 & 0.000000 & 0.0000000 \\
\hline 14 & 0.65 & 0.0153 & 0.1288 & 10.01 & 0.0261 & 0.00000 & 0.0040 & 1.39 & 0.000604 & 0.000000 & 0.0000450 \\
\hline 15 & 0.70 & 0.0332 & 0.1185 & 9.98 & 0.0000 & 0.00170 & 0.0174 & 1.31 & 0.000643 & 0.000100 & 0.0001196 \\
\hline 16 & 0.75 & 0.0000 & 0.0000 & 10.18 & 0.0250 & 0.00042 & 0.0071 & 1.19 & 0.000309 & 0.000070 & 0.0000000 \\
\hline 17 & 0.80 & 0.0000 & 0.0887 & 10.81 & 0.0000 & 0.00140 & 0.0181 & 1.18 & 0.000370 & 0.000088 & 0.0000063 \\
\hline 18 & 0.85 & 0.0281 & 0.0000 & 11.49 & 0.0028 & 0.00230 & 0.0091 & 1.14 & 0.000396 & 0.000105 & 0.0000063 \\
\hline 19 & 0.90 & 0.0099 & 0.1738 & 13.65 & 0.0000 & 0.00001 & 0.0143 & 1.09 & 0.000367 & 0.000000 & 0.0000264 \\
\hline 20 & 0.95 & 0.0346 & 0.6620 & 15.06 & 0.0131 & 0.00000 & 0.0100 & 1.02 & 0.000267 & 0.000000 & 0.0000082 \\
\hline 21 & 1.00 & 0.0381 & 0.0000 & 16.83 & 0.0155 & 0.00000 & 0.0016 & 1.00 & 0.000654 & 0.000055 & 0.0000000 \\
\hline 22 & 1.05 & 0.0476 & 0.2495 & 18.08 & 0.0054 & 0.00217 & 0.0003 & 0.95 & 0.000570 & 0.000080 & 0.0000488 \\
\hline 23 & 1.10 & 0.0197 & 0.2612 & 18.17 & 0.0000 & 0.00252 & 0.0000 & 0.94 & 0.000310 & 0.000139 & 0.0000000 \\
\hline 24 & 1.15 & 0.0795 & 0.0000 & 22.67 & 0.0030 & 0.00297 & 0.0000 & 0.91 & 0.000523 & 0.000193 & 0.0000411 \\
\hline
\end{tabular}


APPENDIX 5.3n $\quad$ MD3 growth band data

\begin{tabular}{|c|c|c|c|c|c|c|c|c|c|c|c|}
\hline \multirow{2}{*}{ Spot Number } & \multirow{2}{*}{ Distance from outer shell (mm) } & \multicolumn{10}{|c|}{ MD3 growth band transect L1 corrected data $(\mathrm{mmol} / \mathrm{mol})$} \\
\hline & & $\mathrm{Li} / \mathrm{Ca}$ & $\mathrm{B} / \mathrm{Ca}$ & $\mathrm{Mg} / \mathrm{Ca}$ & $\mathrm{Al} / \mathrm{Ca}$ & $\mathrm{Mn} / \mathrm{Ca}$ & $\mathrm{Zn} / \mathrm{Ca}$ & $\mathrm{Sr} / \mathrm{Ca}$ & $\mathrm{Ba} / \mathrm{Ca}$ & $\mathrm{Pb} / \mathrm{Ca}$ & $\mathrm{U} / \mathrm{Ca}$ \\
\hline 1 & 0.00 & 0.0217 & 0.1026 & 6.44 & 0.062 & 0.00514 & 0.0000 & 4.79 & 0.00407 & 0.0000805 & 0.0005034 \\
\hline 2 & 0.05 & 0.0242 & 0.0970 & 8.93 & 0.333 & 0.00752 & 0.0175 & 3.74 & 0.00397 & 0.0001746 & 0.0002628 \\
\hline 3 & 0.10 & 0.0058 & 0.0064 & 10.28 & 0.553 & 0.00361 & 0.0088 & 2.30 & 0.00162 & 0.0001038 & 0.0000657 \\
\hline 4 & 0.15 & 0.0000 & 0.0430 & 6.52 & 0.000 & 0.00000 & 0.0187 & 1.38 & 0.00038 & 0.0000256 & 0.0000467 \\
\hline 5 & 0.20 & 0.0199 & 0.0411 & 4.99 & 0.000 & 0.00512 & 0.0163 & 1.37 & 0.00056 & 0.0001144 & 0.0000000 \\
\hline 6 & 0.25 & 0.0302 & 0.0000 & 6.18 & 0.070 & 0.00670 & 0.0187 & 1.34 & 0.00050 & 0.0000000 & 0.0000099 \\
\hline 7 & 0.30 & 0.0048 & 0.0505 & 4.94 & 0.266 & 0.00000 & 0.0122 & 1.36 & 0.00061 & 0.0000640 & 0.0000000 \\
\hline 8 & 0.35 & 0.0036 & 0.0151 & 3.83 & 0.000 & 0.00092 & 0.0143 & 1.44 & 0.00045 & 0.0000086 & 0.0000183 \\
\hline 9 & 0.40 & 0.0007 & 0.0000 & 3.35 & 0.013 & 0.00000 & 0.0065 & 1.33 & 0.00044 & 0.0000591 & 0.0000000 \\
\hline 10 & 0.45 & 0.0223 & 0.0000 & 2.99 & 0.000 & 0.00000 & 0.0105 & 1.24 & 0.00042 & 0.0000234 & 0.0000144 \\
\hline 11 & 0.50 & 0.0008 & 0.0137 & 3.32 & 0.058 & 0.00202 & 0.0080 & 1.25 & 0.00053 & 0.0000881 & 0.0000000 \\
\hline 12 & 0.55 & 0.0117 & 0.0000 & 3.41 & 0.004 & 0.00223 & 0.0000 & 1.22 & 0.00049 & 0.0000546 & 0.0000370 \\
\hline 13 & 0.60 & 0.0113 & 0.0542 & 3.38 & 0.013 & 0.00117 & 0.0049 & 1.21 & 0.00039 & 0.0000460 & 0.0000000 \\
\hline 14 & 0.65 & 0.0000 & 0.0227 & 3.98 & 0.000 & 0.00235 & 0.0080 & 1.12 & 0.00043 & 0.0000000 & 0.0000185 \\
\hline 15 & 0.70 & 0.0120 & 0.0158 & 4.16 & 0.000 & 0.00366 & 0.0042 & 1.09 & 0.00037 & 0.0000000 & 0.0000163 \\
\hline
\end{tabular}




\begin{tabular}{|c|c|c|c|c|c|c|c|c|c|c|c|}
\hline \multirow{2}{*}{ Spot Number } & \multirow{2}{*}{ Distance from outer shell (mm) } & \multicolumn{10}{|c|}{ MD3 growth band transect L2 corrected data $(\mathrm{mmol} / \mathrm{mol})$} \\
\hline & & $\mathrm{Li} / \mathrm{Ca}$ & $\mathbf{B} / \mathbf{C a}$ & $\mathrm{Mg} / \mathrm{Ca}$ & $\mathrm{Al} / \mathrm{Ca}$ & $\mathrm{Mn} / \mathbf{C a}$ & $\mathrm{Zn} / \mathbf{C a}$ & Sr88/Ca & $\mathrm{Ba} / \mathrm{Ca}$ & $\mathrm{Pb} / \mathrm{Ca}$ & $\mathrm{U} / \mathrm{Ca}$ \\
\hline 1 & 0.00 & 0.0043 & 0.0294 & 17.46 & 0.254 & 0.00702 & 0.0135 & 1.60 & 0.00171 & 0.0000547 & 0.0000943 \\
\hline 2 & 0.05 & 0.0215 & 0.0648 & 24.52 & 3.698 & 0.01777 & 0.0079 & 1.82 & 0.00524 & 0.0002306 & 0.0000817 \\
\hline 3 & 0.10 & 0.0536 & 0.1404 & 49.56 & 5.435 & 0.03563 & 0.0052 & 2.89 & 0.00685 & 0.0002503 & 0.0001766 \\
\hline 4 & 0.15 & 0.0429 & 0.0651 & 24.25 & 1.865 & 0.01023 & 0.0077 & 2.94 & 0.00378 & 0.0002493 & 0.0001240 \\
\hline 5 & 0.20 & 0.0420 & 0.0296 & 19.91 & 0.794 & 0.00677 & 0.0108 & 1.56 & 0.00220 & 0.0001510 & 0.0000492 \\
\hline 6 & 0.25 & 0.0058 & 0.0003 & 9.92 & 0.006 & 0.00422 & 0.0099 & 1.44 & 0.00081 & 0.0000268 & 0.0000342 \\
\hline 7 & 0.30 & 0.0067 & 0.0099 & 4.87 & 0.001 & 0.00205 & 0.0097 & 1.51 & 0.00064 & 0.0000570 & 0.0000043 \\
\hline 8 & 0.35 & 0.0474 & 0.0272 & 4.43 & 0.053 & 0.00215 & 0.0012 & 1.44 & 0.00064 & 0.0000000 & 0.0000093 \\
\hline 9 & 0.40 & 0.0239 & 0.0000 & 3.85 & 0.000 & 0.00142 & 0.0067 & 1.46 & 0.00063 & 0.0000539 & 0.0000000 \\
\hline 10 & 0.45 & 0.0056 & 0.0163 & 3.79 & 0.004 & 0.00449 & 0.0058 & 1.25 & 0.00043 & 0.0000100 & 0.0000148 \\
\hline 11 & 0.50 & 0.0121 & 0.0000 & 3.81 & 0.000 & 0.00277 & 0.0043 & 1.15 & 0.00042 & 0.0000645 & 0.0000139 \\
\hline 12 & 0.55 & 0.0148 & 0.0176 & 4.48 & 0.009 & 0.00197 & 0.0122 & 1.02 & 0.00039 & 0.0000646 & 0.0000000 \\
\hline 13 & 0.60 & 0.0276 & 0.0014 & 5.59 & 0.002 & 0.00047 & 0.0004 & 1.15 & 0.00046 & 0.0000000 & 0.0000171 \\
\hline 14 & 0.65 & 0.0193 & 0.0168 & 7.39 & 0.006 & 0.00322 & 0.0046 & 1.25 & 0.00045 & 0.0000227 & 0.0000176 \\
\hline 15 & 0.70 & 0.0189 & 0.0000 & 5.83 & 0.000 & 0.00670 & 0.0072 & 0.99 & 0.00030 & 0.0000926 & 0.0000000 \\
\hline 16 & 0.75 & 0.0000 & 0.0000 & 5.88 & 0.013 & 0.00567 & 0.0064 & 1.06 & 0.00038 & 0.0000433 & 0.0000011 \\
\hline 17 & 0.80 & 0.0320 & 0.0250 & 7.29 & 0.005 & 0.00818 & 0.0058 & 0.95 & 0.00044 & 0.0000895 & 0.0000159 \\
\hline 18 & 0.85 & 0.0262 & 0.0441 & 7.47 & 0.006 & 0.00545 & 0.0041 & 1.24 & 0.00093 & 0.0000260 & 0.0000000 \\
\hline
\end{tabular}

